\author{
Mon og r a p h \\ urn:1sid:zoobank.org:pub:B234C53F-BB56-4F3D-B400-F214E19DCF90
}

\title{
Revision of the Oriental species of the genus Sphegina Meigen, 1822 (Diptera: Syrphidae)
}

\author{
Jeroen VAN STEENIS ${ }^{1, *}$, Heikki HIPPA ${ }^{2} \&$ Valeri A. MUTIN ${ }^{3}$ \\ ${ }^{1}$ Research Associate, Naturalis Biodiversity Center, Leiden; Hof der Toekomst 48, \\ 3823 HX Amersfoort, the Netherlands. \\ ${ }^{2}$ Zoological Museum, Biodiversity Unit, FI-20014 University of Turku, Finland. \\ ${ }^{3}$ Amur State University of Humanities and Pedagogy, Komsomolsk-na-Amure, 681000, Russia. \\ *Corresponding author: jvansteenis@syrphidaeintrees.com \\ 2Email: heikki.hippa@gmail.com \\ ${ }^{3}$ Email: valerimutin@mail.ru \\ ${ }^{1}$ urn:1sid:zoobank.org:author:C7F0D01C-B182-4B93-AF73-E4154367B535 \\ ${ }^{2}$ urn:1sid:zoobank.org:author:546524AD-3BD1-4830-842F-EEEE7DF4799B \\ ${ }^{3}$ urn:1sid:zoobank.org:author:625E0F27-4538-417D-9155-6141947F04EA
}

\section{Table of contents}

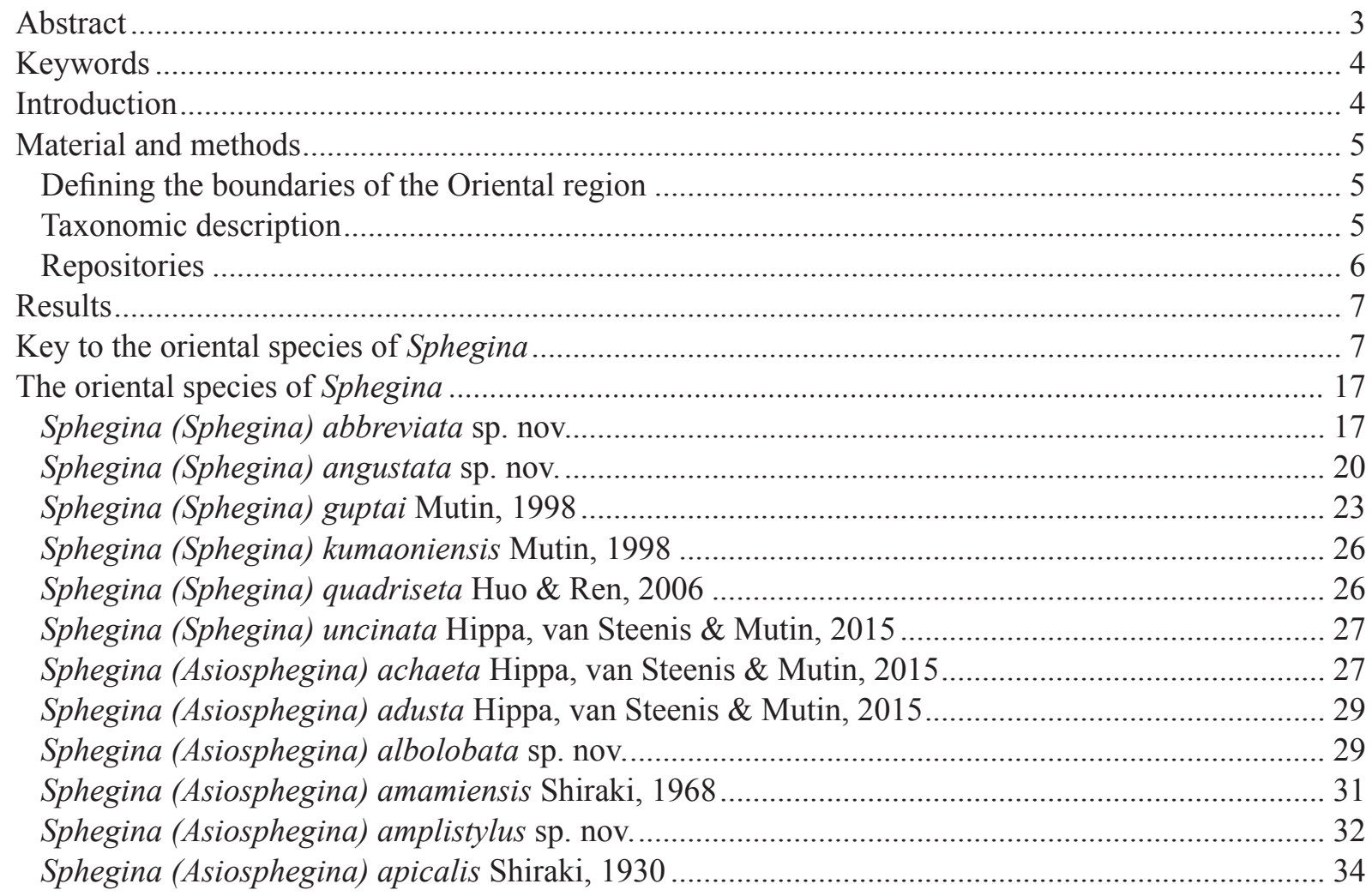




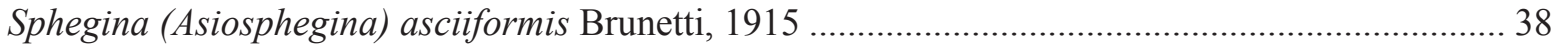

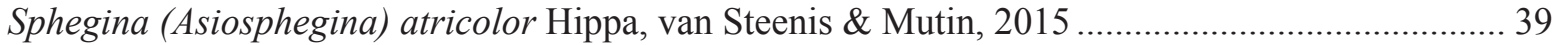

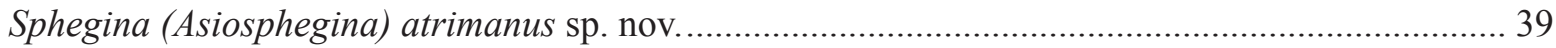

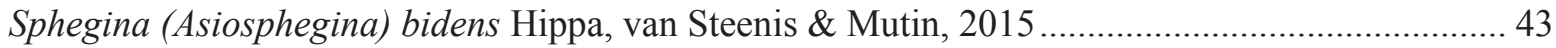

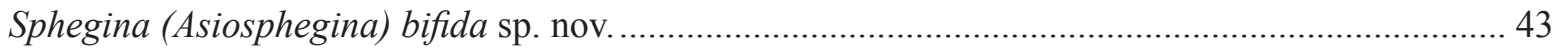

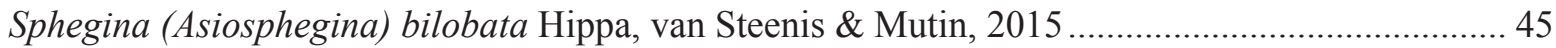

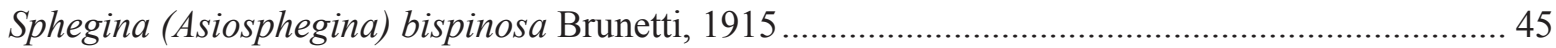

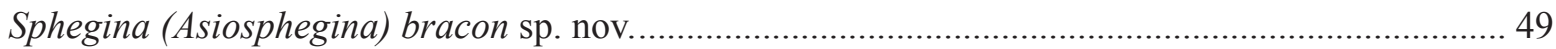

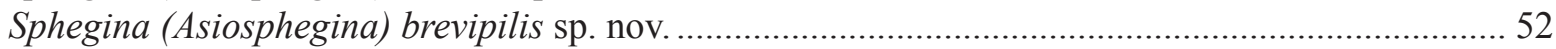

Sphegina (Asiosphegina) carinata Hippa, van Steenis \& Mutin, 2015 ........................................... 55

Sphegina (Asiosphegina) cerina Hippa, van Steenis \& Mutin, 2015 ................................................ 55

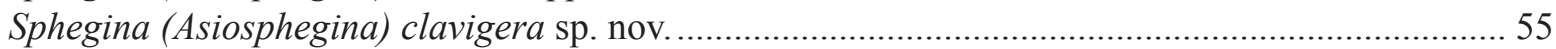

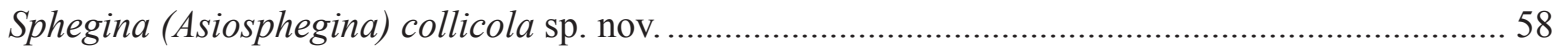

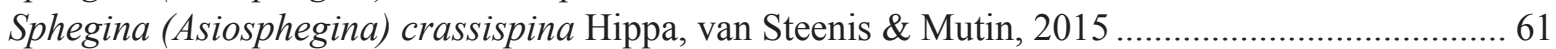

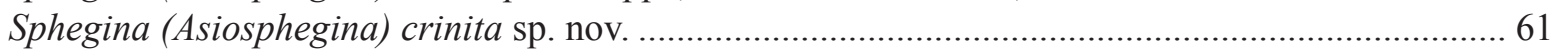

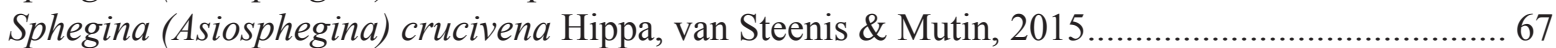

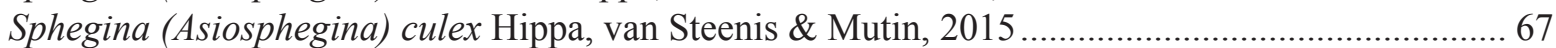

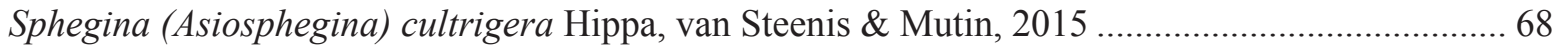

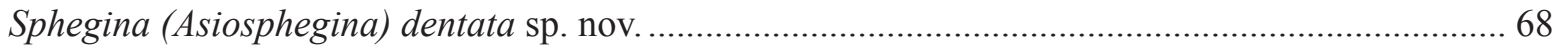

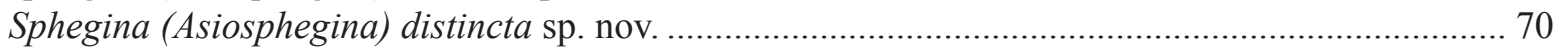

Sphegina (Asiosphegina) ensifera Hippa, van Steenis \& Mutin, 2015 ............................................. 71

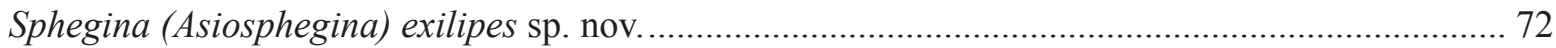

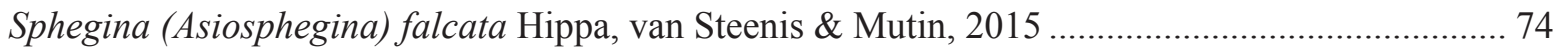

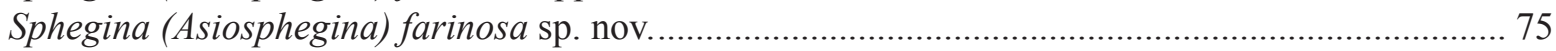

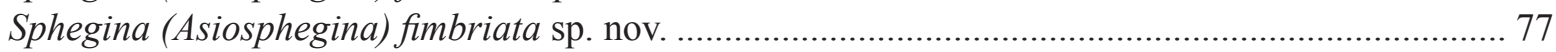

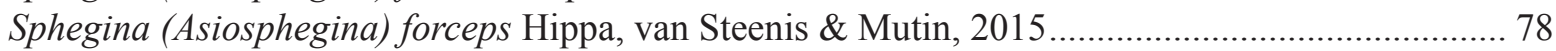

Sphegina (Asiosphegina) forficata Hippa, van Steenis \& Mutin, 2015 ............................................. 79

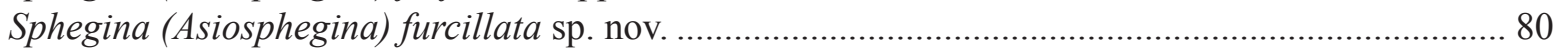

Sphegina (Asiosphegina) furva Hippa, van Steenis \& Mutin, 2015 ................................................. 83

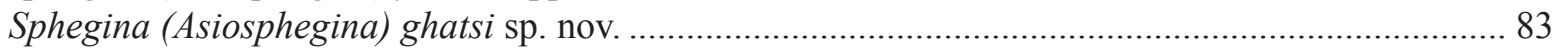

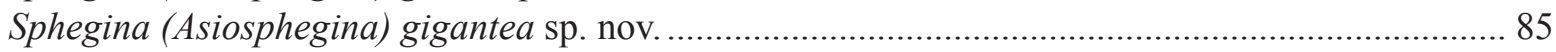

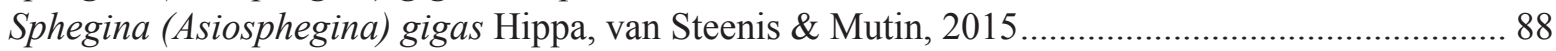

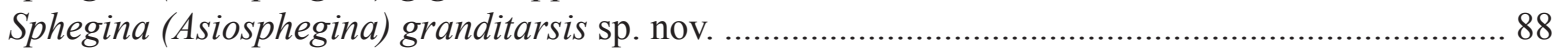

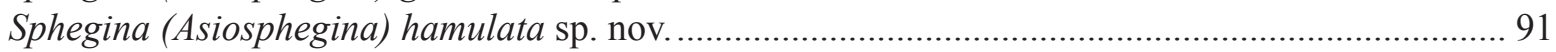

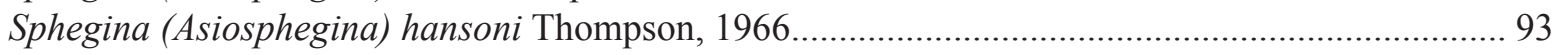

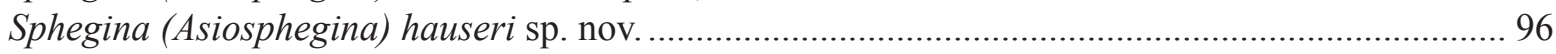

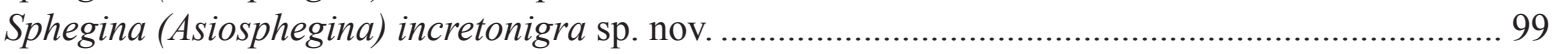

Sphegina (Asiosphegina) index Hippa, van Steenis \& Mutin, 2015............................................ 102

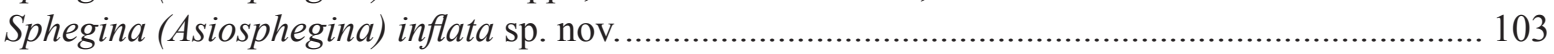

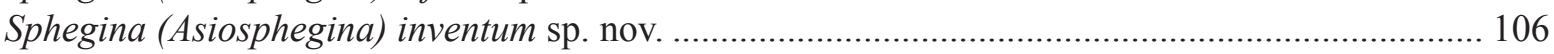

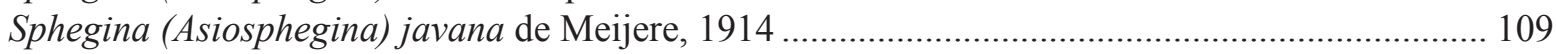

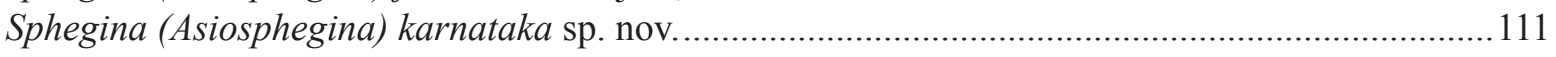

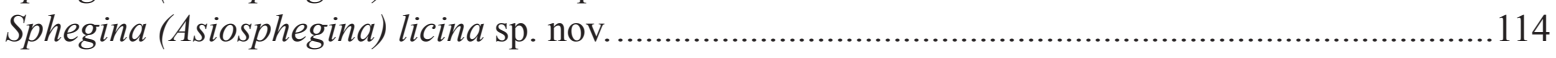

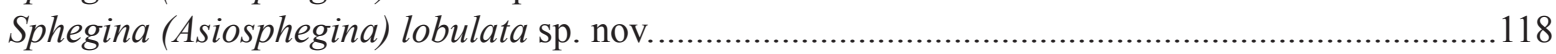

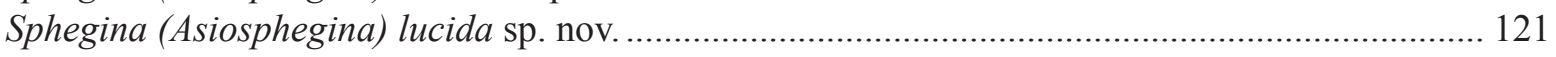

Sphegina (Asiosphegina) malaisei Hippa, van Steenis \& Mutin, 2015 ........................................ 124

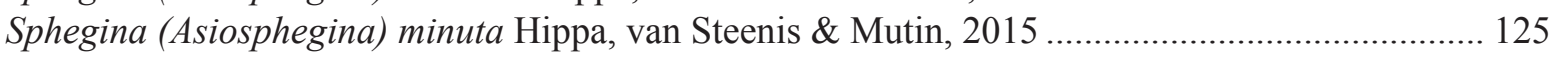

Sphegina (Asiosphegina) mirifica Hippa, van Steenis \& Mutin, 2015 ........................................ 125

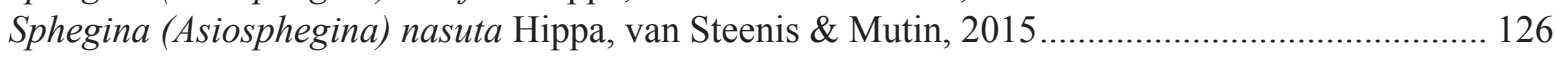

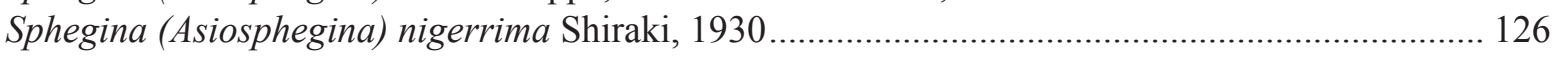




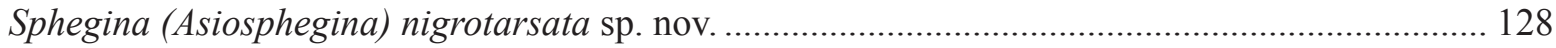

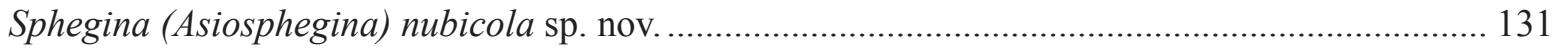

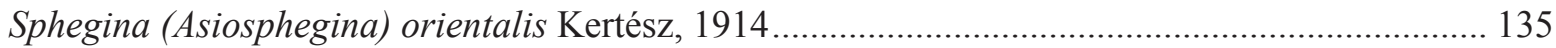

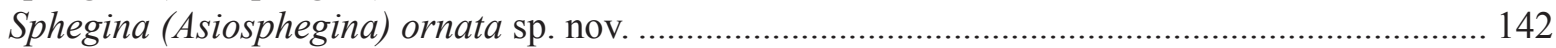

Sphegina (Asiosphegina) parvula Hippa, van Steenis \& Mutin, 2015 ............................................. 145

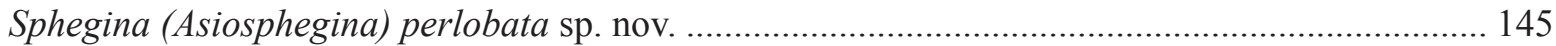

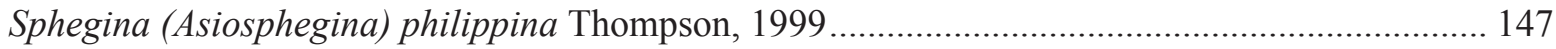

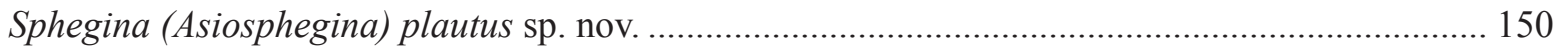

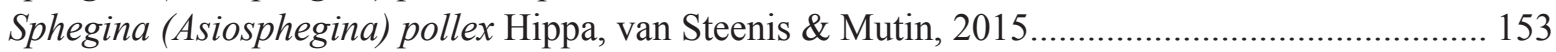

Sphegina (Asiosphegina) pollinosa Hippa, van Steenis \& Mutin, 2015 .......................................... 153

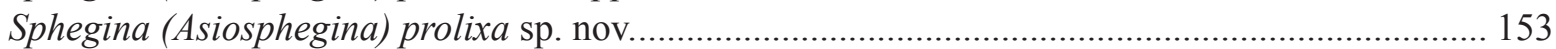

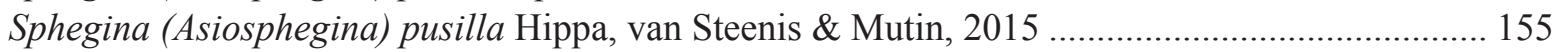

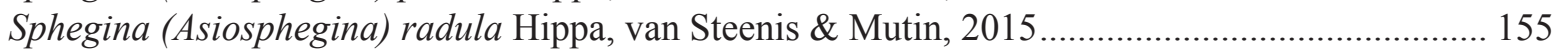

Sphegina (Asiosphegina) raduloides Hippa, van Steenis \& Mutin, 2015 ...................................... 155

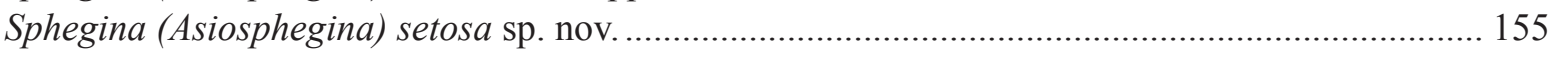

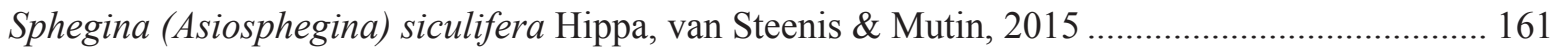

Sphegina (Asiosphegina) simplex Hippa, van Steenis \& Mutin, 2015 .......................................... 161

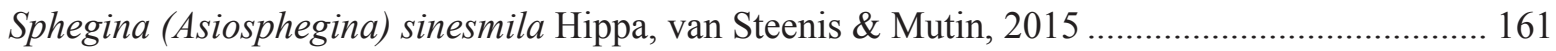

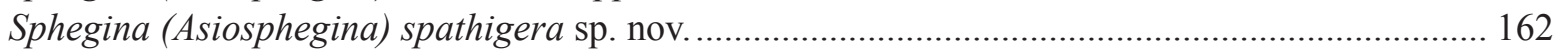

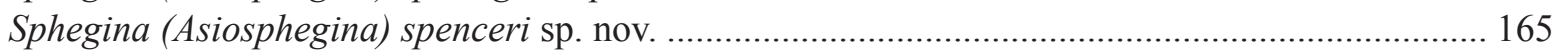

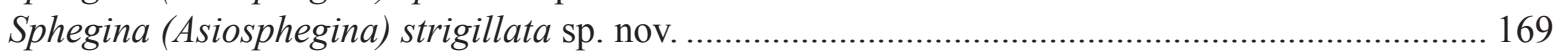

Sphegina (Asiosphegina) subradula Hippa, van Steenis \& Mutin, 20151 .................................... 172

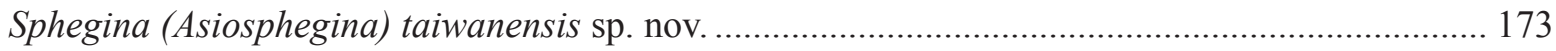

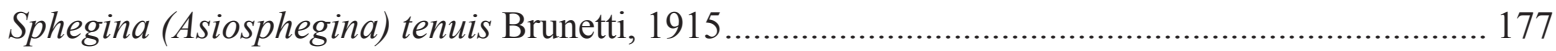

Sphegina (Asiosphegina) trichaeta Hippa, van Steenis \& Mutin, 2015 ......................................... 178

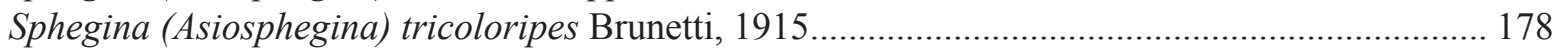

Sphegina (Asiosphegina) trispina Hippa, van Steenis \& Mutin, 2015 ........................................ 180

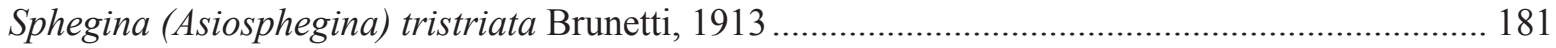

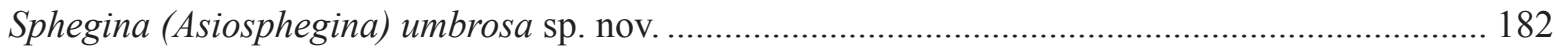

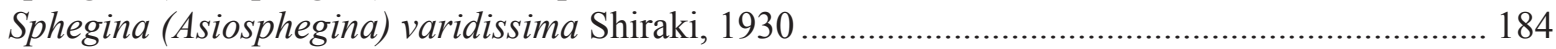

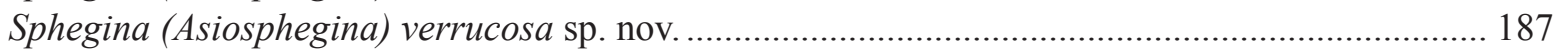

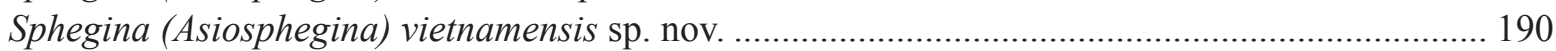

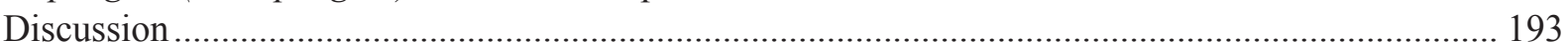

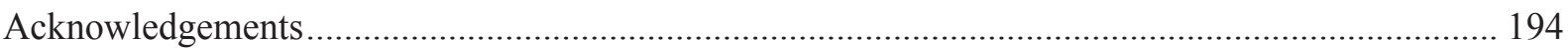

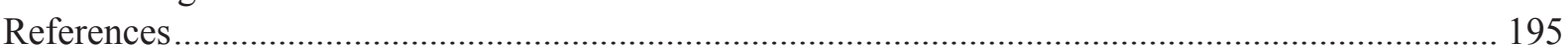

Abstract. The Oriental species of the genus Sphegina Meigen, 1822 are revised. The following 43 new species are described: Sphegina (Sphegina) abbreviata sp. nov. (Nepal), S. (S.) angustata sp. nov. (Nepal), S. (Asiosphegina) albolobata sp. nov. (Vietnam), S. (Asiosphegina) amplistylus sp. nov. (Philippines), S. (A.) atrimanus sp. nov. (Vietnam), S. (A.) bifida sp. nov. (Sabah, Malaysia), S. (A.) bracon sp. nov. (Vietnam), S. (A.) brevipilis sp. nov. (China), S. (A.) clavigera sp. nov. (Vietnam), $S$. (A.) collicola sp. nov. (Malaysia), $S$. (A.) crinita sp. nov. (Java, Indonesia; Malaysia), S. (A.) dentata sp. nov. (Taiwan), S. (A.) distincta sp. nov. (Vietnam), S. (A.) exilipes sp. nov. (Java, Indonesia), S. (A.) farinosa sp. nov. (Sabah, Malaysia), S. (A.) fimbriata sp. nov. (Thailand), S. (A.) furcillata sp. nov. (Vietnam), S. (A.) ghatsi sp. nov. (India), S. (A.) gigantea sp. nov. (China), S. (A.) granditarsis sp. nov. (China), S. (A.) hamulata sp. nov. (India), S. (A.) hauseri sp. nov. (Nepal), S. (A.) incretonigra sp. nov. (Vietnam), S. (A.) inflata sp. nov. (Philippines), S. (A.) inventum sp. nov. (Sabah, Malaysia), S. (A.) karnataka sp. nov. (India), S. (A.) licina sp. nov. (Thailand), S. (A.) lobulata sp. nov. (Vietnam), S. (A.) lucida sp. nov. (Vietnam), S. (A.) nigrotarsata sp. nov. (Vietnam), S. (A.) nubicola sp. nov. 
(Thailand), S. (A.) ornata sp. nov. (China), S. (A.) perlobata sp. nov. (Taiwan), S. (A.) plautus sp. nov. (China), $S$. (A.) prolixa sp. nov. (Malaysia, Thailand), $S$. (A.) setosa sp. nov. (Nepal, India), S. (A.) spathigera sp. nov. (Philippines), S. (A.) spenceri sp. nov. (Vietnam), S. (A.) strigillata sp. nov. (Vietnam), S. (A.) taiwanensis sp. nov. (Taiwan), S. (A.) umbrosa sp. nov. (China), S. (A.) verrucosa sp. nov. (Vietnam) and $S$. (A.) vietnamensis sp. nov. (Vietnam). Sphegina. (A.) tenuis Brunetti, 1915 is not a synonym of $S$. (A.) javana de Meijere, 1914. The males of $S$. (A.) apicalis Shiraki, 1930, S. (A.) tricoloripes Brunetti, 1915 and $S$. (A.) varidissima Shiraki, 1930 and the females of $S$. (A.) achaeta Hippa, van Steenis \& Mutin, 2015, S. (A.) index Hippa, van Steenis \& Mutin, 2015, S. (A.) mirifica Hippa, van Steenis \& Mutin, 2015 and S. (S.) quadriseta Huo \& Ren, 2006 are described for the first time. Sphegina (S.) quadriseta is recorded for the first time in the Oriental region. A key to all the Oriental species of Sphegina is provided. The Oriental fauna of Sphegina now comprises 94 species.

Keywords. Revision, Diptera, Syrphidae, Sphegina, Oriental region, new species.

Van Steenis J., Hippa H. \& Mutin V.A. 2018. Revision of the Oriental species of the genus Sphegina Meigen, 1822 (Diptera: Syrphidae). European Journal of Taxonomy 489: 1-198. https://doi.org/10.5852/ejt.2018.489

\section{Introduction}

The genus Sphegina Meigen, 1822 is Holarctic-Oriental in distribution with 120 described species, of which 72 are Holarctic and 49 Oriental (Pape \& Evenhuis 2018; Hippa et al. 2015). Milesia clunipes Fallén, 1817 was designated as type species of Sphegina by Westwood (1840). There is still an unsettled problem concerning the identity of the type species because Meigen's concept of $S$. clunipes applies to S. elegans Schummel, 1843 (Thompson \& Torp 1986). Stackelberg (1953) divided Sphegina into two subgenera, $S$. (Sphegina) and $S$. (Asiosphegina), but it was not until twenty years later that $S$. sibirica Stackelberg, 1953 was designated as the type species of $S$. (Asiosphegina) (Stackelberg 1974).

The systematic position of Sphegina has been discussed by different authors (Thompson 1972; Rotheray \& Gilbert 1999; Ståhls et al. 2003; Hippa \& Ståhls 2005; Reemer \& Ståhls 2013). It is often placed, together with its sister group Neoascia Williston, 1886 (type species Syrphus podagricus Fabricius, 1775) in the tribe Chrysogastrini in the Syrphidae subfamily Eristalinae. In the two most recent papers based on cladistic analyses these genera were given a different position. Hippa \& Ståls (2005) regarded Sphegina + Neoascia as the sister group of all other Syrphidae and Reemer \& Ståls (2013) placed Neoascia (Sphegina was not included) as the sister group of all other Syrphidae, excluding Microdontinae.

There has been no phylogenetic analysis concerning the genus Sphegina and hence neither the monophyly of its subgenera or the interrelationships of its species are known.

The adults of Sphegina are small to medium-sized, slender Syrphidae with a petiolate abdomen and incrassate metafemur. In flight they recall sphecid or ichneumonid wasps due to the seemingly long hind legs which they often carry hanging down (Röder 1990; Maibach 1993; Torp 1994). For more discussion on the morphological characters and biology of the genus, see Hippa et al. (2015).

A few of years ago, we (Hippa et al. 2015) described the remarkable species diversity of Sphegina found in Kambaiti, Myanmar, with nearly forty sympatric species. The aim of the present work is to review the entire Oriental fauna of Sphegina and describe and name the numerous undescribed species available to us. We also provide redescriptions, based on the study of available type material, of all Oriental Sphegina described prior to our earlier paper (Hippa et al. 2015). 


\section{Material and methods}

\section{Defining the boundaries of the Oriental Region}

The Oriental region, as defined by Udvardy (1975) and Takhtajan et al. (1986) as the Indomalayan Realm or Subkingdom, comprises the tropical ecosystem of the Eurasian continent and of the neighbouring southeast Asian archipelago. The western boundary lies at the western end of the Thar desert (eastern Pakistan). The northern boundary lies along the southern slopes of the Himalaya (latitude $28^{\circ} \mathrm{N}$ ) and, in China, along the northern borders of the Thailandian monsoon forest and south Chinese rainforest (i.e., including the provinces of Fujian, Guangdong, Guanxi and Yunnan and the southern parts of the provinces Zhejiang, Jiangxi and Sichuan up to a latitude of $30^{\circ} \mathrm{N}$ ). The north-eastern border is formed by Taiwan and the Ryukyu islands in the East China sea. The south-eastern border is along the line of Wallace, which is not quite settled yet (Cox 2001; Holt et al. 2013; Kreft \& Jetz 2013), but here the Lesser Sunda Islands, Celebes and the Philippines are included. The old Japanese names of localities in Taiwan are converted into currently used Taiwanese names based on the list given by Kojima et al. (2011).

\section{Taxonomic description}

The terminology used is based on Thompson (1999a) and Hippa et al. (2015). Concerning the latter, the sterna V, VI and VII should have been VI, VII and VIII as they are used in the present paper. In the key and descriptions 'singular' is used to characterize a pair of symmetrical structures, including lateral pollinose maculae on frons and maculae on the terga as well as legs and wings.

The metafemur is either bicoloured, with basal part yellow and apical part black, or biannulated, meaning that the femur is alternating yellow-black-yellow-black annulated. In some specimens with annulated metafemur, the subapical annulus is darker yellow than the basal annulus, often even tawny or reddish. The measurements of the metafemur and metabasitarsus are done in the same way; the length is measured from the base to the apex and the width is measured from the dorsal margin to the ventral margin. These and other measurements, such as the width of the vertex at the anterior ocellus, the width of the head, the width of the ocellar triangle, the length of the ocellar triangle and the length of the frons; the measurements of the basoflagellomere; the length of the scutellum; and the length of the scutellar setae are shown in Figs 3, 11, 13, 19 and 43. The terms tergum (terga) and sternum (sterna) refer to the abdominal terga or sterna.

The preparation of the descriptions and drawings were done as explained in Hippa et al. (2015). Photographs were taken with a Canon EOS 6D camera attached to a Leica Wild M10 stereo microscope. Lighting was provided by 3 flashlights (Yongnuo Speedlite YN600EX-RT) positioned so that the specimens were illuminated from the side. Multiple photos for each specimen were processed with a stacking program (Zerene Stacker version 1.04) and further edited with the photoshop program GIMP ver. 2.8.14. Measurements were taken with the aid of an ocular grid in one of the eyepieces of the Leica Wild M10 stereo microscope.

All the species are extensively described, except for those recently described from Myanmar (Hippa et al. 2015). For several species only, males have been included in the type material as, in most cases, only the male genitalia provide characters for secure species identification. Females have only been included in the type material if we were convinced of the conspecificity. In several cases where the conspecificity was ambiguous, the label information of the specimens is given under 'Additional material' and the matter is discussed under 'Remarks', where necessary. The key is based on male characters only. Some of the characters used also apply to females which means that it is also possible to identify several species from females as well using the key. In order to give the exact label information, the following symbols were used: quotation marks to indicate the separate labels; a slash to separate different lines 
on the same label; square brackets to indicate obvious but missing information; if relevant, the colour and shape of labels is given between square brackets. The transcription of Japanese characters was not always possible, in such cases a cross is used for each letter. The geocoordinates have been standardised and the label citations separated into data fields using semicolons to facilitate data mining and harvesting.

\section{Repositories}

The material studied is preserved in the following collections referred to in the text by their acronyms:

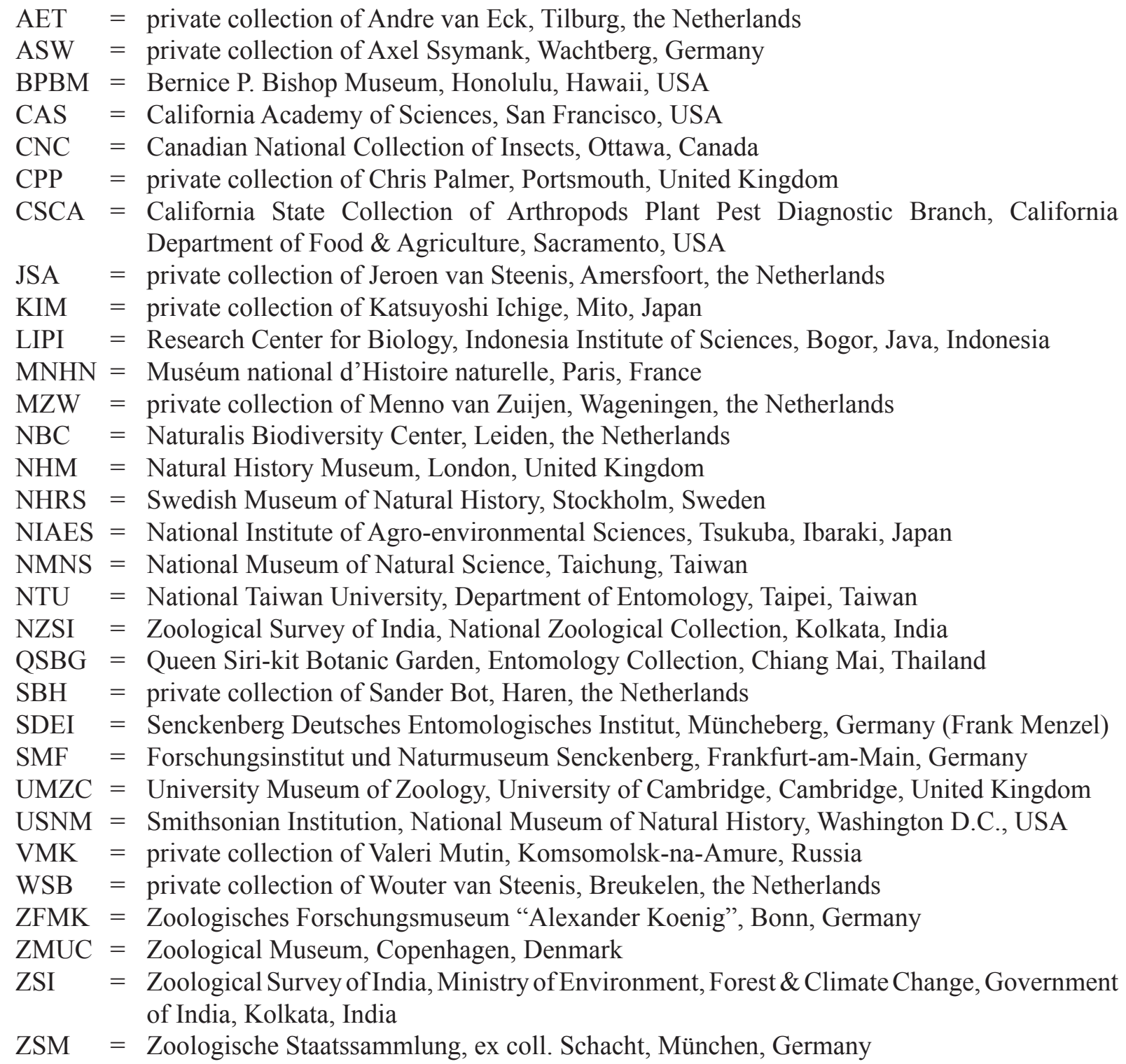




\title{
Results
}

\author{
Class Insecta Linnaeus, 1758 \\ Order Diptera Linnaeus, 1758 \\ Family Syrphidae Latreille, 1802 \\ Subfamily Eristalinae Newman, 1834 \\ Genus Sphegina Meigen, 1822
}

\section{Key to the Oriental species of Sphegina}

1. Sternum I quadratic to oval in shape, pilose; postmetacoxal bridge narrow, arcuate or with large dorso-medial subtriangular incision. (Subgenus Sphegina Meigen, 1822)

- Sternum I narrow lanceolate, several times as long as wide or membranous, non-pilose; postmetacoxal bridge wide, its dorsal margin almost straight, at most with small subtriangular medial incision. (Subgenus Asiosphegina Stackelberg, 1974)

2. Scutellum with 4 long setae at posterior margin; occiput on postero-lateral side of ocellar triangle with very long and strong black pile (Fig. 3E)

S. (S.) quadriseta Huo \& Ren, 2006

- Scutellum with 2 long setae at posterior margin; pile on occiput rather short, of even length throughout (Fig. 3C) ...

3. Tergum III black, with yellow anterior fascia

S. (S.) guptai Mutin, 1998

- Tergum III entirely dark brown to black

4. Terga of nearly uniform width, only slightly widening towards posterior end of tergum IV; frontal prominence rather strongly protruding (Fig. 3C) 5

- Terga widening from posterior end of tergum II towards posterior end of tergum III, then narrowing towards posterior end of tergum IV; frontal prominence very strongly protruding 6

5. Ventral part of face yellow, dorsal part greyish-black; metatibia of nearly uniform width throughout (Fig. 19A); genitalia, Fig. 1B-D

S. (S.) abbreviata sp. nov.

- Face entirely yellow (Fig. 3C); metatibia clearly widened at apical 1/5, club shaped (Fig. 19B); genitalia, Fig. 4B-D

S. (S.) angustata sp. nov.

6. Dorsal line of frontal prominence in profile straight, ending just before the ocellar triangle; mouth edge strongly projecting, vibrissal angle more strongly protruding than the frontal prominence ......................................................... (S.) uncinata Hippa, van Steenis \& Mutin, 2015

- Dorsal line of frontal prominence in profile convex, ending clearly before the ocellar triangle; mouth edge less strongly projecting, vibrissal angle equally or less protruding than the frontal prominence

S. (S.) kumaoniensis Mutin, 1998

7. Tergum I with a horizontal row of 2-4 strong black to yellow setae at lateral margin (e.g., Figs 13B-

C, E, 47B-C, F), in some specimens only one seta is present

- Tergum I with an oblique, sometimes almost transverse row of 3-5 dark brown to light yellow setae or seta-like pile deviating from the other vestiture on the posterolateral part (e.g., Figs 13A, D, 47A, D-E) or without marginal seta-like pile

8. Sternum IV posteriorly with conspicuous long or short, often dark brown to black, setae in an asymmetrical pattern, deviating strongly from other vestiture (e.g., Figs 16A, 17A, 27A, 37B, 42B); surstyli strongly asymmetric (e.g., Figs 16A, 27C, E, 37C, E), in exceptional cases almost symmetrical (e.g., Fig. 42C, E) ... 
- Sternum IV posteriorly at most with groups of longer light yellow seta-like pile in a symmetrical pattern, deviating only slightly from other vestiture, (e.g., Figs 7A, 8A, 12A, 14A, 18A); surstyli almost symmetrical (e.g., Figs 7B, D, 8B, D, 12B, D, 14B, D, 18B-C) ……………………...... 34

9. Wing with infuscate pattern at transverse veins and apex (e.g., Figs 10E, 15D, F) ...................... 10

- Wing hyaline, without infuscate pattern (e.g., Figs 15A, 28C, 35C) ………………………......... 17

10. Sternum I with 2-3 black setae at lateral margin, placed posteriorly (Fig. 13B); metafemur with 1-3 long sub-apical setae antero-dorsally (sometimes these setae are broken off and the sockets may be very hard to see) (Figs 52A, 72E-F); wing vein $\mathrm{R}_{2+3}$ subapically without an appendix (e.g., Figs 10E,

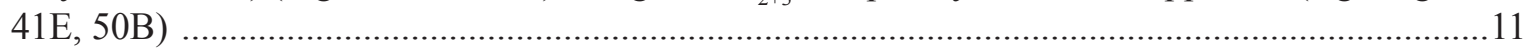

- Sternum I with 2 black setae at lateral margin which are very widely separated, one placed anteriorly the other posteriorly (Fig. 13C); metafemur without long sub-apical setae antero-dorsally (Fig. 33A); wing vein $\mathrm{R}_{2+3}$ with a subapical appendix (e.g., Figs 15F, 23B, 25D) ......................................... 15

11. Metatrochanter with dark brown transverse carina (as in Fig. 72A) ............................................ 12

- Metatrochanter simple, without dark brown transverse carina (Figs 52B, 72E) .......................... 14

12. Sternum IV posteriorly with 8 very long and strong setae on left side, grouped in two separate groups, the most lateral 3 setae clearly stronger than the 5 more medial ones (Fig. 42B); genitalia, Fig. 42C-F ..................................................................................... (A.) hansoni Thompson

- Sternum IV posteriorly with 2 or 3 long and strong setae on left side (Fig. 71B) ......................... 13

13. Sternum IV posteriorly on the left side with 2 very long and strong and several very small black

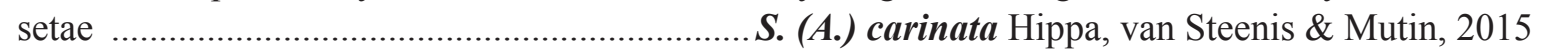

- Sternum IV posteriorly on the left side with 3 rather long and strong and several small black setae (Fig. 71B); genitalia, Fig. 71C-E

S. (A.) ornata sp. nov.

14. Sternum IV with strong posterior setae on left side only slightly longer than those on right side; sternum VII with a long finger-like process anteriorly and a wide conical tubercle posteriorly ............................................................... (A.) index Hippa, van Steenis \& Mutin, 2015

- Sternum IV with strong posterior setae on left side much longer and stronger than on right side (Fig. 16A); sternum VII with a large conical and setose tubercle medially (Fig. 16B); genitalia, Fig. 16C-E .................................................................................... S. (A.) bispinosa Brunetti, 1915

15. Wing with crossvein between $\mathrm{R}_{1}$ and $\mathrm{R}_{2+3}$ (Fig. 41F); scutellum subtriangular with marginal setae short, about as long as length of scutellum; genitalia, Fig. 44B-D ...............S. (A.) hauseri sp. nov.

- Wing without crossvein between $\mathrm{R}_{1}$ and $\mathrm{R}_{2+3}$ (Figs $15 \mathrm{~F}, 23 \mathrm{~B}, 25 \mathrm{D}$ ); scutellum subtriangular to slightly semicircular, with marginal setae long, almost twice as long as scutellum (Fig. 13C) ..... 16

16. Metafemur black with basal 1/4-1/3 yellow; scutellum subtriangular, light to dark brown

S. (A.) crassispina Hippa, van Steenis \& Mutin, 2015

- Metafemur black with basal 1/2 yellow; scutellum semi-circular, black; genitalia, Fig. 20C-E .........

S. (A.) clavigera sp. nov.

17. Metatrochanter with dark brown transverse carina (Fig. 72A); sternum VII with a finger-like process anteriorly and a conical tubercle more posteriorly

S. (A.) malaisei Hippa, van Steenis \& Mutin, 2015

- Metatrochanter simple, without carina (e.g., Figs 33F-G, 95B); sternum VII without modifications (e.g., Fig. 40A), with conical tubercle anteriorly (e.g., Figs 17B, 37A, 80A) or if with long fingerlike process then without additional conical tubercle (e.g., Figs 27B, 85A) ..... 18 
18. Metafemur with 1-3 long sub-apical setae on antero-dorsal surface (Fig. 33G) …...................... 19

- Metafemur without long sub-apical setae on antero-dorsal surface

19. Sternum IV posteriorly with 4 evenly long black setae on left side (Fig. 37B); tubercle on sternum VII with normal pile and seta-like pile (Fig. 37A); genitalia, Fig. 37C-E

S. (A.) gigantea sp. nov.

- Sternum IV posteriorly with 5 long setae on left side, gradually diminishing in length towards medial line or with 3 very long black setae; tubercle on tergum VII with normal pile only

20. Pro- and mesofemur yellow, metafemur yellow on basal $1 / 4-1 / 3$; vein dm-cu strongly oblique and clearly narrower than other nearby veins; tergum I with 3 black setae at lateral margin; tergum III with anterior $1 / 4$ yellow; sternum IV posteriorly on left side with 5 long setae, gradually diminishing in length towards medial line

S. (A.) gigas Hippa, van Steenis \& Mutin, 2015

- Pro- and mesofemur black, metafemur black except narrowly yellow at base; vein dm-cu slightly oblique, as wide as other nearby veins; tergum I with 2 black setae at lateral margin; tergum III with anterior $1 / 3$ yellow; sternum IV posteriorly on the left side with 3 very long black setae and some very short ones more medially S. (A.) trispina Hippa, van Steenis \& Mutin, 2015

21. Sternum IV posteriorly on the left side with 2-4 longer setae set apart from other setae and setulae (e.g., Figs 17A, 27A, 80B) 22

- Sternum IV posteriorly with variable shorter and stronger setulae, without very long setae to the left only (Figs 40A, 57A-C, 58A)

22. Sternum IV posteriorly on the left side with about 4 strong black setae, only slightly longer than other setae on left side, the second seta from left is clearly longer and stronger than the fine ones (Figs 80B, 81B); sternum VII with long setose rounded tubercle (Figs 80A, 81A); genitalia, Figs 80C-E, 81CE S. (A.) setosa sp. nov.

- Sternum IV posteriorly on the left side with 2 or 3 long setae, clearly longer than the fine setae (e.g., Figs 17A, 27A, 85B); sternum VII with conical tubercle without long setae (e.g., Figs 17B, 96A) or with elongate and apically bent finger-like tubercle (Figs 27B, 85A)

23. Sternum IV posteriorly on the left side with 2 longer setae set apart from other setae and setulae (e.g., Figs 17A, 85B); metafemur black and yellow biannulate

- Sternum IV posteriorly on the left side with 3 longer setae set apart from other setae and setulae (Figs 27A, 96B); metafemur bicoloured or biannulate

24. Frons with rectangular light grey pollinose vitta along eye-margin (Fig. 88B); sternum IV posteriorly on the left side with the 2 lateral most strong setae twice as long as the more medial ones on the left side (Fig. 85B); sternum VII short pilose, with elongate finger-like process with curved apex (Fig. 85A); ventral lobe of right surstylus simple (Fig. 85C-E)

S. (A.) spenceri sp. nov.

- Frons with subtriangular light grey pollinose macula at eye-margin (Figs $21 \mathrm{G}, 88 \mathrm{~L}$ ); sternum IV posteriorly on the left side with the 2 lateral most strong setae very long, more than 5 times as long as the other setae (Figs 17A, 34B, 98A); sternum VII with a large rounded conical process with a sharp apical projection (Figs 17B, 34A, 98B); ventral lobe of right surstylus bifid (Figs 17C-E, 34C-E, 98C-G)

25. Genitalia, Fig. 98C-G: superior lobe on the right side with the longer one of the postero-ventral sublobes long, as long as the main part of superior lobe S. (A.) vietnamensis sp. nov.

- Genitalia, Figs 17C-E, 34C-E: superior lobe on right side with the longer one of the posteroventral sublobes short, much shorter than the main part of superior lobe 
26. Genitalia, Fig. 17C-E: superior lobe on the left side with the more anterior one of the postero-ventral sublobes large, several times as long as basally wide, curved, the more posterior one of the sublobes scarcely observable

S. (A.) bracon sp. nov.

- Genitalia, Fig. 34C-E: superior lobe on the left side with the more anterior one of the postero-ventral sublobes small, ca twice as long as basally wide, slightly angled, the more posterior one of the sublobes large

S. (A.) furcillata sp. nov.

27. Metafemur black and yellow biannulate; postpronotum yellow; genitalia, Fig. 27C-E

S. (A.) distincta sp. nov.

- Metafemur yellow on basal $1 / 4-1 / 6$ and black apically; postpronotum black 28

28. Surstyli almost symmetrical (Fig. 96C, E); mesofemur yellow; tergum III with anterior light yellow fascia (Fig. 97D); sternum IV with the longest strong setae longer than the width of sternum (Fig. 96B); genitalia, Fig. 96C-E

S. (A.) verrucosa sp. nov.

- Surstyli asymmetrical; mesofemur dark brown; tergum III with sub-anterior light yellow fascia; sternum IV with the longest strong setae less than half of the width of sternum

S. (A.) trichaeta Hippa, van Steenis \& Mutin, 2015

29. Frons black, shiny except for a small elongate densely grey-pollinose macula anterolaterally (Fig. 54H); postpronotum yellow; genitalia, Fig. 58B-D

S. (A.) lucida sp. nov.

- Frons black, mainly slightly grey-pollinose with subtriangular densely grey-pollinose macula anterolaterally (Fig. 38I); postpronotum black; genitalia, Figs 40B-D, 57D-G 30

30. Protarsus entirely black; sternum IV with posterior marginal area almost symmetrical, with symmetrical patches of long strong brown setae at posterolateral corner, the setae pale (Fig. 40A); genitalia, Fig. 40B-D

S. (A.) hamulata sp. nov.

- Protarsus yellow, with tarsomeres 4 and 5 dark brown to black; sternum IV with posterior marginal area asymmetrical, with asymmetrically placed strong setae or patches of strong setae, the setae at least partly black (e.g., Fig. 57A-C)

31. Scutellar marginal setae rather narrowly separated, distance between setae: length of scutellum 1: 1.4-2.0; genitalia, Fig. 57D-G S. (A.) lobulata sp. nov.

- Scutellar marginal setae very widely separated, distance between setae: length of scutellum 1: 0.91.1

32. Gena brown; metafemur with black setulae on yellow basal part; mesofemur dark brown to brown S. (A.) radula Hippa, van Steenis \& Mutin, 2015

- Gena yellow; metafemur with or without black setulae on yellow basal part; mesofemur brownyellow to yellow

33. Mesofemur entirely yellow; vein dm-cu slightly oblique to vein $M$ as wide as other nearby veins, vein $\mathrm{CuA}_{1}$ extending beyond $\mathrm{dm}$-cu; metafemur with black setulae in yellow basal part

S. (A.) raduloides Hippa, van Steenis \& Mutin, 2015

- Mesofemur dark brown; vein $\mathrm{dm}$-cu strongly oblique and clearly narrower than other nearby veins, vein $\mathrm{CuA}_{1}$ not extending beyond dm-cu; metafemur without black setulae in yellow basal part

S. (A.) subradula Hippa, van Steenis \& Mutin, 2015

34. Metafemur black on apical $1 / 2$ or more, yellow on basal part, or nearly entirely black; metatibia with large rounded apicoventral dens (e.g., Figs 19F, 33E, 52C); scutum entirely but weakly greypollinose 
- Metafemur black and yellow biannulate, or femur predominantly yellow; metatibia without apicoventral dens (e.g., Figs 19D, 33B), if with large rounded dens (Fig. 52F) then scutum with clear pollinose pattern

35. Scutellum semi-circular; sternum IV posteriorly on left side or medially with small lobe (Figs 36A, 78C)

- Scutellum sub-rectangular; sternum IV posteriorly on left side with large lobe (e.g., Figs 8A, 14A, 22B, 49A)

36. Vertex narrow, width of head about 6 times as wide as vertex (Fig. 38F); scutellum entirely grey pollinose; postpronotum yellow; sternum IV with weak postero-medial lobe (Fig. 36A); genitalia, Fig. 36B-D

S. (A.) ghatsi sp. nov.

- Vertex wide, head 4.5 times as wide as vertex (Fig. 84I); scutellum non-pollinose and shiny medially; postpronotum black; sternum IV posteriorly with short, rounded lobe on the left side (Fig. 78C); genitalia, Fig. 78A-B, D-F

S. (A.) prolixa sp. nov.

37. Sternum IV posteriorly on the left side with a wide bifid lobe (Figs 14A, 22B 49A) ................... 38

- Sternum IV posteriorly on the left side with a narrow simple lobe (e.g., Figs 8A, 48B) .............. 40

38. Vein dm-cu perpendicular to vein M; the bifid lobe posteriorly on sternum IV with both sublobes approximately equal in size (Fig. 14A); genitalia, Fig. 14B-D

S. (A.) bifida sp. nov.

- Vein dm-cu oblique to vein M; the bifid lobe posteriorly on sternum IV with the left side sublobe much narrower than the right side one (Figs 22B, 49A)

39. The sublobes of the bifid lobe posteriorly on sternum IV separated by a deep cleft (Fig. 49A); genitalia, Fig. 49B-D: dorsal and ventral lobe of surstylus posteriorly weakly separated

S. (A.) inventum sp. nov.

- The sublobes of the bifid lobe posteriorly on sternum IV separated by a shallow notch (Fig. 22B); genitalia, Fig. 22C-F: dorsal and ventral lobe of surstylus posteriorly separated by a deep notch

S. (A.) collicola sp. nov.

40. Postalar callus white to yellow; scutellum sub-rectangular; lobe posteriorly on sternum IV anteriorly narrow, rather straight and directed posteriorly (Fig. 83A); surstyli symmetrical, left surstylus not inflated, genitalia Fig. 83B-D

S. (A.) spathigera sp. nov.

- Postalar callus black; scutellum semi-circular; lobe posteriorly on sternum IV anteriorly wide and curved laterally (Figs 8A, 48A-B, 74A); surstyli asymmetrical, left surstylus strongly inflated, genitalia Figs 8B-D, 48C-D, 74B-F .

41. Postpronotum black; wing hyaline; genitalia, Fig. 8B-D

S. (A.) amplistylus sp. nov.

- Postpronotum yellow; wing with weak infuscate pattern; genitalia Figs 48C-D, 74B-F

42. Wing infuscated at junction of veins $\mathrm{R}_{2+3}$ and $\mathrm{R}_{4+5}$ and along vein $\mathrm{M}_{1}$; genitalia, Fig. 74B$\mathrm{F}$ S. (A.) philippina Thompson, 1999

- Wing only infuscated at junction of veins $\mathrm{R}_{2+3}$ and $\mathrm{R}_{4+5}$; genitalia, Fig. 48C-D

S. (A.) inflata sp. nov.

43. Wing brownish, without darker infuscated pattern; vein dm-cu meeting vein M obliquely

S. (A.) falcata Hippa, van Steenis \& Mutin, 2015

- Wing hyaline, infuscated apically and at cross-veins; vein $\mathrm{dm}$-cu meeting vein M perpendicularly 
44. Wing vein $\mathrm{R}_{2+3}$ with more or less developed subapical appendix (e.g., Figs 6C, 23E, 35B) ......... 45

- Wing vein $\mathrm{R}_{2+3}$ without subapical appendix (e.g., Figs $15 \mathrm{~B}, 41 \mathrm{C}, 45 \mathrm{~A}$ ) ……………………...... 50

45. Wing without extra crossvein between veins $R_{1}$ and $R_{2+3}$, at most with a short appendix from vein $\mathrm{R}_{2+3}$ into cell $\mathrm{r}_{1}$ (Fig. 35A-B); metafemur evenly curved and with many black setulae on basal yellow part (Fig. 33D)

S. (A.) forficata Hippa, van Steenis \& Mutin, 2015

- Wing with extra crossvein between $\mathrm{R}_{1}$ and $\mathrm{R}_{2+3}$ (e.g., Figs 6C, 23E); metafemur straight, without black setulae on basal yellow part (e.g., Fig. 33B)

46. Sternum IV posteriorly on the left side with a small subtriangular lobe (Figs 7A, 55A), if very small and indistinct then several black tooth-like setulae present on posterior part of sternum (Fig. 87A); genitalia: surstyli with clearly differentiated ventral lobe (Figs 7B, D, 55B, D, 87B, D)

- Sternum IV posteriorly concave, without lobe, without black setulae on posterior part; genitalia: surstyli with hardly differentiated ventral lobe

47. Face and mouth edge black; scutellum medially non-pollinose and shiny; sternum IV with yellowish pile and several black setulae on posterior part (Fig. 87A); genitalia, Fig. 87B-D

S. (A.) strigillata sp. nov.

- Face black, ventral half and mouth edge yellow to dark yellow; scutellum entirely grey pollinose but medially sub-shiny; sternum IV only with light yellow to brown pile

48. Eye with an area of enlarged facets at anterior margin; pro- and mesotarsus with tarsomeres 2-5 dark brown to black; mesofemur and tibia partly dark brown to black; sternum IV posteriorly with a subtriangular lobe on the left side (Fig. 7A); genitalia, Fig. 7B-D S. (A.) albolobata sp. nov.

- Eye without enlarged facets at anterior margin; pro- and mesotarsus with tarsomeres 3-5 dark brown to black; mesofemur and tibia entirely yellow; sternum IV posteriorly with a subtriangular lobe medially (Fig. 55A); genitalia, Fig. 55B-D

S. (A.) licina sp. nov.

49. Metafemur enlarged, slightly curved basally (Fig. 33B); tergum I with 3 strong setae at lateral margin (Fig. 13E)

S. (A.) crucivena Hippa, van Steenis \& Mutin, 2015

- Metafemur only slightly enlarged, club shaped; tergum I with 1-2 strong setae at lateral margin (Fig. 77A) S. (A.) mirifica Hippa, van Steenis \& Mutin, 2015

50. Basoflagellomere elongate, 1.5 times as long as high; frontal prominence protruding (e.g., Figs $38 \mathrm{H}$, 54E, 84C); postpronotum yellow to light-brown 51

- Basoflagellomere short, 1.1-1.3 times as long as high; frontal prominence at most slightly protruding; postpronotum dark brown to black 58

51. Scutum with very obvious pollinose pattern with more and less heavy pollinosity; metafemur strongly incrassate (Fig. 52F); crossvein dm-cu meeting vein M slightly obliquely; sternum IV posteriorly on the left side with a short and wide spoon-shaped lobe (Fig. 53A-B); genitalia, Fig. 53C-F

S. (A.) karnataka sp. nov.

- Scutum nearly entirely and evenly pollinose; metafemur slightly incrassate (e.g., Fig. 41C); crossvein dm-cu meeting vein M perpendicularly; sternum IV simple (e.g., Figs 12A, 66A) ....................... 52

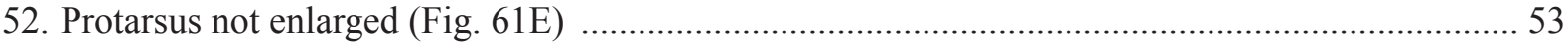

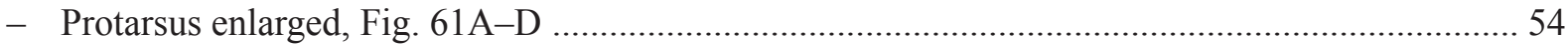

53. Frontal prominence short (Fig. 84L); protarsus with only tarsomeres 4 and 5 black; wing only infuscated along veins; sternum IV with almost straight posterior margin, without postero-lateral patch of long strong pile (Fig. 89A); genitalia, Fig. 89B-D S. (A.) taiwanensis sp. nov. 
- Frontal prominence long (Fig. 84C); protarsus with apex of tarsomeres 2 and 3 and entire tarsomeres 4 and 5 black; wing infuscated along veins and an apical macula; sternum IV with posterior margin deeply medially notched, with posterolateral patch of long strong pile (Fig. 66A); genitalia, Figs 66B-D, 68B-E, 69A-F

S. (A.) orientalis Kertész, 1914

54. Cerci elongate; surstylus large, as long as tergum IX, angle between dorsal and ventral lobe almost right; superior lobe elongate, several times as long as anteriorly wide (Figs 12B-D, 46B-D) .... 55

- Cerci short oval to trapezoidal; surstylus relatively small, shorter than tergum IX, angle between dorsal and ventral lobe acute; superior lobe subtriangular, at most twice as long as anteriorly wide (Figs 39B-E, 62B-D)

55. Protarsus with tarsomere 3 only medially and tarsomeres 4-5 entirely black; protarsus with basitarsomere short, clearly shorter than combined length of tarsomeres 2 and 3; dorsal lobe of surstylus elongate triangular, narrowing gradually towards apex

S. (A.) nasuta Hippa, van Steenis \& Mutin, 2015

- Protarsus with tarsomeres 4 and 5 black and either with tarsomere 3 entirely yellow or entirely black; protarsus with basitarsomere longer, about as long as combined length of tarsomeres 2 and 3; dorsal lobe of surstylus medially constricted, subapically widened

56. Protarsus with tarsomere 1 yellow, on apical half black and tarsomeres $2-5$ entirely black; tarsomere 2 relatively wide, 1.6 times as wide as tibia and only slightly longer than tarsomere 3 (Fig. 61A); genitalia, Fig. 12B-D

S. (A.) atrimanus sp. nov.

- Protarsus with tarsomeres 1 and 2 yellow, tarsomere 3 yellow, on apical half black and tarsomeres 4 and 5 entirely black; tarsomere 2 relatively narrow, 1.3 times wider than tibia and almost 1.5 times as long as tarsomere 3 (Fig. 61C); genitalia, Fig. 46B-D

S. (A.) incretonigra sp. nov.

57. Protarsus with tarsomere 1 yellow, black on apical half and tarsomeres $2-5$ entirely black; tarsomere 1 relatively short, about as long as combined length of tarsomeres 2 and 3; tarsomere 2 very wide, 1.8 times as wide as tibia (Fig. 61B); metafemur anteroventrally with long white pile, almost twice as long as black setae; metatibia without apicoventral dens; only tergum III with anterior yellow fascia; genitalia, Fig. 39B-D

S. (A.) granditarsis sp. nov.

- Protarsus with tarsomere 1 yellow with black sub-apical annulus, tarsomere 2 dark brown to black with basal $1 / 3$ yellow and tarsomeres 3-5 dark brown; tarsomere 1 relatively long, about as long as combined length of tarsomeres 3, 4 and 5; tarsomere 2 rather wide, 1.3-1.5 times as wide as tibia (Fig. 61D); metafemur anteroventrally with short white pile, only slightly longer than black setae; metatibia with narrow apicoventral dens; terga III and IV with yellow anterior fascia (Figs 59F, 63D); genitalia, Fig. 62B-D

S. (A.) nigrotarsata sp. nov.

58. Tergum II dark with anterior yellow fascia; tergum III nearly entirely yellow; thorax light yellow (brownish yellow) with medial and sub-lateral dark brown vittae ....S. (A.) tristriata Brunetti, 1913

- Tergum II black or black with brown to yellow anterior fascia; tergum III black with at most anterior $1 / 3$ yellow; thorax unicolorous dark 59

59. Frontal prominence large, clearly protruding beyond eye in profile; protarsus yellow, in some specimens tarsomere 5 brownish; scutellum sub-rectangular

S. (A.) bidens Hippa, van Steenis \& Mutin, 2015

- Frontal prominence small, at most slightly protruding beyond eye in profile; protarsus yellow with at least tarsomere 5 black; scutellum semi-circular 
60. Face with ventral half yellow to brown-yellow, moderately projected antero-ventrally; protarsus dark brown to black with tarsomeres 1 and 2 yellow; tergum III with anterolateral red macula (Fig. 90A) S. (A.) simplex Hippa, van Steenis \& Mutin, 2015

- Face all black, mouth edge sometimes dark brown, very weakly projected antero-ventrally; protarsus yellow with either tarsomeres 4 and 5 or only tarsomere 5 dark brown to black; tergum III with red to yellow anterior fascia (Fig 70F)

61. Protarsus yellow with tarsomere 5 black, tarsomeres $2-5$ slightly widened (Fig. 61F); genitalia, Fig. 76B-C S. (A.) plautus sp. nov.

- Protarsus yellow with tarsomeres 4 and 5 dark brown to black, tarsomeres of normal width; genitalia, Fig. 18B-C S. (A.) brevipilis sp. nov.

62. Metafemur black and yellow biannulate (e.g., as in Figs 6F, 28B) or femur predominantly red to yellow (e.g., Figs 11E, 95E)

- Metafemur basally yellow, on apical $1 \frac{1}{2}$ or more black (e.g., Figs 19F, 28A), in some cases nearly entirely black

63. Wing with infuscate pattern at crossveins and on apex; thorax light yellow with three black vittae on the scutum; sternum IV with a pair of symmetrical sub medial lobes at posterior margin, the lobes with short black spinose setae (Fig. 11E)

S. (A.) bilobata Hippa, van Steenis \& Mutin, 2015

- Wing hyaline, without infuscate pattern; thorax dark, scutum unicolorous; sternum IV posteriorly unmodified or with one lobe asymmetrically on the left or right side, this lobe without spinose setae (Figs 9A, 31A, 64A, 94A)

64. Vein dm-cu meeting vein M perpendicularly; frontal prominence long (Fig. 38D), with distinct medial furrow; basoflagellomere elongate, 2.5 times as long as wide

S. (A.) forceps Hippa, van Steenis \& Mutin, 2015

- Vein dm-cu meeting vein M obliquely; frontal prominence short (Figs 30K, 38A) with weak medial furrow; basoflagellomere round to slightly elongate, 1.1-1.5 times as long as wide

65. Sternum IV with large bifid lobe posteriorly on right side

S. (A.) amamiensis Shiraki, 1968

- Sternum IV posteriorly without lobe or lobe is placed on the left side

66. Larger flies, length of body more than $6 \mathrm{~mm}$, pleuron extensively yellow or scutum with clear pollinose pattern (Figs 15E, 97B); metafemur predominantly orange-yellow (Fig. 95E); terga brownish

- Smaller flies, length of body less than $5.5 \mathrm{~mm}$, pleuron and scutum uniformly dark brown to black, sometimes scutum with pollinose pattern (e.g., Figs 6E-F, 28E, 63A); metafemur dark brown and yellow biannulate; terga black

67. Pleuron entirely grey pollinose, on bright orange parts sometimes sub-shiny; arista entirely pilose; sterna III and IV more quadratic, ratio length: width 1: 1.4 respectively 1: 0.60 S. (A.) cerina Hippa, van Steenis \& Mutin, 2015

- Pleuron with at least posterior margin of katepisternum non-pollinose and shiny (Fig. 65D); arista only basally pilose; sterna III and IV more elongate, ratio length: width $1: 2.5-2.7$ respectively 1 : $0.9-1.1$; genitalia, Fig. 94B-C S. (A.) varidissima Shiraki, 1930

68. Scutum with pollinose pattern (best viewed dorso-laterally) depending on different density of pollinosity (Fig. 28E); pale markings on tergum III clearly separated from anterior margin (Figs 10B, 70B) 
- Scutum with uniform dense pollinosity (Fig. 79F); pale markings on tergum III at most very narrowly separated from anterior margin (Fig. 79F) ......

69. Pro- and mesoleg entirely yellow

S. (A.) asciiformis Brunetti, 1915

- Pro- and mesoleg yellow with at least tarsomeres 4 and 5 dark brown to black

70. Scutellar marginal setae almost twice as long as length of scutellum and slightly wider set, $0.13-$ $0.19 \mathrm{~mm}$ apart; protarsus yellow with tarsomeres 3-5 darkened (dark brown to black); genitalia, Fig. 31B-C .

S. (A.) farinosa sp. nov.

- Scutellar setae short, at most as long as scutellum and closer set, 0.06-0.08 mm apart; protarsus yellow with tarsomeres 4 and 5 darkened (light-brown to black); genitalia (Figs 9B-E or 64BD)

71. Sternum IV simple, with only a weak rounded lobe posteriorly on left side (Fig. 64A); scutum rather uniformly pollinose; genitalia (Fig. 64B-D) S. (A.) nubicola sp. nov.

- Sternum IV posteriorly on the left side with large subtriangular lobe (Fig. 9A); scutum pollinose with more densely pollinose submedial vitta; genitalia (Fig. 9B-E)

S. (A.) apicalis Shiraki, 1930

72. Sternum IV posteriorly on the left side with yellowish sword-like lobe (Figs 79F, 82A) 73

- Sternum IV posteriorly on the left side without sword-like lobe, at most with short subtriangular lobe (Figs $63 \mathrm{~A}, 67 \mathrm{C}, 82 \mathrm{C}$ ) 75

73. Cercus slightly enlarged, shorter than surstylus; gena black

S. (A.) cultrigera Hippa, van Steenis \& Mutin, 2015

- Cercus strongly enlarged, as long as or longer than surstylus; gena brown 74

74. Cercus as long as surstylus; tergum III with red anterior fascia, 1.5 times as long as tergum IV

S. (A.) siculifera Hippa, van Steenis \& Mutin, 2015

- Cercus longer than surstylus; tergum III with yellow anterior fascia, 1.1 times as long as tergum IV

S. (A.) ensifera Hippa, van Steenis \& Mutin, 2015

75. Cerci asymmetric, greatly enlarged, longer than surstyli; tergum III with anterior yellow fascia

S. (A.) sinesmila Hippa, van Steenis \& Mutin, 2015

- Cerci symmetrical, slightly enlarged, shorter than surstyli; tergum III with sub-anterior yellow or reddish fascia

76. Sternum IV with conspicuous large subtriangular lobe at posterior margin; metatarsus with tarsomere 1 about 2.5 times as long as wide; frons with shiny fascia posteriorly of lunula; tergum III as long as tergum IV S. (A.) parvula Hippa, van Steenis \& Mutin, 2015

- Sternum IV with inconspicuous small lobe at posterior margin; metatarsus with tarsomere 1 about 3 times as long as wide; frons without shiny fascia posteriorly of lunula, entirely grey pollinose; tergum III longer than tergum IV

77. Tergum III 1.2 times as long as tergum IV; right side surstylus without a third lobe between the dorsal and ventral lobes; left side surstylus with a sub-lobe dorsally at the middle of its dorsal lobe S. (A.) minuta Hippa, van Steenis \& Mutin, 2015

- Tergum III 1.4 times as long as tergum IV; right side surstylus with a third lobe between the dorsal and ventral lobes, this lobe with a deep marginal incision; left side surstylus without a sub-lobe dorsally at the middle of its dorsal lobe

S. (A.) pusilla Hippa, van Steenis \& Mutin, 2015 
78. Larger-sized flies (8.3-8.5 mm); pro- and mesolegs unicoloured brown; terga III and IV unicolorous brownish-black (Fig. 10A)

S. (A.) adusta Hippa, van Steenis \& Mutin, 2015

- Smaller-sized flies (4.5-5.5 or 6.5-7.9 mm); pro- and mesolegs at least with basal two or three tarsomeres yellow; terga III and IV dark brown to black with anterior part of tergum III yellow, reddish or brown, paler than the rest of tergum

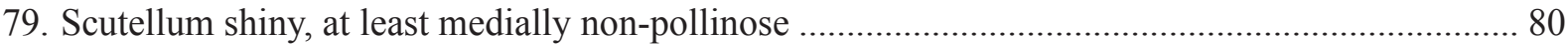

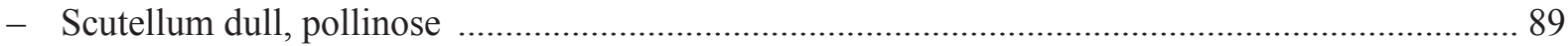

80. Scutum uniformly pollinose; arista long pilose (as in Fig. 43C) ................................................ 81

- Scutum slightly grey pollinose with more densely grey pollinose submedial vitta; arista long pilose (as in Fig. 43C) or only short pilose basally (Fig. 43A, D)

81. Ventral half of face and mouth edge yellow; postpronotum black; katepisternum entirely grey pollinose; genitalia, Fig. 73B-C

S. (A.) perlobata sp. nov.

- Mouth edge black contrasting with yellow ventral half of face; postpronotum yellow; posterior margin of katepisternum widely non-pollinose, shiny (Fig. 65A); genitalia, Fig. 24B-D

S. (A.) crinita sp. nov.

82. Ventral half of face black, edge of mouth dark yellow to black; abdomen non pollinose, shiny black

- Ventral half of face and edge of mouth yellow; abdomen brown-black to black, slightly pollinose and sub-shiny

83. Arista entirely long pilose (as in Fig. 43C); katepisternum entirely grey pollinose 84

- Arista short pilose basally, otherwise bare (Fig. 43A, D); posterior margin of katepisternum nonpollinose, shiny (Fig. 65B-C)

84. The subtriangular lobe at posterior margin of sternum IV with inconspicuous transverse crest near the base; tergum III and IV asymmetric, their posterior margin skewed to the right; metafemur with only extreme base yellow

S. (A.) atricolor Hippa, van Steenis \& Mutin, 2015

- The subtriangular lobe at posterior margin of sternum IV with strong lobe-like transverse crest near the base; tergum III and IV almost symmetric; metafemur with basal $1 / 6$ yellow S. (A.) furva Hippa, van Steenis \& Mutin, 2015

85. Pale fascia on tergum III almost connected to the anterior margin of its tergum (Fig. 93A) ......... 86

- Pale fascia on tergum III clearly positioned sub-anteriorly (Figs 28B, 59E, 63C) ....................... 87

86. Arista with basal $1 / 4$ rather short pilose (Fig. 43D); medial part of frons along eye-margin widely pollinose, dull (Fig. 88G); genitalia (Fig. 91B-E): cerci dentate

S. (A.) tricoloripes Brunetti, 1915

- Arista with basal $1 / 3$ very short pilose; medial part of frons non-pollinose, shiny (Fig. $88 \mathrm{H}$ ); genitalia (Fig. 92B-C): cerci not dentate

S. (A.) umbrosa sp. nov.

87. Katepimeron with anterior half non-pollinose and shiny (Fig. 65C); genitalia (Fig. 60B-C): cerci rounded, simple

S. (A.) nigerrima Shiraki, 1930

- Katepimeron entirely grey pollinose (Fig. 65B); genitalia (Fig. 26C-F): cerci squarish and dentate S. (A.) dentata sp. nov.

88. Pro- and mesofemur predominantly brownish, base and apex narrowly yellow; mesotibia yellow with dark brown apicomedial narrow annulus; metafemur more slender, about 5 times as long as 
wide (Fig. 33C); scutellum with 2 narrowly separated setae at posterior margin; genitalia, Fig. 29BC

S. (A.) exilipes sp. nov.

- Pro- and mesofemur and tibia entirely yellow; metafemur wider, about 4-4.5 times as long as wide (Fig. 52E); scutellum with 2 widely separated setae at posterior margin; genitalia, Fig. 51B$\mathrm{C}$

S. (A.) javana de Meijere, 1914

89. Tergum I on postero-lateral part with almost transverse row of 5 light yellow thin long setae which differ only slightly from surrounding vestiture (Fig. 13A); pro- and mesofemur and tibia at least partly dark

S. (A.) achaeta Hippa, van Steenis \& Mutin, 2015

- Tergum I on postero-lateral part with an oblique row of 4-5 strong yellow setae which differ greatly from surrounding vestiture (like in Figs 13D, 47A, D); pro- and mesofemur and tibia entirely light yellow

90. Sternum IV simple with concave posterior margin, without any lobe (Fig. 32A); tergum IV black with yellow fascia anteriorly; genitalia, Fig. 32B-F ....

- Sternum IV posteriorly on left side with subtriangular lobe; tergum IV black or with red anterolateral macula

91. Pro- and mesolegs entirely yellow; metafemur rather strongly incrassate, 3.4 times as long as wide; tergum III with yellow fascia anteriorly

- Pro- and mesolegs yellow with at least tarsomere 5 dark brown to black; metafemur slightly less incrassate, 3.6-3.8 times as long as wide; tergum III with red fascia or red lateral macula anteriorly

92. Thorax entirely heavily grey pollinose; tergum III with yellow anterior fascia

S. (A.) pollinosa Hippa, van Steenis \& Mutin, 2015

- Thorax lightly pollinose, sub-shiny, with more heavily pollinose submedial vitta; tergum III with yellow sub-anterior fascia

S. (A.) tenuis Brunetti, 1915

93. Proleg yellow with tarsomeres 3-5 dark brown; tergum III black with reddish anterior fascia; tergum IV entirely black; sternum IV with large and deep membranous notch posteriorly occupying more than half the length of sternum

S. (A.) culex Hippa, van Steenis \& Mutin, 2015

- Proleg yellow with tarsomeres 4 and 5 black; terga III and IV black with yellow anterolateral macula; sternum IV with small membranous notch posteriorly delimited in the posterior marginal area only

S. (A.) pollex Hippa, van Steenis \& Mutin, 2015

\title{
The Oriental species of Sphegina
}

\author{
Sphegina (Sphegina) abbreviata sp. nov. \\ urn:1sid:zoobank.org:act:5B6794F9-A978-499D-996F-922B91C12F45
}

Figs 1, 3A, 19A

\section{Differential diagnosis}

Similar to Sphegina (Sphegina) angustata sp. nov., except for the characters given in the key, Sphegina (Sphegina) abbreviata sp. nov. is distinguished by both dorsal and ventral sublobes posteriorly on male superior lobe instead of just a dorsal one and by having the latter apically short and truncate, not long and pointed.

\section{Etymology}

The specific epithet is Latin 'abbreviata', meaning 'shortened', referring to the unusually short abdomen. 


\section{Type material}

\section{Holotype}

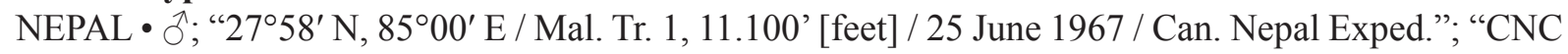
DIPTERA/\# 143316"; CNC.

\section{Paratypes}

NEPAL・ 1 \%; same data as for holotype; "3-5 June 1967”; CNC • 1 \%; same data as for preceding; JSA • 1 ㅇ; same data as for holotype; "18 June 1967"; JSA • 1 O ; same data as for holotype; "19 June 1967"; CNC・ 1 \%; same data as for holotype; "24 June 1967”; CNC.
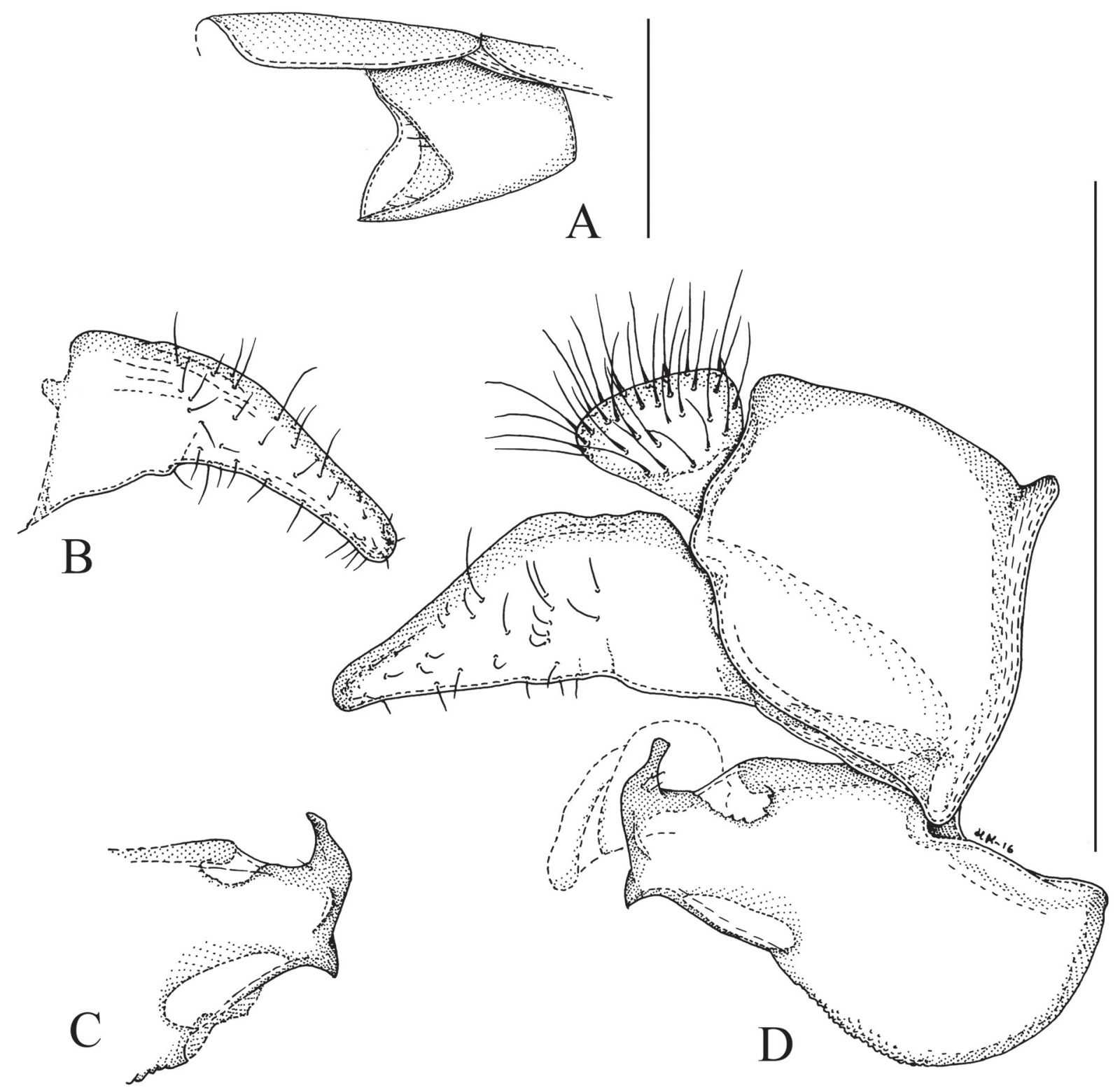

Fig. 1. Sphegina (Sphegina) abbreviata sp. nov., holotype, ô. A. Sternum IV with associated parts, right side, latero-ventral view. B. Left surstylus, lateral view. C. Left superior lobe, lateral view. D. Genitalia, right side, lateral view. Scale bar $=0.5 \mathrm{~mm}$. 


\section{Description}

Male

LENGTH. Body $4.6 \mathrm{~mm}$, wing $4.7 \mathrm{~mm}$.

HEAD. Face in lateral view concave, very strongly projected antero-ventrally; frontal prominence very strongly developed. Ratio width of vertex at anterior ocellus: width of head 1:2.8; ratio width of ocellar triangle: width of vertex 1: 2.8; ratio length of ocellar triangle: length of frons 1: 2.0. Face dull dark brown, ventral half light-brown to yellow, grey pollinose, long pilose along eye-margin. Hypostomal bridge brown, long pale pilose. Gena and mouth edge yellow, pale pollinose with large subtriangular non-pollinose shiny area. Frons and vertex dark brown, predominantly grey pollinose, a subtriangular area posterior of lunula non-pollinose and shiny; pile short, light yellow to brown coloured. Frons with rather deep antero-medial pit and wide medial furrow. Occiput brown, light grey pollinose, light yellow pilose. Eye without enlarged facets at anterior margin. Antenna dark brown, with black setae dorsally on scape and pedicel; basoflagellomere elongate, ratio width: length 1: 1.5; arista pilose, short and relatively thick, about 2.0-2.5 times as long as basoflagellomere.

THORAX. Colour dark brown, weakly greyish pollinose; postpronotum light-brown; scutum and pleuron with very short adpressed pale-brown pile. Scutellum subtriangular, dark brown, grey pollinose, with pile slightly longer than on scutum, with two widely set short setae medially at posterior margin, ratio length of scutellum: length of seta 1: 1.0.

Wing. Entirely microtrichose; hyaline, stigma yellowish. Crossvein dm-cu meeting vein M obliquely and vein $M_{1}$ meeting vein $R_{4+5}$ perpendicularly.

Legs. Pro- and mesoleg light-brown, protarsus brown to dark brown; mesotibia apical 1/4 dark brown; mesotarsus with apical half of basitarsomere and tarsomeres 2-5 dark brown. Metaleg, coxa and trochanter dark brown, metafemur dark brown with basal $1 / 3$ yellow, very weakly incrassate, ratio width: length 1: 6.1; metatibia dark brown and yellow biannulate, club shaped without apicoventral dens; basitarsomere thin, ratio width: length 1: 4.0.

ABDOMEN. Length ratio of terga I: II: III: IV 1: 4.0: 3.3: 3.3; ratio width at posterior margin: medial length of tergum II and III 1: 2.0 and 1: 1.3. Terga brownish; pile mixed dark brown to light-brown, short; tergum I with only normal pile; sternum I elongate oval, ratio width: length 1: 1.9; sterna II-III not sclerotized, sternum IV, Fig. 1A; sterna VI, VII and VIII with long yellow pile. Genitalia, Fig. 1B-D: note the almost symmetrical surstyli and symmetrical superior lobes.

\section{Female}

Similar to male except normal sexual dimorphism.

LENGTH. Body 4.9-5.4 mm, wing 5.4-6.1 mm.

HEAD. Ratio width of vertex at anterior ocellus: width of head 1: 2.7-3.1; ratio width of ocellar triangle: width of vertex 1: 2.7-3.1; ratio length of ocellar triangle: length of frons 1: 1.9-2.2. Basoflagellomere round, ratio width: length 1: 1.0-1.2; arista pilose, short and relatively thick, about 3 times as long as basoflagellomere.

THorax. Scutellum with two closely set medium long setae medially at posterior margin, ratio length of scutellum: length of seta 1: 1.3-1.6.

LeGs. Metaleg, Fig. 19A with basal $1 / 2$ of femur yellow, slender, evenly incrassate, ratio width: length 1 : 5.4-6.1, basitarsomere thin, ratio width: length 1:3.9-4.2. 
ABDomen. Length ratio of terga I: II: III: IV: V 1: 2.7-3.1: 2.6-2.9: 2.4-2.6: 0.8-0.9; ratio width at posterior margin: medial length of tergum II and III 1: 0.74-0.92 and 1: 0.5-0.7. Sternum I rectangular, ratio width: length 1: 0.51-0.61; sternum II rectangular, ratio width: length 1: 1.8-2.3; sternum III trapezoidal, ratio width: length 1: 1.2-1.6; sternum IV squarish, ratio width: length 1: 0.82-1.0; sternum $\mathrm{V}$ rectangular at anterior margin slightly narrowed, ratio width: length $1: 0.3-0.5$.

Sphegina (Sphegina) angustata sp. nov.

urn:1sid:zoobank.org:act:94A6F831-FFFF-49E3-BF04-C13C309E0B48

Figs 2A-B, 3B-C, 4, 19B

\section{Differential diagnosis}

Similar to Sphegina (Sphegina) abbreviata sp. nov. For distinguishing characters, see under that species.

\section{Etymology}

The specific epithet is Latin 'angustata', meaning 'narrowed', referring to the unusually narrow abdomen.

\section{Type material}

\section{Holotype}

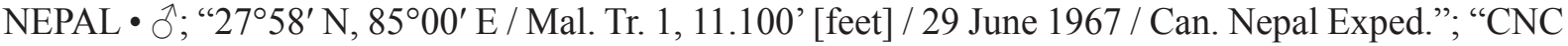
DIPTERA / \# 143315"; CNC.

\section{Paratypes}

NEPAL • 1 đo; same data as for holotype; "19 June 1967"; JSA • 1 क ; same data as for holotype; "3-5 June 1967"; CNC • 1 क ; same data as for holotype; "24 June 1967"; JSA • 1 \%; same data as for holotype; "27 June 1967”; CNC.

\section{Description}

\section{Male}

LeNGTH. Body 5.2-5.4 mm, wing 4.9-5.2 mm.

HEAD. Face in lateral view, Fig. 3C, concave, very strongly projected antero-ventrally; frontal prominence very strongly developed. Ratio width of vertex at anterior ocellus: width of head 1:2.7-3.0; ratio width of ocellar triangle: width of vertex 1:2.4-2.6; ratio length of ocellar triangle: length of frons $1: 2.5-2.8$. Face dull dark brown, ventral half light-brown to yellow, pale pollinose, long pilose along eye-margin. Hypostomal bridge light-brown, long pale pilose. Gena and mouth edge yellow, pale pollinose with large subtriangular non-pollinose shiny area. Frons and vertex dark brown, predominantly grey pollinose, a subtriangular area posterior of lunula non-pollinose and shiny; pile short, light yellow brown. Frons with deep antero-medial pit and wide medial furrow. Occiput brown, light grey pollinose, light yellow pilose. Eye without enlarged facets at anterior margin. Antenna dark brown, with black setae dorsally on scape and pedicel; basoflagellomere oval, ratio width: length 1: 1.1-1.3; arista pilose, short and relatively thick, about 2.0-2.5 times as long as basoflagellomere.

THORAX. Colour dark brown, weakly greyish pollinose; postpronotum yellow to light-brown; scutum and pleuron with very short adpressed pale-brown pile. Scutellum subtriangular, dark brown, grey pollinose, with pile slightly longer than on scutum, with two widely set short setae medially at posterior margin, ratio length of scutellum: length of seta 1: 0.9-1.1. 
WING. Entirely microtrichose; hyaline, stigma yellowish. Crossvein dm-cu meeting vein M obliquely and vein $M_{1}$ meeting vein $R_{4+5}$ perpendicularly.

LEGS. Proleg brown to brown-yellow, tarsomeres 3-4 dark brown to black. Mesofemur yellow with apical $2 / 3$ dark brown; mesotibia yellow with basal $3 / 4$ dark brown; mesotarsus with tarsomeres $2-5$ dark brown. Metaleg dark brown with yellow; femur dark brown on basal 2/5, weakly incrassate, ratio width: length 1 : 4.2-4.6; tibia black and yellow biannulate, club shaped, without apicoventral dens; basitarsomere thin, ratio width: length 1: $3.9-4.2$.

ABDOMEN. Length ratio of terga I: II: III: IV 1: 3.4-3.6: 2.7-3.0: 2.2-2.5; ratio width at posterior margin: medial length of tergum II and III 1: 3.4-3.8 and 1: 2.1-2.4. Terga dark brown; pile mixed dark brown to light-brown, short, laterally on terga I and II long; tergum I with only normal pile; sternum I elongate oval, ratio width: length 1: 1.9-2.1; sterna II-III not sclerotized; sternum IV, Fig. 4A; sterna VI, VII and

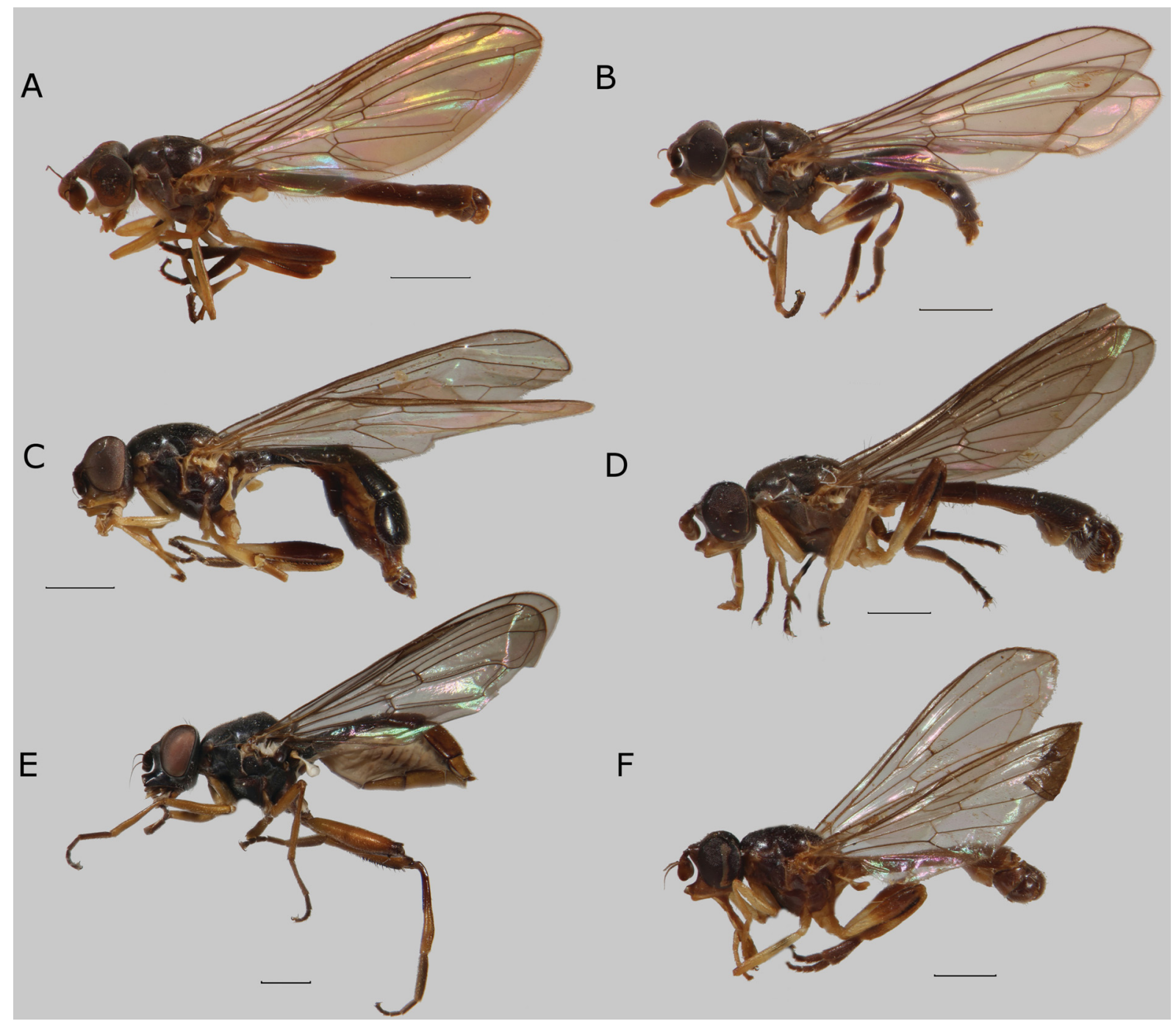

Fig. 2. Habitus, lateral view. A. Sphegina (Sphegina) angustata sp. nov., paratype, $\hat{\jmath}$, Nepal. B. $S$. (S.) angustata sp. nov., paratype, + , Nepal. C. $S$. (S.) guptai Mutin, 1998, paratype, + , India. D. S. (S.) kumaoniensis Mutin, 1998, Ō, Myanmar. E. S. (S.) quadriseta Huo \& Ren, 2006, + , China. F. S. (S.) uncinata Hippa, van Steenis \& Mutin, 2015, paratype, ô, Myanmar. Scale bars $=1.0 \mathrm{~mm}$. 
VIII with long yellow pile. Genitalia, Fig. 4B-D: note the almost symmetrical surstyli and symmetrical superior lobes.

\section{Female}

Similar to the male except normal sexual dimorphism.

LeNGTH. Body 4.8-5.2 mm, wing 5.0-5.5 mm.

HEAD. Ratio width of vertex at anterior ocellus: width of head 1: 3.2-3.4; ratio width of ocellar triangle: width of vertex 1: 2.1-2.4; ratio length of ocellar triangle: length of frons 1: 2.1-2.5 (Fig. 3B). Basoflagellomere round to slightly oval, ratio width: length 1:1.0-1.2; arista pilose, short and relatively thick, about 2.5 times as long as basoflagellomere.

Thorax. Scutellum with two closely set, short setae medially at posterior margin, ratio length of scutellum: length of seta 1: 0.9-1.1.

LeGs. Metaleg, Fig. 19B, with femur slender, only very slightly incrassate, ratio width: length 1: 6.1-7.4, basitarsomere thin, ratio width: length 1: 4.2-4.6.

AвDomen. Length ratio of terga I: II: III: IV: V 1: 4.1-4.5: 3.8-4.2: 3.4-3.7: 1.0-1.3; ratio width at posterior margin: medial length of tergum II and III 1: 1.1-1.4 and 1: 0.5-0.7. Sternum I oval, ratio
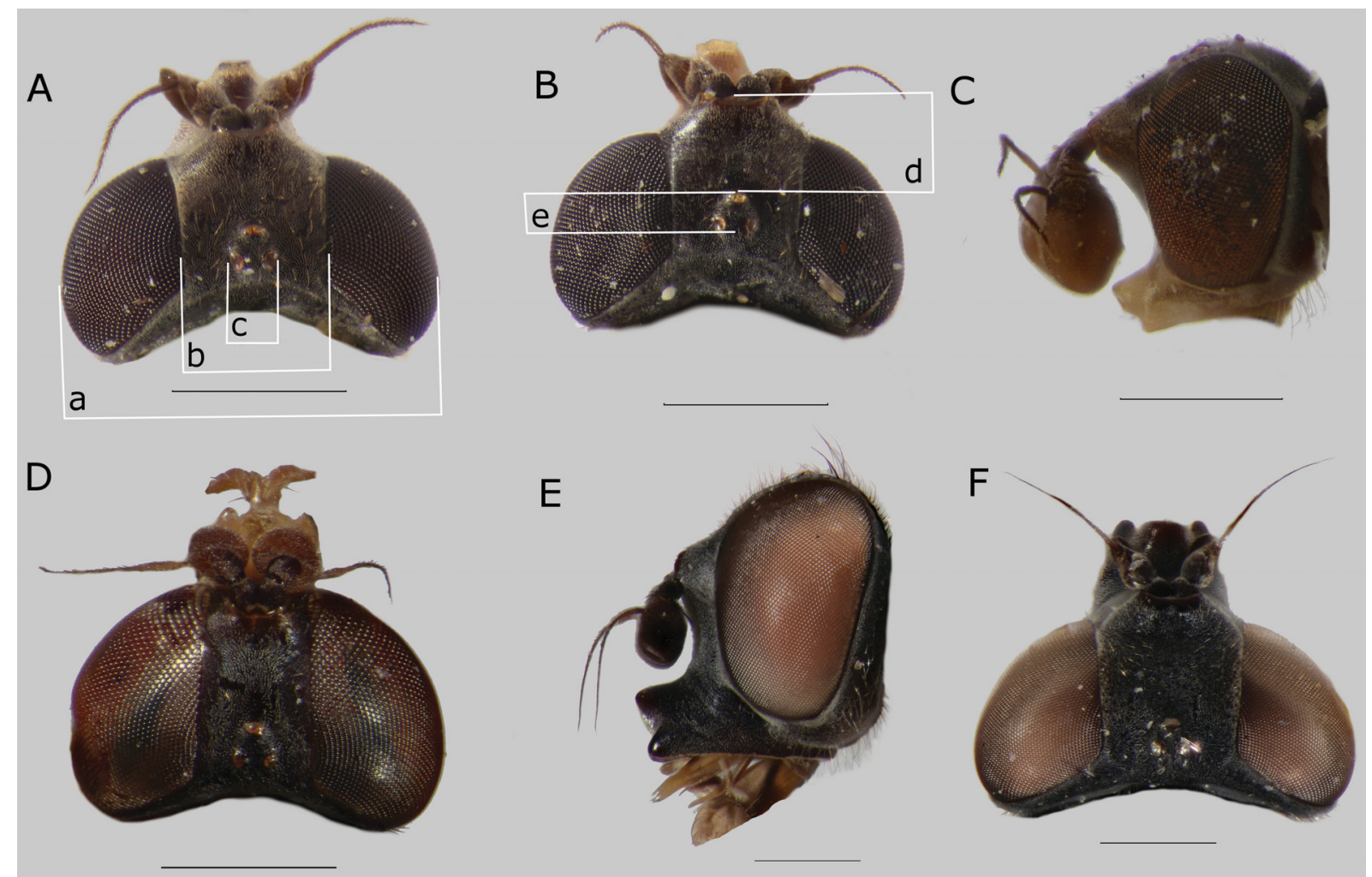

Fig. 3. Head, lateral view (C, E), and dorsal view (A-B, D, F). A. Sphegina (Sphegina) abbreviata sp. nov., paratype, + , Nepal. B. S. (S.) angustata sp. nov., paratype, + , Nepal. C. S. (S.) angustata sp. nov., paratype, ô, Nepal. D. S. (S.) guptai, 1998, holotype, đ̂, India. E-F. S. (S.) quadriseta Huo \& Ren, 2006, + , China. Abbreviations: $\mathrm{a}=$ width of head; $\mathrm{b}=$ width of vertex; $\mathrm{c}=$ width of ocellar triangle; $\mathrm{d}=$ length of frons; $\mathrm{e}=$ length of ocellar triangle. Scale bars $=0.5 \mathrm{~mm}$. 
width: length 1: 0.6-0.8; sternum II oval, ratio width: length 1: 1.7-2.1; sternum III rectangular, ratio width: length 1: 1.2-1.6; sternum IV squarish, ratio width: length 1: 0.9-1.2; sternum V trapezoidal, posterior margin short, ratio width: length 1: 0.5-0.7.

\section{Sphegina (Sphegina) guptai Mutin, 1998}

Figs $2 \mathrm{C}, 3 \mathrm{D}, 5$

Sphegina (Sphegina) guptai Mutin, 1998: 240. Type locality: India, Rahla (holotype, §̊, USNM).

\section{Differential diagnosis}

This species is slightly similar to Sphegina (Sphegina) elegans by general appearance and characters of the male genitalia. It differs from known Oriental species of Sphegina (Sphegina) by the shiny black abdomen with widened terga III and IV. Only Sphegina (Sphegina) quadriseta has a somewhat similar appearance and the differences are discussed under this species. Male genitalia with long, curved, widening towards the apex surstylus with subapical ventral sublobe.
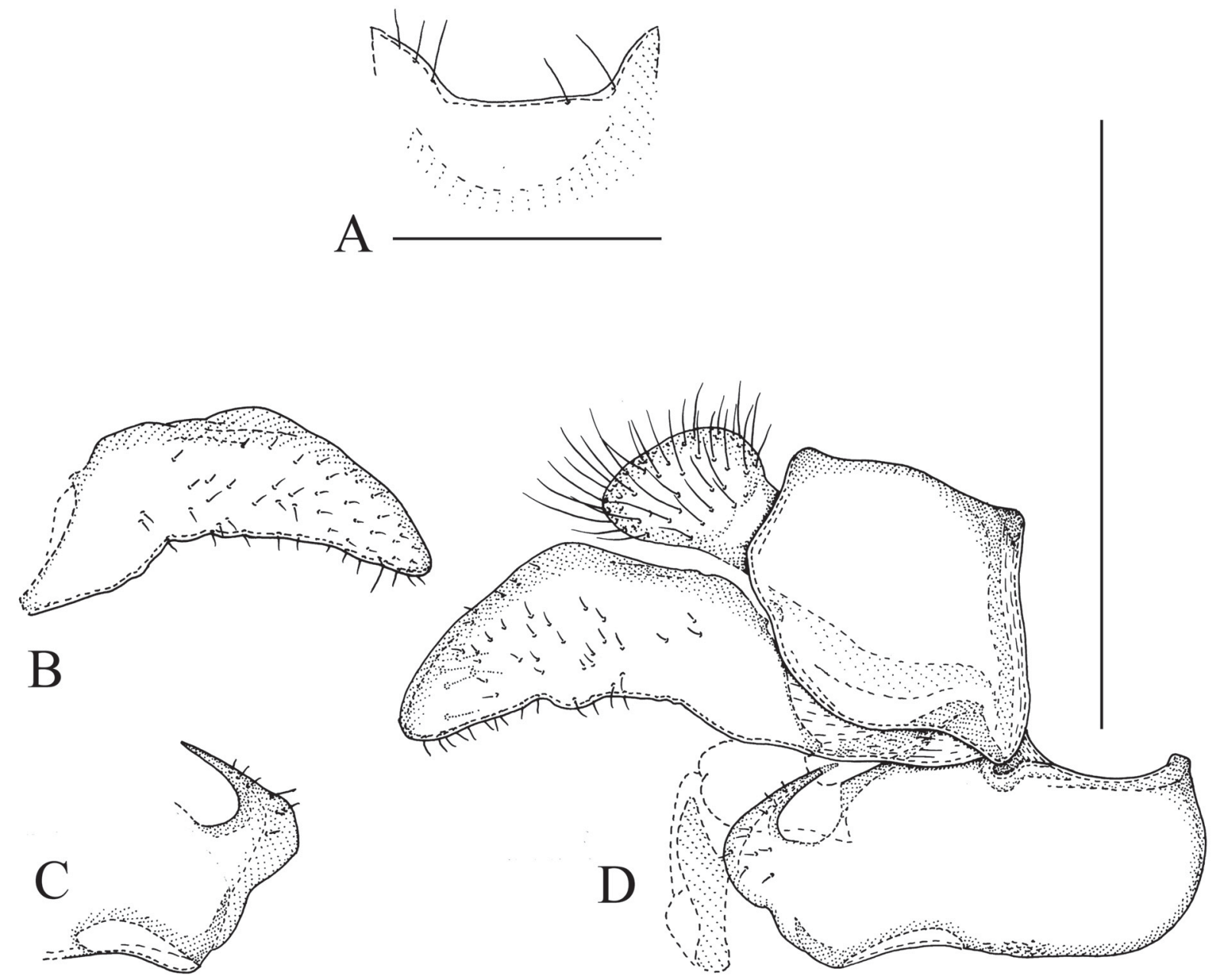

Fig. 4. Sphegina (Sphegina) angustata sp. nov., holotype, ô. A. Posterior part of sternum IV, ventral view. B. Left surstylus, lateral view. C. Left superior lobe, lateral view. D. Genitalia, right side, lateral view. Scale bars $=0.5 \mathrm{~mm}$. 


\section{Material examined}

\section{Holotype}

INDIA • O’; “12.VI.1970, India / Northwest Himalaya / Rahla, 2743 m / (M. Gupta) / No M33”; USNM.

\section{Paratype}

INDIA • O; "India H.P. / Ahla [Rahla?] 2286m / 17.VI.1971, / M. Gupta No M51"; "Ghorpade / collection / Bangalore"; USNM.
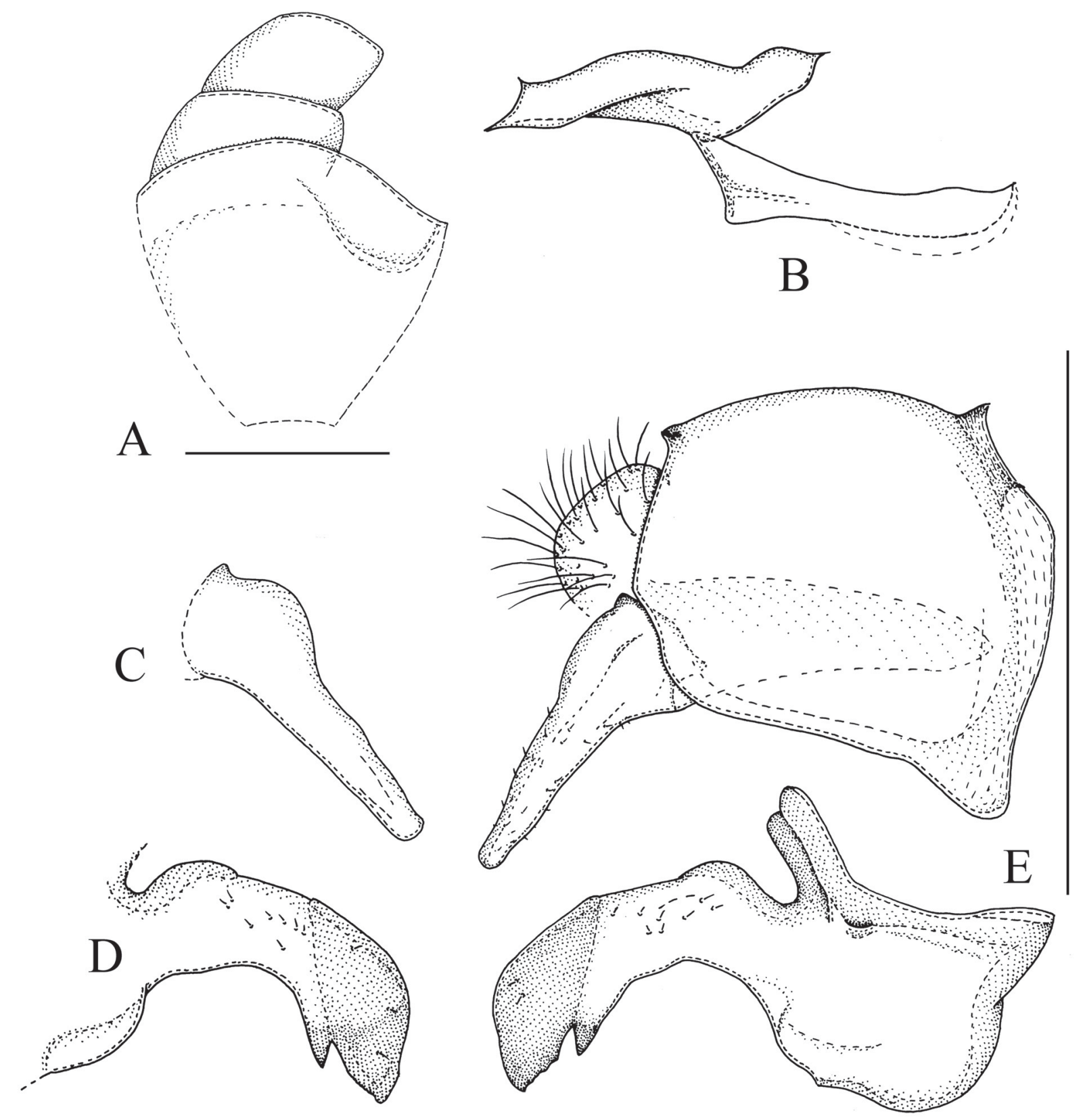

Fig. 5. Sphegina (Sphegina) guptai Mutin, 1998, holotype, ठิ. A. Sterna IV, VI and VII, ventral view. B. Aedeagus, right side, lateral view. C. Left surstylus, lateral view. D. Left superior lobe, lateral view. E. Genitalia, right side, lateral view. Scale bars $=0.5 \mathrm{~mm}$. 


\section{Redescription}

Male

LENGTH. Body $5.2 \mathrm{~mm}$, wing $4.6 \mathrm{~mm}$.

HEAD. Face in lateral view concave, rather weakly projected antero-ventrally; frontal prominence weakly developed. Ratio width of vertex at anterior ocellus: width of head 1:3.2; ratio width of ocellar triangle: width of vertex 1: 2.5; ratio length of ocellar triangle: length of frons $1: 2.2$. Face yellow, pale pollinose, long pilose along eye-margin. Hypostomal bridge yellow, long pale pilose. Gena and mouth edge yellow, yellowish pollinose with large subtriangular non-pollinose shiny area. Frons and vertex dark brown, predominantly grey pollinose, a narrow fascia posterior of lunula non-pollinose and shiny (Fig. 3D); pile short, light yellow to brown. Frons with very weak medial furrow. Occiput brown, light grey pollinose, light yellow pilose. Eye without enlarged facets at anterior margin. Antenna dark brown, with black setae dorsally on scape and pedicel; basoflagellomere squarish, ratio width: length 1: 1.1; arista pilose, about 3 times as long as basoflagellomere.

THORAX. Colour black, weakly greyish pollinose; postpronotum partly dark brown, remainder black; scutum and pleuron with very short adpressed pale-brown pile. Scutellum subtriangular, dark brown, grey pollinose, pile slightly longer than on scutum, with two closely set short setae medially at posterior margin, ratio length of scutellum: length of seta 1: 1.2.

WING. Entirely microtrichose; hyaline, stigma yellowish. Crossvein dm-cu meeting vein M obliquely and vein $M_{1}$ meeting vein $R_{4+5}$ perpendicularly.

LEGs. Proleg yellow, protarsus with tarsomeres 4 and 5 dark brown. Metaleg dark brown with femur yellow on basal half, very weakly incrassate, ratio width: length 1: 5.3; tibia dark brown and yellow biannulate, slightly club shaped, without apicoventral dens, basitarsomere thin, ratio width: length 1:3.9.

ABDOMEN. Length ratio of terga I: II: III: IV 1: 3.3: 2.3: 2.2; ratio width at posterior margin: medial length of tergum II and III 1: 3.0 and 1: 1.3. Terga black, tergum III with sub-anterior dark yellow fascia covering almost half the tergum; pile mixed dark brown to light-brown, short, laterally on terga I and II long; tergum I with only normal pile; sternum I oval, ratio width: length 1: 1.3; sterna II-III sclerotized, ratio width: length respectively 1: 3.6 and 1: 2.1; sterna IV, VI, VII and VIII (Fig. 5A), with long yellow pile. Genitalia, Fig. 5B-D: note the symmetrical surstyli and superior lobes.

\section{Female}

Similar to the male except normal sexual dimorphism.

Length. Body $5.7 \mathrm{~mm}$, wing $5.7 \mathrm{~mm}$.

HEAD. Ventral half of face and mouth edge yellow; mouth edge ventrally of eyes wide; ratio width of vertex at anterior ocellus: width of head 1: 3.1; ratio width of ocellar triangle: width of vertex 1: 2.3; ratio length of ocellar triangle: length of frons 1: 2.1. Basoflagellomere round, as wide as long; arista pilose, about 3 times as long as basoflagellomere.

THorax. Postpronotum yellow. Scutellum with two widely set short setae medially at posterior margin, ratio length of scutellum: length of seta 1:1.1.

WING. Vein dm-cu meeting vein M obliquely.

Legs. Pro- and mesotarsus with tarsomeres 3-5 dark brown. Metafemur with basal $1 / 3$ yellow, slender, ratio width: length 1: 5.4; metatarsus with basitarsomere very thin, ratio width: length 1: 4.6. 
AbDomen. Length ratio of terga I: II: III: IV: V 1: 4.0: 2.9: 2.8: 0.8; ratio width at posterior margin: medial length of tergum II and III 1: 1.7 and 1: 0.7. Tergum V predominantly yellow. Sternum I oval, as wide as long; sternum II rectangular, ratio width: length 1: 1.4; sternum III trapezoidal, ratio width: length 1: 1.6; sternum IV squarish, ratio width: length 1: 0.7; sternum V trapezoidal, posterior margin short, ratio width: length 1: 0.9 .

Sphegina (Sphegina) kumaoniensis Mutin, 1998

Fig. 2D

Sphegina (Sphegina) kumaoniensis Mutin, 1998: 241. Type locality: Khati, Kumaon, India (holotype, o, USNM).

\section{Material examined}

INDIA • 1 ठ̊; "22.08.96, Syrphid NaNa"; "India Himachal Pradesh / about 140 km N Simla / Kuluvalley, 1600-2700m / ex coll R. Wagner"; JSA.

THAILAND • 1 q; “Thailand, Chiang Mai 2500m / Doi Inthanon NP summit marsh / 18³5.361' N, 98²9.157’ E, T70 / 15-22.VII.2006, Malaise Trap / Y. Areeluck leg.”; CSCA.

\section{Remarks}

Earlier known from NW India (Mutin 1998) and NE Myanmar (Hippa et al. 2015).

\section{Sphegina (Sphegina) quadriseta Huo \& Ren, 2006}

Figs 2E, 3E-F

Sphegina quadriseta Huo \& Ren, 2006: 34. Type locality: Honghe Valley, Shaanxi province, China (holotype, $\hat{\partial}$, depository of type unknown).

\section{Differential diagnosis}

Sphegina (Sphegina) quadriseta is dissimilar to other species by the long black pile posterior of posteromedial corner of eye, the scutellum with 4 long black setae at posterior margin and the black and extremely strongly antero-ventrally projected face.

\section{Material examined}

CHINA • 1 क; "China Sichuan Daocheng, 37 km / WNW, 29.153 N, 99.930 E, 3400 m / 23.VI.2009, legit Blank, Liston \& / Taeger 054 China"; CSCA.

\section{Description}

Female

LENGTH. Body $6.9 \mathrm{~mm}$, wing $7.2 \mathrm{~mm}$.

HeAD. Face in lateral view (Fig. 3E), concave, unusually strongly projected antero-ventrally; frontal prominence very strongly developed. Ratio width of vertex at anterior ocellus: width of head 1:2.8; ratio width of ocellar triangle: width of vertex 1:3.3; ratio length of ocellar triangle: length of frons 1:3.1. Head entirely black and grey pollinose; face yellow pilose along eye-margin. Hypostomal bridge long pale pilose. Gena and mouth edge without non-pollinose shiny area. Frons and vertex black, predominantly grey pollinose, a narrow fascia posterior of lunula non-pollinose and shiny (Fig. 3F); pile short, black, posterior of posteromedial corner of eye with patch of very long black pile. Frons with very weak medial 
furrow. Occiput dark brown, light grey pollinose, light yellow pilose. Eye without enlarged facets at anterior margin. Antenna dark brown with black setae dorsally on scape and pedicel; basoflagellomere slightly oval, ratio width: length 1: 1.2; arista pilose, almost 3 times as long as basoflagellomere.

THORAX. Colour black, greyish pollinose; scutum and pleuron with very short adpressed pale-brown pile, medial part of scutum black pilose. Scutellum subtriangular, black, grey pollinose, with pile slightly longer than on scutum, with four setae at posterior margin, the medial two widely set, short, ratio length of scutellum: length of seta 1: 1.3.

WING. Entirely microtrichose; hyaline, stigma yellowish. Crossvein dm-cu meeting vein M obliquely and vein $M_{1}$ meeting vein $R_{4+5}$ perpendicularly.

LEGS. Legs yellow; all tarsi and apical $1 / 3$ of metatibia black; metatibia without apicoventral dens; metafemur very weakly incrassate, ratio width: length $1: 5.5$; metatarsus with basitarsomere very thin, ratio width: length 1: 5.5 .

ABDOMEN. Length ratio of terga I: II: III: IV: V 1: 3.3: 2.8: 2.5: 1.3; ratio width at posterior margin: medial length of tergum II and III 1: 0.9 and 1: 0.6 . Terga black, tergum III medially yellow and terga IV and V entirely yellow; pile mixed dark brown to light-brown, short, laterally on terga I and II long; tergum I with only normal pile; sternum I squarish, ratio width: length 1: 1.3; sterna II-IV sclerotized, trapezoidal to squarish shaped, sternum $\mathrm{V}$ rectangular, ratio width: length respectively $1: 1.1,1: 0.8,1$ : 0.7 and 1: 0.4; sterna VI, VII and VIII with long yellow pile.

\section{Remarks}

In the original description the scutellum and pleuron are described as being shiny black. None of the species of Sphegina studied here have an entirely non-pollinose and shiny pleuron, nor do any of the Palaearctic species as far we know. Most likely the pollinosity is not considered in the description of Sphegina (Sphegina) quadriseta and the scutellum and pleuron are, in our terms, 'slightly pollinose, sub-shiny', which does not correspond exactly to the female described here. However, although the female described here is more pollinose than the male, as originally described, we have concluded that it is the same species and that the original description of the male is inaccurate. Further material and the examination of the holotype of Sphegina (Sphegina) quadriseta is necessary to confirm this. It is, of course, possible that this female belongs to an undescribed species.

Sphegina (Sphegina) uncinata Hippa, van Steenis \& Mutin, 2015

Figs 2F, 19C

Sphegina (Sphegina) uncinata Hippa, van Steenis \& Mutin, 2015: 13. Type locality: Kambaiti, Myanmar (holotype, ô, NHRS).

\section{Remarks}

Only known by the type material from Myanmar, Kambaiti (Hippa et al. 2015).

Sphegina (Asiosphegina) achaeta Hippa, van Steenis \& Mutin, 2015

Figs $6 \mathrm{~A}-\mathrm{B}, 13 \mathrm{~A}$

Sphegina (Asiosphegina) achaeta Hippa, van Steenis \& Mutin, 2015: 58. Type locality: Kambaiti, Myanmar (holotype, $\widehat{\jmath}$, NHRS). 


\section{Material examined}

MYANMAR • 1 क; "N.E. Burma / Kambaiti, 7000 ft. / 7.v.1934 / [leg] R. Malaise" • 1 \%; "N.E. Burma / Kambaiti 7000 ft. / 14.5.1934 [leg] Malaise"; NHM • 1 क; same data as for preceding; JSA • 1 q ; "N.E. Burma / Kambaiti, 7000 ft. / 9.6.1934 [leg] Malaise"; JSA • 1 क; "N.E. Burma, / Kambaiti, 2000 m. / 11.5.1934 [leg] Malaise"; NHRS • 1 q; "N.E. Burma / Kambaiti, 2000 m. / 12.5.1934 [leg] Malaise"; JSA.

\section{Description}

\section{Female}

LeNGTH. Body 6.1-7.2 mm, wing 5.5-6.3 mm.

HEAD. Face in lateral view concave, strongly projected antero-ventrally; frontal prominence strongly developed. Ratio width of vertex at anterior ocellus: width of head 1: 3.5-3.7; ratio width of ocellar triangle: width of vertex 1:2.3-2.5; ratio length of ocellar triangle: length of frons 1: 3.5-4.2. Face dark brown; grey pollinose, long pilose along eye-margin. Hypostomal bridge black, long pale pilose. Gena and mouth edge dark brown with large subtriangular non-pollinose shiny area. Frons and vertex black,

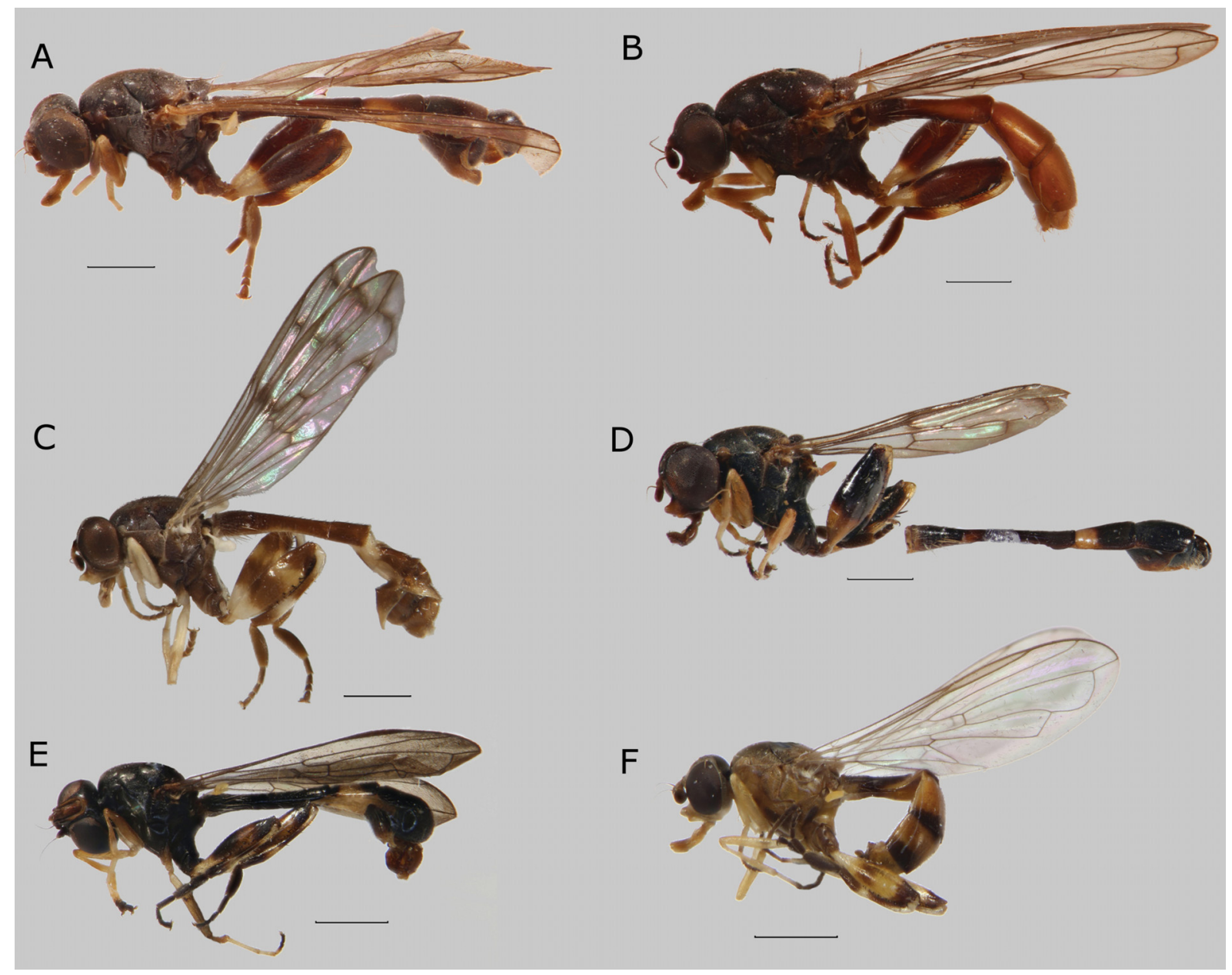

Fig. 6. Habitus, lateral view. A. Sphegina (Asiosphegina) achaeta Hippa, van Steenis \& Mutin, 2015,

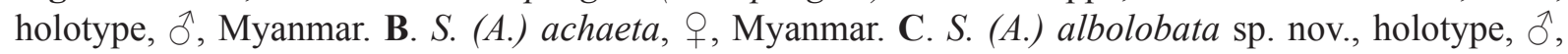
Vietnam. D. S. (A.) amplistylus sp. nov., holotype, ô, Philippines. E. S. (A.) apicalis Shiraki, 1930, ô, Taiwan. F. S. (A.) apicalis,, , Taiwan. Scale bars $=1.0 \mathrm{~mm}$. 
slightly pollinose, except anterior half of frons non-pollinose and shiny; pile short, light yellow. Frons with wide circular depression medially. Occiput black, light grey pollinose, light yellow pilose. Antenna dark brown with black setae dorsally on scape and pedicel; basoflagellomere short-oval, ratio width: length 1: 1.1; arista pilose, slightly more than 2.5 times as long as basoflagellomere.

THoRAX. Colour dark brown to black, postpronotum red-brown; weakly brown pollinose with four grey pollinose vitta on entire scutum, pleuron entirely grey pollinose; scutum and pleuron with very short appressed light yellow pile. Scutellum semi-circular, black, brown pollinose, pile slightly longer than on scutum, with two widely set setae of medium length, ratio length of scutellum: length of seta 1: 1.5-1.7.

WING. Entirely microtrichose; hyaline, stigma yellowish. Crossvein dm-cu meeting vein M obliquely and vein $M_{1}$ meeting vein $R_{4+5}$ perpendicularly.

Legs. Pro- and mesoleg with femora and tibiae dark brown to black on apical $2 / 3$ to $3 / 4$; tarsi with tarsomeres 2-5 black. Metaleg with coxa dark brown, trochanter yellow; femur black with basal $1 / 4$ yellow, incrassate, ratio width: length 1: 3.4-3.6; tibia black and yellow biannulate, without apicoventral dens; tarsus entirely black, basitarsomere thin, ratio width: length $1: 3.8$.

AвDOMEN. Length ratio of terga I: II: III: IV: V 1: 2.4-3.5: 1.8-2.4: 2.4-2.8: 0.5-0.9; ratio width at posterior margin: medial length of tergum II and III 1: 1.2-1.8 and 1: 0.6. Terga black, tergum II with sub-anterior light-brown fascia, anterior $1 / 3$ of tergum III with yellow fascia; pile short, light yellow; tergum I, Fig. 8A with oblique row of 5 white and weak setae at lateral margin; sternum III rectangular, ratio width: length 1: 1.3-1.4; sternum IV trapezoidal, ratio width: length 1: $0.6-0.7$ and sternum $\mathrm{V}$ trapezoidal with widest part anteriorly, ratio width: length 1: 0.7 .

\section{Remarks}

Only known by the type material from Myanmar, Kambaiti (Hippa et al. 2015) and the female specimens studied here from the same locality.

Sphegina (Asiosphegina) adusta Hippa, van Steenis \& Mutin, 2015

Fig. 10A

Sphegina (Asiosphegina) adusta Hippa, van Steenis \& Mutin, 2015: 55. Type locality: Kambaiti, Myanmar (holotype, $\widehat{\jmath}, \mathrm{NHM}$ ).

\section{Remarks}

Only known by the type material from Myanmar, Kambaiti (Hippa et al. 2015).

Sphegina (Asiosphegina) albolobata sp. nov. urn:1sid:zoobank.org:act:46336777-023B-42E2-856A-3DB70790EDB4

Figs 6C, 7, 21A-B

\section{Differential diagnosis}

In addition to the characters in the key, Sphegina (Asiosphegina) albolobata sp. nov. differs from the similar $S$. (A.) licina sp. nov. by having the ventral lobe of both gonostyli narrower, apicodorsal part of the right superior lobe shorter and by having the ventral part of the left superior lobe with more prominent anterior, medial and posterior lobes (Fig. 7B-D). 


\section{Etymology}

The specific epithet is from the Latin 'albolobata', meaning 'white-lobed', referring to the white subtriangular lobe posteriorly on male sternum IV.

\section{Material examined}

\section{Holotype}

VIETNAM - J; "Vietnam: Cao Bang Province / Phia Oac Natl Park, near Phia Den / el. 1000m / 22³2'20" N, 10551'57" E / [12-01] 22.III.2012, coll: SD Gaimari / M Hauser, Pham HT”; CSCA.

\section{Description}

LeNGTH. Body $6.0 \mathrm{~mm}$, wing $4.9 \mathrm{~mm}$.

HEAD. Face in lateral view (Fig. 21A) concave, strongly projected antero-ventrally; frontal prominence strongly developed. Ratio width of vertex at anterior ocellus: width of head 1: 4.2; ratio width of ocellar triangle: width of vertex 1: 2.5; ratio length of ocellar triangle: length of frons 1:2.1. Face black, ventral half yellow; light grey pollinose, long pilose along eye-margin. Hypostomal bridge yellow, long pale pilose. Gena and mouth edge yellow with large subtriangular non-pollinose shiny area. Frons and vertex black, slightly pollinose with densely grey pollinose subtriangular maculae antero-laterally along eyemargin, a large round area posterior of lunula non-pollinose and shiny (Fig. 21B); pile short, light yellow.

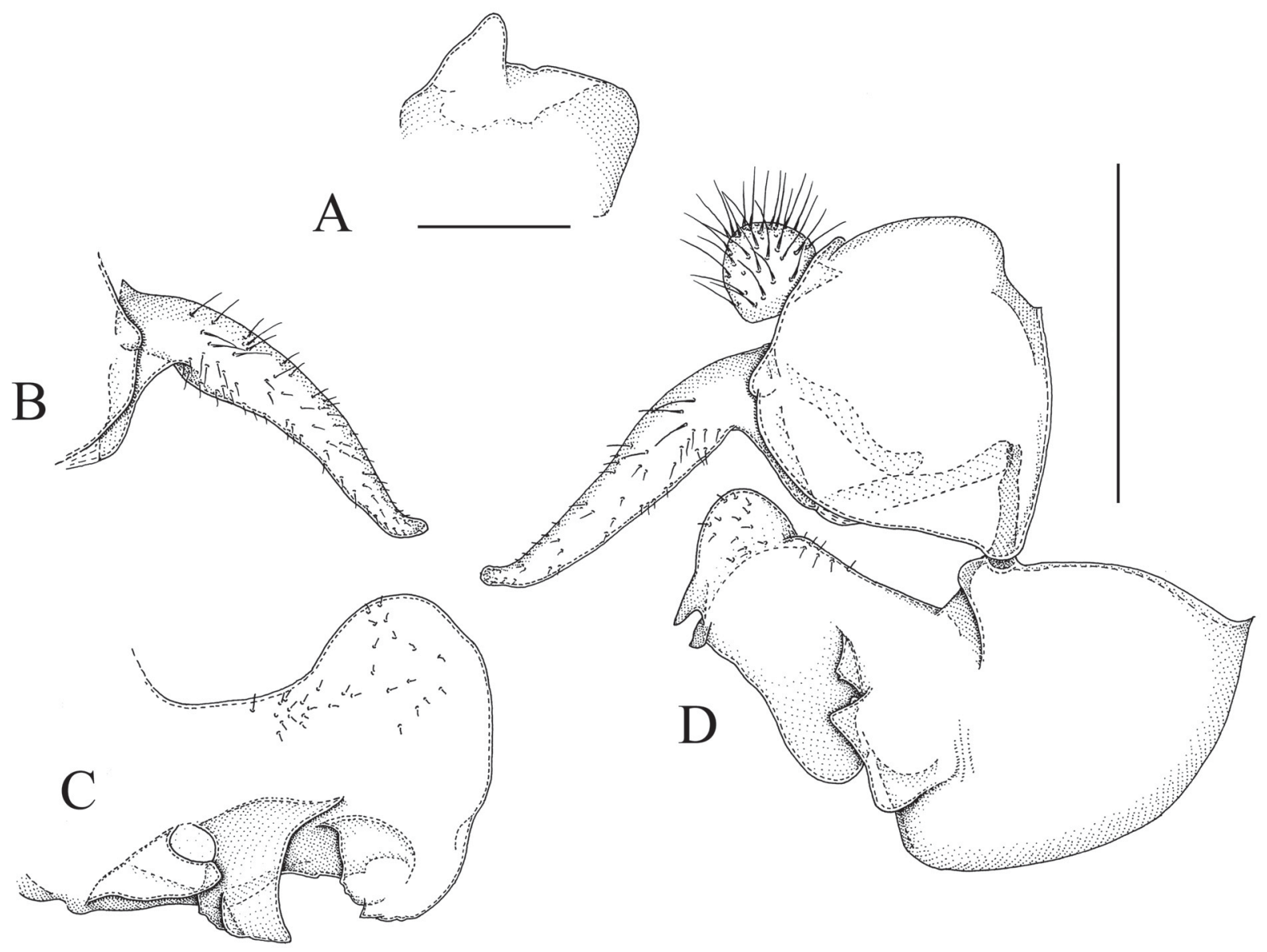

Fig. 7. Sphegina (Asiosphegina) albolobata sp. nov., holotype, Ô. A. Posterior part of sternum IV, ventral view. B. Left surstylus, lateral view. C. Left superior lobe, lateral view. D. Genitalia, right side, lateral view. Scale bars $=0.5 \mathrm{~mm}$. 
Frons with deep pit antero-medially. Occiput black, light grey pollinose, light yellow pilose. Eye with an area of enlarged facets at anterior margin. Antenna with scape and pedicel yellow, basoflagellomere dark yellow with black setae dorsally on scape and pedicel; basoflagellomere oval, ratio width: length 1: 1.2; arista short pilose, nearly 3 times as long as basoflagellomere.

THORAX. Colour dark brown to black, weakly greyish pollinose, scutum with submedial more densely pollinose vitta and dense pollinosity along lateral margin, pleuron entirely grey pollinose; scutum and pleuron with very short adpressed light yellow pile. Scutellum semi lunular, black, sub-shiny and weakly pollinose, with pile slightly longer than on scutum, with two widely set, short setae medially at posterior margin, ratio length of scutellum: length of seta 1: 1.2.

WING. Entirely microtrichose; hyaline, stigma yellowish, membrane brown infuscated at junction of veins $R_{2+3}$ and $R_{4+5}$, along veins bm-cu, $r-m, M_{1}$, at the extra crossvein between $R_{2+3}$ and $R_{1}$, at the junction of veins $M_{1}$ and $R_{4+5}$ and at apical appendix of vein $R_{2+3}$. Crossvein dm-cu meeting vein $M$ perpendicularly and vein $M_{1}$ meeting vein $R_{4+5}$ perpendicularly. Apical part of vein $R_{2+3}$ with long appendix, vein $C u A_{1}$ extending beyond vein $\mathrm{dm}-\mathrm{cu}$.

LEGs. Pro- and mesoleg yellow, tarsomeres $2-5$ black, mesofemur darkened on apical 1/4 and mesotibia darkened on medial $1 / 3$. Metaleg with coxa black, trochanter yellow; femur black and yellow biannulate, slightly incrassate, ratio width: length 1: 3.6; tibia black and yellow biannulate, with short rounded apicoventral dens; tarsus entirely black, basitarsomere thick, ratio width: length 1:3.3.

ABDOMEN. Length ratio of terga I: II: III: IV 1: 3.5: 2.0: 1.5; ratio width at posterior margin: medial length of tergum II and III 1: 4.7 and 1: 1.0. Terga black, anterior $1 / 3$ of tergum III with yellow fascia; pile pale, on terga short, laterally on terga I and II long; tergum I with 3 evenly spaced strong light-brown setae at lateral margin; sternum III rectangular, ratio width: length 1: 3.9; sternum IV, Fig. 7A; sterna VI, VII and VIII simple, with long yellow pile. Genitalia, Fig. 7B-D: cerci small, round; surstyli symmetrical, elongate with rather long and narrow ventral lobe; superior lobes asymmetrical, rounded apically, with several sublobes.

\section{Female}

Unknown.

Sphegina (Asiosphegina) amamiensis Shiraki, 1968

Sphegina amamiensis Shiraki, 1968: 193. Type locality: Amami, Japan (holotype, đ̂, NIAES).

\section{Differential diagnosis}

Sphegina (Asiosphegina) amamiensis is strikingly different from all other species studied here due to the wide bifid lobe on the male sternum IV which is situated on the right side, in all other species having a similar lobe it is situated on the left. Furthermore, it is characterized by the following: frontal prominence short; face black; mouth edge dark brown; basoflagellomere oval, arista short pilose; scutum with pollinose pattern; scutellum with setae rather long and closely set; vein dm-cu slightly oblique; proand mesotarsus with tarsomeres 4 and 5 black; metafemur black and yellow biannulate; tergum I with an oblique row of light yellow setae at lateral margin; tergum III with red-brown fascia on anterior $1 / 2$; sternum IV posteriorly on the right side with a large subtriangular lobe having a widely bilobed apex.

\section{Material examined}

JAPAN • つ’; “Amami / Oshima / Mt Yuwan”; "V-3-1953 / Ryukyu Is. / T. Shiraki”; "Sphegina holotype / amamiensis ô n.sp. / Det T. Shiraki"; "holotype" [red label]; photos of holotype in lateral, dorsal and ventral view studied; NIAES. 
Sphegina (Asiosphegina) amplistylus sp. nov. urn:1sid:zoobank.org:act:54E8023E-E4AC-4393-8CE8-66D9AD6BC700

Figs $6 \mathrm{D}, 8,21 \mathrm{C}$

\section{Differential diagnosis}

Similar to Sphegina (Asiosphegina) inflata sp. nov., S. (A.) philippina and S. (A.) spathigera sp. nov. For distinguishing characters, see under these three species.

\section{Etymology}

The specific epithet is from the Latin 'amplistylus', meaning 'large stylus' and referring to the enlarged left-side surstylus. The name is a noun in apposition.

\section{Material examined}

\section{Holotype}

PHILIPPINES • đ̃; "Philippines / Camarines Sur: Mt. / Isarog 500 m. / 4.IV.1963"; "H.M. Torrevillas / Collector / Bishop"; BPBM.

\section{Description}

Male

Length. Body $6.4 \mathrm{~mm}$, wing $5.3 \mathrm{~mm}$.

HEAD. Face in lateral view concave, weakly projected antero-ventrally; frontal prominence very weakly developed. Ratio width of vertex at anterior ocellus: width of head 1: 5.3; ratio width of ocellar triangle: width of vertex 1: 1.6; ratio length of ocellar triangle: length of frons 1: 2.4. Face black, ventral half dark yellow to brown; light grey pollinose, long pilose along eye-margin. Hypostomal bridge brown, long pale pilose. Gena and mouth edge dark yellow to brown, weakly pollinose with large subtriangular nonpollinose shiny area. Frons and vertex black, slightly pollinose, a narrow subtriangular area posterior of lunula non-pollinose and shiny; pile short, light yellow (Fig. 21C). Frons with weak furrow medially. Occiput black, light grey pollinose, light yellow pilose. Eye with an area of enlarged facets at anterior margin. Antenna brown with black setae dorsally on scape and pedicel; basoflagellomere rectangular, ratio width: length 1: 1.4; arista long pilose, nearly 3 times as long as basoflagellomere.

THORAX. Colour black, weakly greyish pollinose, postpronotum dark brown, grey pollinose, pleuron entirely grey pollinose; scutum and pleuron with very short adpressed light yellow pile. Scutellum short, widely sub-triangular, black, weakly pollinose, long pilose, with pile longer than on scutum, without marginal setae (possibly the setae are broken off).

WING. Entirely microtrichose; hyaline, stigma yellowish; crossvein dm-cu meeting vein $\mathrm{M}$ slightly obliquely and vein $\mathrm{M}_{1}$ meeting vein $\mathrm{R}_{4+5}$ perpendicularly.

Legs. Pro- and mesoleg yellow, tarsomeres 4-5 black. Metaleg with coxa black, trochanter yellow; femur black with basal $1 / 3$ yellow, rather strongly incrassate, ratio width: length 1: 3.6; tibia black and yellow biannulate, with large rounded apicoventral dens; tarsus entirely black, basitarsomere thick, ratio width: length $1: 3.3$.

AвDOMEN. Length ratio of terga I: II: III: IV 1: 3.5: 1.9: 1.6; ratio width at posterior margin: medial length of tergum II and III 1: 3.9 and 1: 0.8 . Terga black, anterior $1 / 3$ of tergum III with dark yellow fascia; pile pale, on terga short, laterally on terga I and II long; tergum I with horizontal row of 3-4 evenly spread brown-yellow setae at lateral margin; sternum III not sclerotized; sternum IV, Fig. 8A; sterna VI, VII and VIII simple, with long yellow pile. Genitalia, Fig. 8B-D: cerci unmodified, roundish; surstyli 
asymmetrical with the dorsal lobe of left surstylus strongly inflated; superior lobe slightly asymmetrical, with several sublobes of which the anteroventral one very long.

\section{Female}

\section{Unknown.}

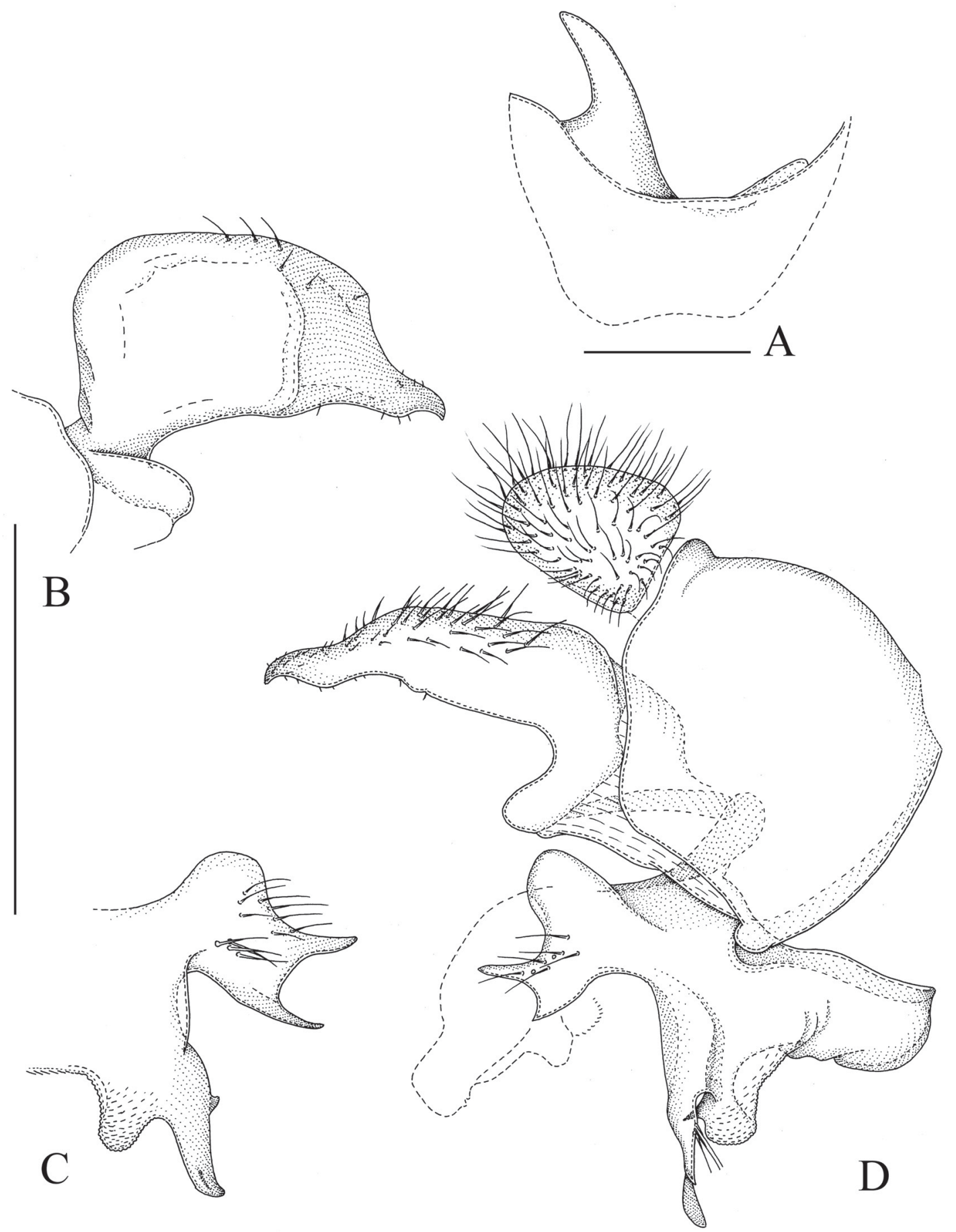

Fig. 8. Sphegina (Asiosphegina) amplistylus sp. nov., holotype, ठ․ A. Sternum IV, ventral view. B. Left surstylus, lateral view. C. Left superior lobe, lateral view. D. Genitalia, right side, lateral view. Scale bars $=0.5 \mathrm{~mm}$. 


\section{Remarks}

In the type material of Sphegina (Asiosphegina) philippina there is a headless specimen (1 +, "P.I.: Mindanao / Bukidnon. 1480 m. / Mt. Katanglad / 27-31.X.1959"; "L.W. Quate / Collector" (BPBM)), see Fig. 6B. This female is not Sphegina (Asiosphegina) philippina, because the postpronotum is black (yellow in $S$. (A.) philippina), the wing is hyaline (slightly infuscated in $S$. (A.) philippina) and tergum $\mathrm{V}$ has the posterior margin straight (incised in $S$. (A.) philippina). This specimen is possibly the female of $S$. (A.) amplistylus sp. nov., but as even the males of all the similar species are very difficult to distinguish from each other without reference to genitalia, the identity of this female remains doubtful.

Sphegina (Asiosphegina) apicalis Shiraki, 1930

Figs 6E-F, 9, 10B, 21D

Sphegina apicalis Shiraki, 1930: 423. Type locality: Musha, Taiwan (holotype,, , NIAES).

\section{Differential diagnosis}

Sphegina (Asiosphegina) apicalis is similar to $S$. (A.) nubicola sp. nov. Except for the characters mentioned in the key, the species is distinguished by the very different male genitalia: in $S$. (A.) apicalis the surstyli are angular (curved in $S$. (A.) nubicola sp. nov.), the ventral lobe of the right surstylus has a prominent sublobe at posterior margin (weak sublobe) and the superior lobes are complicated, with several sublobes (simple, only with posteroventral claw-like sublobe). The female of $S$. (A.) apicalis differs from that of $S$. (A.) nubicola sp. nov. by the squarish basoflagellomere (oval in $S$. (A.) nubicola sp. nov.) and the shape of sterna IV and V which are squarish and slightly rectangular in $S$. (A.) apicalis but widely to very widely rectangular in $S$. (A.) nubicola sp. nov.

\section{Material examined}

Holotype

TAIWAN • đ̄; "Formosa / Musha 1919 / V 18 - VI 15 / T. Okuni / J. Sonan / K. Miy, M. Yosh."; "Sphegina / apicalis n. sp. / Det T. Shiraki"; "Type" [white round label with red circle]; photos of the holotype in lateral and dorsal view studied; NIAES.

\section{Additional material}

TAIWAN • 1 ○’; “Taiwan Nantou / Jenai Meifen / V.1-20.1998 / [leg] C.S. Lin \& W.T. Yai / UV light”; "NMNS ENT / 2889-148"; NMNS • 1 o; " "Taiwan N-Nantou Co. / Road No. 14, NE Puli / Reyen ShiReg. E. Tsuifeng / to Yuanfeng ca $2500-2700 \mathrm{~m} / \mathrm{ca} 24^{\circ} 07^{\prime} \mathrm{N}, 121^{\circ} 13^{\prime} \mathrm{E} / \mathrm{1}$.VII.2000 leg. W. Schacht”; JSA • 1 q; same data as for preceding; "Tsuifeng / ca $24^{\circ} 06^{\prime} \mathrm{N}, 121^{\circ} 11^{\prime} \mathrm{E} / 2200 \mathrm{~m}, 28$. VI-2.VIII.2000";

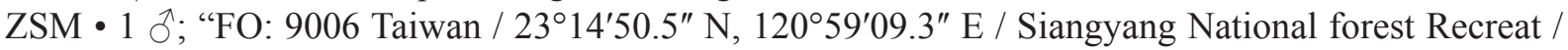
Taichung $2820 \mathrm{mNN}$ / A. Astilbe sp. / leg. A. Ssymank, 29.05.2016"; ASW.

\section{Description}

\section{Male}

LenGth. Body 5.2-5.5 mm, wing 4.4-4.7 $\mathrm{mm}$.

HEAD. Face in lateral view concave, weakly projected antero-ventrally; frontal prominence weakly developed. Ratio width of vertex at anterior ocellus: width of head 1: 3.7-4.0; ratio width of ocellar triangle: width of vertex 1: 2.0-2.3; ratio length of ocellar triangle: length of frons 1: 2.0-2.3. Face black, light grey pollinose, long pilose along eye-margin. Hypostomal bridge yellow to dark yellow, long pale pilose. Gena black, mouth edge brown to dark yellow with large triangular non-pollinose shiny area. Frons and vertex black, predominantly grey pollinose, a very narrow semi-circular area posterior 
of lunula non-pollinose and shiny; pile short, light yellow. Frons with deep pit and weak medial furrow. Occiput black, light grey pollinose, light yellow pilose. Eye with enlarged facets at anterior margin.
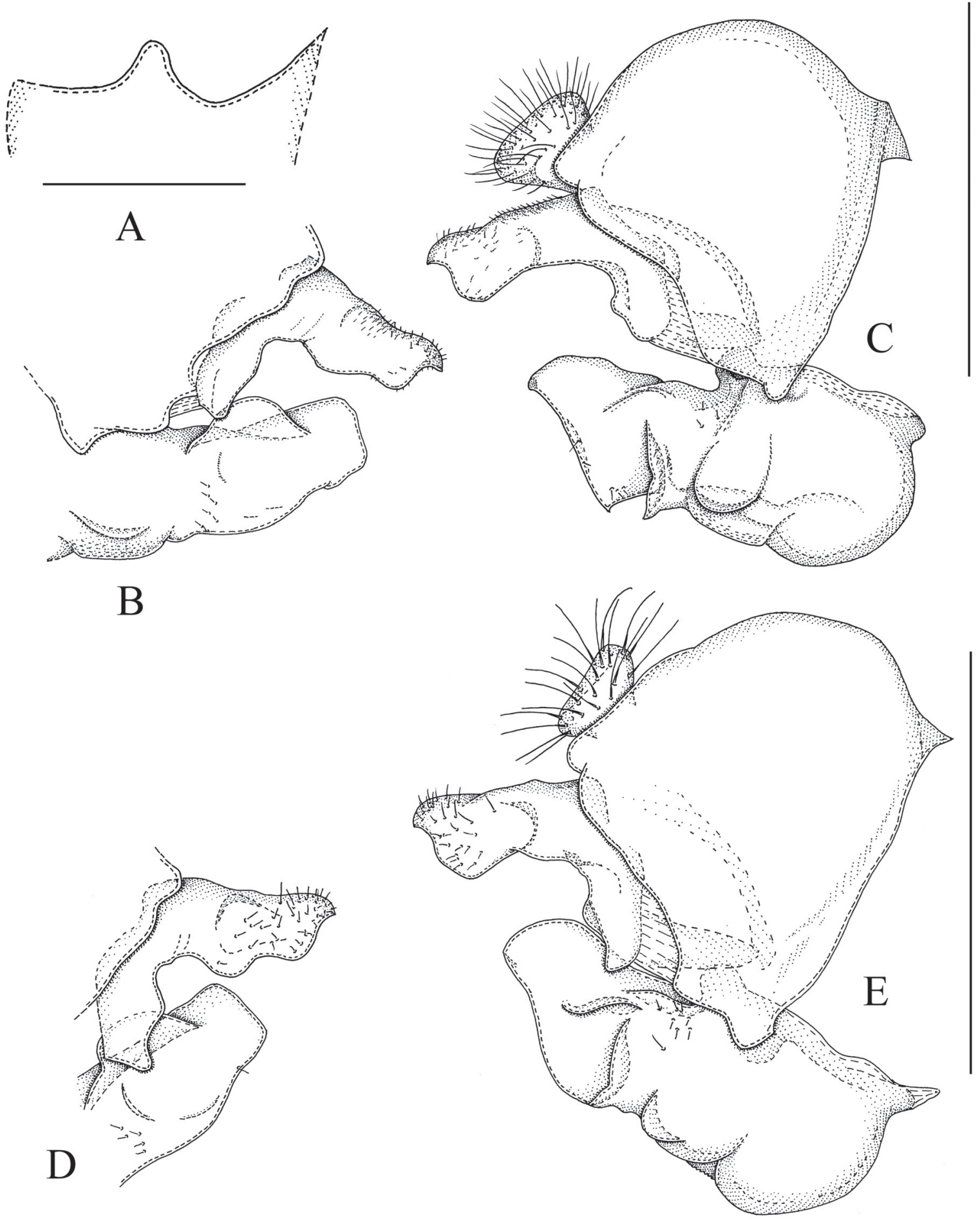

Fig. 9. Sphegina (Asiosphegina) apicalis Shiraki, 1930, đ̂, A-C from Meifeng, D-E from Puli. A. Posterior part of sternum IV, ventral view. B, D. Posterior part of genitalia, left side, lateral view. C, E. Genitalia, right side, lateral view. Scale bars $=0,5 \mathrm{~mm}$. 
Antenna black with black setae dorsally on scape and pedicel; basoflagellomere squarish, ratio width: length 1: 1.0-1.1; arista with basal 1/4 short pilose, about 3 times as long as basoflagellomere.

Thorax. Colour dark brown to black, weakly greyish pollinose, with denser grey pollinose vitta submedially; posterior margin of katepisternum narrowly non-pollinose, shiny; scutum and pleuron with very short adpressed light yellow pile. Scutellum subtriangular, black, shiny, with pile slightly longer than on scutum, with two closely set, short setae medially at posterior margin, ratio length of scutellum: length of seta 1: 0.9-1.2.

WING. Entirely microtrichose; hyaline, stigma yellowish. Crossvein dm-cu meeting vein M obliquely and vein $M_{1}$ meeting vein $R_{4+5}$ perpendicularly.

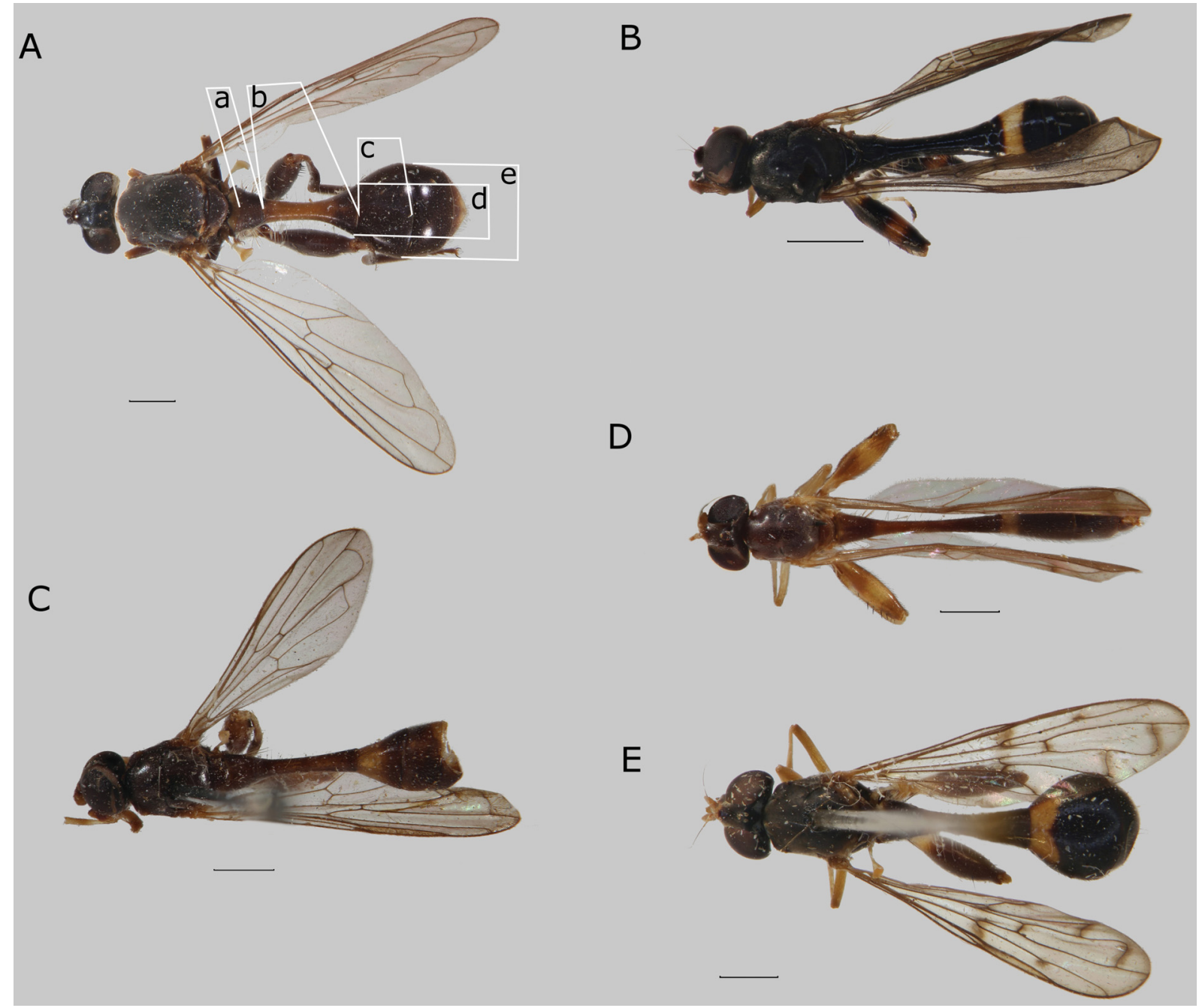

Fig. 10. Habitus, dorsal view. A. Sphegina (Asiosphegina) adusta Hippa, van Steenis \& Mutin,2015, paratype, ${ }^{+}$, Myanmar. B. S. (A.) apicalis Shiraki, 1930, ô, Taiwan. C. S. (A.) atricolor Hippa, van Steenis \& Mutin, 2015, paratype, ô, Myanmar. D. S. (A.) bidens Hippa, van Steenis \& Mutin, 2015, paratype, Ô, Myanmar. E. S. (A.) carinata Hippa, van Steenis \& Mutin, 2015, + , India. Abbreviations: a, b, c are length of terga I, II and III, respectively; d, e are width of terga II and III, respectively. Scale bars $=1.0 \mathrm{~mm}$. 
Legs. Pro- and mesoleg yellow, tarsomeres 4 and 5 black. Metaleg with coxa black, trochanter yellow; femur black and yellow biannulate, incrassate, ratio width: length 1: 4.0-4.5; tibia black and yellow biannulate, without apicoventral dens; tarsus entirely black, basitarsomere very thick, ratio width: length 1: 2.7-3.1.

ABDOMEN. Length ratio of terga I: II: III: IV 1: 3.6-4.0: 1.8-2.1: 1.5-1.7; ratio width at posterior margin: medial length of tergum II and III 1: 2.9-3.2 and 1: 0.7-0.8. Tergum IV slightly skewed to the right. Terga black; tergum III with sub-anterior yellow fascia with upturned V-shaped posterior margin; pile short and pale; tergum I with an oblique row of 4 light yellow setae at lateral margin; sternum III rectangular, ratio width: length 1: 2.3-2.8; sternum IV, Fig. 9A; sterna VI, VII and VIII simple, with long yellow pile. Genitalia (Fig. 9B-E): cerci unmodified, subtriangular; surstyli asymmetrical, the ventral lobe on the right side with subtriangular lobe on posterior margin, on the left side with a long vertical lobe laterally; superior lobe with several sublobes.

\section{Redescription}

\section{Female}

Similar to male except for the usual sexual dimorphism.

Length. Body $5.0 \mathrm{~mm}$, wing $3.9 \mathrm{~mm}$.

HEAD. Face in lateral view Fig. 21D. Ratio width of vertex at anterior ocellus: width of head 1: 3.0; ratio width of ocellar triangle: width of vertex 1: 2.4; ratio length of ocellar triangle: length of frons 1: 3.4. Basoflagellomere squarish, ratio width: length 1: 0.9 ; arista long pilose; about 3 times as long as basoflagellomere.

THorax. Scutellum with two closely set, very short setae medially at posterior margin, ratio length of scutellum: length of seta 1: 0.8 .

LEGS. Metafemur, ratio width: length 1: 3.9, metatarsus with basitarsomere thick, ratio width: length 1: 3.2.

ABDomen. Length ratio of terga I: II: III: IV: V 1: 2.9: 2.5: 1.9: 1.3; ratio width at posterior margin: medial length of tergum II and III 1: 1.0 and 1: 0.8 . Tergum II with postero-lateral large triangular orange-brown maculae; terga III and IV on anterior $1 / 2-3 / 4$ with orange-brown fascia; tergum V anterior $3 / 4$ to entirely orange-brown; sternum III rectangular with slightly wider posterior part, ratio width: length 1: 2.3; sternum IV squarish, ratio width: length 1: 1.2; sternum V rectangular, ratio width: length 1: 0.7 .

\section{Distribution and biology}

Widely distributed in Taiwan at an altitude between 2200-2820 $\mathrm{m}$ and collected between the $1^{\text {st }}$ of May and the $2^{\text {nd }}$ of August. The holotype could, however, have been collected at an altitude of $1150 \mathrm{~m}$ (Kojima et al. 2011). Flower visiting Astilbe longicarpa (Saxifragaceae) near a small brook with water percolating on a steep rocky slope within a mainly older Pinus taiwanensis afforestation and at Siangyang collected together with Sphegina (Asiosphegina) dentata sp. nov., S. (A.) orientalis and S. (A.) taiwanenis sp. nov. (van Steenis et al. in prep).

\section{Remarks}

The species was until now only known from the female holotype. The conspecificity of the males studied here with the holotype is supported by the yellowish mouth edge, the squarish basoflagellomere, the scutum with pollinose pattern, the shiny scutellum, the hyaline wing with crossvein dm-cu meeting vein 
$\mathrm{M}$ obliquely and vein $\mathrm{M}_{1}$ meeting vein $\mathrm{R}_{4+5}$ perpendicularly, the biannulate incrassate metafemur, and the oblique row of 4 light yellow setae at lateral margin of tergum I.

Sphegina (Asiosphegina) asciiformis Brunetti, 1915

Sphegina asciiformis Brunetti, 1915: 223. Type locality: Darjiling, India (holotype, $q$, NZSI).

\section{Differential diagnosis}

See under the Remarks below.

\section{Material examined}

\section{Holotype}

INDIA • O; "Ind. Mus. / Darjiling / alt. 7000 ft. / 29-V-[19]10 / Brunetti"; "TYPE"; "Sphegina / asciiformis / Brun Type + / det Brun. 1923"; "9758 / 112"; "Sphegina asciiformis Brun" [handwritten]; "Zoological Survey of India / [barcode] / ZSI0000004488"; photos of the specimen in lateral and dorsal view studied; the specimen is in bad condition: antennae, left wing, protarsi, meso- and metalegs missing; ZSI.

Description (see also Brunetti 1915, 1923)

\section{Female}

LENGTH. Body $4 \mathrm{~mm}$, wing $4 \mathrm{~mm}$.

HEAD. Face in lateral view concave, weakly projected antero-ventrally; frontal prominence weakly developed. Face black, light grey pollinose. Hypostomal bridge black. Gena black, mouth edge redbrown with large triangular non-pollinose shiny area. Frons and vertex black, predominantly grey pollinose, a rather wide semi-circular area posterior of lunula non-pollinose and shiny. Occiput black, light grey pollinose. Antenna brown to black; arista long.

THORax. Colour dark brown to black, weakly greyish pollinose, with denser grey pollinose vitta submedially; pleuron with greyish pollinosity and white pile. Scutellum semi-circular, black, shiny.

Wing. Entirely hyaline, stigma yellowish. Crossvein dm-cu meeting vein $\mathrm{M}$ obliquely and vein $\mathrm{M}_{1}$ meeting vein $\mathrm{R}_{4+5}$ perpendicularly.

Legs. Pro- and mesoleg yellow. Metafemur black and yellow biannulate, incrassate; metatibia black and yellow biannulate; metatarsus entirely black, basitarsomere thick.

AвDOMEN. Terga black; pile very short and white; tergum II strongly constricted anteriorly and relatively short, about twice as long as tergum I and about 1.5 times as long as each of terga III and IV.

\section{Male \\ Unknown. \\ Remarks}

Only the holotype female of Sphegina (Asiosphegina) asciiformis from Darjeeling, India, is known. By the hyaline wing, oblique vein dm-cu and the short tergum II this species recalls Sphegina (Asiosphegina) apicalis, $S$. (A.) farinosa sp. nov. and $S$. (A.) nubicola sp. nov., but differs by the entirely yellow proand mesolegs (in all others at least tarsomeres 4 and 5 of pro- and mesotarsus black) and by the entirely black abdomen. 
Sphegina (Asiosphegina) atricolor Hippa, van Steenis \& Mutin, 2015

Figs 10C, 11A

Sphegina (Asiosphegina) atricolor Hippa, van Steenis \& Mutin, 2015: 55. Type locality: Kambaiti, Myanmar (holotype, $\lesssim$, NHRS).

\section{Remarks}

Only known by the type material from Myanmar, Kambaiti (Hippa et al. 2015).

Sphegina (Asiosphegina) atrimanus sp. nov.

urn:1sid:zoobank.org:act:5DC1DA56-B25E-42C2-B4F3-969E9FCC830B

Figs 11B, 12, 61A

\section{Differential diagnosis}

Sphegina (Asiosphegina) atrimanus sp. nov. is similar to $S$. (A.) granditarsis sp. nov., $S$. (A.) incretonigra sp. nov., $S$. (A.) nasuta, $S$. (A.) nigrotarsata sp. nov. and $S$. (A.) orientalis but is distinguished by the characters mentioned in the key. In male genitalia these species differ from other Sphegina (Asiosphegina) known to us by having an area of very long setae on the cercus and by having small setae on the

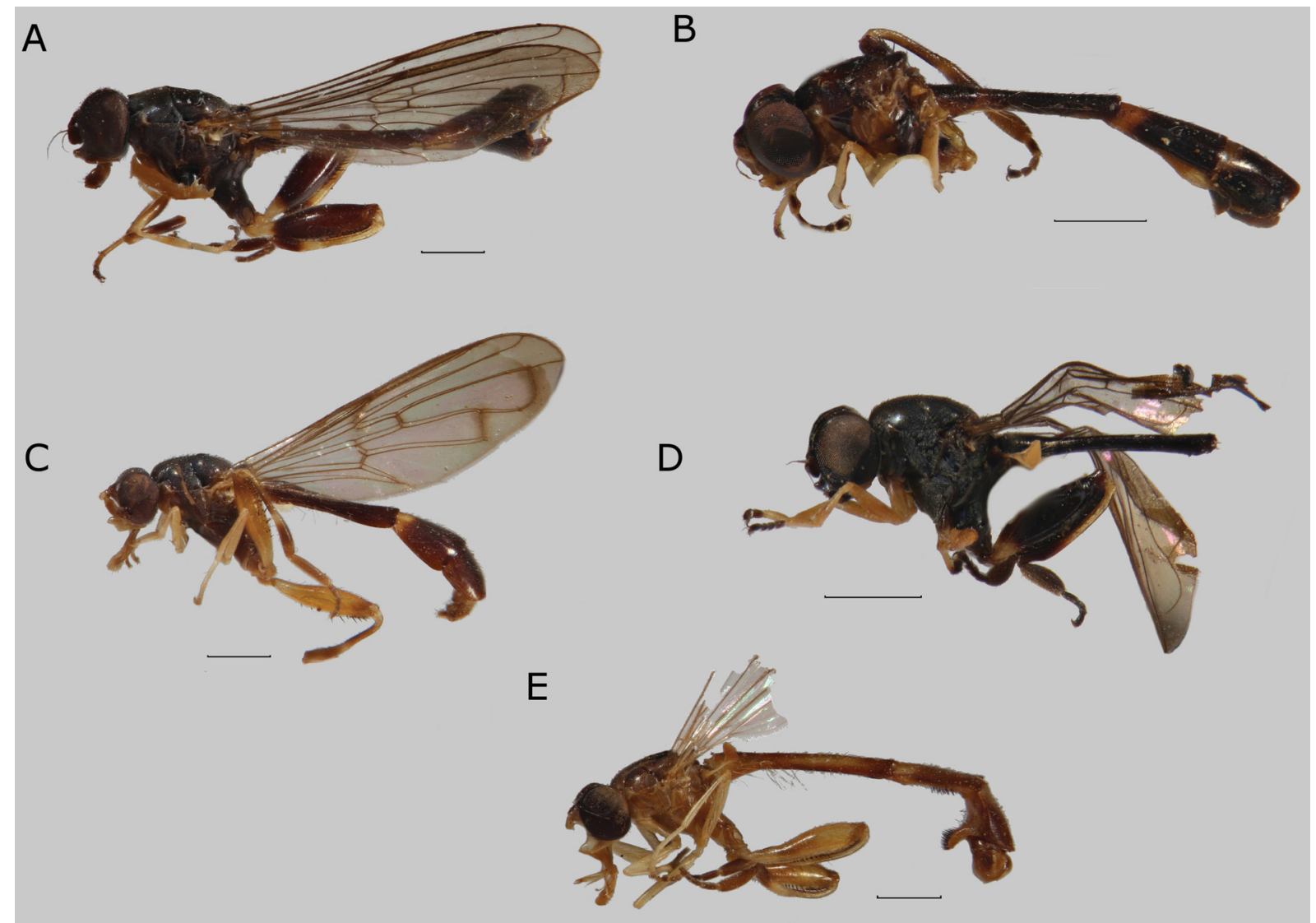

Fig. 11. Habitus, lateral view. A. Sphegina (Asiosphegina) atricolor Hippa, van Steenis \& Mutin, 2015,

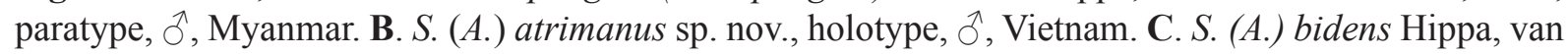
Steenis \& Mutin, 2015, paratype,, , Myanmar. D. S. (A.) bifida sp. nov., holotype, Õ. E. S. (A.) bilobata Hippa, van Steenis \& Mutin, 2015, paratype, ${ }^{\lambda}$, Myanmar. Scale bars $=1.0 \mathrm{~mm}$. 
surstylar apodeme and the membrane between the apodeme and the ventral margin of tergum IX. Sphegina (A.) atrimanus sp. nov. differs from $S$. (A.) granditarsis sp. nov., $S$. (A.) nigrotarsata sp. nov. and $S$. (A.) orientalis by having the angle between dorsal and ventral lobe of the surstylus as a right angle (acute in the others); by having the apex of its ventral lobe long, extending much more ventrally than the posterior part of the surstylar apodeme (both approximately at the same level); and by having the cercus enlarged. Sphegina (A.) atrimanus sp. nov. differs from $S$. (A.) nasuta by having the dorsal lobe of surstylus slightly angled and dilated on the apical part (evenly curved and evenly tapering towards the apex). The genitalia of $S$. (A.) atrimanus sp. nov. and $S$. (A.) incretonigra sp. nov. are almost identical, the former having the apical part of the surstylus, especially on the left side, and the superior lobe wider (Figs $12 \mathrm{~B}-\mathrm{C}$ and $46 \mathrm{~B}-\mathrm{C}$ ).

\section{Etymology}

The specific epithet is from the Latin 'atrimanus', meaning 'black-hand', referring to the predominantly black protarsus. The name is a noun in apposition.

\section{Material examined}

Holotype

VIETNAM • O’; "Viet Nam: Mt. Lang / Bian 1500-2000 / 19.V-8.VI.1961”; “N. R. Spencer / Collector / Bishop"; BPBM.

\section{Description}

\section{Male}

LeNGTH. Body $6.2 \mathrm{~mm}$, wing $5.2 \mathrm{~mm}$.

HEAD. Face in lateral view concave, weakly projected antero-ventrally; frontal prominence strongly developed. Ratio width of vertex at anterior ocellus: width of head 1:5.3; ratio width of ocellar triangle: width of vertex 1: 1.4; ratio length of ocellar triangle: length of frons 1: 1.9. Face black, ventral half yellow; light grey pollinose, long pilose along eye-margin. Hypostomal bridge yellow, long pale pilose. Gena and mouth edge yellow with large subtriangular non-pollinose shiny area. Frons and vertex black; frons largely shiny, non-pollinose except for subtriangular grey pollinose macula at eye-margin; pile short, light yellow. Frons with wide and deep pit antero-medially. Occiput black, light grey pollinose, light yellow pilose. Eye without enlarged facets at anterior margin. Antenna with scape dark brown, pedicel and basoflagellomere dark yellow with black setae dorsally on scape and pedicel; basoflagellomere oval, ratio width: length 1: 1.6; arista short pilose, about 3 times as long as basoflagellomere.

THORAX. Colour dark brown to black, postpronotum and medial part of pleuron yellow; weakly greyish pollinose, pleuron more heavily grey pollinose; scutum and pleuron with very short adpressed light yellow pile. Scutellum subtriangular, black, shiny medially, laterally weakly pollinose, with pile slightly longer than on scutum, with two closely set, very short setae medially at posterior margin, ratio length of scutellum: length of seta 1: 0.7 , but possibly apices of setae broken off.

WING. Partly destroyed on both sides. Entirely microtrichose; hyaline, stigma yellowish, membrane brown infuscated along veins bm-cu, $M_{1}$, at the junction of veins $M_{1}$ and $R_{4+5}$. Crossvein dm-cu meeting vein $M$ perpendicularly and vein $M_{1}$ meeting vein $R_{4+5}$ perpendicularly.

LEGs. Pro- and mesoleg yellow, protarsus with tarsomere 1 on basal half yellow, on apical half black, tarsomeres 2-5 black and mesotarsus with tarsomeres 4 and 5 dark brown to black; protarsus enlarged and flattened, ratio apical width of tibia: width of tarsomere $21: 1.6$. Metaleg with coxa black, trochanter yellow; femur black and yellow biannulate, slightly incrassate and club shaped, ratio width: length 1 : 
4.7; tibia black and yellow biannulate, without apicoventral dens; tarsus entirely black, basitarsomere very thick, ratio width: length $1: 2.9$.

ABDOMEN. Length ratio of terga I: II: III: IV 1: 4.1: 2.7: 2.5; ratio width at posterior margin: medial length of tergum II and III 1: 5.0 and 1: 1.5. Terga black, tergum II with sub-anterior light-brown fascia,

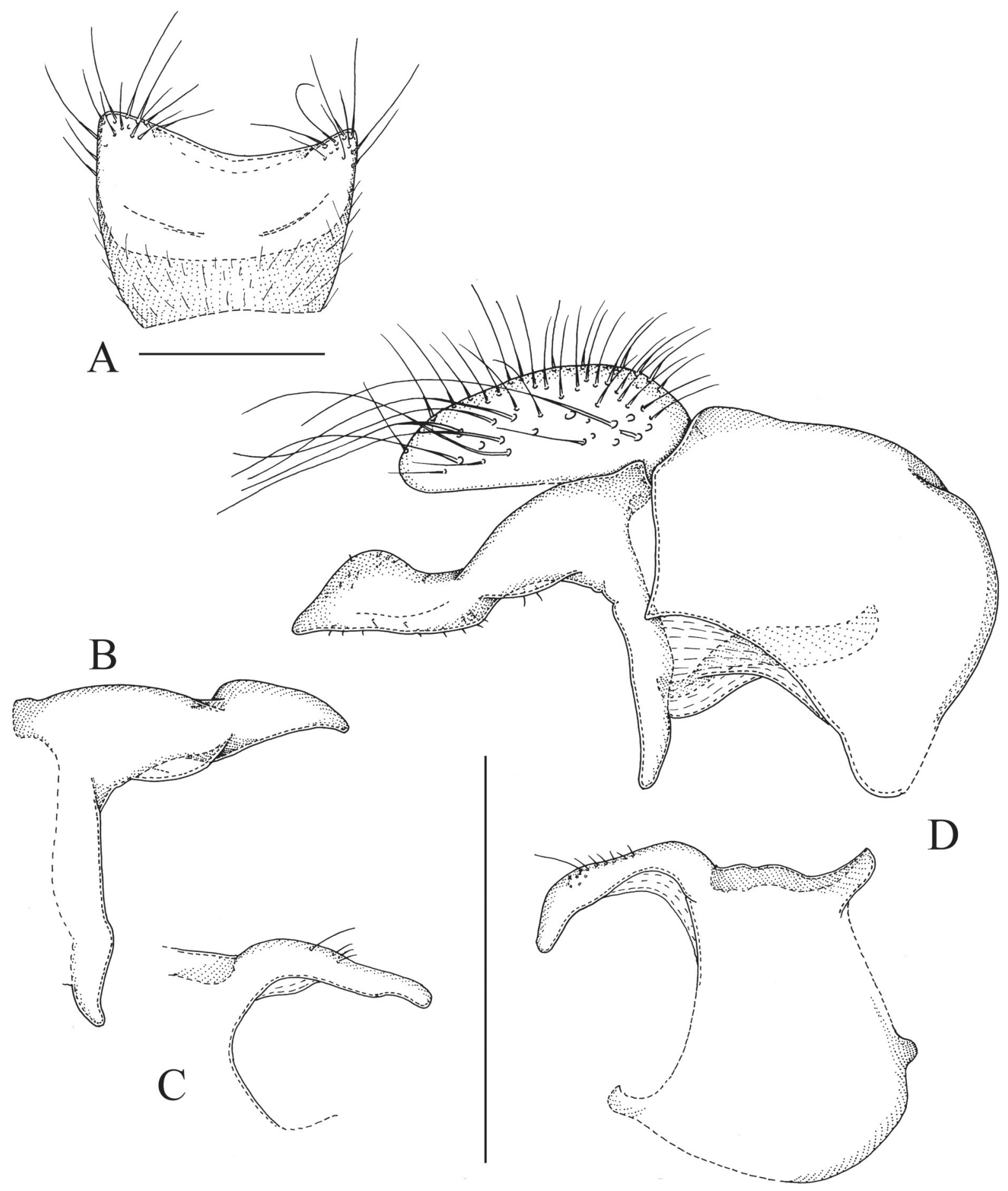

Fig. 12. Sphegina (Asiosphegina) atrimanus sp. nov., holotype, ठ̊. A. Sternum IV, ventral view. B. Left surstylus, lateral view. C. Left superior lobe, lateral view. D. Genitalia, right side, lateral view. Scale bars $=0.5 \mathrm{~mm}$. 
anterior $1 / 3$ of tergum III with yellow fascia; pile pale, on terga short, laterally on terga I and II long; tergum I with 2 widely separated strong yellow setae at lateral margin; sternum III elongate, ratio width: length 1: 4.1; sternum IV, Fig. 12A; sterna VI, VII and VIII simple, with long yellow pile. Genitalia, Fig. 12B-D: note the area of long setose pile deviating from other pilosity on cercus and the small setae on postgonal apodeme and the membrane between the apodeme and ventral margin of tergum IX.

\section{Female}

Unknown.

\section{Distribution and biology}

Collected together with Sphegina (Asiosphegina) lucida sp. nov., S. (A.) nigrotarsata sp. nov., $S$. (A.) spenceri sp. nov. and $S$. (A.) vietnamensis sp. nov.

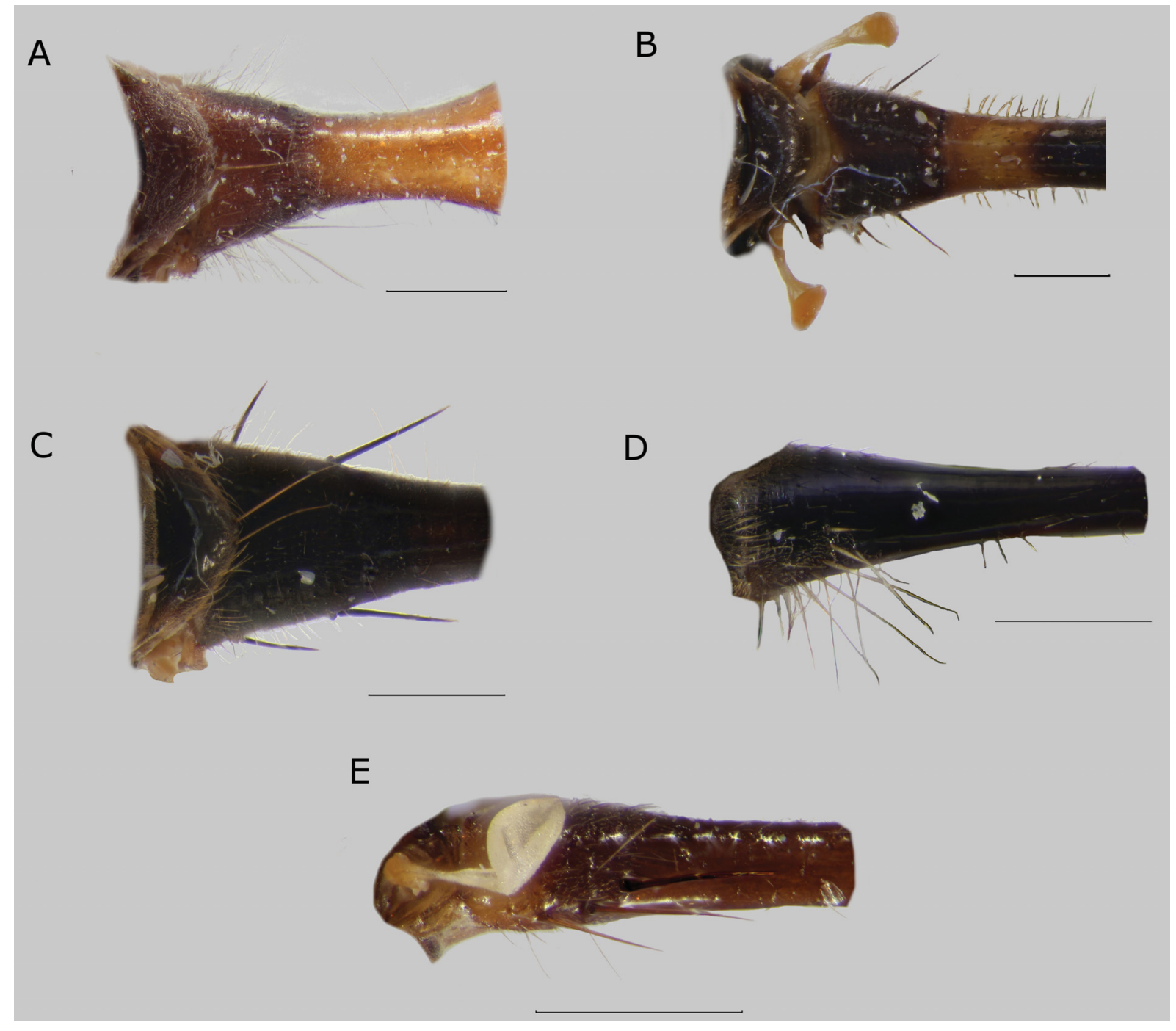

Fig. 13. Tergum I, dorsal view (A-C) and lateral view (D-E). A. Sphegina (Asiosphegina) achaeta Hippa, van Steenis \& Mutin, 2015, , , Myanmar. B. S. (A.) carinata Hippa, van Steenis \& Mutin, 2015, paratype, + , Myanmar. C. $S$. (A.) clavigera sp. nov., paratype,, , Vietnam. D. $S$. (A.) crinita sp. nov., paratype, ô, Java. E. S. (A.) crucivena Hippa, van Steenis \& Mutin, paratype, $\widehat{\jmath}$, Myanmar. Scale bars = $0.5 \mathrm{~mm}$. 


\section{Remarks}

Even if the genitalia of Sphegina (Asiosphegina) atrimanus sp. nov. are largely similar to those of S. (A.) incretonigra sp. nov., we are sure they belong to different species based on the difference in the characters of protarsus which is in the same magnitude between these two species and that of S. (A.) granditarsis sp. nov. and $S$. (A.) nigrotarsata sp. nov.

\section{Sphegina (Asiosphegina) bidens Hippa, van Steenis \& Mutin, 2015}

Figs 10D, 11C

Sphegina (Asiosphegina) bidens Hippa, van Steenis \& Mutin, 2015: 39. Type locality: Kambaiti, Myanmar (holotype, ô, NHRS).

\section{Remarks}

Only known by the type material from Myanmar, Kambaiti (Hippa et al. 2015).

Sphegina (Asiosphegina) bifida sp. nov.

urn:1sid:zoobank.org:act:E16EF3C9-3BE4-4659-B7B0-AC03CF500474

Figs $11 \mathrm{D}, 14,21 \mathrm{E}$

\section{Differential diagnosis}

Very similar to Sphegina (Asiosphegina) collicola sp. nov. and S. (A.) inventum sp. nov. For distinguishing characters, see under $S$. (A.) inventum sp. nov.

\section{Etymology}

The specific epithet is from the Latin 'bifida', meaning 'split into two parts' and referring to the bifid lobe posteriorly on male sternum IV.

\section{Material examined}

\section{Holotype}

MALAYSIA • \’; "Malaysia: Sabah: / 1 km S. Kundasang. / el. 1530 m. 10 Sept.1983 / [leg.] G.F. Hevel \& W.E. Steiner"; “USNMENT / QR code / 01224071”; wings wrinkled and distorted; USNM.

\section{Description}

\section{Male}

LENGTH. Body $5.8 \mathrm{~mm}$, wing; not measurable due to wrinkling of the wing.

HEAD. Face in lateral view concave, very weakly projected antero-ventrally; frontal prominence very weakly developed. Ratio width of vertex at anterior ocellus: width of head 1: 5.9; ratio width of ocellar triangle: width of vertex 1: 1.3; ratio length of ocellar triangle: length of frons 1: 3.3. Face black; light grey pollinose, long pilose along eye-margin. Hypostomal bridge black, long pale pilose. Gena and mouth edge black, gena with large subtriangular non-pollinose shiny area. Frons and vertex black slightly pollinose with circular area posterior of lunula non-pollinose and shiny, with densely grey pollinose vitta sub-anteriorly and posteriorly with velvet black pollinosity; pile short, light yellow. Frons with weak medial furrow. Occiput black, light grey pollinose, light yellow pilose. Eye with an area of enlarged facets at anterior margin (Fig. 21E). Antenna black with black setae dorsally on scape and pedicel; basoflagellomere round, ratio width: length 1: 1.1; arista weakly short pilose, about 3 times as long as basoflagellomere. 
THORAx. Colour dark brown to black, weakly greyish pollinose; posterior margin of katepisternum narrowly non-pollinose, shiny; scutum and pleuron with very short adpressed light yellow pile. Scutellum sub-rectangular, black, sub-shiny and weakly pollinose, with pile slightly longer than on scutum, with two widely set setae; length of setae not measurable as the apices are broken off.

WING. Microtrichose, on basal part of cell bm only sparsely microtrichose, almost bare; hyaline, stigma yellowish. Crossvein dm-cu meeting vein $M$ perpendicularly and vein $M_{1}$ meeting vein $R_{4+5}$ perpendicularly.

LeGs. Pro- and mesoleg yellow, tarsomeres 4 and 5 black. Metaleg with coxa and trochanter black; femur black with basal 1/5 yellow, slightly incrassate, ratio width: length 1: 3.5 ; tibia yellow with apical 1/3

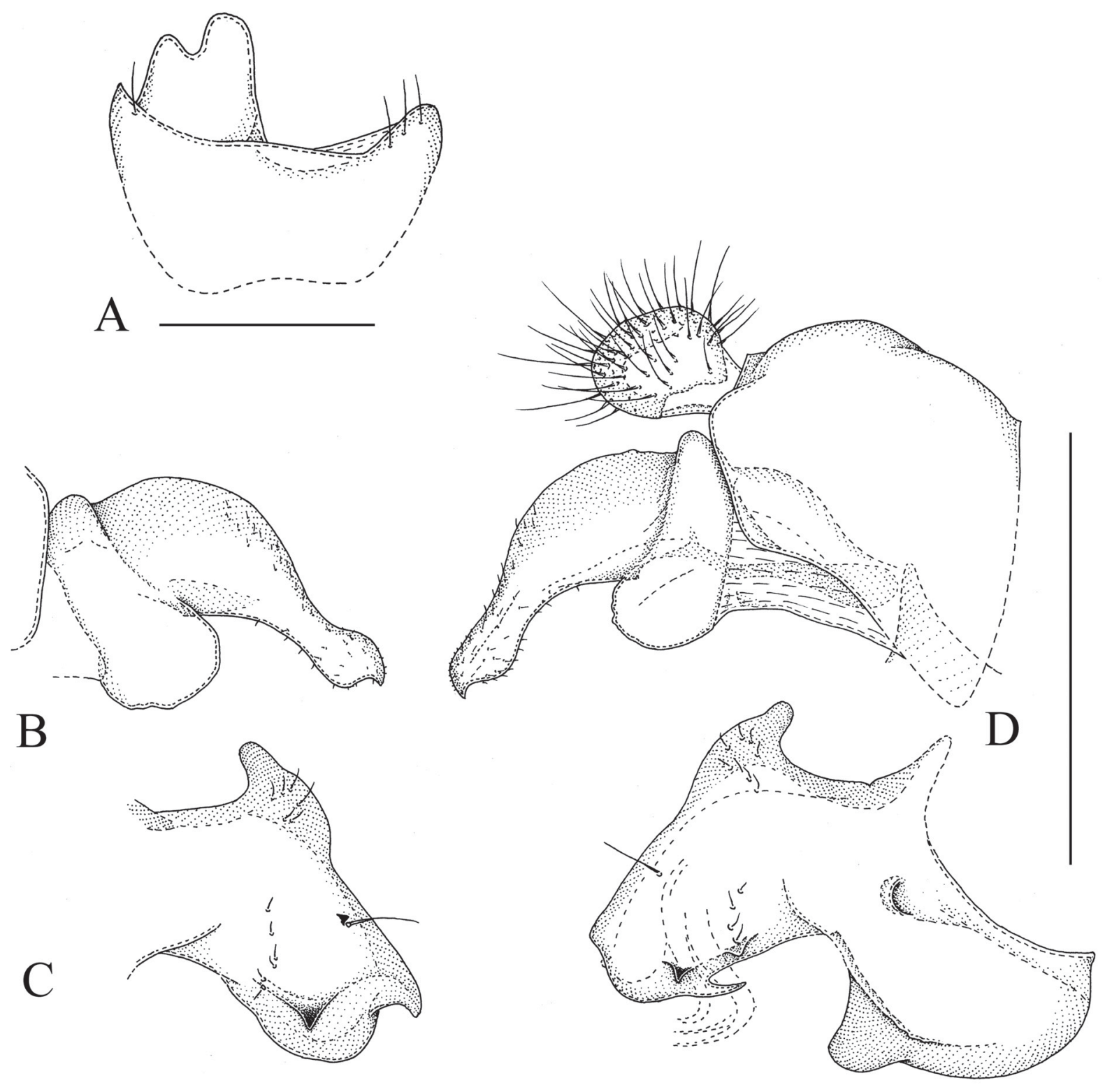

Fig. 14. Sphegina (Asiosphegina) bifida sp. nov., holotype, $\widehat{\jmath}$. A. Sternum IV, ventral view. B. Left surstylus, lateral view. C. Left superior lobe, lateral view. D. Genitalia, right side, lateral view. Scale bars $=0.5 \mathrm{~mm}$. 
black, widened apically, with subtriangular apicoventral dens; tarsus entirely black, basitarsomere very thick, ratio width: length $1: 2.5$.

AвDOMEN. Length ratio of terga I: II: III: IV 1: 3.6: 1.6: 1.4; ratio width at posterior margin: medial length of tergum II and III 1: 6.0 and 1: 0.8. Terga black, anterior 1: 3.4 of tergum III with red-brown fascia; pile pale, on terga short, laterally on terga I and II long; tergum I with 3 strong light yellow setae at lateral margin; sternum IV, Fig. 14A; sterna VI, VII and VIII simple, with short yellow pile. Genitalia, Fig. 14B-D: note the strong asymmetry of surstyli and superior lobes.

\section{Female}

Unknown.

Sphegina (Asiosphegina) bilobata Hippa, van Steenis \& Mutin, 2015

Fig. 11E

Sphegina (Asiosphegina) bilobata Hippa, van Steenis \& Mutin, 2015: 41. Type locality: Kambaiti, Myanmar (holotype, $\hat{\jmath}$, NHRS).

\section{Remarks}

Only known by the type material from Myanmar, Kambaiti (Hippa et al. 2015).

\section{Sphegina (Asiosphegina) bispinosa Brunetti, 1915}

Figs 16, 21H-I, 67D, 72E-F, 77C

Sphegina bispinosa Brunetti, 1915: 223. Type locality: Margerita, Assam, India (syntype, ふ̋, NZSI).

\section{Differential diagnosis}

Sphegina (Asiosphegina) bispinosa is similar to $S$. (A.) hansoni but clearly differentiated by the characters in the key and the strongly asymmetrical surstyli.

\section{Material examined}

Syntype

INDIA - O'; "Margherita, Assam: syntype $q$ Darjiling (7000ft.) 29-v-[19]10 leg Brunetti"; not studied.

\section{Additional material}

INDIA • 1 ô, "India: Darjeeling / Singamari 2031m / 26. v. 1976 / S. Biswas No. B24a"; "Ghorpade / collection / Bangalore"; "Sphegina / (Asiosphegina) / bispinosa Brun. / Mutin det 1998"; USNM • 1 J̈; "India / Himalayas / 196? / V.K. Gupta No. ?"; "Ghorpade / collection / Bangalore"; "Sphegina / (Asiosphegina) / sp. in det / K.D. Ghorpade det 2003"; "USNMENT / QR code / 01224069"; USNM • 1 ภ̊; "Northwest Himalaya / Kulu valley / vi.1970 / No."; "Ghorpade / collection / Bangalore"; "Sphegina / (Asiosphegina) / bispinosa Brun. / Mutin det 1998"; JSA • 1 đ ; "Northwest Himalaya / Manali 1828 m / 16. v. 1970 / M. Gupta No. M5"; "Ghorpade / collection / Bangalore"; "Sphegina / (Asiosphegina) / bispinosa Brun. / Mutin det 1998”; NZSI • 1 O̊’; "India: Sikkim / Gangtok 1871 m / 5. v. 1974 / Ghorpade No. A118"; "Ghorpade / collection / Bangalore"; "Sphegina / (Asiosphegina) / bispinosa Brun. / Mutin

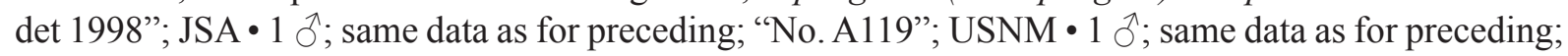
"No. A117"; JSA • 1 क; same data as for preceding; NZSI • 1 ơ; "India: (Uttar Pradesh) / Mussoorie c 1500-2200m / 3-14. vii. 1978 / Copenhagen Zool. Mus. Exp."; "UZM"; "Sphegina / (Asiosphegina) / bispinosa Brun. / Mutin det 1998”; ZMUC • 1 क; "India: Sikkim / Gangtok 1618 m / 11. v. 1966 / D Ram No. T243"; "Ghorpade / collection / Bangalore"; USNM • 1 क; "India: West Bengal / Darjeeling 2176 m 
/ 25. iv. 1974; / Ghorpade No. A110"; "Ghorpade / collection / Bangalore"; "Sphegina / (Asiosphegina) / bispinosa Brun. / Mutin det 1998"; JSA • 1 O+; "India: Bhowali / Kumaon Hills U.P / 1700 m 5-8. vi. 1968 / Gupta No. 310"; "Ghorpade / collection / Bangalore"; "Sphegina / (Asiosphegina) / bispinosa Brun. / Mutin det 1998"; JSA • 1 O+; "Sikkim: Himalaya / Gangtok / 16. v. 1966 / Gupta No. 180"; "Ghorpade / collection / Bangalore"; "Sphegina / (Asiosphegina) / bispinosa Brun. / Mutin det 1998"; USNM • 1 o; " "ex coll Brunetti / Brit.Mus. 1927-184"; "India / Simla / 20-28.vii.1918”; NHM.

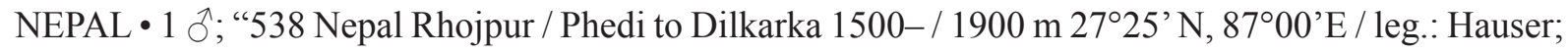
26.V.[19]97”; CSCA.

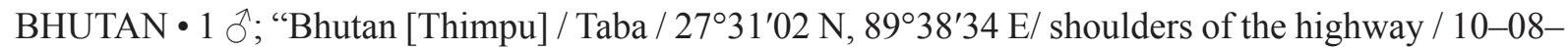
2016, 2379 m / leg. Tsering Nidup \& Wim Klein”; AET.

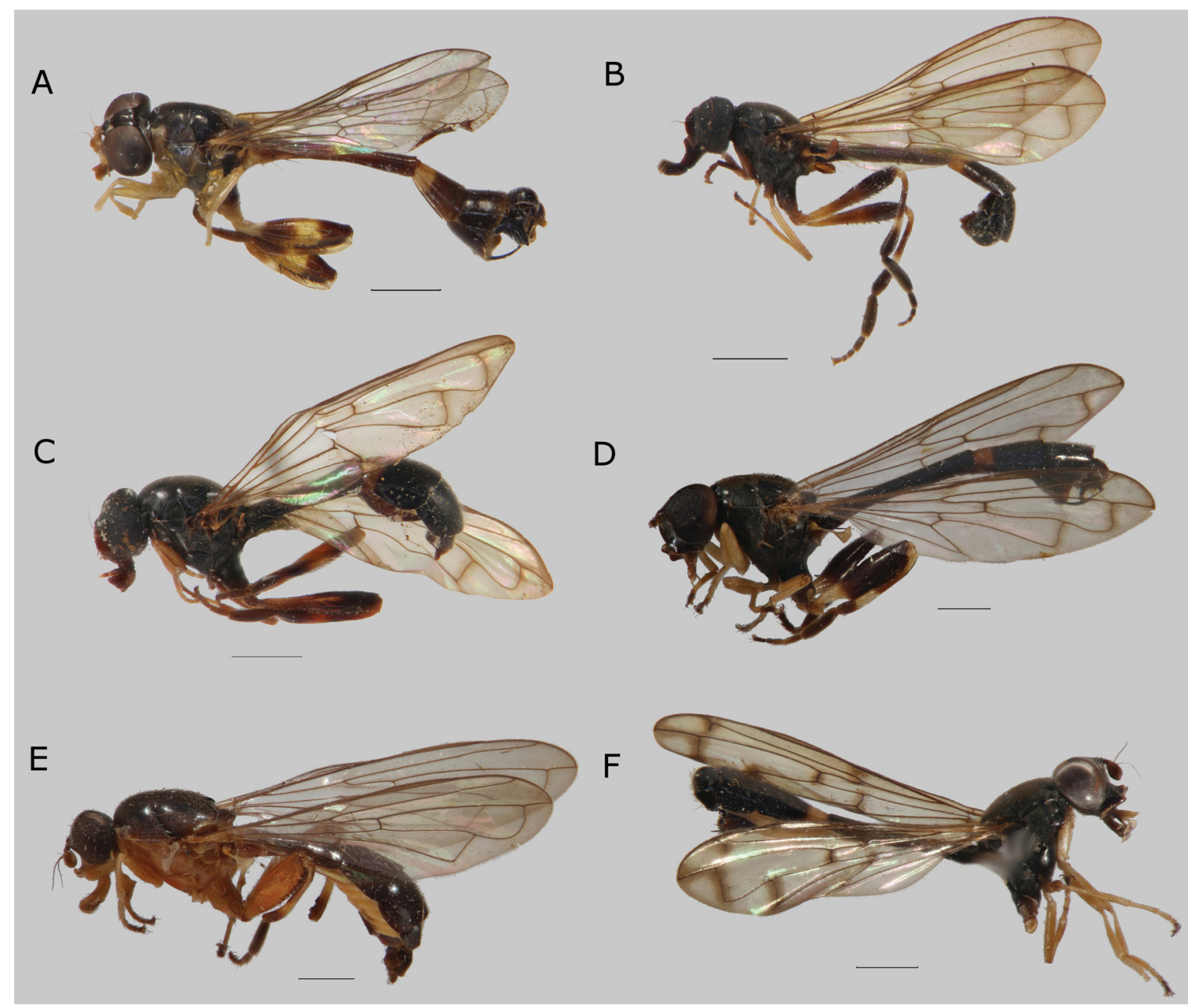

Fig. 15. Habitus, lateral view. A. Sphegina (Asiosphegina) bracon sp. nov., paratype, §,, Vietnam. B. S. (A.) brevipilis sp. nov., paratype, $\widehat{\jmath}$, China. C. S. (A.) brevipilis sp. nov., paratype,, , China. D. S. (A.) carinata Hippa, van Steenis \& Mutin, 2015, paratype, Ô, Myanmar. E. S. (A.) cerina Hippa, van Steenis \& Mutin, 2015, paratype,, , Myanmar. F. S. (A.) clavigera sp. nov., holotype, đ̃, Vietnam. Scale bars $=1.0 \mathrm{~mm}$. 


\section{Description}

\section{Male}

LeNGTH. Body 7.9-9.8 mm, wing 5.8-7.7 mm.

HEAD. Face in lateral view concave, strongly projected antero-ventrally; frontal prominence weakly developed. Ratio width of vertex at anterior ocellus: width of head 1: 3.9-4.4; ratio width of ocellar triangle: width of vertex 1: 1.9-2.2; ratio length of ocellar triangle: length of frons 1: 1.9-2.1. Face
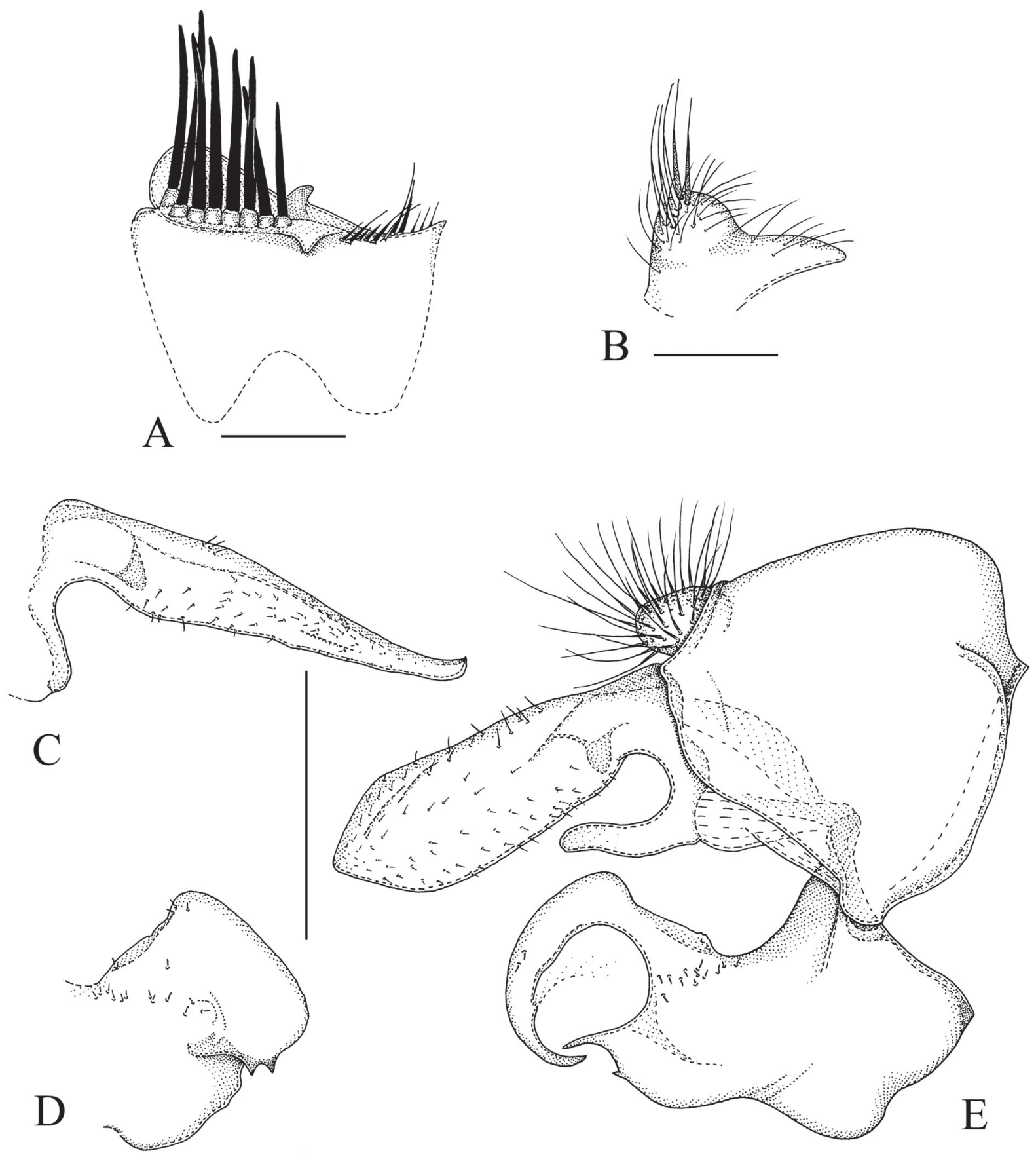

Fig. 16. Sphegina (Asiosphegina) bispinosa Brunetti, 1915, ô, India. A. Sternum IV, ventral view. B. Sternum VII, ventral view. C. Left surstylus, lateral view. D. Left superior lobe, lateral view. E. Genitalia, right side, lateral view. Scale bars $=0.5 \mathrm{~mm}$. 
dull black, long pilose along eye-margin. Hypostomal bridge black, long pale pilose. Gena and mouth edge black, grey pollinose with large subtriangular non-pollinose shiny area. Frons and vertex black, predominantly grey pollinose, a subtriangular area posterior of lunula non-pollinose and shiny; pile short, light yellowish brown (Fig. 21H-I). Frons with deep pit anteriorly and wide medial furrow. Occiput black, light grey pollinose, light yellow pilose. Eye without enlarged facets at anterior margin. Antenna dark brown with black setae dorsally on scape and pedicel; basoflagellomere oval, ratio width: length 1: 1.3-1.4; arista short pilose, about 3.5-4 times as long as basoflagellomere.

THORAX. Colour dark brown to black, postpronotum and dorso-medial part of anepisternum and anepimeron dark brown, weakly greyish pollinose, pleuron entirely grey pollinose; scutum and pleuron with very short adpressed pale-brown pile. Scutellum sub-rectangular, black, pollinose, with pile slightly longer than on scutum, with two closely set, very short setae medially at posterior margin, ratio length of scutellum: length of seta 1: 0.8-0.9.

WING. Entirely microtrichose; hyaline, stigma yellowish, membrane brown infuscated along veins dm$\mathrm{cu}$ and $\mathrm{M}_{1}$. Crossvein dm-cu meeting vein $M$ almost perpendicularly and vein $M_{1}$ meeting vein $R_{4+5}$ perpendicularly.

Legs. Pro- and mesoleg brown to brown-yellow, tarsomeres 4-5 dark brown to black. Metaleg, Fig. 72E, dark brown to black, dark yellow on extreme base of femur and tibia; femur slightly incrassate, ratio width: length 1: 3.9-4.3, with 1-3 long and rather strong subapical setae anterodorsally, basitarsomere thin, ratio width: length $1: 4.3-4.6$.

AbDomen. Length ratio of terga I: II: III: IV 1: 4.1-4.7: 2.4-2.9: 1.9-2.2; ratio width at posterior margin: medial length of tergum II and III $1: 4.0-4.8$ and $1: 1.1-1.2$. Terga black, anterior $1 / 3$ of tergum III with brown-yellow sub-anterior fascia; pile mixed dark brown to pale yellowish, short, laterally on terga II and III long; tergum I (Fig. 77C), with 3-4 strong black setae at lateral margin, posteriormost 2 setae almost vertically placed, one above the other; sternum III rectangular, ratio width: length 1: 1.5-1.8; sternum IV, Fig. 16A; sterna VI, VII and VIII with long yellow pile, sternum VII, Fig. 16B, with a large rounded yellow-pilose/setose conical process, sternum VIII posteriorly with tuft of long mixed yellow and black seta-like pile. Genitalia, Fig. 16C-E: observe the strongly asymmetrical surstyli and superior lobes and the short finger-like lobe subbasally on the medial side of surstyli.

\section{Female}

Similar to the male except the normal sexual dimorphism.

LeNGTH. Body 7.8-9.2 mm, wing 6.1-7.0 mm.

HEAD. Ratio width of vertex at anterior ocellus: width of head 1:3.4-3.7; ratio width of ocellar triangle: width of vertex 1: 2.2-2.5; face slightly narrower than vertex, ratio width of face: width of vertex 1: 1.0-1.1; ratio length of ocellar triangle: length of frons $1: 2.0-2.3$. Basoflagellomere round to slightly oval, ratio width: length 1: 1.1-1.3; arista short pilose, about 3 times as long as basoflagellomere.

THORax. Scutellum with two closely set, very short setae medially at posterior margin, ratio length of scutellum: length of seta 1: 0.9-1.0.

WING. Apex of $\mathrm{R}_{2+3}$ brownish infuscate.

LEGS. Metafemur (Fig. 72F) slightly incrassate, ratio width: length 1: 4.0-4.4, basitarsomere thin, ratio width: length 1: 3.9-4.4. 
AвDomen. Length ratio of terga I: II: III: IV: V 1: 4.2-4.7: 2.9-3.5: 2.1-2.6: 1.2-1.5; ratio width at posterior margin: medial length of tergum II and III 1: 2.3-2.9 and 1: 0.7-0.8. Tergum III black; tergum VI medially divided by a narrow membranous line; sternum III oval, very small, ratio width: length 1: 1.1-1.2; sternum IV trapezoidal, apical margin widest, ratio width: length 1: $0.7-0.9$; sternum V rectangular, ratio width: length $1: 1.1-1.3$.

\section{Remarks}

The specimens mentioned by Brunetti (1923) as types of Shegina (Asiosphegina) bispinosa are not the same specimens as mentioned in the original description (Brunetti 1915). Ghorpade (2015) already discussed this discrepancy and apparently studied the mentioned specimens, concluding they belong to one and the same species.

One of the additional females mentioned by Brunetti (1915) from Bhowali was studied by us and found to be conspecific with Sphegina (Asiosphegina) carinata. This specimen was labelled as cotype of $S$. (A.) bispinosa with a handwritten label. However, in his publication Brunetti (1915) designated only one male and one female as type: "Described from a ${ }^{\lambda}$ (type) from Margherita, Assam, a 9 (type) from Darjiling (7000 ft.) collected by me, 29-v-10; also, two 우 ㅇt taken by Mr. Imms near Bhowali, Kumaon, Western Himalayas (5700 ft.) in July 1909. Type $\delta$ and $\$$ in Indian Museum". Therefore, the supposed female cotype from Bhowali cannot be part of the type series and this is now indicated for this specimen (see the label information under $S$. (A.) carinata).

Sphegina (Asiosphegina) bracon sp. nov. urn:Isid:zoobank.org:act:0A45A27E-8BD9-4371-B219-9A348B37A659

Figs $15 \mathrm{~A}, 17,21 \mathrm{~F}-\mathrm{G}, 25 \mathrm{~A}-\mathrm{B}$

\section{Differential diagnosis}

Sphegina (Asiosphegina) bracon sp. nov is similar to $S$. (A.) furcillata sp. nov. and $S$. (A.) vietnamensis sp. nov., the only reliable differences being the characters in the male genitalia mentioned in the key. In $S$. (A.) furcillata sp. nov. the pile dorsally of wing base is all black (at least partly yellow to dark brown in $S$. (A.) bracon sp. nov. and $S$. (A.) vietnamensis sp. nov.) and the metafemur is slightly less incrassate than in $S$. (A.) vietnamensis sp. nov. Also similar to $S$. (A.) spenceri sp. nov. but easily distinguished by the characters mentioned in the key. The females of $S$. (A.) spenceri sp. nov. differ from the supposed females of $S$. (A.) bracon sp. nov. and $S$. (A.) vietnamensis sp. nov. by the wider vertex with a shiny ridge medially and pollinosity laterally of the ridge more velvet textured than the other pollinosity (in $S$. (A.) bracon sp. nov. and $S$. (A.) vietnamensis sp. nov. vertex narrower and without ridge, anteromedially only a weak pit and medio-lateral pollinosity the same colour as the rest of the pollinosity).

\section{Etymology}

The specific epithet 'bracon' refers to the species of Bracon (Hymenoptera, Braconidae) to which the fly has a superficial similarity. The name is a noun in apposition.

\section{Material examined}

Holotype

VIETNAM • ô; "Viet Nam: Dalat / 6 km S. 1400-1500 m. / 19.VI-7.VII. 1961”; “ N.R. Spencer / Collector / Bishop"; BPBM.

\section{Paratypes}

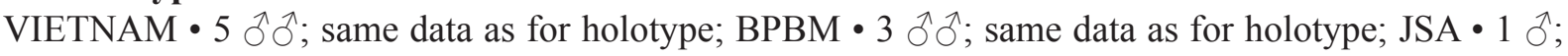
same data as for holotype; "1550 m, 11.IX.1960"; BPBM・2 ठิ ô; "Viet Nam / DiLinh / 1200 m 22-28. 
IV.[19]60"; "S. Quate / Collector"; BPBM • 1 o; same data as for holotype; "L. W. Quate"; BPBM • 35 ổ; "Viet Nam: Fyan / 900-1000 m / 11.VII-9.VIII.1961"; "N. R. Spencer / Collector; / Bishop";

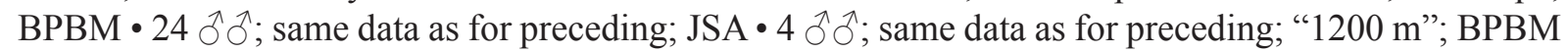
• $2 \widehat{\jmath}$; same data as for preceding; JSA.
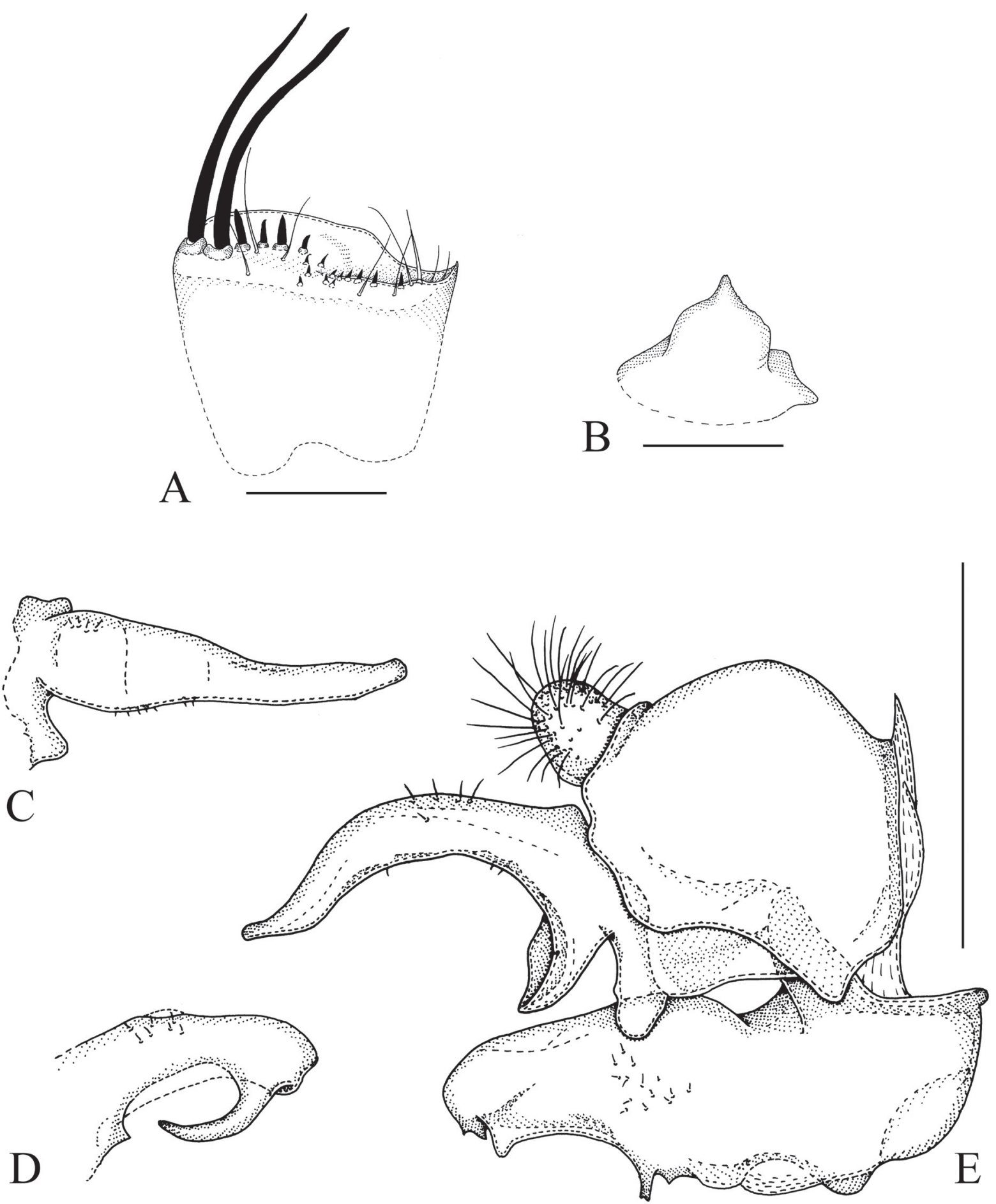

Fig. 17. Sphegina (Asiosphegina) bracon sp. nov., paratype, §. A. Sternum IV, ventral view. B. Sternum VII, ventral view. C. Left surstylus, lateral view. D. Left superior lobe, lateral view. E. Genitalia, right side, lateral view. Scale bars $=0.5 \mathrm{~mm}$. 


\section{Description}

Male

LENGTH. Body 5.9-7.4 mm, wing 4.2-5.0 mm

HEAD. Face in lateral view concave, Fig. 21F, weakly projected antero-ventrally; frontal prominence weakly developed. Ratio width of vertex at anterior ocellus: width of head 1: 4.6-5.0; ratio width of ocellar triangle: width of vertex 1: 1.9-2.1; ratio length of ocellar triangle: length of frons 1: 2.4-2.6. Face black, ventral half brown-yellow, light grey pollinose, long pilose along eye-margin. Hypostomal bridge yellow, long pale pilose. Gena and mouth edge yellow with large subtriangular non-pollinose shiny area. Frons and vertex black, predominantly grey pollinose, a semi-circular area posterior of lunula non-pollinose and shiny; pile short, light yellow (Fig. 21G). Frons with deep medial furrow. Occiput black, light grey pollinose, light yellow pilose. Eye with an area of enlarged facets at anterior margin. Antenna yellow to brown-yellow with black setae dorsally on scape and pedicel; basoflagellomere oval, ratio width: length 1: 1.2-1.4; arista pilose, about 3 times as long as basoflagellomere.

THORAX. Colour dark brown to black, weakly greyish pollinose; postpronotum and dorso-medial part of anepisternum and anepimeron yellow, pleuron entirely grey pollinose; scutum and pleuron with very short adpressed light yellow pile. Scutellum semicircular, black, with slightly concave lateral margin, entirely shiny, with pile slightly longer than on scutum, with two widely set, short setae medially at posterior margin, ratio length of scutellum: length of seta 1: 1.2-1.4.

WING. Entirely microtrichose; hyaline, stigma yellowish. Crossvein dm-cu meeting vein M obliquely and vein $M_{1}$ meeting vein $R_{4+5}$ perpendicularly.

Legs. Pro- and mesoleg yellow, tarsomeres 4-5 black. Metaleg with coxa black, trochanter yellow; femur and tibia black and yellow biannulate; tarsus black with tarsomeres 2 and 3 sometimes dark brown; femur slightly incrassate, ratio width: length 1: 3.9-4.2; tibia with weak and short apicoventral dens, basitarsomere rather narrow to thin, ratio width: length 1: 3.8-4.2.

ABDOMEN. Length ratio of terga I: II: III: IV 1: 3.9-5.0: 1.9-2.2: 1.7-1.9; ratio width at posterior margin: medial length of tergum II and III 1: 3.9-4.4 and 1: 0.8-0.9. Terga black, anterior $1 / 3$ of tergum III with yellow fascia and posterior $1 / 7$ of tergum IV with brown-yellow fascia; pile pale, on terga short, laterally on terga I and II long; tergum I with 2-3 strong dark brown to black setae at lateral margin; sternum III roundish to rectangular, ratio width: length 1: 1.3-2.1; sternum IV, Fig. 17A; sternum VII, Fig. 17B with a large rounded yellow pilose widely conical process with a sharp subtriangular medial projection; sterna VI, VII and VIII simple, with yellow pile. Genitalia, Fig. 17C-E: note the asymmetric surstyli, the bifid ventral lobe of the right-side surstylus and the asymmetric superior lobes with a strong curved finger-like lobe posteroventrally on the left-side one.

\section{Female}

Unknown.

\section{Distribution and biology}

Collected together with Sphegina (Asiosphegina) lucida sp. nov., S. (A.) nigrotarsata sp. nov., $S$. (A.) spenceri $\mathrm{sp}$. nov., $S$. (A.) verrucosa $\mathrm{sp}$. nov. and $S$. (A.) vietnamensis sp. nov.

\section{Remarks}

Among the material studied, the following females were found: 20 o $\circ$; "Viet Nam: Fyan / 900-1000 m. / 11.VII-9.VIII.[19]'61", "N.R. Spencer / Collector / Bishop" (BPBM); 11 qo , same data as for preceding, JSA; $3+q$, same data as for preceding, “1200 m” (BPBM); 2 $q$, same data as for preceding 
(JSA); 2 q, , "Viet Nam: Dalat / 6 km S, 1400-1500 m / 9. VI - 7. VII 1961", "N. R. Spencer / Collector / Bishop" (BPBM); 1 ㅇ, same data as for preceding (JSA); 2 우, "Viet Nam (34 km SE) / Ban Me Thuot 500 m / 16-18.V.1960", "S. Quate / collection" (BPBM); 1 q, "Viet Nam Kontum / N. of Pleiku 550m / 13.V.1960", "L.W. Quate / collection" (BPBM).

These females most likely belong to either Sphegina (Asiosphegina) bracon sp. nov. or to $S$. (A.) vietnamensis sp. nov. The males of these species are only separable by the characters of the genitalia and so the females are not identifiable.

Sphegina (Asiosphegina) brevipilis sp. nov. urn:1sid:zoobank.org:act:E967A246-E746-46E5-A344-3E45C733EA58

Figs 15B-C, 18, 19D, 21J

\section{Differential diagnosis}

Similar to Sphegina (Asiosphegina) plautus sp. nov. and $S$. (A.) simplex. For distinguishing characters, see under the latter.

\section{Etymology}

The specific epithet is from the Latin 'brevipilis', meaning 'short-haired' and referring to the unusually short pile on the male cercus.

\section{Material examined}

Holotype

CHINA: ô;; "Fukien, S. China, / Shaowu: Tachulan / 1000 m. T. Maa"; "3.VI.1942"; BPBM.

\section{Paratypes}

CHINA: 1 ते; same data as for holotype; "IV.1942"; JSA • 1 q; same data as for holotype; "25-30. IV.1943"; BPBM.

\section{Description}

Male

LeNGTH. Body 5.4-5.8 mm, wing 4.3-4.6 mm.

HEAD. Face in lateral view (Fig. 21J) concave, very weakly projected antero-ventrally; frontal prominence very weakly developed. Ratio width of vertex at anterior ocellus: width of head 1: 3.6-4.0; ratio width of ocellar triangle: width of vertex 1: 1.7-1.9; ratio length of ocellar triangle: length of frons 1: 1.92.1. Mouth edge ventrally of eyes very narrow (Fig. 21J). Face black, light grey pollinose, long pilose along eye-margin. Hypostomal bridge black, long pale pilose. Gena and mouth edge black with large subtriangular non-pollinose shiny area. Frons and vertex black, predominantly brown-grey pollinose, a subtriangular area posterior of lunula non-pollinose and shiny and a narrow more densely grey pollinose fascia posterior of shiny part; pile short, light yellow. Frons with rather deep pit antero-medially. Occiput black, light grey pollinose, light yellow pilose. Eye without enlarged facets at anterior margin. Antenna brown-yellow to brown with black setae dorsally on scape and pedicel; basoflagellomere oval, ratio width: length 1: 1.2-1.4; arista long pilose, about 2.5 times as long as basoflagellomere.

THORAX. Colour dark brown to black, weakly greyish pollinose, pleuron more heavily grey pollinose; scutum and pleuron with very short adpressed light yellow pile. Scutellum subtriangular, black, pale pollinose, with pile longer than on scutum, with two widely set, short setae medially at posterior margin, ratio length of scutellum: length of seta 1: 0.1-1.1. 
Wing. Entirely microtrichose; hyaline, stigma yellowish, infuscated at junction of veins $\mathrm{R}_{2+3}$ and $\mathrm{R}_{4+5}$, along crossveins dm-cu and $\mathrm{M}_{1}$ and at the apex of vein $\mathrm{R}_{1+2}$. Crossvein $\mathrm{dm}$-cu meeting vein M obliquely and vein $\mathrm{M}_{1}$ meeting vein $\mathrm{R}_{4+5}$ perpendicularly. Vein $\mathrm{CuA}$, extended, ending at about vein $\mathrm{dm}$-cu.

LEGS. Pro- and mesoleg yellow, protarsus with tarsomeres 1 and 2 dark brown, tarsomeres 3-5 yellow; mesotarsus with tarsomeres 3-5 brown to black. Metaleg, Fig. 19D, with coxa black, trochanter yellow; femur black and yellow biannulate, very slightly incrassate and club shaped, ratio width: length 1 : 6.7-7.2; tibia black and yellow biannulate, with short black apically rounded apicoventral dens; tarsus entirely black, basitarsomere thick, ratio width: length 1: 3.3-3.6.

ABDOMEN. Length ratio of terga I: II: III: IV 1: 5.0-5.3: 2.8-3.2: 1.9-2.2; ratio width at posterior margin: medial length of tergum II and III 1: 3.9-4.2 and 1: 1.2-1.4. Terga black, anterior $1 / 3$ of tergum III with brown-yellow fascia; tergum IV with anterolateral squarish brown-yellow macula; pile pale, on terga short, laterally on terga I and II long; tergum I with 3 strong brown-yellow setae at lateral margin; sternum III rectangular, ratio width: length 1: 2.7-3.0; sternum IV, Fig. 18A; sterna VI, VII and VIII with long yellow pile. Genitalia, Fig. 18B-C: note the unusual pilosity of cercus and the sclerite lying posteriorly from cerci and between the bases of surstyli.

\section{Female}

Similar to male except for the usual sexual dimorphism.

LeNGTH. Body $6.0 \mathrm{~mm}$, wing $5.4 \mathrm{~mm}$.

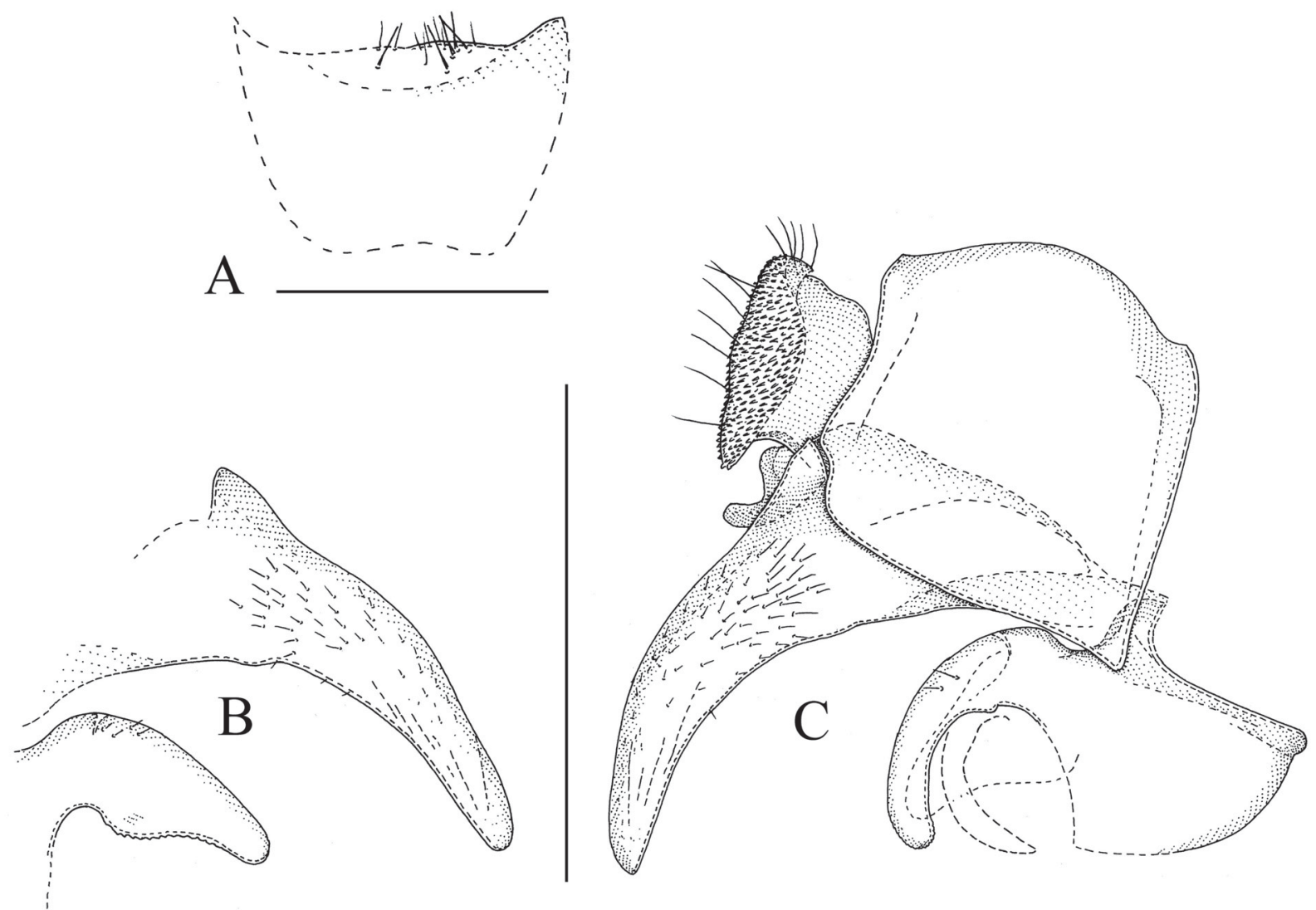

Fig. 18. Sphegina (Asiosphegina) brevipilis sp. nov., holotype, $\widehat{\jmath}$. A. Sternum IV, ventral view. B. Posterior part of genitalia, left side, lateral view. C. Genitalia, right side, lateral view. Scale bars $=$ $0.5 \mathrm{~mm}$. 
HEAD. Face and mouth edge black. Basoflagellomere oval, ratio width: length 1: 1.4; arista long pilose, about 3 times as long as basoflagellomere.

LEGS. Mesoleg predominantly brown; metafemur with ratio width: length 1: 6.3; metatarsus with ratio width: length 1: 3.2 .

AвDOMEN. Length ratio of terga I: II: III: IV: V 1: 3.6: 3.0: 2.2: 0.7 ; ratio width at posterior margin: medial length of tergum II and III 1: 1.6 and 1: 0.9. Tergum I with 3 large brown setae at lateral margin. Tergum III with fascia 1: 3.8 ; sternum III with ratio width: length $1: 2.5$; sternum IV rectangular, ratio width: length 1: 1.6; sternum $\mathrm{V}$ squarish, ratio width: length $1: 1.1$.

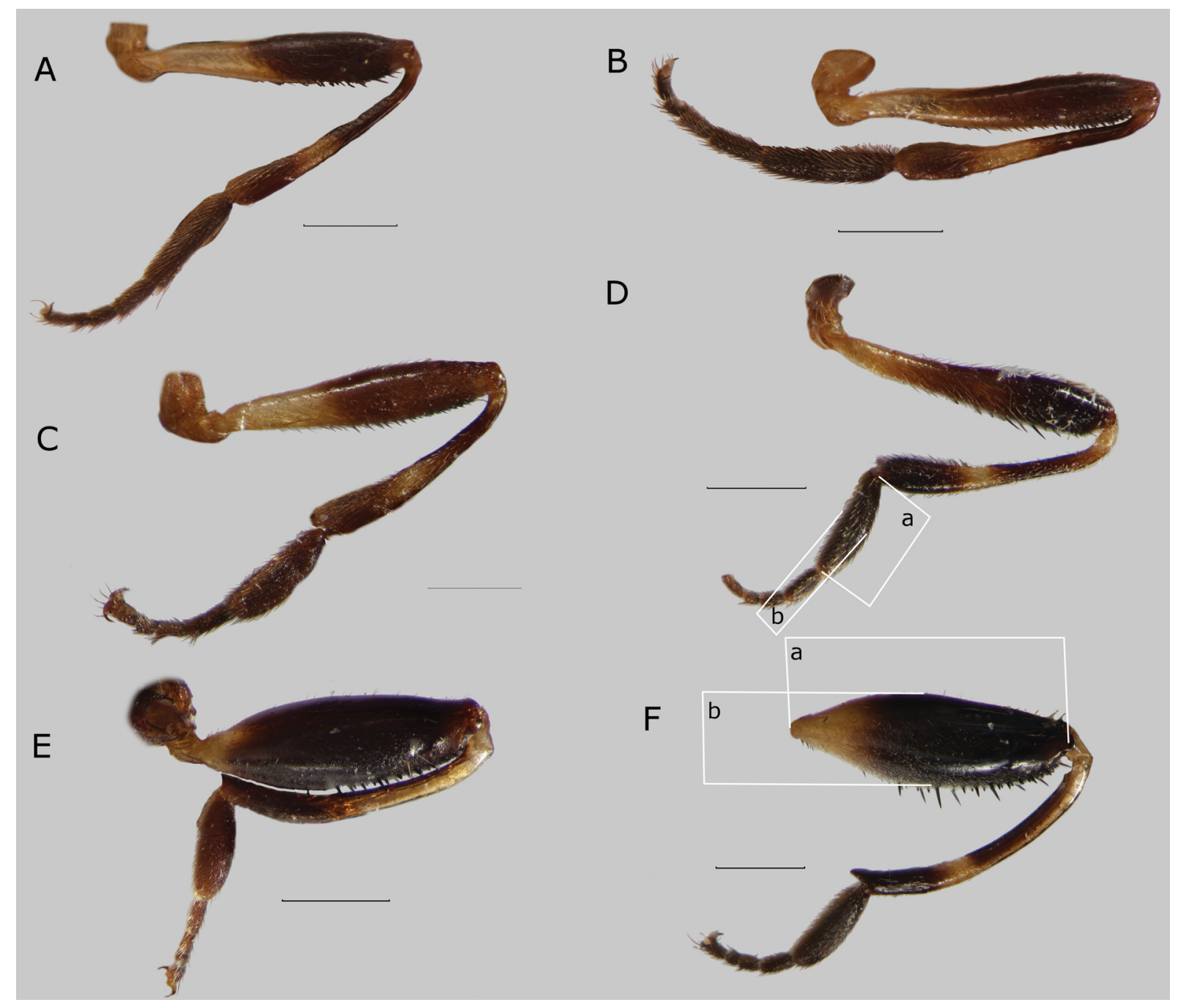

Fig. 19. Metaleg, anterior view. A. Sphegina (Sphegina) abbreviata sp. nov., paratype, $q$, Nepal. B. S. (S.) angustata sp. nov., paratype, ㅇ, Nepal. C. S. (S.) uncinata Hippa, van Steenis \& Mutin, 2015, $\widehat{\partial}$, Myanmar. D. Sphegina (Asiosphegina) brevipilis sp. nov., paratype, $\widehat{\partial}$, China, abbreviations: $\mathrm{a}=$ length of basitarsus of metatarsus; $\mathrm{b}=$ width of basitarsus of metatarsus. E. S. (A.) collicola sp. nov., holotype, ô, Malaysia. F. S. (A.) crinita sp. nov., paratype, + , Java, abbreviations: a = length of metafemur; $b=$ width of metafemur. Scale bars $=0.5 \mathrm{~mm}$. 


\section{Remarks}

The sclerite between the bases of surstyli and posteriorly from the cerci is an unusual structure which Sphegina (Asiosphegina) brevipilis sp. nov. shares with only one other species known to us, $S(A$.) plautus sp. nov. For more discussion, see under the latter.

Sphegina (Asiosphegina) carinata Hippa, van Steenis \& Mutin, 2015

Figs 10E, 13B, 15D

Sphegina (Asiosphegina) carinata Hippa, van Steenis \& Mutin, 2015: 18. Type locality: Kambaiti, Myanmar (holotype, $\hat{\jmath}$, NHRS).

\section{Material examined}

INDIA• 1 ภ’; "Darjeeling / Rangiroon / 6500' [feet] 25. V. 1966 / Gupta, No 487”; "Ghorpade / Collector; / Bangalore"; USNM • 1 क; "India: West Bengal / Darjeeling 2176 m / 29.iv.1974 / Ghorpade No A112”; "Ghorpade / Collector / Bangalore"; JSA • 1 q; "INDIA Meghalaya / Nongph [Nongpoh] forest / 25-28 April 1980 / [leg] Amnon Friedberg"; USNM • 1 q; "Near Bhowali / Kumaon: 5,700ft. / July, 1909 / A.D. Imms"; Sphegina / bispinosa + / Brun. cotype"; "India / A.D. Imms / Reg. 30.V.1913"; "no type specimen! / Sphegina (A.) carinata / Hippa, van Steenis \& Mutin, 2015 / det J. van Steenis, 2017”; UMZC.

\section{Remarks}

Earlier known only from the type material from Myanmar, Kambaiti (Hippa et al. 2015). Concerning the cotype of Sphegina (Asiosphegina) bispinosa in the list of new records, see under $S$. (A.) bispinosa.

Sphegina (Asiosphegina) cerina Hippa, van Steenis \& Mutin, 2015

Fig. 15E

Sphegina (Asiosphegina) cerina Hippa, van Steenis \& Mutin, 2015: 44. Type locality: Kambaiti, Myanmar (holotype, $\hat{o}$, NHRS).

\section{Material examined}

MYANMAR • 1 q; “N.E. Burma / Kambaiti 7000 ft. / 10-22.vi.1934 / [leg] R. Malaise”; NHM.

\section{Remarks}

Only known by the type material from Myanmar, Kambaiti (Hippa et al. 2015) and the material studied here from the same locality.

Sphegina (Asiosphegina) clavigera sp. nov. urn:1sid:zoobank.org:act:2474E568-9004-4D8E-914C-6AA6B7032BF6

Figs 13C, 15F, 20, 25C

\section{Differential diagnosis}

Similar to Sphegina (Asiosphegina) crassispina and S. (A.) hauseri sp. nov. For distinguishing characters, see under the former species. 


\section{Etymology}

The specific epithet is from the Latin 'clavigera', meaning 'bearing claws' and referring to the two clawlike lobes on the male superior lobe.

\section{Material examined}

\section{Holotype}

VIETNAM • đ’; "NW VIETNAM: Tonkin / Hoang Lien N.P. 15 km / W Sa Pa c. 1900 m / 15-21.X.1999

Malaise traps / [leg] C. v. Achterberg; RMNH '99”; NBC.

\section{Paratype}

VIETNAM: 1 ; same data as for holotype; NBC.

\section{Description}

\section{Male}

Length. Body $7.2 \mathrm{~mm}$, wing $6.3 \mathrm{~mm}$.

HEAD. Face in lateral view concave, very strongly projected antero-ventrally; frontal prominence strongly developed. Ratio width of vertex at anterior ocellus: width of head 1: 3.8; ratio width of ocellar triangle: width of vertex 1: 2.4; ratio length of ocellar triangle: length of frons 1: 2.3. Face black, light grey pollinose, long pilose along eye-margin. Hypostomal bridge black, long pale pilose. Gena and mouth edge black with large subtriangular non-pollinose shiny area. Frons and vertex black, slightly pollinose, a narrow subtriangular area posterior of lunula non-pollinose and shiny; pile short, light yellow. Frons without antero-medial depression. Occiput black, light grey pollinose, light yellow pilose. Eye with an area of enlarged facets at anterior margin. Antenna with scape and pedicel black, basoflagellomere dark brown with black setae dorsally on scape and pedicel; basoflagellomere oval, ratio width: length 1: 1.5; arista long pilose, nearly 3.5 times as long as basoflagellomere.

THORAX. Pleuron entirely grey pollinose; scutum and pleuron with very short adpressed light yellow pile. Scutellum subtriangular, black, shiny medially, laterally weakly pollinose, with pile slightly longer than on scutum, with two closely set, long setae medially at posterior margin, ratio length of scutellum: length of seta 1:2.0.

WING. Entirely microtrichose; hyaline, stigma yellowish, membrane brown infuscated at junction of veins $R_{2+3}$ and $R_{4+5}$, along veins bm-cu, $r-m, M_{1}$, at the junction of veins $M_{1}$ and $R_{4+5}$ and at apical appendix of vein $R_{2+3}$. Crossvein dm-cu meeting vein $M$ perpendicularly and vein $M_{1}$ meeting vein $R_{4+5}$ perpendicularly. Apical part of vein $\mathrm{R}_{2+3}$ with short appendix, vein $\mathrm{CuA}_{1}$ slightly extended to vein $\mathrm{dm}-$ $\mathrm{cu}$.

LeGs. Pro- and mesoleg yellow, tarsomeres 4 and 5 black. Metaleg with coxa black, trochanter yellow; femur black with basal half yellow, slightly incrassate, ratio width: length 1: 4.8, dorso-basally slightly concave; tibia black and yellow biannulate, without apicoventral dens; tarsus entirely black, basitarsomere very thin, ratio width: length $1: 4.8$.

ABDOMEN. Length ratio of terga I: II: III: IV 1: 3.0: 1.9: 1.3; ratio width at posterior margin: medial length of tergum II and III 1: 4.4 and 1: 1.1. Terga black, anterior $1 / 3$ of tergum III with yellow fascia; pile pale, on terga short, laterally on terga I and II long; tergum I with 2 widely separated strong black setae at lateral margin; sternum III rectangular with concave posterior margin, ratio width: length $1: 2.3$; sternum IV, Fig. 20B; sterna VI, VII and VIII (Fig. 20A) with long yellow pile, sternum VII with two processes of which the more anterior one is conical with long light-brown setae at base and the more posterior 
one low crescent-shaped. Genitalia, Fig. 20C-E: note the asymmetrical surstyli, the finger-like process basomedially on surstyli and the only slightly asymmetrical superior lobes.

\section{Female}

Similar to the male except normal sexual dimorphism.

LeNGTH. Body $7.3 \mathrm{~mm}$, wing $6.4 \mathrm{~mm}$.

HEAD. Ratio width of vertex at anterior ocellus: width of head 1: 3.6; ratio width of ocellar triangle: width of vertex 1: 2.5; ratio length of ocellar triangle: length of frons 1: 3.3. Mouth edge narrowly brown. Basoflagellomere oval, ratio width: length 1: 1.4, about 3.5 times as long as basoflagellomere.
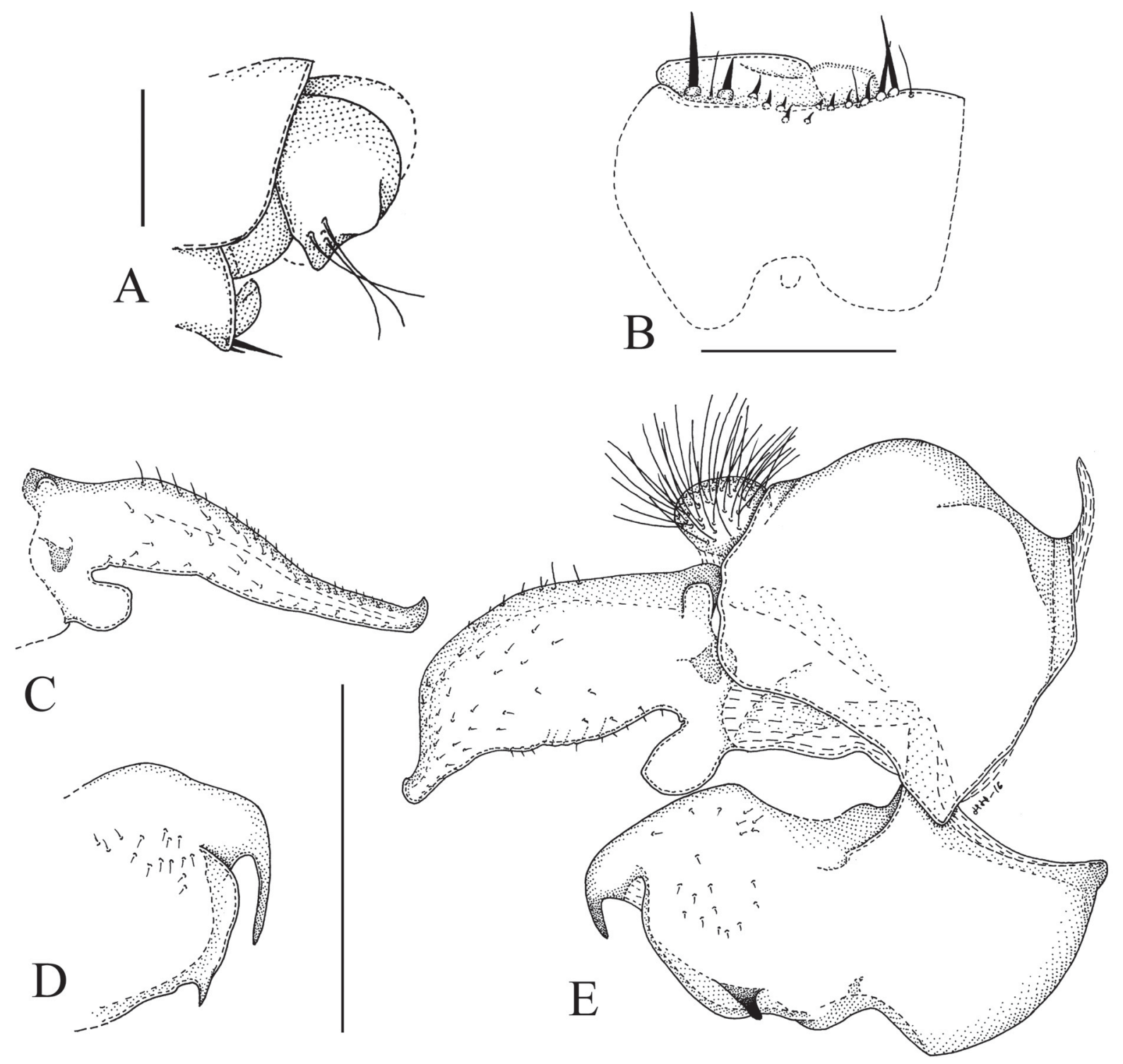

Fig. 20. Sphegina (Asiosphegina) clavigera sp. nov., holotype, ふึ. A. Posterior part of abdomen, left side, lateral view. B. Sternum IV, ventral view. C. Left surstylus, lateral view. D. Left superior lobe, lateral view. E. Genitalia, right side, lateral view. Scale bars $=0.5 \mathrm{~mm}$. 
Thorax. Scutellum with two closely set, long setae medially at posterior margin, ratio length of scutellum: length of seta 1:2.0.

Legs. Metafemur slightly incrassate, ratio width: length $1: 5.6$, yellow on basal $1 / 2$, basitarsomere very thin, ratio width: length 1: 4.6.

ABDOMEN. Length ratio of terga I: II: III: IV: V 1: 2.1: 1.6: 1.0: 0.6; ratio width at posterior margin: medial length of tergum II and III 1: 3.0 and 1: 0.9. Tergum I, Fig. 8D black; tergum II posterior 1/3 yellow; sternum III elongate, ratio width: length 1: 2.8; sternum IV trapezoid, ratio width: length 1: 1.0; sternum $\mathrm{V}$ rectangular, with crenelated posterior margin, ratio width: length 1: 1.2.

\section{Distribution and biology}

Collected together with Sphegina (Asiosphegina) index and $S$. (A.) malaisei in a Malaise trap near the Tram Ton Pass, the highest mountain pass in Vietnam (1900 m), near Fan Si Pan mountain. The Malaise trap had been set up in an area of montane forest disturbed by buffaloes grazing, containing muddy areas and small streams. Despite the cold and wet weather insects were still rather abundantly flying (C. van Achterberg, pers. comm).

Sphegina (Asiosphegina) collicola sp. nov. urn:1sid:zoobank.org:act:BABAB4E8-692E-45E8-BAEB-01F3A141D5BC

Figs 19E, 21K-L, 22, 23A

\section{Differential diagnosis}

Similar to Sphegina (Asiosphegina) bifida sp. nov. and $S$. (A.) inventum sp. nov. For distinguishing characters, see under $S$. (A.) inventum sp. nov.

\section{Etymology}

The specific epithet is from the Latin 'collicola', meaning 'inhabitant of hills' and referring to the type locality on hills.

\section{Material examined}

Holotype

MALAYSIA • J'; "Malaysia, / Penang Island / Penang Hill / 22.xi.1979 / Peter Nielsen leg."; head damaged, antennae missing, slightly discoloured; ZMUC.

\section{Paratype}

MALAYSIA • 1 ○’; "Malaya / 16 mi NE / Kuala Lumpur / 1000' VIII-12-[19]62”; "Collectors: / E.S. Ross / D.Q. Cavagnaro"; most of the legs missing and wings shriveled; CAS.

\section{Description}

\section{Male}

LeNGTH. Body 5.8-6.0 mm, wing 5.1-5.4 mm.

HEAD. Face in lateral view (Fig. 21K) concave, less projected antero-ventrally than frontal prominence; frontal prominence very weakly developed. Ratio width of vertex at anterior ocellus: width of head 1: 7.9; ratio width of ocellar triangle: width of vertex 1: 1.1; ratio length of ocellar triangle: length of frons 1: 3.7. Face black, light grey pollinose, long pilose along eye-margin. Hypostomal bridge black, long pale pilose. Gena and mouth edge black with large subtriangular non-pollinose shiny area. Frons and vertex black, velvet black pollinose, a narrow oval area posterior of lunula shiny non-pollinose and 
2 squarish anterolateral grey pollinose macula along eye-margin (Fig. 21L); pile short, light yellow. Occiput black, light grey pollinose, light yellow pilose. Eye with an area of enlarged facets at anterior margin. Antenna with scape and pedicel black, basoflagellomere dark brown with several black setae dorsally on scape and pedicel; basoflagellomere oval, ratio width: length 1: 1.5; arista long pilose, about 2.5 times as long as basoflagellomere.

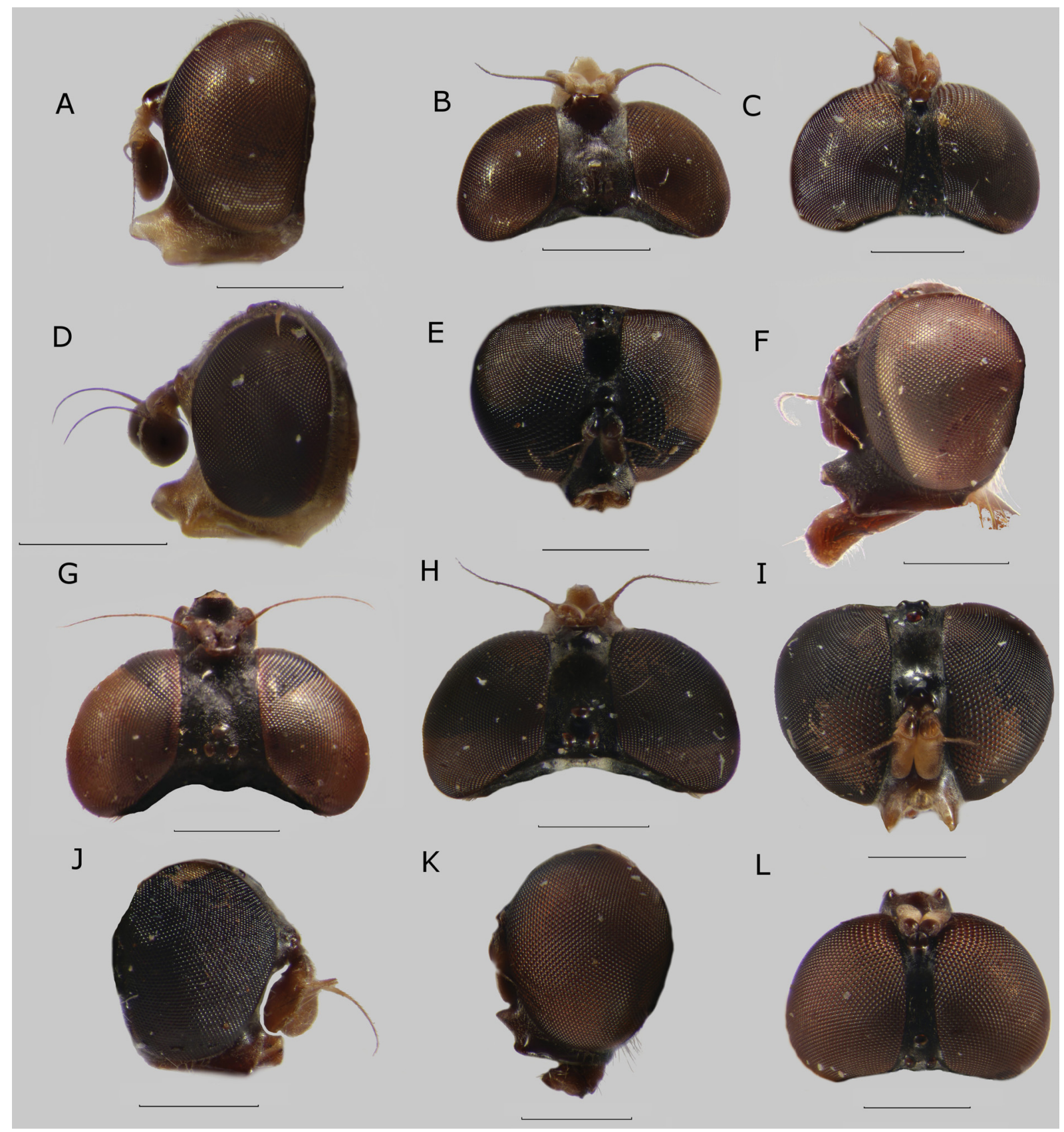

Fig. 21. Head, lateral view (A, D, F, J-K), dorsal view (B, C, G-H, L), frontal view (E, I). A-B. Sphegina (Asiosphegina) albolobata sp. nov., holotype, ô, Vietnam. C. S. (A.) amplistylus sp. nov., holotype, ô, Philippines. D. S. (A.) apicalis Shiraki, 1930, +, Taiwan. E. S. (A.) bifida sp. nov., holotype, đ̃, Sabah, Malaysia. F-G. S. (A.) bracon sp. nov., paratype, đ̃, Vietnam. H-I. S. (A.) bispinosa Brunetti, 1915, ô, Nepal. J. S. (A.) brevipilis sp. nov., holotype, o, China. K-L. S. (A.) collicola sp. nov., paratype, ô, Malaysia. Scale bars $=0.5 \mathrm{~mm}$. 
THORAX. Colour black, greyish pollinose; posterior margin of katepisternum narrowly non-pollinose, shiny; scutum and pleuron with very short adpressed light yellow pile. Scutellum sublunalar, black, greyish pollinose, with pile slightly longer than on scutum, marginal setae broken off in the single specimen.

WING. Entirely microtrichose; hyaline, stigma yellowish. Crossvein dm-cu meeting vein M obliquely and vein $M_{1}$ meeting vein $R_{4+5}$ perpendicularly.

LeGs. Pro- and mesoleg yellow, tarsomeres 4 and 5 brown to dark brown. Metaleg, Fig. 14D, with coxa black, trochanter yellow; femur with basal $1 / 6$ yellow, incrassate, ratio width: length $1: 3.5$; tibia yellow with apical $1 / 3$ black, with short pointed apicoventral dens; tarsus entirely black, basitarsomere thick, ratio width: length 1: 3.1 .
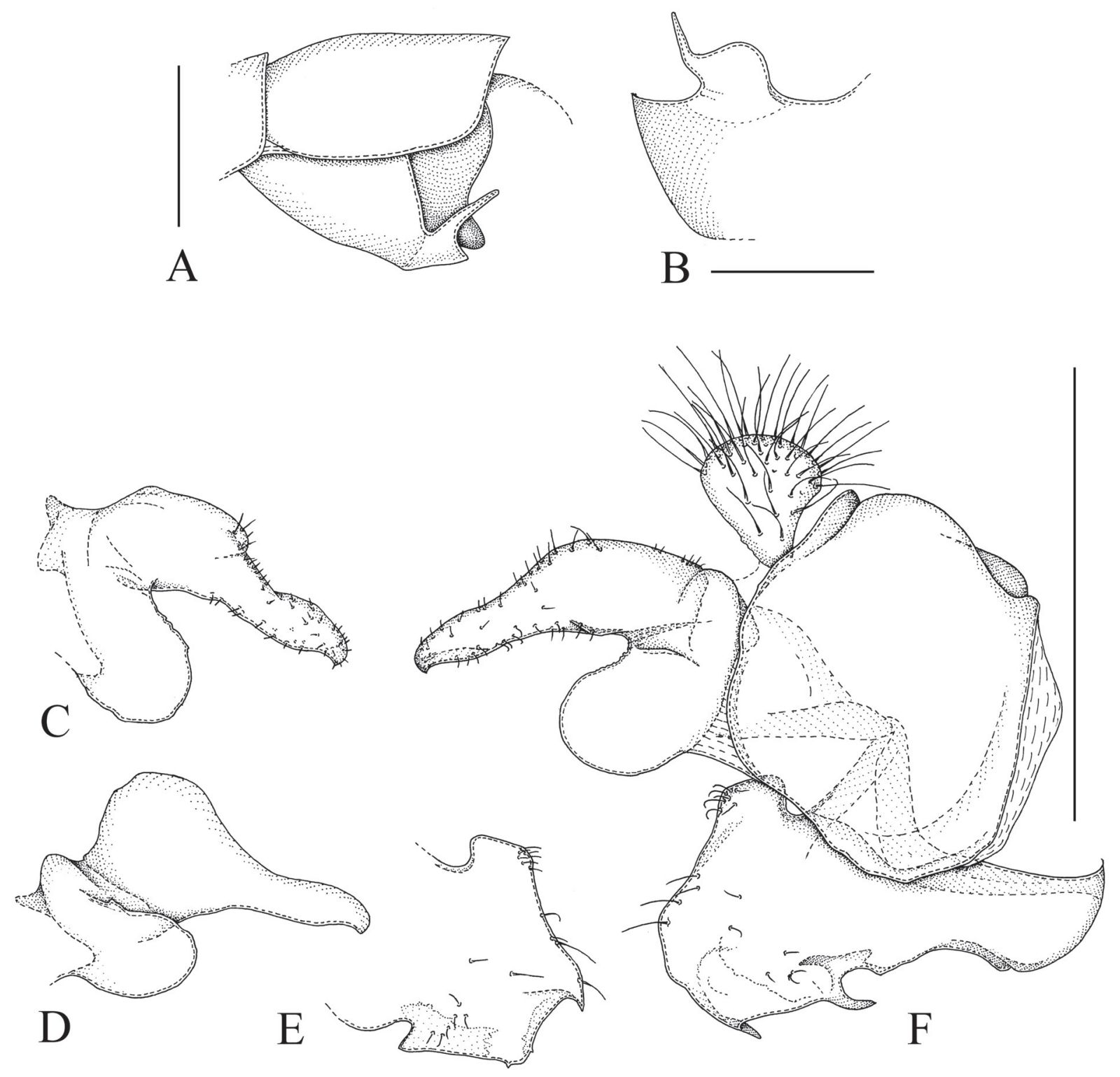

Fig. 22. Sphegina (Asiosphegina) collicola sp. nov., holotype, $\widehat{\jmath}$. A. Posterior part of abdomen, left side, lateral view. B. Sternum IV, left side, ventral view. C. Left surstylus, lateral view. D. Left surstylus, in more latero-ventral view. E. Left superior lobe, lateral view. F. Genitalia, right side, lateral view. Scale bars $=0.5 \mathrm{~mm}$. 
AвDOMEN. Length ratio of terga I: II: III: IV 1: 4.0: 2.0: 1.9; ratio width at posterior margin: medial length of tergum II and III 1: 3.6 and 1: 0.8 . Terga black, anterior $3 / 8$ of tergum III with yellow fascia; pile pale, on terga short, laterally on terga I and II long; tergum I with 3 evenly separated strong light yellow setae at lateral margin; sternum III undifferentiated; sternum IV, Fig. 22B; sterna VI, VII and VIII (Fig. 22B) with long yellow pile, sternum VII with conical rounded tubercle. Genitalia, Fig. 22C-F: note the almost symmetrical surstyli and superior lobes.

\title{
Female
}

Unknown.

Sphegina (Asiosphegina) crassispina Hippa, van Steenis \& Mutin, 2015

Figs 23B, 25D, 33A

Sphegina (Asiosphegina) crassispina Hippa, van Steenis \& Mutin, 2015: 16. Type locality: Kambaiti, Myanmar (holotype, $\hat{\jmath}$, NHRS).

\section{Material examined}

CHINA • 1 ô; "CHINA Sichuan / Mt EMEI / 17-21.IX.1985”; “4 km N / XIANFENG / 1650 m”; NBC.

\section{Remarks}

Earlier only known by the type material from Myanmar, Kambaiti (Hippa et al. 2015). The specimen from China fits well within the variation range exhibited by the type material except for the frons which is more extensively shiny and the frontal prominence which is slightly more protruding.

\author{
Sphegina (Asiosphegina) crinita sp. nov. \\ urn:1sid:zoobank.org:act:DB64D240-C3C6-4ED5-A157-F125C340CB68 \\ Figs 13D, 19F, 23C-D, 24, 30A-B, 65A
}

\section{Differential diagnosis}

In the key the species runs to couplet 81 together with Sphegina (Asiosphegina) perlobata sp. nov., even if the species are not particularly similar. In addition to the characters mentioned in the key, $S$. (A.) crinita sp. nov. is easily distinguished from $S$. (A.) perlobata sp. nov. by its simple, unlobed posterior margin of sternum IV and its simple surstyli as opposed to having them unusually many-lobed and complex respectively. In the male genitalia, $S$. (A.) crinita sp. nov. is similar to $S$. (A.) fimbriata sp. nov., but the superior lobes are very unusual and distinguish the species from it as well as from any other Sphegina. For more discussion, see under the 'Remarks' below.

\section{Etymology}

The specific epithet is from the Latin 'crinita', meaning 'long-haired' and referring to the long setae on the male superior lobe.

\section{Material examined}

\section{Holotype}

INDONESIA - Õ; "Indonesia West Java Gn Halim / un NP, Resort forest Gn Kendeng / Cikaniki, Canopy trail $6^{\circ} 44^{\prime}$ S, $106^{\circ}$ E / 32'Alt 900-1000 m 26.XII- 2.i / 2001 S. Kahono, E. Cholik, Sarino / Malaise Trap 2B, GHNP 2001”; LIPI. 


\section{Paratypes}

INDONESIA • 1 ; ; same data as for holotype; JSA 1 ; ; "Indonesia, W-Java, Gunung / Halimun NP, Cikaniki 950 m / 13-20.iii.2001 Rofik, Sarino / 644'91.1" S, 106²3'25.8" E / Ground Malaise Trap MT 2 B”; ZMFK・ 1 ; ; same data as for preceding; LIPI.

MALAYSIA • 1 đ̊; "Perak F.M.S. / Larut Hills / 3700-4500 ft / 13. Feb[ruary] 1932 / H.M. Pendlebury / [written on underside] ex coll / F.M.S. / Museums"; NHM • 1 § ; "MALAYSIA: Pahang Distr.: / King George V Nat. Park: / Kuala Tahang / 7-14.XII.1958"; "J.L. Gressitt / Collector”; BPBM • 1 \%; "MALAYA: (W) / Perak, Maxwell / Hill 1350 m. / 17-20.III.1958”; "T.C. Maa / Collector / Bishop"; BPBM.

\section{Description}

\section{Male}

Length. Body 6.4-6.9 mm, wing 4.7-5.5 mm.

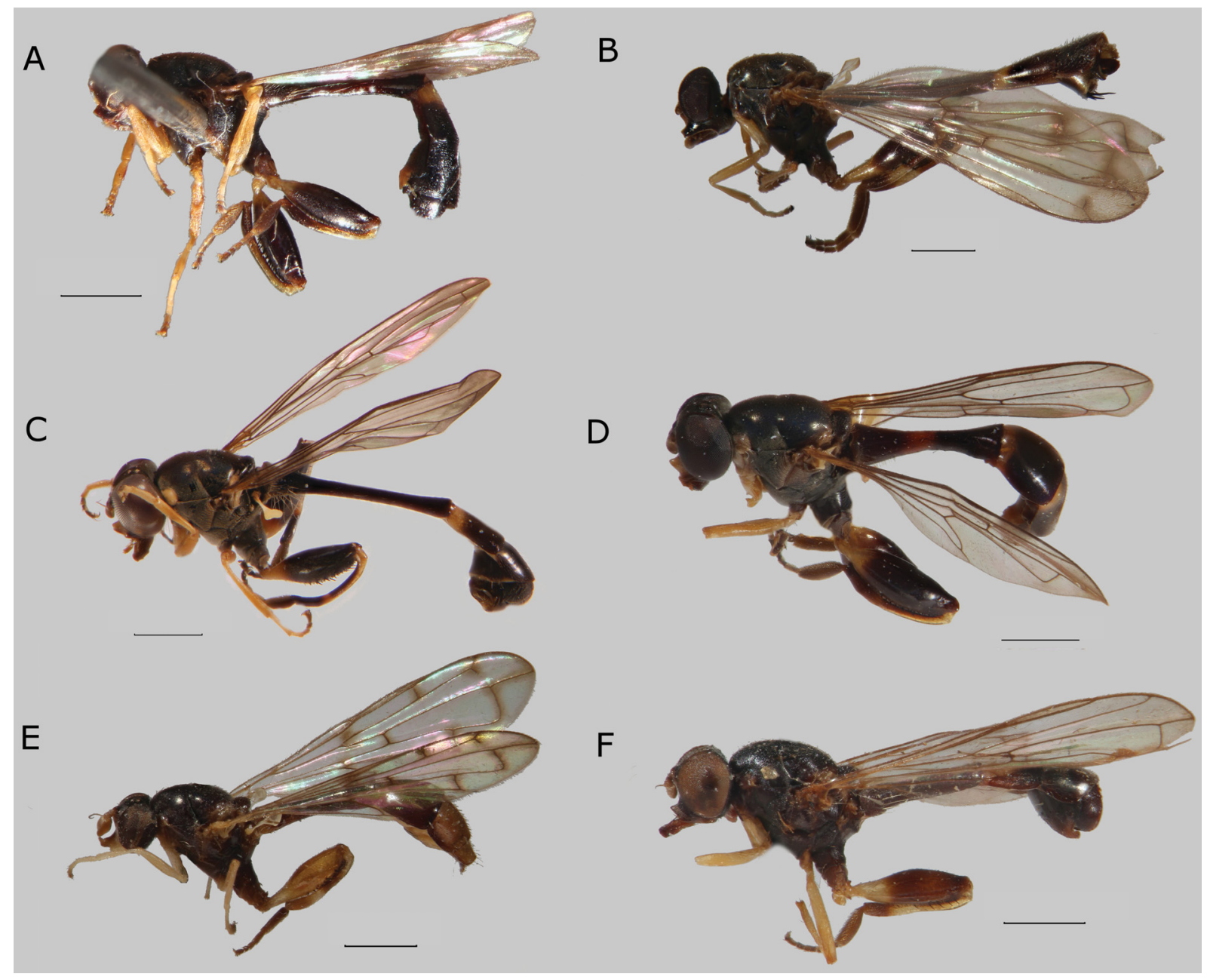

Fig. 23. Habitus, lateral view. A. Sphegina (Asiosphegina) collicola sp. nov., holotype, $\widehat{\jmath}$, Malaysia.

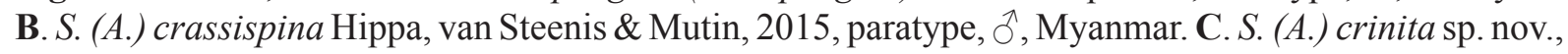
paratype, Õ, Java, Indonesia. D. S. (A.) crinita sp. nov., paratype, + , Malaysia. E. S. (A.) crucivena Hippa, van Steenis \& Mutin, 2015, paratype, , Myanmar. F. S. (A.) culex Hippa, van Steenis \& Mutin, 2015, holotype, ${ }^{\lambda}$, Myanmar. Scale bars $=1.0 \mathrm{~mm}$. 
HEAD. Face in lateral view, Fig. 30A, concave, very weakly projected antero-ventrally; frontal prominence very weakly developed. Ratio width of vertex at anterior ocellus: width of head 1: 7.5-8.9; ratio width of ocellar triangle: width of vertex 1: 1.1-1.4 (1.7); ratio length of ocellar triangle: length of frons 1 : 3.3-3.6 (2.4). Face black, ventral $1 / 3$ to $1 / 2$ yellow; light grey pollinose, long pilose along eye-margin. Hypostomal bridge black, long pale pilose. Gena yellow to dark yellow and mouth edge dark brown to black with large subtriangular non-pollinose shiny area. Frons and vertex black, predominantly brown pollinose, a subtriangular area posterior of lunula non-pollinose and shiny and two large and medially connected maculae of dense grey pollinosity posterior of shiny part (Fig. 30B); pile short, light yellow. Frons with weak but wide medial furrow. Occiput black, light grey pollinose, light yellow pilose. Eye
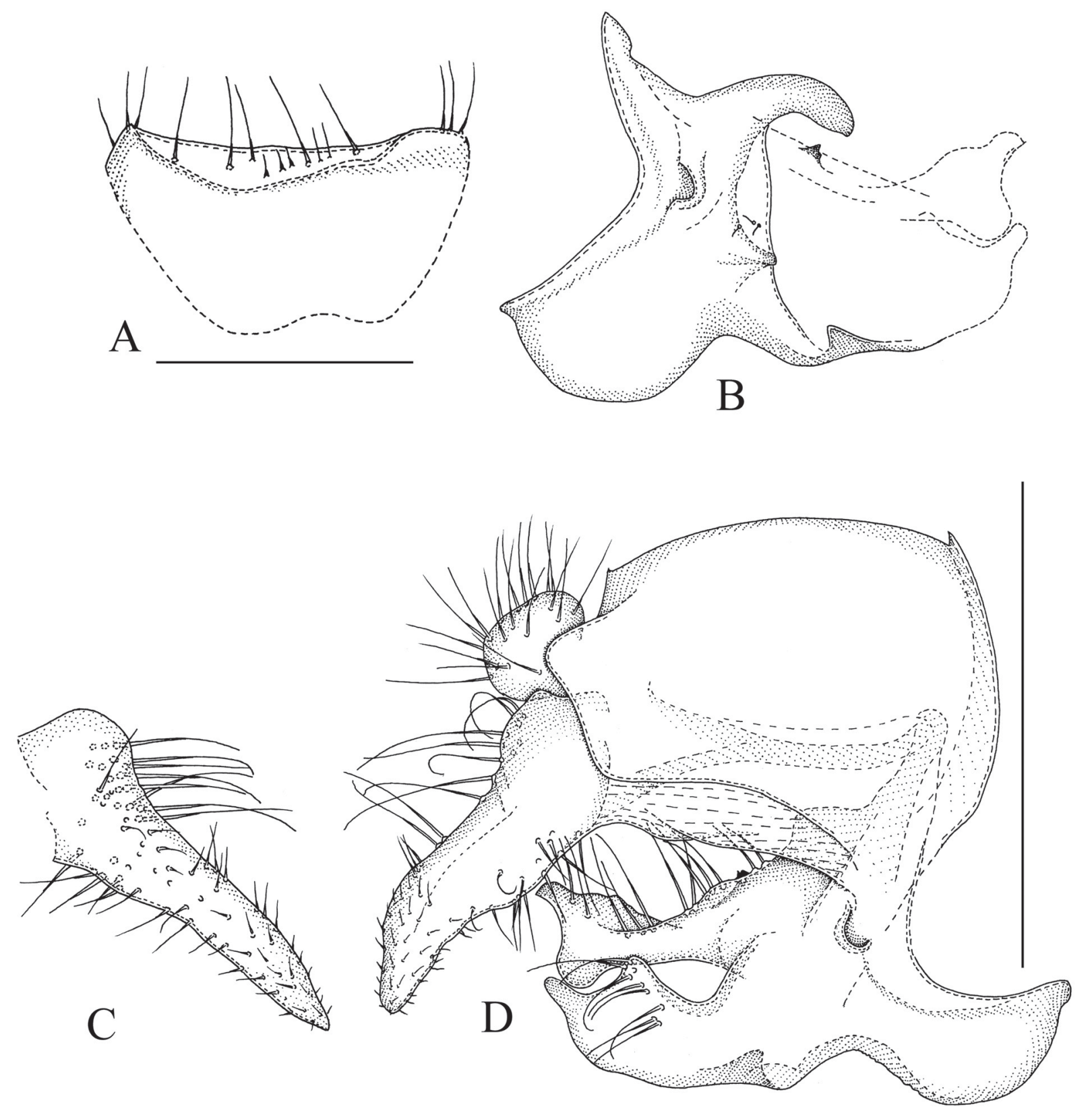

Fig. 24. Sphegina (Asiosphegina) crinita sp. nov., holotype, $\widehat{\partial}(\mathrm{B}-\mathrm{D})$, paratype, $\hat{\jmath}$, Malaysia (A). A. Sternum IV, ventral view. B. Left sternum IX and superior lobe, lateral view. C. Left surstylus, lateral view. D. Genitalia, right side, lateral view. Scale bars $=0.5 \mathrm{~mm}$. 
with an area of enlarged facets at anterior margin. Antenna with scape and pedicel dark brown with black setae dorsally; basoflagellomere light-brown to yellow, oval to subrectangular, ratio width: length 1: 1.1-1.3; arista long pilose; about 3 times as long as basoflagellomere.

THORAX. Colour dark brown to black, weakly greyish pollinose, postpronotum light yellow to brownyellow; posterior margin of katepisternum widely non-pollinose, shiny (Fig. 65A); scutum and pleuron with very short adpressed light yellow pile. Scutellum subrectangular, black, shiny and only weakly pollinose along posterior margin, with pile longer than on scutum, with two (in Malaysian specimen broken off) widely set medium long setae medially at posterior margin, ratio length of scutellum: length of seta $1: 1.4-1.7$.

WING. Microtrichose, bare on baso-medial $1 / 4$ of cell and only weakly microtrichose on cell cup; hyaline, stigma brownish. Crossvein dm-cu meeting vein $M$ obliquely and vein $M_{1}$ meeting vein $R_{4+5}$ perpendicularly.

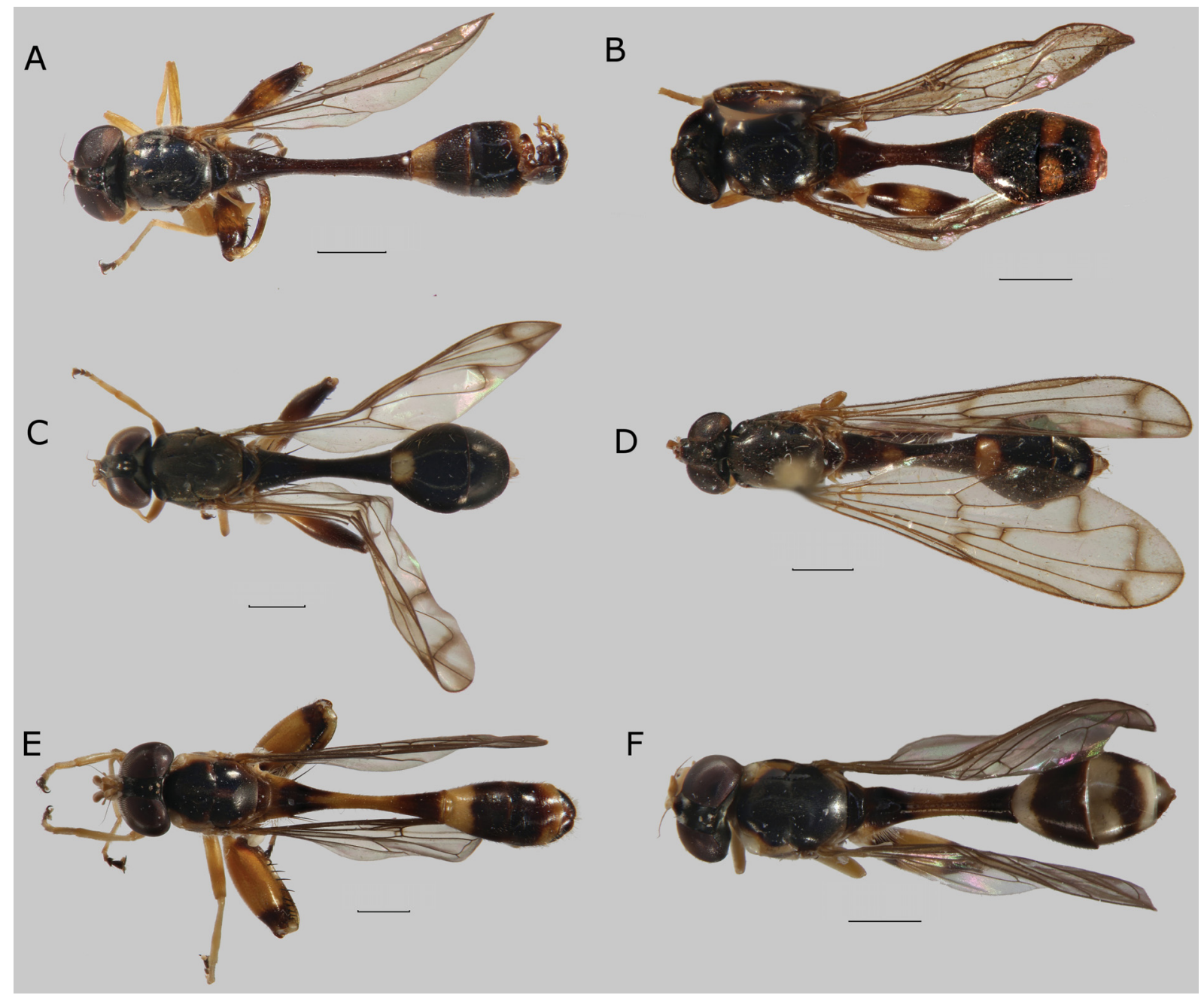

Fig. 25. Habitus, dorsal view. A. Sphegina (Asiosphegina) bracon sp. nov., paratype, $\widehat{\jmath}$, Vietnam. B. S. (A.) cf. bracon sp. nov., q, Vietnam. C. $S$. (A.) clavigera sp. nov., paratype,, , Vietnam. D. S. (A.) crassispina Hippa, van Steenis \& Mutin, 2015, paratype, + , Myanmar. E. S. (A.) distincta sp. nov., paratype, ふึ, Vietnam. F. S. (A.) cf. furcillata sp. nov.,, , Vietnam. Scale bars $=1.0 \mathrm{~mm}$. 
Legs. Pro- and mesoleg yellow, tarsomeres 3-5 black. Metaleg with coxa black, trochanter yellow; femur black with basal $1 / 3$ yellow, strongly incrassate, ratio width: length 1: 3.1-3.5; tibia black and yellow biannulate, with long and wide apicoventral dens; tarsus entirely black, basitarsomere thick, ratio width: length 1: 2.9-3.3 (in Malaysian specimen 3.9).

ABDOMEN. Length ratio of terga I: II: III: IV 1: 4.8-5.4: 2.0-2.4: 1.6-2.0; ratio width at posterior margin: medial length of tergum II and III 1: 4.8-5.6 and 1: $0.8-1.1$. Terga black, anterior $1 / 4$ to $1 / 3$ of tergum III with brown-yellow to yellow fascia; pile pale, on terga short, laterally on terga I and II long; tergum I with an obliquely placed row of $4-5$ strong light yellow setae at lateral margin (Fig. 13D); tergum IV slightly
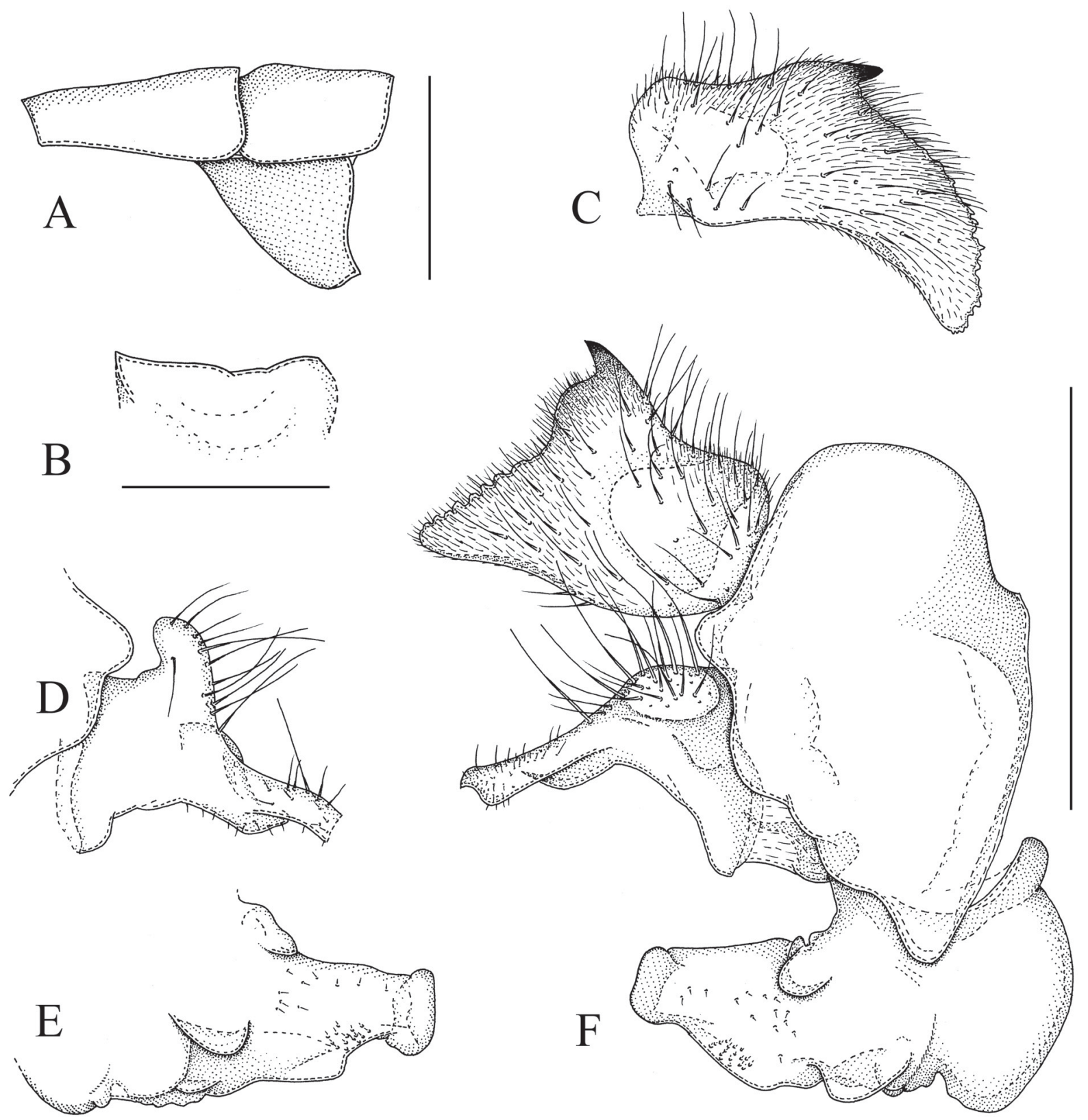

Fig. 26. Sphegina (Asiosphegina) dentata sp. nov., holotype, $\widehat{\jmath}$. A. Terga III and IV and sternum IV, left side lateral view. B. Sternum IV, ventral view. C. Left cercus, lateral view. D. Left surstylus, lateral view. E. Left superior lobe with associated parts, lateral view. F. Genitalia, right side, lateral view. Scale bars $=0.5 \mathrm{~mm}$. 
skewed to the right; sternum III rectangular, ratio width: length 1: 1.8-2.2; sternum IV, Fig. 24A; sterna VI, VII and VIII simple, with long yellow pile. Genitalia, Fig. 24B-D: note the simple symmetrical surstyli and asymmetrical superior lobes; see also under the 'Remarks' below.

\section{Female}

Similar to the male except normal sexual dimorphism.

LenGth. Body 5.8-6.2 mm, wing 4.0-4.4 mm.

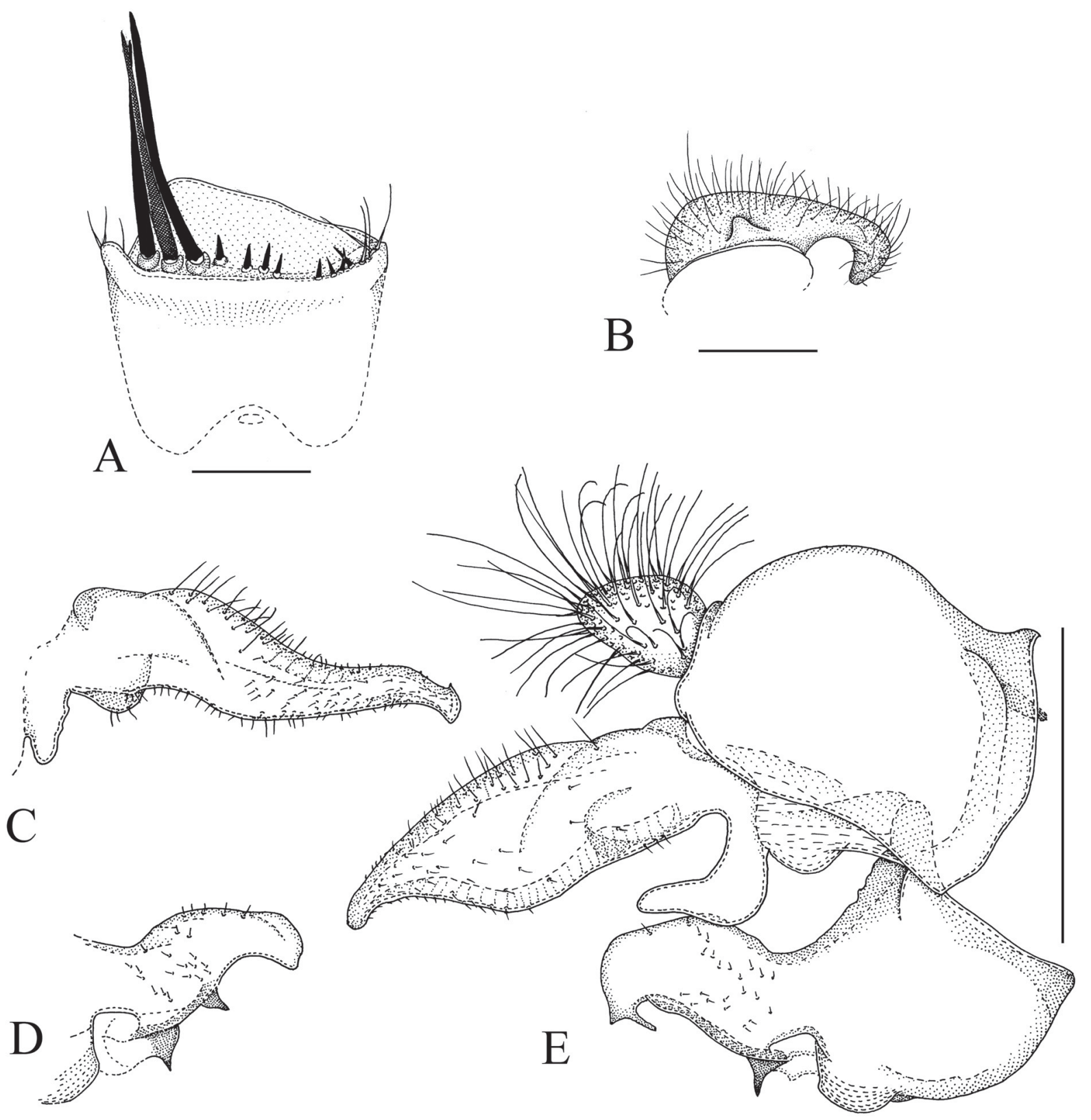

Fig. 27. Sphegina (Asiosphegina) distincta sp. nov., holotype, O̊. A. Sternum IV, ventral view. B. Sternum VII, ventral view. C. Left surstylus, lateral view. D. Left superior lobe with associated parts, lateral view. E. Genitalia, right side, lateral view. Scale bars $=0.5 \mathrm{~mm}$. 
HEAD. Ratio width of vertex at anterior ocellus: width of head 1: 5.2-5.6; ratio width of ocellar triangle: width of vertex 1: 1.3-1.6; ratio length of ocellar triangle: length of frons 1: 2.3-3.8. Basoflagellomere oval, ratio width: length $1: 1.3-1.4$, about 2.5 times as long as basoflagellomere.

THorax. Scutellum with two widely set, medium long setae medially at posterior margin, ratio length of scutellum: length of seta 1: 1.5 .

WING. Entirely microtrichose.

Legs. Metaleg, Fig. 19F, with femur slightly incrassate, ratio width: length 1: 3.4-3.5, yellow on basal $1 / 4-3 / 8$, basitarsomere thick, ratio width: length $1: 2.9-3.2$.

AвDomen. Length ratio of terga I: II: III: IV: V 1: 3.8-5.0: 2.2-2.6: 1.8-2.5: 0.9-1.1; ratio width at posterior margin: medial length of tergum II and III 1: 2.0-2.4 and 1: 0.6-0.7. Tergum I black, lateral setae in some specimens undifferentiated from the other pile; tergum II with dark yellow fascia on antero-medial $1 / 3$; tergum III with yellow fascia on anterior $1 / 6$; tergum IV with anterolateral yellow oval macula; tergum and sternum V entirely yellow; sternum III not sclerotized; sternum IV trapezoidal, ratio width: length 1: $0.8-0.9$; sternum $\mathrm{V}$ rectangular with concave posterior margin, ratio width: length 1 : $0.3-0.4$.

\section{Remarks}

The specimens from Malaysia differ slightly from those from Java in some measurements but the genitalia do not show any differences suggesting that they do not belong to different species. In Sphegina (Asiosphegina) crinita sp. nov. the superior lobes are unusual: the left side one is pushed over the medial line of hypandrium to the right side so that the right side one seems bilobed. Otherwise the genitalia are not much dissimilar to those in $S$. (A.) fimbriata sp. nov. except for rather minor details.

Sphegina (Asiosphegina) crucivena Hippa, van Steenis \& Mutin, 2015

Figs 13E, 23E, 30C, 33B

Sphegina (Asiosphegina) crucivena Hippa, van Steenis \& Mutin, 2015: 34. Type locality: Kambaiti, Myanmar (holotype, ふ̊, NHRS).

\section{Remarks}

Only known by the type material from Myanmar, Kambaiti (Hippa et al. 2015).

Sphegina (Asiosphegina) culex Hippa, van Steenis \& Mutin, 2015

Figs 23F, 30D-E

Sphegina (Asiosphegina) culex Hippa, van Steenis \& Mutin, 2015: 60. Type locality: Kambaiti, Myanmar (holotype, $\widehat{\jmath}$, NHRS).

\section{Remarks}

Only known by the type material from Myanmar, Kambaiti (Hippa et al. 2015). 
Sphegina (Asiosphegina) cultrigera Hippa, van Steenis \& Mutin, 2015

Fig. 28A

Sphegina (Asiosphegina) cultrigera Hippa, van Steenis \& Mutin, 2015: 45. Type locality: Kambaiti, Myanmar (holotype, $\hat{\jmath}$, NHRS).

\section{Remarks}

Only known by the type material from Myanmar, Kambaiti (Hippa et al. 2015).

Sphegina (Asiosphegina) dentata sp. nov. urn:1sid:zoobank.org:act:210AF7E9-4BB2-4239-B7CF-BEA4886D7E87

Figs 26, 28B, 30F-G, 43A, 47A, 65B

\section{Differential diagnosis}

In the key to the species, based on the non-genitalic characters, Sphegina (Asiosphegina) dentata sp. nov. is coupled with $S$. (A.) nigerrima and distinguished by the characters mentioned there. In the male genitalia, the species is similar to Sphegina (Asiosphegina) tricoloripes and $S$. (A.) umbrosa sp. nov. It is distinguished from the latter species by having a strongly sclerotized subapical tooth on the cercus and from the former by having only one cercal tooth instead a row of 3-4 teeth. All the three above mentioned species resemble the East-Palaearctic species Sphegina (Asiosphegina) elongata, S. (A.) freyana and $S$. (A.) grunini but differ from them by having entirely grey pollinose pleura (as opposed to having the pleura extensively non-pollinose and shiny). See also under $S$. (A.) nigerrima sp. nov. and $S$. (A.) umbrosa sp. nov.

\section{Etymology}

The specific epithet is from the Latin 'dentata', meaning 'dentate' and referring to the dentate male cercus.

\section{Material examined}

Holotype

TAIWAN • ○’; “Taiwan C: / Alishan, 2400 m / 3-9.VII.1972”, T.C. Maa / Collector / Bishop”; BPBM.

\section{Paratypes}

TAIWAN • 1 ; ; "Taiwan - Taichung / Haiduan road to / Siangyang National forest / Recreation area

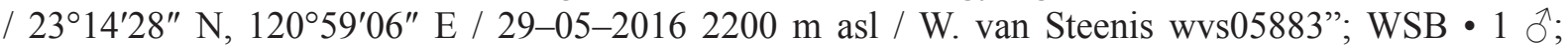
"FO: 9006 Taiwan / 2314'50.5" N, 120 59'09.3" E / Siangyang National forest Recreat / Taichung; $2820 \mathrm{mNN} / \mathrm{A}$. Astilbe sp. / leg. A. Ssymank, 29.05.2016"; ASW • 1 ð’; "Supplementary label / TWN YILAN COUNTY / Mt. TAIPINGSHAN; alt. 1900m / (台湾宜蘭県太平村太平山) / 27 - June, 2010 / Kojirou Katsura leg.”; “[台湾] 挂x本NO.31288 / 宜xx, 太平村Mt. 太平山 / xx 1900 m / MC 探x日 2010.6.27; / Leg. Xxxx" “<xxxx.xx(xx).xx.MEMOx> / Sphegina $\mathrm{x}-\mathrm{x}$ / (xxx) / MEMO へ / ニガキの 托”; KIM・ 1 ภै; same data as for preceding, “31291”; JSA.

\section{Description}

\section{Male}

LeNGTH. Body 7.1-7.9 mm, wing 5.4-5.9 mm.

HEAD. Face in lateral view (Fig. 30F) concave, strongly projected antero-ventrally; frontal prominence weakly developed. Ratio width of vertex at anterior ocellus: width of head 1: 3.7-4.0; ratio width of ocellar triangle: width of vertex 1: 2.2-2.5; ratio length of ocellar triangle: length of frons 1: 3.7-4.0. 
Face black; light grey pollinose, long pilose along eye-margin. Hypostomal bridge black, long pale pilose. Gena and mouth edge black with large subtriangular non-pollinose shiny area. Frons and vertex black, slightly light grey pollinose; a large trapezoidal area posterior of lunula non-pollinose and shiny and posterior of this area a rectangular fascia of denser grey-pollinosity (Fig. 30G); pile short, light yellow. Frons with weak antero-medial pit and rather weak medial furrow. Occiput black, light grey pollinose, light yellow pilose. Eye with an area of slightly enlarged facets at anterior margin. Antenna dark brown to black with black setae dorsally on scape and pedicel; basoflagellomere (Fig. 43A) round, ratio width: length 1: 0.9-1.0; arista only basally short pilose; slightly more than 3 times as long as basoflagellomere.

THorax. Colour black, weakly greyish pollinose sub-shiny, scutum submedially with more densely pollinose vitta and dense pollinosity along lateral margin; posterior margin of katepisternum widely nonpollinose, shiny (Fig. 65B); scutum and pleuron with very short adpressed light yellow pile. Scutellum semicircular, black, shiny and only weakly pollinose along posterior margin, with pile slightly longer

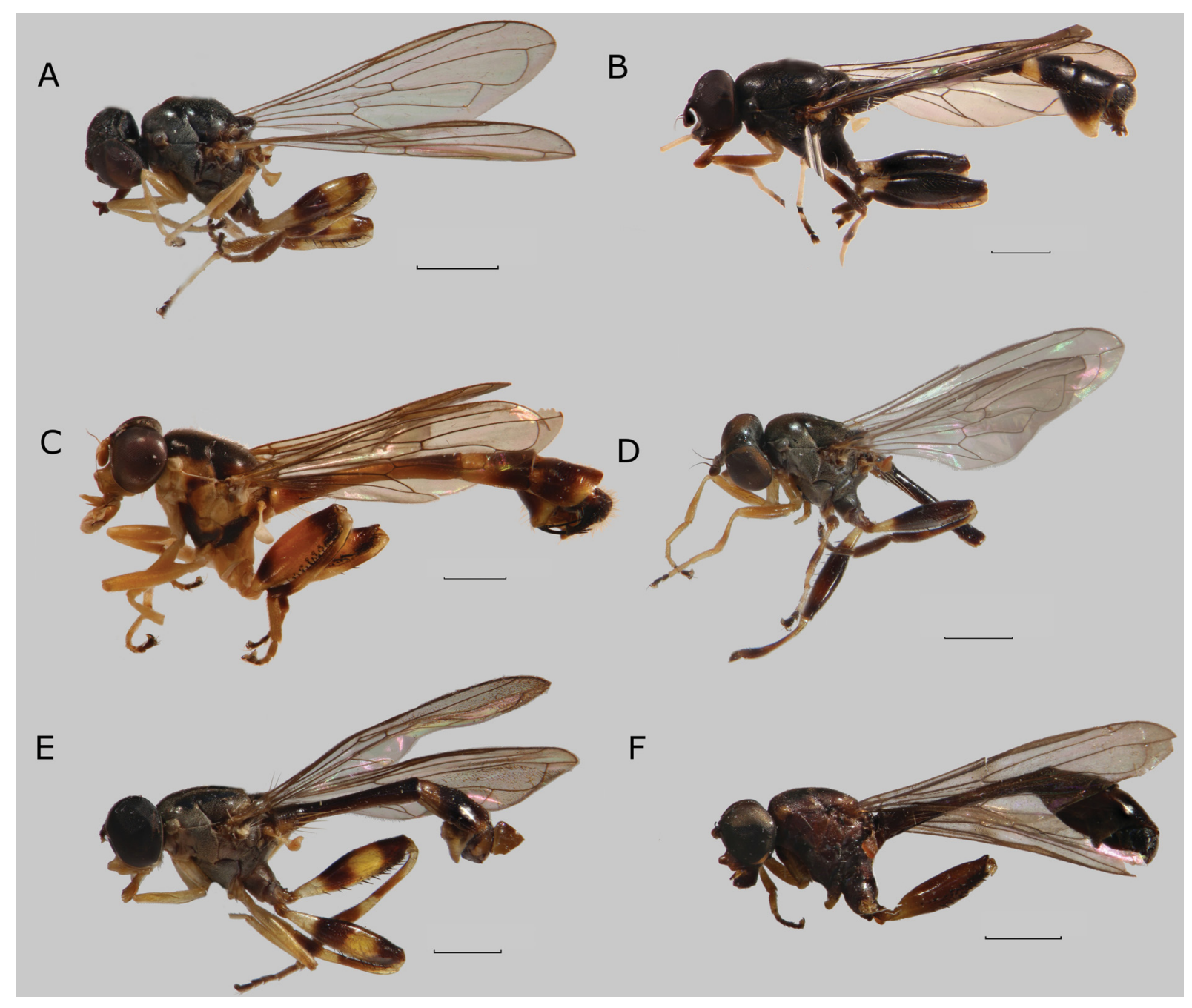

Fig. 28. Habitus, lateral view. A. Sphegina (Asiosphegina) cultrigera Hippa, van Steenis \& Mutin, 2015, paratype, ô, Myanmar. B. S. (A.) dentata sp. nov., paratype, ô, Taiwan. C. S. (A.) distincta sp. nov., paratype, ô, Vietnam. D. S. (A.) exilipes sp. nov., holotype, đ̄, Java, Indonesia. E. S. (A.) farinosa

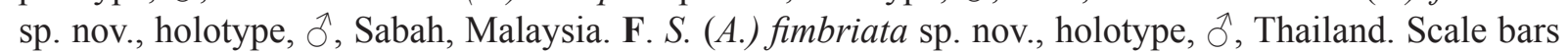
$=1.0 \mathrm{~mm}$. 
than on scutum, with two widely set, very long setae medially at posterior margin, ratio length of scutellum: length of seta 1: 2.3-2.7.

WING. Entirely microtrichose; hyaline, stigma brownish. Crossvein dm-cu meeting vein M obliquely and vein $M_{1}$ meeting vein $R_{4+5}$ perpendicularly.

Legs. Pro- and mesoleg yellow on basal $1 / 10$ of femora and basal $1 / 4-1 / 3$ of tibiae, tarsomeres $1-2$ dark yellow; metafemur black with basal $1 / 5$ yellow, slightly incrassate, ratio width: length $1: 3.7-3.9$; metatibia black and yellow biannulate, without apicoventral dens; metatarsus entirely black, basitarsomere rather thin, ratio width: length $1: 3.8-4.1$.

ABdomen. Length ratio of terga I: II: III: IV 1: 4.5-4.9: 2.0-2.4: 1.6-1.9; ratio width at posterior margin: medial length of tergum II and III 1: 3.9-4.3 and 1: 1.0-1.2. Terga black, sub-anterior $1 / 3$ of tergum III with yellow fascia or squarish lateral macula; pile pale, on terga short, laterally on terga I and II long; tergum IV slightly skewed to the right; tergum I with an oblique row of 4-5 strong light yellow setae at lateral margin (Fig. 47A); sternum III squarish, ratio width: length 1: 1.0-1.2; sternum IV, Fig. 26B; sterna VI, VII and VIII simple, with long yellow pile. Genitalia, Fig. 26C-F: note the only slightly asymmetrical surstyli and superior lobes and asymmetrical dentate cerci.

\section{Female}

Unknown.

\section{Biology}

Flower visiting Astilbe longicarpa (Saxifragaceae) near a small brook with water percolating on a steep rocky slope within a mainly older Pinus taiwanensis afforestation (van Steenis et al. in prep).

Sphegina (Asiosphegina) distincta sp. nov. urn:1sid:zoobank.org:act:1C09D33C-449F-4C59-B0C8-359C8600C13B

Figs 25E, 27, 28C, 30H-I, 43B, 47B

\section{Differential diagnosis}

Sphegina (Asiosphegina) distincta sp. nov. resembles the ca 30 other Oriental Sphegina which have strong spinose setae at the posterior margin of sternum IV. It is not especially similar to any of them and can easily be distinguished by the characters given in the key.

\section{Etymology}

The specific epithet is from the Latin 'distincta', meaning 'different' and referring to the unusually extensive yellow colour of the fly.

\section{Material examined}

Holotype

VIETNAM • O’; "Viet-Nam vi / Ha-noi / Strnad [sic]; 1990", ZFMK Dipt / QR code / 00011899"; ZFMK.

\section{Paratypes}

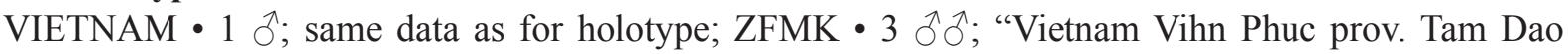
/ 21 $1^{\circ} 27^{\prime} 52^{\prime \prime} \mathrm{N}, 105^{\circ} 38^{\prime} 46^{\prime \prime}$ E $1.200 \mathrm{~m} /$ 19-22.VI.2014 hand collected / leg. M. Hauser \& N. von

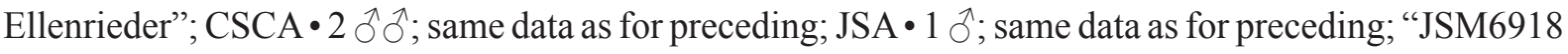
/ CNC464909"; DNA voucher specimen, in alcohol; CNC. 


\section{Description}

LeNGTH. Body 8.4-9.9 mm, wing 5.8-6.5 mm.

HEAD. Face in lateral view (Fig. 30H) concave, strongly projected antero-ventrally; frontal prominence weakly developed. Ratio width of vertex at anterior ocellus: width of head 1: 4.6-5.0; ratio width of ocellar triangle: width of vertex 1: 1.7-1.9; ratio length of ocellar triangle: length of frons 1: 2.4-3.1. Face dark brown, ventral half light-brown to dark yellow or entirely yellow, light grey pollinose, long pilose along eye-margin. Hypostomal bridge brown to dark brown, long pale pilose. Gena and mouth edge pale pollinose, dark yellow to light yellow with large subtriangular non-pollinose shiny area. Frons and vertex black, predominantly brown-grey pollinose, a squarish area posterior of lunula non-pollinose and shiny and narrow densely grey pollinose fascia posterior of shiny part (Fig. 30I); pile short, light yellow. Frons with rather deep and narrow medial furrow. Occiput black, light grey pollinose, light yellow pilose. Eye with slightly enlarged facets at anterior margin. Antenna brown-yellow to yellow with black setae dorsally on scape and pedicel; basoflagellomere (Fig. 43B) oval, ratio width: length 1 : 1.1-1.3; arista long pilose, about 2.5 times as long as basoflagellomere.

THORAx. Colour dark brown to black, weakly greyish pollinose; postpronotum, anterolateral margin and dorso-medial part of anepisternum and anepimeron brown-yellow to yellow, pleuron entirely grey pollinose; scutum and pleuron with very short adpressed light yellow pile. Scutellum sub-rectangular, black, pollinose, with pile longer than on scutum, with two widely set, very short setae medially at posterior margin, ratio length of scutellum: length of seta 1: $0.81-0.89$, about 8 additional shorter and weaker setae along posterior margin.

WING. Entirely microtrichose; hyaline, stigma yellowish. Crossvein dm-cu meeting vein M obliquely and vein $\mathrm{M}_{1}$ meeting vein $\mathrm{R}_{4+5}$ perpendicularly. Vein $\mathrm{CuA}$ s slightly extended to vein $\mathrm{dm}$-cu.

LeGs. Pro- and mesoleg yellow, tarsomeres 4 and 5 black. Metaleg with coxa black, trochanter yellow; femur black and yellow biannulate, with black parts narrow, slightly incrassate, ratio width: length 1: 3.7-4.0 and with long pile dorsally; tibia black and yellow biannulate, with short widely rounded apicoventral dens; tarsus black with tarsomeres 2 and 3 dark yellow to brown, basitarsomere thin, ratio width: length $1: 3.9-4.4$.

ABDOMEN. Length ratio of terga I: II: III: IV 1: 5.3-5.6: 2.4-2.6: 1.9-2.2; ratio width at posterior margin: medial length of tergum II and III $1: 4.5-4.8$ and $1: 0.9-1.1$. Terga black, anterior $1 / 3-1 / 2$ of tergum III with brown-yellow fascia; pile pale, on terga short, laterally on terga I and II long; tergum I with 3 strong brown-yellow to black setae at lateral margin (Fig. 47B); sternum III rectangular, ratio width: length 1: 1.4-1.8, or sclerotized part undifferentiated; sternum IV, Fig. 27A; sterna VI, VII and VIII, with long yellow pile, sternum VII, Fig. 22B, with a small tubercle and a hook shaped projection. Genitalia, Fig. $27 \mathrm{C}-\mathrm{E}$ : note the asymmetrical surstyli and superior lobes.

\section{Female}

Unknown.

Sphegina (Asiosphegina) ensifera Hippa, van Steenis \& Mutin, 2015 Fig. $30 \mathrm{~J}-\mathrm{K}$

Sphegina (Asiosphegina) ensifera Hippa, van Steenis \& Mutin, 2015: 48. Type locality: Kambaiti, Myanmar (holotype, ${ }_{0}$, NHRS). 


\section{Remarks}

Only known by the type material from Myanmar, Kambaiti (Hippa et al. 2015).

Sphegina (Asiosphegina) exilipes sp. nov.

urn:1sid:zoobank.org:act:BB30096D-780C-4C5C-B40F-A60EC7E4BB3D

Figs 28D, 29, 30L, 33C

\section{Differential diagnosis}

Sphegina (Asiosphegina) exilipes sp. nov. is similar to $S$. (A.) javana. In addition to the characters mentioned in the key, $S$. (A.) exilipes sp. nov. differs by a slightly narrower metafemur (see measurements in the descriptions) and the following differences in male genitalia: ventral lobe of right surstylus rectangular (more elongate and with pointed apex in $S$. (A.) javana); dorsal lobe of right surstylus straight with a ventral sublobe (the apical part curved dorsally and without ventral sublobe); sternum IX with strong transverse ridge-like lobe (a weak ridge present on dorsal part only); superior lobe posteriorly simple (with two triangular teeth).

\section{Etymology}

The specific epithet is from the Latin 'exilipes', meaning 'thin-legged' and referring to the slender metafemur.
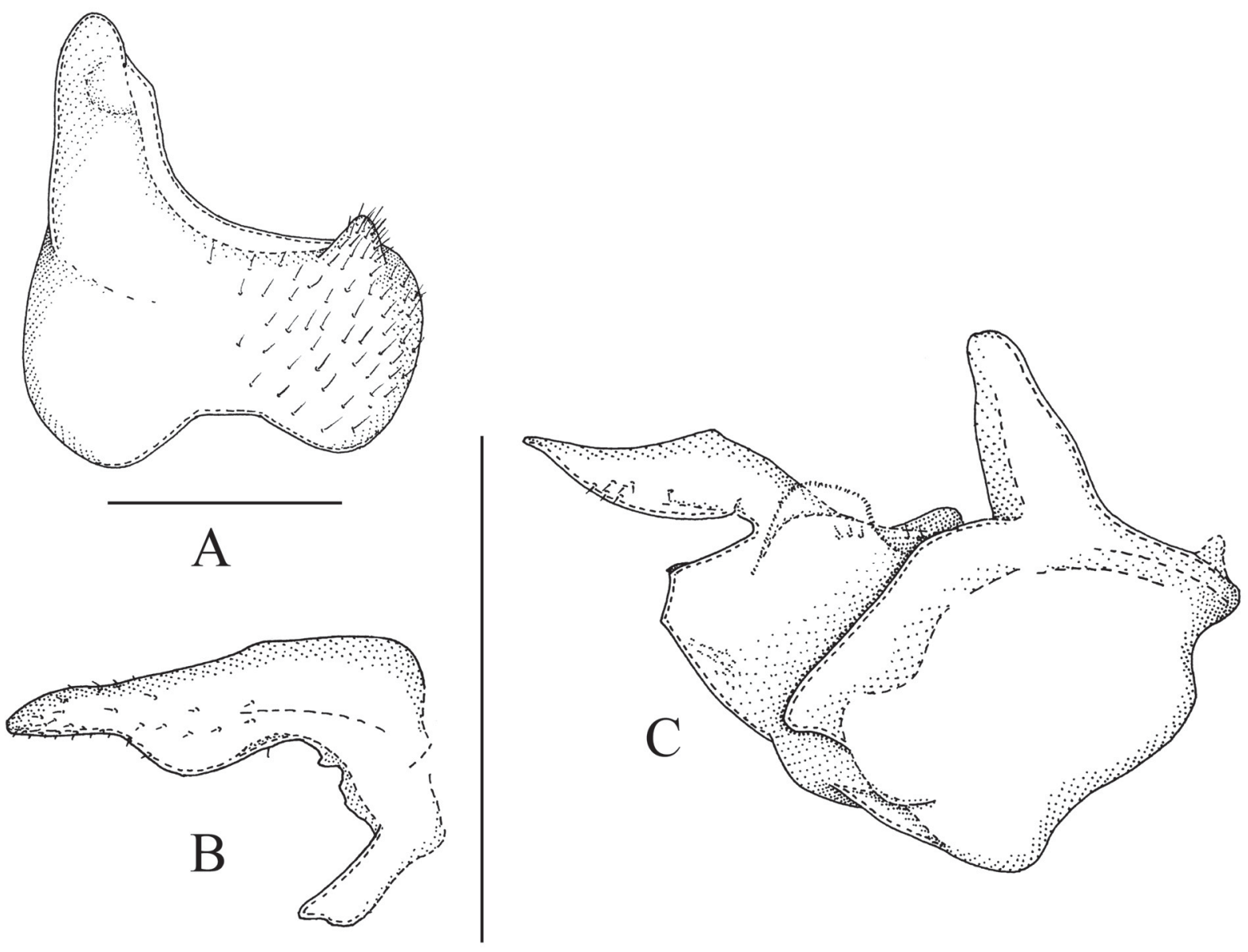

Fig. 29. Sphegina (Asiosphegina) exilipes sp. nov., holotype, $\widehat{\jmath}$. A. Sternum IV, ventral view. B. Right surstylus, lateral view. C. Right sternum IX and superior lobe, lateral view. Scale bars $=0.5 \mathrm{~mm}$. 


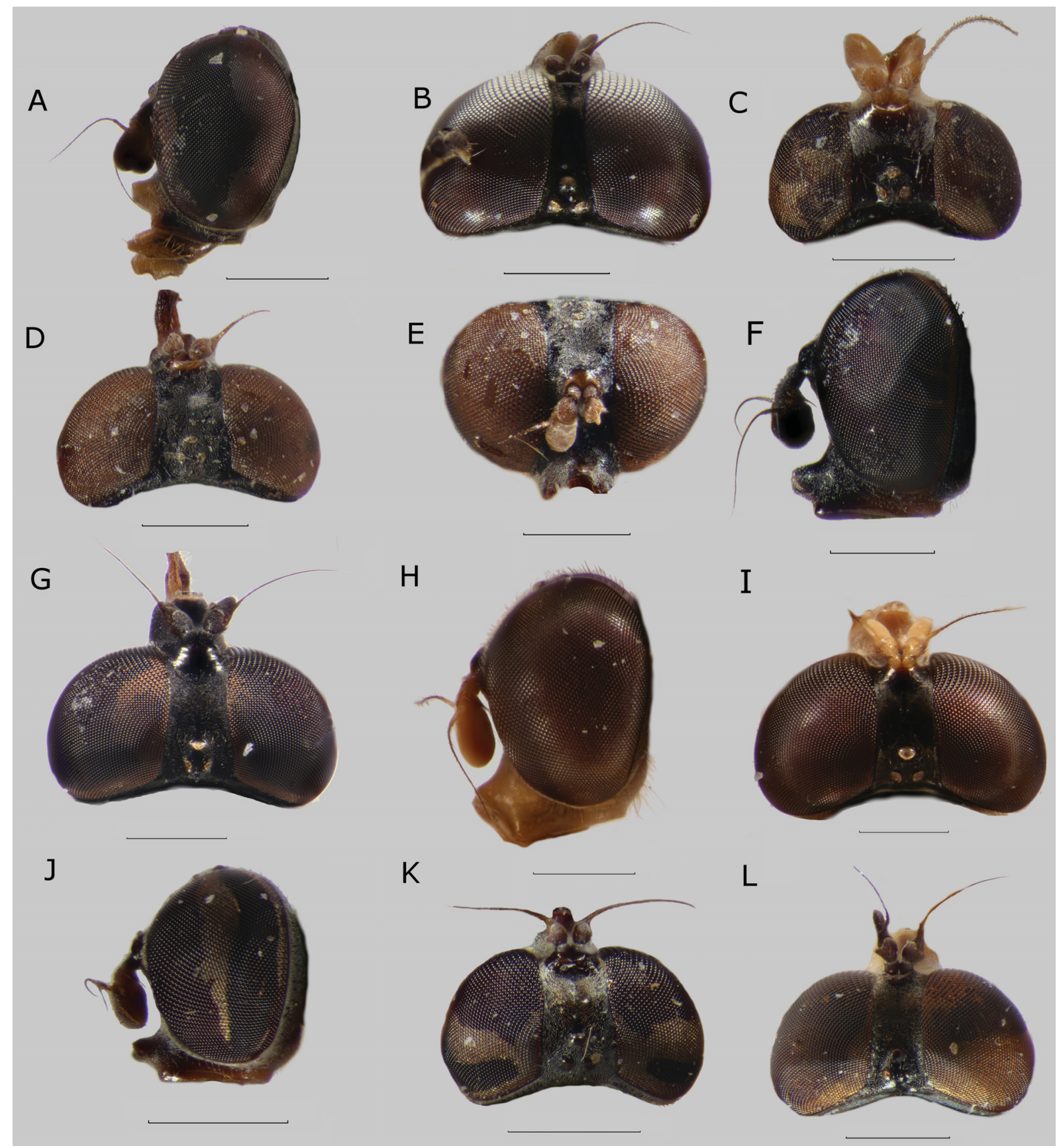

Fig. 30. Head, lateral view (A, F, H, J), dorsal view (B-D, G, I, K-L) and frontal view (E). A-B. Sphegina (Asiosphegina) crinita sp. nov., paratype, Õ, Java, Indonesia. C. S. (A.) crucivena Hippa, van Steenis \& Mutin, 2015, paratype, ๆ, Myanmar. D-E. S. (A.) culex Hippa, van Steenis \& Mutin, 2015, holotype, ô, Myanmar. F-G. S. (A.) dentata, sp. nov., paratype, Õ, Taiwan. H-I. S. (A.) distincta sp. nov., paratype, đ̊, Vietnam. J-K. S. (A.) ensifera Hippa, van Steenis \& Mutin, 2015, paratype, đ̂, Myanmar.

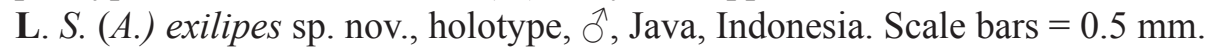




\section{Material examined}

Holotype

INDONESIA • ぶ; Java; “Pangrango / 2000 m / 14.VI.’19 DvL”; terga III-VIII missing; NBC.

\section{Description}

Male

LENGTH. Body not measurable due to missing part of abdomen, wing $5.2 \mathrm{~mm}$.

HEAD. Face in lateral view concave, very weakly projected antero-ventrally; frontal prominence very weakly developed. Ratio width of vertex at anterior ocellus: width of head 1: 5.3; ratio width of ocellar triangle: width of vertex 1:2.0; ratio length of ocellar triangle: length of frons 1: 2.7. Face yellow, light grey pollinose, long pilose along eye-margin. Hypostomal bridge yellow, long pale pilose. Gena and mouth edge yellow, pale pollinose, with large subtriangular non-pollinose shiny area. Frons and vertex black, sub-shiny, slightly grey pollinose, a circular area posterior of lunula non-pollinose and shiny and with narrow more densely grey pollinose fascia posterior of the shiny part; pile short, light yellow (Fig. 30L). Frons with long, very wide but shallow medial furrow. Occiput black, light grey pollinose, light yellow pilose. Eye with enlarged facets at anterior margin. Antenna dark brown to black with black setae dorsally on scape and pedicel; basoflagellomere oval, ratio width: length 1: 1.3; arista short pilose on basal half only, about 3 times as long as basoflagellomere.

THorax. Colour dark brown to black, scutum with densely grey pollinose vitta submedially; postpronotum and dorso-medial part of anepisternum and anepimeron brown-yellow; posterior margin of katepisternum narrowly non-pollinose, shiny; scutum and pleuron with very short adpressed light yellow pile. Scutellum semicircular, black, shiny, with pile slightly longer than on scutum, with two closely set medium long setae medially at posterior margin, ratio length of scutellum: length of seta 1 : 1.6.

WING. Microtrichose, basal 1/5 of cell cup bare; hyaline, stigma yellowish. Crossvein dm-cu meeting vein $M$ strongly oblique and vein $M_{1}$ meeting vein $R_{4+5}$ perpendicularly.

LEGs. Proleg yellow, tarsomeres 4 and 5 black; mesofemur nearly entirely dark yellow, tibia dark yellow on apico-medial 1/4, tarsomeres 4 and 5 black. Metaleg, Fig. 33C, with coxa black, trochanter dark brown; femur with basal $1 / 3$ yellow, slightly incrassate, ratio width: length $1: 5.1$; tibia nearly entirely dark brown to black, without apicoventral dens; tarsus entirely black, basitarsomere rather thin, ratio width: length 1:3.9.

ABDomEN. Length ratio of terga I and II 1: 5.3; ratio width at posterior margin: length of tergum II is 1 : 3.8. Terga black; pile pale, on terga short, laterally on terga I and II long; tergum I with an oblique row of 4-5 light yellow setae at lateral margin; sternum IV, Fig. 29A; VI, VII and VIII lost. Genitalia, Figs 29B, 24C: tergum IX, cerci, and left side surstylus and superior lobe destroyed.

\section{Female}

Unknown.

Sphegina (Asiosphegina) falcata Hippa, van Steenis \& Mutin, 2015

Fig. $47 \mathrm{C}$

Sphegina (Asiosphegina) falcata Hippa, van Steenis \& Mutin, 2015: 32. Type locality: Kambaiti, Myanmar (holotype, $\hat{\jmath}$, NHRS).

\section{Remarks}

Only known by the type material from Myanmar, Kambaiti (Hippa et al. 2015). 
Sphegina (Asiosphegina) farinosa sp. nov.

urn:1sid:zoobank.org:act:2789161A-821F-47E3-9B80-83C8A0622DBB

Figs 28E, 31, 38A, 47D

\section{Differential diagnosis}

In the key Sphegina (Asiosphegina) farinosa sp. nov. is coupled together with $S$. (A) apicalis and $S$. (A.) nubicola sp. nov. Except for the characters mentioned in the key, it differs from both by having asymmetrical cerci; from $S$. (A.) nubicola sp. nov. by having a large sublobe dorsally on the superior lobe; and from $S$. (A.) apicalis by having this sublobe longer than wide, instead of wider than long.

\section{Etymology}

The specific epithet is from the Latin 'farinosa', meaning 'mealy' and referring to the extensively pollinose body of the fly.

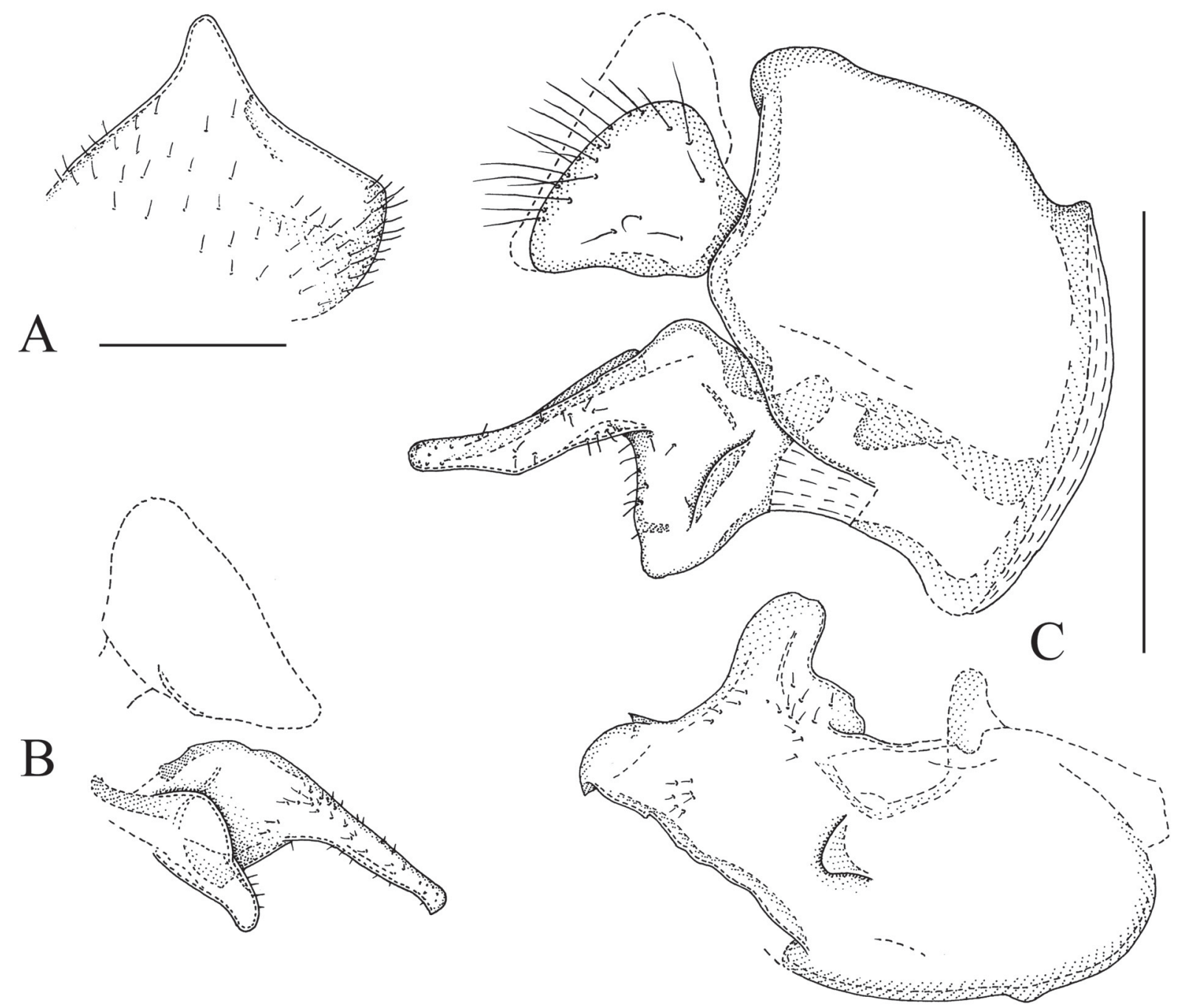

Fig. 31. Sphegina (Asiosphegina) farinosa sp. nov., holotype, $\widehat{~}$. A. Posterior part of sternum IV, lateroventral view. B. Left cersus and surstylus, lateral view. C. Genitalia, right side, lateral view. Scale bars = $0.5 \mathrm{~mm}$. 


\section{Material examined}

\section{Holotype}

SABAH • ○’; "British N. Borneo / Mt. Kinabalu Kam- / barangay 2140 m / X-22-30-1958”; "T.C. Maa / Collector / No.”; prolegs missing; NHM.

\section{Description}

Male

LeNGTH. Body $5.9 \mathrm{~mm}$, wing $5.3 \mathrm{~mm}$.

HEAD. Face in lateral view concave, weakly projected antero-ventrally; frontal prominence weakly developed. Ratio width of vertex at anterior ocellus: width of head 1: 5.3; ratio width of ocellar triangle: width of vertex 1: 1.9; ratio length of ocellar triangle: length of frons 1: 2.4. Face black, ventral half yellow, light grey pollinose, long pilose along eye-margin. Hypostomal bridge yellow, long pale pilose. Gena and mouth edge yellow with large subtriangular non-pollinose shiny area. Frons and vertex black, predominantly grey pollinose, a subtriangular area posterior of lunula non-pollinose and shiny (Fig. 38A); pile short, light yellow. Frons with weak medial furrow. Occiput black, light grey pollinose, light yellow pilose. Eye without enlarged facets at anterior margin. Antenna brown-yellow with black setae dorsally on scape and pedicel; basoflagellomere oval, ratio width: length 1: 1.3; arista short pilose, about 3 times as long as basoflagellomere.

THORAX. Colour dark brown to black, weakly greyish pollinose, scutum with denser grey pollinose vitta submedially; postpronotum and dorso-medial part of anepisternum and anepimeron brown-yellow; posterior margin of katepisternum narrowly non-pollinose, shiny; scutum and pleuron with very short adpressed light yellow pile. Scutellum semicircular, black, shiny, with pile slightly longer than on scutum, with two widely set, long setae medially at posterior margin, ratio length of scutellum: length of seta $1: 1.9$.

WING. Microtrichose, basal $1 / 3$ of cell cup bare; hyaline, stigma yellowish. Crossvein dm-cu meeting vein $\mathrm{M}$ slightly obliquely and vein $\mathrm{M}_{1}$ meeting vein $\mathrm{R}_{4+5}$ perpendicularly.

LEGS. Mesoleg yellow, tarsomeres 3-5 brown to black. Metaleg with coxa black, trochanter yellow; femur black and yellow biannulate, slightly incrassate, ratio width: length 1: 4.1; tibia black and yellow biannulate, without apicoventral dens; tarsus entirely black, basitarsomere rather thin, ratio width: length 1: 4.0 .

ABDOMEN. Length ratio of terga I: II: III: IV 1: 3.7: 1.6: 1.2; ratio width at posterior margin: medial length of tergum II and III 1: 3.4 and 1: 0.8. Tergum IV slightly skewed to the right. Terga black, anterior $1 / 2$ of tergum III with brown-yellow fascia; pile pale, on terga short, laterally on terga I and II long; tergum I with an oblique row of five yellow setae at lateral margin (Fig. 47D); sternum III not sclerotized; sternum IV, Fig. 31A; sterna VI, VII and VIII with long yellow pile. Genitalia, Fig. 31B-C: note the asymmetrical cerci and slightly asymmetrical surstyli; the left superior lobe not drawn, similar to the right one.

\section{Female}

Unknown. 
Sphegina (Asiosphegina) fimbriata sp. nov.

urn:1sid:zoobank.org:act:09FC2232-2D13-4691-A180-B2582ABE1C94

Figs 28F, 32, 38B

\section{Differential diagnosis}

The species is similar to Sphegina (Asiosphegina) crinita sp. nov. For comparison and distinguishing characters see under the latter.

\section{Etymology}

The specific epithet is from the Latin 'fimbriata', meaning 'fringed' and referring to the fringe of long setae on left-side of the male superior lobe.
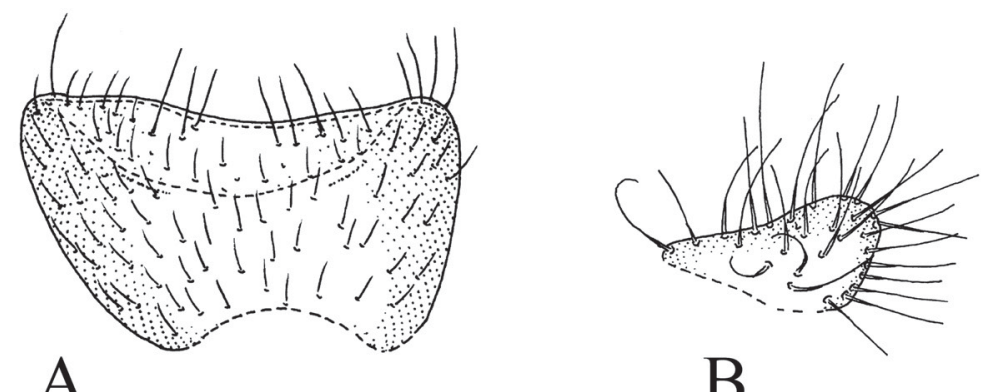

$\mathrm{B}$
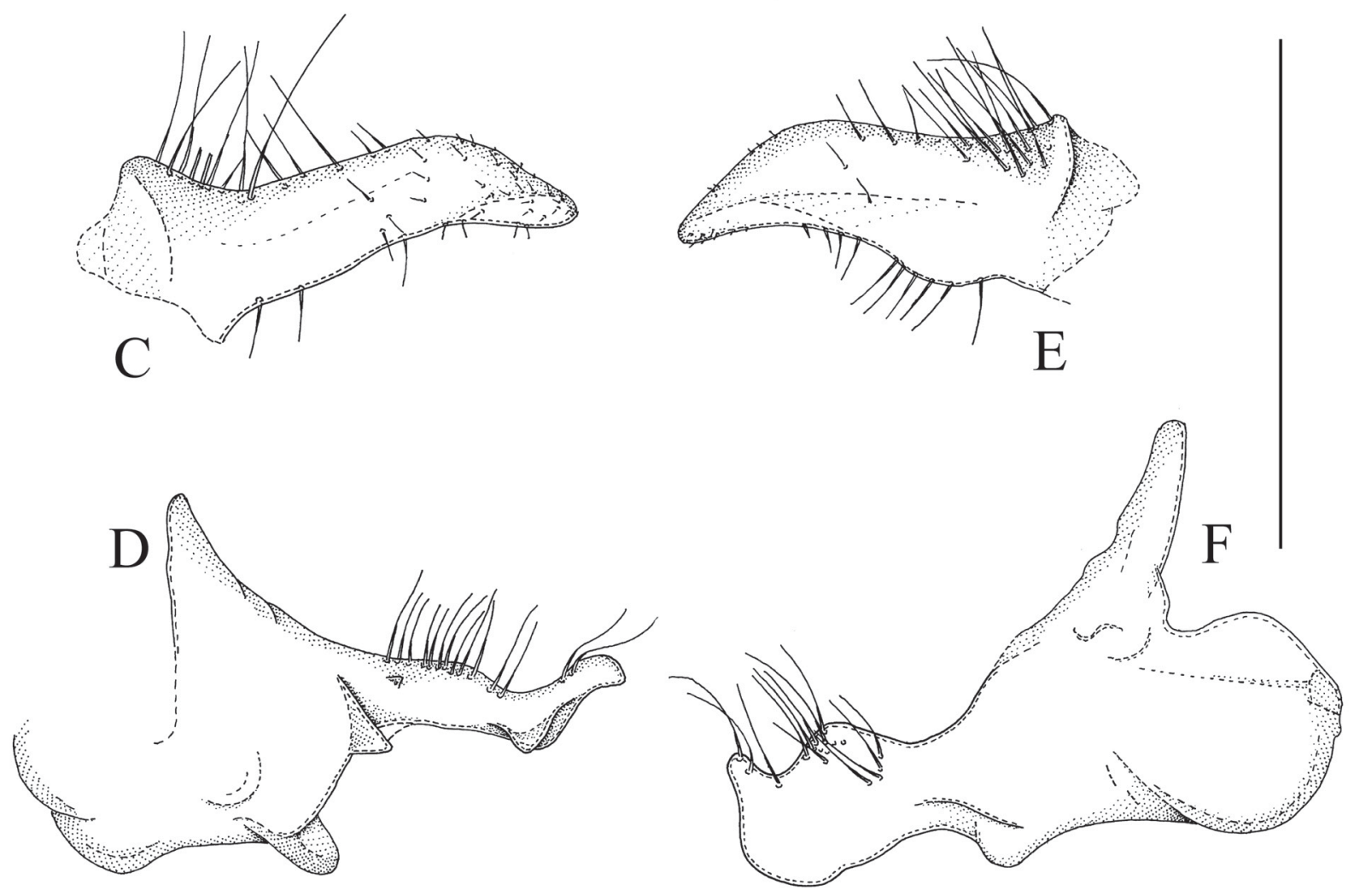

Fig. 32. Sphegina (Asiosphegina) fimbriata sp. nov., holotype, $\widehat{\jmath}$. A. Sternum IV, ventral view. B. Left cercus, lateral view. C. Left surstylus, lateral view. D. Sternum IX and superior lobe, left side, lateral view. E. Right surstylus, lateral view. F. Sternum IX and superior lobe, right side, lateral view. Scale bars $=0.5 \mathrm{~mm}$. 


\section{Material examined}

Holotype

THAILAND • ડ̄; "Thailand / Chiangmai Prov. / Doi Suthep / 1-5.IV.1958”; "T.C. Maa / Collector / Bishop"; antenna, left proleg, both mesolegs, left metaleg and right tarsomeres 4-5 of metatarsus missing; BPBM.

\section{Description}

\section{Male}

LeNGTH. Body $5.9 \mathrm{~mm}$, wing $4.6 \mathrm{~mm}$.

HEAD. Face in lateral view concave, very weakly projected antero-ventrally; frontal prominence very weakly developed. Ratio width of vertex at anterior ocellus: width of head 1: 5.5; ratio width of ocellar triangle: width of vertex 1: 1.7; ratio length of ocellar triangle: length of frons 1: 1.6. Face black, ventral half brown yellow, light grey pollinose, long pilose along eye-margin. Hypostomal bridge brown, long pale pilose. Gena and mouth edge brown-yellow with large subtriangular non-pollinose shiny area. Frons and vertex black, slightly pollinose, a narrow subtriangular area posterior of lunula non-pollinose and shiny (Fig. 38B); pile short, light yellow. Occiput black, light grey pollinose, light yellow pilose. Eye with an area of enlarged facets at anterior margin. Antenna lost.

THORAX. Colour black, weakly greyish pollinose, postpronotum, postalar callus and dorso-medial part of anepisternum and anepimeron brown-yellow, pleuron entirely grey pollinose; scutum and pleuron with very short adpressed light yellow pile. Scutellum sub-rectangular, black, greyish pollinose, with pile slightly longer than on scutum, no marginal setae observable, probably broken off.

WING. Entirely microtrichose; hyaline, stigma yellowish. Crossvein dm-cu meeting vein $M$ very obliquely and vein $\mathrm{M}_{1}$ meeting vein $\mathrm{R}_{4+5}$ perpendicularly.

Legs. Proleg yellow, tarsomeres 3-5 black. Metaleg with coxa black, trochanter yellow; femur orangebrown, strongly incrassate, ratio width: length 1: 3.1; tibia black and yellow biannulate, with long subtriangular apicoventral dens; tarsus entirely black, basitarsomere thick, ratio width: length 1:3.5.

ABDOMEN. Length ratio of terga I: II: III: IV 1: 3.6: 1.7: 1.4; ratio width at posterior margin: medial length of tergum II and III 1: 4.5 and 1: 0.9. Terga black, anterior $1 / 3$ of tergum III and anterior $1 / 6$ of tergum IV with yellow anterolateral maculae; pile pale, on terga short, laterally on terga I and II long; tergum I with an oblique row of 4 white setae at lateral margin; sternum III not entirely visible as it is partly hidden under sternum II; sternum IV, Fig. 32A; sterna VI, VII and VIII simple, with long yellow pile. Genitalia, Fig. 32B-F: note the nearly symmetrical surstyli and asymmetrical superior lobes.

\section{Female}

Unknown.

Sphegina (Asiosphegina) forceps Hippa, van Steenis \& Mutin, 2015

Fig. 38C-D

Sphegina (Asiosphegina) forceps Hippa, van Steenis \& Mutin, 2015: 42. Type locality: Kambaiti, Myanmar (holotype, $\hat{\jmath}$, NHRS).

\section{Remarks}

Only known by the type material from Myanmar, Kambaiti (Hippa et al. 2015). 
Sphegina (Asiosphegina) forficata Hippa, van Steenis \& Mutin, 2015

Figs 33D, 35A-B

Sphegina (Asiosphegina) forficata Hippa, van Steenis \& Mutin, 2015: 33. Type locality: Kambaiti, Myanmar (holotype, $\curvearrowright$, NHRS).

\section{Remarks}

Only known by the type material from Myanmar, Kambaiti (Hippa et al. 2015).

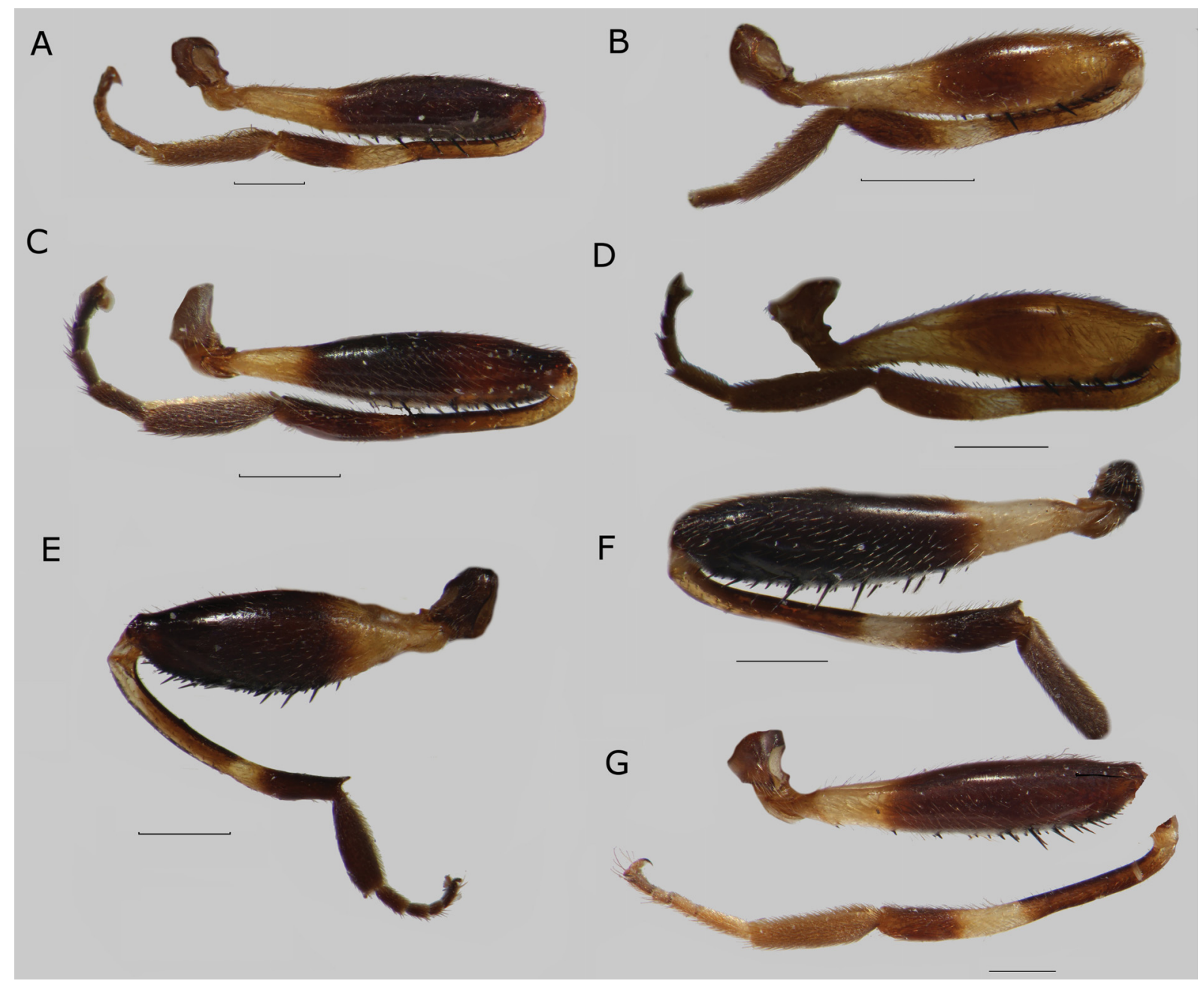

Fig. 33. Metaleg, anterior view. A. Sphegina (Asiosphegina) crassispina Hippa, van Steenis \& Mutin, 2015, paratype, +, Myanmar. B. S. (A.) crucivena Hippa, van Steenis \& Mutin, 2015, paratype, ô, Myanmar. C. S. (A.) exilipes sp. nov., holotype, ô, Java. D. S. (A.) forficata Hippa, van Steenis \& Mutin,

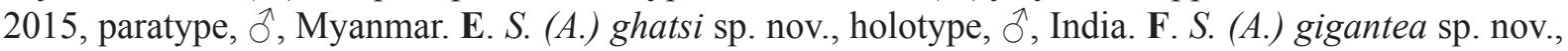
holotype, ${ }^{\lambda}$, China. G. S. (A.) gigas Hippa, van Steenis \& Mutin, 2015, paratype, +, Myanmar. Scale bars $=0.5 \mathrm{~mm}$. 


\section{Sphegina (Asiosphegina) furcillata sp. nov. urn:1sid:zoobank.org:act:870892C9-D28F-4E43-8F8B-92289D8C49AB}

Figs 25F, 34, 35C-D

\section{Differential diagnosis}

Similar to Sphegina (Asiosphegina) bracon sp. nov. and S. (A.) vietnamensis sp. nov. For distinguishing characters, see under $S$. (A.) bracon sp. nov.

\section{Etymology}

The specific epithet is from the Latin 'furcillata', meaning 'forked' and referring to the forked ventral lobe of male surstylus.

\section{Material examined}

\section{Holotype}

VIETNAM • đ̊; "C. Vietnam: Thua Thien Hué / Phong Dién N. R., near base-camp / 50-100 m; 3.iv.2001 / [leg] R. de Vries. RMNH'01”; NBC.

\section{Description}

Male

LENGTH. Body $7.1 \mathrm{~mm}$, wing $4.7 \mathrm{~mm}$

HEAD. Face in lateral view concave, weakly projected antero-ventrally; frontal prominence very weakly developed. Ratio width of vertex at anterior ocellus: width of head 1: 4.8; ratio width of ocellar triangle: width of vertex 1: 1.8; ratio length of ocellar triangle: length of frons 1: 2.9. Face black, ventral half brown-yellow, light grey pollinose, long pilose along eye-margin. Hypostomal bridge yellow, long pale pilose. Gena and mouth edge yellow with large subtriangular non-pollinose shiny area. Frons and vertex black, predominantly grey pollinose, a semi-circular area posterior of lunula non-pollinose and shiny; pile short, light yellow. Frons with deep medial furrow. Occiput black, light grey pollinose, light yellow pilose. Eye with an area of enlarged facets at anterior margin. Antenna yellow to brown-yellow with black setae dorsally on scape and pedicel; basoflagellomere oval, ratio width: length 1: 1.2; arista pilose, about 3 times as long as basoflagellomere.

THORAX. Colour dark brown to black, weakly greyish pollinose; postpronotum and dorso-medial part of anepisternum and anepimeron yellow, pleuron entirely grey pollinose; scutum and pleuron with very short adpressed light yellow pile, dorsally of wing base with some black pile. Scutellum semicircular, black, with slightly concave lateral margin, shiny, with pile slightly longer than on scutum, with two widely set, short setae medially at posterior margin, ratio length of scutellum: length of seta 1: 1.2.

Wing. Entirely microtrichose; hyaline, stigma yellowish. Crossvein dm-cu meeting vein M obliquely and vein $M_{1}$ meeting vein $R_{4+5}$ perpendicularly.

Legs. Pro- and mesoleg yellow, tarsomeres 4-5 black. Metaleg with coxa black, trochanter yellow; femur black and yellow biannulate, slightly incrassate, ratio width: length 1: 3.7; tibia black and yellow biannulate with weak and short apicoventral dens; tarsus dark brown with tarsomeres 2 and 3 dark yellow, basitarsomere very thin, ratio width: length 1: 4.6 .

AвDOMEN. Length ratio of terga I: II: III: IV 1: 3.5: 1.7: 1.8; ratio width at posterior margin: medial length of tergum II and III 1: 3.9 and 1: 0.9. Terga black, anterior 1/2.5 of tergum III with yellow fascia; pile pale, on terga short, laterally on terga I and II long; tergum I with 2-3 strong dark brown to black setae at lateral margin; sternum III rectangular, ratio width: length 1: 1.4; sternum IV, Fig. 34B; sterna VI, VII 

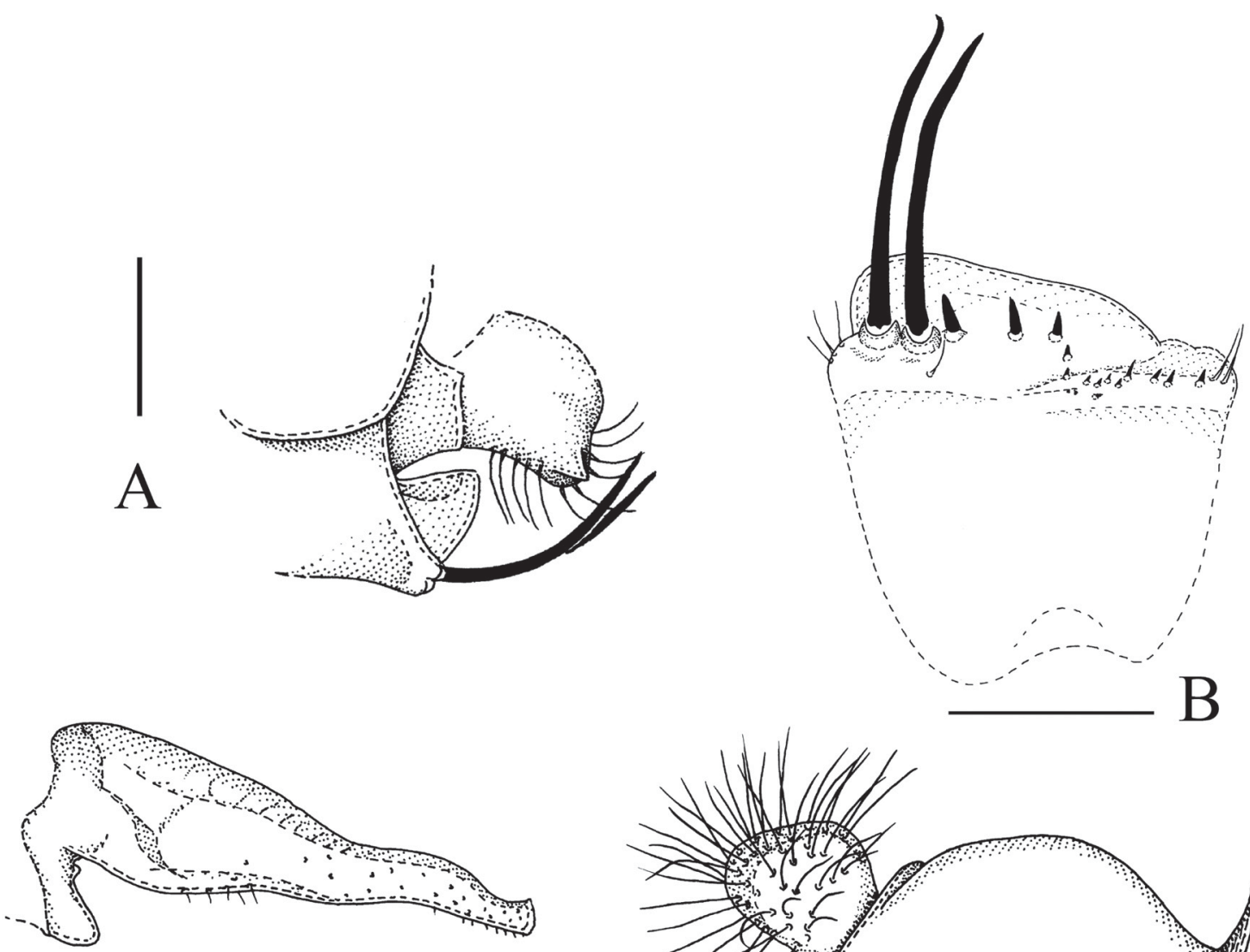

$\mathrm{C}$
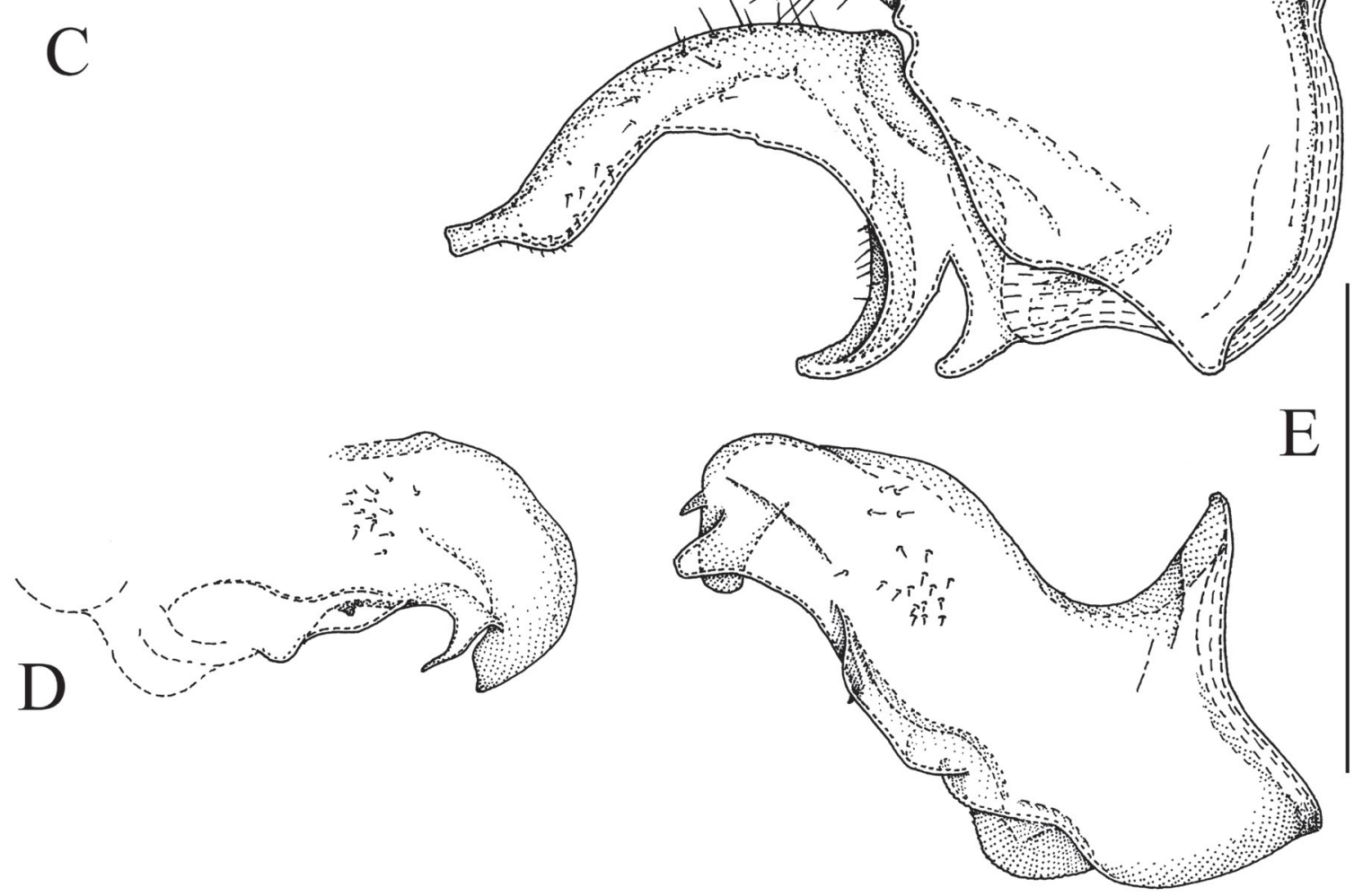

Fig. 34. Sphegina (Asiosphegina) furcillata sp. nov., holotype, ठ̂. A. Posterior part of abdomen, left side lateral view. B. Sternum IV, ventral view. C. Left surstylus, lateral view. D. Left superior lobe with associated parts, lateral view. E. Genitalia, right side, lateral view. Scale bars $=0.5 \mathrm{~mm}$. 
and VIII with long yellow pile, sternum VII with a large yellow-pilose crescent-like process with a sharp tooth-like medial projection. Genitalia, Fig. 34C-E: note the asymmetrical surstyli with bifid ventral lobe on the right side and the asymmetrical superior lobes.

\section{Female}

\section{Unknown.}

\section{Distribution and biology}

The habitat of the holotype was a secondary forest regrown after devastation during the Vietnam war in the 1960's, with many streams and some small rivers. The Malaise trap was placed close to one of the smaller streams in an open, partially shaded, wooded area. The habitat where the female specimen (see below) was collected was at $500 \mathrm{~m}$ a.s.1. in a disturbed lowland forest close to a river with large bamboo thickets. Due to the construction of a dam it was partly flooded (C. van Achterberg, pers. comm).

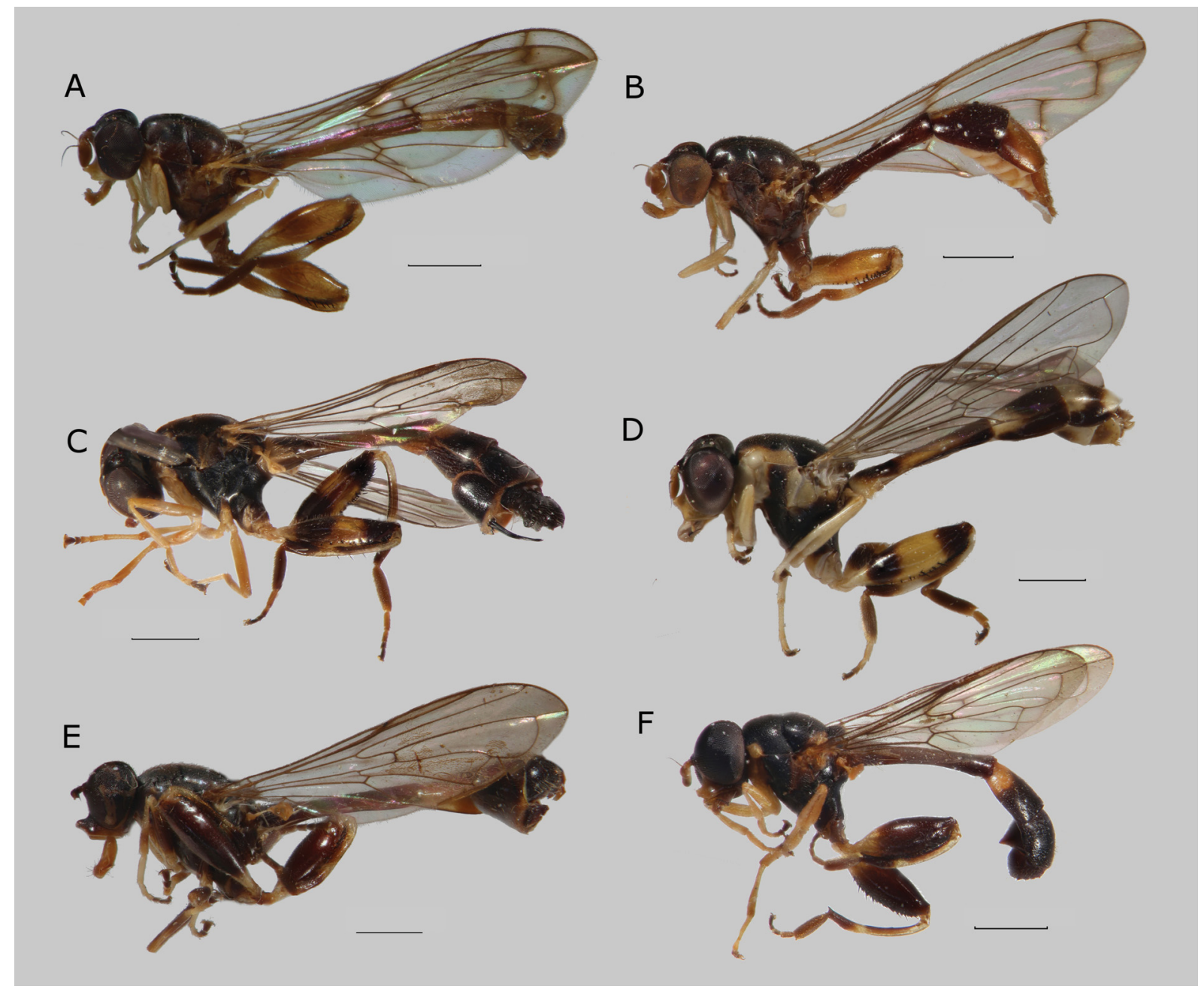

Fig. 35. Habitus, lateral view. A. Sphegina (Asiosphegina) forficata Hippa, van Steenis \& Mutin, 2015, paratype, §, Myanmar. B. S. (A.) forficata, paratype, +, Myanmar. C. S. (A.) furcillata sp. nov., holotype,

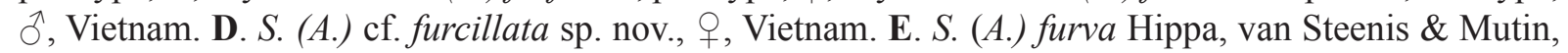

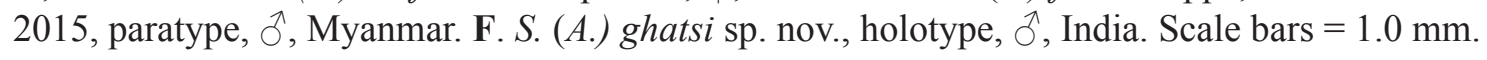




\section{Remarks}

We have also studied a female which possibly belongs to this species: 1 q, "S. Vietnam Dak Lak / Chu Yang Sin N.P., nr dam / c. 500 m. 3-9.vi.2007 / Mal.[aise] traps [leg] C. v. Achterberg / \& R. de Vries, RMNH '07' (NBC). This female has all the diagnostic characters of Sphegina (Asiosphegina) furcillata sp. nov. but has no enlarged setae at lateral margin of tergum I.

Sphegina (Asiosphegina) furva Hippa, van Steenis \& Mutin, 2015

Figs $35 \mathrm{E}, 38 \mathrm{E}$

Sphegina (Asiosphegina) furva Hippa, van Steenis \& Mutin, 2015: 58. Type locality: Kambaiti, Myanmar (holotype, $\widehat{\jmath}, \mathrm{NHM}$ ).

\section{Remarks}

Only known byl the type material from Myanmar, Kambaiti (Hippa et al. 2015).

Sphegina (Asiosphegina) ghatsi sp. nov. urn:1sid:zoobank.org:act:1BE2A8FF-B184-469B-B4E1-47C2746C6934

Figs 33E, 35F, 36, 38F

\section{Differential diagnosis}

Sphegina (Asiosphegina) ghatsi sp. nov. is not particularly similar to any other known Sphegina. In the key it runs to couplet 31 together with Sphegina (Asiosphegina) prolixa sp. nov. Except for the characters mentioned in the key, the species can be separated by their strikingly different genitalia, particularly the superior lobes. In $S$. (A.) ghatsi sp. nov. the superior lobe is very simple and short subtriangular whereas in $S$. (A.) prolixa sp. nov. it is long, curved and posteriorly bilobed, with the ventral lobe exceedingly long.

\section{Etymology}

The specific epithet is derived from the type locality, the Ghats mountains.

\section{Material examined}

\section{Holotype}

INDIA: О̊; "India: Karna. St. / Mudigere (18 km W) / 7 Apr 1980 Mathis / \& Friedberg coll”; USNM.

\section{Description}

\section{Male}

Length. Body $5.8 \mathrm{~mm}$, wing $4.4 \mathrm{~mm}$.

HEAD. Face in lateral view concave, weakly projected antero-ventrally; frontal prominence very weakly developed. Ratio width of vertex at anterior ocellus: width of head 1: 6.0; ratio width of ocellar triangle: width of vertex 1: 1.5; ratio length of ocellar triangle: length of frons 1: 2.3. Face black, light grey pollinose, long pilose along eye-margin. Hypostomal bridge yellow, long pale pilose. Gena and mouth edge yellow with large subtriangular non-pollinose shiny area. Frons and vertex black, slightly pollinose, a squarish area posterior of lunula non-pollinose and shiny (Fig. 38F); pile short, light yellow. Frons with clear but narrow furrow medially. Occiput black, light grey pollinose, light yellow pilose. Eye with an area of enlarged facets at anterior margin. Antenna brown-yellow with black setae dorsally on scape and pedicel; basoflagellomere oval, ratio width: length 1: 1.3; arista short pilose, about 3 times as long as basoflagellomere. 
THORAX. Colour black, postpronotum, postalar callus and dorso-medial part of anepisternum and anepimeron yellow; greyish pollinose, posterior margin of katepisternum narrowly non-pollinose, shiny; scutum and pleuron with very short adpressed light yellow pile. Scutellum semi-lunular shaped, black, weakly pollinose, with pile slightly longer than on scutum, without observable setae at posterior margin, unclear if they are broken off.
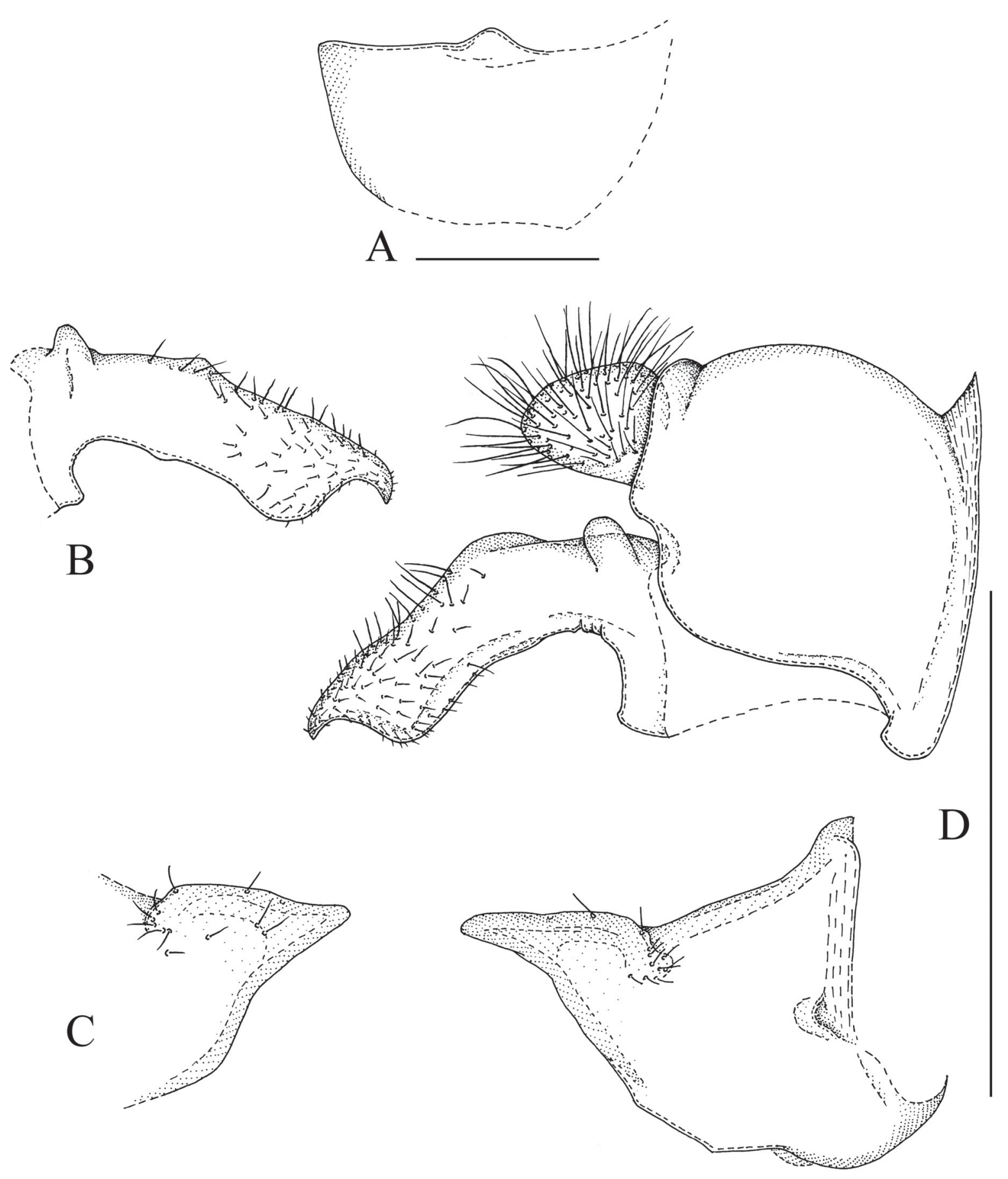

Fig. 36. Sphegina (Asiosphegina) ghatsi sp. nov., holotype, Ô. A. Sternum IV, ventral view. B. Left surstylus, lateral view. C. Left superior lobe, lateral view. D. Genitalia, right side, lateral view. Scale bars $=0.5 \mathrm{~mm}$. 
WING. Entirely microtrichose; hyaline, stigma yellowish. Crossvein $\mathrm{dm}$-cu meeting vein $\mathrm{M}$ slightly obliquely and vein $M_{1}$ meeting vein $R_{4+5}$ perpendicularly.

LeGs. Pro- and mesoleg yellow, tarsomeres 4 and 5 black. Metaleg, Fig. 33E, with coxa black, trochanter yellow; femur black with basal $1 \frac{1}{3}$ yellow, strongly incrassate, ratio width: length 1: 3.0; tibia black and yellow biannulate with long and wide apicoventral dens; tarsus entirely black, basitarsomere thick, ratio width: length $1: 3.2$.

ABDOMEN. Length ratio of terga I: II: III: IV 1: 3.2: 2.0: 1.8; ratio width at posterior margin: medial length of tergum II and III 1: 2.7 and 1: 0.7 . Terga black, anterior $2 / 5$ of tergum III with yellow fascia; pile pale, on terga short, laterally on terga I and II long; tergum I with a more or less horizontal row of 3-4 light yellow setae at lateral margin; sternum III without sclerotized part; sternum IV, Fig. 36A; sterna VI, VII and VIII simple, with long yellow pile. Genitalia, Fig. 36B-D: note the symmetrical surstyli and superior lobes.

Female

Unknown.

Sphegina (Asiosphegina) gigantea sp. nov. urn:1sid:zoobank.org:act:3326F11E-6280-474F-8733-20E6FAF54191

Figs 33F, 37, 38G, 41A

\section{Differential diagnosis}

Sphegina (Asiosphegina) gigantea sp. nov. is similar to those other Sphegina which have strong setae posteriorly on the male sternum IV, especially $S$. (A.) gigas and $S$. (A.) trispina with which it shares the hyaline wing in combination with the presence of long sub-apical setae antero-dorsally on the hind femur. Except for the characters appearing in the key, it also differs from $S$. (A.) gigas and $S$. (A.) trispina by having male sternum IV with a very narrow posterior submembranous flange (in $S$. (A.) gigas and $S$. (A.) trispina very wide). Sternum VII has a conical tubercle with long light pile as in $S$. (A.) trispina, but the pile is more seta-like; $S$. (A.) gigas has a long finger-like process with long light yellow pile. Thus, the male genitalia of these three species are significantly different (see also Hippa et al. 2015).

\section{Etymology}

The specific epithet is from the Latin 'gigantea', meaning 'gigantic' and referring to the large size of the fly.

\section{Material examined}

\section{Holotype}

CHINA • O'; "Sichuan: / Luding 9 km SE / 29.861 N, 102.314 E / 2100 m / 01.VII.2009 leg. / Blank, Liston, Taeger / 074 China"; CSCA.

\section{Description}

\section{Male}

LeNGTH. Body $8.5 \mathrm{~mm}$, wing $7.3 \mathrm{~mm}$.

HEAD. Face in lateral view concave, strongly projected antero-ventrally; frontal prominence weakly developed. Ratio width of vertex at anterior ocellus: width of head 1: 4.5 ratio width of ocellar triangle: width of vertex 1: 2.0; ratio length of ocellar triangle: length of frons 1: 2.4. Face black, light grey pollinose, long pilose along eye-margin. Hypostomal bridge black, long pale pilose. Gena and mouth 
edge black with large subtriangular non-pollinose shiny area. Frons and vertex black, slightly pollinose, a wide subtriangular area posterior of lunula non-pollinose and shiny and a wide posterolateral densely grey-pollinose fascia (Fig. 38G); pile short, light yellow. Frons with weak pit antero-medially. Occiput black, light grey pollinose, light yellow pilose. Eye without enlarged facets at anterior margin. Antenna brown with black setae dorsally on scape and pedicel; basoflagellomere squarish, ratio width: length 1: 1.1 ; arista long pilose, slightly more than 3.5 times as long as basoflagellomere.
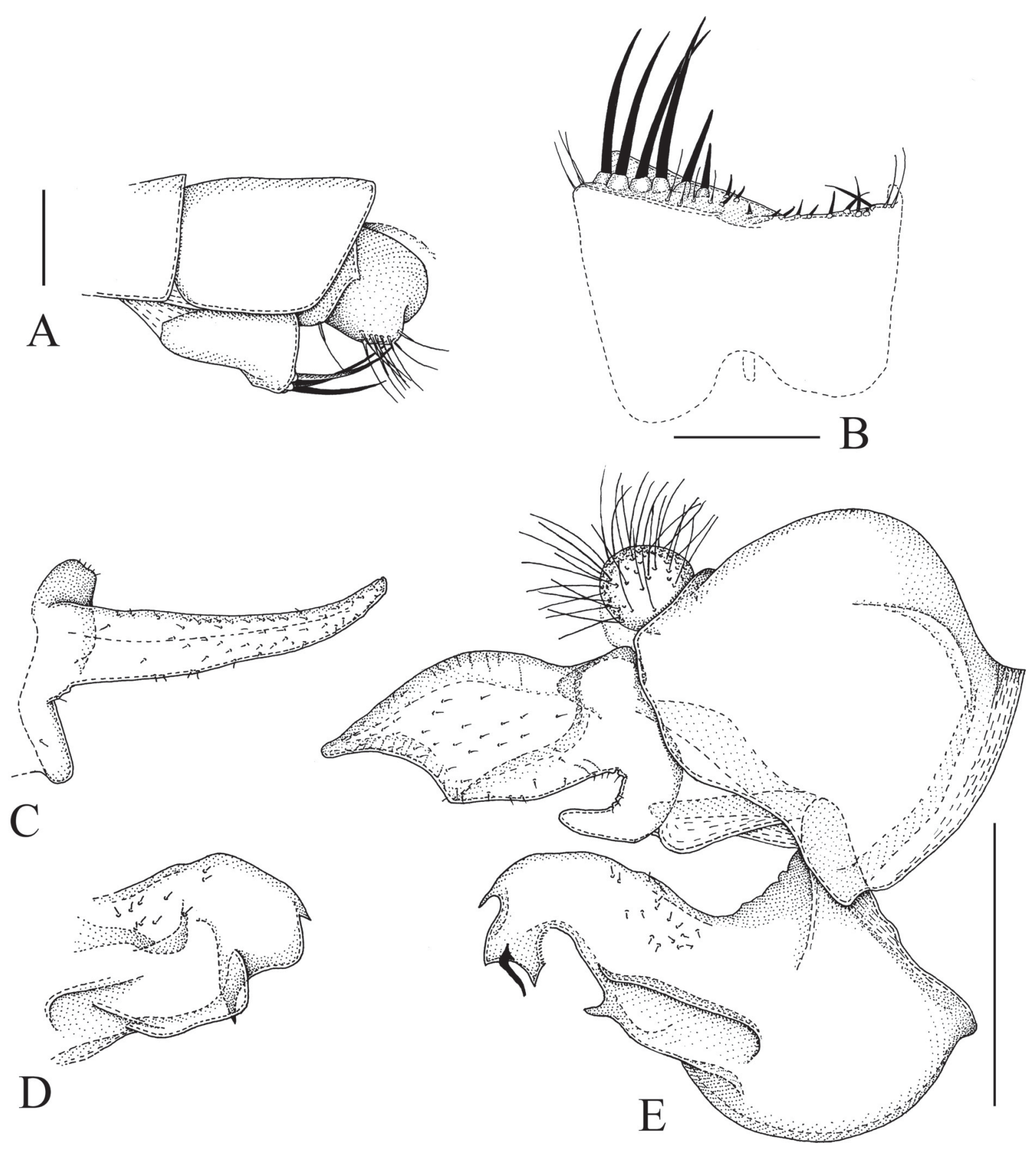

Fig. 37. Sphegina (Asiosphegina) gigantea sp. nov., holotype, $\widehat{\jmath}$. A. Posterior part of abdomen, left side lateral view. B. Sternum IV, ventral view. C. Left surstylus, lateral view. D. Left superior lobe, lateral view. E. Genitalia, right side, lateral view. Scale bars $=0.5 \mathrm{~mm}$. 


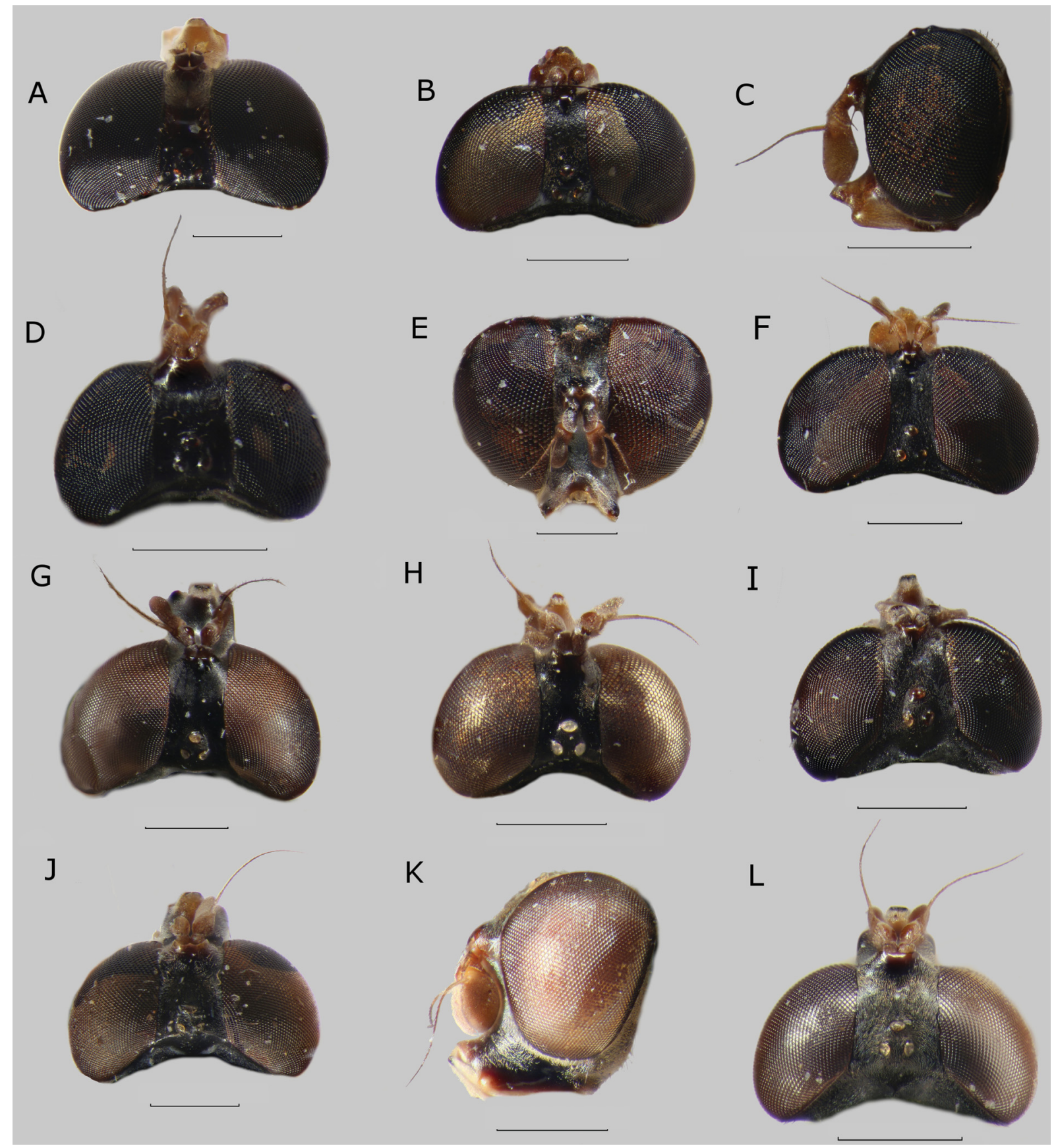

Fig. 38. Head, lateral view $(\mathrm{C}, \mathrm{K})$, dorsal view (A-B, D, F-J, L) and frontal view (E). A. Sphegina (Asiosphegina) farinosa sp. nov., holotype, ô, Sabah, Malaysia. B. S. (A.) fimbriata sp. nov., holotype, ô, Thailand. C-D. S. (A.) forceps Hippa, van Steenis \& Mutin, 2015, paratype, $̂$, Myanmar. E. S. (A.) furva

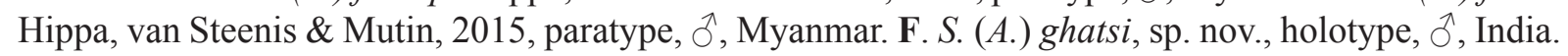
G. $S$. (A.) gigantea sp. nov., holotype, $\hat{\jmath}$, China. H. S. (A.) granditarsis sp. nov., paratype, $\widehat{\jmath}$, Thailand. I. S. (A.) hamulata sp. nov., holotype, ô, India. J. S. (A.) hansoni Thompson, 1966, holotype, ô, Nepal. K-L. S. (A.) hauseri sp. nov., paratype, $\hat{\jmath}$, Nepal. Scale bars $=0.5 \mathrm{~mm}$. 
THORAX. Colour black, weakly greyish pollinose sub-shiny, pleuron entirely and more heavily grey pollinose; scutum and pleuron with very short adpressed light yellow pile. Scutellum subtriangular, black, weakly greyish pollinose, with pile slightly longer than on scutum, with two closely set, long setae medially at posterior margin, ratio length of scutellum: length of seta 1:2.2.

WING. Entirely microtrichose; hyaline, stigma yellowish. Crossvein dm-cu meeting vein M slightly obliquely and vein $\mathrm{M}_{1}$ meeting vein $\mathrm{R}_{4+5}$ perpendicularly. Vein $\mathrm{Cu} \mathrm{A}_{1}$ extending beyond vein dm-cu.

Legs. Pro- and mesoleg yellow; femur black on medial $1 / 3-4 / 5$, tibia with apico-medial $1 / 3-1 / 4$ black, tarsomeres 4 and 5 black. Metaleg, Fig. 33F, with coxa black, trochanter yellow; femur black with basal $1 / 3$ yellow, slightly incrassate, ratio width: length $1: 4.7$, with a row of 3 long black setae anteriorly on basal yellow part and two long sub-apical setae antero-dorsally; tibia black and yellow biannulate with pointed apicoventral dens; tarsus entirely black, basitarsomere very thin, ratio width: length 1: 5.0.

ABDOMEN. Length ratio of terga I: II: III: IV 1: 3.5: 1.8: 1.5; ratio width at posterior margin: medial length of tergum II and III 1: 5.8 and 1: 1.0. Terga black, anterior $1 / 3$ of tergum III with yellow fascia; pile pale, on terga short, laterally on terga I and II long; tergum I with 3 evenly spaced strong black setae at lateral margin; sternum III rectangular, ratio width: length 1: 1.9; sternum IV, Fig. 37B; sterna VI, VII and VIII with long yellow pile, sternum VII with a low conical tubercle with long light setae-like pile. Genitalia, Fig. 37C-E: note the asymmetrical surstyli and superior lobes and the short subbasal finger-like lobe on the medial side of the right surstylus.

\section{Female}

Unknown.

Sphegina (Asiosphegina) gigas Hippa, van Steenis \& Mutin, 2015

Figs 33G, 41B

Sphegina (Asiosphegina) gigas Hippa, van Steenis \& Mutin, 2015: 22. Type locality: Kambaiti, Myanmar (holotype, ô, NHRS).

\section{Material examined}

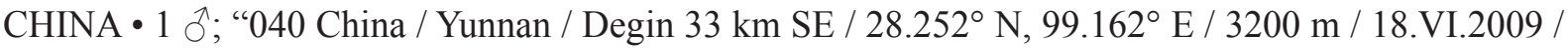
Blank, Liston \& Tager"; CSCA.

\section{Remarks}

Known only by the type material from Myanmar, Kambaiti (Hippa et al. 2015) and the specimen studied here.

Sphegina (Asiosphegina) granditarsis sp. nov. urn:1sid:zoobank.org:act:8CA0261F-47AE-4A24-89F2-3C25376BC975

Figs $38 \mathrm{H}, 39,41 \mathrm{C}, 61 \mathrm{~B}$

\section{Differential diagnosis}

Sphegina (Asiosphegina) granditarsis sp. nov. is similar to $S$. (A.) atrimanus sp. nov., S. (A.) incretonigra sp. nov., $S$. (A.) nasuta, $S$. (A.) nigrotarsata sp. nov. and $S$. (A.) orientalis. Except for the characters mentioned in the key $S$. (A.) granditarsis sp. nov. differs from the other mentioned species by having only very sparse pile posteriorly on male sternum IV. The male genitalia are similar to those of 
S. (A.) orientalis, but the dorsal lobe of surstylus is not widened on the apical part and the ventral lobe is pointed, not obtuse. Moreover, the long seta-like pile on the cercus is much longer. See also under S. (A.) atrimanus sp. nov.

\section{Etymology}

The specific epithet is from the Latin 'granditarsis', meaning 'having a large tarsus' and referring to the enlarged and flattened protarsus.

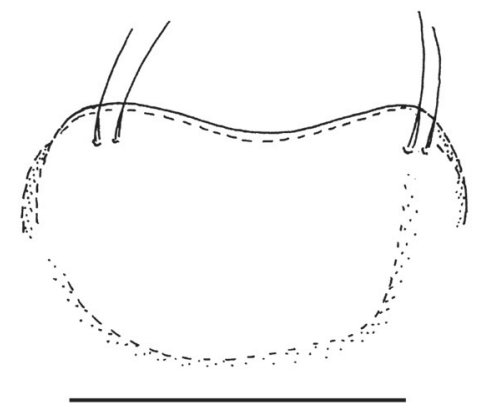

A

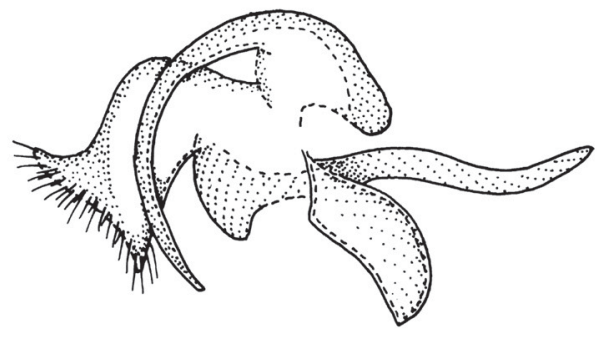

$\mathrm{B}$

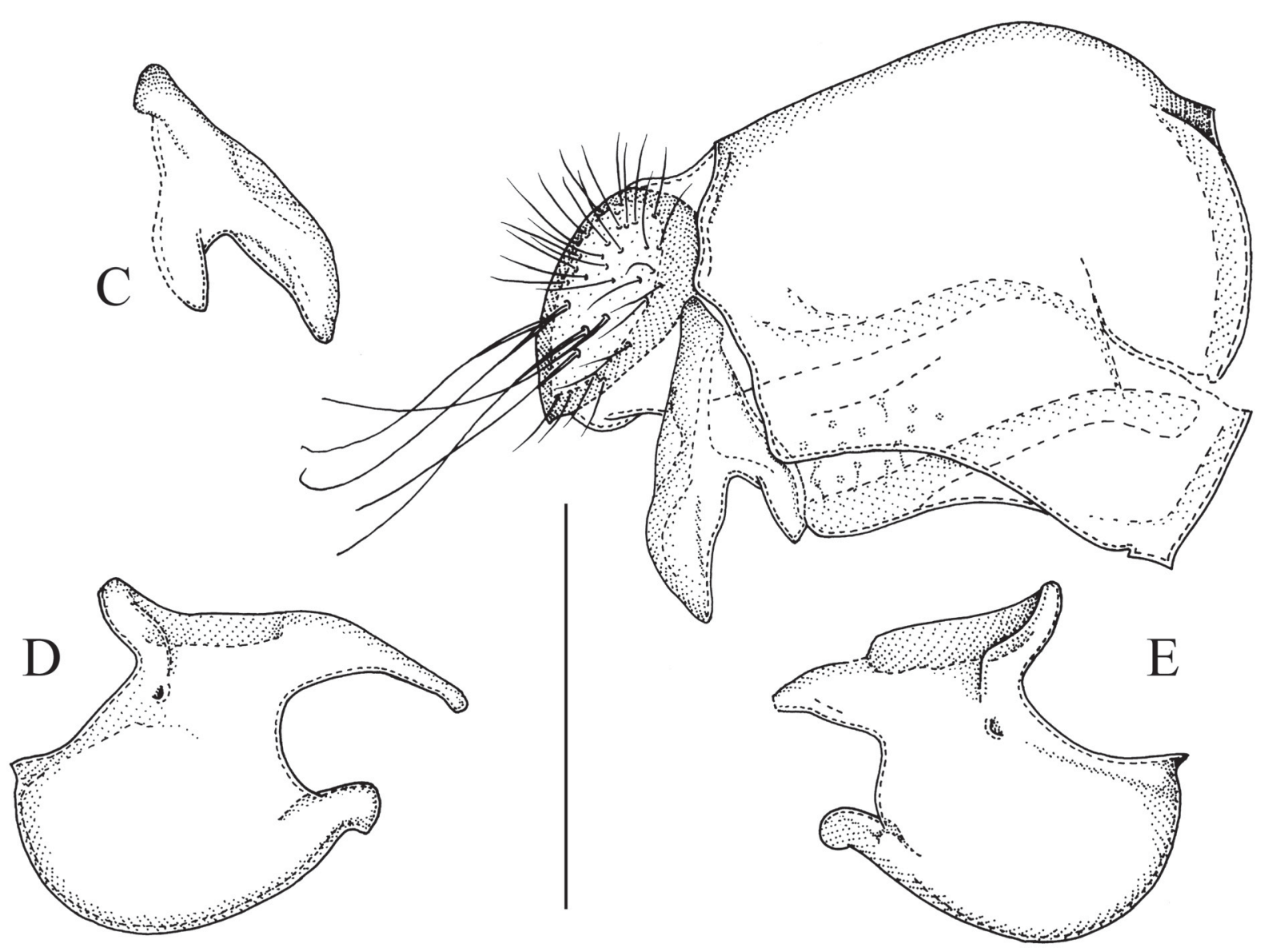

Fig. 39. Sphegina (Asiosphegina) granditarsis sp. nov., holotype, đ̂. A. Posterior part of sternum IV, ventral view. B. Aedeagus, right side lateral view. C. Left surstylus, lateral view. D. Sternum IX and superior lobe, left side lateral view. E. Genitalia right side lateral view. Scale bars $=0.5 \mathrm{~mm}$. 


\section{Material examined}

\section{Holotype}

CHINA • O’; "South China / Guandong Prov. / Chebaling; / [leg.] A. Lelej; 21 VI 1990”; NBC.

\section{Description}

\section{Male}

LeNGTH. Body 6.6-7.0 mm, wing 5.2-5.8 mm.

HEAD. Face in lateral view concave, strongly projected antero-ventrally; frontal prominence strongly developed. Ratio width of vertex at anterior ocellus: width of head 1: 5.3; ratio width of ocellar triangle: width of vertex 1: 1.6; ratio length of ocellar triangle: length of frons 1: 2.0. Face black, ventral half yellow; light grey pollinose, long pilose along eye-margin. Hypostomal bridge dark yellow, long pale pilose. Gena and mouth edge yellow with large subtriangular non-pollinose shiny area. Frons and vertex black, slightly pollinose, a narrow subtriangular area posterior of lunula non-pollinose and shiny (Fig. 38H); pile short, light yellow. Frons with deep pit anteromedially and wide but weak medial furrow. Occiput black, light grey pollinose, light yellow pilose. Eye without enlarged facets at anterior margin. Antenna dark yellow to brown with black setae dorsally on scape and pedicel; basoflagellomere elongate, ratio width: length 1: 1.7; arista long pilose, about 2 times as long as basoflagellomere.

THORAX. Colour black, postpronotum and dorso-medial part of anepisternum and anepimeron yellow; weakly greyish pollinose, pleuron entirely more heavily grey pollinose; scutum and pleuron with very short adpressed light yellow pile. Scutellum semicircular, black, shiny, with pile slightly longer than on scutum, with two widely set, very short setae medially at posterior margin, ratio length of scutellum: length of seta 1: 0.7 .

WING. Entirely microtrichose; hyaline, stigma yellowish, membrane brown infuscated at junction of veins $\mathrm{R}_{2+3}$ and $\mathrm{R}_{4+5}$, along veins bm-cu, $\mathrm{r}-\mathrm{m}, \mathrm{M}_{1}$ and on the wing apex. Crossvein dm-cu meeting vein $\mathrm{M}$ perpendicularly and vein $\mathrm{M}_{1}$ meeting vein $\mathrm{R}_{4+5}$ perpendicularly.

LeGs. Proleg yellow, tarsomere 1 black on apical half and tarsomeres 2-5 entirely black; protarsus, Fig. 61B, enlarged and flattened, ratio apical width of tibia: width of tarsomere $21: 1.8$; basitarsomere about as long as combined length of tarsomeres 2 and 3. Metaleg with coxa black, trochanter yellow; femur black with basal 1/5 yellow, slightly incrassate and club shaped, ratio width: length 1: 5.3 , anteroventrally with long white pile, pile almost twice as long as black setae; tibia black and yellow biannulate, without apicoventral dens; tarsus entirely black, basitarsomere thick, ratio width: length 1: 3.1 .

ABDOMEN. Length ratio of terga I: II: III: IV 1: 2.9: 2.0: 1.5; ratio width at posterior margin: medial length of tergum II and III 1: 3.0 and 1: 1.4. Terga black, anterior $1 / 5$ of tergum III with yellow fascia; pile pale, on terga short, laterally on terga I and II long; tergum I with 2 widely separated, strong, light yellow setae at lateral margin; sternum III not sclerotized; sternum IV, Fig. 39A; sterna VI, VII and VIII simple, with long yellow pile. Genitalia, Fig. 39B-E: note the very long setose pile on cercus, symmetrical surstyli and superior lobes and the small setae on the membrane between the ventral margin of tergum IX and the gonostylar apodemes.

\section{Female}

Unknown. 


\section{Sphegina (Asiosphegina) hamulata sp. nov. urn:1sid:zoobank.org:act:27D750EC-4C1C-4D05-B742-F34748CBE9ED}

Figs 38I, 40, 41D

\section{Differential diagnosis}

Sphegina (Asiosphegina) hamulata sp. nov. is not especially similar to any other known Sphegina and is easily distinguished by the characters mentioned in the key. It resembles a number of those species which have strong setae posteriorly on male sternum IV, but the setae are all pale (in the other species at least a number of them are black). In addition, the sternum is almost symmetrical (distinctly asymmetrical), except for the submembranous flange posteriorly from the setae which is situated on the left side. The asymmetrical surstyli with the right-side one wider than the left-side one occur commonly in this group. The narrow hook-shaped left surstylus is unique.

\section{Etymology}

The specific epithet is from the Latin 'hamulata', meaning 'with a little hook' and referring to the posteriorly hooked right side surstylus.

\section{Material examined}

\section{Holotype}

INDIA • O'; "India, W.B. [West Bengal] / Rangiroon 6500' [ft] / 24.V 1962 / [leg] Gupta"; "Ghorpade / Collector / Bangalore"; USNM.

\section{Description}

\section{Male}

Length. Body $6.0 \mathrm{~mm}$, wing $4.6 \mathrm{~mm}$.

HEAD. Face in lateral view concave, weakly projected antero-ventrally; frontal prominence weakly developed. Ratio width of vertex at anterior ocellus: width of head 1:3.8; ratio width of ocellar triangle: width of vertex 1: 2.2; ratio length of ocellar triangle: length of frons 1: 2.2. Face black, light grey pollinose long pilose along eye-margin. Hypostomal bridge black, long pale pilose. Gena and mouth edge black with large subtriangular non-pollinose shiny area. Frons and vertex black, slightly pollinose, a semi-circular area posterior of lunula non-pollinose and shiny (Fig. 38I); pile short, light yellow. Frons with deep pit anteromedially and wide but weak medial furrow. Occiput black, light grey pollinose, light yellow pilose. Eye without enlarged facets at anterior margin. Antenna with scape and pedicel black, basoflagellomere dark brown, with black setae dorsally on scape and pedicel; basoflagellomere oval, ratio width: length 1: 1.1; arista long pilose, about 2.5 times as long as basoflagellomere.

THORAX. Colour black, weakly greyish pollinose, pleuron entirely more heavily grey pollinose; scutum and pleuron with very short adpressed light yellow pile. Scutellum crescent-shaped, black, grey pollinose, with pile slightly longer than on scutum, with two closely set, short setae, as long as length of scutellum.

WING. Entirely microtrichose; hyaline, stigma yellowish. Crossvein dm-cu meeting vein M obliquely and vein $M_{1}$ meeting vein $R_{4+5}$ perpendicularly.

LeGs. Pro- and mesoleg yellow, protarsus entirely black, mesotarsus with tarsomere 2 brown and tarsomeres 3-5 black. Metaleg with coxa black, trochanter yellow; femur black with basal $1 / 3$ yellow, slightly incrassate, ratio width: length 1: 4.2; tibia black and yellow biannulate, with short rounded apicoventral dens; tarsus entirely black, basitarsomere rather thin, ratio width: length 1: 3.8 .

AвDOMEN. Length ratio of terga I: II: III: IV 1: 3.7: 2.1: 1.8; ratio width at posterior margin: medial length of tergum II and III 1: 4.3 and 1: 1.1. Terga black, anterior $1 / 4$ of tergum III with yellow fascia; pile 
pale, on terga short, laterally on terga I and II long; tergum I with 2 widely separated strong light-brown setae at lateral margin; sternum III squarish, ratio width: length 1: 1.5; sternum IV, Fig. 40A; sterna VI, VII and VIII simple, with long yellow pile. Genitalia, Fig. 40B-D: note the asymmetrical surstyli and superior lobes.

\section{Female}

\section{Unknown.}
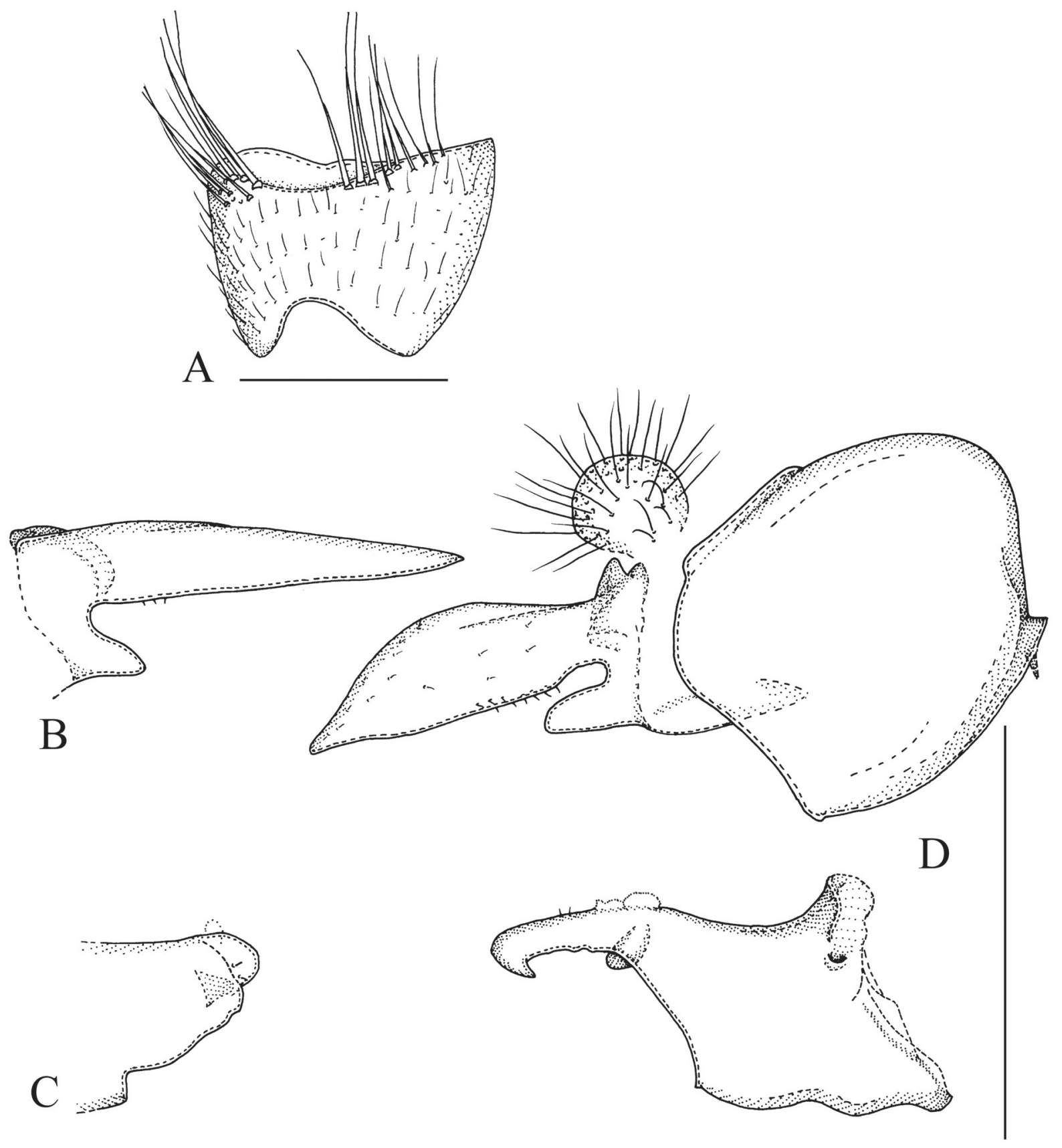

Fig. 40. Sphegina (Asiosphegina) hamulata sp. nov., holotype, §̊. A. Sternum IV, ventro-lateral view. B. Left surstylus, lateral view. C. Left superior lobe and associated parts, lateral view. D. Genitalia, right side, lateral view. Scale bars $=0.5 \mathrm{~mm}$. 
Sphegina (Asiosphegina) hansoni Thompson, 1966

Figs 38J, 41E, 42, 52A

Sphegina hansoni Thompson, 1966: 42. Type locality: Parewavir, Nepal (holotype, §, USNM).

\section{Differential diagnosis}

Sphegina (Asiosphegina) hansoni resembles other Sphegina with strongly asymmetrical male sternum IV posteriorly armed with strong black setae, but is easily distinguished by the characters given in the key. The carinate metatrochanter is a more unique character which it shares only with Sphegina (Asiosphegina) carinata, $S$. (A.) malaisei and $S$. (A.) ornata sp. nov. In the male genitalia, the almost symmetrical surstyli is a unique character within this group of species.

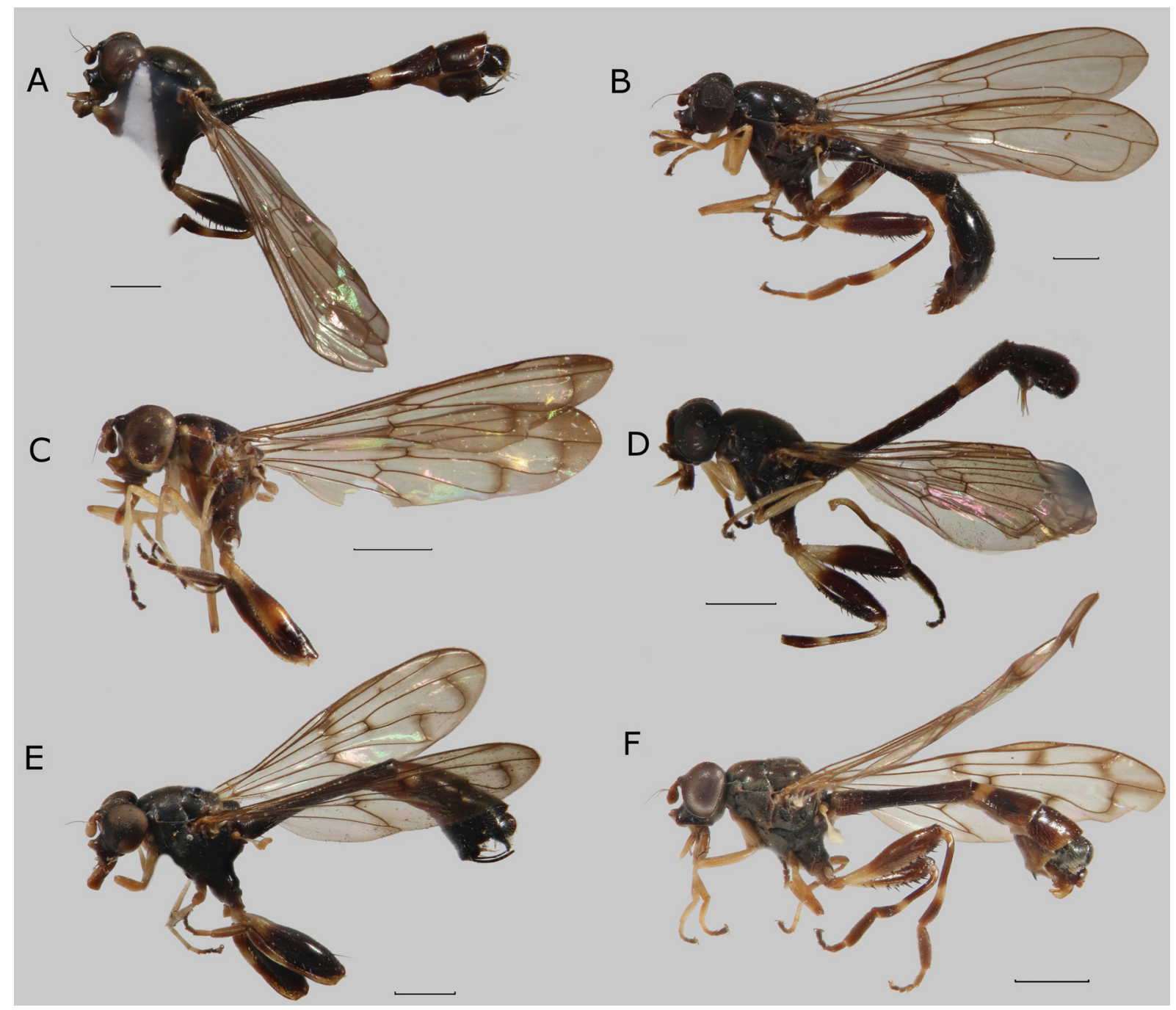

Fig. 41. Habitus, lateral view. A. Sphegina (Asiosphegina) gigantea sp. nov., holotype, đ, China. B. S. (A.) gigas Hippa, van Steenis \& Mutin, 2015, paratype, 9 , Myanmar. C. S. (A.) granditarsis sp. nov., paratype, Õ, Thailand. D. S. (A.) hamulata sp. nov., holotype, Ô, India. E. S. (A.) hansoni Thompson, 1966, holotype, ठ̊, Nepal, Malaysia. F. S. (A.) hauseri sp. nov., paratype, ठ̃, Nepal. Scale bars $=1.0 \mathrm{~mm}$. 


\section{Material examined}

Holotype

NEPAL • \'; Sphegina hansoni: "Parewavir Nepal / elev. III. 26.1957 / leg. Edward I. Coher G. P. Joshi”; "holotype / Sphegina / hansoni / Thompson "64" [faded red label]; genitalia on slide in Canada balsam, tergum IX and cerci lost; USNM.

\section{Redescription}

\section{Male}

LENGTH. Body $7.1 \mathrm{~mm}$, wing $5.9 \mathrm{~mm}$.

HEAD. Face in lateral view concave, very strongly projected antero-ventrally; frontal prominence strongly developed. Ratio width of vertex at anterior ocellus: width of head 1:3.8; ratio width of ocellar triangle: width of vertex 1: 2.3; ratio length of ocellar triangle: length of frons 1: 3.3. Face black; light grey pollinose, long pilose along eye-margin. Hypostomal bridge black, long pale pilose. Gena and mouth edge black with large subtriangular non-pollinose shiny area. Frons and vertex black; grey pollinose, a narrow area posterior of lunula yellow, non-pollinose and shiny (Fig. 38J); pile short, light yellow. Frons with deep pit antero-medially and wide furrow medially. Occiput black, light grey pollinose, light yellow pilose. Eye without enlarged facets at anterior margin. Antenna with scape and pedicel brownyellow, basoflagellomere yellow, with black setae dorsally on scape and pedicel; basoflagellomere oval, ratio width: length 1: 1.3; arista long pilose, nearly 3.5 times as long as basoflagellomere.

THORAX. Colour dark brown to black, scutum with dense grey-brown pollinosity and pleuron with slight grey pollinosity, sub-shiny; scutum and pleuron with very short adpressed light yellow pile. Scutellum semicircular, black, slightly grey pollinose sub-shiny, with pile slightly longer than on scutum, with two widely set, very short setae medially at posterior margin, ratio length of scutellum: length of seta 1:0.7.

WING. Entirely microtrichose; hyaline, stigma yellowish, membrane brown infuscated at junction of veins $R_{2+3}$ and $R_{4+5}$, along veins bm-cu, r-m and $M_{1}$. Crossvein dm-cu meeting vein $M$ perpendicularly and vein $M_{1}$ meeting vein $R_{4+5}$ perpendicularly.

LeGs. Pro- and mesoleg yellow, tarsomeres 3-5 black. Metaleg, Fig. 52A, with coxa black, trochanter yellow with dark brown transverse carina; femur black with basal $1 / 4$ yellow, slightly incrassate, ratio width: length 1: 4.4; tibia black and yellow biannulate without apicoventral dens; tarsus entirely brownyellow to dark brown, basitarsomere thin, ratio width: length 1: 4.5 .

AвDOMEN. Length ratio of terga I: II: III: IV 1: 4.2: 2.4: 1.5; ratio width at posterior margin: medial length of tergum II and III 1: 5.1 and 1: 1.0. Terga black, anterior $1 / 3$ of tergum III with brown-yellow fascia; pile pale, on terga short, laterally on terga I and II long; tergum I with row of 3 strong black setae at lateral margin; sternum III rectangular, ratio width: length 1: 1.5; sternum IV, Fig. 42B; sterna VI, VII and VIII with long yellow pile, sternum VII with elongate light yellow pilose finger-like tubercle anteriorly. Genitalia, Fig. 42F (the hypandrium is on the slide with the left side up and the right-side superior lobe is drawn by focusing the microscope to that side): note the almost symmetrical surstyli and the asymmetrical superior lobes.

\section{Female}

Unknown. 

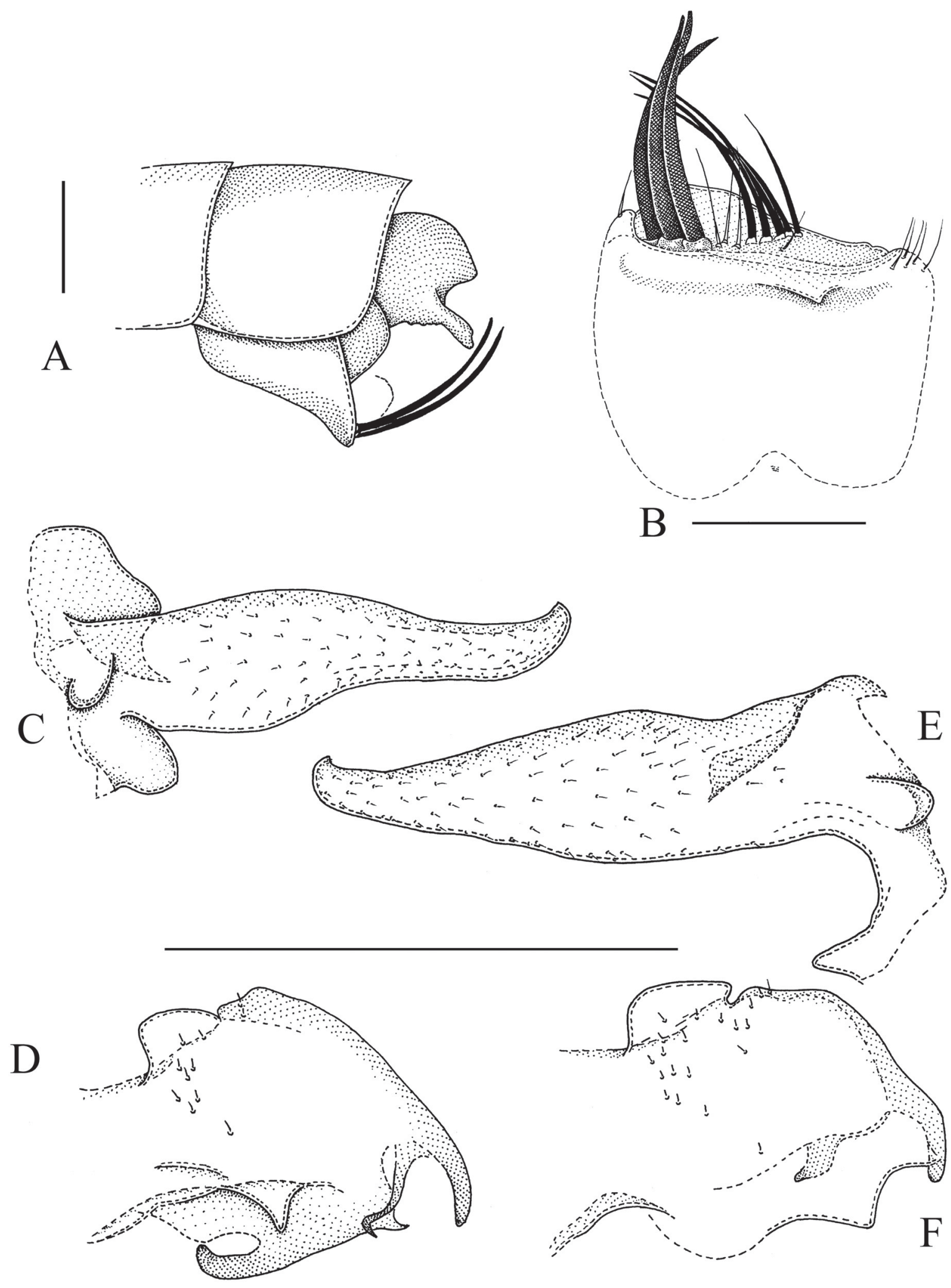

$\mathrm{B}$

Fig. 42. Sphegina (Asiosphegina) hansoni Thompson, 1966, holotype, đ̂. A. Posterior part of abdomen, left side lateral view. B. Sternum IV, ventral view. C-F. Genitalia. C. Left surstylus, lateral view. D. Right superior lobe, lateral view, focused in microscope from left side. E. Right surstylus, lateral view. F. Left superior lobe, lateral view. Scale bars $=0.5 \mathrm{~mm}$. 
Sphegina (Asiosphegina) hauseri sp. nov. urn:1sid:zoobank.org:act:6D61A95A-E548-41FC-8282-569D50970BE0

Figs $38 \mathrm{~K}-\mathrm{L}, 41 \mathrm{~F}, 43 \mathrm{C}, 44,50 \mathrm{~A}$

\section{Differential diagnosis}

Sphegina (Asiosphegina) hauseri sp. nov. resembles those other Sphegina which have a strongly asymmetrical male sternum IV posteriorly armed with many strong black setae, but is easily distinguished by the characters given in the key. Among these species the male genitalia of $S$. (A.) hauseri sp. nov. are unique in having the curved surstylus expanded on apical half.

\section{Etymology}

The species is named after Dr. Martin Hauser who provided the type material.

\section{Material examined}

\section{Holotype}

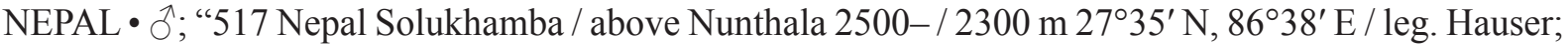
13.V.[19]97"; CSCA.

\section{Paratypes}

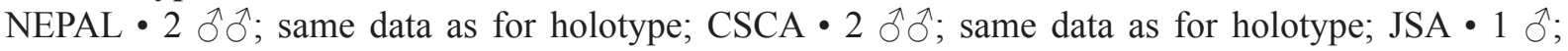

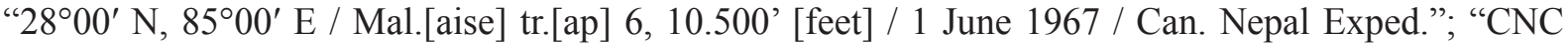
Diptera / \# 143325" [white label with blue border]; CNC • 1 क; same data as for preceding; "Mal. tr. 7 9900' / 21-27 May 1967”; “CNC Diptera / \# 143327”; JSA • 1 \&; “ “2756' N, 8500' E / Mal.[aise] tr.

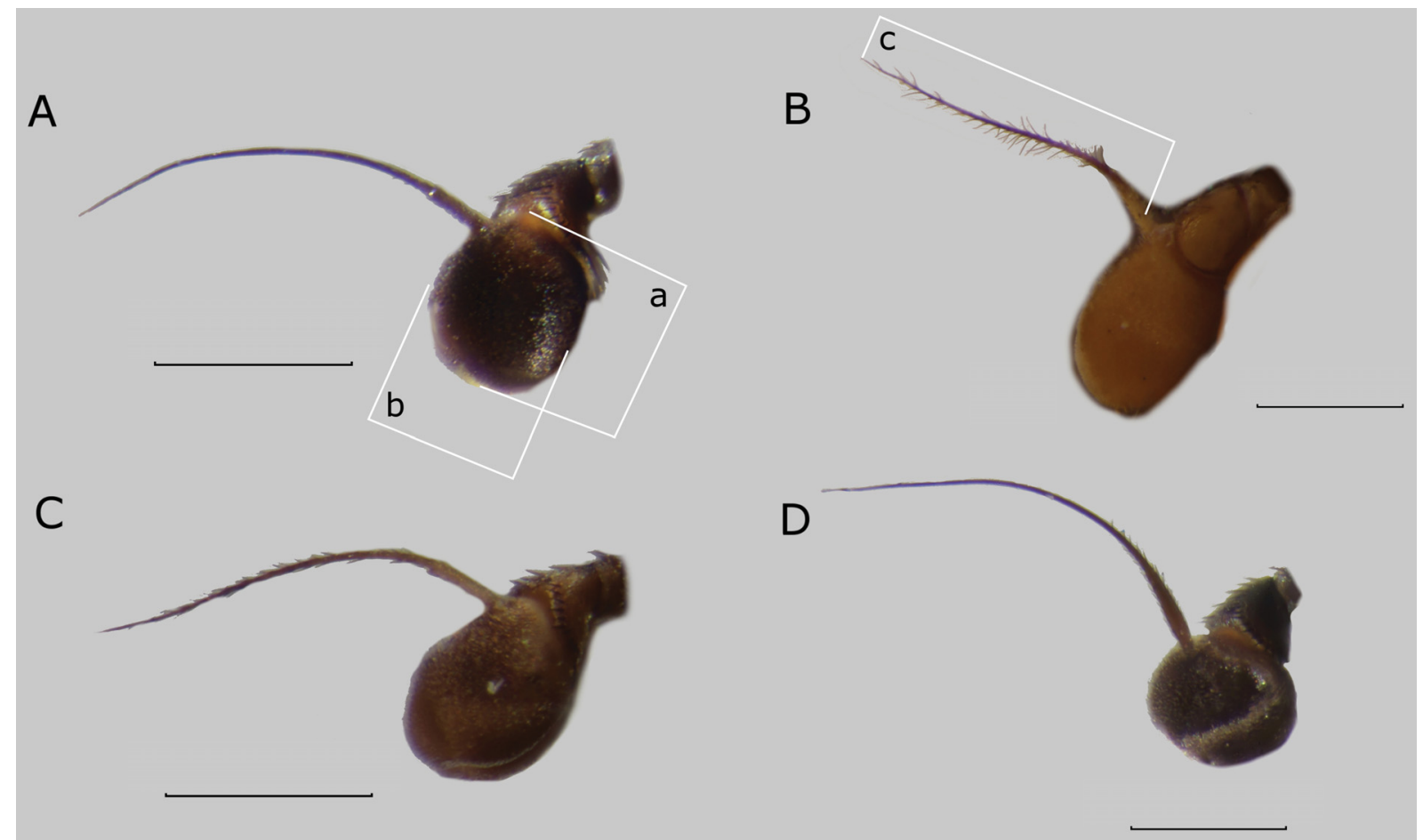

Fig. 43. Basoflagellomere, lateral view. A. Sphegina (Asiosphegina) dentata sp. nov., paratype, Ô, Taiwan. B. S. (A.) distincta sp. nov., paratype, ภ̂, Vietnam. C. S. (A.) hauseri sp. nov., paratype, ô, Nepal. D. S. (A.) tricoloripes Brunetti, 1915, ㅇ, India. Abbreviations: a = length of basoflagellomere; $\mathrm{b}=$ width of basoflagellomere; $\mathrm{c}=$ length of arista. Scale bars $0.25 \mathrm{~mm}$. 
[ap] 8, 10.100' [feet] / 28 May 1967 / Can. Nepal Exped."; "CNC Diptera / \# 143326” [white label with blue border]; CNC.

\section{Description}

\section{Male}

LENGTH. Body 5.8-6.5 mm, wing 4.9-5.4 mm.

HEAD. Face in lateral view (Fig. 38K) concave, strongly projected antero-ventrally; frontal prominence weakly developed. Ratio width of vertex at anterior ocellus: width of head 1:3.4-3.6; ratio width of ocellar triangle: width of vertex 1: 2.3-2.4; ratio length of ocellar triangle: length of frons 1: 2.2-2.4.

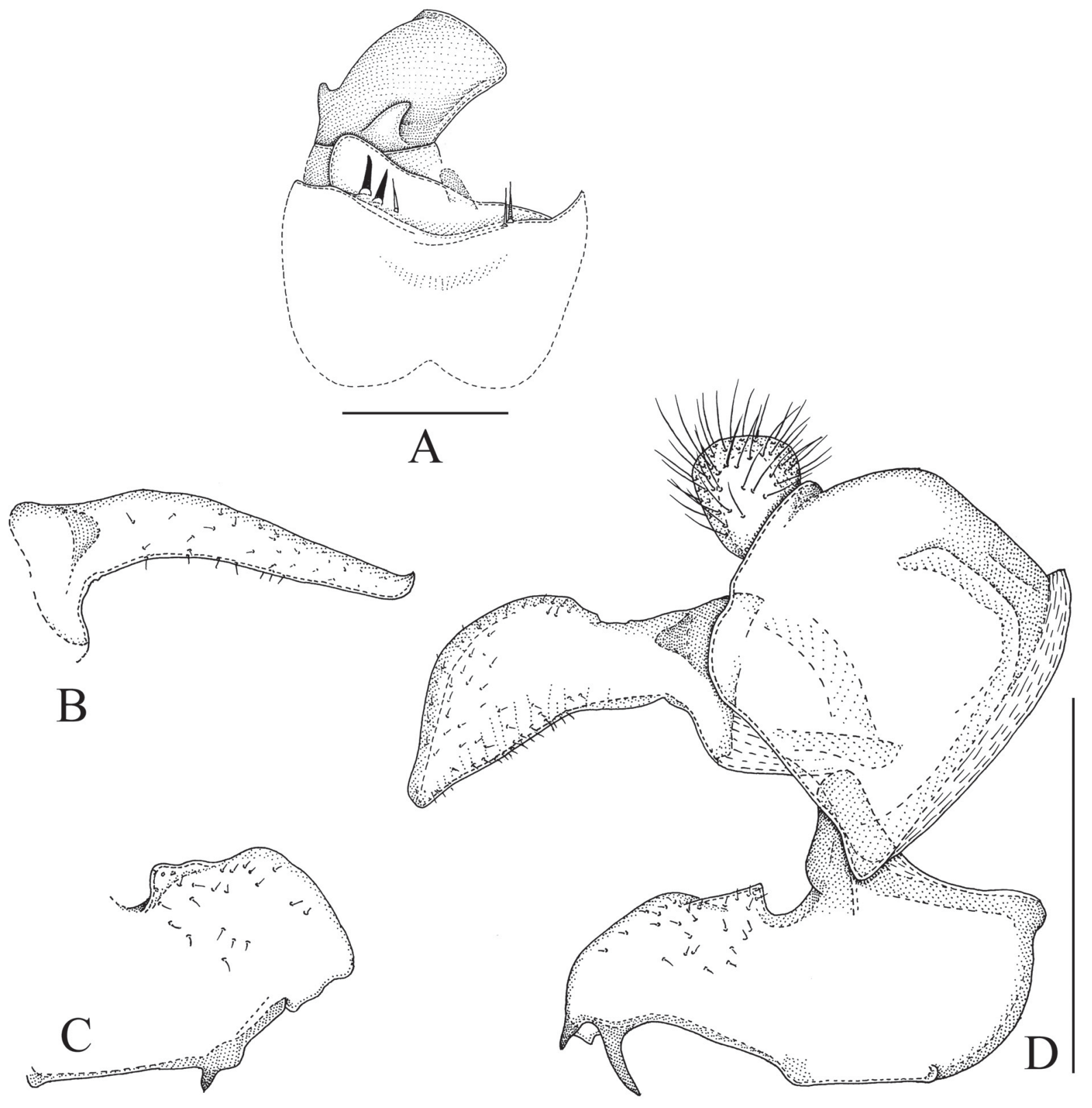

Fig. 44. Sphegina (Asiosphegina) hauseri sp. nov., holotype, $\widehat{\jmath}$. A. Sterna IV, VI and VII, ventral view. B. Left surstylus, lateral view. C. Left superior lobe, lateral view. D. Genitalia, right side lateral view. Scale bars $=0.5 \mathrm{~mm}$. 
Face black, light grey pollinose, long pilose along eye-margin. Hypostomal bridge black, long pale pilose. Gena and mouth edge black with large subtriangular non-pollinose shiny area. Frons and vertex black, slightly pale pollinose, a narrow semi-circular area posterior of lunula non-pollinose and shiny (Fig. 38L); pile short, light yellow. Frons with deep wide pit antero-medially. Occiput black, light grey pollinose, light yellow pilose. Eye without enlarged facets at anterior margin. Antenna dark yellow to brown with black setae dorsally on scape and pedicel; basoflagellomere, Fig. 43C, short oval, ratio width: length 1: 1.3-1.4; arista rather long pilose, about 3 times as long as basoflagellomere.

THORAX. Colour black, postalar callus brown-yellow; weakly greyish pollinose, pleuron entirely grey pollinose; scutum and pleuron with very short adpressed light yellow pile. Scutellum subtriangular, brown-yellow, shiny, with pile slightly longer than on scutum, with two closely set short setae medially at posterior margin, ratio length of scutellum: length of seta 1: 0.8-1.2.

WING. Entirely microtrichose; hyaline, stigma yellowish, membrane brown infuscated at junction of veins $R_{2+3}$ and $R_{4+5}$, along veins bm-cu, $r-m, d m-c u, M_{1}$, appendices of vein $R_{2+3}$ and apical part of vein $R_{4+5}$. Crossvein dm-cu meeting vein $M$ perpendicularly and vein $M_{1}$ meeting vein $R_{4+5}$ perpendicularly. Short appendices at medial part of vein $R_{2+3}$ and at apical part of vein $R_{2+3}$.

LeGs. Pro and mesoleg yellow, tarsomeres 4 and 5 dark brown, in some specimens tarsomere 3 light brown. Metaleg with coxa black, trochanter yellow; femur black with basal $1 / 4-1 / 3$ yellow, slightly incrassate and club shaped, ratio width: length 1: 4.8-5.0; tibia black and yellow biannulate without apicoventral dens; tarsus entirely black, basitarsomere rather narrow, ratio width: length 1: 3.8-4.2.

ABDOMEN. Length ratio of terga I: II: III: IV 1: 2.7-2.9: 1.9-2.2: 1.3-1.5; ratio width at posterior margin: medial length of tergum II and III 1: 3.5-3.7 and 1: 1.0-1.1. Terga black, anterior $1 / 3$ of tergum III with yellow sub-anterior fascia and posterior dark brown fascia; tergum IV with posterior dark brown fascia; pile pale, on terga short, laterally on terga I and II long; tergum I with 2 widely separated strong black setae at lateral margin; sternum III rectangular with sharply concave posterior margin, ratio width: length 1: 1.6-1.9; sternum IV, Fig. 44A; sterna VI, VII and VIII with long yellow pile, sternum VII anteriorly with a narrow sharp-tipped process. Genitalia, Fig. 44B-D: note the asymmetrical surstyli and superior lobes and the subbasal conical lobe on the medial side of both surstyli.

\section{Female}

Similar to male except for the usual sexual dimorphism.

LENGTH. Body 5.6-6.2 mm, wing 5.2-5.8 mm.

HEAD. Ratio width of vertex at anterior ocellus: width of head 1:2.9-3.2; ratio width of ocellar triangle: width of vertex 1: 2.4-2.6; ratio length of ocellar triangle: length of frons 1: 2.2-2.4. Basoflagellomere short oval, ratio width: length 1: 1.2-1.4; arista long pilose, about 3 times as long as basoflagellomere.

Thorax. Scutum submedially with dense brown-grey pollinosity. Scutellum with two closely set, very short setae medially at posterior margin, ratio length of scutellum: length of seta 1: 0.42-0.86.

LEGS. Metafemur with basal third yellow, ratio width: length 1: 4.7-5.2; metatarsus with basitarsomere rather thin, ratio width: length $1: 3.8-4.1$.

AвDomen. Length ratio of terga I: II: III: IV: V 1: 3.3-3.8: 2.5-2.9: 1.9-2.3: 0.4-0.6; ratio width at posterior margin: medial length of tergum II and III $1: 2.4-2.8$ and 1: $0.7-0.8$. Tergum II medially with oval yellow macula and posteriorly with brown-yellow fascia; tergum III with yellow fascia on anterior $2 / 5$; tergum IV with posterior $3 / 4$ brown-yellow; tergum $V$ predominantly brown-yellow; tergum VI with 
posteromedial membranous cleft; sternum III rectangular, ratio width: length 1: 2.1-2.4; sternum IV trapezoidal with anterior part narrower and posterior margin slightly concave, ratio width: length 1 : 0.6-0.7; sternum $\mathrm{V}$ rectangular with convex posterior margin, ratio width: length 1: 0.7-0.9.

\section{Sphegina (Asiosphegina) incretonigra sp. nov.}

urn:1sid:zoobank.org:act:60F79E70-AE6A-443B-B23E-CEF39EC5D3A8

Figs 45A, 46, 54A, 61C

\section{Differential diagnosis}

Similar to Sphegina (Asiosphegina) atrimanus sp. nov., S. (A.) granditarsis sp. nov., S. (A.) nasuta and $S$. (A.) nigrotarsata sp. nov. For distinguishing characters, see under $S$. (A.) atrimanus sp. nov. and $S$. (A.) granditarsis sp. nov.

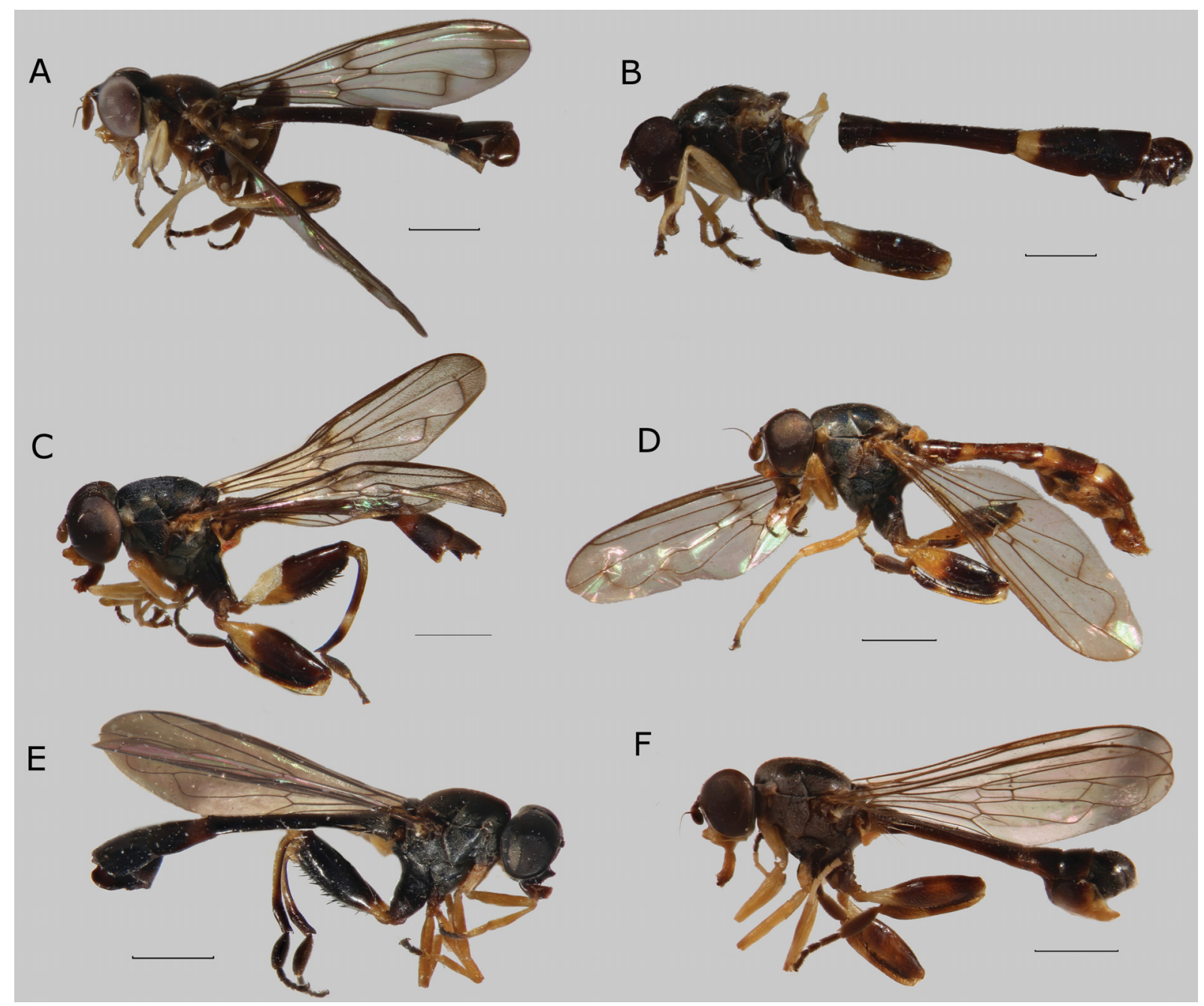

Fig. 45. Habitus, lateral view. A. Sphegina (Asiosphegina) incretonigra sp. nov., holotype, $\hat{o}$, Vietnam. B. S. (A.) index Hippa, van Steenis \& Mutin, 2015, holotype, Ô, Myanmar. C. S. (A.) inflata sp. nov., holotype, Ỏ, Philippines. D. S. (A.) cf. inflata sp. nov., + , Philippines. E. S. (A.) inventum sp. nov., holotype, Ô, Sabah, Malaysia. F. S. (A.) javana de Meijere, 1914, lectotype ô, Java, Indonesia. Scale bars $=1.0 \mathrm{~mm}$. 


\section{Etymology}

The specific epithet is from the Latin 'incretonigra', meaning 'chalk-white and black' and referring to the protarsus which is chalk-white on the basal segments and black on the apical segments.

\section{Material examined}

\section{Holotype}

VIETNAM • đ’; "S. Vietnam: Lam Dong / Bidoup Nuiba N.P., nr Da Lat / Mal.[aise] trap 13-18; 1600 1650 m / 12-19.x.2005 [leg] C. v. Achter- / berg \& R. de Vries, RMNH ‘05”; NBC.

\section{Description}

\section{Male}

LeNGTH. Body $6.2 \mathrm{~mm}$, wing $4.8 \mathrm{~mm}$.

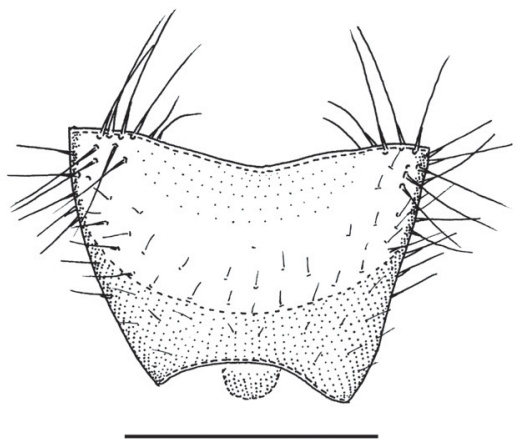

A
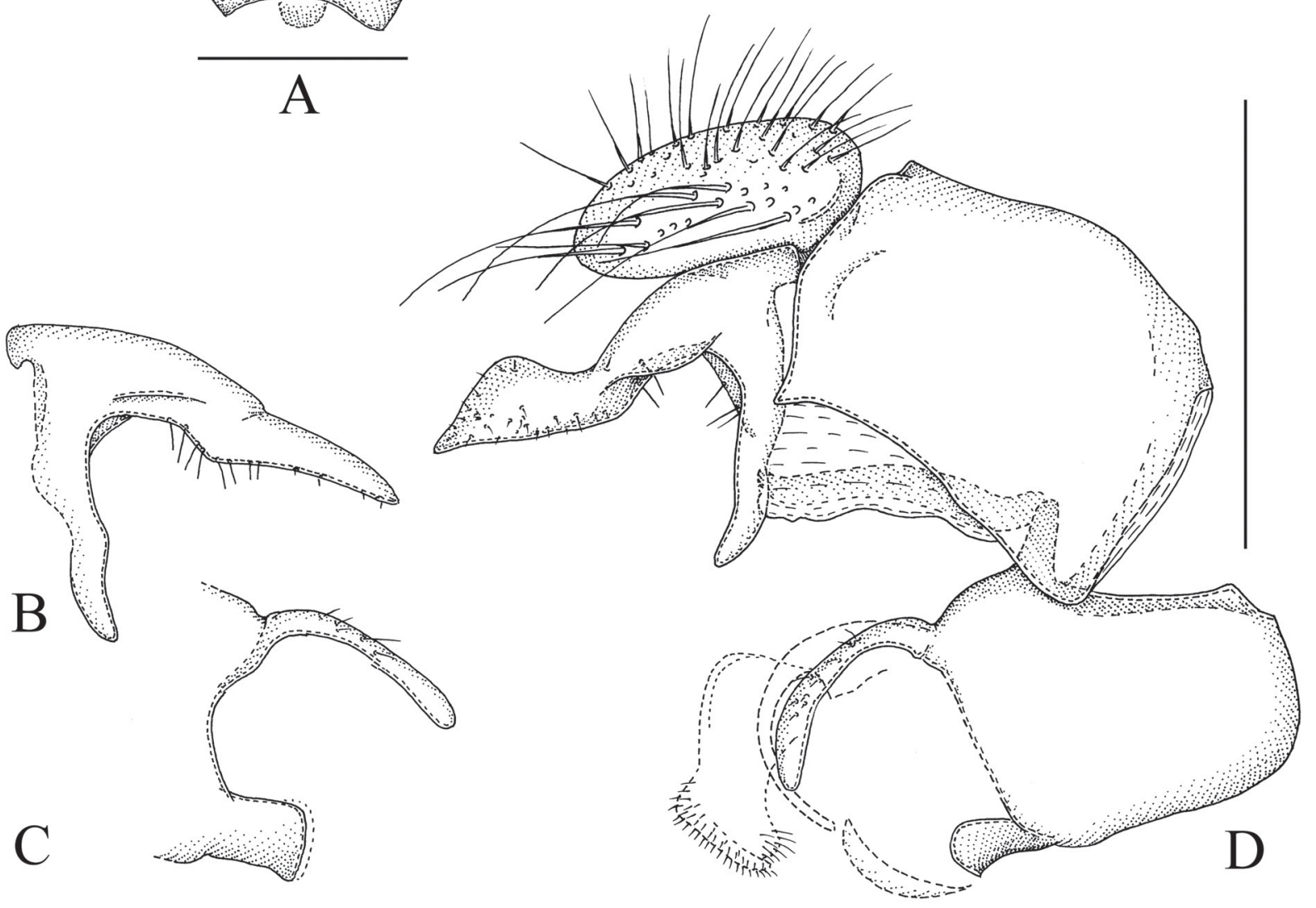

Fig. 46. Sphegina (Asiosphegina) incretonigra sp. nov., holotype, $\delta^{\lambda}$. A. Sternum IV, ventral view. B. Left surstylus, lateral view. C. Superior lobe with associated parts, left side, lateral view. D. Genitalia, right side lateral view. Scale bars $=0.5 \mathrm{~mm}$. 
HEAD. Face in lateral view concave, strongly projected antero-ventrally; frontal prominence strongly developed. Ratio width of vertex at anterior ocellus: width of head 1: 5.2; ratio width of ocellar triangle: width of vertex 1: 1.7. Face black, ventral half yellow; light grey pollinose, long pilose along eye-margin. Hypostomal bridge yellow, long pale pilose. Gena and mouth edge yellow with large subtriangular non-pollinose shiny area. Frons and vertex black; frons largely shiny, non-pollinose except for narrow subtriangular grey pollinose macula at eye-margin (Fig. 54A); vertex sub-shiny, slightly pollinose; pile short, light yellow. Frons without medial furrow. Occiput black, light grey pollinose, light yellow pilose. Eye without enlarged facets at anterior margin. Antenna yellow with black setae dorsally on scape and pedicel; basoflagellomere elongate, ratio width: length 1: 1.8; arista pilose, about 2 times as long as basoflagellomere.

Thorax. Colour black; postpronotum, post-alar callus and dorso-medial part of anepisternum and anepimeron brown-yellow; weakly greyish pollinose, pleuron entirely more heavily grey pollinose; scutum and pleuron with very short adpressed light yellow pile. Scutellum sub-triangular, black, entirely shiny, with pile slightly longer than on scutum, with two widely set very short setae medially at posterior margin, ratio length of scutellum: length of seta 1: 0.9 .

WING. Entirely microtrichose; hyaline, stigma yellowish, membrane brown infuscated at junction of veins $\mathrm{R}_{2+3}$ and $\mathrm{R}_{4+5}$, along vein $\mathrm{dm}-\mathrm{cu}, \mathrm{r}-\mathrm{m}$ and apical part from vein $\mathrm{M}_{1}$. Crossvein dm-cu meeting vein $M$ perpendicularly and vein $M_{1}$ meeting vein $R_{4+5}$ perpendicularly.

Legs. Pro- and mesoleg yellow, tarsomeres 4 and 5 black, tarsomere 3 of protarsus on apical half black. Protarsus, Fig. 61C, enlarged and flattened, ratio apical width of tibia: width of tarsomere 2 1: 1.3; basitarsomere about as long as combined length of tarsomeres 2 and 3, tarsomere 2 almost 1.5 times as long as tarsomere 3. Metaleg with coxa black, trochanter yellow; femur black and yellow biannulate, slightly incrassate and club shaped, ratio width: length 1: 5.1; tibia brown to light-brown, without apicoventral dens; tarsus entirely black; basitarsomere thick, ratio width: length 1:3.1.

ABDOMEN. Length ratio of terga I: II: III: IV 1: 2.9: 2.2: 1.7; ratio width at posterior margin: medial length of tergum II and III 1: 3.9 and 1: 1.8. Terga black, anterior $1 / 3$ of tergum III and anterior $1 / 6$ of tergum IV with yellow fascia; pile pale, on terga short, laterally on terga I and II long; tergum I with 2 widely separated, strong, light yellow setae at lateral margin; sternum III rectangular, ratio width: length 1: 3.4; sternum IV, Fig. 46A; sterna VI, VII and VIII simple, with long yellow pile. Genitalia, Fig. 46B-D: note the long setose pile on cercus and the nearly symmetrical surstyli and superior lobes; the membrane between the lateral margin of tergum IX and the surstylar apodemes bears inconspicuous small setae similar to, e.g., Sphegina (Asiosphegina) orientalis.

\section{Female}

Unknown.

\section{Distribution and biology}

The specimen was collected in a Malaise trap in the Bidoup Nuiba National Park near Da Lat. The Malaise trap was set up in an area of undisturbed primary montane forest on rather steep slopes. The forest is rather isolated and protected. (C. van Achterberg, pers. comm). 
Sphegina (Asiosphegina) index Hippa, van Steenis \& Mutin, 2015

Figs 45B, 50B, 52B

Sphegina (Asiosphegina) index Hippa, van Steenis \& Mutin, 2015: 19. Type locality: Kambaiti, Myanmar (holotype, $\widehat{O}$, NHRS).

\section{Material examined}

CHINA • 1 O; "Fukien, S. China / Shaowu: Tachulan / 1000 m. T. Maa"; "25-30.IV.1943”; BPBM.

MYANMAR • 1 \%; "N.E. Burma / Kambaiti 7000 ft / 26-5-1934 [leg] Malaise"; "Paratype $q$ / Sphegina (Asiosphegina) / malaisei Hippa, / van Steenis \& Mutin, 2015” [red label]; JSA.

THAILAND • 1 q; “Thailand, Chiang Mai / Doi Inthanon NP / checkpoint $21700 \mathrm{~m} / 18^{\circ} 31.559^{\prime} \mathrm{N}$, 98²9.941' E / 26.X-2.XI.2006 Malaise trap / Y. Areeluck leg. T 383"; QSBG • 1 क ; "Thailand, Chiang

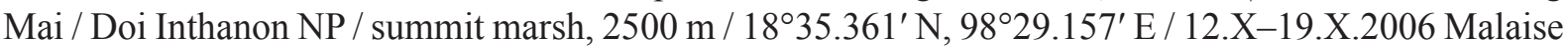
Trap / Y. Areeluck leg. T 368"; JSA.

VIETNAM • 1 o, 1 क; "NW VIETNAM: Tonkin / Hoang Lien N.P., 15 km, / W Sa Pa c. 1900 m / 15-21.X.1999 Malaise traps / [leg] C. v. Achterberg, RMNH '99"; NBC • 1 क; same data as for preceding; JSA • 1 q; "NW Vietnam (Ton Kin) / Sin Chay / 15-21.X.1999 / 1900 mtr. Mal. Trap / C. van Achterberg"; JSA.

\section{Description}

\section{Female}

LeNGTH. Body 6.0-6.9 mm, wing 4.8-5.5 mm

HEAD. Face in lateral view concave, strongly projected antero-ventrally; frontal prominence weakly developed. Ratio width of vertex at anterior ocellus: width of head 1: 2.9-3.3; ratio width of ocellar triangle: width of vertex 1: 2.5-2.9; ratio length of ocellar triangle: length of frons 1: 2.8-3.2. Face black; grey pollinose, long pilose along eye-margin. Hypostomal bridge black, long pale pilose. Gena and mouth edge dark brown to black with large subtriangular non-pollinose shiny area. Frons and vertex black, slightly pollinose, a rectangular non-pollinose and shiny area posterior of lunula; pile short, light yellow. Frons with wide circular pit and wide furrow medially. Occiput black, light grey pollinose, light yellow pilose. Antenna dark brown with black setae dorsally on scape and pedicel; basoflagellomere long-oval, ratio width: length 1: 1.5-1.6; arista long pilose, about 2.5 times as long as basoflagellomere.

THORAX. Colour black, postpronotum light yellow; weakly grey pollinose, pleuron entirely more heavily grey pollinose; scutum and pleuron with very short adpressed light yellow pile. Scutellum subtriangular, black, shiny, only slightly pollinose, with pile slightly longer than on scutum, with two closely set, long setae medially at posterior margin, ratio length of scutellum: length of seta 1: 1.9-2.3.

WING. Entirely microtrichose; hyaline, stigma yellowish, crossveins brown infuscated. Crossvein dm-cu meeting vein $M$ perpendicularly and vein $\mathrm{M}_{1}$ meeting vein $\mathrm{R}_{4+5}$ perpendicularly.

Legs. Pro- and mesoleg yellow, tarsomeres 4 and 5 black. Metaleg, Fig. 52B, with coxa dark brown, trochanter yellow; femur black with basal $1 / 3$ yellow, slightly incrassate and basally curved, with a long black seta anterodorsally near apex, ratio width: length 1: 5.0-5.4; tibia black and yellow biannulate, without apicoventral dens; tarsus entirely black, first tarsomere thin, ratio width: length 1: 3.2-3.4.

ABDomen. Length ratio of terga I: II: III: IV: V 1: 2.7-3.0: 2.3-2.6: 1.5-1.8: 0.6-0.7; ratio width at posterior margin: medial length of tergum II and III 1: 2.5-2.9 and 1: 0.8-0.9. Terga black, tergum II 
with anterior dark-orange fascia; tergum III with orange-yellow macula latero-medially; terga III and IV dark-orange; pile of terga short, light yellow; tergum I with one anterolateral strong black seta; sternum III rectangular, ratio width: length 1: 1.3-1.5; sternum IV rectangular, ratio width: length 1: 0.6-0.7 and sternum $\mathrm{V}$ squarish with convex posterior margin, width: length 1: 1.0-1.1.

\section{Distribution and biology}

Known from Myanmar, SE China, Thailand and Vietnam. A montane (1700-2500 m) species apparently with two flight periods: mid-May and from mid-October to early November. In Myanmar it was collected in a cloud forest with streams and swampy areas at an altitude of $2000 \mathrm{~m}$. The specimen from Vietnam was collected in a Malaise trap near the Tram Ton Pass, the highest mountain pass in Vietnam (1900 m), near Fan Si Pan mountain. The Malaise trap had been set up in an area of montane forest disturbed by grazing buffaloes, containing muddy areas and small streams. Despite the cold and wet weather insects were rather abundantly flying (C. van Achterberg, pers. comm).

\section{Remarks}

The species was previously known only by the holotype from Myanmar, Kambaiti (Hippa et al. 2015). One of the female paratypes of Sphegina (Asiosphegina) malaisei turned out to be the hitherto undescribed female of $S$. (A.) index. This particular specimen has very faintly infuscated wing and a slightly darkened ventral side of the metatrochanter giving a false impression of a carina.

Sphegina (Asiosphegina) inflata sp. nov. urn:1sid:zoobank.org:act:5B6FF03A-F176-4590-A3E5-945346141D62

Figs 45C-D, 48, 50C, 52C, 54B

\section{Differential diagnosis}

Similar to Sphegina (Asiosphegina) amplistylus sp. nov., S. (A.) philippina and S. (A.) spathigera sp. nov. For distinguishing characters, see under $S$. (A.) philippina and $S$. (A.) spathigera sp. nov.

\section{Etymology}

The specific epithet is from the Latin 'inflata', meaning 'inflated' and referring to the inflated left-side surstylus.

\section{Material examined}

\section{Holotype}

PHILIPPINES • Оં; "P.I. Negros Or. / L. Balinsasayao / 1-7.X.1959”; "L.W. Quate / Collector”; "USNMENT / QR-code / 01224064"; "Paratype /Sphegina / philippina / Thompson" [yellow label]; USNM.

\section{Description}

Male

LeNGTH. Body $5.7 \mathrm{~mm}$, wing $4.3 \mathrm{~mm}$.

HEAD. Face in lateral view concave, weakly projected antero-ventrally; frontal prominence very weakly developed. Ratio width of vertex at anterior ocellus: width of head 1: 6.6; ratio width of ocellar triangle: width of vertex 1: 1.3; ratio length of ocellar triangle: length of frons 1: 2.7. Face black, ventral half yellow; light grey pollinose, long pilose along eye-margin. Hypostomal bridge dark yellow, long pale pilose. Gena and mouth edge yellow with large subtriangular non-pollinose shiny area. Frons and vertex black, slightly pollinose, a narrow subtriangular area posterior of lunula non-pollinose and shiny 
(Fig. 54B); pile short, light yellow. Frons with weak furrow medially. Occiput black, light grey pollinose, light yellow pilose. Eye with an area of enlarged facets at anterior margin. Antenna brown with black setae dorsally on scape and pedicel; basoflagellomere rectangular, ratio width: length 1: 1.4; arista long pilose, nearly 3 times as long as basoflagellomere.

THorax. Colour black, weakly greyish pollinose, postpronotum dark brown, densely grey pollinose; posterior margin of katepisternum narrowly non-pollinose, shiny; scutum and pleuron with very short adpressed light yellow pile. Scutellum short, widely sub-triangular, black, weakly pollinose, long pilose, with pile longer than on scutum, no longer marginal setae observable, it is possible the setae are broken off.

A
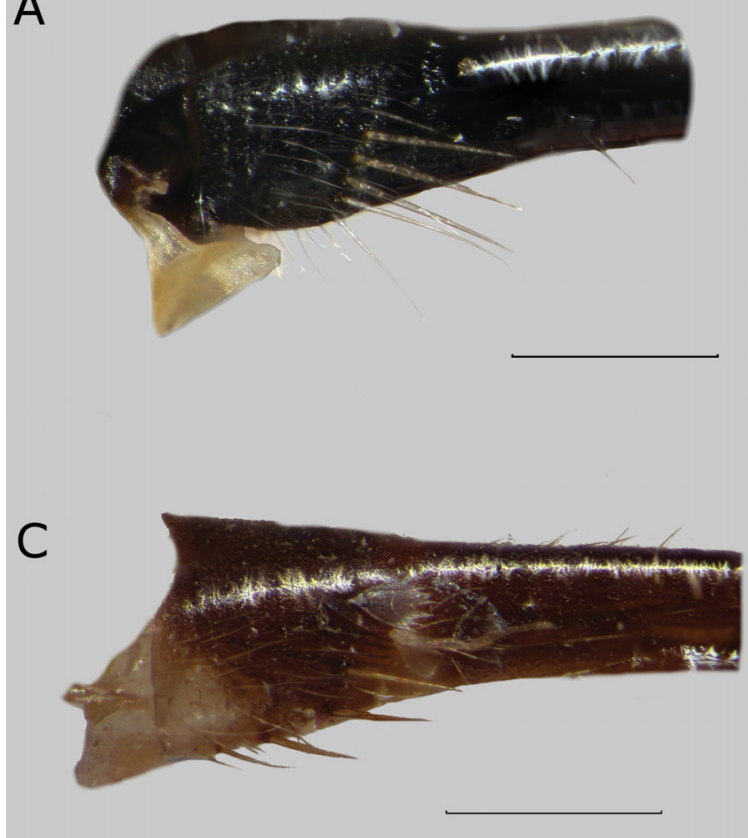

E

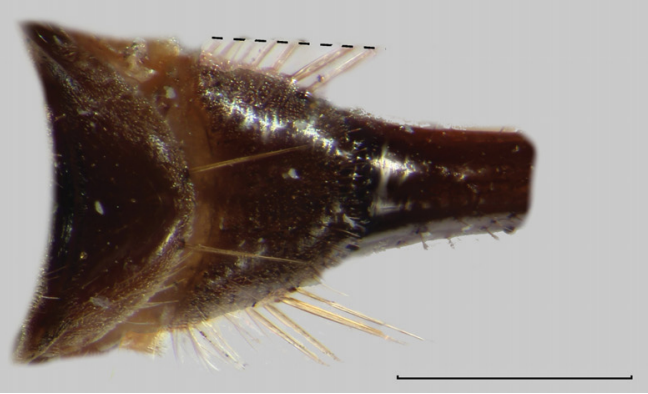

B

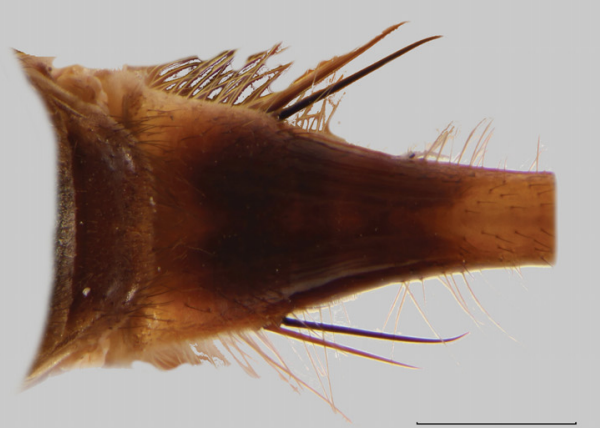

D

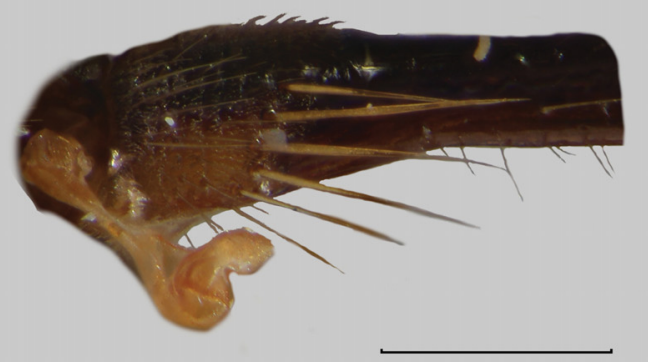

$\mathrm{F}$

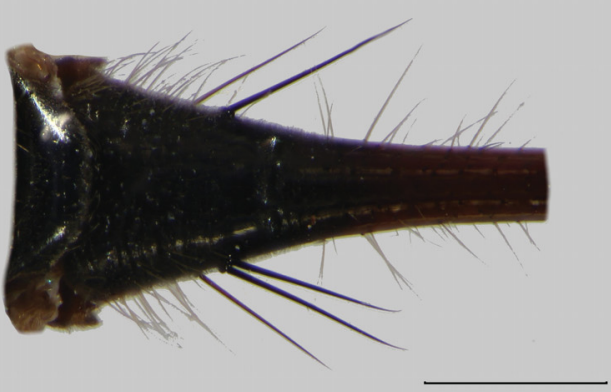

Fig. 47. Tergum I, lateral view (A, C-D) and dorsal view (B, E-F). A. Sphegina (Asiosphegina) dentata sp. nov., paratype, đ̃, Taiwan. B. S. (A.) distincta sp. nov., paratype, đ̃, Vietnam. C. S. (A.) falcata Hippa,

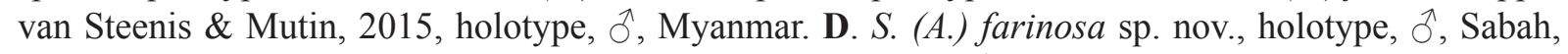
Malaysia. E. S. (A.) javana de Meijere, 1914, Paralectotype Õ, Java, Indonesia. F. S. (A.) lobulata sp. nov., paratype, $\sigma^{\lambda}$, Vietnam. Dotted line indicates unknown length of right sided setae, the right metaleg (erased in GIMP) obscured these setae. Scale bars $=0.5 \mathrm{~mm}$, 
WING. Entirely microtrichose; hyaline, stigma yellowish, membrane brown infuscated at junction of veins $R_{2+3}$ and $R_{4+5}$. Crossvein dm-cu almost perpendicular to vein $M$ and vein $M_{1}$ meeting vein $R_{4+5}$ perpendicularly.

LeGs. Pro- and mesoleg yellow, tarsomeres 4-5 black. Metaleg (as in Fig. 52C) with coxa black, trochanter yellow; femur black with basal $1 / 3$ yellow, strongly incrassate, ratio width: length 1: 3.3 ; tibia black and yellow biannulate with large rounded apicoventral dens; tarsus entirely black, basitarsomere thick, ratio width: length 1: 3.0 .

ABDOMEN. Length ratio of terga I: II: III: IV 1: 2.9: 1.5: 1.3; ratio width at posterior margin: medial length of tergum II and III 1: 2.9 and 1: 0.8 . Terga black, anterior $1 / 3$ of tergum III with dark brown squarish macula; pile pale, on terga short, laterally on terga I and II long; tergum I with horizontal row of 3 evenly spaced brown-yellow setae at lateral margin; sternum III not sclerotized; sternum IV, Fig. 48B; sterna
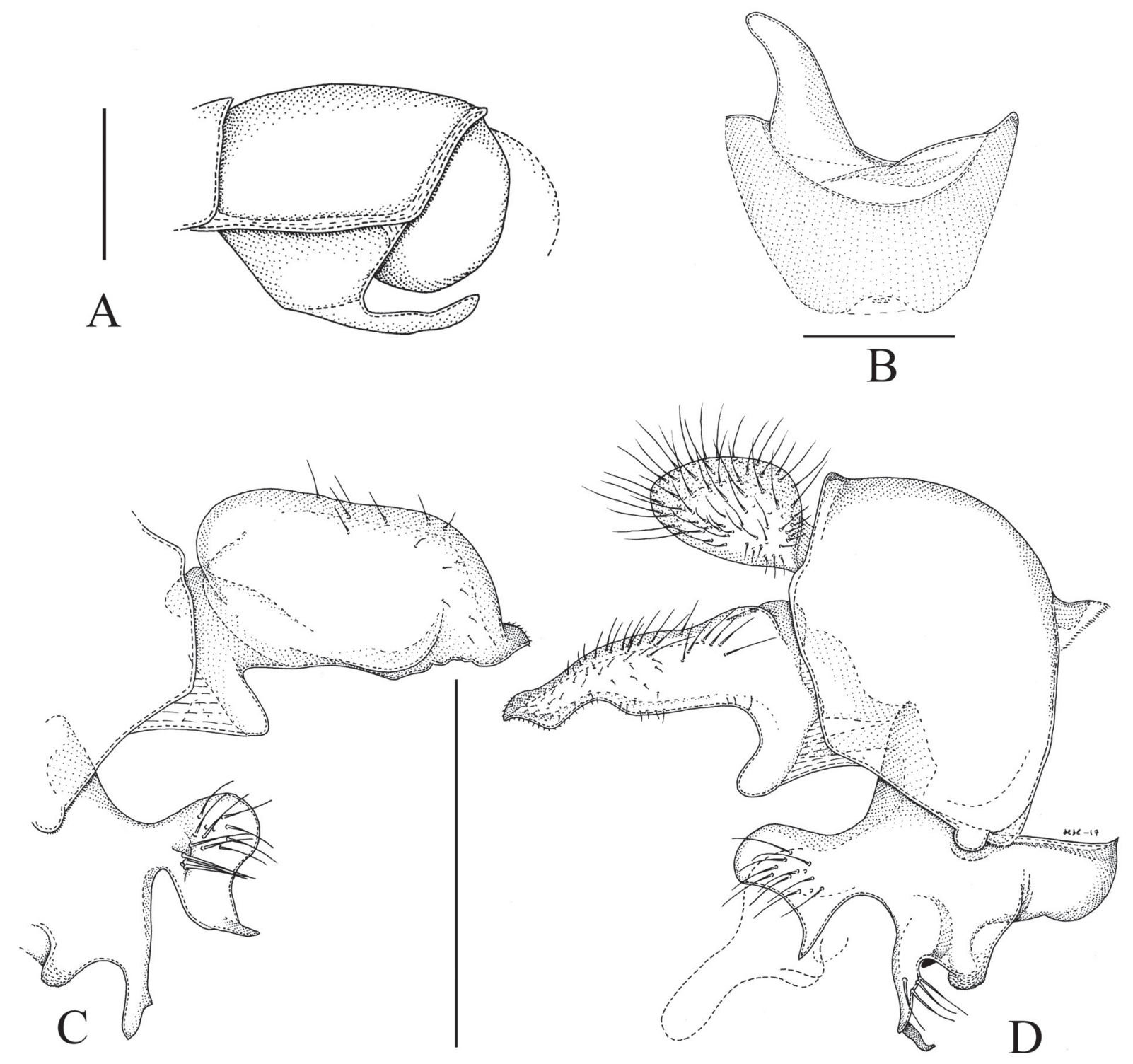

Fig. 48. Sphegina (Asiosphegina) inflata sp. nov., holotype, $\widehat{\jmath}$. A. Posterior part of abdomen, left side lateral view. B. Sternum IV, ventral view. C. Posterior part of genitalia, left side, lateral view. D. Genitalia right, side, lateral view. Scale bars $=0.5 \mathrm{~mm}$. 
VI, VII and VIII simple, with long yellow pile. Genitalia, Fig. 48C-D: note the asymmetrical surstyli and nearly symmetrical superior lobes.

\section{Female}

Unknown.

\section{Remarks}

In the type material of Sphegina (Asiosphegina) philippina there is a female ("P.I.: Luzon / Camarines Sur / Mt. Isarog, Pili / 800 m, 30.IV.1965", "H.M. Torrevillas / Collector / Bishop", coll BPBM, which cannot be $S$. (A.) philippina because its vertex is wider. This specimen is possibly the female of $S$. (A.) inflata sp. nov., but as even the males of these similar species are very difficult to distinguish from each other without reference to genitalia the identity of this female remains doubtful.

Sphegina (Asiosphegina) inventum sp. nov. urn:1sid:zoobank.org:act:D1F99D1E-296C-43CF-BEBF-6BF3036E772E

Figs 45E, 49, 50D, 52D, 54C

\section{Differential diagnosis}

Similar to Sphegina (Asiosphegina) bifida sp. nov. and S. (A.) collicola sp. nov. Except for the characters given in the key, the species is distinguished from $S$. (A.) bifida sp. nov. by having the male superior lobe on both sides wider (higher) than long instead of longer than wide; and from $S$. (A.) collicola sp. nov. by having the more posterior one of the ventral tooth-like projections on the right superior lobe lateral instead of marginal and by having the respective projection on the left side superior lobe large and sharp instead of small and rounded.

\section{Etymology}

The specific epithet inventum is composed of the Latin words 'in ventum', meaning 'under the wind'. It is a translation of the informal Malayan name of Sabah, 'Negeri Di Bawah Bayu', meaning 'land under the wind' and referring to the type locality of the species. The name is a noun in apposition.

\section{Material examined}

\section{Holotype}

INDONESIA • ○ં; “Sabah / Mt. Kinabalu / 5000 ft. / 1-5.v.1973 / [leg.] K.M. Guichard”; NHM.

\section{Description}

\section{Male}

LeNGTH. Body $6.1 \mathrm{~mm}$, wing $4.5 \mathrm{~mm}$.

HEAD. Face in lateral view concave, very weakly projected antero-ventrally; frontal prominence very weakly developed. Ratio width of vertex at anterior ocellus: width of head 1: 6.6; ratio width of ocellar triangle: width of vertex 1: 1.1; ratio length of ocellar triangle: length of frons 1: 2.1. Face black, light grey pollinose, long pilose along eye-margin. Hypostomal bridge black, long pale pilose. Gena and mouth edge black with large subtriangular non-pollinose shiny area. Frons and vertex black, velvet black pollinose, a narrow oval area posterior of lunula shiny and non-pollinose and 2 squarish anterolateral grey pollinose macula along eye-margin; pile short, light yellow. Frons with narrow and weak furrow medially. Occiput black, light grey pollinose, light yellow pilose. Eye without enlarged facets at anterior margin Antennae missing. 
THorax. Colour black, greyish pollinose, postpronotum dark yellow; posterior margin of katepisternum narrowly non-pollinose, shiny; scutum and pleuron with very short adpressed light yellow pile. Scutellum widely sub-triangular, black, greyish pollinose, with pile slightly longer than on scutum, without detectable longer setae at posterior margin, possibly the setae are broken off.

WING. Entirely microtrichose; hyaline, stigma yellowish. Crossvein dm-cu meeting vein M obliquely and vein $M_{1}$ meeting vein $R_{4+5}$ perpendicularly.

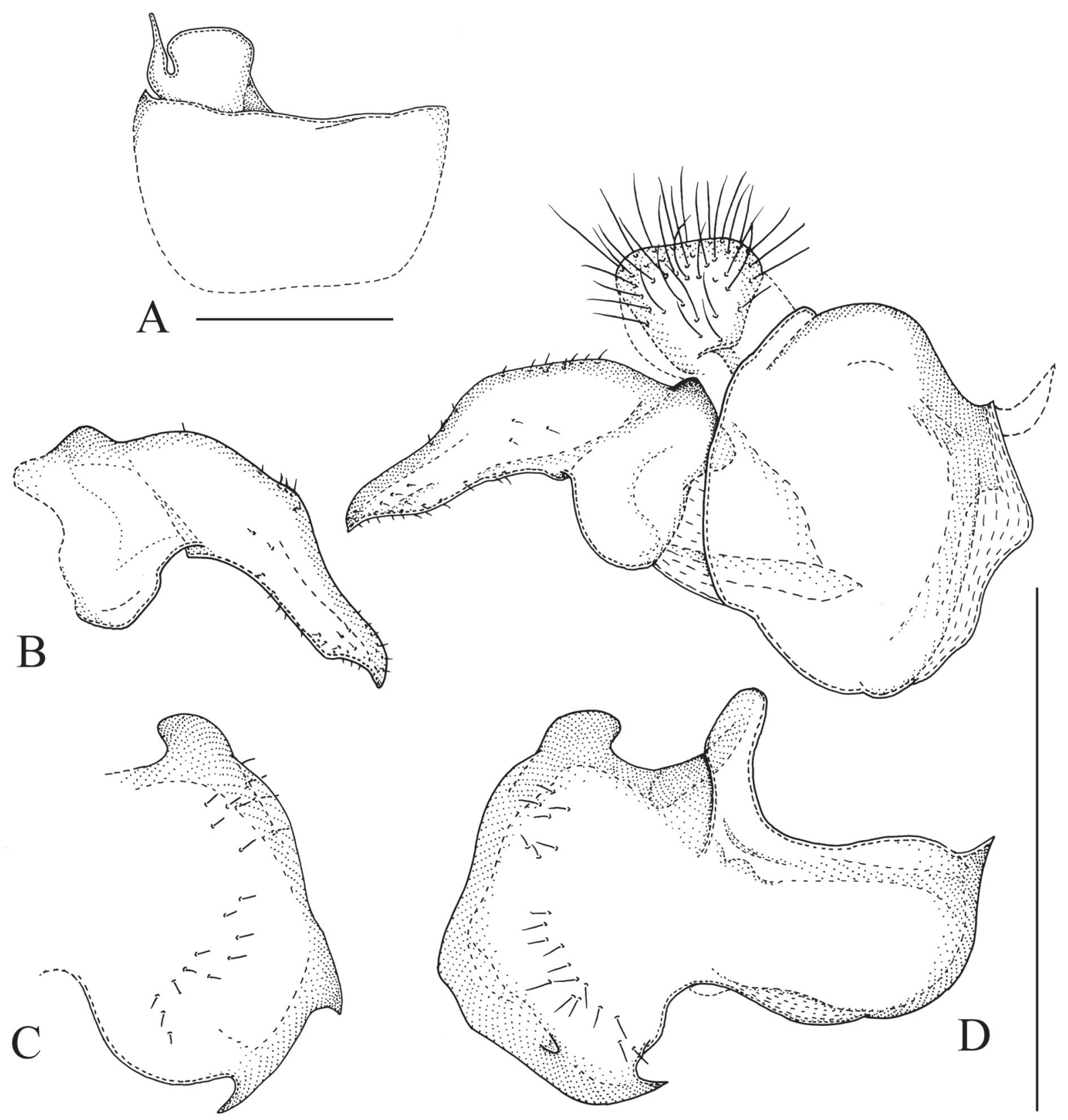

Fig. 49 Sphegina (Asiosphegina) inventum sp. nov., holotype, ふ̂. A. Sternum IV, ventral view. B. Left surstylus, lateral view. C. Left superior lobe, lateral view. D. Genitalia, right side, lateral view. Scale bars $=0.5 \mathrm{~mm}$. 
LeGs. Pro- and mesoleg yellow, with coxae black; protarsus with tarsomeres 2-5 black; mesotarsus with tarsomeres 3-5 black. Metaleg with coxa black, trochanter yellow; femur black with basal 1/5 yellow, incrassate, ratio width: length 1: 3.5; tibia yellow, apical $1 / 3$ black, with rounded apicoventral dens; tarsus entirely black, basitarsomere very thick, ratio width: length 1:2.6.

AвDOMEN. Length ratio of terga I: II: III: IV 1: 3.5: 1.6: 1.4; ratio width at posterior margin: medial length of tergum II and III 1: 5.0 and 1: 0.9. Terga black, anterior $1 / 3$ of tergum III with yellow medially widely interrupted fascia; pile pale, on terga short, laterally on terga I and II long; tergum I with 3 evenly separated strong yellow setae at lateral margin; sternum III not well sclerotized; sternum IV, Fig. 49A; sterna VI, VII and VIII with long yellow pile, sternum VI anteriorly with low and weakly rounded process. Genitalia, Fig. 49B-D: note the only slightly asymmetrical surstyli and superior lobes.

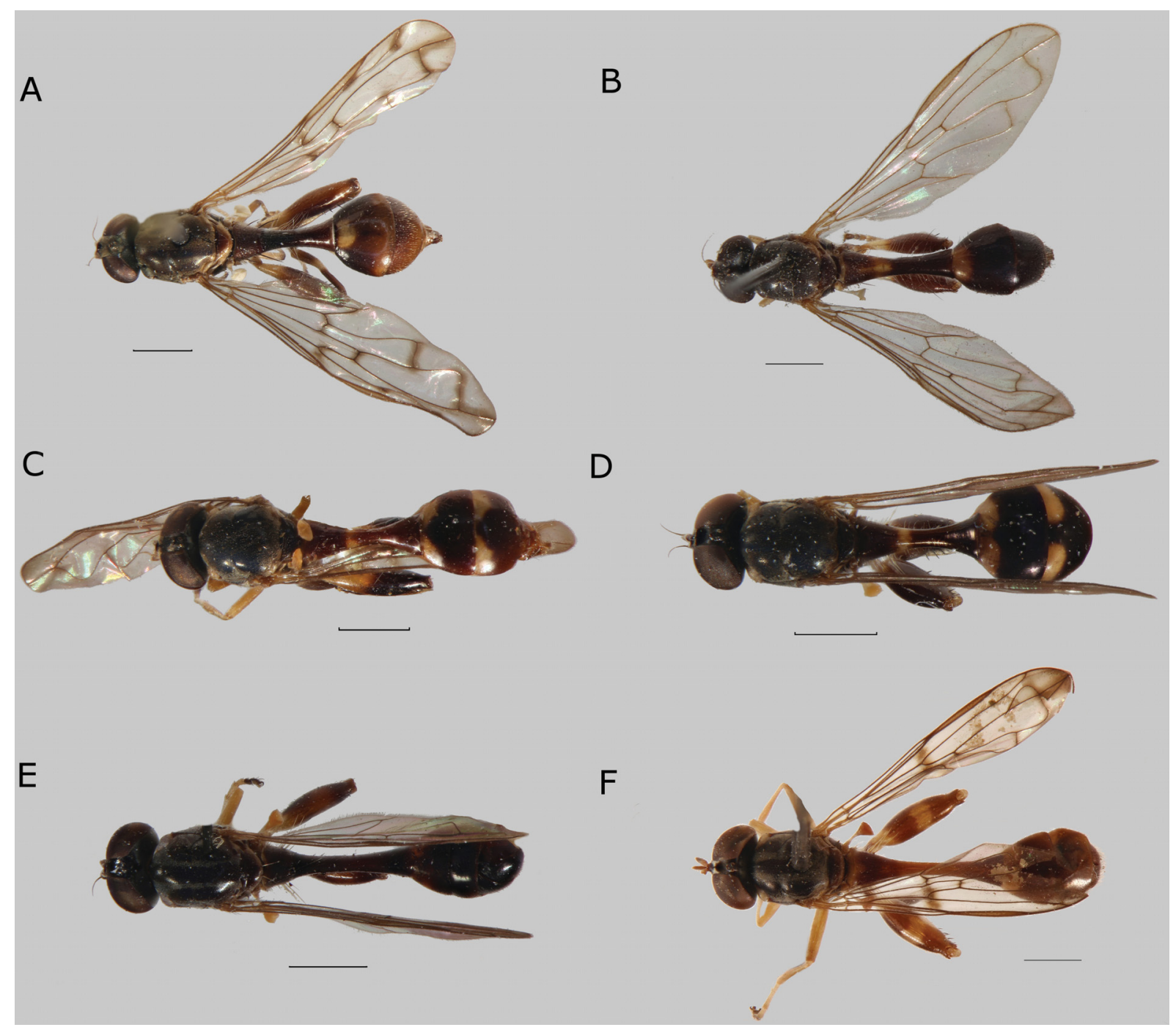

Fig. 50. Habitus, dorsal view. A. Sphegina (Asiosphegina) hauseri sp. nov., paratype, ${ }$, Nepal. B. S. (A.) index Hippa, van Steenis \& Mutin, 2015, , Myanmar. C. S. (A.) cf. inflata sp. nov., +, Philippines. D. S. (A.) inventum sp. nov., paratype, , Sabah, Malaysia. E. S. (A.) javana de Meijere, 1914, lectotype $\widehat{\partial}$, Java, Indonesia. F. S. (A.) karnataka sp. nov., paratype, $\widehat{\partial}$, India. Scale bars $=1.0 \mathrm{~mm}$. 


\section{Description}

\section{Female}

Similar to the male except normal sexual dimorphism and the following.

LENGTH. Body 5.2-5.6 mm, wing 3.9-4.2 mm.

HEAD. Ratio width of vertex at anterior ocellus: width of head 1: 4.9-5.1; ratio width of ocellar triangle: width of vertex 1: 1.6-1.8; ratio length of ocellar triangle: length of frons 1: 2.4-2.7 (Fig. 54C). Antenna dark brown; basoflagellomere slightly elongate, ratio width: length 1: 1.5-1.7; arista about 2.5 times as long as basoflagellomere.

THORAX. Scutellum semi-circular, rather long pilose.

WING. Crossvein dm-cu meeting vein M slightly oblique.

LEGs. Metafemur, Fig. 52D, slightly incrassate, ratio width: length 1: 3.5-3.6, yellow on basal 1/4; metatarsus with basitarsomere very thick, ratio width: length $1: 2.7-3.0$.

ABdomen. Length ratio of terga I: II: III: IV: V 1: 3.1-3.4: 2.1-2.3: 1.9-2.1: 1.0-1.2; ratio width at posterior margin: medial length of tergum II and III 1: 2.1-2.3 and 1: 0.6-0.7. Tergum I black with 2 or 3 strong yellow setae at lateral margin; tergum II with dark yellow fascia on antero-medial $1 / 3$; tergum III with yellow upturned V-shaped fascia on anterior $1 / 3-1 / 4$; tergum IV with oval lateral yellow macula on anterior $1 / 4$; tergum $\mathrm{V}$ with anterior half yellow and posterior half black; sternum III elongated, ratio width: length 1: 1.9-2.1; sternum IV rectangular with slightly concave posterior margin, ratio width: length 1: 0.8-0.9; sternum $\mathrm{V}$ oval with concave posterior margin, ratio width: length 1: 1.4-1.7.

\section{Distribution and biology}

Collected in a Malaise trap which stood in a partially disturbed primary forest along a tributary of the Ritan river close to Long Pa Sia village. The trap was placed on the river bank and was in full shade under the forest canopy (C. van Achterberg, pers. comm).

\section{Remarks}

The following females may belong to Sphegina (Asiosphegina) inventum sp. nov. based on the velvet black pollinosity on medial part of the frons, the yellow postpronotum, extensively yellow abdomen and relatively dark pro- and mesotarsus with respectively tarsomeres $2-5$ and 3-5 black (in the similar S. (A.) bifida sp. nov. the postpronotum is black; pro- and mesotarsus with tarsomeres 4 and 5 black; abdomen with narrow brown fascia on tergum III): 1 o , "Malaysia: Sabah: / $1 \mathrm{~km} \mathrm{~S}$. Kundasang / el 1530 m. 11 Sept. 1983 / G.F. Hevel \& W.E. Steiner" (BPBM); 1 + , "Malaysia-SW, Sabah / along Ritan river / c. 1170 m. 8-10.IV.1987 / Mal. trap 10, RMNH '87 / C. v. Achterberg" (NBC).

\section{Sphegina (Asiosphegina) javana de Meijere, 1914}

Figs 45F, 47E, 50E, 51, 52E

Sphegina javana de Meijere, 1914: 166. Type locality: Gunung Gedeh, Java, Indonesia (lectotype, Oૈ, $\mathrm{NBC}$ ).

\section{Differential diagnosis}

Sphegina (Asiosphegina) javana is similar to S. (A.) exilipes sp. nov. For distinguishing characters, see under the latter. 


\section{Material examined}

Lectotype (here designated)

JAVA - O’; "E. Jacobson / Goenoeng Gedeh / Java Maart 1911"; NBC.

Paralectotype (here designated)

JAVA $\bullet 1$ के; same data as for lectotype; NBC.

\section{Redescription}

\section{Male}

LenGth. Body 5.1-5.7 mm, wing 3.8-4.6 mm.
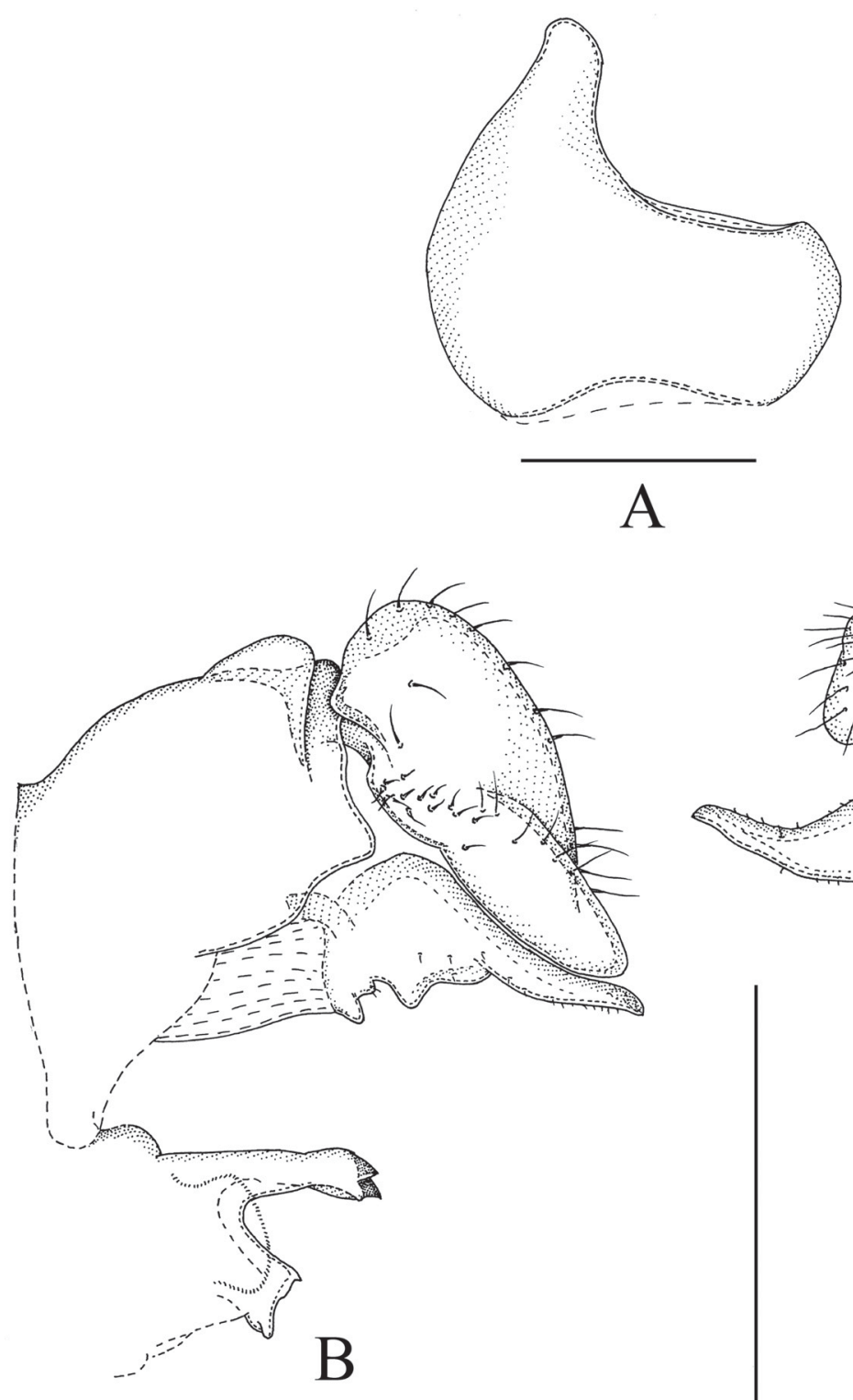

A

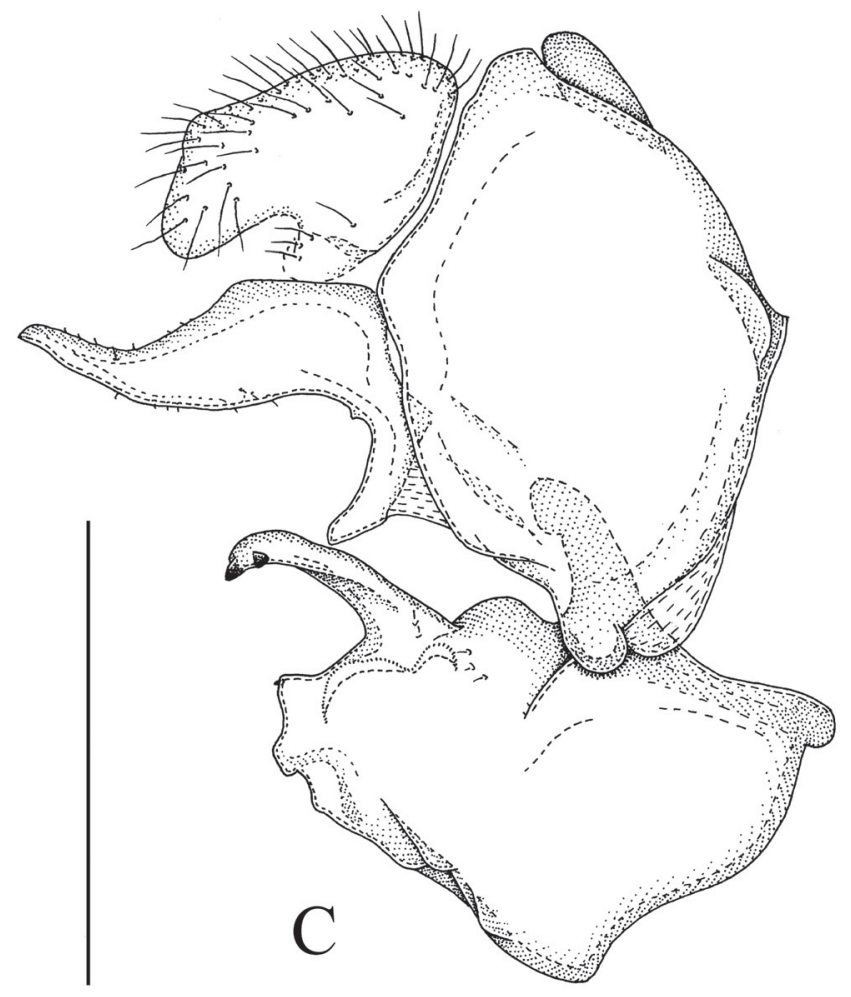

Fig. 51. Sphegina (Asiosphegina) javana de Meijere, 1914, paralectotype, $\widehat{\jmath}$. A. Sternum IV, ventral view. B. Genitalia left side, lateral view. C. Genitalia right side, lateral view. Scale bars $=0.5 \mathrm{~mm}$. 
HEAD. Face in lateral view concave, weakly projected antero-ventrally; frontal prominence weakly developed. Ratio width of vertex at anterior ocellus: width of head 1: 4.8-5.2; ratio width of ocellar triangle: width of vertex 1: 1.7-1.8; ratio length of ocellar triangle: length of frons 1: 2.2-2.4. Face yellow, light grey pollinose, long pilose along eye-margin. Hypostomal bridge yellow, long pale pilose. Gena and mouth edge yellow with large subtriangular non-pollinose shiny area. Frons and vertex black, sub-shiny, slightly grey pollinose, a circular area posterior of lunula non-pollinose and shiny and with narrow more densely grey pollinose fascia posterior of shiny part; pile short, light yellow. Frons with weak pit anteriorly and weak but wide furrow medially. Occiput black, light grey pollinose, light yellow pilose. Eye with enlarged facets at anterior margin. Antenna dark brown to black with black setae dorsally on scape and pedicel; basoflagellomere oval, ratio width: length 1:1.1-1.2; arista with basal 1/5 short pilose, about 3 times as long as basoflagellomere.

THorax. Colour dark brown to black, greyish pollinose; scutum with more densely grey pollinose vitta submedially (in lectotype vitta narrower and scutum otherwise less pollinose than in paralectotype); postpronotum brown-yellow; posterior margin of katepisternum narrowly non-pollinose, shiny; scutum and pleuron with very short adpressed light yellow pile. Scutellum semicircular, black, shiny, with pile slightly longer than on scutum, with two widely set, short setae medially at posterior margin, ratio length of scutellum: length of seta 1: 1.2-1.4.

WING. Microtrichose, bare on basal 1/5-1/3 of cell cup CuP; hyaline, stigma yellowish. Crossvein dm-cu strongly oblique to vein $\mathrm{M}$ and vein $\mathrm{M}_{1}$ meeting vein $\mathrm{R}_{4+5}$ perpendicularly.

LeGs. Pro- and mesoleg yellow, tarsomeres 4 and 5 black. Metaleg, Fig. 52E, with coxa black, trochanter yellow; femur black and yellow biannulate, slightly incrassate, ratio width: length 1: 3.9-4.2; tibia black and yellow biannulate, without apicoventral dens; tarsus entirely black, basitarsomere thin, ratio width: length $1: 3.7-4.5$.

АвDOMEN. Length ratio of terga I: II: III: IV 1: 5.5-5.9: 2.1-2.6: 1.6-2.1; ratio width at posterior margin: medial length of tergum II and III 1: 3.7-3.9 and 1: 0.6-0.7. Terga black, anterior 1: 2.5-2.8 of tergum III with brown-yellow fascia; pile pale, on terga short, laterally on terga I and II long; tergum I, Fig. 47E, with an oblique row of 4-5 light yellow setae at lateral margin; sternum III rectangular, ratio width: length 1: 1.7-1.8; sternum IV, Fig. 51A; sterna VI, VII and VIII simple, with long yellow pile. Genitalia, Fig. 51B-C: note the unusual lobe posterodorsally on the left side of tergum IX, asymmetrical cerci and only slightly asymmetrical surstyli and superior lobes

\section{Female}

Unknown.

Sphegina (Asiosphegina) karnataka sp. nov. urn:1sid:zoobank.org:act:5189A7C3-FA7B-45CA-8083-528F13F3DABE

Figs 50F, 52F, 53, 54D-E, 56A

\section{Differential diagnosis}

Very different from all other Sphegina and easily distinguished by the characters given in the key. The spoon-shaped lobe posteriorly on male sternum IV (without expanded apical part in other species) and the deeply bilobed surstylus, with the ventral lobe on the right side as long as the dorsal one (much shorter) are easily observed and unique characters. 


\section{Etymology}

The specific epithet is derived from the type locality, Karnataka State in India. The name is a noun in apposition.

\section{Material examined}

\section{Holotype}

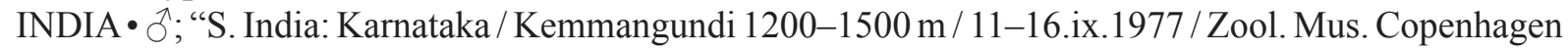
Exp"; ZMUC.

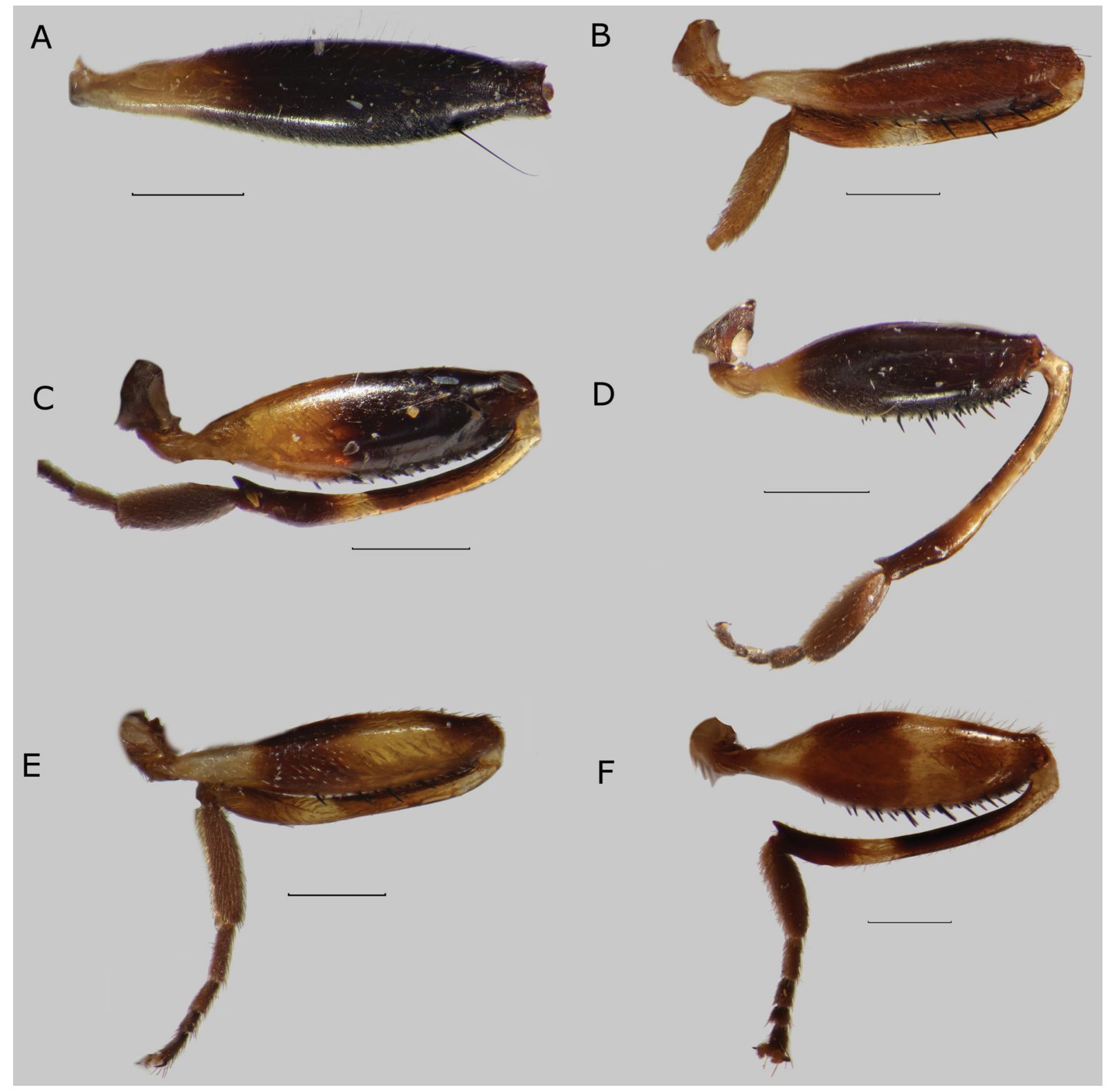

Fig. 52. Metaleg, dorsal view (A) and anterior view (B-F). A. Sphegina (Asiosphegina) hansoni Thompson, 1966, holotype, đ̃, Nepal. B. S. (A.) index Hippa, van Steenis \& Mutin, 2015, q, Kambaiti.

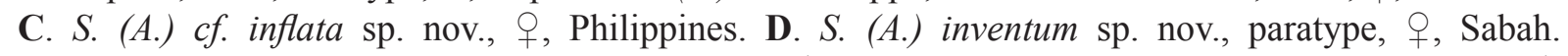
E. $S$. (A.) javana de Meijere, 1914, paralectotype, ô, Java. F. S. (A.) karnataka sp. nov., paratype, ô, India. Scale bars $=0.5 \mathrm{~mm}$. 


\section{Paratype}

INDIA $\bullet 1$ ते; same data as for holotype; arista missing; JSA.

\section{Description}

\section{Male}

LeNGTH. Body 6.9-7.2 mm, wing 5.3-5.5 mm.
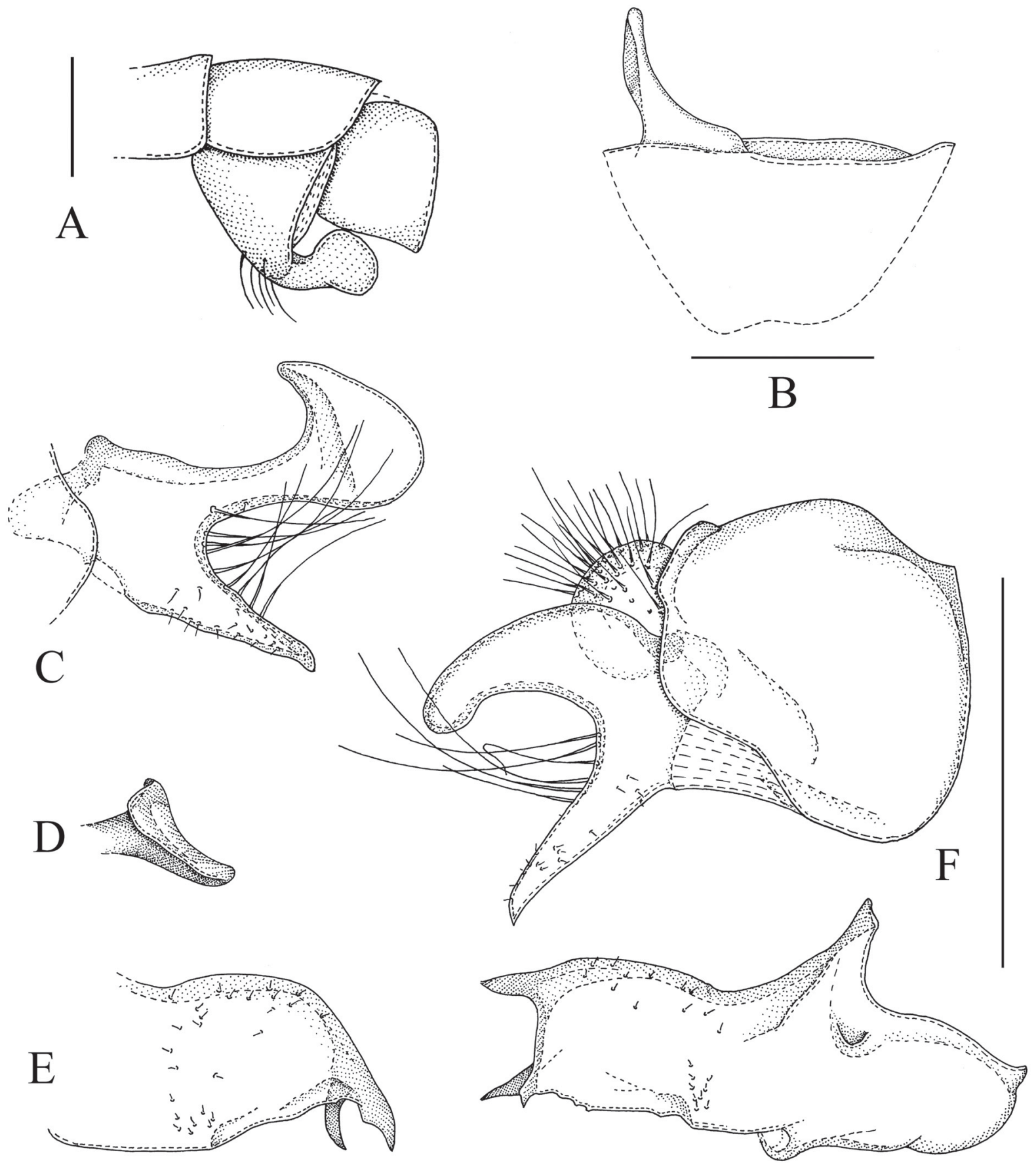

Fig. 53. Sphegina (Asiosphegina) karnataka sp. nov., holotype, $\widehat{\jmath}$. A. Posterior part of abdomen, left side lateral view. B. Sternum IV, ventral view. C. Left surstylus, lateral view. D. apex of dorsal lobe of left surstylus, dorsal view. E. Left superior lobe, lateral view. F. Genitalia, right side, lateral view. Scale bars $=0.5 \mathrm{~mm}$. 
HEAD. Face in lateral view (Fig. 54D) concave, strongly projected antero-ventrally; frontal prominence very weakly developed. Ratio width of vertex at anterior ocellus: width of head 1: 6.1-6.5; ratio width of ocellar triangle: width of vertex 1:1.1-1.2; ratio length of ocellar triangle: length of frons 1: 2.1-2.4. Face yellow, light grey pollinose, long pilose along eye-margin. Hypostomal bridge yellow, long pale pilose. Gena and mouth edge yellow with large subtriangular non-pollinose shiny area. Frons and vertex black, predominantly grey pollinose, a trapezoidal area posterior of lunula non-pollinose and shiny, a wide subtriangular macula of heavier grey pollinosity at eye-margin posterior of the shiny part, and medial part with sooty-black pollinosity (Fig. 54E); pile short, light yellow. Frons with weak medial furrow. Occiput black, light grey pollinose, light yellow pilose. Eye with an area of enlarged facets at anterior margin. Antenna yellow with black setae dorsally on scape and pedicel; basoflagellomere elongate, ratio width: length 1: 1.8-2.0; arista long pilose, about 3 times as long as basoflagellomere.

THORAX. Colour brown to dark brown, weakly greyish pollinose, scutum with more densely grey pollinose vitta submedially and laterally; postpronotum, postalar callus and dorso-medial part of anepisternum and anepimeron brown-yellow; posterior margin of katepisternum widely non-pollinose, shiny; scutum and pleuron with very short adpressed light yellow pile. Scutellum sub-rectangular, black, slightly pollinose, with pile slightly longer than on scutum, with two very widely set, very short setae medially at posterior margin, ratio length of scutellum: length of seta 1: $0.8-0.9$.

WING. Microtrichose, extensively bare on basal cells; hyaline, stigma yellowish, infuscated along veins bm-cu, dm-cu, $M_{1}$ and $R_{4+5}$ apically from junction with vein $M_{1}$ and at junction of veins $R_{2+3}$ and $R_{4+5}$. Crossvein dm-cu meeting vein $M$ slightly oblique to nearly perpendicular and vein $M_{1}$ meeting vein $R_{4+5}$ perpendicularly.

Legs. Pro- and mesoleg yellow, tarsomeres 3-5 black. Metaleg, Fig. 52F, with coxa and trochanter black; femur black and yellow biannulate, strongly incrassate, ratio width: length 1:3.3-3.5; tibia black and yellow biannulate with long apicoventral dens; tarsus entirely black, basitarsomere rather thin, ratio width: length $1: 3.5-3.7$.

ABDOMEN. Length ratio of terga I: II: III: IV 1: 3.8-4.0: 1.8-2.1: 1.3-1.5; ratio width at posterior margin: medial length of tergum II and III 1: $3.2-3.5$ and 1: 0.7-0.8. Terga dark brown, anterior $1 / 3$ of tergum III with brown-yellow fascia which is medially strongly constricted; pile pale, on terga short, laterally on terga I and II long; tergum I with a horizontal row of 3 strong brown-yellow setae at lateral margin; sternum III not sclerotized; sternum IV, Fig. 53B; sterna VI, VII and VIII simple, with long yellow pile. Genitalia, Fig. 53C-F: note the slightly asymmetrical surstyli with the transversely expanded apex of dorsal lobe on the left side one, and the asymmetrical superior lobes.

\section{Female}

Unknown.

Sphegina (Asiosphegina) licina sp. nov. urn:1sid:zoobank.org:act:1372EDE8-F63B-4A5E-9D04-73326D717F31

Figs $54 \mathrm{~F}-\mathrm{G}, 55,56 \mathrm{~B}, 59 \mathrm{~A}$

\section{Differential diagnosis}

Sphegina (Asiosphegina) licina sp. nov. is somewhat similar to $S$. (A.) albolobata sp. nov. For distinguishing characters, see under the latter. 


\section{Etymology}

The specific epithet is from the Latin 'licina', meaning 'bent upwards' and referring to the upwards bent male superior lobe.

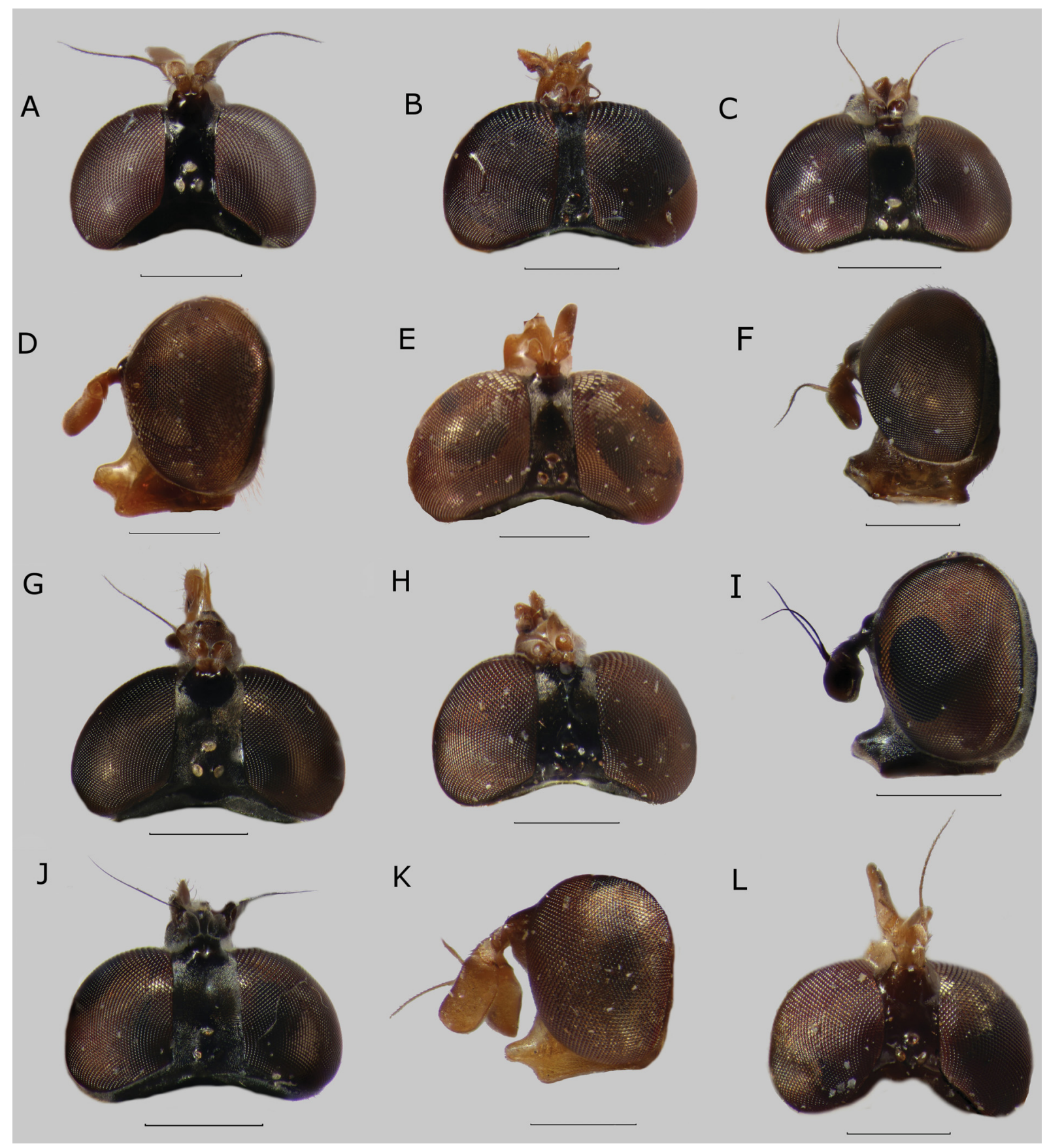

Fig. 54. Head, lateral view (D, F, I, K) and dorsal view (A-C, E, G-H, J, L). A. Sphegina (Asiosphegina) incretonigra sp. nov., holotype, $\widehat{\partial}$, Vietnam. B. S. (A.) inflata sp. nov., holotype, Õ, Philippines. C. S. (A.) inventum sp. nov., paratype,, , Sabah, Malaysia. D-E. S. (A.) karnataka sp. nov., paratype, $\widehat{\partial}$, India. F-G. S. (A.) licina sp. nov., holotype, đ̂, Thailand. H. S. (A.) lucida sp. nov., paratype, ð̂, Vietnam. I-J. S. (A.) nigerrima Shiraki, 1930, ठૈ, Taiwan. K-L. S. (A.) nigrotarsata sp. nov., paratype, đ̂, Vietnam. Scale bars $=0.5 \mathrm{~mm}$. 


\section{Material examined}

\section{Holotype}

THAILAND - ; ; "Thailand Chiang Mai Chomtong / Doi Inthanon NP, Siribhume waterfall / trap 1 $18.546^{\circ}$ N, $98.509^{\circ}$ E 1376 m / 2-29.V.2014 [leg] W. Srisuka \& R. Sawkord / Mal.[aise] Tp. QSBG 2014-132"; QSBG.

\section{Description}

\section{Male}

LENGTH. Body $7.2 \mathrm{~mm}$, wing $5.5 \mathrm{~mm}$

HEAD. Face in lateral view, Fig. 54F, concave, weakly projected antero-ventrally; frontal prominence weakly developed; mouth edge ventrally of eyes very wide. Ratio width of vertex at anterior ocellus: width of head 1: 4.0; ratio width of ocellar triangle: width of vertex 1: 2.1; ratio length of ocellar triangle: length of frons 1: 1.8. Face black, ventral half dark yellow, light grey pollinose, long pilose

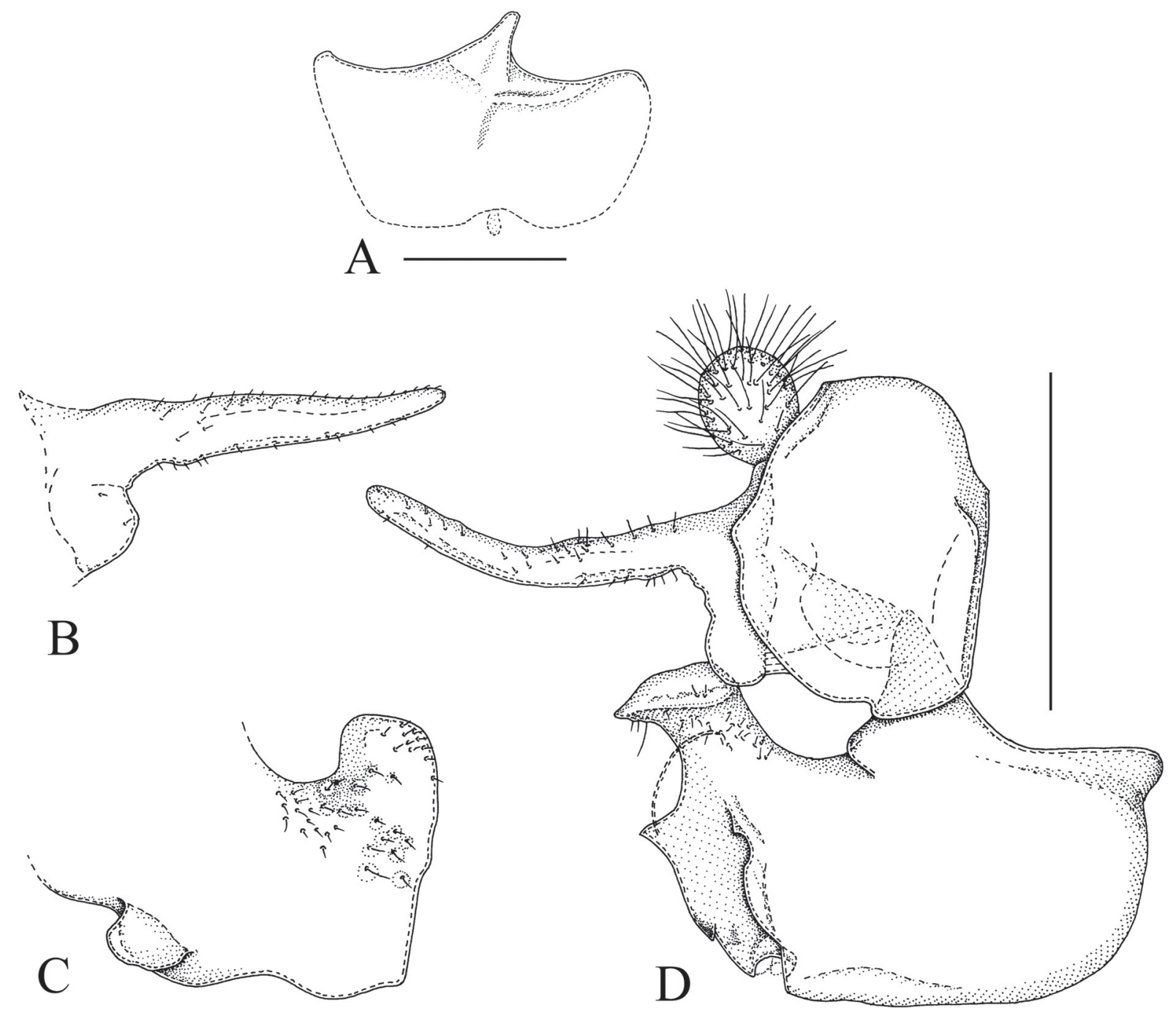

Fig. 55. Sphegina (Asiosphegina) licina sp. nov., holotype, ठ․ A. Sternum IV, ventral view. B. Left surstylus, lateral view. C. Left superior lobe with associated parts, lateral view. D. Genitalia, right side, lateral view. Scale bars $=0.5 \mathrm{~mm}$. 
along eye-margin. Hypostomal bridge brown, long pale pilose. Gena and mouth edge brown-yellow with large subtriangular non-pollinose shiny area. Frons and vertex black, grey pollinose sub-shiny, a trapezoidal area posterior of lunula non-pollinose and shiny and posteriorly from the shiny part with large subtriangular densely grey pollinose macula at eye-margin (Fig. 54G); pile short, light yellow. Frons with elongate oval furrow medially. Occiput black, light grey pollinose, light yellow pilose. Eye without enlarged facets at anterior margin. Antenna with scape and pedicel brown-yellow, basoflagellomere light-brown to yellow with black setae dorsally on scape and pedicel; basoflagellomere squarish, ratio width: length 1: 1.1; arista long pilose, 2.5 times as long as basoflagellomere.

THorax. Colour dark brown to black, greyish pollinose, scutum with vague more heavily grey pollinose vitta submedially, pleuron entirely grey pollinose; scutum and pleuron with very short adpressed light yellow pile. Scutellum sub-triangular, black, slightly greyish pollinose sub-shiny, with pile slightly longer than on scutum, with two widely set short setae medially at posterior margin, ratio length of scutellum: length of seta 1: 1.3 .

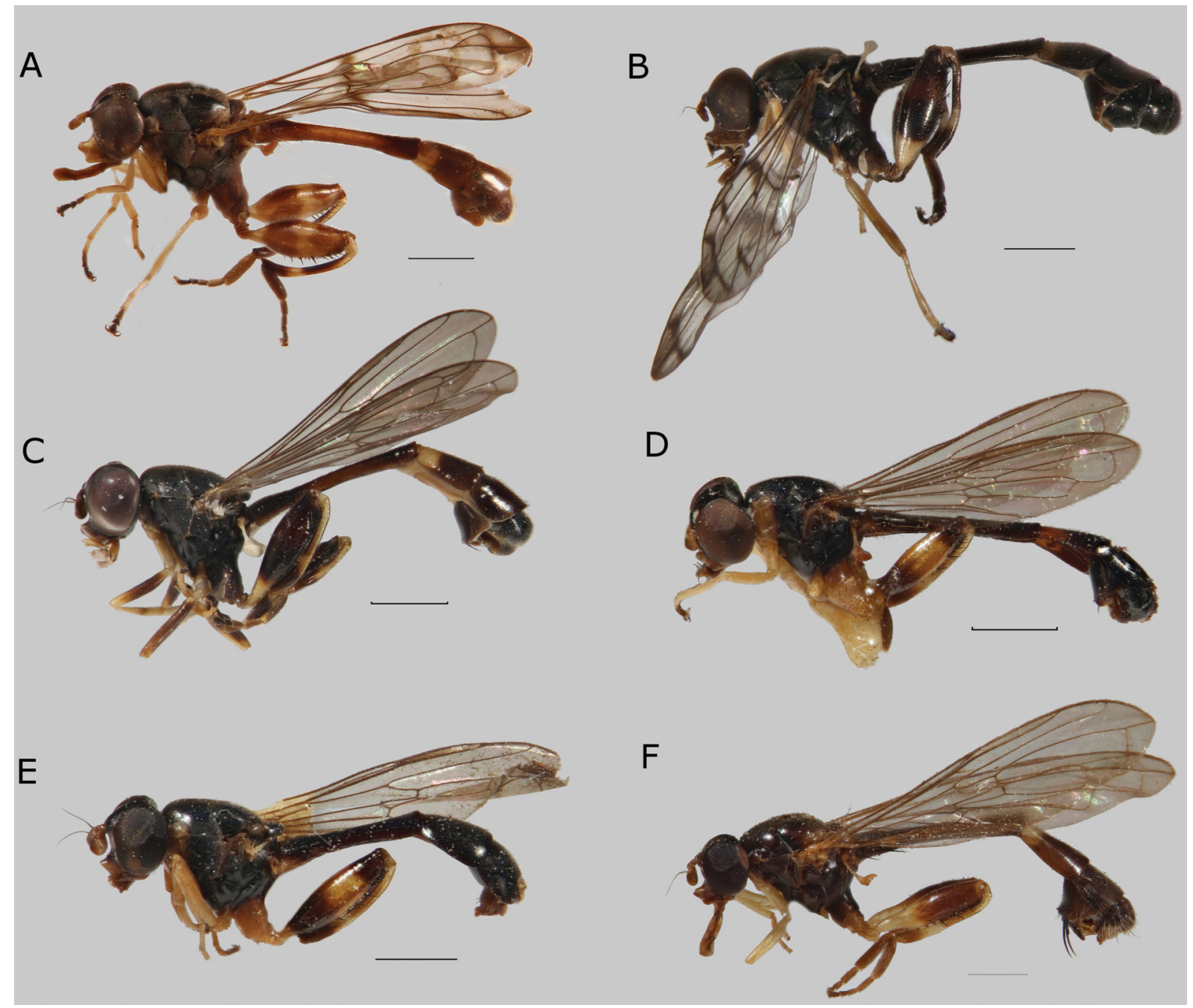

Fig. 56. Habitus, lateral view. A. S. (A.) karnataka sp. nov., paratype, đ̊, India. B. Sphegina (Asiosphegina) licina sp. nov., holotype, ô, Thailand. C. S. (A.) lobulata sp. nov., paratype, ô, Vietnam. D. S. (A.) lucida

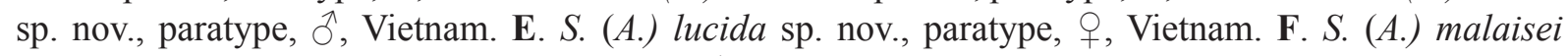
Hippa, van Steenis \& Mutin, 2015, paratype, $\hat{\partial}$, Myanmar. Scale bars $=1.0 \mathrm{~mm}$. 
WING. Microtrichose, basal 1/10 of cell cup bare; hyaline, stigma yellowish, membrane brown infuscated at junction of veins $R_{2+3}$ and $R_{4+5}$, along veins bm-cu, r-m, bm-cu and $M_{1}$, at apical end of veins $R_{2+3}$ and $\mathrm{R}_{4+5}$ and at appendices of vein $\mathrm{R}_{2+3}$. Crossvein dm-cu meeting vein $M$ perpendicularly and vein $M_{1}$ meeting vein $R_{4+5}$ perpendicularly. Vein $R_{2+3}$ with medial and subapical appendix, vein $C u A_{1}$ extending beyond vein $\mathrm{dm}-\mathrm{cu}$.

Legs. Pro- and mesoleg yellow, tarsomeres 3-5 dark brown to black. Metaleg with coxa and trochanter black; femur black with basal $1 / 4$ yellow, strongly incrassate, ratio width: length 1: 3.4; tibia black and yellow biannulate with short rounded apicoventral dens; tarsus entirely black, basitarsomere thin, ratio width: length 1: 4.0 .

ABDOMEN. Length ratio of terga I: II: III: IV 1: 3.8: 1.9: 1.4; ratio width at posterior margin: medial length of tergum II and III 1: 4.0 and 1: 0.7. Terga black, tergum II with sub-anterior lateral brown-yellow macula, tergum III with a brown-yellow fascia on anterior $1 / 4$; pile pale, on terga short, laterally on terga I and II long; tergum I with 3 brown setae at lateral margin; sternum III rectangular, ratio width: length 1: 2.3; sternum IV, Fig. 55A: note the unusually medial position of the lobe at posterior margin; sterna VI, VII and VIII simple, with long yellow pile. Genitalia, Fig. 55B-D: note the slightly asymmetrical surstyli and superior lobes.

\section{Female}

Unknown.

Sphegina (Asiosphegina) lobulata sp. nov. urn:1sid:zoobank.org:act:01493A30-4C65-46F3-AF5D-47CD4D81670C

Figs 47F, 56C, 57A-G, 59B

\section{Differential diagnosis}

Sphegina (Asiosphegina) lobulata sp. nov. is similar to $S$. (A.) radula, $S$. (A.) raduloides and $S$. (A.) subradula. Except for the characters mentioned in the key, it is distinguished by having the dorsal lobe of male surstylus on both sides equally wide (wider on the left side in the other species) and by having the ventral lobe of the right side surstylus with notched posterior margin (even margin in the others). All the species mentioned resemble Sphegina (Asiosphegina) nigrapicula Huo, Ren \& Zheng, 2007, from China. The latter differs by having all the setae posteriorly on male tergum IV rather thin and those on the right side all short, shorter than on the left side.

\section{Etymology}

The specific epithet is from the Latin 'lobulata', meaning 'having lobes' and referring to the lobes on the male superior lobe.

\section{Material examined}

Holotype

VIETNAM • ○̊; "Viet-Nam vi / Ha-noi / Strnad [sic], 1990"; ZFMK Dipt / QR code / 00011900"; ZFMK.

\section{Paratypes}

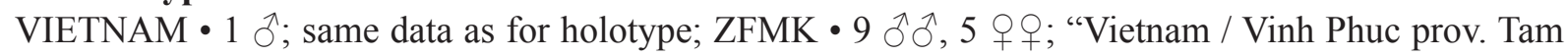
Dao / 21 ${ }^{\circ} 27^{\prime} 52^{\prime \prime}$ N, 105³8'46" E 1.200 m / 19-22.VI.2014 hand collected / leg. M. Hauser \& N. von

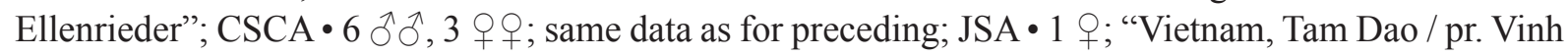
Phu 1000 m / forest 10.11.1990 / leg. N. Nartshuk"; "coll V. Mutin"; VMK. 


\section{Description}

\section{Male}

LeNGTH. Body 6.9-7.3 mm, wing 4.4-5.1 mm

HEAD. Face in lateral view concave, weakly projected antero-ventrally; frontal prominence very weakly developed. Ratio width of vertex at anterior ocellus: width of head 1: 4.5-4.7; ratio width of ocellar triangle: width of vertex 1: 1.7-1.9; ratio length of ocellar triangle: length of frons 1: 2.8-3.0. Face black, light grey pollinose, long pilose along eye-margin. Hypostomal bridge black, long pale pilose. Gena and mouth edge black with large subtriangular non-pollinose shiny area. Frons and vertex black,

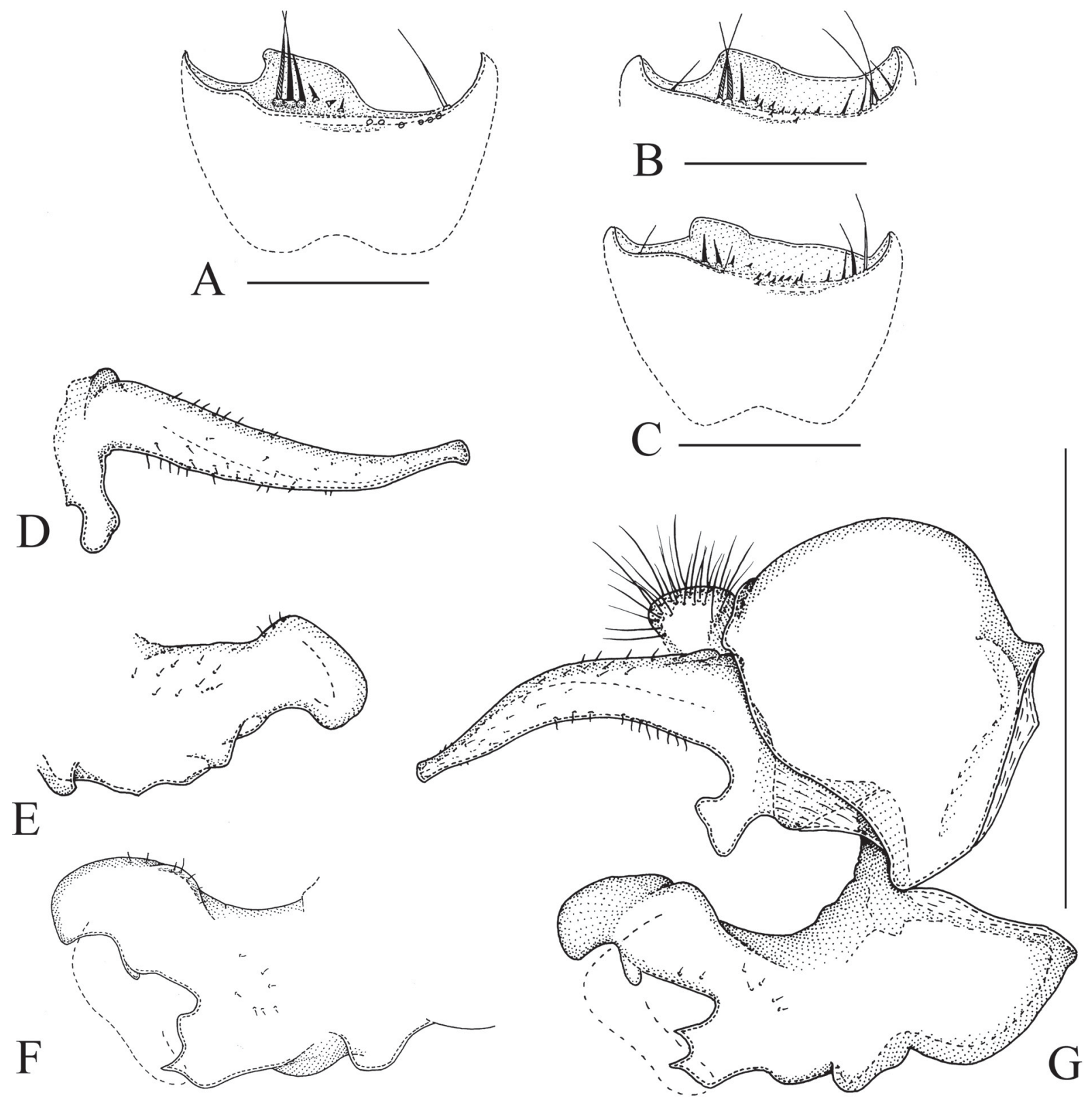

Fig. 57. Sphegina (Asiosphegina) lobulata sp. nov., holotype, § (A, D, E, G), paratype, ð Tam Dao 1 (C, F) and paratype, $\widehat{\jmath}$ Tam Dao 2 (B). A-C. Sternum IV, ventral view. D. Left surstylus, lateral view. E. Left superior lobe with associated parts, lateral view. F. Right superior lobe with associated parts, lateral view. G. Genitalia, right side, lateral view. Scale bars $=0.5 \mathrm{~mm}$. 
predominantly grey pollinose, a large more densely pollinose rectangular area posteriorly from lunula with antero-medial semi-circular non pollinose macula; pile short, light yellow. Frons with narrow medial furrow. Occiput black, light grey pollinose, light yellow pilose. Eye with enlarged facets at anterior margin. Antenna black with black setae dorsally on scape and pedicel; basoflagellomere elongate, ratio width: length 1: 1.9-2.2; arista long pilose, slightly more than 3 times as long as basoflagellomere.

THORAX. Colour black, weakly greyish pollinose, pleuron entirely more heavily grey pollinose; scutum and pleuron with very short adpressed light yellow pile. Scutellum semicircular, black, shiny, with pile slightly longer than on scutum, with two widely set, very short setae medially at posterior margin, ratio length of scutellum: length of seta 1: 0.8 .

WING. Entirely microtrichose; brown tinged, stigma yellowish. Crossvein dm-cu meeting vein M obliquely and vein $M_{1}$ meeting vein $R_{4+5}$ perpendicularly.

Legs. Pro- and mesofemur and tibia black with only base and apex narrowly yellow or entirely yellow to dark yellow; pro- and mesotarsus with tarsomeres 3 and 4 black. Metaleg with coxa black and trochanter yellow; femur black with basal $1 / 4$ yellow or black and yellow biannulate, slightly incrassate, ratio width: length 1: 3.6-3.8, with basally 3 black setulae in the yellow part; tibia black and yellow biannulate with short but widely rounded apicoventral dens; tarsus entirely black, basitarsomere rather thin, ratio width: length 1: 3.7-3.9.

ABDOMEN. Length ratio of terga I: II: III: IV 1: 4.7-4.9: 2.0-2.2: 1.6-1.7; ratio width at posterior margin: medial length of tergum II and III 1: 6.0-6.1 and 1: 1.0-1.1. Terga black, anterior $1 / 3$ of tergum III with yellow fascia; pile pale, on terga short, laterally on terga I and II long; tergum I, Fig. 47F with a horizontal row of 3 long, strong, black setae at lateral margin; sternum III elongate, subtriangular, ratio width: length 1: 3.2-3.3; sternum IV, Fig. 57A-C; sternum VII anteriorly with wide but weak tubercle and posteriorly with low ridge like tubercle; sterna VI, VII and VIII with long yellow pile. Genitalia, Fig. 57D-G: note the equally wide and almost symmetrical surstyli and the slightly asymmetrical superior lobes.

\section{Female}

Similar to male except for the usual sexual dimorphism.

LeNGTH. Body 5.7-6.1 mm, wing 4.5-4.9 mm.

HEAD. Ratio width of vertex at anterior ocellus: width of head 1: 3.8-4.3; ratio width of ocellar triangle: width of vertex 1: 1.8-2.1; ratio length of ocellar triangle: length of frons 1:2.0-2.3. Basoflagellomere oval, ratio width: length 1: 1.4-1.7; arista long pilose, about 2.5 times as long as basoflagellomere.

THORAX. Scutellum with two widely set, very short setae medially at posterior margin, ratio length of scutellum: length of seta 1: 0.8-0.9.

Legs. Metafemur, ratio width: length 1:3.9-4.3; metatarsus with basitarsomere thick, ratio width: length $1: 3.1-3.3$.

ABDOMEN. Length ratio of terga I: II: III: IV: V 1: 3.5-3.9: 2.5-2.9: 2.0-2.4: 0.9-1.3; ratio width at posterior margin: medial length of tergum II and III 1:2.9-3.3 and 1: 0.8-0.9. Tergum II predominantly dark yellow; anterior $1 / 3$ of tergum III with orange-brown fascia; terga IV and V predominantly to entirely dark yellow; sternum III rectangular, ratio width: length 1: 2.8-3.2; sternum IV crescent-shaped with convex posterior margin, ratio width: length 1: $0.4-0.6$; sternum $\mathrm{V}$ rectangular, ratio width: length 1 : $0.7-0.8$. 


\title{
Remarks
}

The colouration of the legs shows a high degree of interspecific variation with extensively blackcoloured forms to predominantly yellow-coloured ones. The yellow-coloured specimens tend to have a yellow mouth edge, yellow basoflagellomere and yellow proepisternum and proepimeron. There are many intermediate specimens in which the yellow gradually shifts from dark yellow via brown and dark red-brown to black. All females and two males belong to the yellow form and no differences have been found in any other character including the male genitalia. The existence of intermediate specimens and the lack of differences in the genitalia indicates that all these specimens belong to one species. The holotype is an extensively black-coloured specimen.

\author{
Sphegina (Asiosphegina) lucida sp. nov. \\ urn:1sid:zoobank.org:act:561D1E5E-EDBF-4FAD-86ED-69DF3D2B73A2
}

Figs $54 \mathrm{H}, 56,58 \mathrm{~A}-\mathrm{D}, 59 \mathrm{C}$

\section{Differential diagnosis}

Sphegina (Asiosphegina) lucida sp. nov. is not especially similar to any other species and is easily distinguished by the characters given in the key. The male genitalia resemble those of Sphegina (Asiosphegina) spenceri sp. nov. but the surstyli are much longer and the superior lobes are more simple, lacking a posteroventral bifid sublobe on the right side and a sharp ventral sublobe on the left side.

\section{Etymology}

The specific epithet is from the Latin ' $l u c i d a$ ', meaning 'shiny' and referring to the shiny frons, especially in the female.

\section{Material examined}

\section{Holotype}

VIETNAM • đ̊; "Viet Nam: Fyan; / 1200 m / 11.VII-9.VIII.1961"; "N. R. Spencer / Collector / Bishop"; BPBM.

\section{Paratypes}

VIETNAM • $3 \widehat{\jmath} \widehat{\partial}, 6$ + $q$; same data as for holotype; BPBM $\bullet 2 \hat{\jmath}, 3$ q $q$; same data as for holotype;

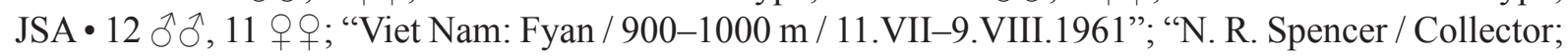

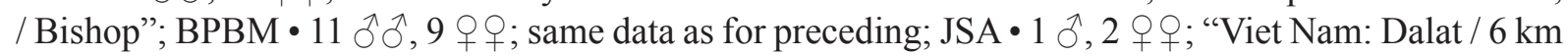
S 1400-1500 m / 9.VI-7.VII 1961"; "N. R. Spencer / Collector / Bishop"; BPBM • 1 O; "Viet Nam: Mt. Lang / Bian 1500-2000 m / 19. V-8. VI 1961"; "N. R. Spencer / Collector / Bishop"; JSA.

\section{Additional material}

NEW GUINEA • 1 क ; “West New Guinea / Vogelkop Kebar Val. / W of Manokwari 550 m / 4-31.I.1962”; "L. W. Quate / Collector"; BPBM・ 1 क; same data as for preceding; JSA.

\section{Description}

\section{Male}

Length. Body 5.5-5.9 mm, wing 4.1-4.4 mm.

HEAD. Face in lateral view concave, weakly projected antero-ventrally; frontal prominence very weakly developed. Ratio width of vertex at anterior ocellus: width of head 1: 4.1-4.6; ratio width of ocellar triangle: width of vertex 1: 1.9-2.0; ratio length of ocellar triangle: length of frons 1: 3.8-4.0. Face with dorsal half dark brown to black and ventral half orange-brown to dark brown; light grey pollinose, long pilose along eye-margin. Hypostomal bridge dark brown, long pale pilose. Gena and mouth edge 
orange-brown to dark brown with large subtriangular non-pollinose shiny area. Frons and vertex black, with small subtriangular medial macula posteriorly of lunula grey-pollinose, otherwise brightly shiny (Fig. 54H); pile short, light yellow. Frons with narrow medial rim and anteriorly from ocelli with deep V-shaped furrow. Occiput black, non-pollinose and shiny, light yellow pilose. Eye with slightly enlarged facets at anterior margin. Antenna orange to orange-brown with black setae dorsally on scape and pedicel; basoflagellomere short oval, ratio width: length 1: 1.1-1.3; arista long pilose, nearly 3 times as long as basoflagellomere.

THORAx. Colour black, postalar callus and proepimeron brown-yellow; weakly greyish pollinose, pleuron sub-shiny; scutum and pleuron with very short adpressed light yellow pile. Scutellum sub-triangular, brown-yellow, shiny on posterior $2 / 3$ to $1 / 2$, with pile slightly longer than on scutum, with two widely set short setae medially at posterior margin, ratio length of scutellum: length of seta 1:1.2-1.3.

WING. Entirely microtrichose; hyaline, stigma yellowish. Crossvein dm-cu meeting vein M obliquely and vein $M_{1}$ meeting vein $R_{4+5}$ perpendicularly.

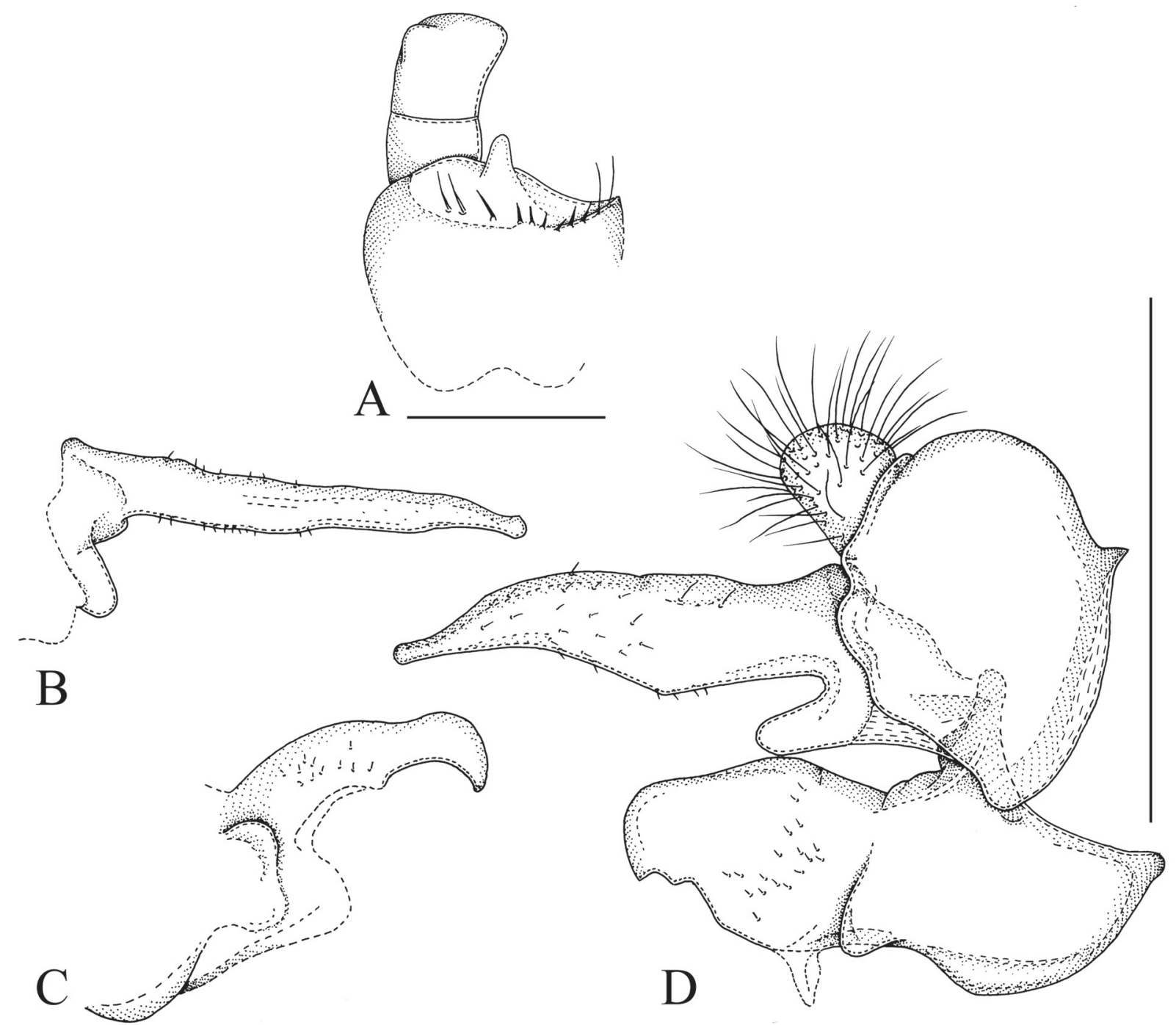

Fig. 58. Sphegina (Asiosphegina) lucida sp. nov., holotype, $\widehat{\jmath}$. A. Sterna IV, VI and VII, ventral view. B. Left surstylus, lateral view. C. Left superior lobe with associated parts, lateral view. D. Genitalia, right side, lateral view. Scale bars $=0.5 \mathrm{~mm}$. 
Legs. Pro- and mesoleg yellow, tarsomeres 4 and 5 black. Metaleg with coxa black, trochanter yellow, femur black and yellow biannulate, slightly incrassate, ratio width: length 1: 3.9-4.3; tibia black and yellow biannulate with wide, short, rounded apicoventral dens; tarsus entirely black, basitarsomere rather thin, ratio width: length 1: 3.6-4.0.

AвDomen. Length ratio of terga I: II: III: IV 1: 4.2-4.4: 2.0-2.1: 1.8-1.9; ratio width at posterior margin: medial length of tergum II and III 1: 4.4-4.7 and 1: 1.0-1.1. Terga black, tergum II anteriorly with mediolateral small light-brown macula; anterior $1 / 3$ of tergum III with yellow fascia with posterior margin deeply incised; pile pale, on terga short, laterally on terga I and II long; tergum I with a row of 2-3 strong light-brown setae at lateral margin; sternum III rectangular, ratio width: length 1: 1.6-1.9; sterna VI, VII and VIII (Fig. 58A) with long yellow pile, sternum VIII with low widely rounded elevation posteriorly. Genitalia, Fig. 58B-D: note the asymmetrical surstyli and superior lobes.

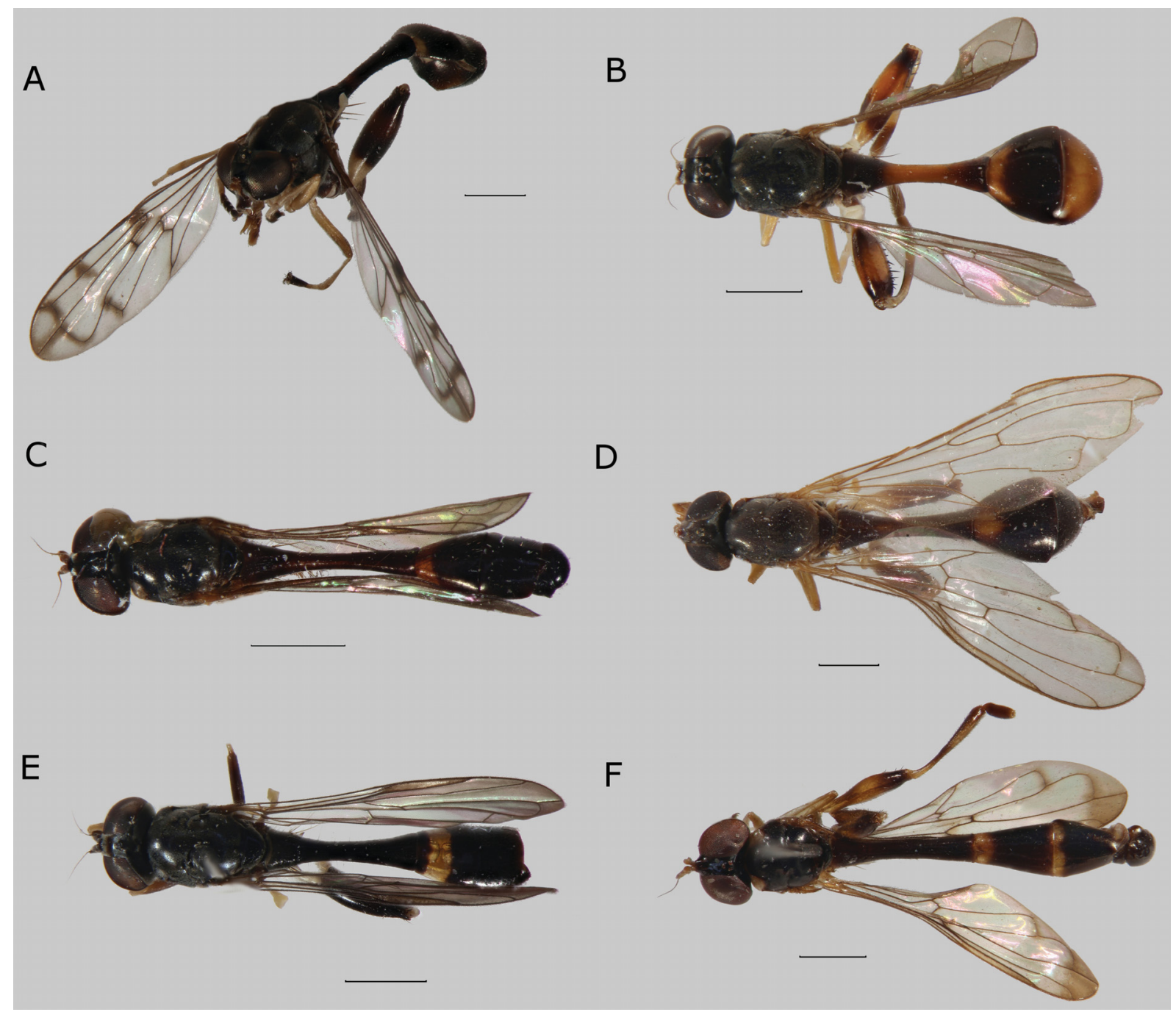

Fig. 59. Habitus, dorsal view. A. Sphegina (Asiosphegina) licina sp. nov., holotype, $\widehat{\partial}$ (fronto-dorsal), Thailand. B. S. (A.) lobulata sp. nov., paratype, , , Vietnam. C. S. (A.) lucida sp. nov., paratype, ô, Vietnam. D. S. (A.) malaisei Hippa, van Steenis \& Mutin, 2015, paratype, + , Myanmar. E. S. (A.) nigerrima Shiraki, 1930, đ̂, Taiwan. F. S. (A.) nigrotarsata sp. nov., paratype, đ̂, Vietnam. Scale bars $=1.0 \mathrm{~mm}$. 
Female

Similar to male except for the usual sexual dimorphism.

LeNGTH. Body 5.2-5.9 mm, wing 4.1-4.5 mm.

HEAD. Ratio width of vertex at anterior ocellus: width of head 1: 3.6-3.9; ratio width of ocellar triangle: width of vertex 1: 1.9-2.1; ratio length of ocellar triangle: length of frons 1: 3.3-3.6. Basoflagellomere oval, ratio width: length 1: 1.2-1.4; arista long pilose, about 2.5 times as long as basoflagellomere.

THORAX. Scutellum with two widely set short setae medially at posterior margin, ratio length of scutellum: length of seta $1: 1.2-1.4$.

Legs. Metafemur with ratio width: length 1: 3.6-4.1; metatarsus with basitarsomere rather thin, ratio width: length $1: 3.8-4.1$.

ABDOMEN. Length ratio of terga I: II: III: IV: V 1: 4.0-4.2: 2.5-2.9: 2.3-2.9: 0.9-1.1; ratio width at posterior margin: medial length of tergum II and III 1: 2.6-2.9 and 1: 0.8 . Tergum III anteriorly with orange-brown lateral macula to a narrow fascia; tergum IV with anterior $1 / 2$ dark brown; tergum $\mathrm{V}$ entirely orange-brown; sternum III rectangular, ratio width: length 1: 1.8-2.2; sternum IV crescentshaped with convex posterior margin, ratio width: length 1: 1.7-2.1; sternum $\mathrm{V}$ rectangular, ratio width: length 1: $0.4-0.5$.

\section{Remarks}

The two females from New Guinea are morphologically similar to the females from Vietnam. The large geographic distance and especially the altitude at which the specimens have been collected differ so much that it is possible that the specimens from New Guinea belong to a different species. As no males are known from New Guinea, the specimens are here tentatively assigned to Sphegina (Asiosphegina) lucida sp. nov.

Sphegina (Asiosphegina) malaisei Hippa, van Steenis \& Mutin, 2015 Figs 56F, 72A, 59D

Sphegina (Asiosphegina) malaisei Hippa, van Steenis \& Mutin, 2015: 21. Type locality: Kambaiti, Myanmar (holotype, $\widehat{\jmath}$, NHRS).

\section{Material examined}

VIETNAM - 1 q; "NW VIETNAM: Tonkin / Hoang Lien N.P., 15 km / W Sa Pa c. 1900 m / 1521.X.1999 Malaise traps / [leg] C. v. Achterberg RMNH '99”; NBC.

THAILAND • 1 ㅇ; “"Thailand, Chiang Mai / Doi Inthanon NP / Kew Mae Pan 2200 m / 18³3.163' N, 98²8.8' E / 13.IX-21.IX.2006 Malaise Trap / Y. Areeluck leg. T 251”; QSBG.

\section{Distribution and biology}

Known from NE Myanmar, N Vietnam and N Thailand. In Myanmar collected in a cloud forest with streams and swampy areas at an altitude of $2000 \mathrm{~m}$. The specimen from Vietnam was collected by a Malaise trap near the Tram Ton Pass, the highest mountain pass of Vietnam (1900 m), near Fan Si Pan mountain. The Malaise trap was set up in an area of montane forest disturbed by grazing buffaloes, containing muddy areas and small streams. Despite the cold and wet weather insects were still rather abundantly flying (C. van Achterberg, pers. comm). 
Sphegina (Asiosphegina) minuta Hippa, van Steenis \& Mutin, 2015

Fig. $63 \mathrm{~A}$

Sphegina (Asiosphegina) minuta Hippa, van Steenis \& Mutin, 2015: 52. Type locality: Kambaiti, Myanmar (holotype, $\hat{\jmath}$, NHRS).

\section{Remarks}

Only known by the type material from Myanmar, Kambaiti (Hippa et al. 2015).

Sphegina (Asiosphegina) mirifica Hippa, van Steenis \& Mutin, 2015

Figs 63B, 77A

Sphegina (Asiosphegina) mirifica Hippa, van Steenis \& Mutin, 2015: 36. Type locality: Kambaiti, Myanmar (holotype, $\partial^{\lambda}, \mathrm{NHM}$ ).

\section{Material examined}

MYANMAR • 1 क; "N.E. Burma / Kambaiti 2000 m / 12-17.6.[19]34 [leg] Malaise”; JSA.

\section{Description}

Female

Length. Body $6.9 \mathrm{~mm}$, wing $5.9 \mathrm{~mm}$.

HEAD. Face in lateral view concave, weakly projected antero-ventrally; frontal prominence weakly developed. Ratio width of vertex at anterior ocellus: width of head 1:3.5; ratio width of ocellar triangle: width of vertex 1: 2.3; ratio length of ocellar triangle: length of frons 1: 3.0. Face dark brown to black; grey pollinose, long pilose along eye-margin. Hypostomal bridge dark brown, long pale pilose. Gena black, mouth edge red-brown with large subtriangular non-pollinose shiny area. Frons and vertex dark brown, slightly greyish pollinose, except frons with semi-circular non-pollinose and shiny part posteriorly from lunula; pile short, light yellow. Frons with weak, wide pit antero-medially. Occiput black, light grey pollinose, light yellow pilose. Eye without enlarged facets at anterior margin. Antenna dark brown with black setae dorsally on scape and pedicel; basoflagellomere missing.

THORAX. Colour dark brown to black, grey pollinose, pleuron entirely more heavily grey pollinose; scutum and pleuron with very short adpressed light yellow pile. Scutellum semicircular, dark brown, sub-shiny, faintly pollinose, with pile slightly longer than on scutum, with two very widely set, very short setae medially at posterior margin, ratio length of scutellum: length of setae 1: 0.9 .

WING. Entirely microtrichose; hyaline, stigma yellowish, membrane brown infuscated at junction of veins $R_{2+3}$ and $R_{4+5}$, along veins bm-cu, dm-cu, $r-m, M_{1}$, the extra crossvein between $R_{2+3}$ and $R_{1}$, at the junction of veins $M_{1}$ and $R_{4+5}$ and at apical appendix of vein $R_{2+3}$. Crossvein dm-cu meeting vein $M$ perpendicularly and vein $M_{1}$ meeting vein $R_{4+5}$ perpendicularly. Apical part of vein $R_{2+3}$ with long appendix and extra crossvein between veins $\mathrm{R}_{1}$ and $\mathrm{R}_{2+3}$.

Legs. Pro- and mesoleg with femora and tibiae dark brown to black on apical $2 / 3$ to $3 / 4$; tarsi with tarsomeres 2-5 black. Metaleg with coxa dark brown and trochanter yellow; femur yellow to orangeyellow, incrassate, ratio width: length 1: 4.2; tibia black and yellow biannulate, without apicoventral dens; tarsus entirely black, basitarsomere thick, ratio width: length 1: 3.3 .

AвDomen. Length ratio of terga I: II: III: IV: V 1: 2.7: 2.3: 1.6: 0.8; ratio width at posterior margin: medial length of tergum II and III 1: 2.1 and 1: 0.9. Tergum I brown, terga II-V orange-yellow; pile 
pale, on terga short, laterally on terga I and II long; tergum I, Fig. 77A with 2 strong light yellow setae at lateral margin; sternum III ellipsoidal, ratio width: length 1: 2.8; sternum IV trapezoidal, ratio width: length 1: 1.6, and sternum $\mathrm{V}$ squarish with strong transverse rim at posterior margin, ratio width: length 1: 1.1 .

\section{Remarks}

Known only from the type material from Myanmar, Kambaiti (Hippa et al. 2015) and the here studied specimen.

Sphegina (Asiosphegina) nasuta Hippa, van Steenis \& Mutin, 2015

Fig. $84 \mathrm{~A}$

Sphegina (Asiosphegina) nasuta Hippa, van Steenis \& Mutin, 2015: 37. Type locality: Kambaiti, Myanmar (holotype, $\hat{\jmath}$, NHRS).

\section{Remarks}

Only known by the type material from Myanmar, Kambaiti (Hippa et al. 2015).

Sphegina (Asiosphegina) nigerrima Shiraki, 1930

Figs 54I-J, 59E, 60, 63C, 65C, 72B, 77B

Sphegina nigerrima Shiraki, 1930: 425. Type locality: Rantaisan, Taiwan (holotype, §̊, NTU).

\section{Differential diagnosis}

Similar to Sphegina (Asiosphegina) atricolor, S. (A.) dentata sp. nov., S. (A.) furva and S. (A.) umbrosa sp. nov. For distinguishing characters, see under $S$. (A.) dentata sp. nov.

\section{Material examined}

\section{Holotype}

TAIWAN • $\widehat{O}$ "Rantaisan / Formosa / 13.III.1926 / S. Issiki"; "Sphegina / nigerrima / Det. T. Shiraki"; "Type"[round labelled with red circles]; "1029"; NTU.

\section{Additional material}

TAIWAN • 1 ô; "Taiwan N-Nantou Co. / Road No. 14, NE Puli / Reyen Shi-Reg., E Tsuifeng / to

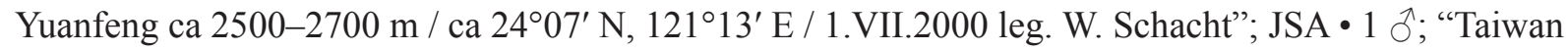
C: / Alishan 2400 m / 3-9.VII.1972"; T.C. Maa / Collector / Bishop"; BPBM • 1 §;; "TW Taichung

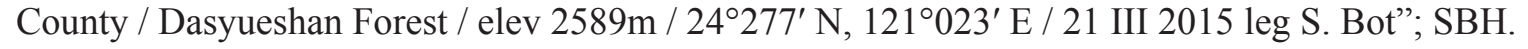

\section{Redescription}

\section{Male}

LeNGTH. Body 5.9-6.5 mm, wing 4.4-4.8 mm.

HEAD. Face in lateral view (Fig. 54I) concave, weakly projected antero-ventrally; frontal prominence weakly developed. Ratio width of vertex at anterior ocellus: width of head 1:3.9-4.3; ratio width of ocellar triangle: width of vertex 1: 1.9-2.2; ratio length of ocellar triangle: length of frons 1: 2.3-2.6. Face black, light grey pollinose, long pilose along eye-margin. Hypostomal bridge black, long pale pilose. Gena and mouth edge black with large subtriangular non-pollinose shiny area. Frons and vertex black, predominantly grey pollinose, a rectangular area posterior of lunula non-pollinose and shiny and 
densely grey pollinose macula lateral of shiny area (Fig. 54J); pile short, light yellow. Frons with weak medial furrow. Occiput black, light grey pollinose, light yellow pilose. Eye without enlarged facets at anterior margin. Antenna black with black setae dorsally on scape and pedicel; basoflagellomere squarish, ratio width: length 1: 1.1-1.2; arista bare, a basally with short and scattered pile, about 3.5 times as long as basoflagellomere.

THorax. Colour dark brown to black; scutum weakly greyish pollinose laterally and with wide greypollinose vitta submedially, otherwise non pollinose, shiny; katepisternum pollinose, posterior margin widely non-pollinose, shiny (Fig. 65C); katepimeron pollinose, anterior part non-pollinose, shiny; scutum and pleuron with very short adpressed light yellow pile. Scutellum subtriangular, black, shiny, with pile slightly longer than on scutum, with two widely set, very long setae medially at posterior margin, ratio length of scutellum: length of seta 1:2.2-2.6.

WING. Microtrichose, basal $1 / 3$ of cell cup bare; hyaline, stigma yellowish. Crossvein dm-cu meeting vein $\mathrm{M}$ obliquely and vein $\mathrm{M}_{1}$ meeting vein $\mathrm{R}_{4+5}$ perpendicularly.

LeGs. Profemur yellow with medial $1 / 2-3 / 5$ black; mesofemur yellow with apical $3 / 4$ black; pro- and metatibia yellow, black on apical $1 / 2$; pro- and metatarsus yellow with tarsomeres $3-5$ black. Metaleg,
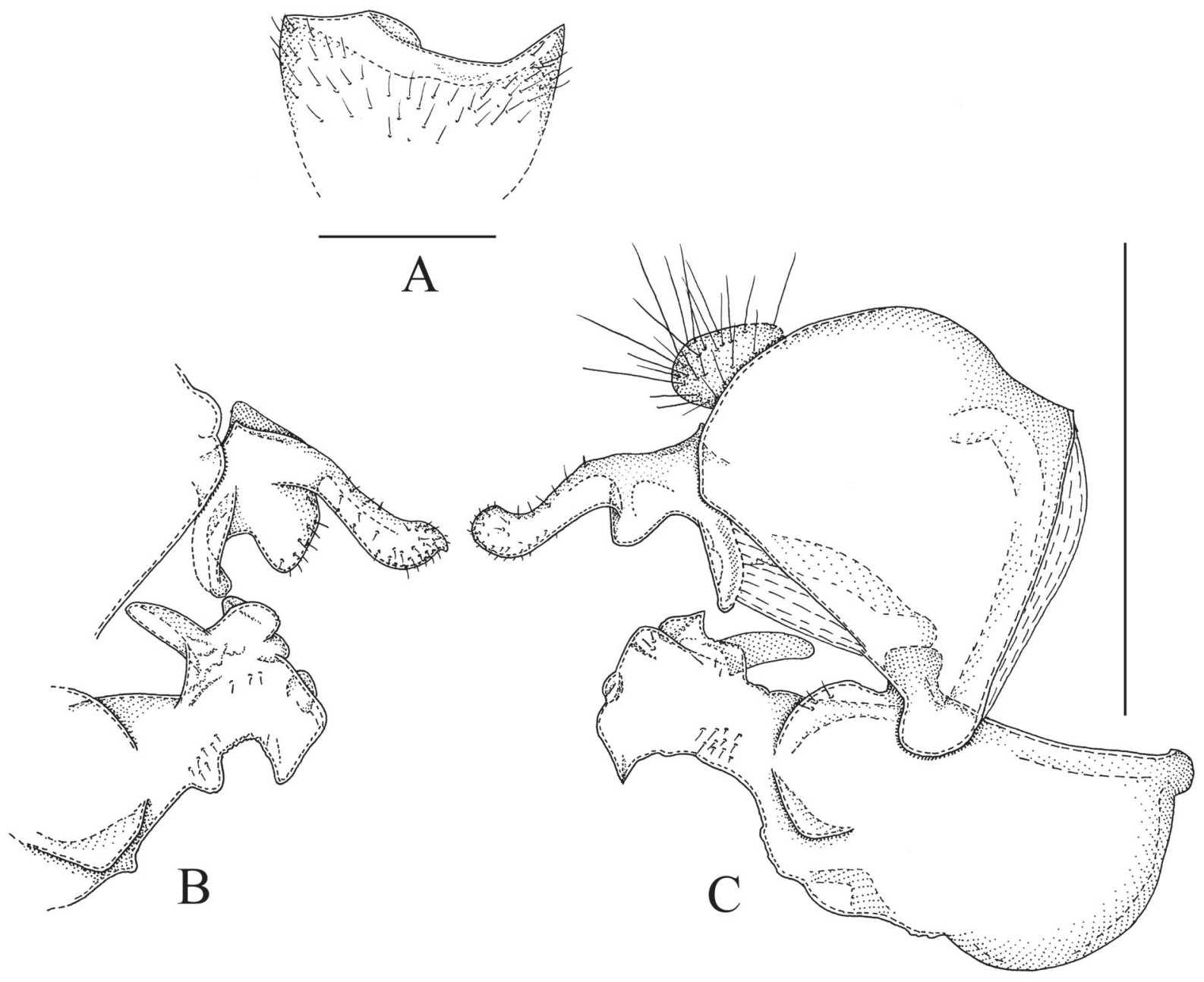

Fig. 60. Sphegina (Asiosphegina) nigerrima Shiraki, 1930, $ð$ from Puli, Taiwan. A. Sternum IV, ventral view. B. Posterior part of genitalia, left side, lateral view. C. Genitalia, right side, lateral view. Scale bars $=0.5 \mathrm{~mm}$. 
Fig. 72B, with coxa black and trochanter yellow; femur black with basal $1 / 4-1 / 3$ yellow, incrassate, ratio width: length 1:3.4-3.8, in profile baso-dorsally slightly concave, with long seta-like pile apico-dorsally; tibia black and yellow biannulate, without apicoventral dens; tarsus entirely black, basitarsomere thick, ratio width: length 1: 3.1-3.4.

ABDOMEN. Length ratio of terga I: II: III: IV 1: 3.8-4.3: 1.6-2.0: 1.5-1.8; ratio width at posterior margin: medial length of tergum II and III 1: 5.3-5.8 and 1: 0.9. Tergum IV skewed to the right. Terga black, anterior $1 / 2$ of tergum III with sub-anterior lateral brown-yellow squarish macula; pile pale, on terga short, laterally on terga I and II long; tergum I, Fig. 72B, with an oblique row of 5 light yellow setae at lateral margin; sternum III rectangular with concave posterior margin, ratio width: length 1: 1.3-1.5; sternum IV, Fig. 60A; sterna VI, VII and VIII simple, with long yellow pile. Genitalia, Fig. 60B-C: note the slightly asymmetrical surstyli and superior lobes.

\section{Female}

Unknown.

Sphegina (Asiosphegina) nigrotarsata sp. nov. urn:1sid:zoobank.org:act:2AC19DE0-951E-4CF2-A8E7-A9DF00B00B18

Figs $54 \mathrm{~K}-\mathrm{L}, 59 \mathrm{~F}, 61 \mathrm{D}, 62,63 \mathrm{D}$

\section{Differential diagnosis}

Similar to Sphegina (Asiosphegina) atrimanus sp. nov., S. (A.) granditarsis sp. nov., S. (A.) incretonigra sp. nov., $S$. (A.) nasuta and $S$. (A.) nigrotarsata sp. nov. For distinguishing characters, see under $S$. (A.) atrimanus sp. nov. and $S$. (A.) granditarsis sp. nov.

\section{Etymology}

The specific epithet is from the Latin 'nigrotarsata', meaning 'with black tarsus' and referring to the predominantly black protarsus.

\section{Material examined}

\section{Holotype}

VIETNAM • đ’; "Viet Nam Mt. Lang / Bian 1500-2000 / 19.V-8.VI.1961"; "N. R. Spencer / Collector / Bishop"; BPBM.

\section{Paratypes}

VIETNAM • 1 \% ; same data as for holotype; JSA • 1 đ; "Viet Nam / Dalat 1500 m / 26-27.IX 1960"; "J.L. Gressitt / collector"; BPBM・ 1 Ō; Viet Nam: Fyan / 1200 m / 11.VII-9.VIII.1961"; "N. R. Spencer / collector / Bishop"; BPBM・ 1 § ; same data as for preceding; JSA.

\section{Description}

Male

Length. Body 6.7-7.4 mm, wing 5.1-5.9 mm.

HEAD. Face in lateral view, Fig. 54K, concave, strongly projected antero-ventrally; frontal prominence strongly developed; mouth edge very narrow. Ratio width of vertex at anterior ocellus: width of head 1: 4.7-4.9; ratio width of ocellar triangle: width of vertex 1: 1.4-1.7; ratio length of ocellar triangle: length of frons 1: 3.0-3.4. Face black, ventral half yellow, light grey pollinose, long pilose along eyemargin. Hypostomal bridge dark brown to black, long pale pilose. Gena and mouth edge yellow with large subtriangular non-pollinose shiny area. Frons and vertex black, frontal prominence long, shiny 
(Fig. 54L); pile short, light yellow. Frons with deep pit and wide furrow medially. Occiput black, light grey pollinose, ocellar triangle non-pollinose shiny, light yellow pilose. Eye without enlarged facets at anterior margin. Antenna with scape and pedicel dark yellow to brown, basoflagellomere dark brown to black with black setae dorsally on scape and pedicel; basoflagellomere elongate, ratio width: length 1 : 2.0-2.3; arista short pilose, about 3.5 times as long as basoflagellomere.

THorax. Colour dark brown to black, postpronotum and dorso-medial part of anepisternum and anepimeron yellow, weakly greyish pollinose, pleuron entirely more heavily grey pollinose; scutum and pleuron with very short adpressed light yellow pile. Scutellum semicircular, black, sub-shiny and weakly pale pollinose, with pile slightly longer than on scutum, with two closely set, very short setae medially at posterior margin, ratio length of scutellum: length of seta 1: 0.6-0.7.

WING. Entirely microtrichose; hyaline, stigma yellowish, membrane brown infuscated at junction of veins $R_{2+3}$ and $R_{4+5}$, along veins bm-cu, r-m and $M_{1}$, at apical end of vein $R_{2+3}$ and apical part of wing around vein $R_{4+5}$. Crossvein dm-cu meeting vein $M$ perpendicularly and vein $M_{1}$ meeting vein $R_{4+5}$ perpendicularly.

Legs. Pro- and mesoleg yellow; protarsus, Fig. $61 \mathrm{D}$, with tarsomeres $2-5$ wide and flattened, tarsomere 1 with black sub-apical annulus, tarsomere 2 with apical $2 / 3$ dark brown to black and tarsomeres 3-5 dark brown; mesotarsus with tarsomere 5 dark brown to black. Metaleg with coxa black and trochanter

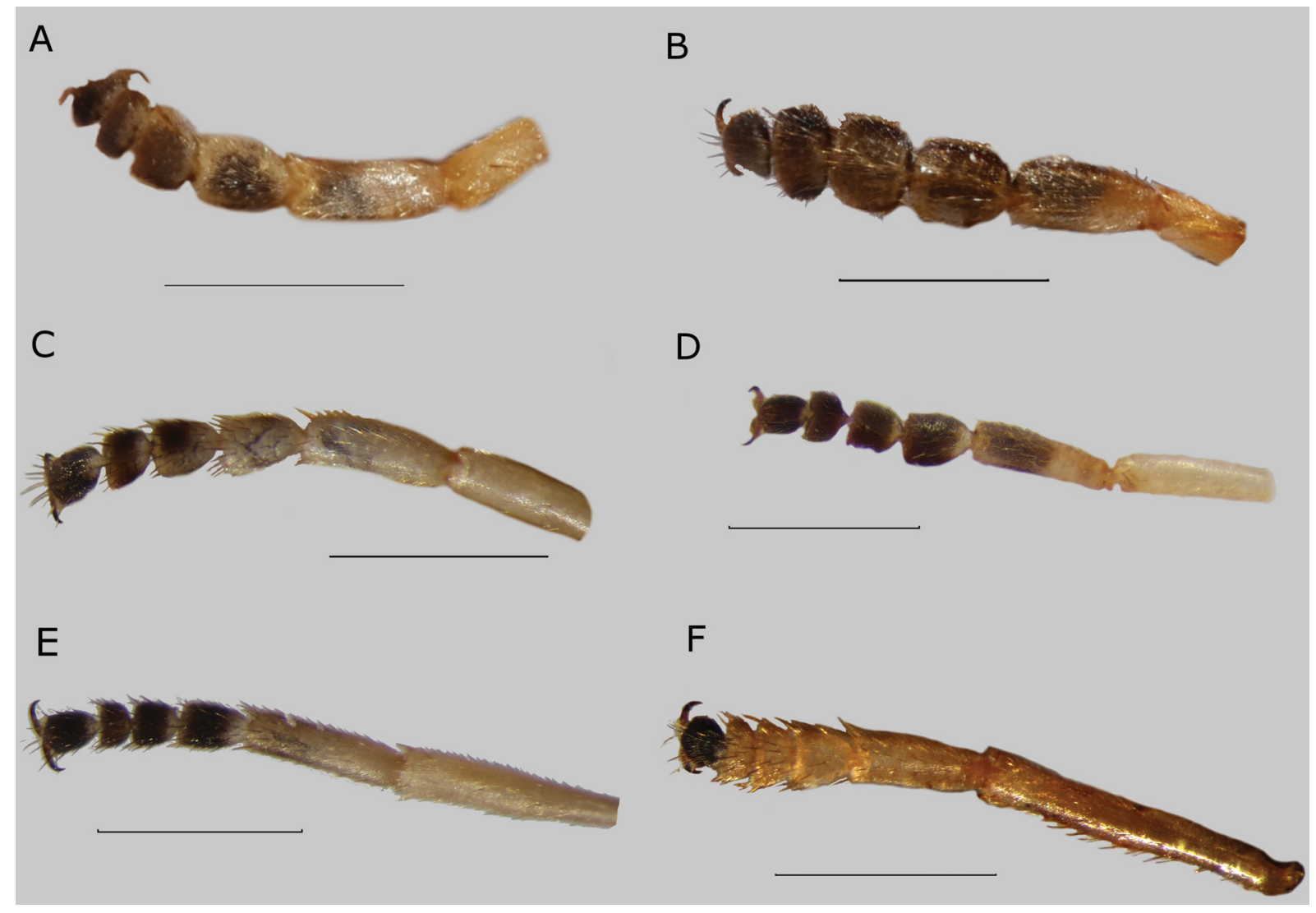

Fig. 61. Protarsus, dorsal view. A. Sphegina (Asiosphegina) atrimanus sp. nov., holotype, ð̃, Vietnam.

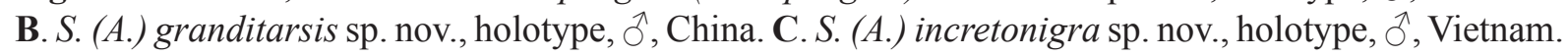
D. S. (A.) nigrotarsata sp. nov., paratype, ô, Vietnam. E. S. (A.) orientalis Kertész, 1914, đิ, Taiwan. F. $S$. (A.) plautus sp. nov., holotype, $\hat{\jmath}$, China. Scale bars $0.5 \mathrm{~mm}$. 
yellow; femur black and yellow biannulate, slender club shaped, ratio width: length 1: 4.7-5.1; tibia black and yellow biannulate with short sharp subtriangular apicoventral dens; tarsus entirely black, basitarsomere very thick, ratio width: length 1: 2.7-3.1.

AвDOMEN. Length ratio of terga I: II: III: IV 1: 3.2-3.6: 2.3-2.6: 1.8-2.1; ratio width at posterior margin: medial length of tergum II and III 1: 4.6-5.0 and 1: 1.0-1.3. Terga black, anterior $1 / 4$ of tergum III with straight yellow fascia; anterior $1 / 5$ of tergum IV with yellow posteromedially incised fascia; pile pale, on terga short, laterally on terga I and II long; tergum I with horizontal row of 2 strong dark brown to light yellow setae at lateral margin; sternum III rectangular, ratio width: length 1: 2.2-3.4; sternum IV, Fig. 62A; sterna VI, VII and VIII simple, with long yellow pile. Genitalia, Fig. 62B-D: note the group of long seta-like pile on cercus, nearly symmetrical surstyli and superior lobes and the small setae on the membrane at the surstylar apodemes.

\section{Female}

Unknown.

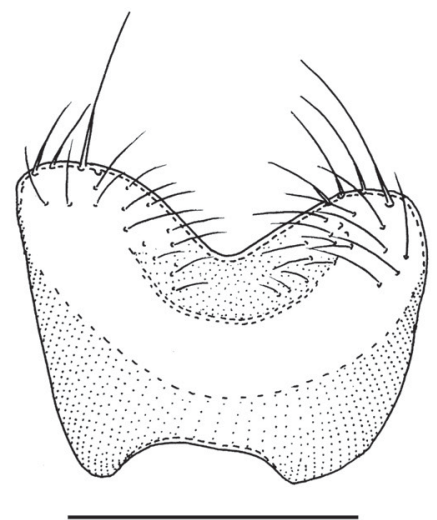

A
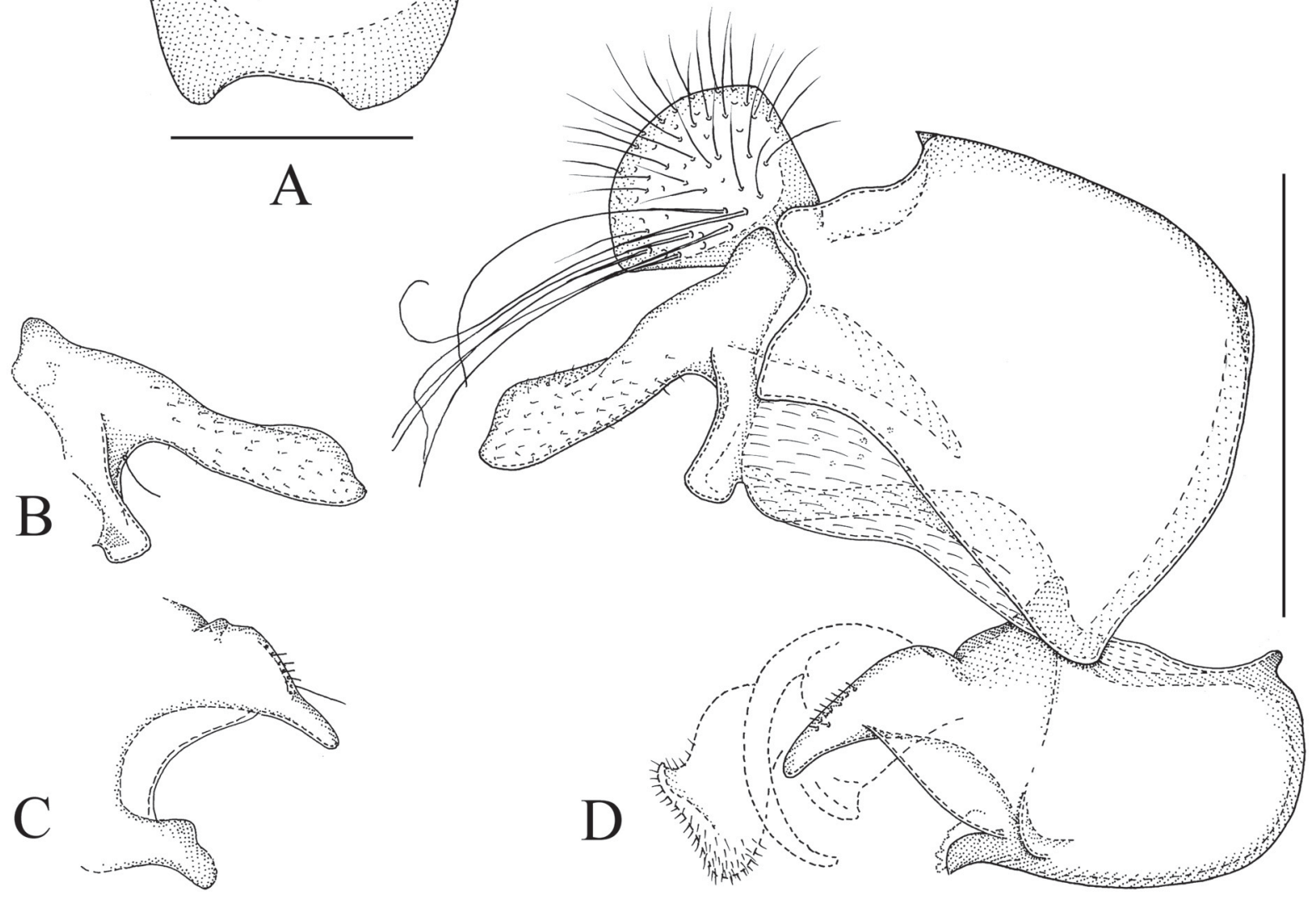

Fig. 62. Sphegina (Asiosphegina) nigrotarsata sp. nov., holotype, ठ̊. A. Sternum IV, ventral view. B. Left surstylus, lateral view. C. Left superior lobe with associated parts, lateral view. D. Genitalia, right side, lateral view. Scale bars $=0.5 \mathrm{~mm}$. 
Sphegina (Asiosphegina) nubicola sp. nov.

urn:1sid:zoobank.org:act:9B888AE7-1401-4E38-84B6-B5A2A653C7B0

Figs 63E, 64, 70A-B, 84B

\section{Differential diagnosis}

Sphegina (Asiosphegina) nubicola sp. nov. is similar to $S$. (A.) apicalis and $S$. (A.) farinosa sp. nov. but is distinguished by the characters given in the key. See also under $S$. (A.) apicalis and $S$. (A.) farinosa sp. nov.

\section{Etymology}

The specific epithet is from the Latin 'nubicola', meaning 'cloud-dweller' and referring to the high altitude of the type locality.

\section{Material examined}

Holotype

THAILAND • O'; “THAILAND: "Chiang Mai: Chomthong / Doi Inathon NP Summit trap 3/18.585 N, 98.483 E 2545m, 1.IV.- / 2.V.2014 [leg] W. Siruka \& R. Sawkord Mal / Tp. QSBG 2014-80”; very teneral specimen without clear colours; QSBG.

\section{Paratypes}

THAILAND • 1 $\widehat{\partial}, 3$ 9 \% ; same data as for holotype; JSA • 5 qq ; same data as for holotype; QSBG • 1 ; same data as for holotype; "Summit trap 1 / QSBG 2014-78"; QSBG • 2 우; same data as for holotype; "Summit trap 1 / QSBG 2014-79"; JSA • 3 + $\circ$; same data as for preceding; QSBG • 1 ; same data as for holotype; "Summit trap 2/ QSBG 2014-83"; QSBG • 8 q 9 ; same data as for holotype; "Summit trap 2 / 2-29.V.2014 / QSBG 2014-126"; CSCA • 14 + $\circ$; same data as for preceding; JSA • 18 웅 same data as for preceding; QSBG • 8 우; same data as for holotype; "2-9.V.2014 / QSBG 2014-127"; CSCA • 11 우; same data as for preceding; JSA • 20 우; same data as for preceding; $\mathrm{QSBG} \bullet 2$ 우; same data as for holotype; "Kiew maepan trail trap 2; / $2210 \mathrm{~m} 18.555^{\circ} \mathrm{N}, 98.479^{\circ} \mathrm{E} /$ 30.VII-27.VIII.2014 / QSBG 2014-215"; QSBG • 2 우; same data as for preceding; "2200 m / Malaise $18^{\circ} 33.162^{\prime}$ N, $98^{\circ} 28.81^{\prime}$ E / 29.iv-6.v.2007 Y. Areeluck leg. T1853”; QSBG.

\section{Additional material}

VIETNAM • 1 क; "Viet Nam: Mt Lang / Bian 1500-2000 m / 19.V-8.VI.1961"; "N.R. spencer / Collector / Bishop"; BPBM・ 1 q; same data as for preceding; JSA.

\section{Description}

Male

LeNGTH. Body 4.0-4.1 mm, wing 3.7-3.8 mm.

HEAD. Face in lateral view concave, weakly projected antero-ventrally; frontal prominence very weakly developed. Ratio width of vertex at anterior ocellus: width of head 1: 3.6-3.8; ratio width of ocellar triangle: width of vertex 1: 3.6-3.8; ratio length of ocellar triangle: length of frons 1: 2.0-2.2. Face creamy white, light grey pollinose, long pilose along eye-margin. Hypostomal bridge creamy-white, long pale pilose. Gena and mouth edge creamy white with large subtriangular non-pollinose shiny area. Frons and vertex light-brown, slightly pollinose with small semi-circular shiny area posteriorly to lunula; postero-laterally to shiny area with wide, subtriangular densely grey pollinose macula (Fig. 84B); pile short, light yellow. Frons with deep depression anteromedially and weak medial furrow. Occiput lightbrown, light grey pollinose, light yellow pilose. Eye without enlarged facets at anterior margin. Antenna with scape and pedicel light-brown, basoflagellomere brown to dark brown with black setae dorsally 
on scape and pedicel; basoflagellomere oval, ratio width: length 1:1.1-1.2; arista basally short pilose, about 2.5 times as long as basoflagellomere.

THORAX. Colour light-brown, postpronotum light yellow, weakly greyish pollinose, posterior margin of katepisternum narrowly non-pollinose, shiny; scutum and pleuron with very short adpressed light yellow pile. Scutellum [due to wrinkled shape not well seen] light-brown, shiny, laterally slightly pollinose, with pile slightly longer than on scutum, with two closely set, very short setae medially at posterior margin, ratio length of scutellum: length of seta 1: 0.7-0.8.

WING. Entirely microtrichose; hyaline, stigma yellowish. Crossvein dm-cu meeting vein M obliquely and vein $M_{1}$ meeting vein $R_{4+5}$ perpendicularly.

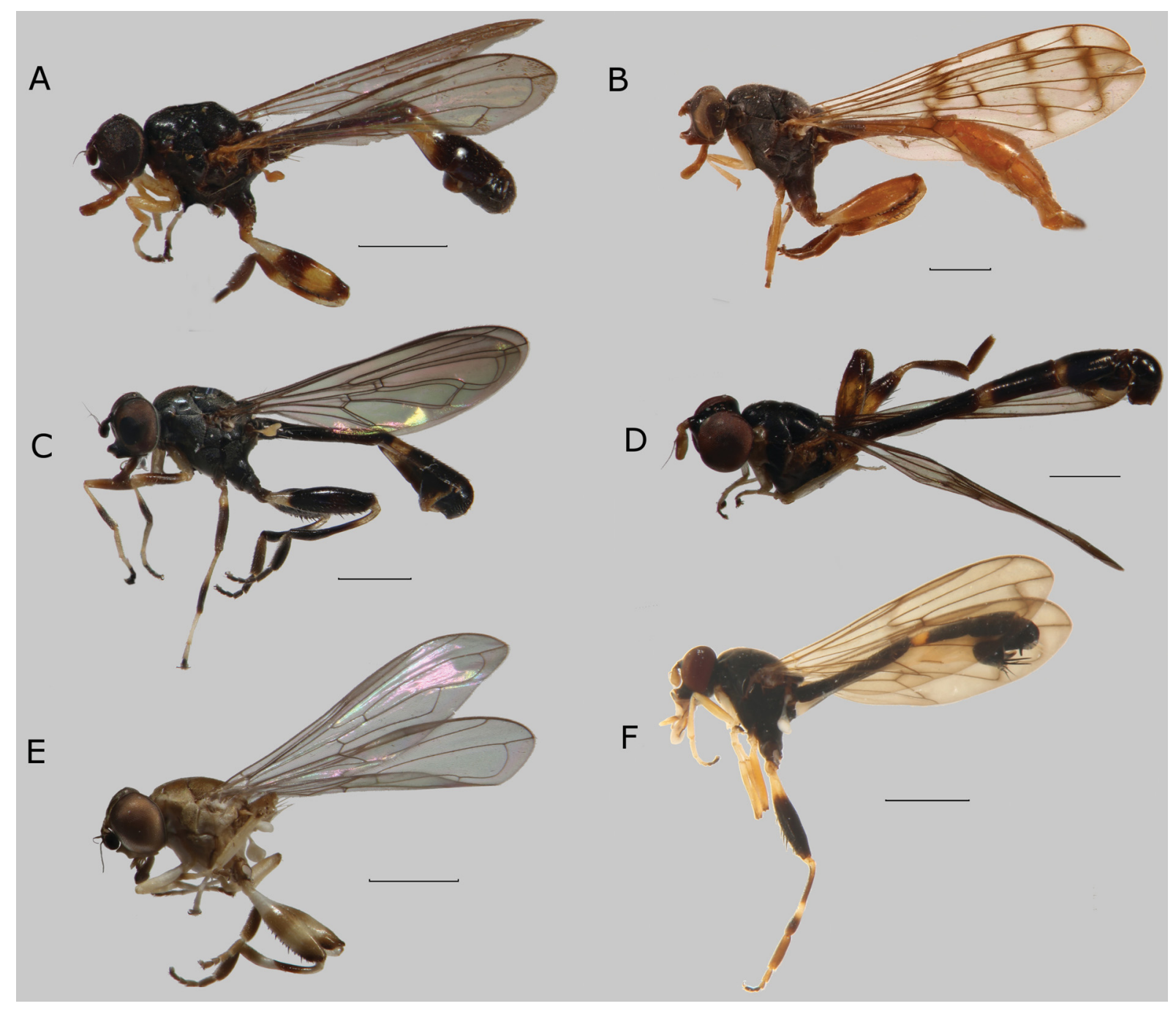

Fig. 63. Habitus, lateral view. A. Sphegina (Asiosphegina) minuta Hippa, van Steenis \& Mutin, 2015, paratype, ô, Myanmar. B. S. (A.) mirifica Hippa, van Steenis \& Mutin, 2015, + , Myanmar. C. S. (A.) nigerrima Shiraki, 1930, ठ̃, Taiwan. D. S. (A.) nigrotarsata sp. nov., paratype, ô, Vietnam. E. S. (A.) nubicola sp. nov., holotype, ô, Thailand. F. S. (A.) ornata sp. nov., holotype, ô, China. Scale bars $=1.0 \mathrm{~mm}$. 
Legs. Pro- and mesoleg light yellow, tarsomeres 4-5 light to dark brown. Metaleg with coxa and trochanter light- to dark brown; femur black and yellow biannulate, slightly incrassate, ratio width: length 1: 4.0-4.2; tibia black and yellow biannulate, without apicoventral dens; tarsus entirely light- to dark brown, basitarsomere very thick, ratio width: length 1: 2.7-2.9.

AвDomen. Length and width ratios of terga not measurable. Terga light-brown, anterior $1 / 4-1 / 3$ of tergum III with creamy white to yellow fascia; pile pale, on terga short, laterally on terga I and II long; tergum I with an oblique row of 4 light yellow setae at lateral margin; sternum IV, Fig. 64A; sterna VI, VII and VIII simple, with long yellow pile. Genitalia, Fig. 64B-D: note the asymmetrical surstyli and slightly asymmetrical superior lobes.

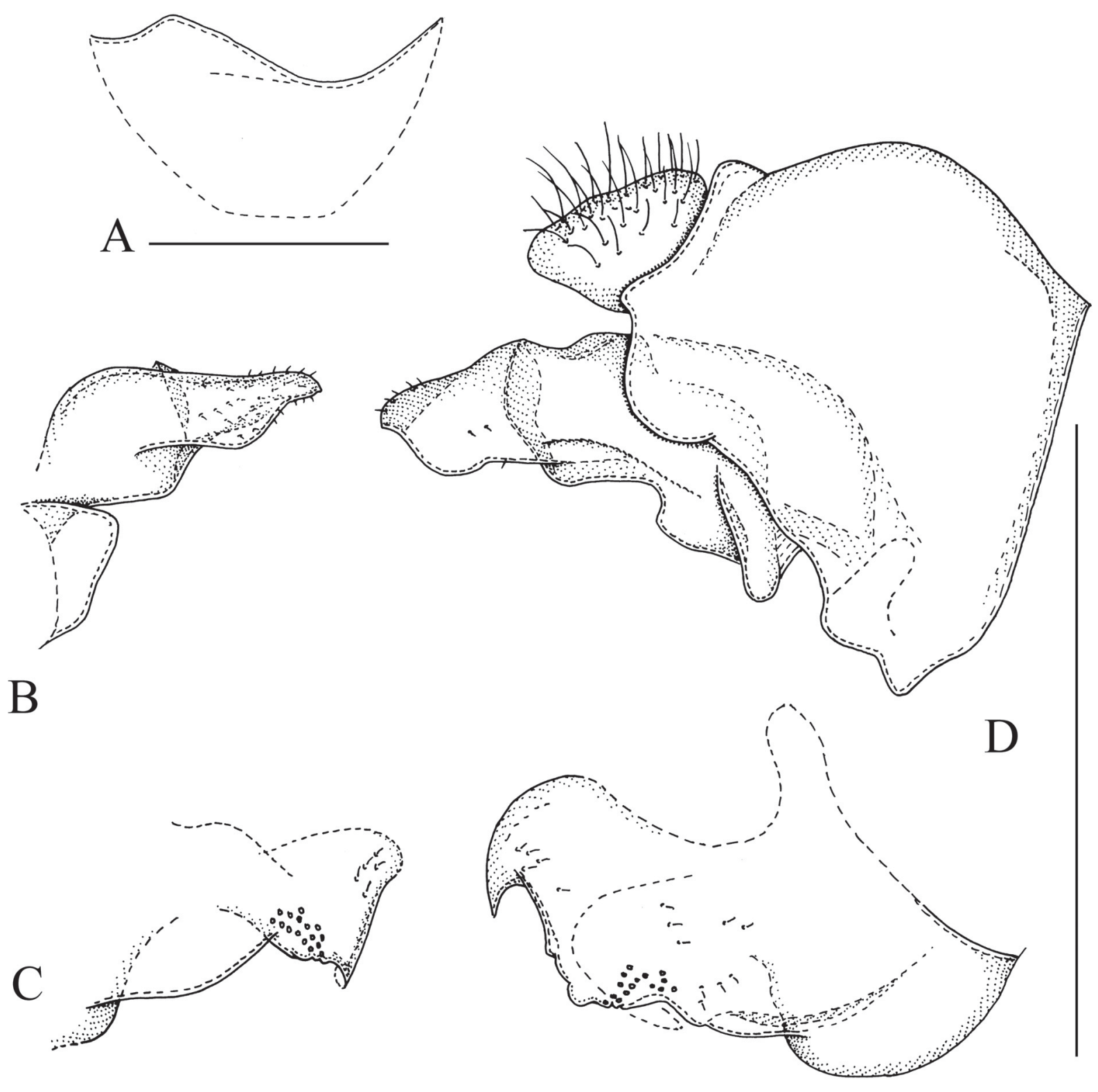

Fig. 64. Sphegina (Asiosphegina) nubicola sp. nov., holotype, $\widehat{\jmath}$. A. Sternum IV, ventral view. B. Left surstylus, lateral view. C. Left superior lobe with associated parts, lateral view. D. Genitalia, right side, lateral view. Scale bars $=0.5 \mathrm{~mm}$. 
Female

Similar to male except for the usual sexual dimorphism.

LeNGTH. Body 4.4-4.8 mm, wing 4.2-4.7 mm.

HEAD. Face in lateral view concave, very weakly projected antero-ventrally; frontal prominence weakly developed. Ratio width of vertex at anterior ocellus: width of head 1: 3.3-3.6; ratio width of ocellar triangle: width of vertex 1: 2.1-2.3; ratio length of ocellar triangle: length of frons 1:3.4-3.8. Face black to ventral half light-brown, mouth edge from light yellow to light-brown to orange. Basoflagellomere oval, ratio width: length $1: 1.2-1.3$.

Thorax. Scutellum semi-circular and shiny with two rather closely set very short setae medially at posterior margin, ratio length of scutellum: length of seta 1: 0.8-0.9.

LEGS. In some specimens tarsomere 3 of pro- and mesotarsus light-brown to black; metafemur, ratio width: length 1: 4.1-4.3; metatarsus with basitarsomere thick, ratio width: length 1:2.9-3.2.

ABDOMEN. Length ratio of terga I: II: III: IV: V 1: 2.7-3.0: 2.2-2.4: 1.8-2.1: 0.9; ratio width at posterior margin: medial length of tergum II and III 1: $0.9-1.0$ and 1: 0.6 . Abdomen predominantly black (Fig. 70A) with only anterior $1 / 4$ of tergum III dark yellow or terga III-V with light yellow fascia on anterior $1 / 2-3 / 4$ (Fig. 70B); sternum III rectangular, ratio width: length 1: 1.8-2.4; sternum IV widely rectangular, ratio

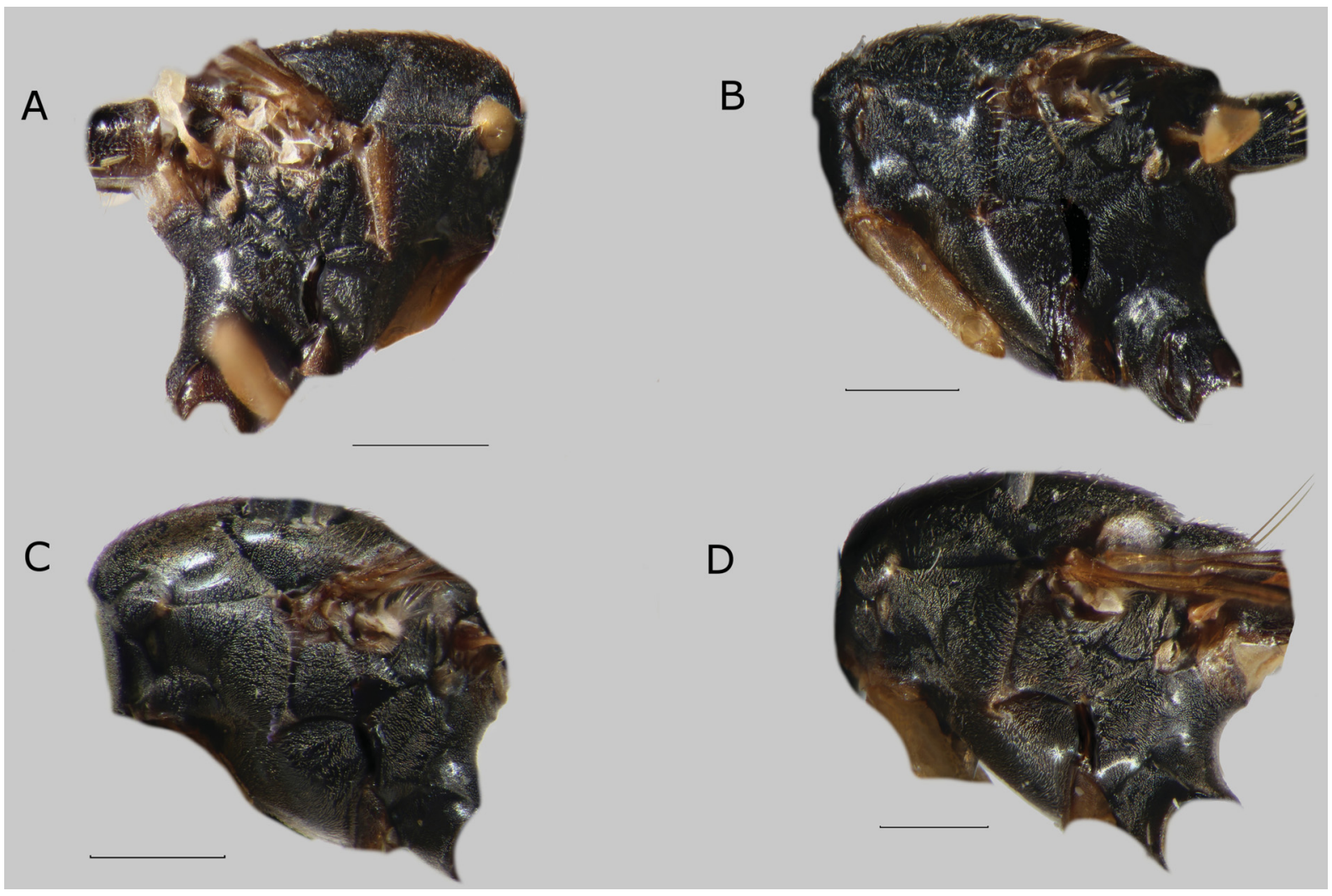

Fig. 65. Pleuron, lateral view. A. Sphegina (Asiosphegina) crinita sp. nov., holotype, đ̂, Java, Indonesia. B. S. (A.) dentata sp. nov., holotype, đ̃, Taiwan. C. S. (A.) nigerrima Shiraki, 1930, đ̂, Taiwan. D. S. (A.) varidissima Shiraki, 1930, đ, Taiwan. Scale bars $0.5 \mathrm{~mm}$. 
width: length 1: 0.6 ; sternum $\mathrm{V}$ widely rectangular with concave posterior margin, ratio width: length 1: $0.3-0.4$.

\section{Remarks}

The females from Vietnam are not included in the type material as they are slightly different from the other females and possibly represent an undescribed species.

\section{Sphegina (Asiosphegina) orientalis Kertész, 1914}

Figs 61E, 66, 67A-B, 68-69, 70C, 84C

Sphegina orientalis Kertész, 1914: 73. Type locality: Kosempo, Taiwan (lectotype, ð, NMHB).

\section{Differential diagnosis}

Sphegina (Asiosphegina) orientalis is similar to $S$. (A.) atrimanus sp. nov., S. (A.) granditarsis sp. nov., $S$. (A.) nasuta and $S$. (A.) nigrotarsata sp. nov. For distinguishing characters, see under $S$. (A.) atrimanus sp. nov. and $S$. (A.) granditarsis sp. nov.

\section{Material examined}

TAIWAN • 1 ô;; "Formosa / Sauter"; "Taihorin / 1911, VII."; “orientalis Kert / det. Kertész"; "coll. Klöcker"; "Lectotypus Sphegina / orientalis Kertész / design. Thompson" [red label, partly handwritten], “orientalis / Kertész"; partly destroyed specimen; USNM.

\section{Additional material}

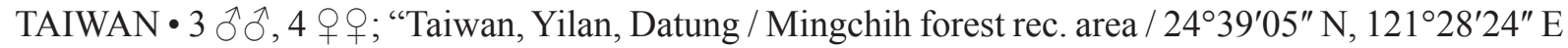

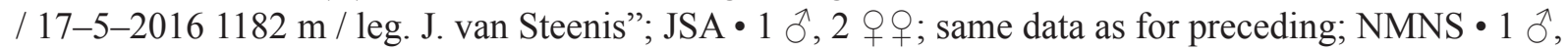
1 ㅇ same data as for preceding; NTU • 1 + ; same data as for preceding; " $24^{\circ} 38^{\prime} 40^{\prime \prime} \mathrm{N}, 121^{\circ} 27^{\prime} 40^{\prime \prime} \mathrm{E}$ / 1120 m"; JSA • 1 q; same data as for preceding; NTU • 1 \%; same data as for preceding; "leg. W. van Steenis"; NMNS • 3 우; same data as for preceding; NTU • 4 우; same data as for preceding; WSB • 1 क ; same data as for preceding; " $24^{\circ} 38^{\prime} 40^{\prime \prime}$ N, $121^{\circ} 27^{\prime} 40^{\prime \prime}$ E / 1120 m / leg. W. van Steenis";

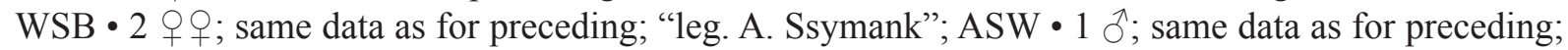
WSB • 1 O ; same data as for preceding; "leg. B. Lechner-Ssymank"; ASW • 1 त; same data as for

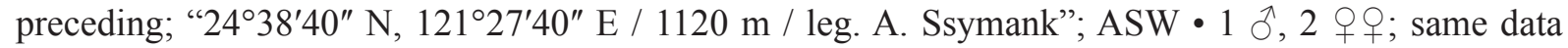
as for preceding; " $24^{\circ} 31^{\prime} 46^{\prime \prime} \mathrm{N}, 121^{\circ} 27^{\prime} 43^{\prime \prime}$ E/ 1112m.a.s.l. / leg C J Palmer"; CPP • 1 क; same data as for preceding; NTU • 1 q; same data as for preceding; " $24^{\circ} 39^{\prime} 04^{\prime \prime} \mathrm{N}, 121^{\circ} 28^{\prime} 19^{\prime \prime} \mathrm{E} / 1157 \mathrm{~m}$.a.s.1. / leg C J Palmer"; CPP• 2 우; same data as for preceding; "leg MP van Zuijen”; MZW • 2 우; same data as for preceding; NTU • 1 Oे, 1 क ; same data as for preceding; "Roadside / $1050 \mathrm{~m}$ a.s.l. / leg MP van Zuijen"; MZW • 1 क; same data as for preceding; "J.H. Skevington, A.D. Young / JSM8411-14 CNC566911-14"; DNA voucher specimens, in alcohol; CNC • 1 o, 1 ㅇ; same data as for preceding; NMNS • 1 ठ̊; " "Taiwan, Mingchih, small rocky valley / Ren'ai, Nantou / 1-6-2016, $1080 \mathrm{~m}$ a.s.1. /

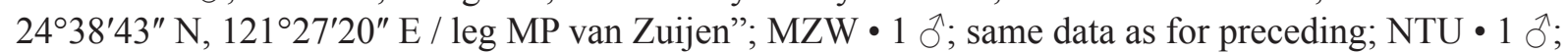
same data as for preceding; "J.H. Skevington / JSM7929 CNC569410"; DNA voucher specimen, in alcohol; CNC • 1 \%; same data as for preceding; "A.D. Young, rich fern / vegetation in rocky, forested / creek valley / JSM8078 / CNC569431"; DNA voucher specimen, in alcohol; CNC • 1 q; "FO: 8996

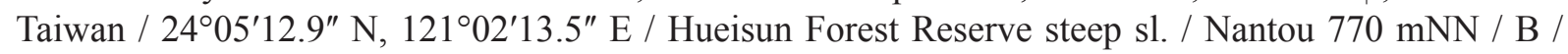
leg B. Lechner-Ssymank 20.05.2016"; ASW • 1 P; "Taiwan Hualien, Yuli / Antong traversing trail / ca $12 \mathrm{~km}$ SSW of Yuli / $23^{\circ} 16^{\prime} 48^{\prime \prime} \mathrm{N}, 121^{\circ} 21^{\prime} 9^{\prime \prime}$ E / 24-5-2016 $1182 \mathrm{~m} /$ leg. J. van Steenis"; JSA • 1 o; "Taiwan Taiting / Tenping / 13.III.1990 / C.C. Chiang / Sweeping net"; "NMNS ENT / 592-6"; NMNS• 1 P; "Taiwan Ilan / Wufangchi / 16.X.1990 / C.C. Chiang / Sweeping"; "NMNS ENT / 754-28"; NMNS

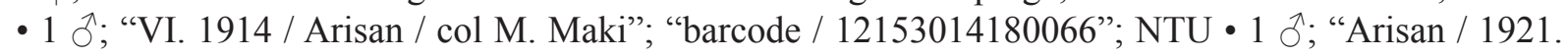


X-10 / Col I. Nitobe"; "barcode / $12153014180069 " ;$ NTU • 1 § ; same data as for preceding; "barcode / 73"; NTU • 5 우; same data as for preceding; with barcodes 68, 70 to 72 and 74; NTU • 1 \% ; "Arisan / 21.IV-8.VI. [19]19 / Col T. Shiraki"; "barcode / 63"; NTU • 1 đ̊; "Kobayasti / Rosti 2.VIII.1923 / Col. T Shiraki"; "barcode / 99"; NTU • 1 Õ; "Formosa / Arisan 1918 / X 2- 23 / J. Sonan, / M. Yoshino"; "barcode / 79"; NTU • 1 ठ̊;; "Taiheizan / 25 and 29-VIII-1923 / Col. T Shiraki"; "barcode / 94"; NTU •

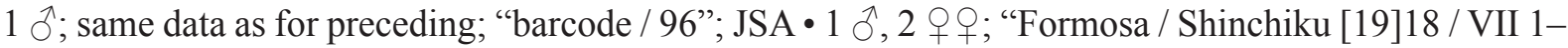
30; / J. Sonan / M. Miyake"; with barcodes 80, 81, and 83 respectively; 1 o ; same data as for preceding; "barcode / 84"; JSA.

VIETNAM • 1 ठ̊; "N. Vietnam Tonkin / Hoang Lien N.P. Pansi Pan Mt / 2320 m prim. Forest 24.iv- / 2.v.2000 [leg] Mai Phu Quy \& / Nguyen M. Tam RMNH'00”; NBC.

CHINA • 1 ภ̊; "CHINA Sichuan / Mt EMEI / 17-21.IX.1985”; "4 km N / XIANFENG / 1650 m”; JSA • 3 ふึगे, 1 ㅇ; "Fukien, S. China / Shaowu: Tachulan / 1000 m T. Maa"; "24.IV-15.VII.1942"; BPBM •

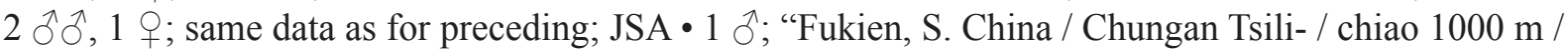
1942 T. Maa”; “19.X.1942”; BPBM.
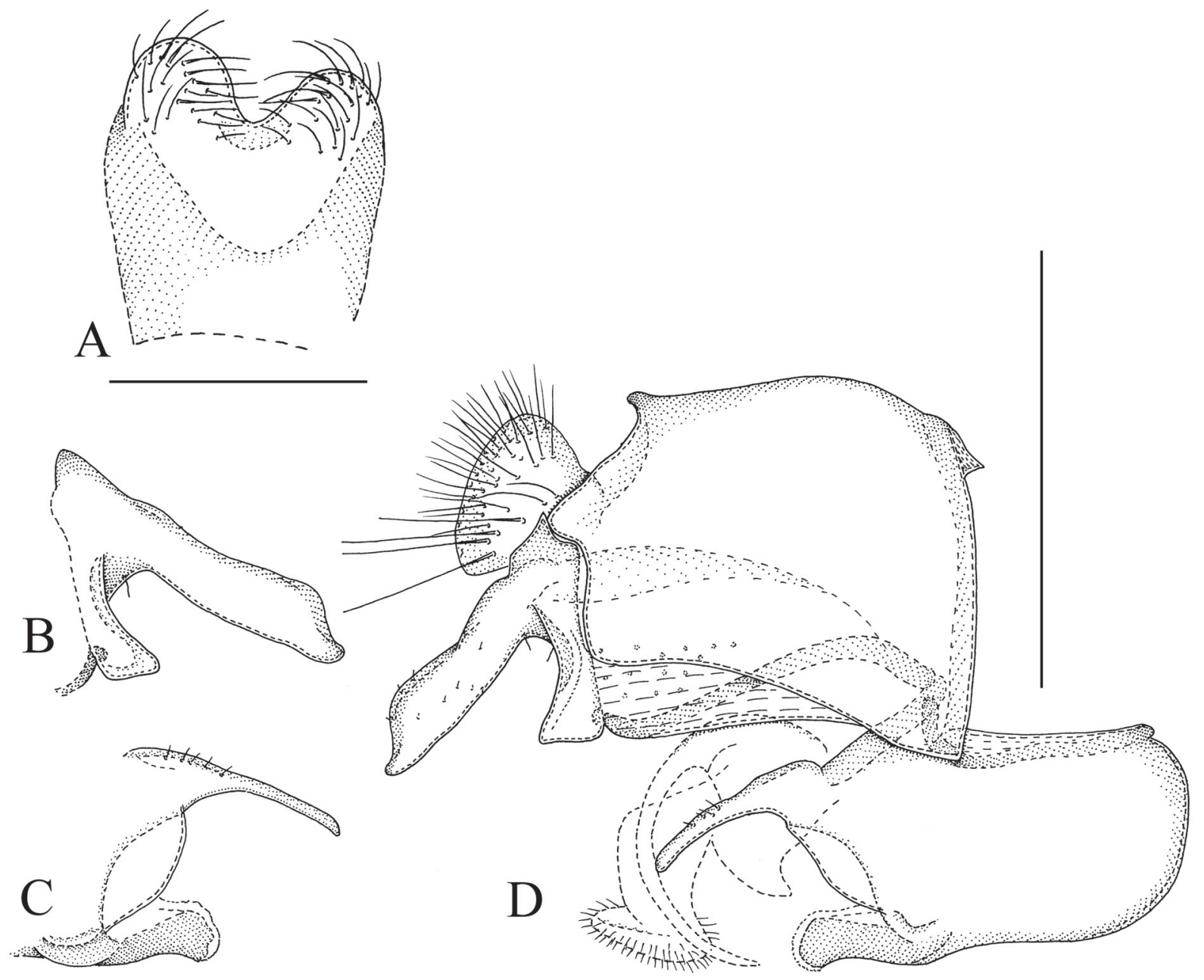

Fig. 66. Sphegina (Asiosphegina) orientalis Kertész, 1914, ô Vietnam. A. Sternum IV, ventral view. B. Left surstylus, lateral view. C. Left superior lobe with associated parts, lateral view. D. Genitalia, right side, lateral view. Scale bars $=0.5 \mathrm{~mm}$. 
JAPAN • 1 §’; "Ryukyu Is / Iricomote I. / Ushiku-mori 425 m / 11.III.1964”; “C.M. Yoshimoto / G.J. Harrell / Collector"; "U.S.-Japan / Co-op. Sci. / Programme"; BPBM • 1 q; "Ryukyu Is / Iricomote I. / Nakara Gawa / 0-200 m 12.III.'64”; “C.M. Yoshimoto / G.J. Harrell / Collector”; "U.S.-Japan / Co-op. Sci. / Programme"; BPBM - 1 O+; "Japan: Okinawa Island, / roadside and trail NE of / Mount Yonaha $26.735864^{\circ} \mathrm{N}, 128.230661^{\circ}$ E 7.vi.2016 / J.H. Skevington, A.D. Young, / S. Bot JSM8741, / CNC573355"; DNA voucher specimen, in alcohol; CNC • 1 त, 1 q; same data as for preceding; “26.735862 $\mathrm{N}, 128.230659^{\circ} \mathrm{E} / \mathrm{CNC} 560675-6 ” ;$ CNC.

\section{Redescription}

\section{Male}

Length. Body 6.3-7.2 mm, wing 5.1-5.9 mm.

HEAD. Face in lateral view concave, strongly projected antero-ventrally; frontal prominence weakly developed. Ratio width of vertex at anterior ocellus: width of head 1: 4.0-4.4; ratio width of ocellar

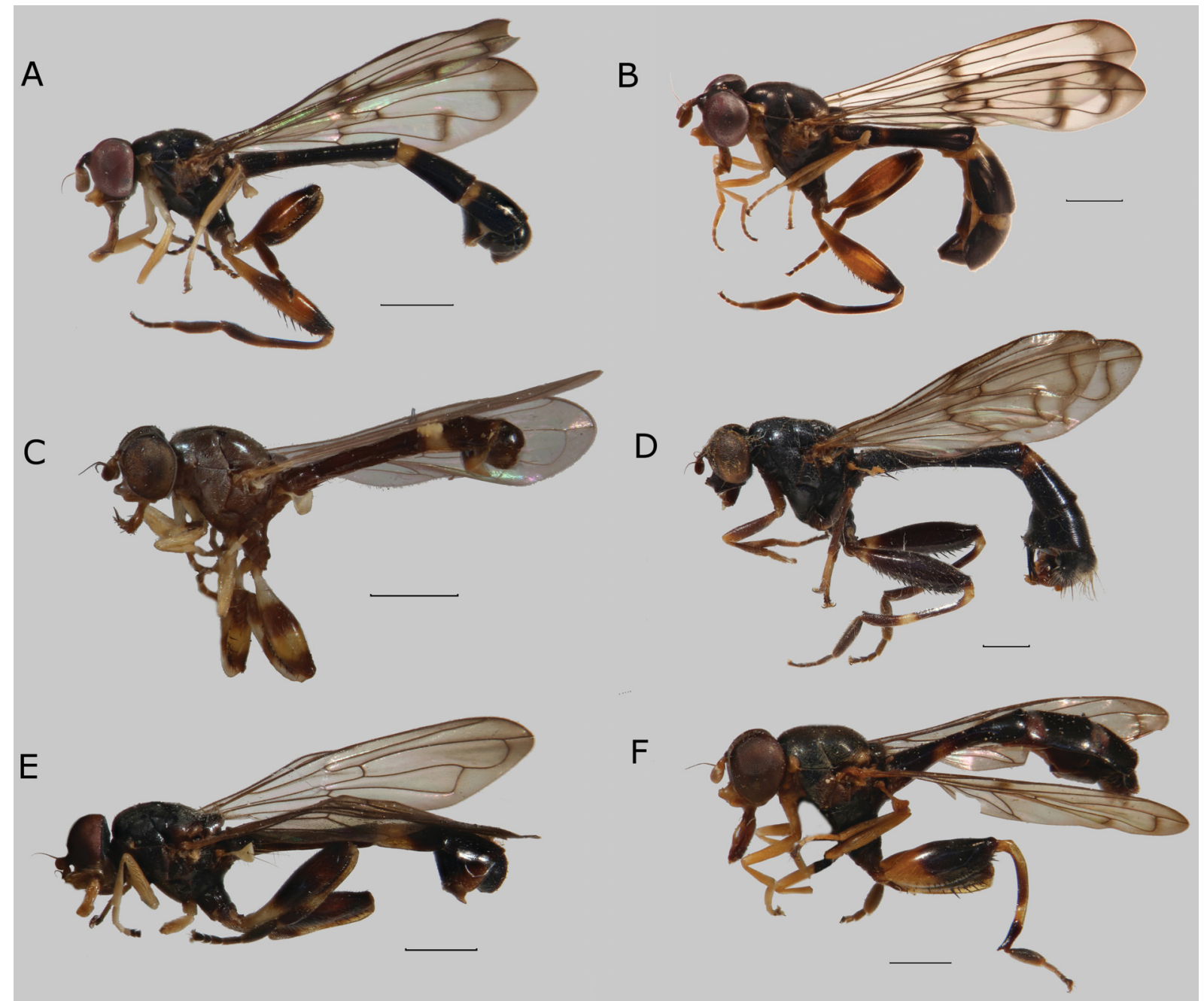

Fig. 67. Habitus, lateral view. A. Sphegina (Asiosphegina) orientalis Kertész, 1914, Ô, Taiwan. B. S. (A.) orientalis, ㅇ, Taiwan. C. S. (A.) parvula Hippa, van Steenis \& Mutin, 2015, paratype, ô,

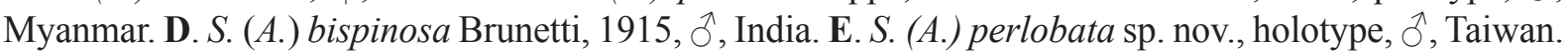
F. S. (A.) philippina Thompson, 1999, paratype, $q$ from Culasi, Philippines. Scale bars $=1.0 \mathrm{~mm}$. 
triangle: width of vertex 1: 1.6-1.9; ratio length of ocellar triangle: length of frons 1:2.4-2.8. Face black, ventral half yellow, light grey pollinose, long pilose along eye-margin. Hypostomal bridge black, long pale pilose. Gena and mouth edge yellow with large subtriangular non-pollinose shiny area, posterior part of mouth edge dark brown to black. Frons and vertex black, frontal prominence long, shiny with grey pollinose subtriangular macula antero-laterally at eye-margin (Fig. 84C); pile short, light yellow. Frons with deep anteromedial pit and wide medial furrow. Occiput black, light grey pollinose, ocellar triangle non-pollinose shiny, light yellow pilose. Eye without enlarged facets at anterior margin. Antenna with scape and pedicel dark yellow to brown, basoflagellomere dark brown to black with black setae dorsally on scape and pedicel; basoflagellomere elongate, ratio width: length 1:2.1-2.3; arista short pilose, about 3 times as long as basoflagellomere.

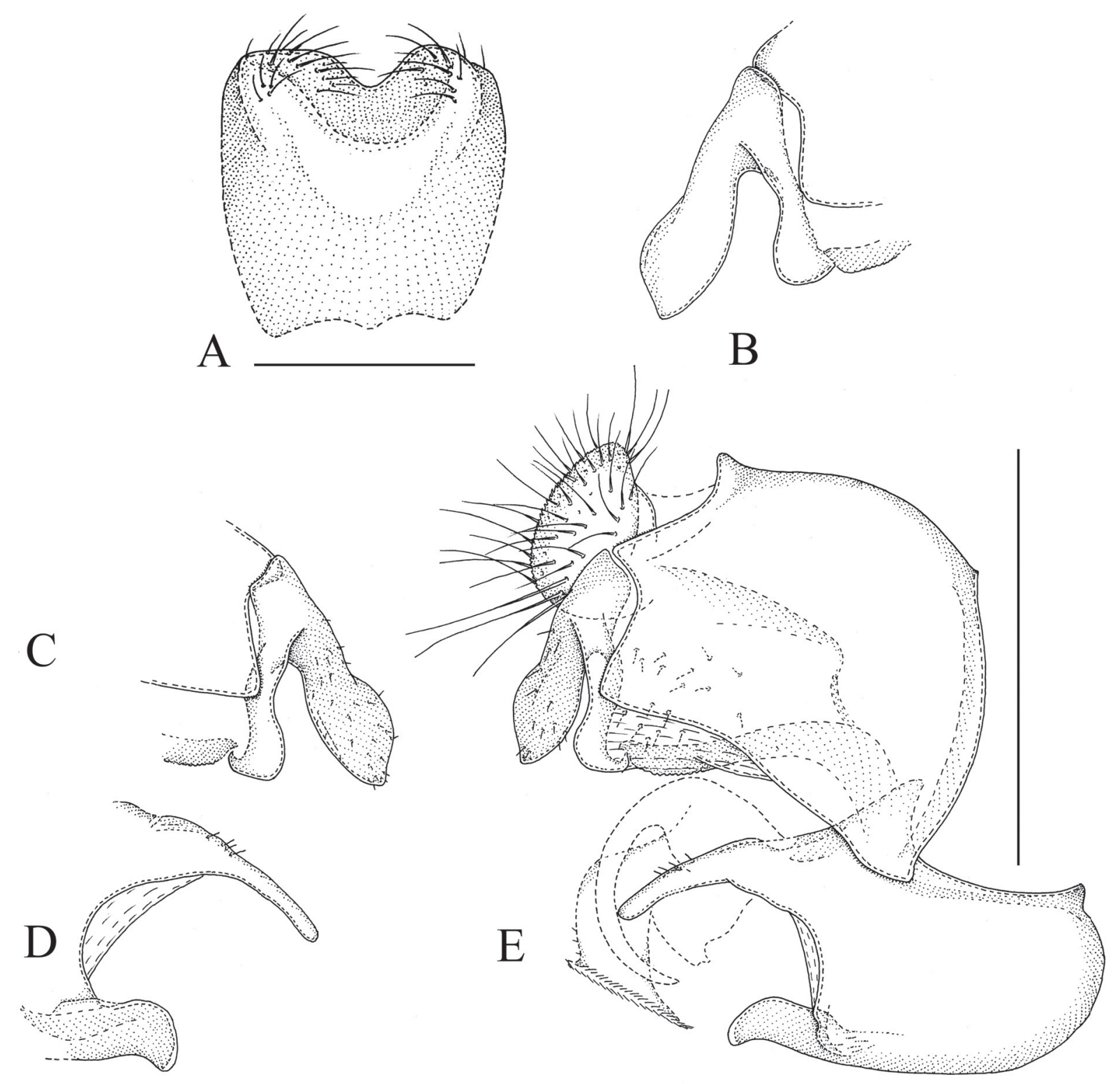

Fig. 68. Sphegina (Asiosphegina) orientalis Kertész, 1914, Ô, Taiwan, specimen 1 (A), Ô, Taiwan, Mingchih, specimen 2 (B-E). A. Sternum IV, ventral view. B. Right surstylus, postero-lateral view. C. Left surstylus, lateral view. D. Left superior lobe with associated parts, lateral view. E. Genitalia, right side, lateral view. Scale bars $=0.5 \mathrm{~mm}$. 
THORAX. Colour dark brown to black, postpronotum, and dorso-medial part of anepisternum and anepimeron yellow, weakly greyish pollinose; katepimeron at least medially non-pollinose and shiny (the specimens from the Ryukyu Islands with almost entirely pollinose katepimeron); scutum and pleuron with very short adpressed light yellow pile. Scutellum subtriangular, black, weakly pollinose
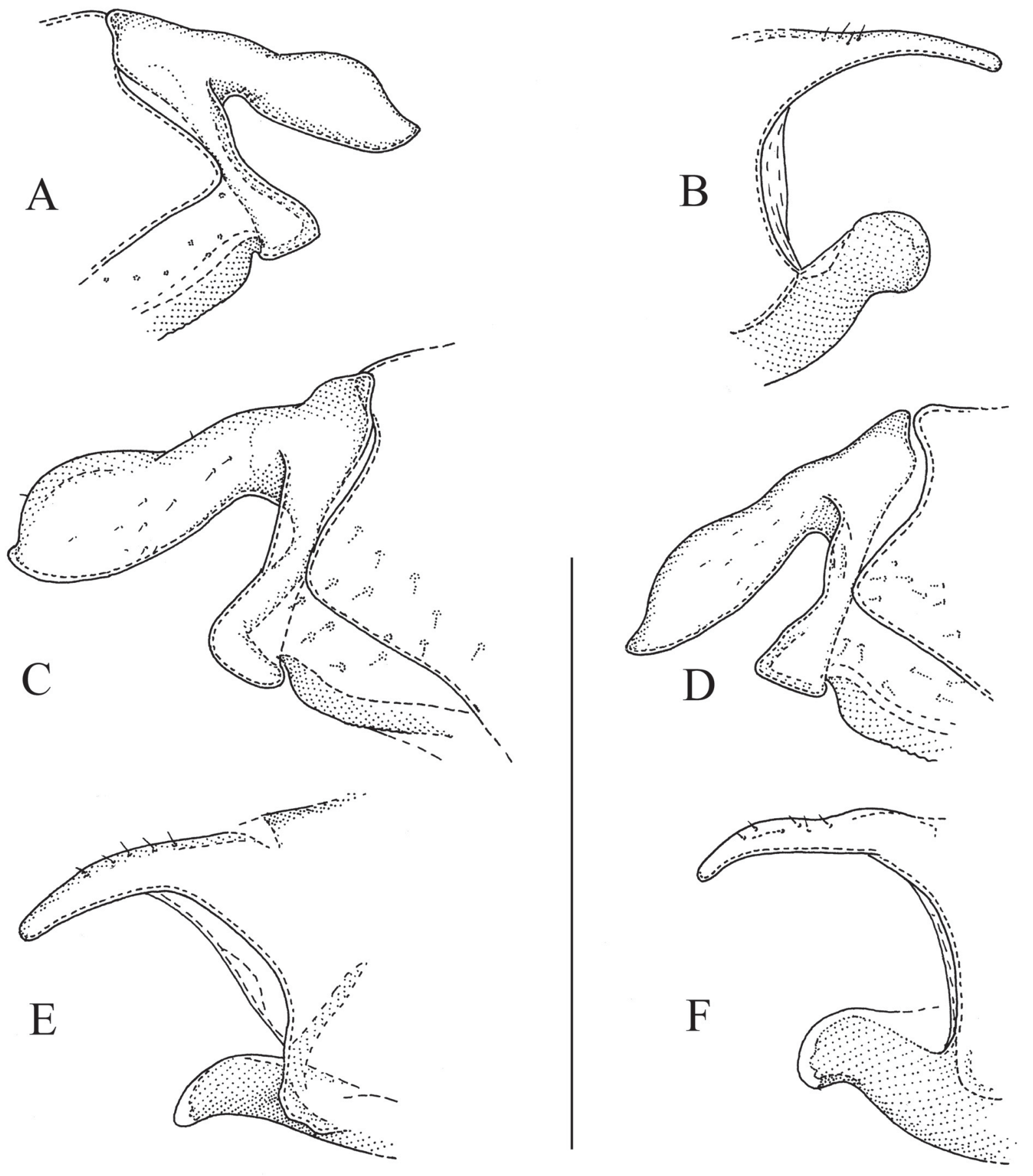

Fig. 69. Sphegina (Asiosphegina) orientalis Kertész, 1914, male genitalia, China, Mt Emei (A-B, D, F) and Taiwan specimens 1, Mingchih (C, E). A. Left surstylus with associated parts, lateral view. B. Left superior lobe with associated parts, lateral view. C-D. Right surstylus with associated parts, lateral view. E-F. Right superior lobe with associated parts, lateral view. Sale bar $=0.5 \mathrm{~mm}$. 
sub-shiny and, with pile slightly longer than on scutum, with two closely set, very short setae medially at posterior margin, ratio length of scutellum: length of seta 1: 0.7-0.8.

WING. Entirely microtrichose; hyaline, stigma yellowish, membrane brown infuscated at junction of veins $R_{2+3}$ and $R_{4+5}$, along veins bm-cu, $r-m$ and $M_{1}$, at apical end of vein $R_{2+3}$ and apical part of wing around vein $R_{4+5}$. Crossvein dm-cu meeting vein $M$ perpendicularly and vein $M_{1}$ meeting vein $R_{4+5}$ perpendicularly.

Legs. Pro- and mesoleg yellow; protarsus (Fig. 61E) with tarsomere 1 with black sub-apical annulus, tarsomere 2 with apical $2 / 3$ dark brown to black and tarsomeres 3-5 dark brown; mesotarsus with tarsomeres 3-5 dark brown to black. Metaleg with coxa black and trochanter yellow; femur black and yellow biannulate, slender, ratio width: length 1: 5.0-5.4; tibia black and yellow biannulate with short sharp subtriangular apicoventral dens; tarsus entirely black, basitarsomere thick, ratio width: length 1 : 3.1-3.5.

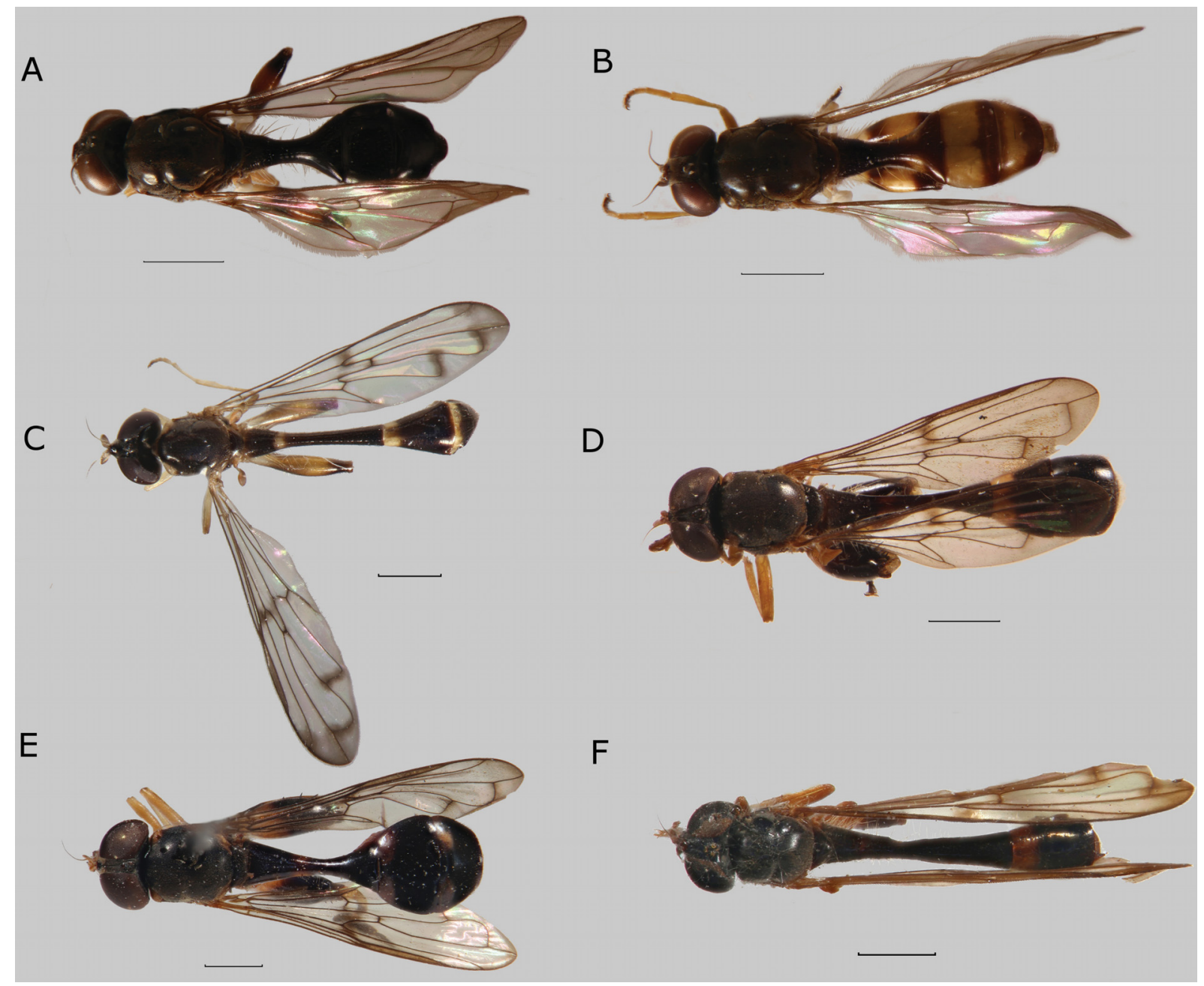

Fig. 70. Habitus, dorsal view. A. Sphegina (Asiosphegina) nubicola sp. nov., paratype, ${ }^{\text {, }}$, Thailand, dark form. B. S. (A.) nubicola sp. nov., paratype, q, Thailand, light form. C. S. (A.) orientalis Kertész, 1914, ô, Taiwan. D. S. (A.) philippina Thompson, 1999, holotype, đ̊, Philippines. E. S. (A.) philippina, paratype,, , Culasi, Philippines. F. S. (A.) plautus sp. nov., paratype, $\hat{\jmath}$, China. Scale bars $=1.0 \mathrm{~mm}$. 
AвDOMEN. Length ratio of terga I: II: III: IV 1: 3.0-3.5: 1.9-2.2: 1.5-1.8; ratio width at posterior margin: medial length of tergum II and III 1: 8.9-9.6 and 1: 4.8-5.3. Terga black, anterior $1 / 4$ of tergum II and anterior $2 / 3$ of tergum III with straight yellow fascia; anterior $1 / 5$ of tergum IV with posteromedially incised yellow fascia; pile pale, on terga short, laterally on terga I and II long; tergum I with row of 2-3 strong dark brown setae at lateral margin; sternum III elongate, ratio width: length 1: 3.7-4.1; sternum IV, Figs 66A, 68A; sterna VI, VII and VIII simple, with long yellow pile. Genitalia, Figs 66B-D, 68B-E, 69A-F: note the group of long seta-like pile on cercus, nearly symmetrical surstyli and superior lobes and the small setae on the membrane at the surstylar apodemes and the slight differences in the shape of surstyli and the superior lobes between the specimens from Taiwan and Vietnam.

\section{Female}

Similar to male except for the usual sexual dimorphism.

Length. Body 5.1-5.6 mm, wing 3.8-4.3 mm.

HEAD. Ratio width of vertex at anterior ocellus: width of head 1:3.8-4.3; ratio width of ocellar triangle: width of vertex 1: 1.8-2.0; ratio length of ocellar triangle: length of frons 1: 3.0-3.4. Frons sub-shiny slightly grey pollinose with wide but weak furrow. Basoflagellomere elongate, ratio width: length 1 : 1.6-1.9; arista long pilose; about 3 times as long as basoflagellomere.

THorax. Scutellum with two widely set, very short setae medially at posterior margin, ratio length of scutellum: length of seta 1: 0.7-0.9.

Legs. Protarsus with tarsomere $2-5$ with apical half dark-grey coloured; metafemur, ratio width: length 1: 4.7-5.3; metatarsus with basitarsomere thick, ratio width: length 1: 3.2-3.6.

ABdomen. Length ratio of terga I: II: III: IV: V 1: 3.0-3.4: 2.5-2.8: 2.1-2.4: 0.9-1.0; ratio width at posterior margin: medial length of tergum II and III 1:2.0-2.5 and 1: 0.8-0.9. Terga II, III and IV with yellow to dark yellow fascia on respectively anterior $1 / 10,1 / 3$ and $1 / 5$; sternum III short oval, ratio width: length 1: 1.6-1.9; sternum IV rectangular with strongly concave posterior margin, ratio width: length 1 : 1.6-1.9; sternum $\mathrm{V}$ rectangular, ratio width: length 1: 1.2-1.5.

\section{Distribution and biology}

Widely distributed throughout Taiwan and also recorded from N. Vietnam, S. China and the Ryukyu Islands, Japan. Lowland to high montane $(50-2820 \mathrm{~m})$ species collected from the end of April until the end of July and between the $17^{\text {th }}$ and $21^{\text {st }}$ of September. In Taiwan abundantly collected on a cold misty day along a lakeshore and roadside in semi-shady humid forest margins with a dense herb layer dominated by Oenanthe javanica Blume (DC). Other habitats were humid semi-shady roadsides in wide-leaved forests, oil palm plantations or afforestations dominated by Pinus taiwanensis Hayata. Flower visiting has been observed on Oenanthe javanica, Astilbe longicarpa Hayata (Hayata), Bidens pilosa L., Cyclospermum leptophyllum (Pers.) Sprague, Erigeron annuus (L.) Pers. and Ranunculus spp. Flies were also seen flying low through the vegetation (van Steenis et al. in prep). The specimen from Vietnam was collected in a Malaise trap near Fan Si Pan mountain at about $2300 \mathrm{~m}$ a.s.1. The Malaise trap was set up in an area of open and low montane forest partly grazed by buffalos, containing muddy areas and small streams. Despite the cold and wet weather insects were still rather abundantly flying (C. van Achterberg, pers. comm).

\section{Remarks}

Sphegina (Asiosphegina) orientalis is a variable species based on external and genital characters. The Okinawa population differ from the Taiwanese population by the partly non-pollinose and shiny 
katepimeron; the genitalia, however, fall within the range found in this species. The genitalia from the Okinawa population are more similar to those from Taiwan compared with those from China. We think these differences are due to geographical variation rather than different speciation and have refrained from creating additional new species. Only if more material becomes available with extensive DNA sampling could another conclusion be drawn.

Sphegina (Asiosphegina) ornata sp. nov. urn:1sid:zoobank.org:act:9628A866-6804-449D-AE33-E28CD41FE998

Figs $63 \mathrm{~F}, 71,72 \mathrm{C}$

\section{Differential diagnosis}

Sphegina (Asiosphegina) ornata sp. nov. is similar to $S$. (A.) carinata and $S$. (A.) index but is distinguished by the characters mentioned in the key. The male genitalia in all these three species are very similar. Sphegina (Asiosphegina) ornata sp. nov. and $S$. (A.) index are distinguished at once from $S$. (A.) carinata by lacking a finger-like pointed sublobe dorsally on the superior lobe. In addition, $S$. (A.) ornata sp. nov. is distinguished from $S$. (A.) index by having the ventral sublobes on the superior lobes many times as long as wide instead of being about as long as wide.

\section{Etymology}

The specific epithet is from the Latin 'ornata', meaning 'richly adorned' and referring to the many sublobes on the superior lobe.

\section{Material examined}

Holotype

CHINA: O’; "China: Emeishan Co., / Leshan, Mt. Emei / 29.574947º N, 103.396333 E / 18-20.v.2016

O. Lonsdale / JSM8676 CNC572081"; DNA voucher specimen; CNC.

\section{Paratype}

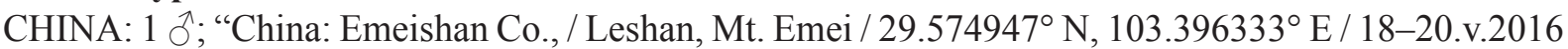

O. Lonsdale / JSM8672, CNC572077”; DNA voucher specimen; JSA.

\section{Description}

\section{Male}

LenGTH. Body 8.2-8.7 mm, wing 6.2-6.9 $\mathrm{mm}$.

HEAD. Face in lateral view concave, strongly projected antero-ventrally; frontal prominence strongly developed. Ratio width of vertex at anterior ocellus: width of head 1: 3.6-3.9; ratio width of ocellar triangle: width of vertex 1: 2.7-3.0; ratio length of ocellar triangle: length of frons 1: 2.6-2.9. Face black; light grey pollinose, long pilose along eye-margin. Hypostomal bridge black, long pale pilose. Gena and mouth edge black with large subtriangular non-pollinose shiny area. Frons and vertex black, slightly pollinose with densely grey pollinose subtriangular macula antero-laterally at eye-margin, a large round area posterior of lunula non-pollinose and shiny; pile short, light yellow. Frons with deep pit antero-medially. Occiput black, light grey pollinose, light yellow pilose. Eye without enlarged facets at anterior margin. Antenna with scape and pedicel yellow, basoflagellomere dark yellow, with black setae dorsally on scape and pedicel; basoflagellomere oval, ratio width: length 1: 1.2-1.4; arista long pilose, nearly 3 times as long as basoflagellomere.

THORAX. Colour black, weakly greyish pollinose, pleuron entirely grey pollinose; scutum and pleuron with very short adpressed light yellow pile. Scutellum crescent-shaped, black, sub-shiny and weakly 
pollinose, with pile slightly longer than on scutum, with two closely set long setae medially at posterior margin, ratio length of scutellum: length of seta 1: 1.8-2.0.

WING. Entirely microtrichose; hyaline, stigma yellowish, membrane brown infuscated at junction of veins $R_{2+3}$ and $R_{4+5}$, along veins dm-cu, $r-m, M_{1}$, at the junction of veins $M_{1}$ and $R_{4+5}$. Crossvein dmcu meeting vein $M$ perpendicularly and vein $M_{1}$ meeting vein $R_{4+5}$ perpendicularly. Vein bm-cu with anterior half very weakly sclerotized.

LEGS. Pro- and mesoleg yellow, tarsomeres 4-5 black. Metaleg, Fig. 72C, with coxa black and trochanter yellow with darkened transverse carina; femur black with basal $1 / 3$ yellow, slightly incrassate, ratio
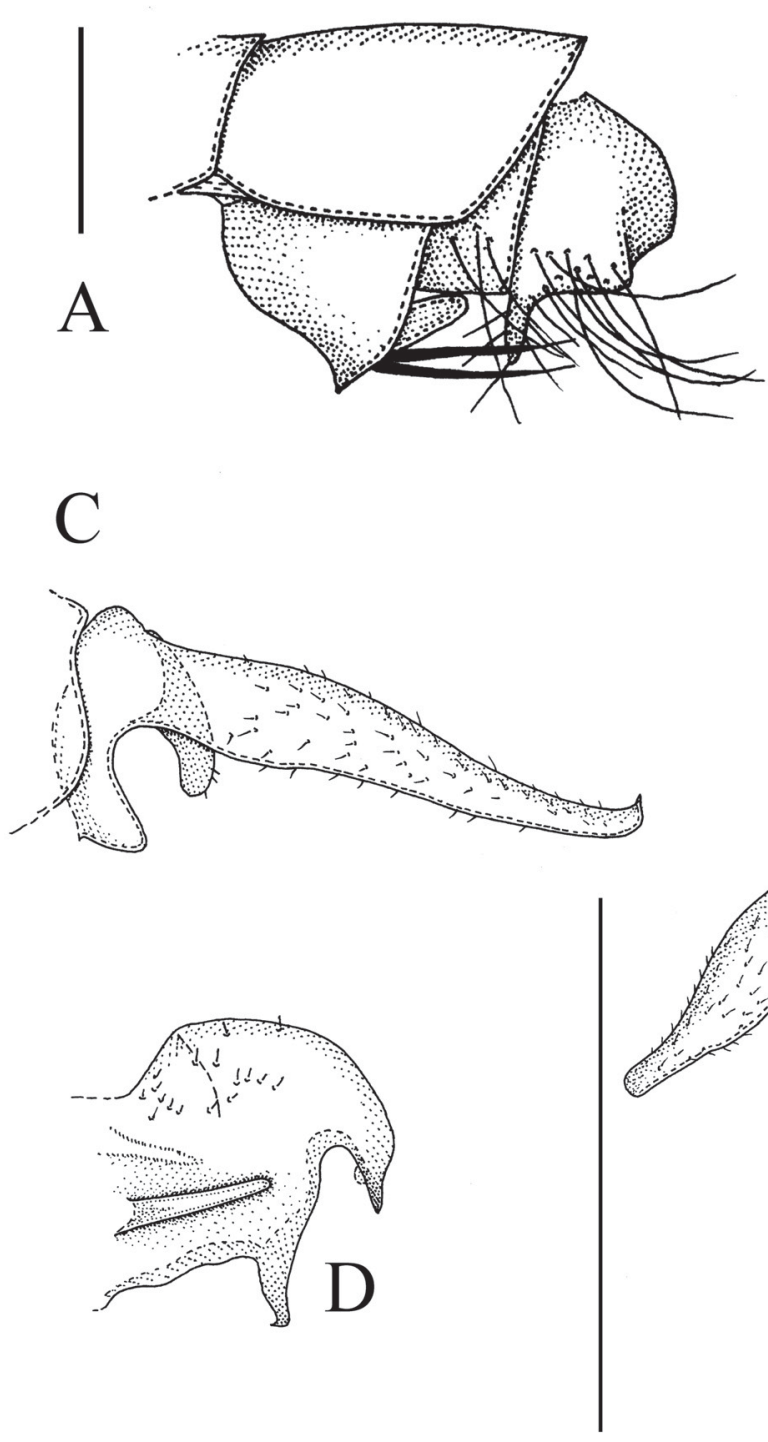

Fig. 71. Sphegina (Asiosphegina) ornata sp. nov., holotype, ठิ. A. Posterior part of abdomen, left side lateral view. B. Sternum IV, ventral view. C. Left surstylus, lateral view. D. Left superior lobe with associated parts, lateral view. E. Genitalia, right side, lateral view. Scale bars $=0.5 \mathrm{~mm}$. 
width: length 1: 4.9-5.4; tibia black and yellow biannulate without apicoventral dens; tarsus entirely black, basitarsomere rather thin, ratio width: length 1: 3.6-3.8.

ABdomen. Length ratio of terga I: II: III: IV 1: 2.5-2.8: 1.7-2.1: 1.4-1.6; ratio width at posterior margin: medial length of tergum II and III 1:3.2-3.5 and 1: 0.9-1.0. Terga black, anterior $1 / 3$ of tergum III with yellow fascia; pile pale, on terga short, laterally on terga I and II long; tergum I with 2 widely spaced strong black setae at lateral margin; sternum III rectangular, ratio width: length 1: 3.5-3.9; sternum IV, Fig. 71B; sterna VI and VIII simple, with long yellow pile; sternum VII with long conical antero-ventral and rounded postero-ventral process, both covered with long yellow seta like pile. Genitalia, Fig. 71CE: note the asymmetrical surstyli, the subbasal lobe on the medial side of surstyli, and the asymmetrical superior lobes.

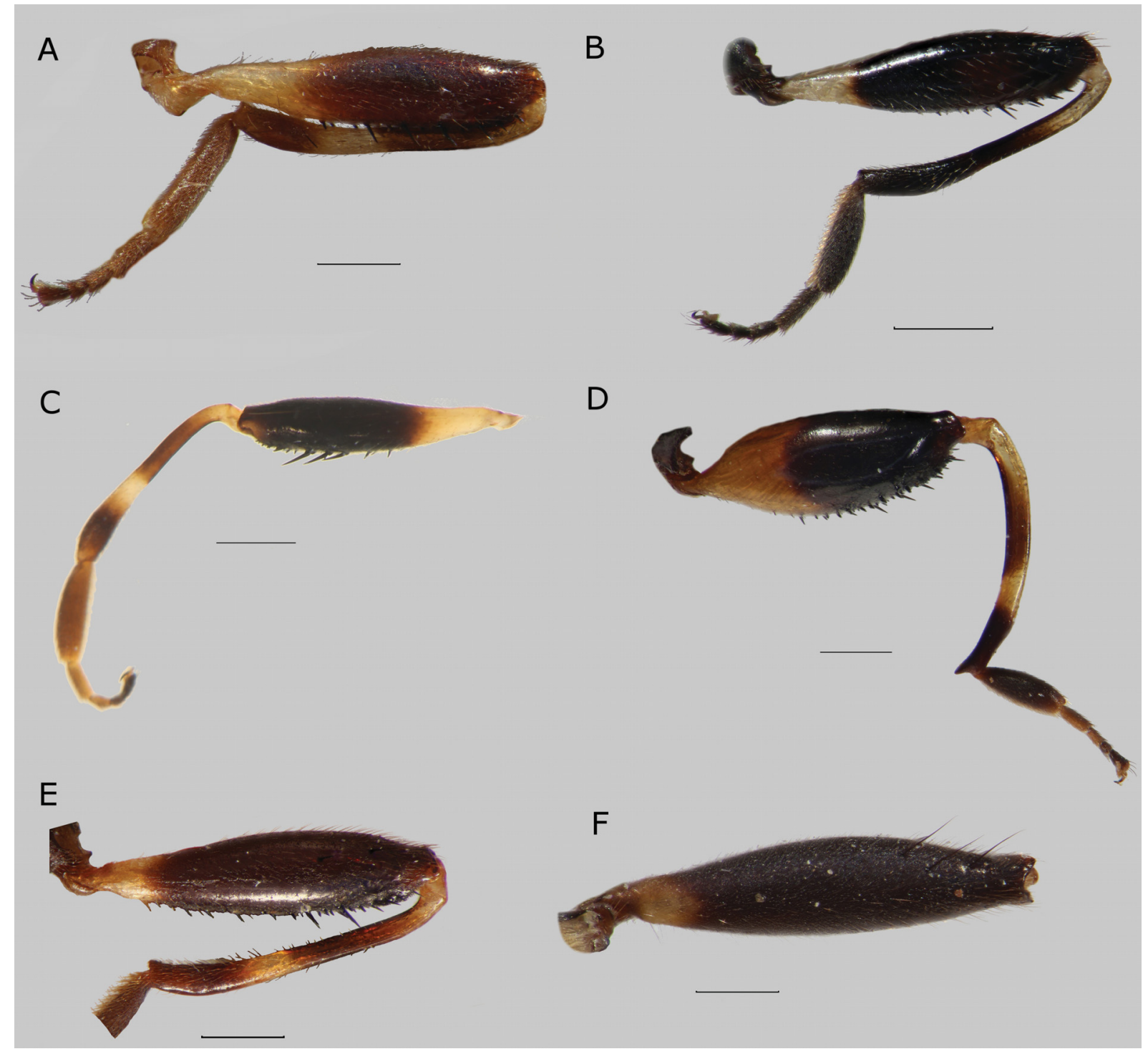

Fig. 72. Metaleg, anterior view (A-E) and dorsal view (F). A. Sphegina (Asiosphegina) malaisei Hippa, van Steenis \& Mutin, 2015, paratype,, , Myanmar. B. S. (A.) nigerrima Shiraki, 1930, ठิ, Taiwan. C. S. (A.) ornata sp. nov., holotype, ${ }^{\lambda}$, China. D. S. (A.) philippina, Thompson, 1999, paratype,, , Philippines. E. S. (A.) bispinosa Brunetti, 1915, đ̂, Nepal. F. S. (A.) bispinosa, , , India. Scale bars = $0.5 \mathrm{~mm}$. 
Female

Unknown.

Sphegina (Asiosphegina) parvula Hippa, van Steenis \& Mutin, 2015

Figs $67 \mathrm{C}, 84 \mathrm{D}$

Sphegina (Asiosphegina) parvula Hippa, van Steenis \& Mutin, 2015: 50. Type locality: Kambaiti, Myanmar (holotype, $\hat{O}^{\lambda}, \mathrm{NHRS}$ ).

\section{Remarks}

Only known by the type material from Myanmar, Kambaiti (Hippa et al. 2015).

Sphegina (Asiosphegina) perlobata sp. nov. urn:1sid:zoobank.org:act:4FB34389-E0E6-4B9A-BED2-BD2F5DEB3E16

Figs 67E, 73, 84D-E

\section{Differential diagnosis}

Similar to Sphegina (Asiosphegina) crinita sp. nov., but with very different genitalia. For distinguishing characters, see under Sphegina (Asiosphegina) crinita sp. nov.

\section{Etymology}

The specific epithet is from the Latin 'perlobata', meaning 'exceedingly lobed' and referring to the unusually many-lobed surstylus.

\section{Material examined}

\section{Holotype}

TAIWAN - O’; "Taiwan Nantou / Sanlinchi / 19.V.1991 / [leg] C.C. Chiang / Sweeping \& Sucking"; "NMNS ENT / 1128-98"; NMNS.

\section{Paratype}

TAIWAN - 1 क; "Taiwan Siangyang National / Forest Recreational Area / trails 23.247361 ${ }^{\circ} \mathrm{N}$, $120.985917^{\circ}$ E 29.v.2016 / J.H. Skevington, A.D. Young / JSM8521 CNC571926”; DNA voucher specimen; CNC.

\section{Description}

\section{Male}

LENGTH. Body $6.7 \mathrm{~mm}$, wing $5.2 \mathrm{~mm}$.

HEAD. Face in lateral view, Fig. 84E, concave, weakly projected antero-ventrally; frontal prominence weakly developed. Ratio width of vertex at anterior ocellus: width of head 1: 4.7; ratio width of ocellar triangle: width of vertex 1: 1.7; face as wide as vertex; ratio length of ocellar triangle: length of frons 1: 2.8. Face black, ventral half yellow; light grey pollinose, long pilose along eye-margin. Hypostomal bridge yellow, long pale pilose. Gena and mouth edge yellow with large subtriangular non-pollinose shiny area. Frons and vertex black, grey pollinose, a wide trapezoidal area posterior of lunula nonpollinose and shiny (Fig. 84D); pile short, light yellow. Frons with deep pit antero-medially. Occiput black, light grey pollinose, light yellow pilose. Eye without enlarged facets at anterior margin. Antenna with scape and pedicel dark brown, with black setae dorsally on scape and pedicel; basoflagellomere oval, ratio width: length 1: 1.2; arista long pilose, about 3 times as long as basoflagellomere. 
THORAX. Colour black, weakly greyish pollinose, pleuron entirely grey pollinose; scutum and pleuron with very short adpressed light yellow pile. Scutellum subtriangular, black, shiny, with pile slightly longer than on scutum, with two widely set, medium long setae medially at posterior margin, ratio length of scutellum: length of seta $1: 1.5$.

WING. Entirely microtrichose; hyaline, stigma yellowish. Crossvein dm-cu meeting vein M obliquely and vein $M_{1}$ meeting vein $R_{4+5}$ perpendicularly.

LEGS. Pro- and mesoleg yellow, tarsomeres 4 and 5 black. Metaleg with coxa black and trochanter yellow; femur black with basal $1 / 3$ yellow, slightly incrassate, ratio width: length 1: 4.8 in profile basodorsally slightly concave; tibia black and yellow biannulate without apicoventral dens; tarsus entirely black, basitarsomere rather thin, ratio width: length $1: 3.8$.

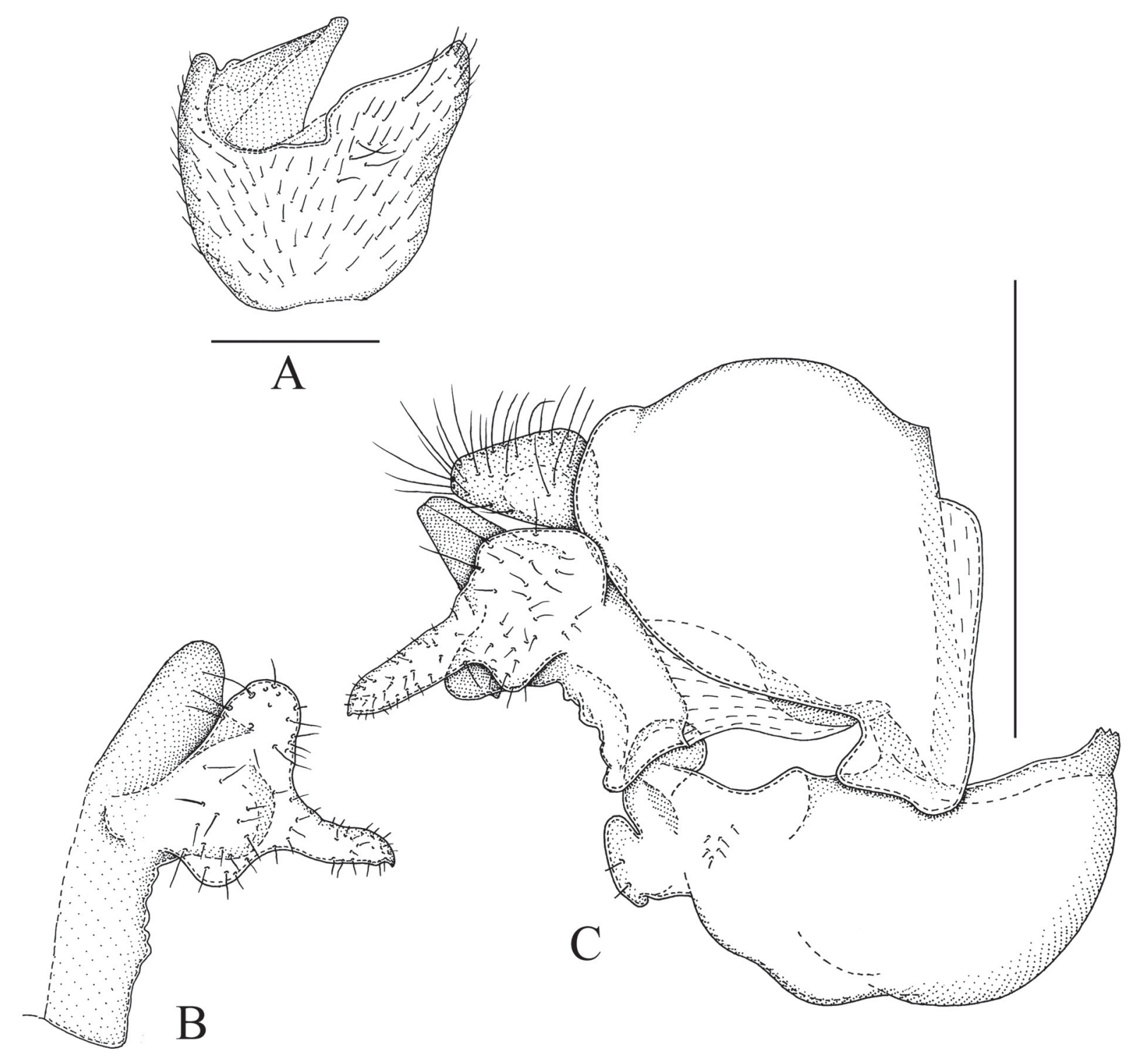

Fig. 73. Sphegina (Asiosphegina) perlobata sp. nov., holotype, ठิ. A. Sternum IV, ventral view. B. Left surstylus, lateral view. C. Genitalia, right side, lateral view. Scale bars $=0.5 \mathrm{~mm}$. 
ABDOMEN. Length ratio of terga I: II: III: IV 1: 3.5: 2.3: 1.9; ratio width at posterior margin: medial length of tergum II and III 1: 4.0 and 1: 1.1. Terga black, anterior $1 / 2$ of tergum III with yellow fascia; pile pale, on terga short, laterally on terga I and II long; tergum I with oblique row of 5 light yellow setae at anterolateral margin; tergum IV with posterior margin skewed to the right; sternum III rectangular with concave posterior margin, ratio width: length 1: 2.8; sternum IV, Fig. 73A; sterna VI, VII and VIII simple, with long yellow pile. Genitalia, Fig. 73B-C: note the unusually many-lobed and almost symmetrical surstyli; the left side superior lobe is deformed and not drawn, it is similar to the right side one.

\section{Female}

Similar to male except for the usual sexual dimorphism.

Length. Body $6.3 \mathrm{~mm}$, wing $5.4 \mathrm{~mm}$.

HEAD. Ratio width of vertex at anterior ocellus: width of head 1: 3.6; ratio width of ocellar triangle: width of vertex 1: 2.2; ratio length of ocellar triangle: length of frons 1: 2.8. Basoflagellomere yellow, slightly elongate, ratio width: length 1: 1.3; arista long pilose; about 3 times as long as basoflagellomere.

Thorax. Postpronotum, post-alar callus and medio-dorsal part of pleuron yellow; Scutellum subrectangular, black, rather long pilose, with two closely set, very short setae medially at posterior margin, ratio length of scutellum: length of seta 1:0.7.

WING. Hyaline, entirely microtrichose; vein dm-cu meeting vein M slightly oblique.

Legs. Protarsus with tarsomeres $2-5$ dark brown to black; metafemur yellow on basal $1 / 2$; metatarsus with basitarsomere thick, ratio width: length 1:3.0.

ABDOMEN. Length ratio of terga I: II: III: IV: V 1: 4.6: 2.5:2.5: 1.5; ratio width at posterior margin: length of tergum II 1: 2.6. Tergum III with yellow fascia on anterior $3 / 4$; sterna not visible due to wrinkling of the abdomen.

Sphegina (Asiosphegina) philippina Thompson, 1999

Figs 67F, 70D-E, 72D, 74, 77D, 84F-G

Sphegina (Asiosphegina) philippina Thompson, 1999b: 206. Type locality: Misamis, Philippines (holotype, $\widehat{\jmath}, \mathrm{BPBM})$.

\section{Differential diagnosis}

Similar to Sphegina (Asiosphegina) amplistylus sp. nov., S. (A.) inflata sp. nov. and S. (A.) spathigera sp. nov. For distinguishing characters, see under $S$. (A.) amplistylus sp. nov.

\section{Material examined}

\section{Holotype}

PHILIPPINES • đ̇; "P.I. Misamis or. / Mt. Balatukan, 15 km / SW of Gingoog 1000 / -2000m 27-30. IV.[19]60"; "H. Torrevillas / collector"; BPBM.

\section{Paratypes}

PHILIPPINES • 1 § ; "P.I.: Mindanao / Mis. Or. Mt. Pomalihi / 21 km W. Gingoog City / 800-1000 m 30.IV.1965"; "H.M. Torrevillas / Collector / Bishop"; BPBM • 1 q; "Culasi Pannay / PI June 1918 / M. Gregor"; "USNMENT / QR-code / 01224063”; USNM・ 1 q; "Baguio / Benguet / Baker”; "C.P. Baker 
/ collection / 1927”; "USNMENT / QR-code / 01224067”; USNM • 1 q; same data as for preceding; "21050"; "Sphegina / orientalis / [det] Sack, Kertesz"; "USNMENT / QR-code / 01224066"; USNM • 1 \&; "Mt Makiling / Luzon Baker"; "1486"; "C.P. Baker / Collection / 1927”; "Type” [red label], "Type No / 52908 / USNM" [red label], "Sphegina / philippina / Hull n.sp."; "Paratype / Sphegina / philippina / Thompson" [yellow label], "USNMENT / QR-code / 01224065"; USNM • 1 q; "P.I. Negros Or. / L. Balinsasayao / 1-7.X.1959"; "Light Trap / L.W. Quate", Paratype / Sphegina / philippina / Thompson" [yellow label], "USNM / Exchange / Nov. 2013"; "CNC DIPTERA / \# 225407" [white label with blue border]; CNC.
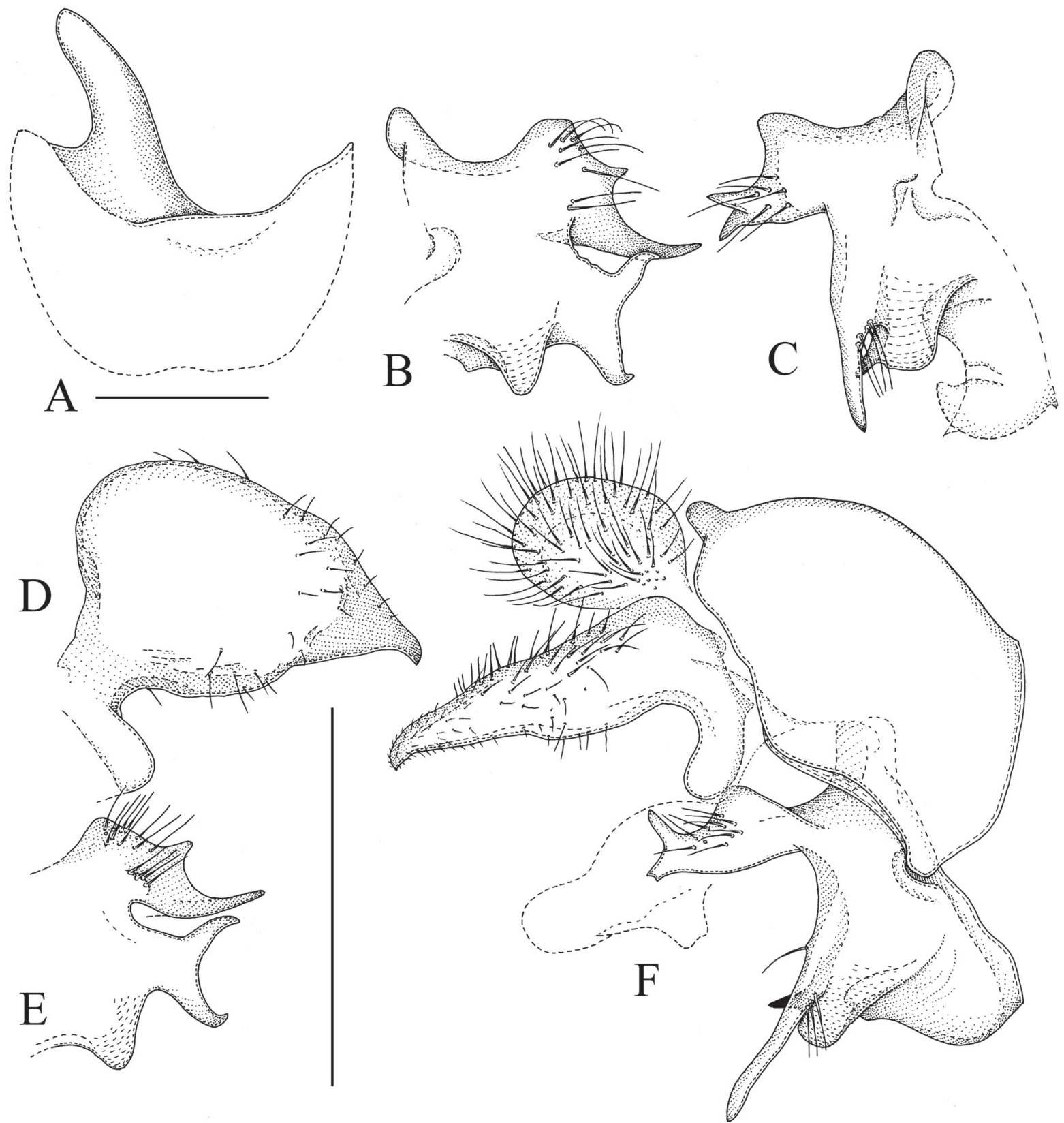

Fig. 74. Sphegina (Asiosphegina) philippina Thompson, 1999, holotype, § (B-C) and paratype, ठิ, Mindanao (A, D-F). A. Sternum IV, ventral view. B, E. Left superior lobe, lateral view. C. Right superior lobe with associated parts, lateral view. D. Left surstylus, lateral view. F. Genitalia, right side, lateral view. Scale bars $=0.5 \mathrm{~mm}$. 


\section{Redescription}

Male

Length. Body 6.5-7.7 mm, wing 5.2-5.8 mm.

HEAD. Face in lateral view concave, weakly projected antero-ventrally; frontal prominence very weakly developed. Ratio width of vertex at anterior ocellus: width of head 1: 6.5-6.9; ratio width of ocellar triangle: width of vertex 1: 1.3-1.5; ratio length of ocellar triangle: length of frons 1:2.3-3.0. Face black, ventral half yellow; light grey pollinose, long pilose along eye-margin. Hypostomal bridge yellow, long pale pilose. Gena and mouth edge yellow, pale pollinose, with large subtriangular non-pollinose shiny area. Frons and vertex black, slightly pollinose, a narrow subtriangular area posterior of lunula nonpollinose and shiny; pile short, light yellow. Frons with weak furrow medially. Occiput black, light grey pollinose, light yellow pilose. Eye with an area of enlarged facets at anterior margin (Fig. 84G). Antenna brown with black setae dorsally on scape and pedicel; basoflagellomere rectangular, ratio width: length 1: 1.5-1.6; arista long pilose, nearly 3 times as long as basoflagellomere.

THORAX. Colour black, weakly greyish pollinose, postpronotum dark brown, densely grey pollinose; posterior margin of katepisternum in some specimens narrowly non-pollinose, shiny, otherwise entirely grey pollinose and dull; scutum and pleuron with very short adpressed light yellow pile. Scutellum short and widely sub-triangular, black, weakly pollinose, long pilose, with pile longer than on scutum, without marginal setae, but it is possible the setae are broken off.

WING. Entirely microtrichose; hyaline, stigma yellowish, membrane brown infuscated at junction of veins $R_{2+3}$ and $R_{4+5}$ and along vein $M_{1}$. Crossvein dm-cu meeting vein $M$ slightly oblique and vein $M_{1}$ meeting vein $R_{4+5}$ perpendicularly.

Legs. Pro- and mesoleg yellow, tarsomeres 4-5 black, in paratype tarsomere 3 of protarsus light-brown. Metaleg with coxa black, trochanter yellow; femur black with basal 1/3-3/7 yellow, strongly incrassate, ratio width: length 1: 2.9-3.1; tibia black and yellow biannulate with large rounded apicoventral dens; tarsus entirely black, basitarsomere thick, ratio width: length 1: 3.1-3.3.

ABDOMEN. Length ratio of terga I: II: III: IV 1: 3.0-3.5: 1.3-1.5: 1.3-1.5; ratio width at posterior margin: medial length of tergum II and III 1: 3.9-4.5 and 1: 0.7-0.8. Terga black, anterior $1 / 2$ of tergum III with dark brown squarish lateral macula; pile pale, on terga short, laterally on terga I and II long; tergum I with horizontal row of 3-4 evenly spread brown-yellow setae at lateral margin; sternum III not sclerotized; sternum IV, Fig. 74A; sterna VI, VII and VIII simple, with long yellow pile. Genitalia, Fig. 74B-F: note the strongly asymmetrical surstyli and superior lobes.

\section{Female}

Similar to male except for the usual sexual dimorphism.

LeNGTH. Body 6.2-6.6 mm, wing 5.2-5.8 mm.

HEAD. Ratio width of vertex at anterior ocellus: width of head 1: 6.2-6.9; ratio width of ocellar triangle: width of vertex 1: 1.4-1.6; ratio length of ocellar triangle: length of frons 1: 3.2-3.7 (Fig. 84F). Ventral half of face and anterior $3 / 4$ of mouth edge yellow; frons and vertex evenly grey-pollinose, sub-shiny with non-pollinose and shiny semi-circular macula posterior of lunula; basoflagellomere yellow, elongate, ratio width: length 1: 1.4-1.6; arista long pilose; about 3 times as long as basoflagellomere.

Thorax. Postpronotum, post-alar callus and medio-dorsal part of pleuron yellow; Scutellum subrectangular, black, rather long pilose, without marginal setae, probably broken off. 
WING. Microtrichose, extreme base of cell bm bare; infuscated at junction of veins $R_{2+3}$ and $R_{4+5}$ and along veins dm-cu, $M_{1}$. Crossvein dm-cu meeting vein $M$ almost perpendicularly.

LEGs. Protarsus with tarsomeres 4-5 dark brown to black. Metafemur, Fig. 72D, yellow on basal 1: 2.52.7, ratio width: length 1:2.7-3.1; metatarsus with basitarsomere thick, ratio width: length 1:2.7-3.0.

ABDOMEN. Length ratio of terga I: II: III: IV: V 1: 3.0-3.7: 1.9-2.4: 1.6-2.1: 1.0-1.2; ratio width at posterior margin: medial length of tergum II and III 1: 1.7-2.0 and 1: 0.5-0.6. Tergum I, Fig. 77D, without stronger setae at lateral margin, with normal pile only. Terga II, III and IV with dark yellow fascia on respectively sub-anterior $1 / 8$, anterior $1 / 4$ and anterior $1 / 3$; sternum III short oval, ratio width: length 1: 1.4-1.9; sternum IV rectangular, ratio width: length 1: 0.9-1.2; sternum V rectangular, ratio width: length 1: $0.8-1.0$.

\section{Remarks}

In addition to Sphegina (Asiosphegina) philippina, the following three new species were found in the type material: $S$. (A.). amplistylus sp. nov., $S$. (A.) inflata sp. nov. and $S$. (A.) spathigera sp. nov. One male paratype ("Baguio Benguet Baker", coll Sack (SMF)) was not found in the SMF (pers. comm. Ximo Mengual) nor in any other museum listed in the material and methods section above and its identity remains unclear.

Sphegina (Asiosphegina) plautus sp. nov. urn:1sid:zoobank.org:act:3431A2B3-67BD-4350-B199-C423EC4AFE59

Figs $61 \mathrm{~F}, 70 \mathrm{~F}, 75 \mathrm{~A}-\mathrm{B}, 76,84 \mathrm{H}, 95 \mathrm{~A}$

\section{Differential diagnosis}

Sphegina (Asiosphegina) plautus sp. nov. is very similar to $S$. (A.) brevipilis sp. nov., both are also similar to Sphegina (Asiosphegina) simplex. For distinguishing characters, see under $S$. (A.) brevipilis sp. nov.

\section{Etymology}

The specific epithet is a Latin cognomen 'plautus', meaning 'flat-footed' and referring to the widened protarsus. The name is a noun in apposition.

\section{Material examined}

Holotype

CHINA • Õ'; "Fukien, S. China / Shaowu: Tachulan / 1000 m T. Maa"; "6-10.V.1943"; BPBM.

\section{Paratypes}

CHINA • 1 '; same data as for holotype; "19.V.1942"; JSA • 1 क ; same data as for holotype; "25-30. IV.1943"; BPBM.

\section{Description}

\section{Male}

LenGth. Body 5.9-6.2 mm, wing 5.0-5.3 $\mathrm{mm}$.

HEAD. Face in lateral view (Fig. 84H) concave, weakly projected antero-ventrally; frontal prominence very weakly developed. Ratio width of vertex at anterior ocellus: width of head 1:4.0-4.3; ratio width of ocellar triangle: width of vertex 1: 1.6-1.8; ratio length of ocellar triangle: length of frons 1: 1.6-1.8. Face black, light grey pollinose, long pilose along eye-margin. Hypostomal bridge black, long pale 
pilose. Gena and mouth edge black, pale pollinose, with large subtriangular non-pollinose shiny area. Frons and vertex black, predominantly brown-grey pollinose, a subtriangular area posterior of lunula non-pollinose and shiny and narrow densely grey pollinose fascia posterior of shiny part; pile short, light yellow. Frons with rather deep pit antero-medially. Occiput black, light grey pollinose, light yellow pilose. Eye without enlarged facets at anterior margin. Antenna brown-yellow to brown with black setae dorsally on scape and pedicel; basoflagellomere oval, ratio width: length 1:1.1-1.3; arista long pilose, about 2.5 times as long as basoflagellomere.

THORAX. Colour dark brown to black, weakly greyish pollinose, pleuron entirely grey pollinose; scutum and pleuron with very short adpressed light yellow pile. Scutellum sharply subtriangular, black, pale pollinose, with pile longer than on scutum, with two very widely set, very short setae medially at posterior margin, ratio length of scutellum: length of seta 1: 0.7-0.9.

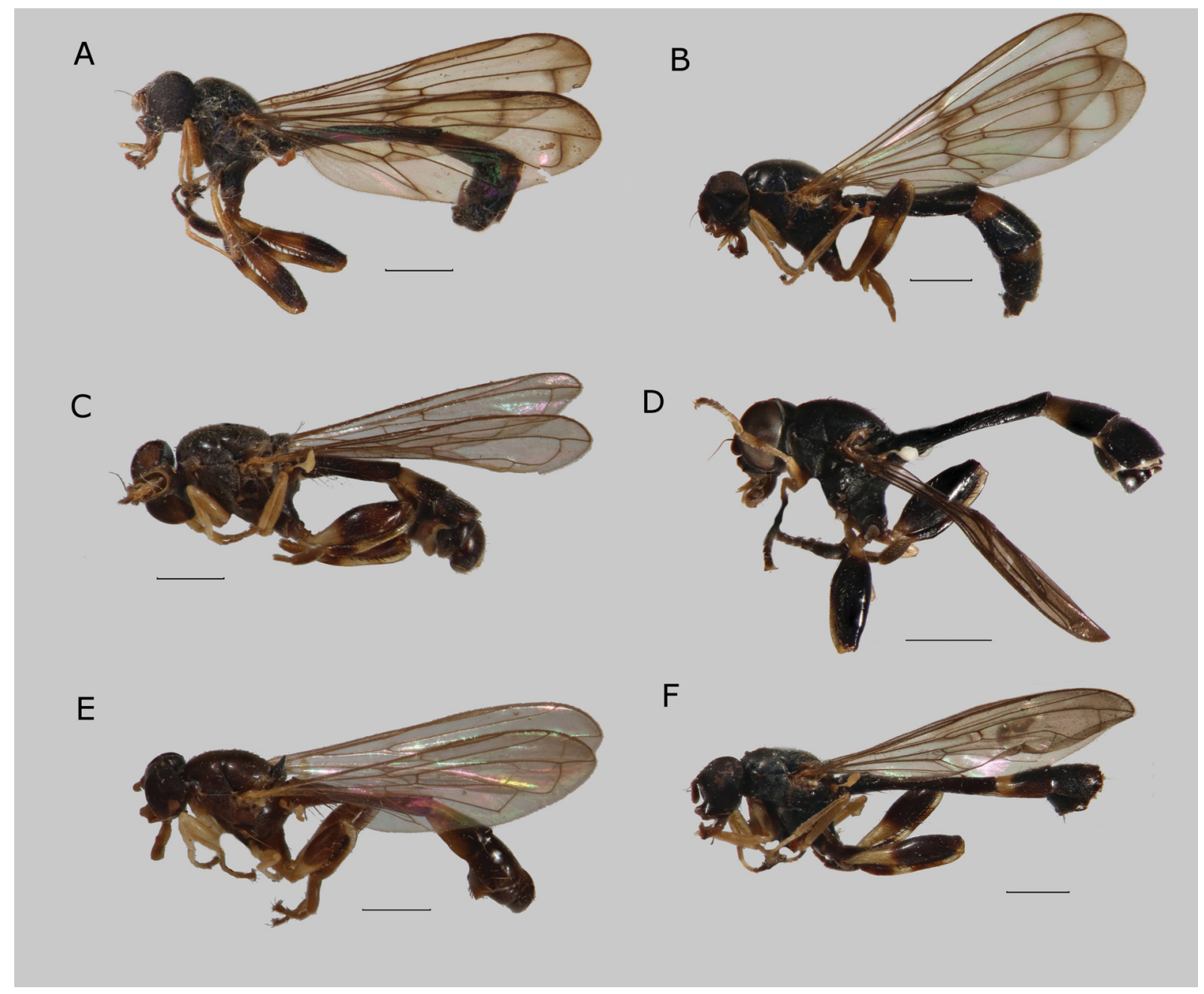

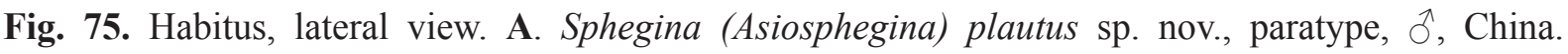
B. S. (A.) plautus sp. nov., paratype, , China. C. S. (A.) pollinosa Hippa, van Steenis \& Mutin, 2015,

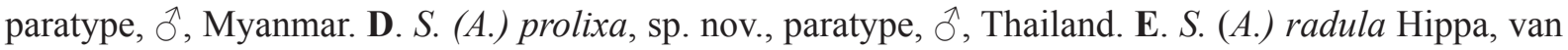
Steenis \& Mutin, 2015, paratype, §̂, Myanmar. F. S. (A.) setosa sp. nov., paratype, §̂, Nepal. Scale bars $=1.0 \mathrm{~mm}$. 
Wing. Entirely microtrichose; hyaline, stigma yellowish, infuscated at junction of veins $\mathrm{R}_{2+3}$ and $\mathrm{R}_{4+5}$, along crossveins dm-cu and $M_{1}$ and at the apex of vein $R_{1+2}$. Crossvein dm-cu meeting vein M obliquely and vein $\mathrm{M}_{1}$ meeting vein $\mathrm{R}_{4+5}$ perpendicularly. Vein $\mathrm{CuA}$, very slightly extended beyond vein $\mathrm{dm}-\mathrm{cu}$.

LeGs. Pro- and mesoleg yellow, tarsomere 5 black; protarsus, Fig. 61F, with tarsomeres 2-5 short and wide, slightly flattened. Metaleg, Fig. 95A, with coxa black and trochanter yellow; femur black and yellow biannulate, very slightly incrassate and club shaped, ratio width: length 1: 6.1-6.4; tibia black and yellow biannulate with light yellow, short, sharply subtriangular apicoventral dens; tarsus entirely black, basitarsomere very thick, ratio width: length $1: 2.5-2.8$.

ABDOMEN. Length ratio of terga I: II: III: IV 1: 5.0-5.3: 2.8-3.2: 1.9-2.2; ratio width at posterior margin: medial length of tergum II and III 1: 3.9-4.2 and 1: 1.2-1.4. Terga black, anterior $1 / 3$ of tergum III with brown-yellow fascia; tergum IV with anterolateral squarish brown-yellow macula; pile pale, on terga short, laterally on terga I and II long; tergum I with 3 strong brown-yellow setae at lateral margin; sternum III rectangular, ratio width: length 1: 2.7-3.0; sternum IV, Fig. 76A; sterna VI, VII and VIII simple, with long yellow pile. Genitalia, Fig. 76B-C: note the unusually short pilosity of cercus, the unusual sclerite posteriorly from the base of cercus, symmetrical surstyli and slightly asymmetrical superior lobes.

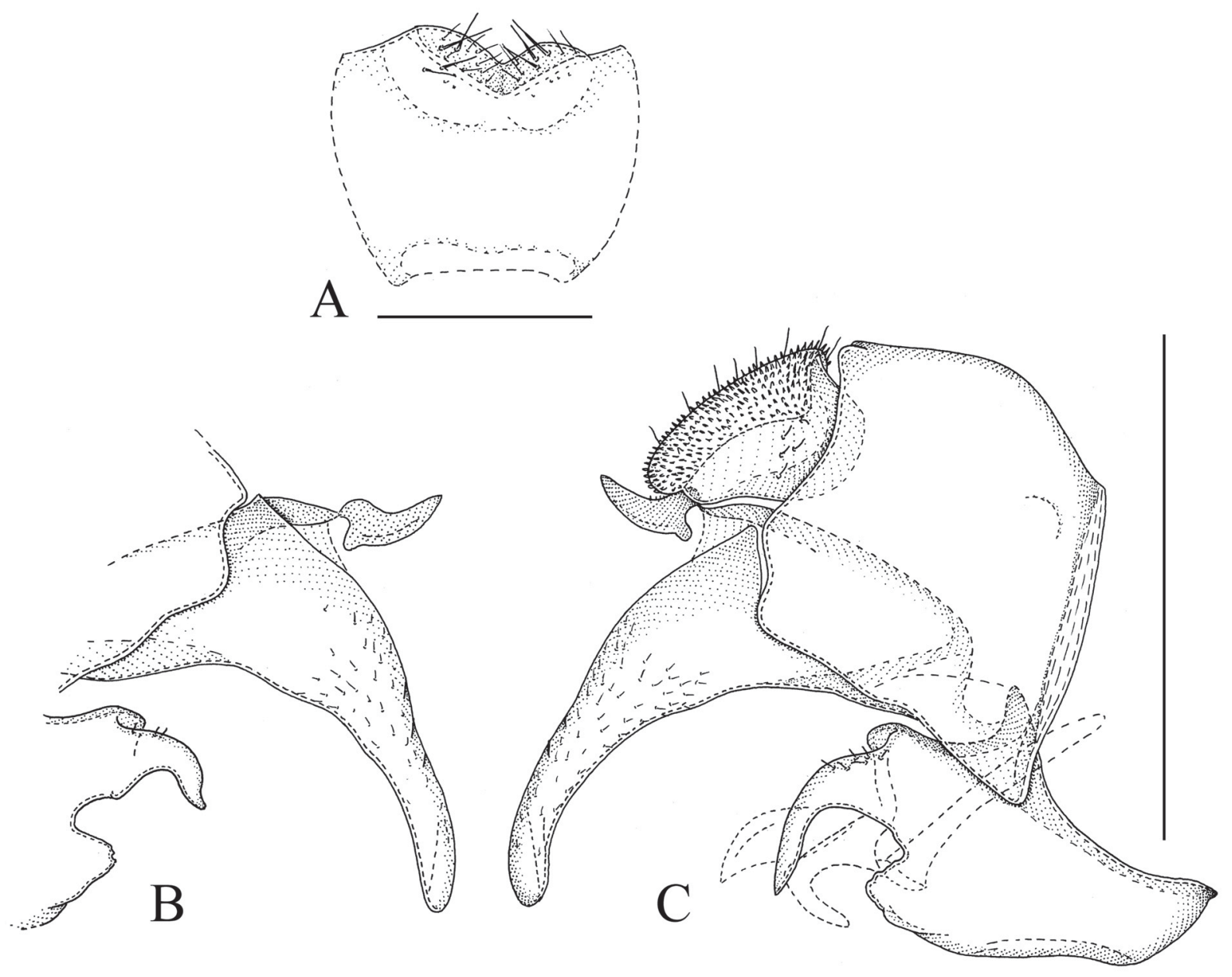

Fig. 76. Sphegina (Asiosphegina) plautus sp. nov., holotype, ふ̊. A. Sternum IV, ventral view. B. Posterior part of genitalia, left side, lateral view. C. Genitalia, right side, lateral view. Scale bars $=0.5 \mathrm{~mm}$. 


\section{Female}

Similar to male except for the usual sexual dimorphism.

LeNGTH. Body $6.4 \mathrm{~mm}$, wing $5.8 \mathrm{~mm}$.

HEAD. Ventral half of face and anterior half of mouth edge brown. Basoflagellomere short oval, ratio width: length 1: 1.2; arista long pilose, about 3 times as long as basoflagellomere.

THorax. Scutellum with two very widely set, short setae medially at posterior margin, ratio length of scutellum: length of seta 1: 1.2 .

LEGS. Metafemur ratio width: length 1: 5.9; metatarsus with basitarsomere thick, ratio width: length 1: 3.1.

ABDomen. Length ratio of terga I: II: III: IV: V 1: 3.5: 2.9: 1.9: 0.8; ratio width at posterior margin: medial length of tergum II and III 1: 1.6 and 1: 0.9. Tergum I with 3 large brown setae at lateral margin. Tergum III on anterior $2 / 5$ with yellow fascia; tergum IV antero-laterally with large lunulate macula; sternum III rectangular, ratio width: length 1: 3.0; sternum IV trapezoidal with anterior part thinner, ratio width: length 1: 1.9; sternum $\mathrm{V}$ rectangular with convex posterior margin, ratio width: length 1: 0.9 .

Sphegina (Asiosphegina) pollex Hippa, van Steenis \& Mutin, 2015

Fig. 79A

Sphegina (Asiosphegina) pollex Hippa, van Steenis \& Mutin, 2015: 61. Type locality: Kambaiti, Myanmar (holotype, ${ }^{\lambda}$, NHRS).

\section{Remarks}

Only known by the type material from Myanmar, Kambaiti (Hippa et al. 2015).

Sphegina (Asiosphegina) pollinosa Hippa, van Steenis \& Mutin, 2015

Fig. $75 \mathrm{C}$

Sphegina (Asiosphegina) pollinosa Hippa, van Steenis \& Mutin, 2015: 59. Type locality: Kambaiti, Myanmar (holotype, $\hat{\jmath}$, NHRS).

\section{Remarks}

Only known by the type material from Myanmar, Kambaiti (Hippa et al. 2015).

Sphegina (Asiosphegina) prolixa sp. nov. urn:1sid:zoobank.org:act:CD691191-6E81-42FC-8F1F-42619911DB72

Figs 75D, 78, 79B, 84I-J

\section{Differential diagnosis}

In the non-genitalic characters the species is similar to Sphegina (Asiosphegina) ghatsi sp. nov. and is distinguished by the characters given in the key. In the male genitalia the species are not especially similar. Sphegina (Asiosphegina) prolixa sp. nov. is easily distinguished from $S$. (A.) ghatsi sp. nov., as well as any other known Sphegina, by the narrow and extremely long sublobe posteroventrally on its superior lobe. 


\section{Etymology}

The specific epithet is from the Latin 'prolixa', meaning 'stretched out or long' and referring to the exceedingly long posteroventral lobe on the male right-side superior lobe.

\section{Material examined}

\section{Holotype}

MALAYSIA • O'; "W. Malaysia: / Selangor / [leg] A.E. Stubbs / BMNH 1974-87"; "Genting Tea Estate / Genting Sembah, / forest 2000 feet / 24-27.xii.1972"; terga III-VIII and the long thin extension of the superior lobe missing; NHM.

\section{Paratype}

THAILAND • 1 क; "Thailand: Chiang Mai Pt. Doi Inthanon / National Park Huai Sai Leung yellow falls; / 18³1' N, 98²7' E; 1000 m; 3-12.III.2002; / Malaise trap"; QSBG.

\section{Description}

Male

LeNGTH. Body $5.2 \mathrm{~mm}$, wing 3.4-3.9 mm.

HEAD. Face in lateral view concave, weakly projected antero-ventrally; frontal prominence weakly developed. Ratio width of vertex at anterior ocellus: width of head 1: 4.5-4.7; ratio width of ocellar triangle: width of vertex 1: 1.4-1.5; ratio length of ocellar triangle: length of frons 1: 1.7-2.0. Face black, light grey pollinose, long pilose along eye-margin. Hypostomal bridge black, long pale pilose. Gena and mouth edge black, pale pollinose with large subtriangular non-pollinose shiny area. Frons and vertex black; with dense velvet-black pollinosity, with an oval area posterior of lunula non-pollinose and shiny, with subtriangular grey pollinose lateral macula posteriorly from shiny area (Fig. 84I); pile short, light yellow. Frons with narrow and weak furrow medially. Occiput black, light grey pollinose, light yellow pilose. Eye with an area of slightly enlarged facets at anterior margin (Fig. 84J). Antenna with scape and pedicel dark brown, basoflagellomere light-brown, with black setae dorsally on scape and pedicel; basoflagellomere rectangular, ratio width: length 1: 1.3-1.4; arista nearly bare, 3.5 times as long as basoflagellomere.

THORAX. Colour black, weakly greyish pollinose; posterior margin of katepisternum narrowly nonpollinose, shiny; scutum and pleuron with very short adpressed light yellow pile. Scutellum semicircular, black, shiny medially and weakly pale pollinose laterally, with pile slightly longer than on scutum, without marginal setae, probably broken off.

WING. Entirely microtrichose; hyaline, stigma yellowish. Crossvein dm-cu meeting vein $\mathrm{M}$ almost perpendicularly and vein $M_{1}$ meeting vein $R_{4+5}$ perpendicularly.

LEGS. Pro- and mesoleg with femur dark yellow on medial $1 / 4-1 / 3$; tibia with dark brown annulus on apicomedial $1 / 5-1 / 3$ and tarsomere 1 on apical half and entire tarsomeres $3-5$ and in paratype also tarsomere 2 black. Metaleg with coxa black, trochanter yellow; femur black with basal 1/5-1/4 yellow, incrassate, ratio width: length 1: 3.2-3.4; tibia yellow with apical half dark brown to black, with long and wide apicoventral dens; tarsus entirely black, basitarsomere thick, ratio width: length 1: 3.0-3.4.

ABDOMEN. Length ratio of terga I: II: III: IV 1: 3.1-3.7: 1.8: 1.7; ratio width at posterior margin: medial length of tergum II and III 1: 3.6-4.0 and 1: 0.8. Terga black, anterior $3 / 8$ of tergum III with yellow fascia; tergum IV with narrow elongate dark brown macula along anterolateral margin; pile pale, on terga short, laterally on terga I and II long; tergum I with horizontal row of 4-6 irregularly placed light yellow setae at lateral margin; sternum III not sclerotized; sternum IV, Fig. 78C; sterna VI, VII and VIII simple, with long yellow pile. Genitalia, Fig. 78A-B, D-F: note the symmetrical surstyli and asymmetrical superior lobes. 


\section{Female}

Unknown.

\section{Remarks}

Among the material studied a female (1 9 ; "Thailand: Chiang Mai Prov. / Chiang Mai Botanical Garden QSBG / 18.8955 ${ }^{\circ}$ N, 98.8636 E / 11-25.VII.2013, coll M. Hauser" (CSCA)) was found which may belong to this species.

Sphegina (Asiosphegina) pusilla Hippa, van Steenis \& Mutin, 2015

Sphegina (Asiosphegina) pusilla Hippa, van Steenis \& Mutin, 2015: 53. Type locality: Kambaiti, Myanmar (holotype, $\widehat{\partial}$, NHRS).

\section{Remarks}

Only known by the type material from Myanmar, Kambaiti (Hippa et al. 2015).

Sphegina (Asiosphegina) radula Hippa, van Steenis \& Mutin, 2015

Figs 75E, 79C-D

Sphegina (Asiosphegina) radula Hippa, van Steenis \& Mutin, 2015: 27. Type locality: Kambaiti, Myanmar (holotype, $\hat{\jmath}$, NHRS).

\section{Material examined}

INDIA • 1 đ̊; "Sikkim: Himalaya / Gangtok 5500' [ft] / 17.V. 1966 / T. Chand No T261"; "Ghorpade / Collection / Bangalore"; USNM • 1 ơं; same data as for preceding; "15.V 1966 (T. Chand) No 255"; USNM.

\section{Remarks}

Previously known only from the type material from Myanmar, Kambaiti (Hippa et al. 2015).

Sphegina (Asiosphegina) raduloides Hippa, van Steenis \& Mutin, 2015

Figs 77E, 79E

Sphegina (Asiosphegina) raduloides Hippa, van Steenis \& Mutin, 2015: 29. Type locality: Kambaiti, Myanmar (holotype, $\hat{\jmath}$, NHRS).

\section{Remarks}

Only known by the type material from Myanmar, Kambaiti (Hippa et al. 2015).

Sphegina (Asiosphegina) setosa sp. nov.

urn:1sid:zoobank.org:act:2DCB6D0F-B4A5-4BF9-AB31-FD1478B886BC

Figs $75 \mathrm{~F}, 80-81$, 95B

\section{Differential diagnosis}

Sphegina (Asiosphegina) setosa sp. nov. is not especially similar to other Sphegina and is easily recognized by the characters in the key. 


\section{Etymology}

The specific epithet is from the Latin 'setosa', referring to the strong setae on the tubercle on male sternum VI.

\section{Material examined}

\section{Holotype}

NEPAL - O; "Nepal, nr Ktmd. [Kathmandu] / Bhurumche 85-9500‘ [ft] / Oak forest / 5-VI-[19]67 / Can. Nepal Exp. '67”; “CNC DIPTERA / \# 143310”; CNC.

\section{Paratype}

NEPAL $・ 1$ §; same data as for holotype; JSA.

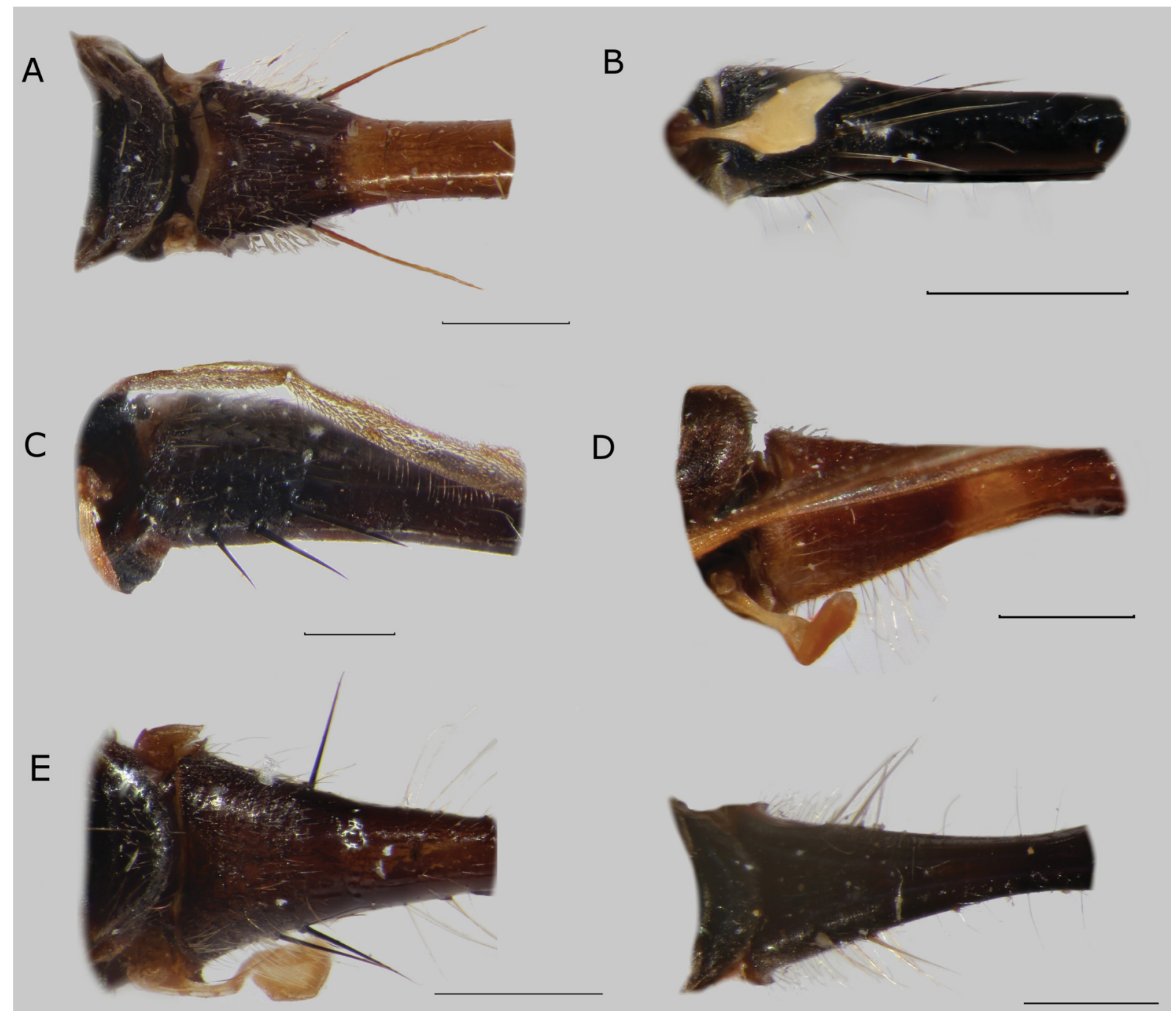

Fig. 77. Tergum I, dorsal view (A, E-F) and lateral view (B-D). A. Sphegina (Asiosphegina) mirifica Hippa, van Steenis \& Mutin, 2015, +, Myanmar. B. S. (A.) nigerrima Shiraki, 1930, ô, Taiwan. C. S. (A.) bispinosa Brunetti, 1915, Ô, Nepal. D. S. (A.) philippina Thompson, 1999, paratype,, , Philippines. E. S. (A.) raduloides Hippa, van Steenis \& Mutin, 2015, paratype, Ô, Myanmar. F. S. (A.) cf. spathigera sp. nov.,, , Philippines. Scale bars $=0.5 \mathrm{~mm}$. 


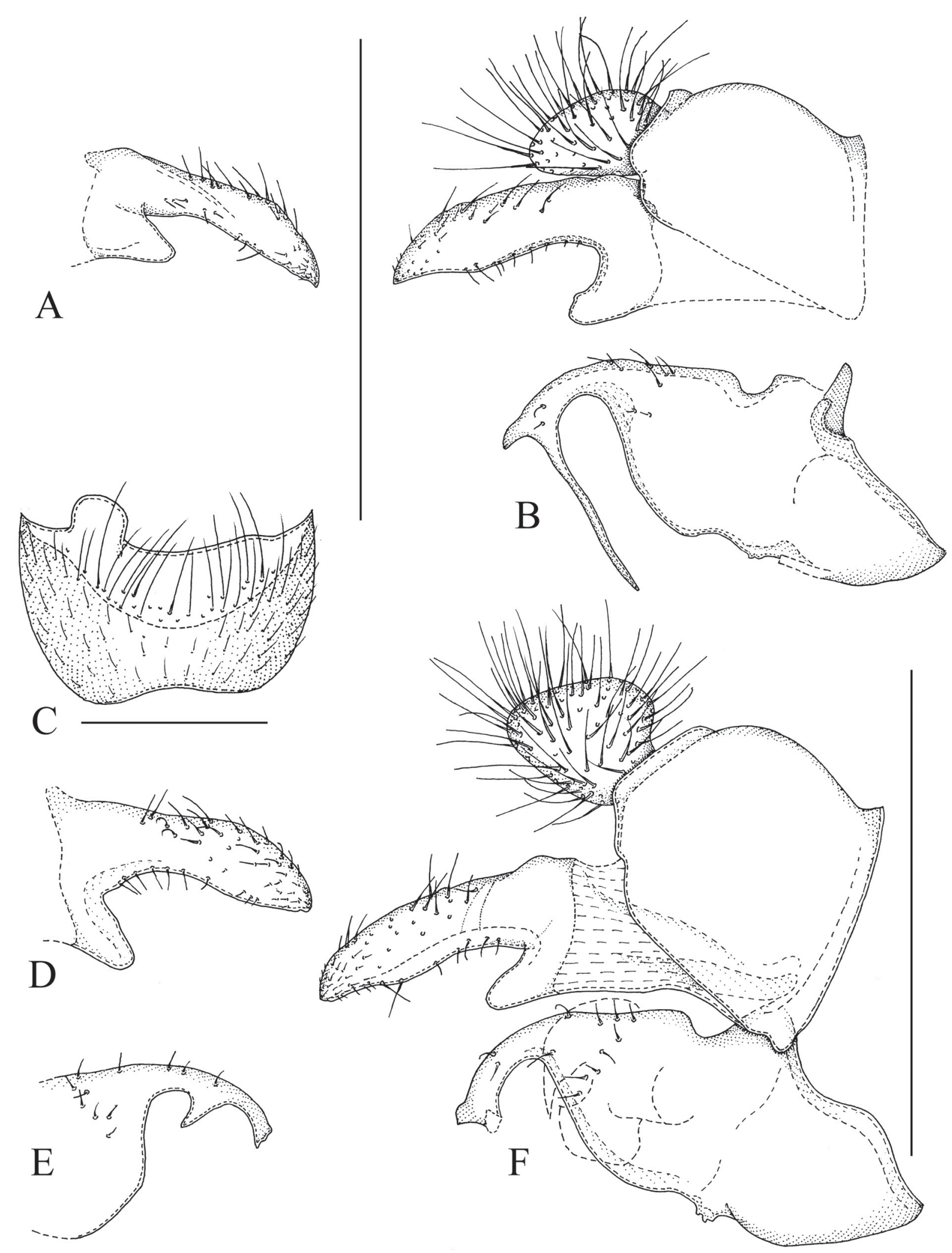

Fig. 78. Sphegina (Asiosphegina) prolixa sp. nov., holotype, $\widehat{\partial}(\mathrm{A}-\mathrm{B})$ and paratype, $\widehat{\partial}(\mathrm{C}-\mathrm{F})$. A, D. Left surstylus, lateral view. B, F. Genitalia, right side, lateral view. C. Sternum IV, ventral view. E. Left superior lobe, lateral view. Scale bars $=0.5 \mathrm{~mm}$. 
INDIA • 1 đ̊; "India, W.B. / Rangiroon 6500' [ft] / 24.V 1962 / [leg.] Gupta”; "Ghorpade / Collection / Bangalore"; badly damaged specimen, without head and almost no mid legs; USNM.

\section{Description}

\section{Male}

\section{LENGTH. Body 6.5-7.1 mm, wing 5.4-5.6 mm.}

HEAD. Face in lateral view concave, strongly projected antero-ventrally; frontal prominence weakly developed. Ratio width of vertex at anterior ocellus: width of head 1: 3.7-3.9; ratio width of ocellar triangle: width of vertex 1: 2.4-2.6; ratio length of ocellar triangle: length of frons 1: 2.4-2.6. Face black, light grey pollinose, long pilose along eye-margin. Hypostomal bridge black, long pale pilose. Gena and mouth edge black, pale pollinose with large subtriangular non-pollinose shiny area. Frons and vertex black, predominantly grey pollinose, a wide medial vitta posterior of lunula non-pollinose and shiny; pile short, light yellow. Frons with deep anteromedial pit and wide medial furrow. Occiput black,

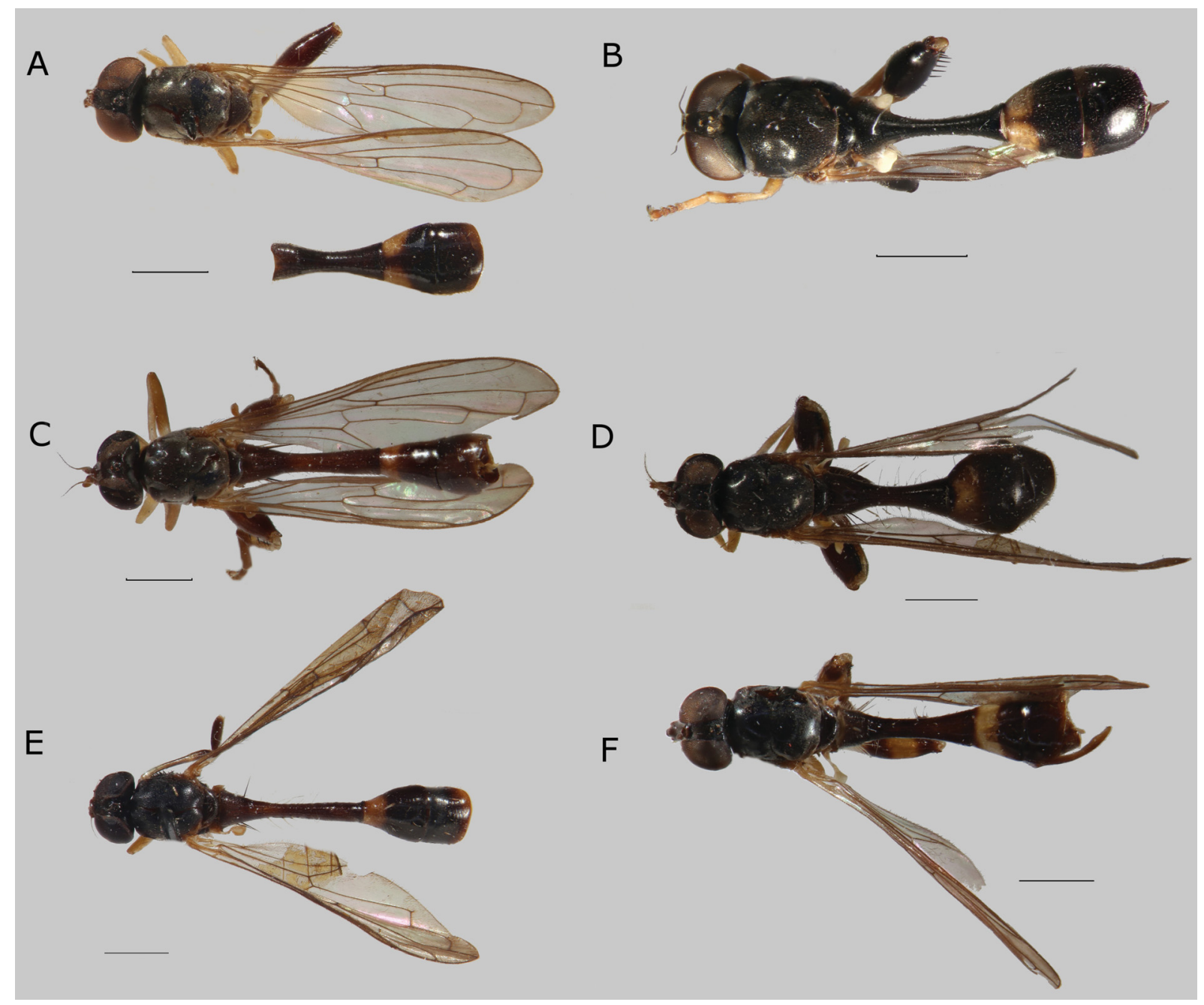

Fig. 79. Habitus, dorsal view. A. Sphegina (Asiosphegina) pollex Hippa, van Steenis \& Mutin, 2015, paratype, đ̃, Myanmar. B. S. (A.) prolixa, sp. nov., paratype, ठ̂, Thailand. C. S. (A.) radula Hippa, van Steenis \& Mutin, 2015, paratype, O, Myanmar. D. S. (A.) radula, paratype,, , Myanmar. E. $S$. (A.) raduloides Hippa, van Steenis \& Mutin, 2015, paratype, đ, Myanmar. F. S. (A.) siculifera

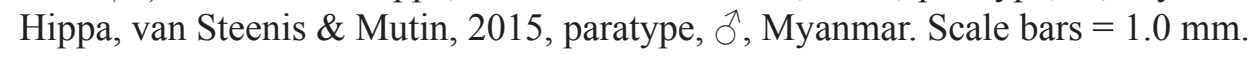


light grey pollinose, light yellow pilose. Eye without enlarged facets at anterior margin. Antenna brown with black setae dorsally on scape and pedicel; basoflagellomere oval, ratio width: length 1: 1.4-1.6; arista long pilose, nearly 4 times as long as basoflagellomere.

THORAX. Colour dark brown to black, weakly greyish pollinose, pleuron entirely more heavily grey pollinose; scutum and pleuron with very short adpressed light yellow pile. Scutellum semicircular, dark brown, grey pollinose, pile slightly longer than on scutum (the setae broken but still fixed to scutellum),
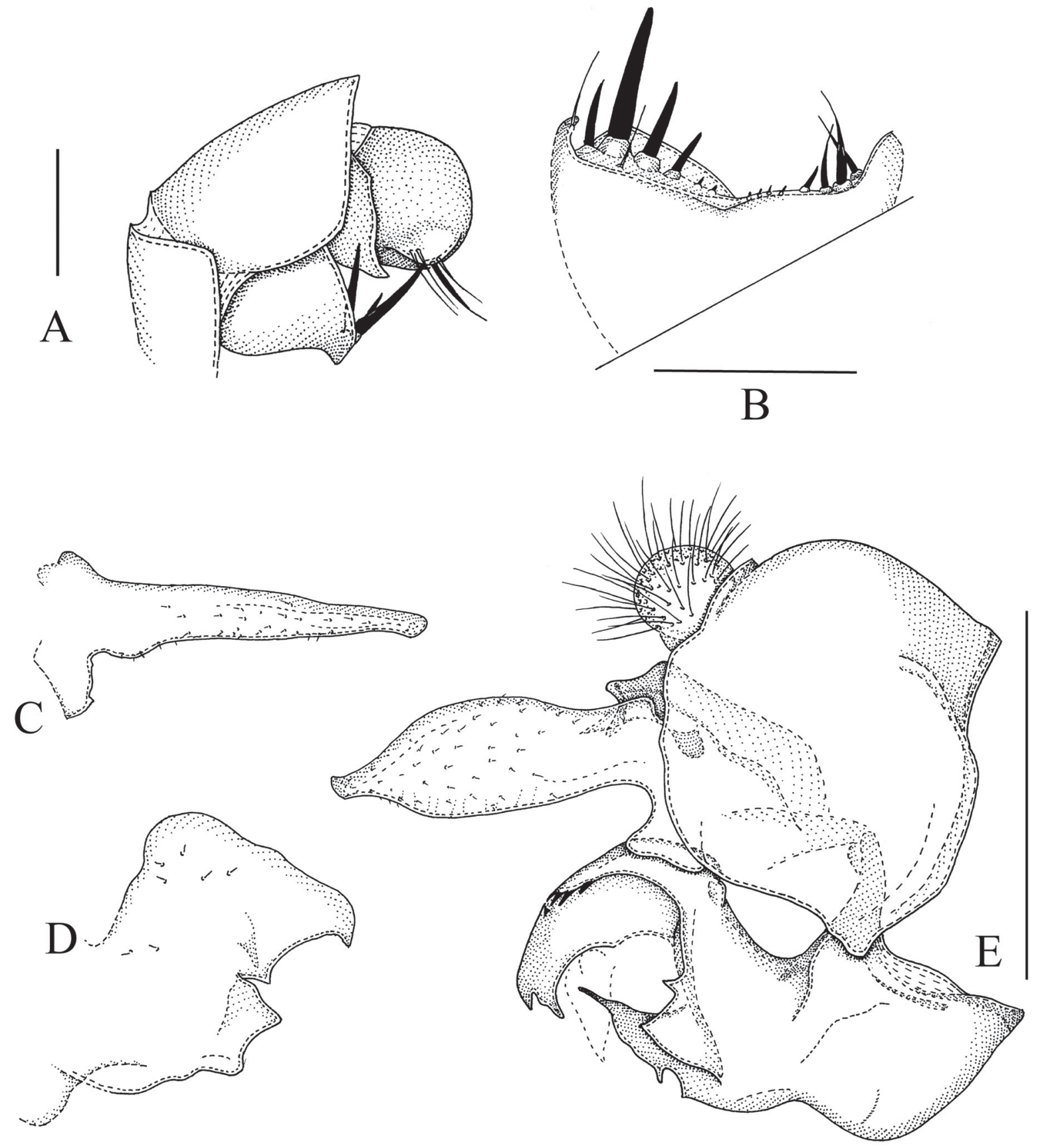

Fig. 80. Sphegina (Asiosphegina) setosa sp. nov., holotype, ô. A. Posterior part of abdomen, left side lateral view. B. Sternum IV, ventral view. C. Left surstylus, lateral view. D. Left superior lobe with associated parts, lateral view. E. Genitalia, right side, lateral view. Scale bars $=0.5 \mathrm{~mm}$. 
with widely set medium long setae medially at posterior margin, ratio length of scutellum: length of seta 1: $1.5-1.9$.

WING. Entirely microtrichose; hyaline, stigma yellowish. Crossvein dm-cu meeting vein $\mathrm{M}$ almost perpendicularly and vein $M_{1}$ meeting vein $R_{4+5}$ perpendicularly.

LeGs. Pro- and mesoleg yellow, tarsomeres 4 and 5 brown to black. Metaleg, Fig. 95B, with coxa black, trochanter yellow; femur black with basal $1 / 2$ yellow, slightly incrassate, ratio width: length $1: 4.2-5.0$, in profile baso-dorsally slightly concave; tibia black and yellow biannulate with very weak rounded apicoventral dens; tarsus entirely black, basitarsomere rather thin, ratio width: length 1: 3.7-4.0.
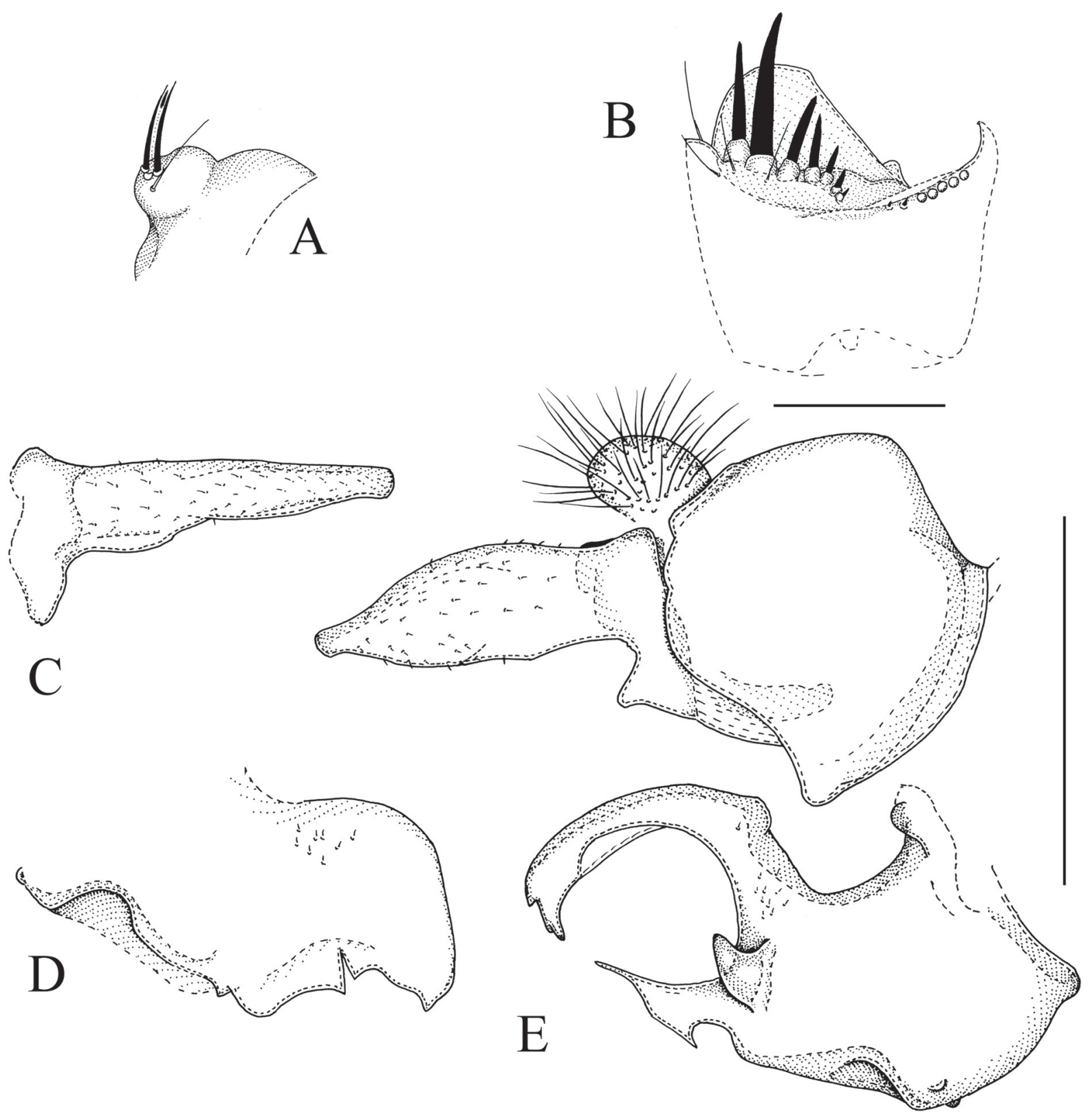

Fig. 81. Sphegina (Asiosphegina) setosa sp. nov., paratype, ô, India. A. Sternum VII, ventral view. B. Sternum IV, ventral view. C. Left surstylus, lateral view. D. Left superior lobe with associated parts, lateral view. E. Genitalia, right side, lateral view. Scale bars $=0.5 \mathrm{~mm}$. 
AвDOMEN. Length ratio of terga I: II: III: IV 1: 4.4-4.7: 1.9-2.3: 1.5-2.0; ratio width at posterior margin: medial length of tergum II and III 1: 4.7-5.9 and 1: 0.9-1.2. Tergum IV slightly skewed to the right. Terga black, anterior $1 / 3$ of tergum III with yellow fascia; pile pale, on terga short, laterally on terga I and II long; tergum I with 2-3 widely separated black setae at lateral margin; sternum III rectangular, ratio width: length 1: 1.7-2.0; sternum IV, Figs 80B, 81B; sternum VII with long black seta associated with pale ones on a rounded tubercle; sterna VI and VIII simple, with long yellow pile. Genitalia, Figs $80 \mathrm{C}-$ E, 81C-E: note the strongly asymmetrical surstyli and superior lobes.

\section{Female}

Unknown.

\section{Remarks}

Among the material studied, there are two specimens (1 \%; "Nepal, nr Ktmd. / Godavari 6000' [feet] / VII.17-20.1967 / Mal tr., Can. Exp.”; CNC. IndiA: 1 \&; "School of Entomology / St John’s College / Agra-2 India"; "Kumaon Survey / II.2 Ramgarh / M.S. Mani \& Party / 18, 20, 22-24.VI.1974”; "11 2-24.VI.74"; "Ghorpade / Collection / Bangalore" (JSA)) possibly belonging to this species.

Sphegina (Asiosphegina) siculifera Hippa, van Steenis \& Mutin, 2015 Figs 79F, 82A

Sphegina (Asiosphegina) siculifera Hippa, van Steenis \& Mutin, 2015: 47. Type locality: Kambaiti, Myanmar (holotype, $\widehat{\jmath}$, NHRS).

\section{Remarks}

Only known by the type material from Myanmar, Kambaiti (Hippa et al. 2015).

Sphegina (Asiosphegina) simplex Hippa, van Steenis \& Mutin, 2015

Figs $82 \mathrm{~B}, 90 \mathrm{~A}$

Sphegina (Asiosphegina) simplex Hippa, van Steenis \& Mutin, 2015: 38. Type locality: Kambaiti, Myanmar (holotype, ${ }^{\lambda}$, NHRS).

\section{Remarks}

Only known by the type material from Myanmar, Kambaiti (Hippa et al. 2015).

Sphegina (Asiosphegina) sinesmila Hippa, van Steenis \& Mutin, 2015

Fig. $82 \mathrm{C}$

Sphegina (Asiosphegina) sinesmila Hippa, van Steenis \& Mutin, 2015: 49. Type locality: Kambaiti, Myanmar (holotype, ふึ, NHRS).

\section{Remarks}

Only known by the type material from Myanmar, Kambaiti (Hippa et al. 2015). 


\section{Sphegina (Asiosphegina) spathigera sp. nov.}

urn:1sid:zoobank.org:act:FDBA2015-5C39-4069-B719-60FAE1EE8982

Figs 77F, 82D-E, 83, 84K, 88A

\section{Differential diagnosis}

Similar to Sphegina (Asiosphegina) amplistylus sp. nov., S. (A.) inflata sp. nov. and S. (A.) philippina. Except for the characters mentioned in the key it is distinguished by the wide bilobed apex of the dorsal lobe of surstylus on both sides (narrow, unilobed in the other species).

\section{Etymology}

The specific epithet is from the Latin 'spathigera', meaning 'bearing a short pointless sword' and referring to that kind of lobe posterolaterally on the left side of male sternum IV.

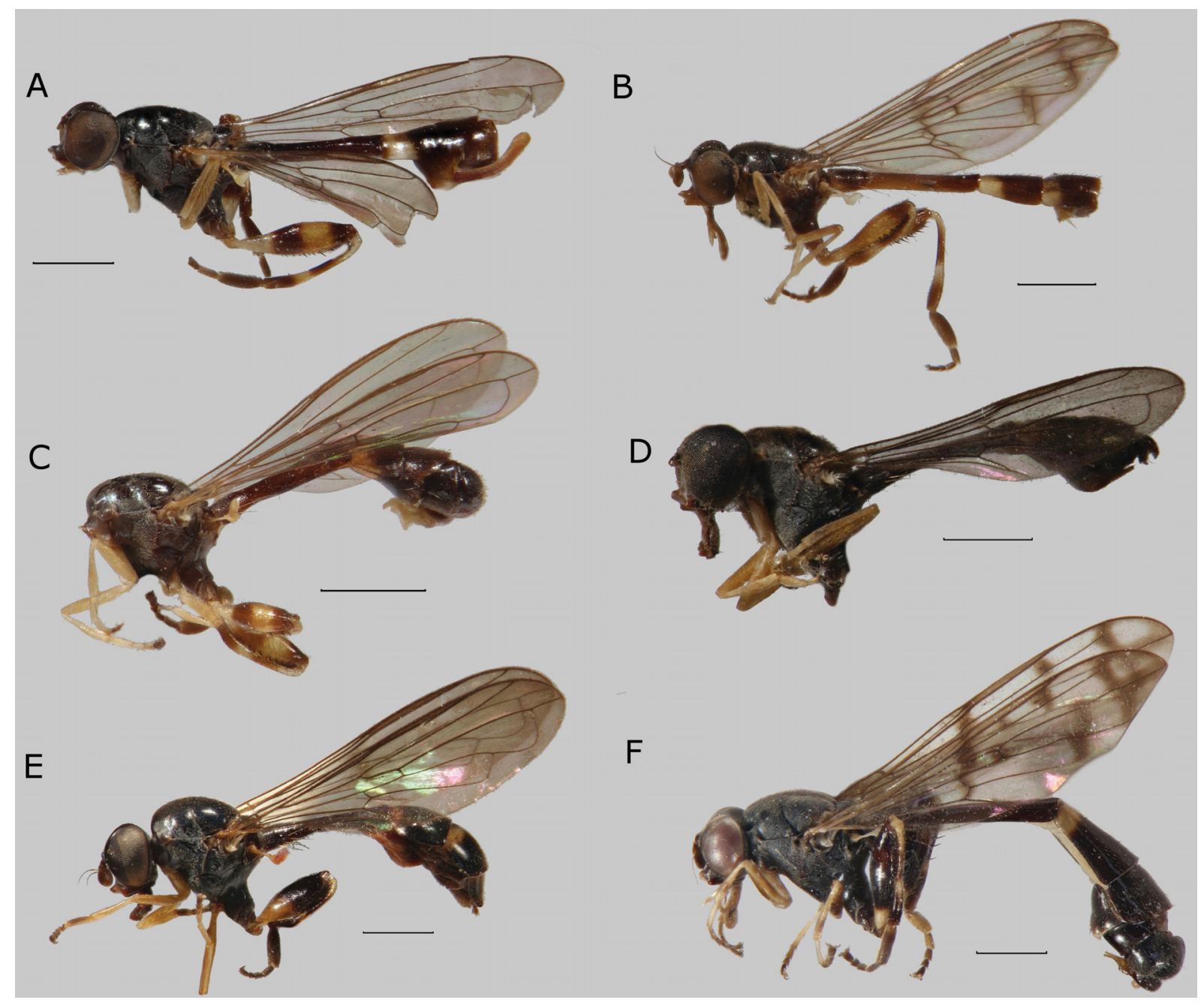

Fig. 82. Habitus, lateral view. A. Sphegina (Asiosphegina) siculifera Hippa, van Steenis \& Mutin, 2015, paratype, đ, Myanmar. B. S. (A.) simplex Hippa, van Steenis \& Mutin, 2015, paratype, đૈ, Myanmar. C. $S$. (A.) sinesmila Hippa, van Steenis \& Mutin, 2015, paratype, ô, Myanmar. D. S. (A.) spathigera sp. nov., holotype, ${ }_{\curvearrowright}$, Philippines. E. S. (A.) cf. spathigera sp. nov.,, , Philippines. F. S. (A.) strigillata sp. nov., paratype, $\partial^{\lambda}$, Vietnam. Scale bars $=1.0 \mathrm{~mm}$. 


\section{Material examined}

Holotype

PHILIPPINES • đ̊; "Philippines / Ifugao Province / Jacmal Bunhian / 4 km E Mayoyao 800- / $1000 \mathrm{~m}$ 1-10.V.1967"; "H.M. Torrevillas / Collector / Bishop"; BPBM.

\section{Description}

\section{Male}

LeNGTH. Body $5.6 \mathrm{~mm}$, wing $4.2 \mathrm{~mm}$.

HEAD. Face in lateral view concave, weakly projected antero-ventrally; frontal prominence very weakly developed. Ratio width of vertex at anterior ocellus: width of head 1: 5.2; ratio width of ocellar triangle:
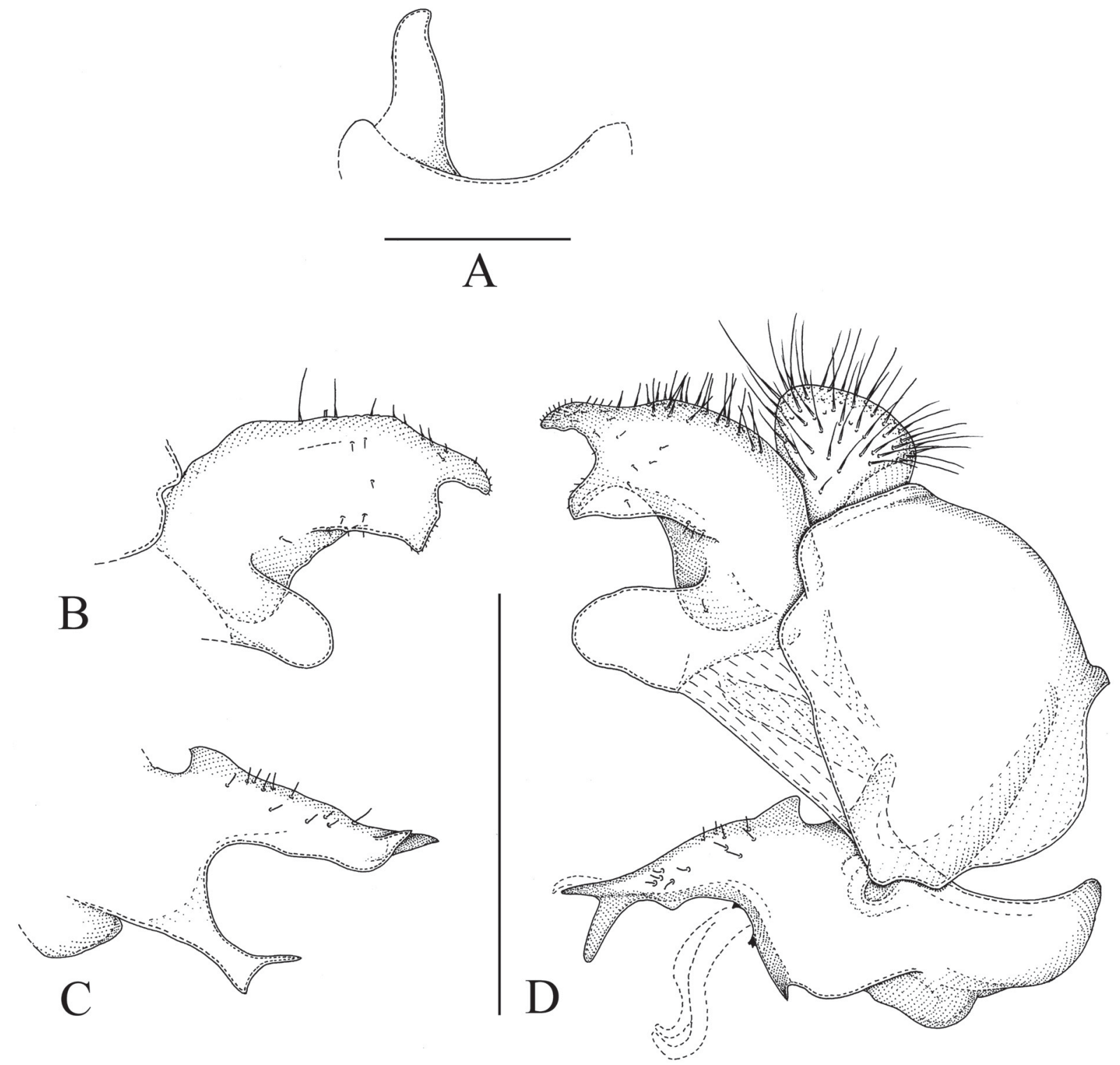

Fig. 83. Sphegina (Asiosphegina) spathigera sp. nov., holotype, $ð$. A. Posterior part of sternum IV, ventral view. B. Left surstylus, lateral view. C. Left superior lobe with associated parts, lateral view. D. Genitalia, right side, lateral view. Scale bars $=0.5 \mathrm{~mm}$. 


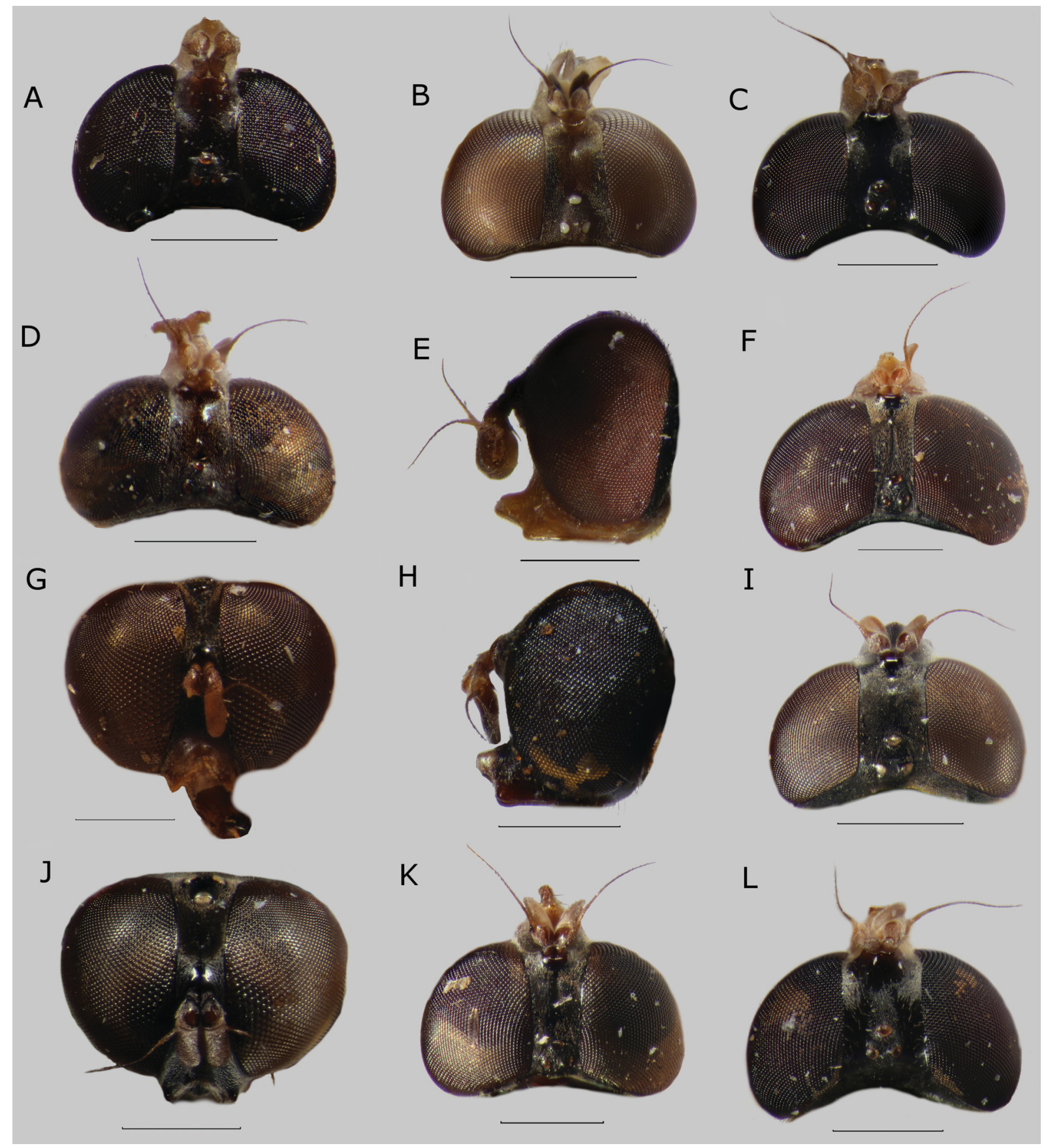

Fig. 84. Head, lateral view (E, H), dorsal view (A-D, F, I, K-L) and frontal view (G, J). A. Sphegina (Asiosphegina) nasuta Hippa, van Steenis \& Mutin, 2015, paratype, ô, Myanmar. B. S. (A.) nubicola sp. nov., holotype, đ̃, Thailand. C. S. (A.) orientalis Kertész, 1914, o, Taiwan. D. S. (A.) parvula Hippa, van Steenis \& Mutin, 2015, paratype, ô, Myanmar. D-E. S. (A.) perlobata sp. nov., holotype, đ̂, Taiwan. F. S. (A.) philippina, Thompson, 1999, paratype, + , Philippines. G. S. (A.) philippina, holotype, ô,

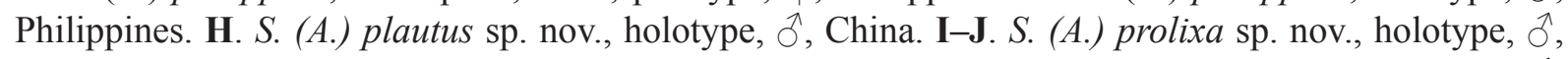
Malaysia. K. S. (A.) cf. spathigera sp. nov., +, Philippines. L. S. (A.) taiwanensis sp. nov., paratype, ${ }^{\wedge}$, Taiwan. Scale bars $=0.5 \mathrm{~mm}$. 
width of vertex 1: 1.5; ratio length of ocellar triangle: length of frons 1: 2.5. Face black, ventral half dark yellow to brown, light grey pollinose, long pilose along eye-margin. Hypostomal bridge dark brown, long pale pilose. Gena and mouth edge brown to dark brown, pale pollinose with large subtriangular nonpollinose shiny area. Frons and vertex black, slightly pollinose, a narrow subtriangular area posterior of lunula non-pollinose and shiny (Fig. 88A); pile short, light yellow. Frons with weak furrow medially. Occiput black, light grey pollinose, light yellow pilose. Eye with an area of enlarged facets at anterior margin. Antenna brown with black setae dorsally on scape and pedicel; basoflagellomere rectangular, ratio width: length 1: 1.4; arista long pilose, nearly 3 times as long as basoflagellomere.

THORAX. Colour black, weakly greyish pollinose, postpronotum dark brown, grey pollinose, pleuron entirely more heavily grey pollinose; scutum and pleuron with very short adpressed light yellow pile. Scutellum short and widely sub-triangular, black, weakly pale pollinose, long pilose, with pile longer than on scutum, without marginal setae, possibly the setae are broken off.

WING. Entirely microtrichose; hyaline, stigma yellowish. Crossvein dm-cu meeting vein $\mathrm{M}$ slightly obliquely and vein $\mathrm{M}_{1}$ meeting vein $\mathrm{R}_{4+5}$ perpendicularly.

Legs. Pro- and mesoleg yellow, tarsomeres 4-5 black, tarsomere 3 of protarsus brown. Metaleg with coxa black, trochanter yellow; femur black with basal $1 / 3$ yellow, strongly incrassate, ratio width: length 1: 3.1; tibia black and yellow biannulate with large rounded apicoventral dens; tarsus entirely black, basitarsomere thick, ratio width: length 1:3.2.

ABDOMEN. Length ratio of terga I: II: III: IV 1: 4.0: 2.1: 1.6; ratio width at posterior margin: medial length of tergum II and III 1: 2.5 and 1: 0.7 . Terga black, anterior $1 / 3$ of tergum III with dark yellow fascia; pile pale, on terga short, laterally on terga I and II long; tergum I with horizontal row of 3-4 evenly spread brown-yellow setae at lateral margin; sternum III not sclerotized; sternum IV, Fig. 83A; sterna VI, VII and VIII simple, with long yellow pile. Genitalia, Fig. 83B-D: note the almost symmetrical surstyli and asymmetrical superior lobes.

\section{Female}

Unknown.

\section{Remarks}

In the type material of Sphegina (Asiosphegina) philippina there is one specimen (1 $q$, "P.I.: Mindanao / Bukidnon. 1480 m. / Mt. Katanglad / 27-31.X.1959", "L.W. Quate / Collector" (BPBM)) which is not S. (A.) philippina because the vertex (Fig. 84K) is wide (narrower in S. (A.) philippina), the postpronotum is black (yellow in $S$. (A.) philippina) and the wing is hyaline (infuscated in $S$. (A.) philippina). It is possible that this specimen is the female of $S$. (A.) spathigera sp. nov., but as even the males of the species similar to $S$. (A.) philippina are very difficult to distinguish from each other without reference to the genitalia the identity of this female remains open.

Sphegina (Asiosphegina) spenceri sp. nov. urn:1sid:zoobank.org:act:104143FD-884E-4527-A2E9-8E42D0DA2F79

Figs $85,86 \mathrm{~A}-\mathrm{B}, 88 \mathrm{~B}-\mathrm{C}$

\section{Differential diagnosis}

Similar to Sphegina (Asiosphegina) bracon sp. nov., S. (A.) furcillata sp. nov. and S. (A.) vietnamensis sp. nov., but should be easily distinguished by the characters given in the key. The male is easily distinguished by having the two most lateral setae on the left side of sternum IV about twice as long as 
the other strong seta rather than about ten times as long. Also, by the normal undivided ventral lobe of surstylus instead of a bifid one.

\section{Etymology}

The species is named after Mr Neal Spencer, an entomologist specialising in the biocontrol of weeds and director of the USDA ARS Pest Management and Agricultural Systems Research Unit at Sidney, USA. He has been a great collector of Diptera and collected the type material of this species.

\section{Material examined}

Holotype

VIETNAM • O’; "Viet Nam: Dalat / 6km S. 1400-1500 m / 9.VI-7.VII.1961"; "N. R. Spencer / Collector / Bishop"; BPBM.

\section{Paratypes}

VIETNAM • $6 \widehat{\partial}, 1$; ; same data as for holotype; BPBM • $4 \hat{\jmath}$; same data as for preceding; JSA •

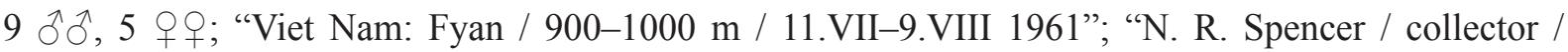

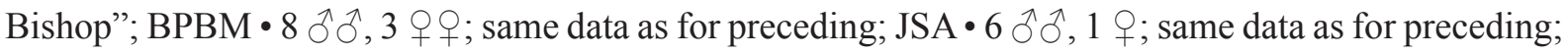

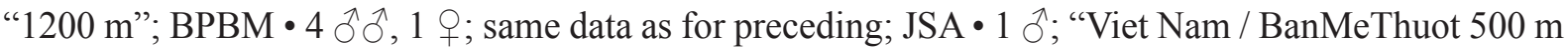
/ 16-18.V.1960"; "L.W. Quate / Collector"; BPBM • 1 đ̊; "Viet Nam: Mt. Lang / Bian 1500-2000 / 19. V- 8.VI 1961"; "N. R. Spencer / collector / Bishop"; BPBM.

\section{Description}

\section{Male}

LeNGTH. Body 6.1-7.8 mm, wing 4.4-6.1 mm.

HEAD. Face in lateral view, Fig. 88C, concave, weakly projected antero-ventrally; frontal prominence very weakly developed. Ratio width of vertex at anterior ocellus: width of head 1:3.8-4.1; ratio width of ocellar triangle: width of vertex 1: 1.9-2.1; ratio length of ocellar triangle: length of frons 1: 3.1-3.5. Face with dorsal half dark brown to black and ventral half orange-brown to dark brown, light grey pollinose, long pilose along eye-margin. Hypostomal bridge dark brown, long pale pilose. Gena and mouth edge orange-brown to dark brown, pale pollinose with large subtriangular non-pollinose shiny area. Frons and vertex black, pale pollinose with narrow subtriangular area posterior of lunula nonpollinose and shiny, with grey-brown pollinose macula posterolaterally of shiny part (Fig. 88B); pile short, light yellow. Frons with very weak pit antero-medially and weak shiny ridge postero-medially towards ocellar triangle, laterally of this ridge the pollinosity is more velvet-black than other pollinosity. Occiput black, non-pollinose and shiny, light yellow pilose. Eye with enlarged facets at anterior margin. Antenna brown to orange-brown with black setae dorsally on scape and pedicel; basoflagellomere short oval to slightly elongate, ratio width: length 1: 1.3-1.5; arista long pilose, about 3 times as long as basoflagellomere.

THORAX. Colour dark brown to black, postpronotum, postalar callus, proepimeron and medio-dorsal part of pleuron yellow to brown-yellow; weakly greyish pollinose, pleuron sub-shiny; scutum and pleuron with very short adpressed light yellow pile. Scutellum sub-rectangular, brown-yellow to brown, entirely grey pollinose, in some specimens sub-shiny, with pile slightly longer than on scutum, with two very widely set, short setae medially at posterior margin, ratio length of scutellum: length of seta 1:1.0-1.2.

WING. Entirely microtrichose; hyaline, stigma yellowish. Crossvein dm-cu meeting vein M obliquely and vein $M_{1}$ meeting vein $R_{4+5}$ perpendicularly. 
Legs. Pro- and mesoleg yellow, tarsomeres 4 and 5 black. Metaleg with coxa black, trochanter yellow; femur black and yellow biannulate, slightly incrassate, ratio width: length 1: 3.3-3.9; tibia black and yellow biannulate with wide and short rounded apicoventral dens; tarsus black with tarsomeres 2 and 3 brownish, basitarsomere rather thin, ratio width: length 1: 3.6-3.9.
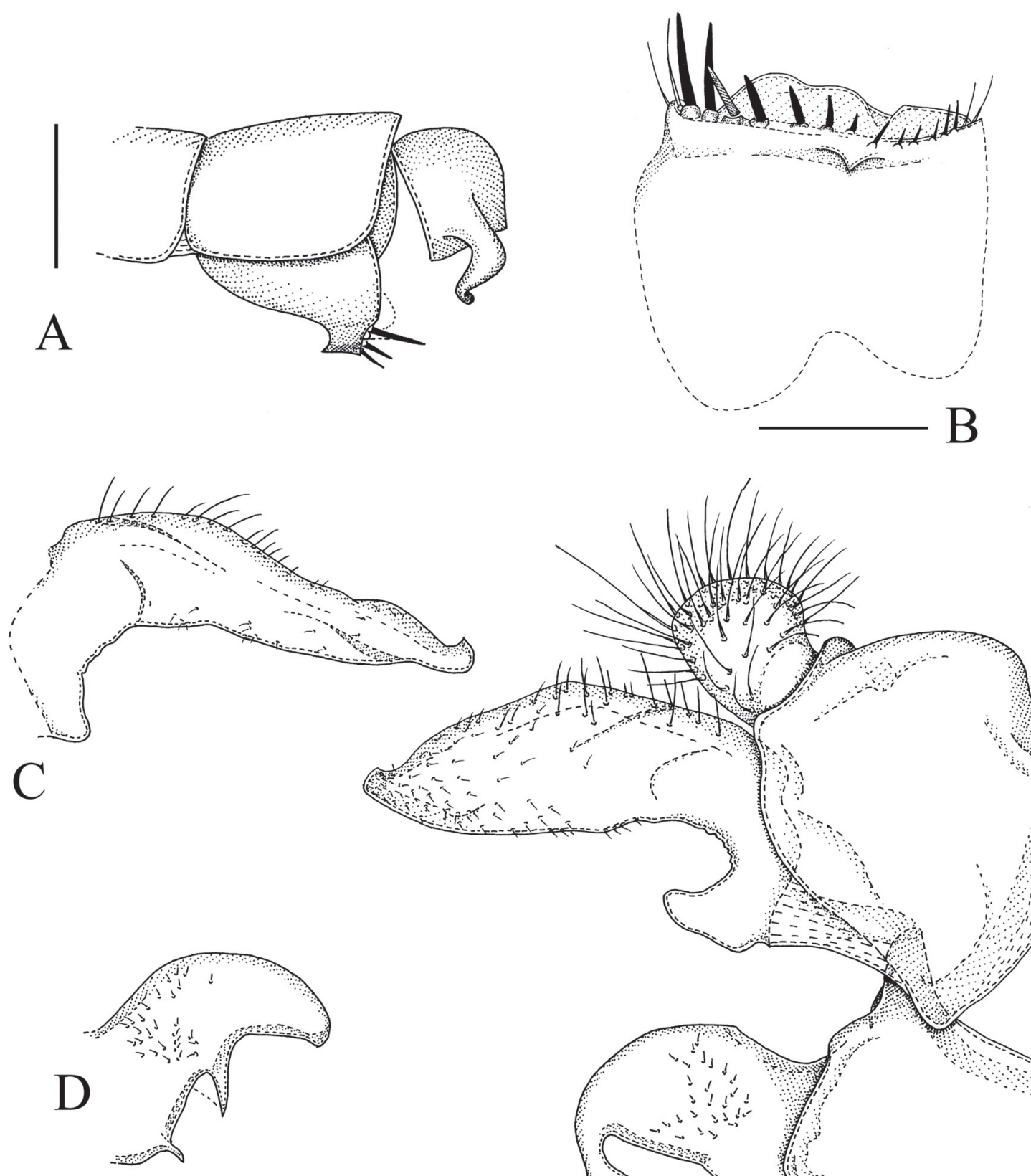
AвDOMEN. Length ratio of terga I: II: III: IV 1: 5.5-5.9: 2.3-2.6: 1.8-2.1; ratio width at posterior margin: medial length of tergum II and III 1: 4.0-4.3 and 1: 1.0-1.2. Terga black, anterior $1 / 3$ of tergum III with orange-brown fascia; pile pale, on terga short, laterally on terga I and II long; tergum I with 2-3 strong light-brown setae at lateral margin; sternum III rectangular, ratio width: length 1: 1.6-1.8; sternum IV, Fig. 85B; sternum VI with long yellow pile; sternum VII short pilose, posteriorly with elongate cone shaped process with curved apex. Genitalia, Fig. 85C-E: note the asymmetrical surstyli and superior lobes.

\section{Female}

Similar to male except for the usual sexual dimorphism.

LeNGTH. Body 5.1-7.0 mm, wing 4.2-5.7 mm.

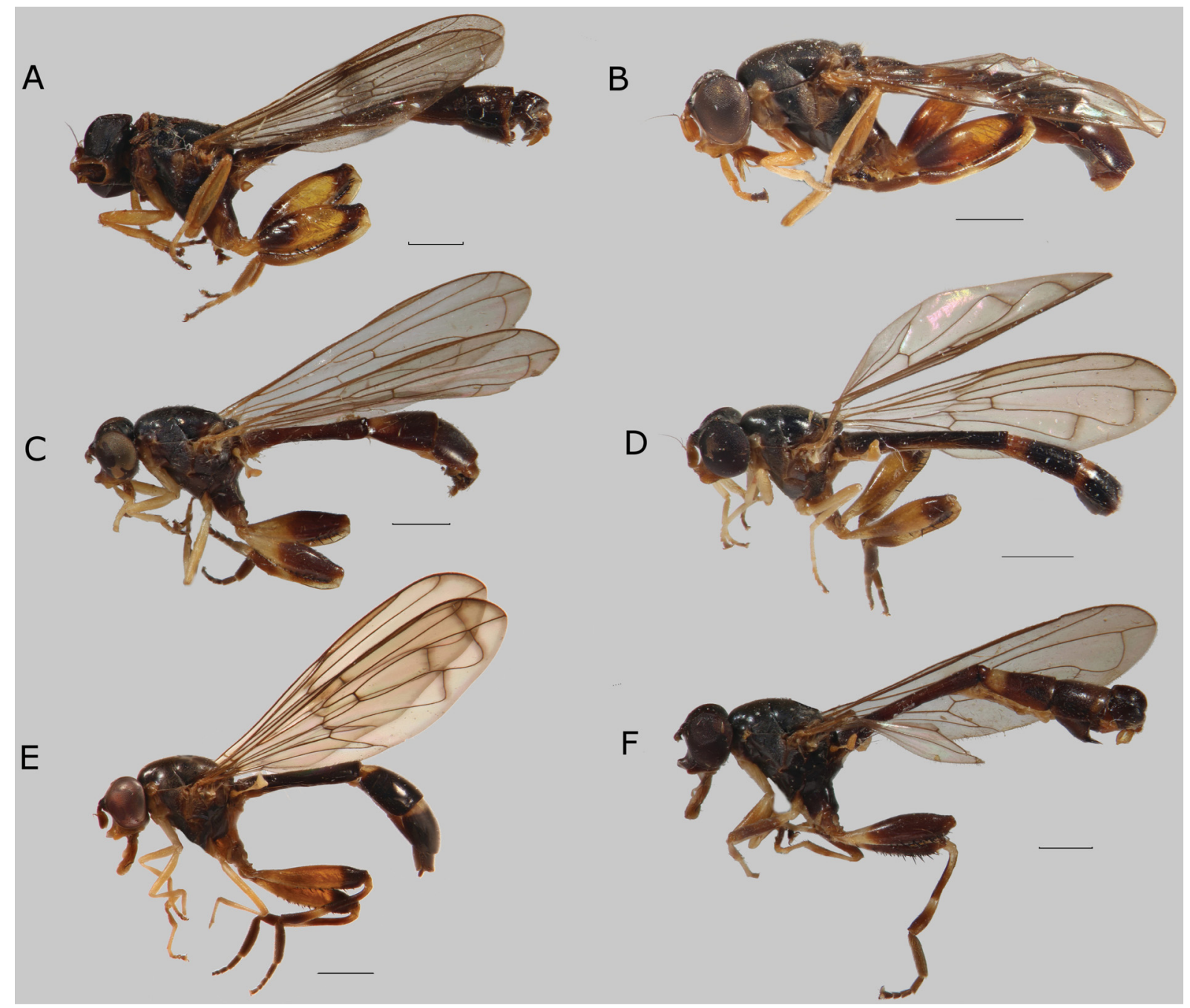

Fig. 86. Habitus, lateral view. A. Sphegina (Asiosphegina) spenceri sp. nov., paratype, ઊ̂, Vietnam. B. S. (A.) spenceri sp. nov., paratype,, , Vietnam. C. S. (A.) subradula Hippa, van Steenis \& Mutin, 2015, paratype, + , Myanmar. D. S. (A.) taiwanensis sp. nov., paratype, §̃, Taiwan. E. S. (A.) taiwanensis sp. nov., paratype, +, Taiwan. F. S. (A.) trichaeta Hippa, van Steenis \& Mutin, 2015, paratype, Ô, Myanmar. Scale bars $=1.0 \mathrm{~mm}$. 
HEAD. Ratio width of vertex at anterior ocellus: width of head 1:3.7-4.2; ratio width of ocellar triangle: width of vertex 1: 1.9-2.1; ratio length of ocellar triangle: length of frons 1: 3.5-3.9. Basoflagellomere oval, ratio width: length 1: 1.2-1.4; arista long pilose, 2.5 to 3 times as long as basoflagellomere.

Thorax. Scutellum with two widely set, very short setae medially at posterior margin, ratio length of scutellum: length of seta 1: 0.8-0.9.

LEGS. Metafemur, ratio width: length 1: 3.6-3.8; metatarsus with basitarsomere rather thin, ratio width: length 1: 3.7-3.9.

ABdomen. Length ratio of terga I: II: III: IV: V 1: 3.6-4.0: 2.5-2.7: 2.3-2.8: 0.9-1.1; ratio width at posterior margin: medial length of tergum II and III $1: 2.1-2.3$ and $1: 0.66-0.75$. Anterior $1 / 4$ of tergum III with sub-anterior yellow fascia, lateral margin dark yellow to yellow on anterior $3 / 5$; terga III and IV with antero-medial small oval to very large rectangular yellow macula; sternum III elongate, ratio width: length 1: 1.7-1.9; sternum IV trapezoidal with concave anterior margin, ratio width: length 1: $0.5-0.6$; sternum $\mathrm{V}$ widely rectangular, ratio width: length $1: 0.5-0.6$.

Sphegina (Asiosphegina) strigillata sp. nov.

urn:1sid:zoobank.org:act:E2A984A9-0B7B-47B4-BE19-1E7DCA8A28FF

Figs 82F, 87, 88D-E, 90B-C, 95C

\section{Differential diagnosis}

This species is not very similar to any described species of Sphegina and should be easily distinguished by the characters given in the key.

\section{Etymology}

The specific epithet is from the Latin 'strigillata', meaning 'with a scraper' and referring to the scraperlike posterior part of male sternum IV.

\section{Material examined}

\section{Holotype}

VIETNAM - O'; "N. Vietnam Tonkin / Hoang Lien N.P. Pansi Pan Mt / 2320 m. prim. Forest 24.iv- / 2.v.2000 [leg] Mai Phu Quy \& / Nguyen M. Tam, RMNH'00”; NBC.

\section{Paratypes}

VIETNAM・ 1 ; ; same data as for holotype; JSA 1 1 ; same data as for holotype; NBC.

\section{Description}

Male

LENGTH. Body 7.8-8.1 mm, wing 5.6-5.9 mm

HEAD. Face in lateral view, Fig. 88E, concave, weakly projected antero-ventrally; frontal prominence strongly developed. Ratio width of vertex at anterior ocellus: width of head 1: 3.5-3.7; ratio width of ocellar triangle: width of vertex 1: 1.9-2.1; ratio length of ocellar triangle: length of frons 1: 1.82.1. Face black, light grey pollinose, long pilose along eye-margin. Hypostomal bridge black, long pale pilose. Gena and mouth edge dark brown, pale pollinose with large subtriangular non-pollinose shiny area. Frons and vertex black, large rectangular vitta posterior of lunula non-pollinose and shiny (Fig. 88D); pile short, light yellow. Frons with very weak and narrow medial furrow. Occiput black, light grey pollinose, light yellow pilose. Eye without enlarged facets at anterior margin. Antenna brown- 
yellow with black setae dorsally on scape and pedicel; basoflagellomere oval, ratio width: length 1 : 1.2-1.4; arista long pilose, about 3.5 times as long as basoflagellomere.

THORAX. Colour dark brown to black, weakly greyish pollinose, scutum with densely grey pollinose vitta submedially, pleuron entirely grey pollinose; scutum and pleuron with very short adpressed light yellow pile. Scutellum sub-triangular, black, shiny, with pile slightly longer than on scutum, with two widely set short setae medially at posterior margin, ratio length of scutellum: length of seta 1: 1.1-1.4.

WING. Entirely microtrichose, hyaline, stigma yellowish, membrane brown infuscated at junction of veins $R_{2+3}$ and $R_{4+5}$, along veins bm-cu, r-m, dm-cu and $M_{1}$, and at medial and apical appendices of vein $R_{2+3}$. Crossvein dm-cu meeting vein $M$ perpendicularly and vein $M_{1}$ meeting vein $R_{4+5}$ perpendicularly.

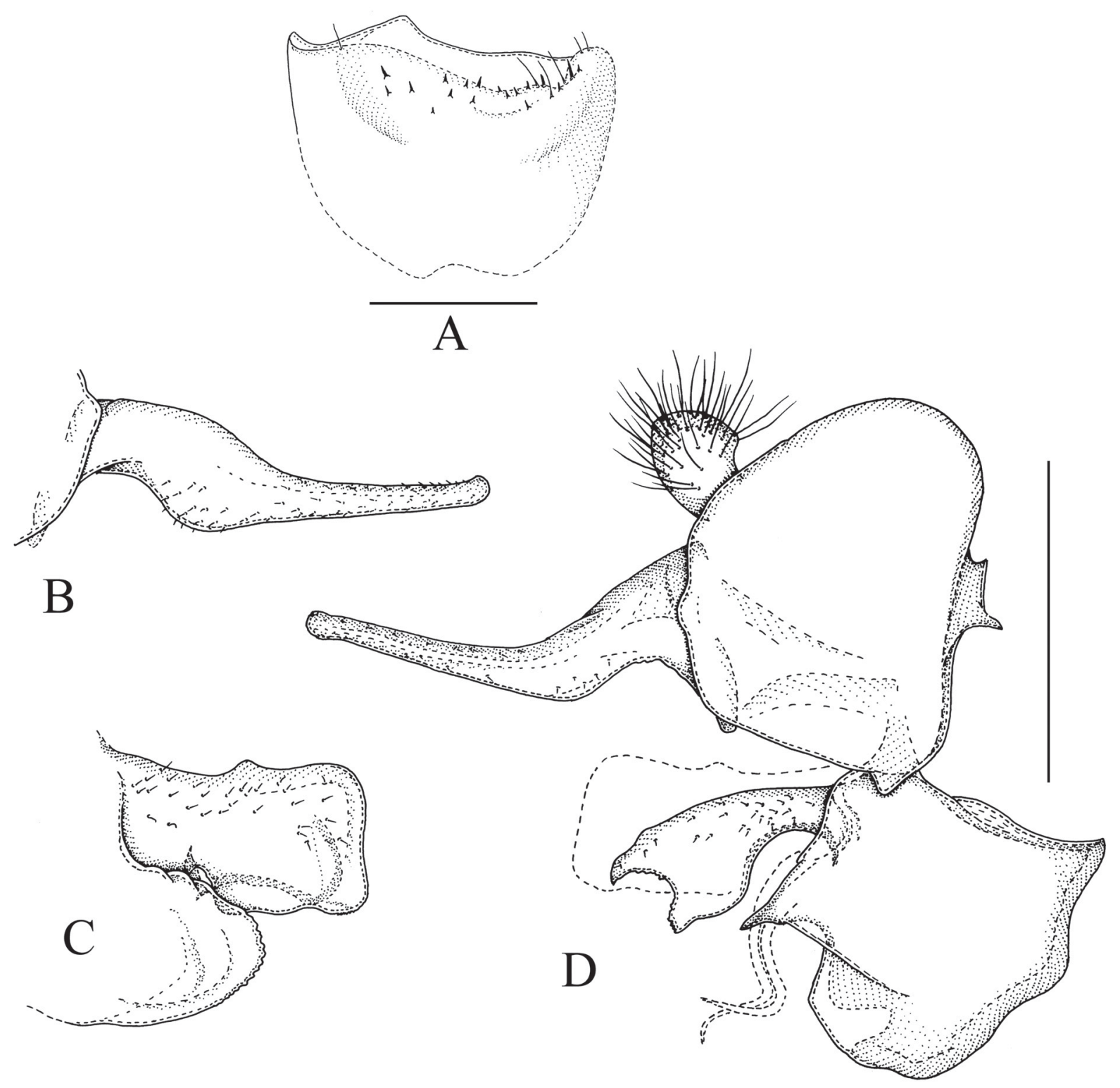

Fig. 87. Sphegina (Asiosphegina) strigillata sp. nov., holotype, ठ․ A. Sternum IV, ventral view. B. Left surstylus, lateral view. C. Left superior lobe with associated parts, lateral view. D. Genitalia, right side, lateral view. Scale bars $=0.5 \mathrm{~mm}$. 
Legs. Pro- and mesofemur yellow, baso-medial $1 / 4-1 / 2$ black; pro- and mesotibia yellow, apico-medial 1/5-1/4 black; pro- and mesotarsus yellow, tarsomeres 3-5 brown to black. Metaleg, Fig. 95C, with coxa and trochanter black; femur black and yellow biannulate, incrassate, ratio width: length 1: 3.8-4.0; tibia

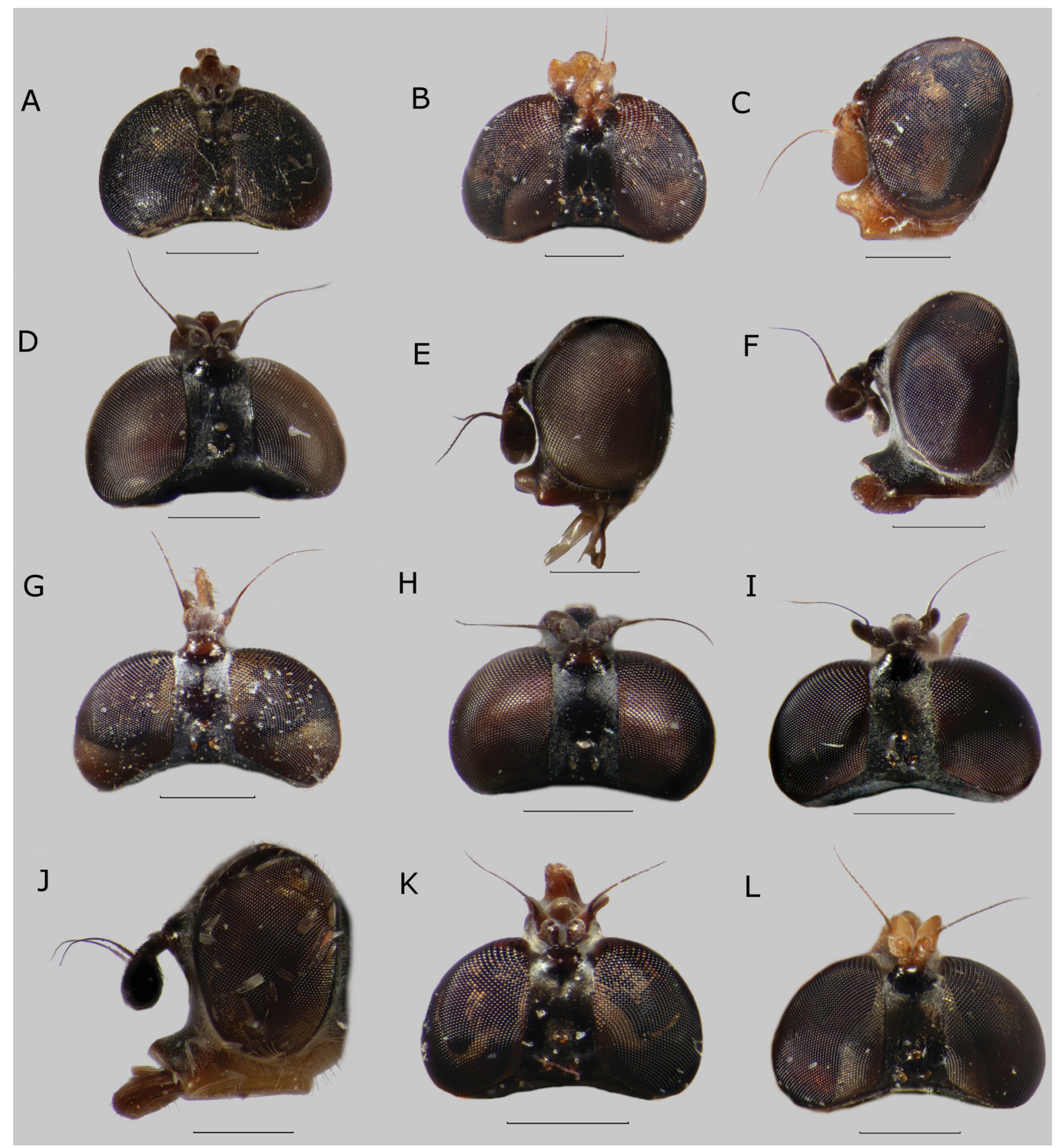

Fig. 88. Head. lateral view (C, E, F, J) and dorsal view (A-B, D, G-I, K-L). A. Sphegina (Asiosphegina) spathigera sp. nov., holotype, ठิ, Philippines. B-C. S. (A.) spenceri sp. nov., paratype, ठิ, Vietnam. D-E. S. (A.) strigillata sp. nov., holotype, ô, Vietnam. F. S. (A.) tricoloripes, Brunetti, 1915, o, India.

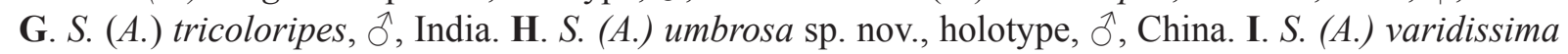
Shiraki, 1930, đ̃, Taiwan. J. S. (A.) varidissima, ๆ, Taiwan. K. S. (A.) verrucosa sp. nov., paratype, ô, Vietnam. L. S. (A.) vietnamensis sp. nov., paratype, $\partial$, Vietnam. Scale bars $=0.5 \mathrm{~mm}$. 
black and yellow biannulate without apicoventral dens; tarsus entirely black, basitarsomere rather thin, ratio width: length 1: 3.7-3.9.

ABDOMEN. Length ratio of terga I: II: III: IV 1: 4.7-4.9: 2.8-3.1: 1.5-1.7; ratio width at posterior margin: medial length of tergum II and III $1: 5.4-5.6$ and $1: 1.4-1.6$. Terga black, anterior $1 / 4-1 / 3$ of tergum III with yellow fascia; pile pale, on terga short, laterally on terga I and II long; tergum I with a horizontal row of 3-4 strong black setae at lateral margin; sternum III elongate, ratio width: length 1: 2.6-2.8; sternum IV, Fig. 87A; sterna VI, VII and VIII simple, with long yellow pile. Genitalia, Fig. 87B-D: note the almost symmetrical surstyli and asymmetrical superior lobes.

\section{Female}

Similar to male except for the normal sexual dimorphism.

Length. Body $7.2 \mathrm{~mm}$, wing $6.1 \mathrm{~mm}$.

HEAD. Ratio width of vertex at anterior ocellus: width of head 1: 3.4; ratio width of ocellar triangle: width of vertex 1: 2.2; ratio length of ocellar triangle: length of frons 1: 3.0. Frons with densely grey pollinose fascia anteriorly of shiny part. Basoflagellomere oval, ratio width: length 1: 1.3; arista about 3 times as long as basoflagellomere.

THORAX. Scutellum with two very widely set, short setae medially at posterior margin, ratio length of scutellum: length of setae 1: 1.1 .

Legs. Metafemur incrassate, ratio width: length 1: 3.9; metatarsus with basitarsomere rather thin, ratio width: length $1: 3.7$.

ABdomen. Length ratio of terga I: II: III: IV: V 1: 2.8: 2.2: 1.6: 0.7; ratio width at posterior margin: medial length of tergum II and III 1: 2.4 and 1: 0.8. Tergum I brown, terga II-V orange-yellow; tergum I with 2 widely separated strong black setae at lateral margin; sternum III rectangular, ratio width: length 1: 3.0; sternum IV trapezoidal, ratio width: length 1: 1.1 and sternum V squarish, ratio width: length 1: 1.0 .

\section{Distribution and biology}

The specimen from Vietnam was collected in a Malaise trap near Fan Si Pan Mountain at a height of about $2300 \mathrm{~m}$ a.s.1. The Malaise trap was set up in an area of open and low montane forest partly grazed by buffalos, containing muddy areas and small streams. Despite the cold and wet weather, insects were still rather abundantly flying (C. van Achterberg, pers. comm.).

Sphegina (Asiosphegina) subradula Hippa, van Steenis \& Mutin, 2015

Fig. $86 \mathrm{C}$

Sphegina (Asiosphegina) subradula Hippa, van Steenis \& Mutin, 2015: 30. Type locality: Kambaiti, Myanmar (holotype, $\widehat{\partial}$, NHRS).

\section{Remarks}

Only known by the type material from Myanmar, Kambaiti (Hippa et al. 2015). 


\section{Sphegina (Asiosphegina) taiwanensis sp. nov. \\ urn:lsid:zoobank.org:act:F8585237-DC89-4AA0-9DD4-98A5F28C3E7F}

Figs 84L, 86D-E, 89, 90D

\section{Differential diagnosis}

Sphegina (Asiosphegina) taiwanensis sp. nov. is not very similar to any other species and is distinguished by the characters given in the key. It keys out together with Sphegina (Asiosphegina) orientalis and three other similar species and should be easily distinguished by the non-genitalic character given there. The male genitalia differ greatly, e.g., the surstyli are unilobed, not bilobed, and the cercal pilosity is normal, not with an area of very long seta-like pile.

\section{Etymology}

The specific epithet is from the Latin 'taiwanensis', meaning 'of Taiwan' and referring to the type locality in Taiwan.

\section{Material examined}

Holotype

TAIWAN • O'; "Taiwan N-Nantou Co. / Road No. 14, NE Puli / Reyen Shi-Reg., E Tsuifeng / to Yuanfeng ca $2500-2700 \mathrm{~m} / \mathrm{ca} 24^{\circ} 07^{\prime} \mathrm{N}, 121^{\circ} 13^{\prime} \mathrm{E} / 1$.VII.2000 leg. W. Schacht”; NMNS.

\section{Paratypes}

TAIWAN • 1 क ; same data as for holotype; "Meifeng / ca $24^{\circ} 06^{\prime} \mathrm{N}, 121^{\circ} 10^{\prime} \mathrm{E} / 2200 \mathrm{~m}$ 9-11.IX.2002"; ZSM • 1 Ô, 1 q; "Taiwan / Alishan, Chaiayi / Hsien 2400 m / 12-16.VI.1965"; "T. Maa \& K.S. Lin /

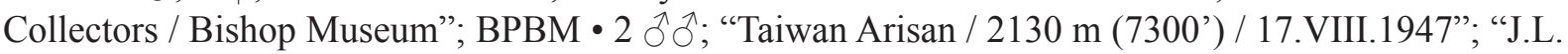

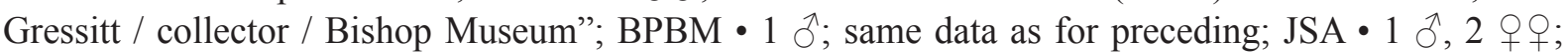

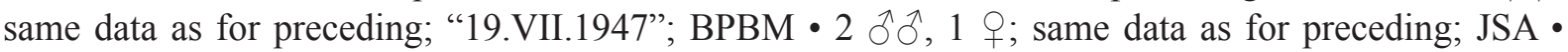
1 q; same data as for preceding; "22.VII.1947”; BPBM • 1 ô, 3 q $q$; "Taiwan C.: / Alisan 2400 m / 3-9.VII.1972"; "T.C. Maa / Collector / Bishop"; BPBM • 1 §, 2 ф $q$; same data as for preceding; JSA • 1 J'; "Taiwan Nantou / Meifeng / VI.11-VII.9.2002 / C.S. Lin \& W.T. Yang / Malaise trap (KCN)"; NMNS ENT / 4477-806"; NMNS • 1 क ; same data as for preceding; "4477-523"; NMNS • 1 §े; same data as for preceding; "VIII.6-IX.11.2001"; "6014-2294"; JSA • 1 \%; same data as for preceding; "IX.10-XI.15.2002"; "4913-331”; NMNS • 1 ठ̊; "Taiwan Nantou / Sanlinchi / 19.V.1991 / [leg] C.C. Chiang / Sweeping \& Sucking"; "NMNS ENT / 1128-74"; NMNS • 1 ठ̊; "Taiwan Taichung / Anmashan / 1.V.1990 / C.C. Chiang / Sweeping net"; "NMNS ENT / 583-45"; JSA • 1 O; "Taiwan Nantou / Sungkang / III.11.1999 / W.T Yang / UV light"; "NMNS ENT / 3151-1284”; JSA • 1 ㅇ; "Taiwan Nantou / Hsini Patungkuan / 20-22.VI.1990 / J.T. Yang / Sweeping net"; "NMNS ENT / 611-129"; NMNS • "1 q; Taiheizan / 26 VIII 1923 / Col T. Shiraki”; " barcode / 12153014180090"; NTU • 1 q; same data as for preceding; "barcode / 91"; NTU • 1 + ; "Arisan / 1912-X-20 / Col. I Nitobe"; "3508”; "barcode / 12153014180067"; NTU • 1 क; "Formosa / Karenko - 19 / VII. 20-VIII 4 / T. Okuni / J. Sonan / K. Miy,

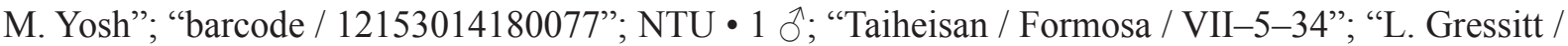
Collector"; "Frank M. Hull / Collection / C.N.C. 1973"; "CNC DIPTERA / \# 179653" [white label with blue border]; CNC • 1 \%; "Taiwan Siangyang National / Forest Recreational Area / trails, $23.247361^{\circ} \mathrm{N}$, $120.985917^{\circ}$ E, 29.v.2016 / J.H. Skevington, A.D. Young / JSM8520, CNC571925” [DNA voucher specimen, in alcohol]; CNC • 1 q; "Taiwan, Yilan, Datung / Mingchih forest rec. area / $24^{\circ} 39^{\prime} 05^{\prime \prime} \mathrm{N}$, $121^{\circ} 28^{\prime} 24^{\prime \prime}$ E / 17-5-2016, $1182 \mathrm{~m} /$ leg. J. van Steenis"; JSA • 1 \%; same data as for preceding; "leg. W van Steenis"; WSB - 1 क; "Taiwan Taichung Haiduan / Siangyang For. recr. Area / $23^{\circ} 14^{\prime} 50^{\prime \prime}$ N, 120 59'09" E / 29-05-2016, 2310-2400m / leg. J. van Steenis"; JSA • 1 o; same data as for preceding; NMNS • 1 क ; same data as for preceding; NTU • 1 \&; "Taiwan - Taichung / Haiduan road to / Siangyang National forest / Recreation area / 23 ${ }^{\circ} 14^{\prime} 28^{\prime \prime}$ N , 120 $59^{\prime} 06^{\prime \prime}$ E / 29-05-2016, 2200m asl / W. van Steenis; 


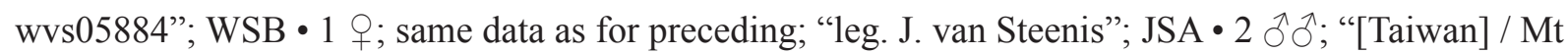
Lalashan / 1300-1500 m / Taoyuan Hsien / 17.iv.1981 / Kenji Ohara"; KIM • 1 ô;; "[Taiwan] / AlishanChushan / Alishan Chiai / 13.iv.1984 / Kenji Ôhara"; KIM.

\section{Description}

\section{Male}

LeNGTH. Body 4.8-6.1 mm, wing 4.2-5.1 mm.

HEAD. Face in lateral view concave, weakly projected antero-ventrally; frontal prominence weakly developed. Ratio width of vertex at anterior ocellus: width of head 1: 3.8-4.1; ratio width of ocellar triangle: width of vertex 1: 1.8-2.2; ratio length of ocellar triangle: length of frons 1: 2.1-2.4. Face black, ventral half yellow; light grey pollinose, long pilose along eye-margin. Hypostomal bridge black, long pale pilose. Gena and mouth edge yellow, pale pollinose with large subtriangular non-pollinose shiny area, posterior part of mouth edge dark brown to black. Frons and vertex black, frontal prominence shiny with grey pollinose subtriangular macula antero-laterally at eye-margin (Fig. 84L); pile short, light yellow. Frons with deep antero-medial pit and weak but wide furrow medially. Occiput black, light grey pollinose, ocellar triangle non-pollinose shiny, light yellow pilose. Eye without enlarged facets at anterior margin. Antenna with scape and pedicel dark yellow to brown with black setae dorsally,

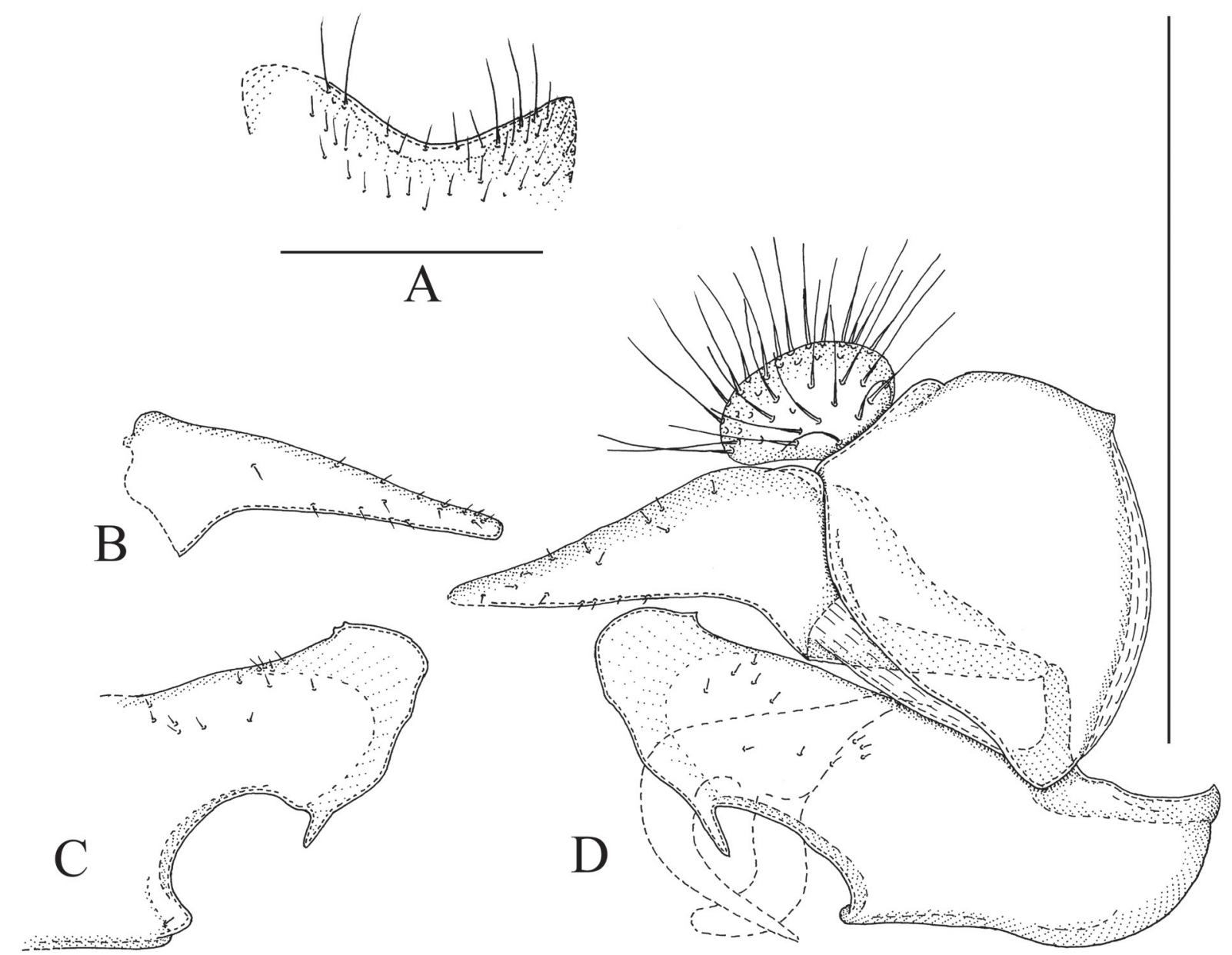

Fig. 89. Sphegina (Asiosphegina) taiwanensis sp. nov., holotype, $\widehat{\partial}$. A. Posterior part of sternum IV, ventral view. B. Left surstylus, lateral view. C. Left superior lobe with associated parts, lateral view. D. Genitalia, right side, lateral view. Scale bars $=0.5 \mathrm{~mm}$. 
basoflagellomere dark brown to black; basoflagellomere elongate, ratio width: length 1: 1.7-1.9; arista long pilose, about 2.5 times as long as basoflagellomere.

THORAX. Colour dark brown to black, weakly greyish pollinose; postpronotum, postalar callus and dorsomedial part of anepisternum and anepimeron yellow; posterior part of anepisternum and katepisternum very weakly pollinose, shiny; scutum and pleuron with very short adpressed light yellow pile. Scutellum

A
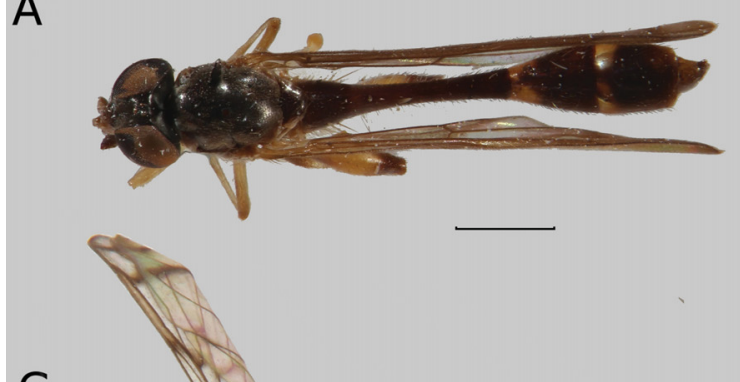

C

C

$E$

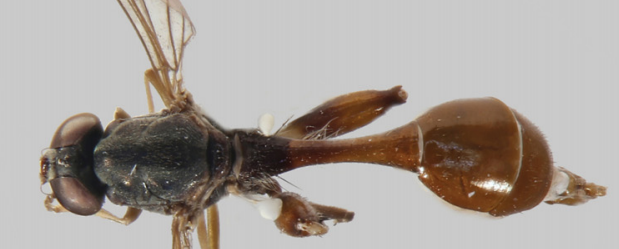

E

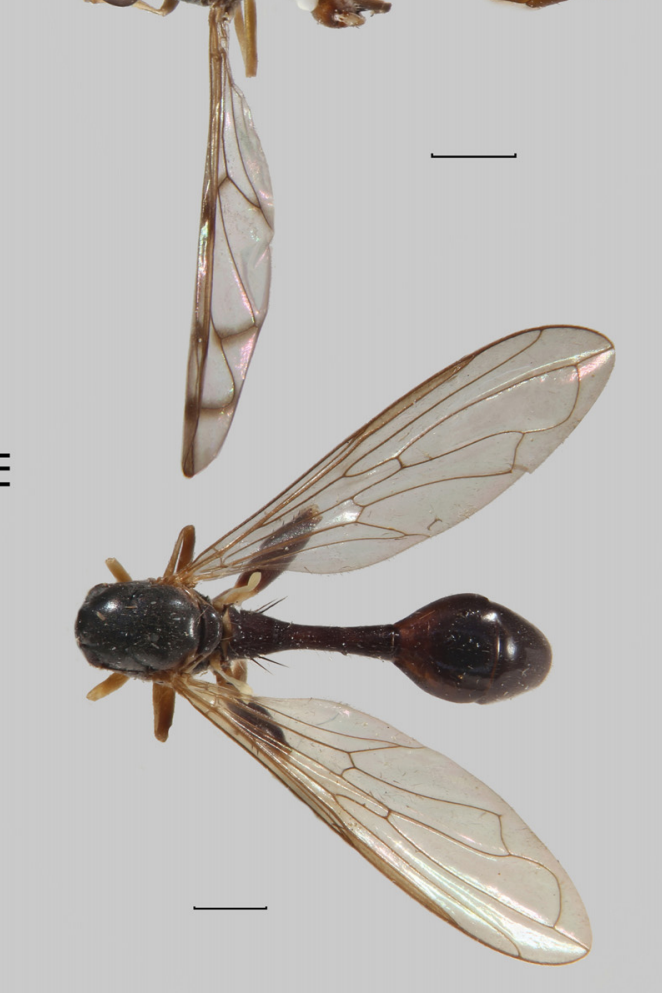

B

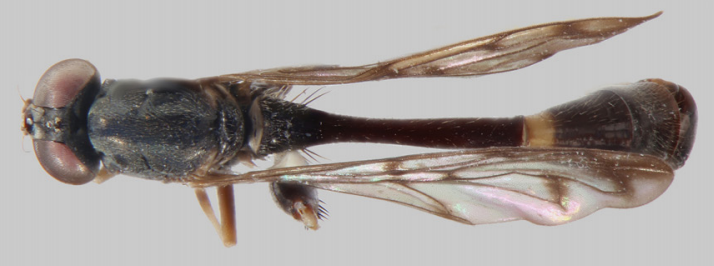

D
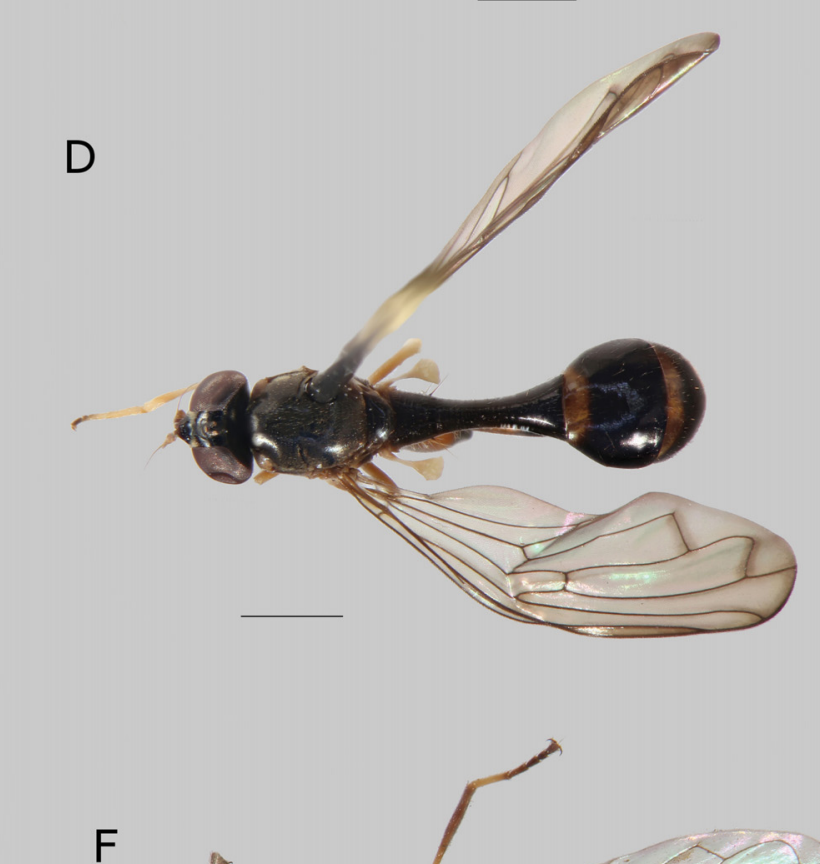

$\mathrm{F}$

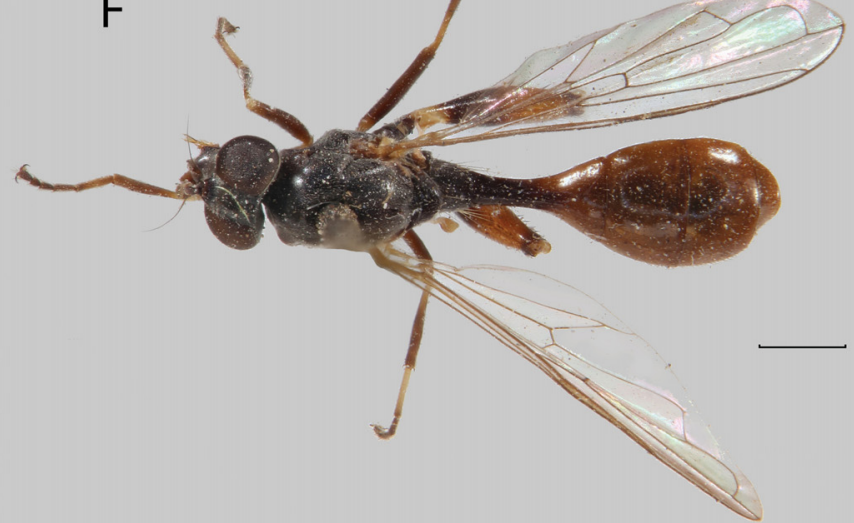

Fig. 90. Habitus, dorsal view. A. Sphegina (Asiosphegina) simplex Hippa, van Steenis \& Mutin, 2015,

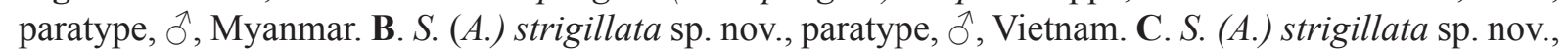
paratype,, , Vietnam. D. S. (A.) taiwanensis sp. nov., paratype, $q$, Taiwan. E. S. (A.) trichaeta Hippa, van Steenis \& Mutin, 2015, paratype,, , Myanmar. F. S. (A.) tricoloripes Brunetti, 1915,, , India. Scale bars $=1.0 \mathrm{~mm}$. 
semicircular, black, sub-shiny and weakly pollinose, with pile slightly longer than on scutum, with two widely set, very short setae medially at posterior margin, ratio length of scutellum: length of seta 1: 0.6.

WING. Entirely microtrichose; hyaline, stigma yellowish, membrane brown infuscated at junction of veins $R_{2+3}$ and $R_{4+5}$, along veins bm-cu, r-m and $M_{1}$ and at apical end of vein $R_{2+3}$. Crossvein dm-cu meeting vein $M$ perpendicularly and vein $M_{1}$ meeting vein $R_{4+5}$ perpendicularly.

Legs. Pro- and mesoleg yellow, tarsomeres 4 and 5 dark-grey to black. Metaleg with coxa black, trochanter yellow; femur black and yellow biannulate, slender, ratio width: length 1: 4.1-4.9; tibia black and yellow biannulate without apicoventral dens; tarsus entirely black, basitarsomere rather thin, ratio width: length 1: 3.4-3.9.

ABDomEN. Length ratio of terga I: II: III: IV 1: 3.4-3.7: 2.2-2.5: 1.8-2.1; ratio width at posterior margin: medial length of tergum II and III 1: 3.8-4.1 and 1: 1.1-1.3. Terga black, lateral margin of terga I and II narrowly brown-yellow; terga III and IV on anterior $1 / 4-1 / 3$ with brown-yellow fascia; pile pale, on terga short, laterally on terga I and II long; tergum I with row of 2-3 strong dark brown setae at lateral margin; sternum III elongate, ratio width: length 1: 2.8-3.4; sternum IV, Fig. 89A; sterna VI, VII and VIII simple, with long yellow pile. Genitalia, Fig. 89B-D: note the almost symmetrical surstyli and superior lobes.

\section{Female}

Similar to male except the usual sexual dimorphism.

Length. Body 4.8-6.1 mm, wing 4.3-5.7 mm.

HEAD. Ratio width of vertex at anterior ocellus: width of head 1:3.3-3.6; ratio width of ocellar triangle: width of vertex 1:2.1-2.4; ratio length of ocellar triangle: length of frons 1:2.9-3.1. Hypostomal bridge dark brown to black. Frons sub-shiny, slightly grey pollinose, with deep, wide antero-medial pit and wide but weak medial furrow. Basoflagellomere slightly elongate, ratio width: length 1: 1.2-1.5; arista long pilose; about 2.5 times as long as basoflagellomere.

Thorax. Scutellum with two widely set, very short setae medially at posterior margin, ratio length of scutellum: length of seta 1: 0.8-0.9.

Legs. Metafemur slightly enlarged, ratio width: length 1: 4.7-5.3; metatarsus with basitarsomere thick, ratio width: length 1: 3.5-4.0.

ABDOMEN. Length ratio of terga I: II: III: IV: V 1: 2.8-3.1: 2.2-2.8: 2.1-2.7: 0.8-0.9; ratio width at posterior margin: medial length of tergum II and III 1: 1.7-2.1 and 1: 0.7-0.9. Terga II, III and IV with yellow to dark yellow fascia on respectively anterior $1 / 10,1 / 3$ and $1 / 5$; sternum III rectangular, ratio width: length 1: 2.4-2.6; sternum IV rectangular with concave posterior margin, ratio width: length 1: 1.4-1.6; sternum $\mathrm{V}$ rectangular, ratio width: length 1: 1.0-1.3.

\section{Distribution and biology}

Widespread in Taiwan. Low to high montane $(1182-2700 \mathrm{~m})$ species with flight period from midMarch until mid-September. Abundantly collected on a cold misty day along lakeshore and roadside in semi-shady humid forest margins with a dense herb layer dominated by Oenanthe javanica. Also collected near a small brook, with water percolating from a steep rocky slope within a mainly older Pinus taiwanensis afforestation. Other flowers visited were Oenanthe javanica, Astilbe longicarpa and Erigeron annuus (van Steenis et al. in prep). 
Sphegina (Asiosphegina) tenuis Brunetti, 1915

Sphegina tenuis Brunetti, 1915: 224. Type locality: India, Darjiling (holotype, §, NZSI).

\section{Type material}

The holotype from India was not examined by us, but is redescribed based on data in the literature.

\section{Differential diagnosis}

See under the Remarks below.

\section{Description}

\section{Male}

See also Brunetti $(1915,1923)$.

LENGTH. Body $4.5 \mathrm{~mm}$.

HEAD. Face in lateral view clearly concave. Face black, light grey pollinose. Hypostomal bridge black. Gena black, mouth edge red-brown. Frons dull black, grey pollinose. Occiput grey. Antenna black, arista long.

THORAX. Colour black, weakly greyish pollinose, with denser grey pollinose vitta submedially; pleuron with greyish pollinosity and grey-yellowish pile.

WING. Entirely hyaline, stigma yellowish.

Legs. Pro- and mesoleg yellow, tarsi with tarsomeres 4 and 5 black. Metaleg with coxae black; femur basal half yellow, apical half black, incrassate; metatibia black and yellow biannulate; metatarsus entirely black, basitarsomere rather thick.

ABDOMEN. Terga black; tergum II slightly constricted anteriorly and very long; tergum III with sub-basal yellow fascia. Genitalia large, apparently globular.

\section{Female}

Unknown.

\section{Remarks}

Only the holotype male of Sphegina (Asiosphegina) tenuis from Darjeeling, India, is known. By the hyaline wing, yellow pro- and mesolegs with two black apical tarsomeres and sub-anterior yellow fascia on tergum III it recalls other small species like Sphegina (Asiosphegina) minuta, S. (A.) pusilla and $S$. (A.) philippina but differs by the mesonotum sub-shiny with three grey-pollinose vittae and the metafemur yellow basally and black apically.

The synonymy with Sphegina (Asiosphegina) javana (Pape \& Evenhuis 2018) is rejected based on the bicoloured metafemur (biannulate in $S$. (A.) javana); the black face (yellow $S$. (A.) javana) and the yellow sub-anterior fascia on tergum III (anterior in $S$. (A.) javana). 
Sphegina (Asiosphegina) trichaeta Hippa, van Steenis \& Mutin, 2015

Figs $86 \mathrm{~F}, 90 \mathrm{E}$

Sphegina (Asiosphegina) trichaeta Hippa, van Steenis \& Mutin, 2015: 25. Type locality: Kambaiti, Myanmar (holotype, $\hat{\jmath}$, NHM).

\section{Remarks}

Only known by the type material from Myanmar, Kambaiti (Hippa et al. 2015).

Sphegina (Asiosphegina) tricoloripes Brunetti, 1915

Figs 43D, 88F-G, 90F, 91, 93A

Sphegina tricoloripes Brunetti, 1915: 225. Type locality: Kumaon, India (holotype, + , NZSI).

\section{Differential diagnosis}

Sphegina (Asiosphegina) tricoloripes is very similar to $S$. (A.) dentata sp. nov. It is also similar to Sphegina (Asiosphegina) atricolor, $S$. (A.) furva, $S$. (A.) nigerrima and $S$. (A.) umbrosa sp. nov. For distinguishing characters, see under $S$. (A.) dentata sp. nov.

\section{Material examined}

\section{Holotype}

INDIA • O; " "near Bhowali / Kumaon: 5,700 ft / A. D. Imms [leg] 1910 / 2 $2^{\text {nd }}$ July"; "Sphegina / tricolor / Brun Type +"; "Sphegina / tricoloripes / Brun. Type + / det. Brun. 1923"; "TYPE"; "1985 / HI"; "Sphegina tricoloripes Brun."; "Zoological Survey of India / barcode / ZSI0000004489"; photo of holotype in lateral and dorsal view examined; NZSI.

\section{Additional material}

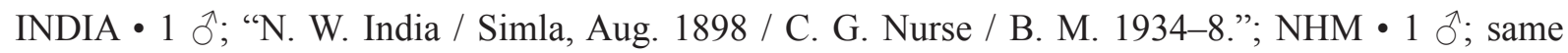
data as for preceding; "Sept 1898"; JSA • 1 q; "Sphegina / tricoloripes / Brun $\odot$ / det. Brun. 1921-2"; "Sphegina / (Asiosphegina) / tricoloripes Brun / Mutin det 1998"; "N. W. India / Simla, Aug. 1898 / C. G. Nurse / B. M. 1934-8.”; NHM • 1 đ’; "Kunj Kharak / N. Tal Hills / 24. 5.27 / 8000 ft.”; NHM • 1 ; ; same data as for preceding; JSA 1 万; ; same data as for preceding; "N.E. India / T. Jermyn / B.M. 1949-53"; "Sphegina (Asiosphegina) tricoloripes Brun. / Mutin det. 1998"; NHM • 1 ð’; same data as for preceding; "Naini Hills / 7-8000 ft"; JSA • 1 क; "Kashmir / Gulmarg / 23. VI. 01; / Fletcher coll.";

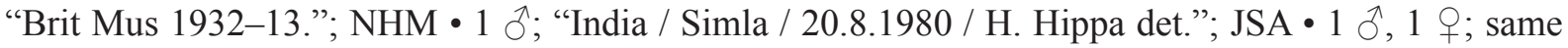
data as for preceding; "21.8.1980"; JSA • 1 क; "India; 8-9000 [feet] / on way 6 / Dhenkund / 15.VI. [19]64 / Gupta coll 58"; "Ghorpade / collection / Bangalore"; JSA • 1 क; same data as for preceding; USNM • 1 + ; "India (Kashmir) / Gulmarg c. 2600-3000 m / 17. VIII. - 5. IX 1978 / Copenhagen Zool. Mus. Exp.”; ZMUC.

\section{Description}

\section{Male}

LeNGTH. Body 6.3-7.4 mm, wing 5.0-5.9 mm.

HEAD. Face in lateral view concave, strongly projected antero-ventrally; frontal prominence strongly developed. Ratio width of vertex at anterior ocellus: width of head 1: 4.6-4.9; ratio width of ocellar triangle: width of vertex 1: 1.8-2.1; ratio length of ocellar triangle: length of frons 1: 3.9-4.1. Face black; light grey pollinose, long pilose along eye-margin. Hypostomal bridge black, long pale pilose. Gena and mouth edge black, pale pollinose with large subtriangular non-pollinose shiny area. Frons 
and vertex black, slightly light grey pollinose with densely grey pollinose rectangular fascia anteriorly, a large trapezoidal area posterior of lunula non-pollinose and shiny (Fig. 88G); pile short, light yellow. Frons with deep medial furrow. Occiput black, light grey pollinose, light yellow pilose. Eye with an area of slightly enlarged facets at anterior margin. Antenna dark brown to black with black setae dorsally on scape and pedicel; basoflagellomere round, ratio width: length 1: 1.0-1.1; arista only basally short pilose; about 2.5 times as long as basoflagellomere.

THorax. Colour black, weakly greyish pollinose sub-shiny, scutum with submedial more densely pollinose vitta and dense pollinosity along lateral margin; posterior margin of katepisternum widely non-pollinose, shiny; scutum and pleuron with very short adpressed light yellow pile. Scutellum semicircular, black, shiny and only weakly pollinose along posterior margin, with pile slightly longer than on scutum, with two widely set, medium long setae medially at posterior margin, ratio length of scutellum: length of seta 1:1.7-1.9.

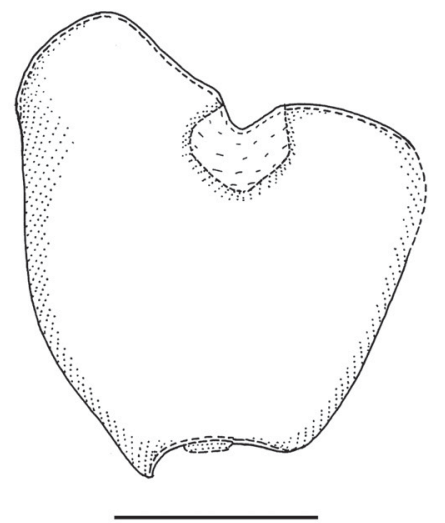

A

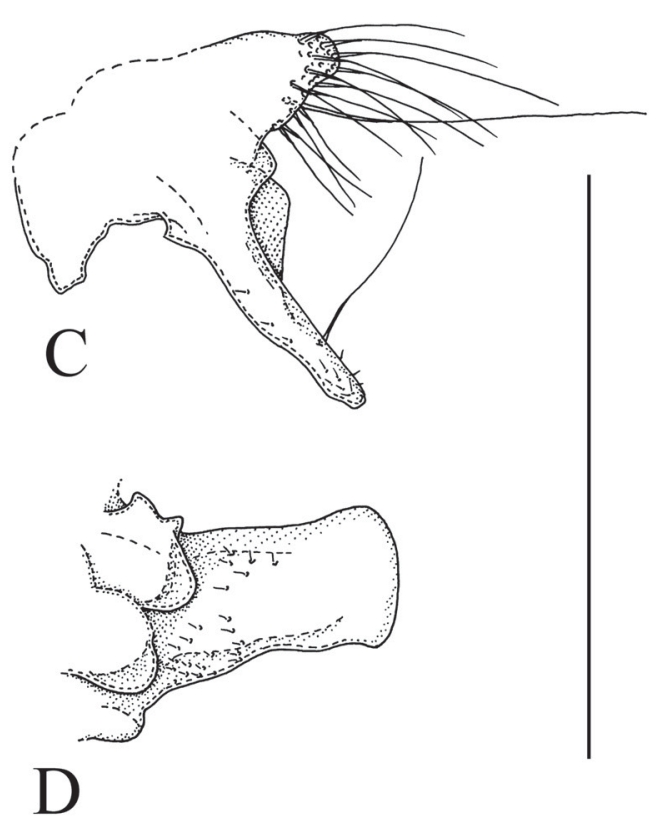

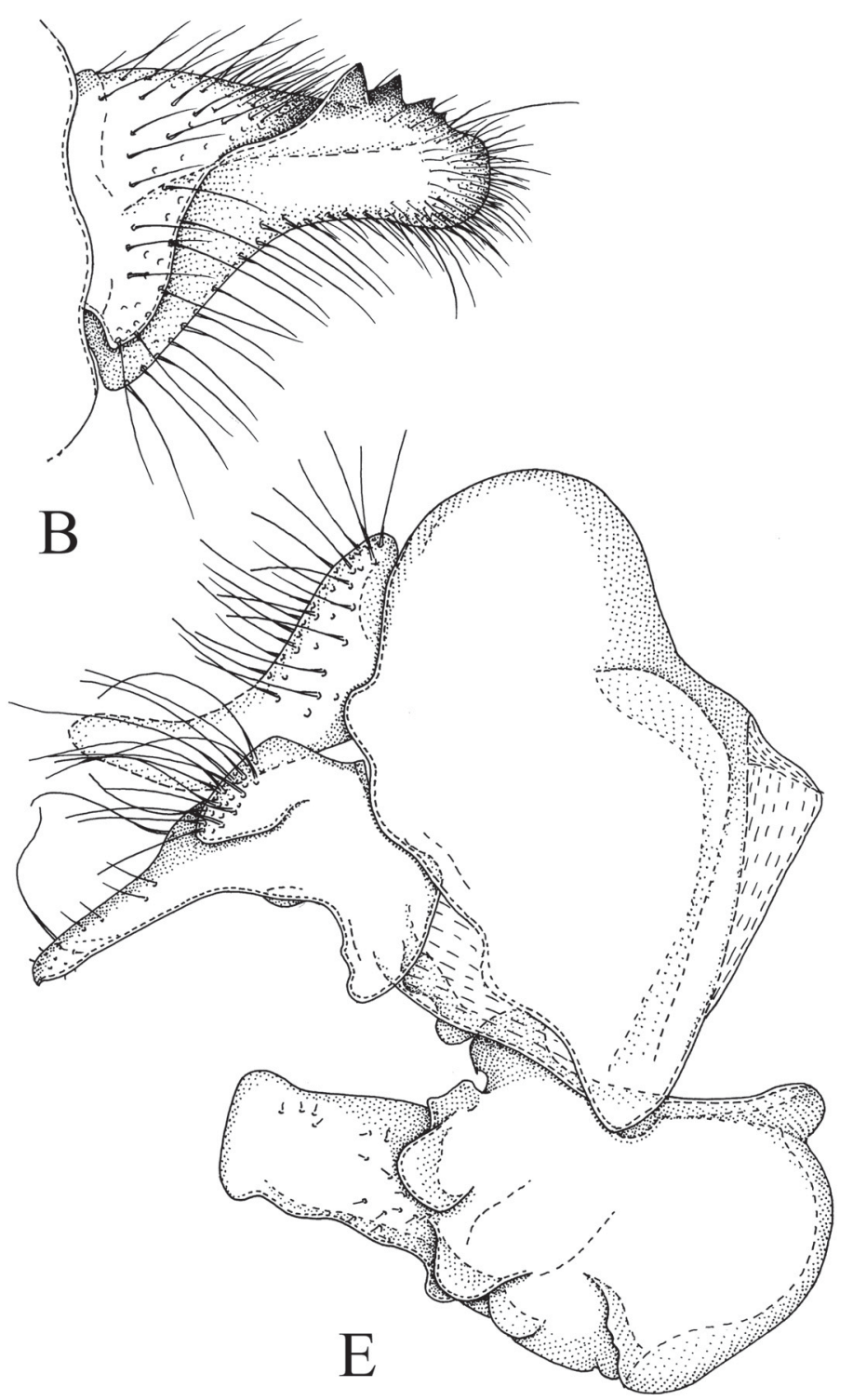

Fig. 91. Sphegina (Asiosphegina) tricoloripes Brunetti, 1915, §̂, Shimla, India. A. Sternum IV, ventral view. B. Cerci, left side lateral view. C. Left surstylus, lateral view. D. Left superior lobe with associated parts, lateral view. E. Genitalia, right side, lateral view. Scale bars $=0.5 \mathrm{~mm}$. 
WING. Microtrichose, bare on basal $1 / 3$ of cell cup; hyaline, stigma brownish. Crossvein dm-cu meeting vein $M$ obliquely and vein $M_{1}$ meeting vein $R_{4+5}$ perpendicularly.

Legs. Pro- and mesoleg black, yellow on basal $1 / 10$ of femora and basal $1 / 4-1 / 3$ of tibiae, dark yellow on tarsomeres 1-2. Metaleg with coxa and trochanter black; metafemur black with basal $1 / 4$ yellow, slightly incrassate, ratio width: length 1: 4.0-4.2; metatibia black and yellow biannulate, without apicoventral dens; metatarsus entirely black, basitarsomere rather thin, ratio width: length 1: 3.5-3.7.

AвDOMEN. Length ratio of terga I: II: III: IV 1: 5.2-5.5: 2.3-2.6: 2.2-2.6; ratio width at posterior margin: medial length of tergum II and III 1: 3.6-3.9 and 1: 0.8-0.9. Terga black, anterior $1 / 3$ of tergum III with yellow fascia; pile pale, on terga short, laterally on terga I and II long; tergum IV slightly skewed to the right; tergum I with an oblique row of 4-6 strong light yellow setae at lateral margin; sternum III rectangular, ratio width: length 1: 1.3-2.5; sternum IV, Fig. 91A; sterna VI, VII and VIII simple, with long yellow pile. Genitalia, Fig. 91B-E: note the asymmetrical cerci, slightly asymmetrical surstyli and nearly symmetrical superior lobes.

\section{Female}

Similar to the male except normal sexual dimorphism.

LeNGTH. Body 5.5-6.0 mm, wing 4.4-5.0 mm.

HEAD. Face in lateral view, Fig. 88F, concave, very strongly projected antero-ventrally; frontal prominence very strongly developed. Ratio width of vertex at anterior ocellus: width of head 1:3.4-3.7; ratio width of ocellar triangle: width of vertex 1:2.3-2.6; ratio length of ocellar triangle: length of frons 1: 3.5-3.9. Basoflagellomere, Fig. 43D, round to squarish, ratio width: length 1: $0.8-1.0$, about 3.5 times as long as basoflagellomere.

Thorax. Scutellum with two widely set, short setae medially at posterior margin, ratio length of scutellum: length of seta 1: 1.1-1.4.

Legs. Metafemur yellow on basal $1 / 4$ and extreme apex orange-brown, slightly incrassate, ratio width: length 1: 4.2-4.7; metatarsus with basitarsomere thick, ratio width: length 1: 3.2-3.5.

ABDomen. Length ratio of terga I: II: III: IV: V 1: 4.0-4.4: 2.3-2.6: 2.1-2.5: 1.0-1.3; ratio width at posterior margin: medial length of tergum II and III 1: 1.3-1.6 and 1: 0.6-0.7. Tergum I black; tergum II with posterior $1 / 3$ orange or tergum entirely black; terga III-V entirely orange or medial and posterior parts of terga III and IV dark-orange and tergum V entirely dark-orange; sternum III trapezoidal, ratio width: length 1: 0.88-0.95; sternum IV trapezoidal, ratio width: length 1: 0.7-0.9; sternum V rectangular, with concave posterior margin, ratio width: length 1: $0.2-0.3$.

\section{Remarks}

This is a very characteristic species based on the abdominal colour pattern of the female and furthermore due to the only basally short pilose arista; tergum I with an oblique row of 4-6 strong, light yellow setae; posterior margin of katepisternum widely non-pollinose, shiny; extensively black legs and the cercus with a row of 3-4 teeth.

Sphegina (Asiosphegina) trispina Hippa, van Steenis \& Mutin, 2015

Sphegina (Asiosphegina) trispina Hippa, van Steenis \& Mutin, 2015: 24. Type locality: Kambaiti, Myanmar (holotype, $\hat{\jmath}$, NHRS). 


\section{Remarks}

Only known by the type material from Myanmar, Kambaiti (Hippa et al. 2015).

Sphegina (Asiosphegina) tristriata Brunetti, 1913

Sphegina tristriata Brunetti, 1913: 165. Type locality: Rotung, India (holotype, +, NZSI).

\section{Differential diagnosis}

Based on the description and the photo of the type specimens it looks similar to Sphegina (Asiosphegina) bidens and also slightly similar to $S$. (A.) orientalis. It is distinguished from these by the characters given in the key.

\section{Material examined}

\section{Holotype}

INDIA • O+; "Ind. Mus. / Rotung / 1400 ft. / Kemp abor Exp. / 6-13-III-[19]12"; "Sphegina / tristriata / Brun. Type + / det. Brun. 1923"; "Sphegina / tristriata / Brun. Type O"; "TYPE"; "1983 / HI"; "Sphegina tristriata Brun.", Zoological Survey of India / barcode / ZSI0000004490"; photo of holotype in lateral and dorsal view studied; NZSI.

\section{Description}

Male
Unknown.
Female
See Brunetti $(1913,1923)$.

LeNGTH. Body $6 \mathrm{~mm}$, wing $4.5 \mathrm{~mm}$.

HeAd. Face in lateral view concave. Face black, light grey pollinose. Hypostomal bridge black. Gena and mouth edge yellowish. Frons and vertex black, grey pollinose. Antenna brownish-yellow.

THORAx. Colour brownish-yellow, weakly greyish pollinose, with denser grey pollinose vitta submedially; pleuron with greyish pollinosity pile. Scutellum brownish-yellow, grey pollinose.

WING. Entirely hyaline, stigma yellowish, brown infuscated at junction of veins $\mathrm{R}_{2+3}$ and $\mathrm{R}_{4+5}$, along veins bm-cu, r-m and $M_{1}$, at apical end of vein $R_{2+3}$ and apical part of wing around vein $R_{4+5}$. Crossvein $\mathrm{dm}$-cu meeting vein $\mathrm{M}$ almost perpendicularly and vein $\mathrm{M}_{1}$ meeting vein $\mathrm{R}_{4+5}$ perpendicularly.

LEGS. Pro- and mesoleg yellow, apex of tarsi brownish. Metafemur black and yellow biannulate.

ABDOMEN. Terga black; pile very short and white; tergum II slightly constricted anteriorly and long; colour of tergum III entirely whitish-yellow.

\section{Remarks}

The species is only known on the basis of the holotype from "Rotung, N. E. Frontier of India" (Brunetti 1913). It was described as female in Brunetti $(1913,1923)$, however, Brunetti (1923) mentioned after the description that the species was "Described from a unique $\widehat{\delta}$ ". The holotype has lost the posterior part of abdomen from tergum III onwards and it is not possible to see if the actual specimen is male or female. Based on the very elongate tergum II and the seemingly narrow frons, the specimen is most likely a male, however, the entirely whitish-yellow coloured tergum III is more a female character. 
Sphegina (Asiosphegina) umbrosa sp. nov.

urn:1sid:zoobank.org:act:1DC2CEBB-9E6D-4DC3-A4E5-562C914D0756

Figs $88 \mathrm{H}, 92,93 \mathrm{~A}, 95 \mathrm{D}, 97 \mathrm{~A}$

\section{Differential diagnosis}

Similar to Sphegina (Asiosphegina) dentata sp. nov. and S. (A.) tricoloripes. For distinguishing characters, see under the latter. In the male genitalia the species is reminiscent of a few other Sphegina (Asiosphegina) which have the cerci as large or larger than the surstyli. It differs from all these by the unusually large and humpbacked tergum IX.

\section{Etymology}

The specific epithet is derived from the Latin 'umbrosus', meaning 'dark-shaded' and referring to the overall dark brown colour of the body and especially the dark-shaded legs.

\section{Material examined}

\section{Holotype}

CHINA • 7 ; "CHINA: Zhejiang Province, / Qingliangfeng National Nature / Reserve, ex: Malaise trap / 4-11.v.2012"; CSCA.
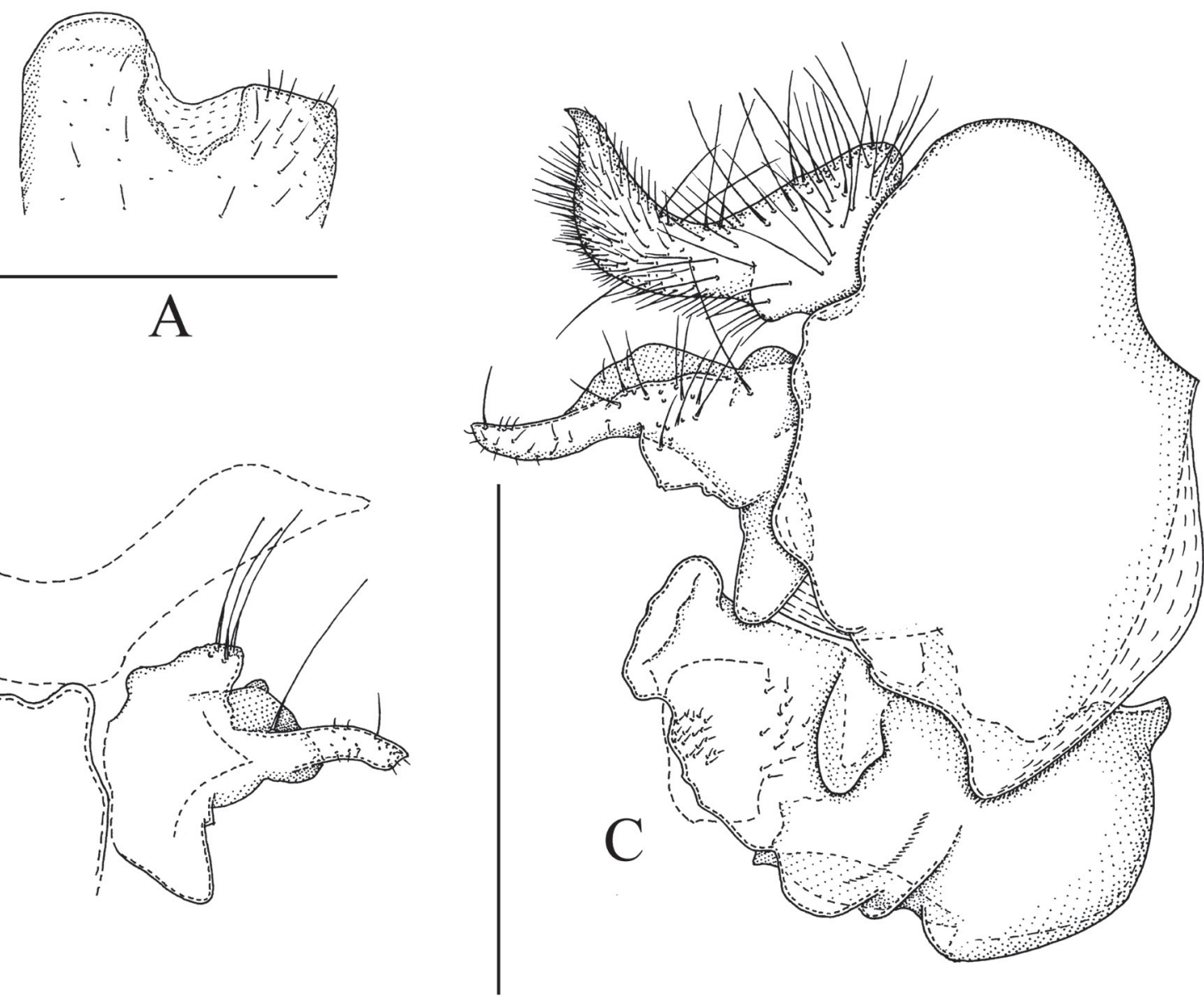

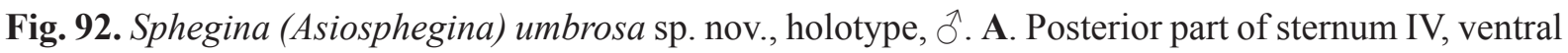
view. B. Left cercus and surstylus, lateral view. C. Genitalia, right side, lateral view. Scale bars $=0.5 \mathrm{~mm}$. 


\section{Description}

Male

Length. Body $6.2 \mathrm{~mm}$, wing $4.5 \mathrm{~mm}$.

HEAD. Face in lateral view concave, very weakly projected antero-ventrally; frontal prominence weakly developed. Ratio width of vertex at anterior ocellus: width of head 1:3.7; ratio width of ocellar triangle: width of vertex 1: 2.4; ratio length of ocellar triangle: length of frons 1: 3.0. Face black, light grey pollinose, long pilose along eye-margin. Hypostomal bridge black, long pale pilose. Gena and mouth edge black, pale pollinose with large subtriangular non-pollinose shiny area. Frons and vertex black, slightly pollinose, a wide fascia posterior of lunula and a large round macula anterior of ocelli nonpollinose and shiny, with wide densely grey-pollinose fascia medially (Fig. $88 \mathrm{H}$ ); pile short, light yellow. Frons flat, without any depression medially. Occiput black, light grey pollinose, light yellow pilose. Eye without enlarged facets at anterior margin. Antenna dark brown with black setae dorsally on scape and pedicel; basoflagellomere round, ratio width: length 1: 1.0; arista short pilose only basally, nearly 3.5 times as long as basoflagellomere.

THorax. Colour black, slightly pollinose, scutum sub-shiny with submedial light grey pollinose vitta and grey-pollinose lateral margin, pleuron entirely more heavily grey pollinose; scutum and pleuron with very short adpressed light yellow pile. Scutellum sub-triangular, black, shiny medially, laterally

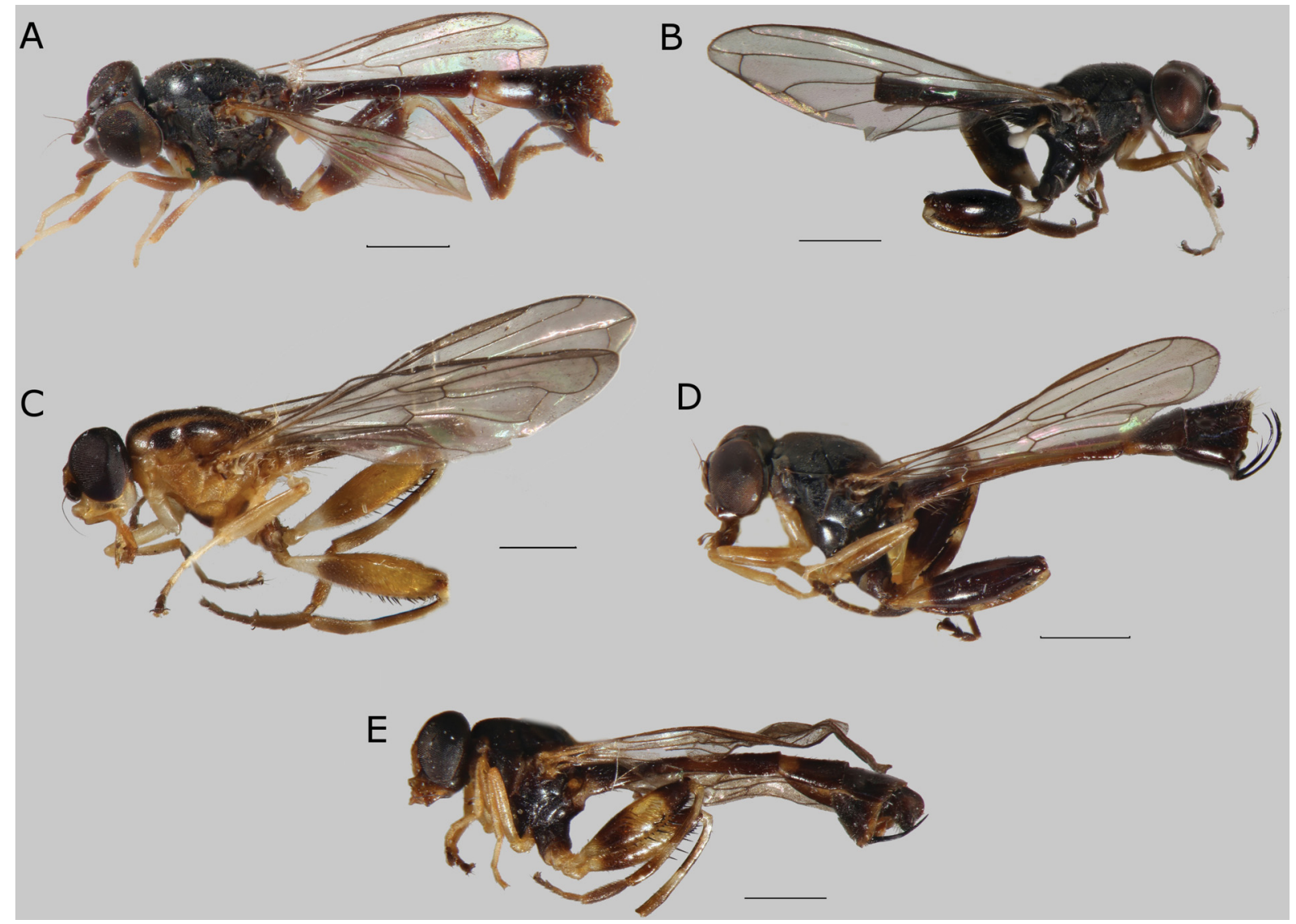

Fig. 93. Habitus, lateral view. A. Sphegina (Asiosphegina) tricoloripes Brunetti, 1915, §ิ, India. B. S. (A.) umbrosa sp. nov., holotype, đ̂, China. C. S. (A.) varidissima Shiraki, 1930, đ̃, Taiwan, yellow form. D. S. (A.) verrucosa sp. nov., paratype, ふૈ, Vietnam. E. S. (A.) vietnamensis sp. nov., paratype, ठ̃, Vietnam. Scale bars $=1.0 \mathrm{~mm}$. 
weakly pollinose, with pile slightly longer than on scutum, with two widely set very long setae medially at posterior margin, ratio length of scutellum: length of seta 1:2.4.

WING. Microtrichose, basal $1 / 3$ of cell cup bare; hyaline, stigma yellowish. Crossvein dm-cu meeting vein M obliquely and vein $M_{1}$ meeting vein $R_{4+5}$ perpendicularly.

Legs. Pro- and mesoleg yellow; medial $3 / 4$ of femur, apico-medial half of tibia and tarsomeres $3-5$ black. Metaleg, Fig. 95D, with coxa black, trochanter yellow; femur black with basal $1 / 3$ yellow, incrassate, ratio width: length 1: 4.0; tibia black and yellow biannulate, without apicoventral dens; tarsus entirely black, basitarsomere rather thin, ratio width: length $1: 3.8$.

ABDOMEN. Length ratio of terga I: II: III: IV 1: 3.8: 1.9: 1.8; ratio width at posterior margin: medial length of tergum II and III 1: 3.4 and 1: 0.8. Terga black, tergum III with sub-anterior yellow fascia on anterior half; pile pale, on terga short, laterally on terga I and II long; tergum I with a horizontal row of 4 white setae at lateral margin; tergum IV with posterior margin skewed to the right; sternum III not sclerotized; sternum IV, Fig. 92A; sterna VI, VII and VIII simple, with long yellow pile. Genitalia, Fig. 92B-C: note the large humpbacked tergum IX, enlarged slightly asymmetrical cerci and slightly asymmetrical surstyli; superior lobe on the left side is deformed and not drawn, it is similar to the right side one.

Female

Unknown.

Sphegina (Asiosphegina) varidissima Shiraki, 1930

Figs 65D, 88I-J, 93C, 94, 95E, 97B-C

Sphegina varidissima Shiraki, 1930: 421. Type locality: Taiwan, Horisha (holotype,, , NIAES).

\section{Differential diagnosis}

Sphegina (Asiosphegina) varidissima is dissimilar to other species of Asiosphegina by the colour and pollinosity of the scutum and the overall brownish colour. It resembles somewhat Sphegina (Asiosphegina) cerina in body colour but differs by the characters mentioned in the key. The male genitalia are unique, especially the symmetrical superior lobes which are basally narrowed, and which are separated from sternum IX by a transverse crest-like lobe posteriorly on the latter.

\section{Material examined}

\section{Holotype}

TAIWAN • O; "Horisha / 10.V.1913 / col. M. Maki"; "Sphegina / striata n. sp. / Det T. Shiraki: "Type" [white round label with red circle]; photo of holotype in lateral and dorsal view studied; NIAES.

\section{Additional material}

TAIWAN • 1 ơ; "Taiwan Taoyuan / Fuhsing / 1992.II.20 / [leg.] C.Y. Lee / Sweeping net”; "1452-358”; NMNS • 1 ○े; "Taiwan Nantou / Meifeng; / V.11.2004 / [leg.] C.S. Lin / Sweeping net"; "NMNS ENT / 4507 27”; JSA • 1 O;; "Taiwan Nantou / Meifeng / 26-28.V.1997 / C.S. Lin \& W.T. Yang / UV light trap"; "NMNS ENT / 2680-807”; NMNS • 1 क; "Taiwan N-Nantou Co. / Road No. 14, NE Puli / Reyen Shi-Reg., Tsuifeng / ca $24^{\circ} 06^{\prime} \mathrm{N}, 121^{\circ} 11^{\prime}$ E / 2200 m 28.VI-2.VII.2000 / leg. W. Schacht"; "holotype and one third / of paratypes resulting / from this material are / property of Taiwan!"; "Syrphidae / spec 30 / det. W. Schacht"; JSA. 


\section{Description}

\section{Male}

LeNGTH. Body 6.9-7.4 mm, 5.3-5.9 wing mm.

HEAD. Face in lateral view concave, strongly projected antero-ventrally; frontal prominence strongly developed. Ratio width of vertex at anterior ocellus: width of head 1: 3.7-4.2; ratio width of ocellar triangle: width of vertex 1: 1.8-2.1; ratio length of ocellar triangle: length of frons 1: 2.1-2.3. Face entirely yellow (as in holotype) to predominantly black. Gena and mouth edge yellow, pale pollinose, with large subtriangular non-pollinose shiny area. Frons sub-shiny, slightly grey pollinose with wide but weak medial furrow (Fig. 88I). Scape and pedicel yellow or black. Basoflagellomere black squarish, ratio width: length 1: 1.0-1.1; arista short pilose basally; about 3.5 times as long as basoflagellomere.

THORAX. Colour from dark brown to black to predominantly yellow, pollinose, scutum dark with more densely grey pollinose submedial vitta or scutum yellow with 3 shiny black vittae. Pleuron entirely yellow to predominantly black; posterior margin of katepisternum widely non-pollinose, shiny (Fig. 65D). Scutellum semicircular, black, with posterior margin narrowly pollinose, rest non-pollinose and shiny, long pilose, with two widely set long setae medially at posterior margin, ratio length of scutellum: length of seta 1: 1.8-2.0.

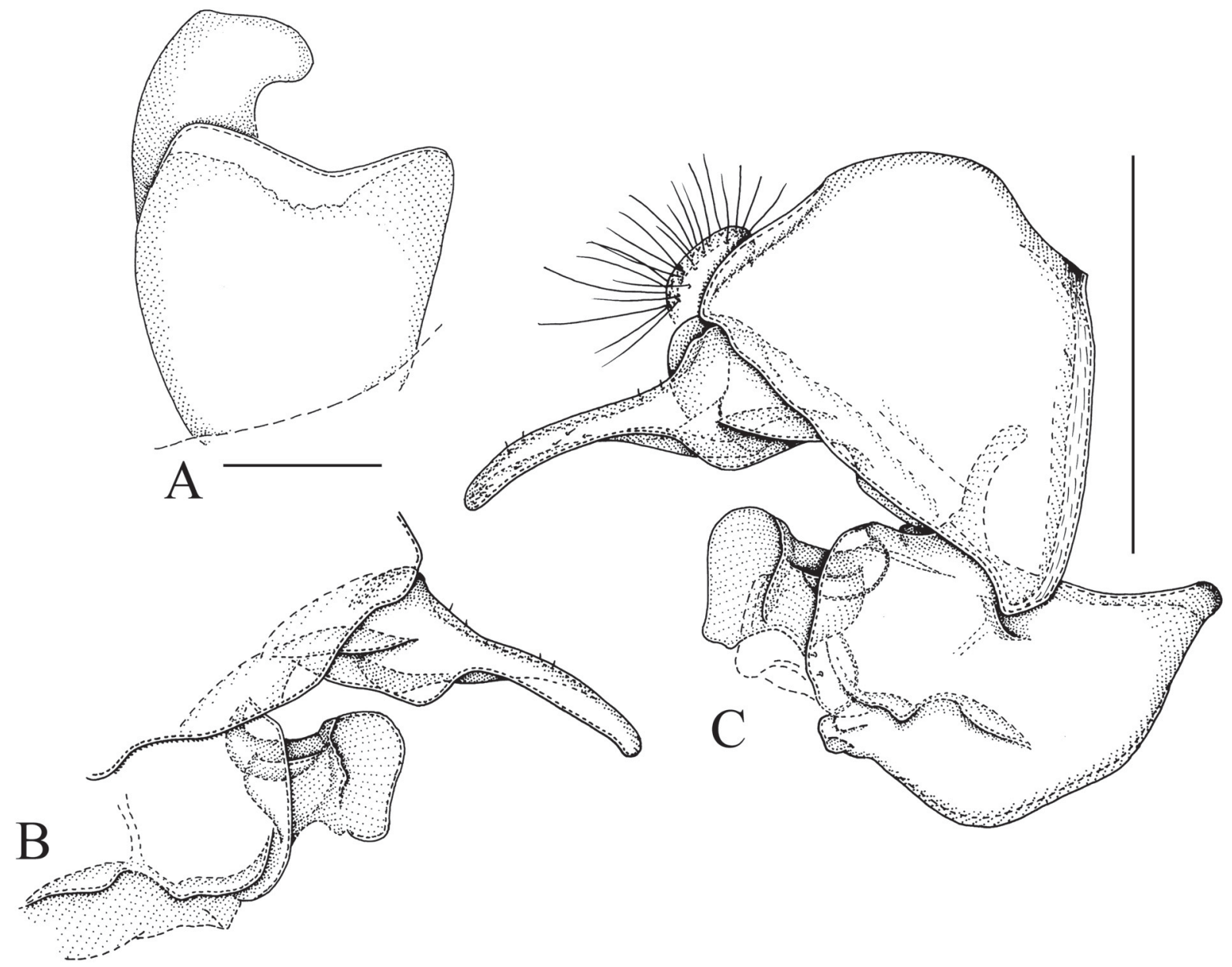

Fig. 94. Sphegina (Asiosphegina) varidissima Shiraki, 1930, ô Fuhsing, Taiwan. A. Sterna IV and VI, ventral view. B. Left surstylus and superior lobe with associated parts, lateral view. C. Genitalia, right side, lateral view. Scale bars $=0.5 \mathrm{~mm}$. 
WING. Microtrichose, cell cup with basal 1/10 slightly microtrichose, almost bare; hyaline, stigma yellowish. Crossvein dm-cu meeting vein $M$ obliquely and vein $M_{1}$ meeting vein $R_{4+5}$ perpendicularly.

Legs. Colour yellow. Pro- and mesotibia dark yellow; pro- and mesobasitarsus dark brown, other tarsomeres dark brown to black. Metaleg, Fig. 95E, with coxa and trochanter yellow; femur predominantly yellow or biannulate, slightly incrassate, ratio width: length 1: 4.1-4.3; tibia black and yellow biannulate, without apical dens; tarsus with basitarsomere thin, ratio width: length 1: 3.8-4.0.

ABDomen. Length ratio of terga I: II: III: IV 1: 3.8-4.1: 1.8-2.2: 1.2-1.4; ratio width at posterior margin: medial length of tergum II and III 1: 3.5-3.9 and 1: 1.0-1.1. Tergum III black with sub-anterior fascia covering $1 / 3$ of the tergum; pile pale, on terga short, laterally on terga I and II long; tergum I with oblique row of 4-5 light yellow setae laterally; sternum III rectangular, ratio width: length 1: 2.5-2.7; sternum

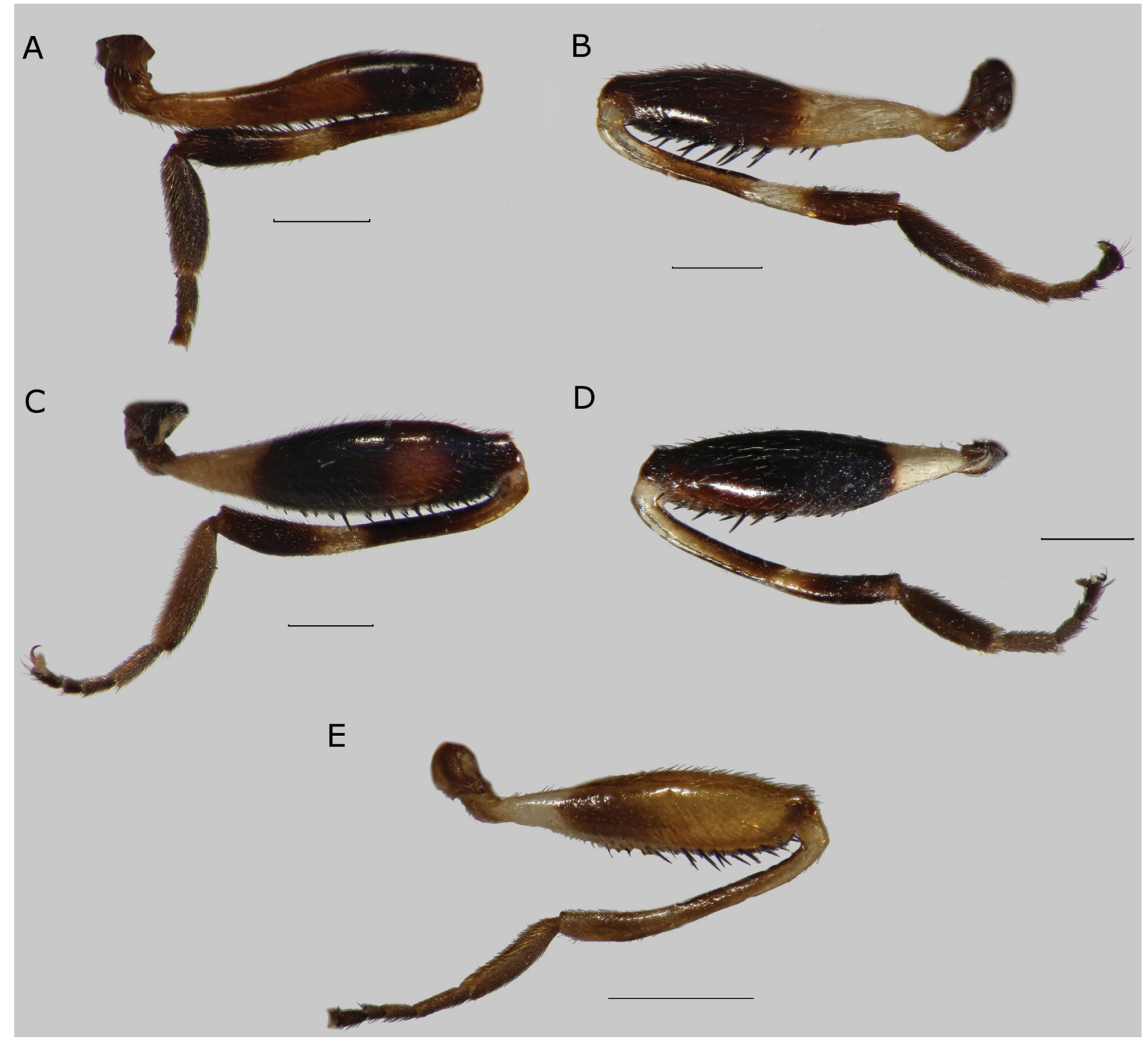

Fig. 95. Metaleg, anterior view. A. Sphegina (Asiosphegina) plautus sp. nov., holotype, $\hat{\jmath}$, China.

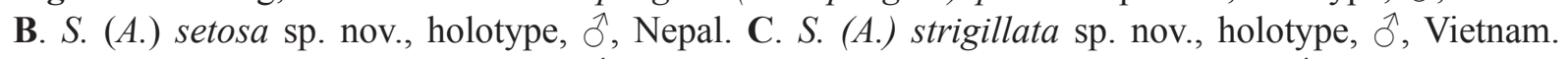
D. $S$. (A.) umbrosa sp. nov., holotype, ô, China. E. S. (A.) varidissima Shiraki, 1930, Ô, Taiwan, yellow form. Scale bars $=0.5 \mathrm{~mm}$. 
IV, Fig. 94A; sterna VI, VII and VIII simple, with long yellow pile. Genitalia, Fig. 94B-C: note the almost symmetrical surstyli and superior lobes.

\section{Redescription of female}

Similar to the male except normal sexual dimorphism.

LeNGTH. Body 7.4-7.8 mm, wing 6.1-6.7 mm

HeAD. Lateral view, Fig. 88J; ratio width of vertex at anterior ocellus: width of head 1: 3.0-3.4; ratio width of ocellar triangle: width of vertex 1: 2.6-2.9; ratio length of ocellar triangle: length of frons 1: 4.1-4.5. Mouth edge yellow. Face entirely yellow (as in holotype) to predominantly black. Frons subshiny, slightly grey pollinose, with wide but weak medial furrow. Scape and pedicel yellow or black. Basoflagellomere black squarish, ratio width: length 1: 0.86-0.98; arista short pilose basally; about 3 times as long as basoflagellomere.

THORAX. Scutellum black with posterior margin narrowly pollinose, rest non-pollinose and shiny, with two very widely set, long setae medially at posterior margin, ratio length of scutellum: length of seta 1 : $2.0-2.3$.

WING. Microtrichose, cell cup with basal 1/10 bare.

LEGS. Pro- and mesotibia dark yellow; pro- and mesobasitarsus dark brown, other tarsomeres dark brown to black; metafemur ratio width: length 1: 4.1-4.3; metatarsus with basitarsomere thin, ratio width: length $1: 3.8-4.1$.

ABdomen. Length ratio of terga I: II: III: IV: V 1: 3.0-3.4: 2.4-2.7: 2.2-2.5: 1.1-1.3; ratio width at posterior margin: medial length of tergum II and III 1: 1.2-2.4 and 1: 0.6-0.7. Tergum II black or with posterolateral orange subtriangular macula; tergum III black to orange-brown with small black anteromedial macula; tergum IV yellow with anteromedial black macula to entirely orange-brown; tergum V entirely orange-brown; sternum III trapezoidal, ratio width: length 1: 2.5-2.7; sternum IV rectangular, ratio width: length 1: 0.9-1.1; sternum $\mathrm{V}$ rectangular with concave posterior margin, ratio width: length 1: 0.4-0.5.

\section{Remarks}

The species is, as several Palaearctic species (e.g., Sphegina (Asiosphegina) fasciata Shiraki, 1968 and $S$. (A.) sibirica), unusually variable in colouration but otherwise there is nothing to indicate that there is more than one species involved.

Sphegina (Asiosphegina) verrucosa sp. nov. urn:1sid:zoobank.org:act:33C0BA9B-A7AD-40E0-86E0-A5F4867DE075

Figs $88 \mathrm{~K}, 93 \mathrm{D}, 96,97 \mathrm{D}$

\section{Differential diagnosis}

Similar to Sphegina (Asiosphegina) distincta sp. nov. and S. (A.) trichaeta. It is distinguished from both species by the male sternum IV having at the posterior margin on the left side, in addition to the three very strong and long setae, two elongated but shorter ones. In the male genitalia, Sphegina (Asiosphegina) verrucosa sp. nov. is distinguished from $S$. (A.) trichaeta by having the dorsal lobe of the right surstylus wider than the left one, not vice versa; and from $S$. (A.) distincta sp. nov. by having the dorsal lobe of surstyli narrow, narrower than the superior lobes, instead of wider than the superior lobes. The scraper-like surface baso-dorsally on the hypandrium is a unique character of this species 


\section{Etymology}

The specific epithet is from the Latin 'verrucosa', meaning 'warty or rough' and referring to the rough scraper-like baso-dorsal part of male hypandrium.

\section{Material examined}

\section{Holotype}

VIETNAM • O'; "Viet Nam Dak Song / 76 km SW of / BanMeThuot 870 m / 19-21.V.1960"; "L.W. Quate / Collector"; BPBM.

\section{Paratypes}

VIETNAM • 1 đ; same data as for holotype; JSA • 1 đ; "Viet Nam: Fyan / 900-1000 m / 11. VII 9.VIII.1961"; "N. R. Spencer / Collector"; BPBM • 1 đ̃; "Viet Nam / BanMeThuot $900 \mathrm{~m} / 16$ 18.V.1960"; "L.W. Quate / Collector”; JSA.

\section{Description}

\section{Male}

LengTh. Body 5.3-5.6 mm, wing 3.9-4.3 mm

HEAD. Face in lateral view concave, weakly projected antero-ventrally; frontal prominence weakly developed. Ratio width of vertex at anterior ocellus: width of head 1: 3.8-4.1; ratio width of ocellar triangle: width of vertex 1: 1.8-1.9; ratio length of ocellar triangle: length of frons 1: 1.7-2.0. Face black, light grey pollinose, long pilose along eye-margin. Hypostomal bridge black, long pale pilose. Gena and mouth edge black, pale pollinose with large subtriangular non-pollinose shiny area. Frons and vertex black, slightly grey pollinose, a semi-circular area posterior of lunula non-pollinose and shiny and a wide densely grey pollinose fascia posterior of shiny area (Fig. 88K); pile short, light yellow. Frons with weak medial furrow. Occiput black, light grey pollinose, light yellow pilose. Eye with an area of enlarged facets at anterior margin. Antenna with scape and pedicel dark brown to black, basoflagellomere light- to dark brown, with black setae dorsally on scape and pedicel; basoflagellomere squarish, ratio width: length 1:1.1-1.2; arista long pilose, nearly 3 times as long as basoflagellomere.

THORAX. Colour dark brown to black, weakly greyish pollinose, pleuron entirely more heavily grey pollinose; scutum and pleuron with very short adpressed light yellow pile. Scutellum semicircular, black, grey pollinose, with pile slightly longer than on scutum, with two closely set very short setae medially at posterior margin, ratio length of scutellum: length of seta 1: 0.5-0.6.

Wing. Entirely microtrichose; hyaline, stigma yellowish. Crossvein dm-cu meeting vein M strongly oblique and vein $M_{1}$ meeting vein $R_{4+5}$ perpendicularly.

Legs. Pro- and mesoleg yellow, femora with dark brown medial annulus, tarsomeres 4 and 5 black. Metaleg with coxa black, trochanter yellow; femur black with basal $1 / 4$ yellow, incrassate, ratio width: length 1: 4.0-4.2; tibia black and yellow biannulate with short wide and rounded apicoventral dens; tarsus entirely black, basitarsomere thick, ratio width: length 1: 3.2-3.5.

ABDOMEN. Length ratio of terga I: II: III: IV 1: 3.9-4.1: 1.8-2.0: 1.7-1.9; ratio width at posterior margin: medial length of tergum II and III 1: 4.2-4.5 and 1: 0.8-0.9. Terga black, anterior $2 / 5$ of tergum III with brown-yellow fascia; pile pale, on terga short, laterally on terga I and II long; tergum I with 2 light to dark brown setae at posterolateral margin; sternum III oval with incised anterior margin, ratio width: length 1: 2.4-2.6; sternum IV, Fig. 96B; sterna VI, VII and VIII with long yellow pile, sternum VII anteroventrally with subtriangular lobe and postero-ventrally with conical process. Genitalia, Fig. 96C-E: note the asymmetrical surstyli, subbasal lobe on the medial side of surstyli and asymmetrical superior lobes. 


\section{Female}

Unknown

\section{Remarks}

We have one specimen (1 9 , "Viet Nam: Fyan / 900-1000 m / 11. VII-9.VIII.1961", "N. R. Spencer / Collector" (BPBM)) which possibly belongs to this species. The differences amongst females of similar species are so subtle that it does not seem wise to include this female in the type series, nor give a description.
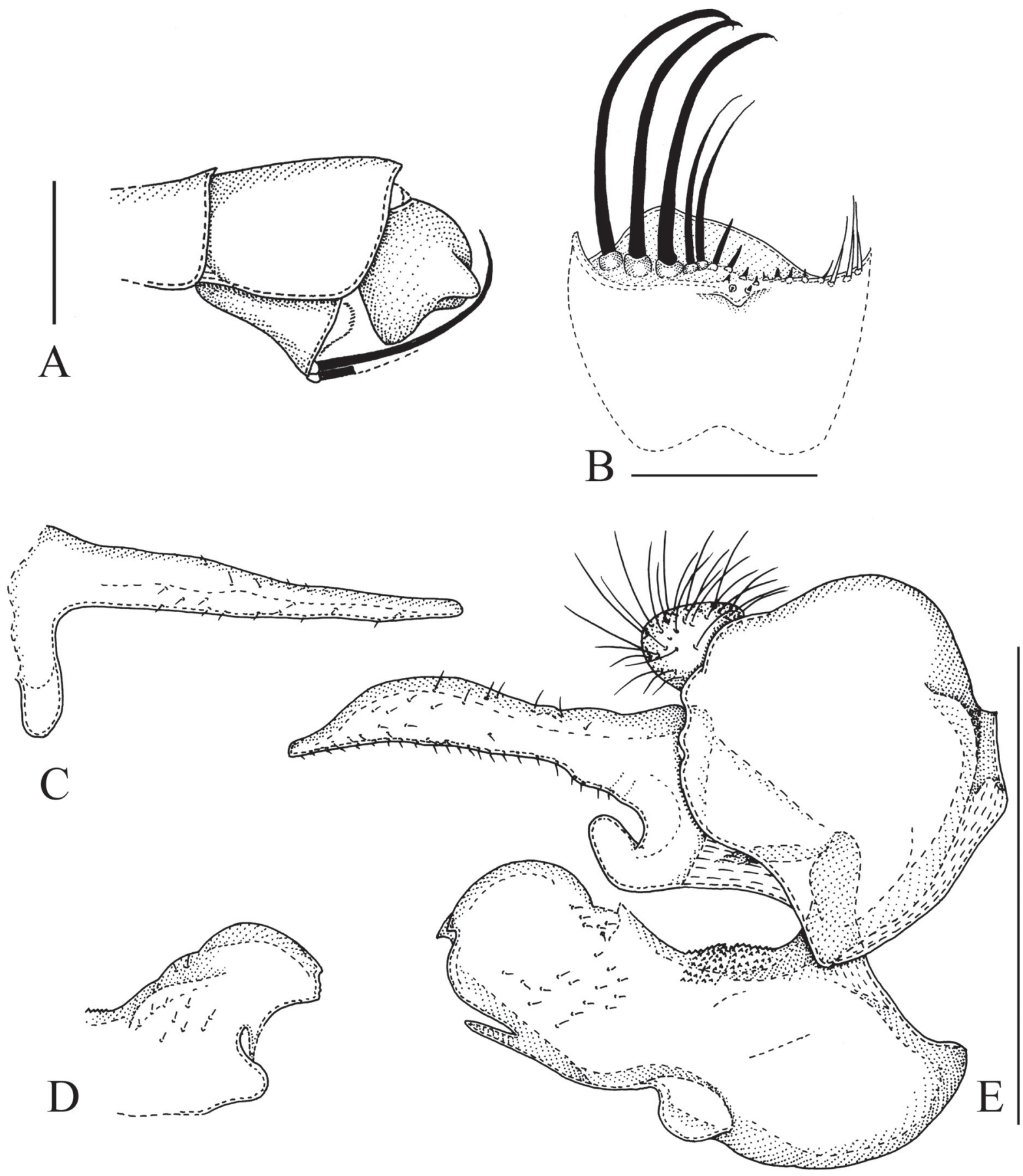

Fig. 96. Sphegina (Asiosphegina) verrucosa sp. nov., holotype, $\widehat{\jmath}$. A. Posterior part of abdomen, left side lateral view. B. Sternum IV, ventral view. C. Left surstylus, lateral view. D. Left superior lobe with associated parts, lateral view. E. Genitalia, right side, lateral view. Scale bars $=0.5 \mathrm{~mm}$. 
Sphegina (Asiosphegina) vietnamensis sp. nov.

urn:1sid:zoobank.org:act:0930F518-0F49-4608-9B37-770DAAB6320A

Figs 88L, 93E, 97E, 98

\section{Differential diagnosis}

Similar to Sphegina (Asiosphegina) bracon sp. nov. and S. (A.) furcillata sp. nov. For distinguishing characters, see under $S$. (A.) bracon sp. nov.

\section{Etymology}

The specific epithet is from the Latin 'vietnamensis', meaning 'of Vietnam' and referring to the type locality, Vietnam.

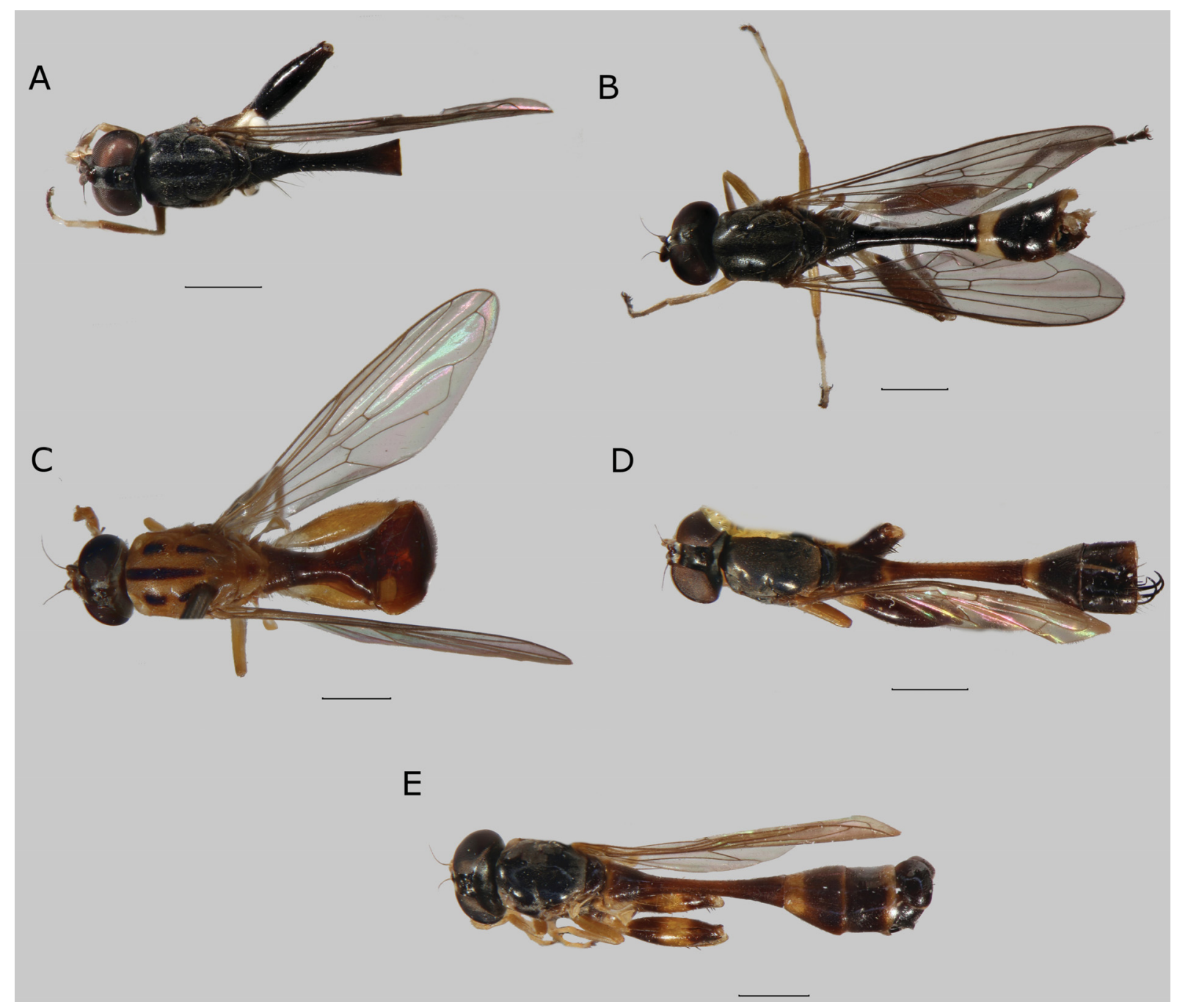

Fig. 97. Habitus, dorsal view. A. Sphegina (Asiosphegina) umbrosa sp. nov., holotype, đ, China. B. S. (A.) varidissima Shiraki, 1930, Õ, Taiwan. C. S. (A.) varidissima, + , Taiwan, yellow form. D. S. (A.) verrucosa sp. nov., paratype, $\hat{\jmath}$, Vietnam. E. S. (A.) vietnamensis sp. nov., paratype, $\widehat{\partial}$, Vietnam. Scale bars $=1.0 \mathrm{~mm}$. 


\section{Material examined}

Holotype

VIETNAM • ○’; “Viet Nam: Fyan / 900-1000 m / 11.VII-9.VIII.'61”; “ N.R. Spencer / Collector / Bishop"; BPBM.

\section{Paratypes}

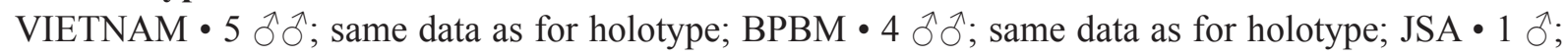
"Viet Nam: Mt. Lang / Bian 1500-2000 / 19.V-8.VI.1961"; "N. R. Spencer / Collector / Bishop"; BPBM • 1 đ̊; "Viet Nam: Dalat / 6km S. 1400-1500 m / 9.VI-7.VII.1961"; "N. R. Spencer / Collector; / Bishop"; BPBM.

\section{Description}

Male

LeNGTH. Body 6.3-7.2 mm, wing 4.2-5.1 mm

HEAD. Face in lateral view concave, weakly projected antero-ventrally; frontal prominence very weakly developed. Ratio width of vertex at anterior ocellus: width of head 1: 4.4-4.8; ratio width of ocellar triangle: width of vertex 1: 1.7-1.9; ratio length of ocellar triangle: length of frons 1: 2.4-2.9. Face black, ventral half brown-yellow, light grey pollinose, long pilose along eye-margin. Hypostomal bridge brown-yellow, long pale pilose. Gena and mouth edge yellow, pale pollinose with large subtriangular non-pollinose shiny area. Frons and vertex black, predominantly grey pollinose, a semi-circular area posterior of lunula non-pollinose and shiny (Fig. 88L); pile short, light yellow. Frons with deep medial furrow. Occiput black, light grey pollinose, light yellow pilose. Eye with an area of enlarged facets at anterior margin. Antenna yellow to brown-yellow with black setae dorsally on scape and pedicel; basoflagellomere oval, ratio width: length 1: 1.2-1.6; arista pilose, about 3 times as long as basoflagellomere.

THORAX. Colour dark brown to black, weakly greyish pollinose; postpronotum and dorso-medial part of anepisternum and anepimeron yellow, pleuron entirely more heavily grey pollinose; scutum and pleuron with very short adpressed light yellow pile. Scutellum semicircular with concave lateral margin, black, shiny, with pile slightly longer than on scutum, with two widely set short setae medially at posterior margin, ratio length of scutellum: length of seta 1: 0.9-1.1.

WING. Entirely microtrichose; hyaline, stigma yellowish. Crossvein dm-cu meeting vein M obliquely and vein $M_{1}$ meeting vein $R_{4+5}$ perpendicularly.

LEGs. Pro- and mesoleg yellow, tarsomeres 4-5 black. Metaleg with coxa black, trochanter yellow; femur black and yellow biannulate, slightly incrassate, ratio width: length 1: 3.8-4.1; tibia black and yellow biannulate, with weak and short apicoventral dens; tarsus black, in some specimens tarsomeres 2 and 3 dark brown, basitarsomere thin, ratio width: length $1: 3.9-4.4$.

ABDOMEN. Length ratio of terga I: II: III: IV 1: 4.8-5.7: 2.1-2.7: 1.8-2.1; ratio width at posterior margin: medial length of tergum II and III 1:3.9-4.2 and 1: $0.8-0.9$. Terga black, anterior $1 / 3-1 / 2$ of tergum III with yellow fascia and posterior $1 / 5$ of tergum IV with brown-yellow fascia; pile pale, on terga short, laterally on terga I and II long; tergum I with 2-3 strong dark brown to black setae at lateral margin; sternum III squarish to rectangular, ratio width: length 1: 1.5-2.1; sternum IV, Fig. 98A; sterna VI, VII and VIII with long yellow pile, sternum VII with a large rounded yellow pilose widely conical processes with a narrower sharp medial projection. Genitalia, Fig. 98C-G: note the asymmetrical surstyli, bifid ventral lobe of right surstylus and the slightly asymmetrical superior lobes. 


\section{Female}

Not separable from female of Sphegina (Asiosphegina) bracon sp. nov. and S. (A.) furcillata sp. nov.
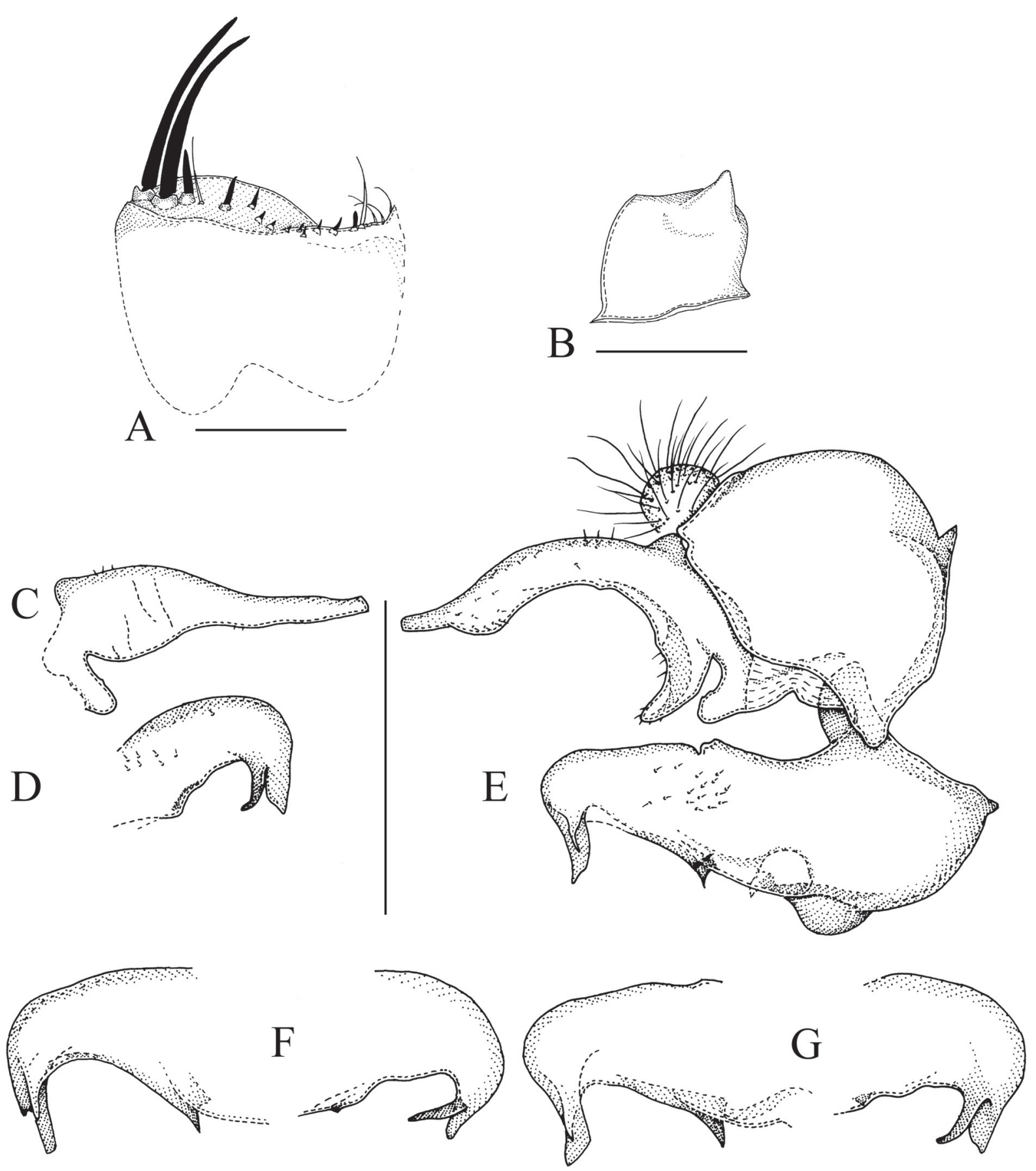

Fig. 98. Sphegina (Asiosphegina) vietnamensis sp. nov., holotype, ô (A-E), paratype 1 (F) and paratype $2(G)$. A. Sternum IV, ventral view. B. Sternum VII, ventral view. C. Left surstylus, lateral view. D. Left superior lobe with associated parts, lateral view. E. Genitalia, right side, lateral view. F-G. Left and right superior lobe, lateral view. Scale bars $=0.5 \mathrm{~mm}$. 


\section{Discussion}

The extraordinary diversity of the genus Sphegina in Kambaiti, Myanmar was previously described by Hippa et al. (2015) adding 35 species to a total of 14 Oriental species. This paper adds another 43 previously undescribed species. With the inclusion of one reinstated species and one new record for the Oriental fauna, the total number of described species in the Oriental region now stands at 94. In the material studied, we found several females clearly different from the species described here which may add up to 16 additional undescribed species to the total. Additionally, considering the number of species based on only one or two specimens, it is highly likely that there are many more undescribed species to be discovered. Hippa et al. (2015) estimated the number of endemic species in Kambaiti to be between 42 and 46. Thirty-six are currently described. During this work several specimens were studied by the first author from already relatively well investigated areas like Taiwan (Shiraki 1930; van Steenis et al. in prep) and also from almost none investigated areas like Bhutan. In this material several additional undescribed species were found indicating the number of Oriental species of Sphegina will be much higher. With the already 16 known but undescribed species (female specimens only) and the undescribed species (based on males) from Taiwan and Bhutan it is likely that there will be between 30 and 60 additional undescribed species in the Oriental region. It is unknown why the genus is so diverse in the Oriental region. A possible explanation for high diversity in the Kambaiti area in Myanmar is briefly discussed by van Steenis (2015). It is possible this explanation may extend to the entire Oriental region as a whole.

The main distribution and species richness of Oriental Sphegina (Fig. 99) seems to correspond with the mountain ranges in the North-West with additional records from other mountain regions (Fig. 100). A mountainous distribution is explainable as species of Sphegina inhabit forested areas with streams and rivers, often foraging close to water bodies in shaded conditions and preferring cooler conditions than is usual for Syrphidae (Reemer et al. 2009; Hippa et al. 2015). Larvae live in rotting hardwood in wet conditions often in streams but also on wet forest floor; other larval habitats are sap runs and rot holes (Hartley 1961; E.L. Rotheray 1990; G.E. Rotheray 2013).

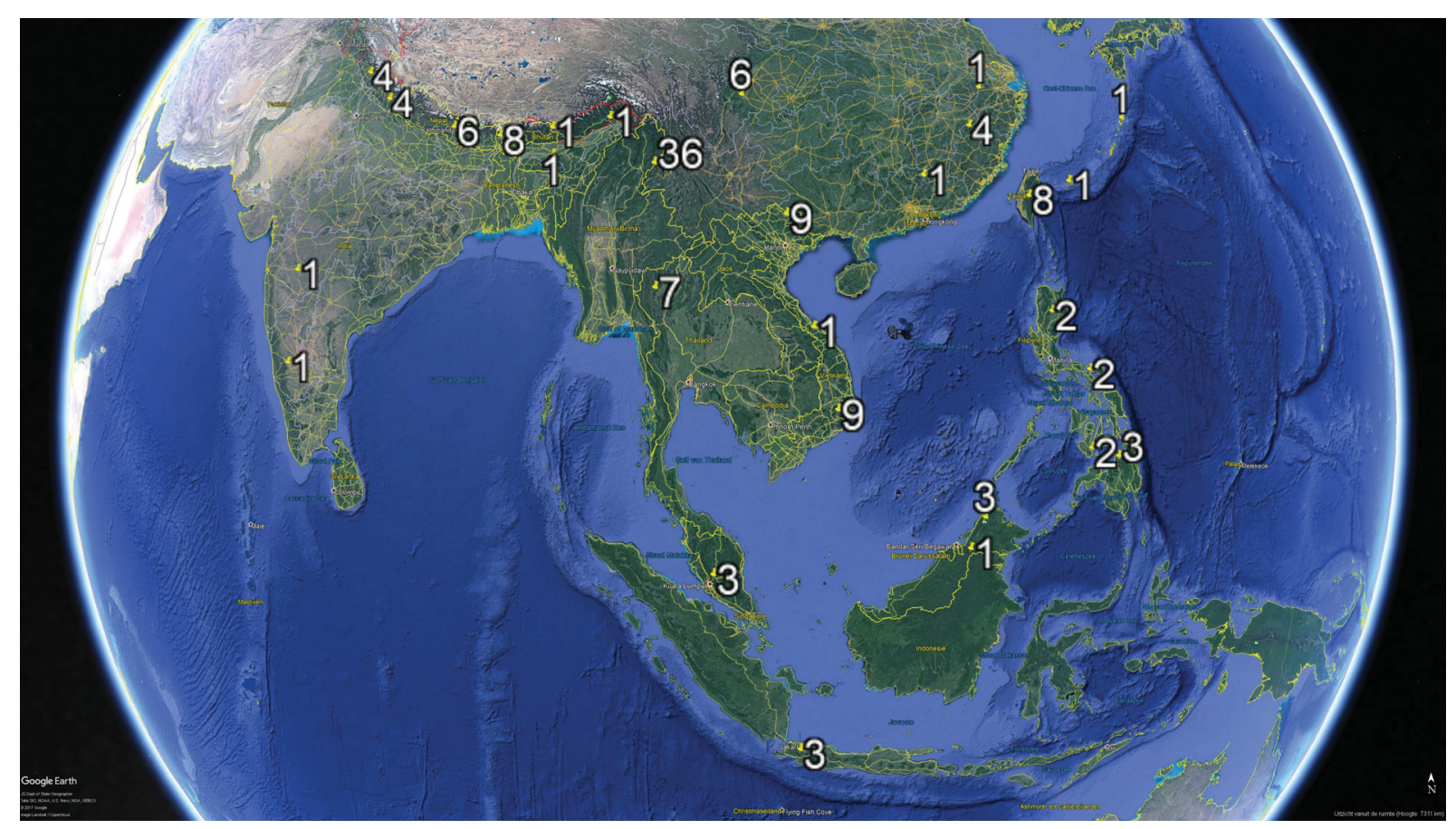

Fig. 99. Distribution of Sphegina in the Oriental region, with number of species for each region. 
Oriental species are often cold tolerant (C. van Achterberg pers. com.), flying in moist and densely shaded conditions close to small streams. Sometimes, they fly in great numbers and with several species together (Claussen 1980; Mutin et al. 2016; van Steenis et al. in prep). The Kambaiti area combines most of the favourable aspects for a high species diversity (Hippa et al. 2015). It seems as if the Kambaiti area has an unusual high number of species within the genus Sphegina, which is, so far, not seen anywhere else in the world. This is likely explained by the lack of thorough investigations in the South-Eastern part of the Himalaya and the Hengduan Mountain Range bordering China and Myanmar (van Steenis 2015). Future studies are necessary in order to test this hypothesis. They should be conducted within the near future to capture a picture of the biodiversity before habitat destruction becomes too severe, although it may already be too late for certain area (Stotz et al. 2003; Kahrl et al. 2005; Beffasti \& Galanti 2011; Chakravarty et al. 2012; Min 2012; Mon et al. 2012).

\section{Acknowledgements}

We wish to thank the following curators for the loan of material in their care: Awit Suwito (Bogor), Ximo Mengual (Bonn), Wouter van Steenis (Breukelen), Ed Turner and Russel Stebbings (Cambridge, U.K.), Wichai Srisuka (Chiang Mai), Thomas Pape (Copenhagen), Irene Rademacher (Frankfurt-am-Main), Sander Bot (Haren), Jim Boone (Honolulu), Dhriti Banerjee and Jayita Sengupta (Kolkata), Pasquale Ciliberti (Leiden), Nigel Wyatt (London), Katsuyoshi Ichige (Mito), Frank Menzel (Müncheberg), Marion Kotrba and Dieter Doczkal (München), Andrew Young and Jeff Skevington (Ottawa), Christophe Daugeron (Paris), Chris Palmer (Portsmouth), Martin Hauser (Sacramento), Chris Grinter and Jere

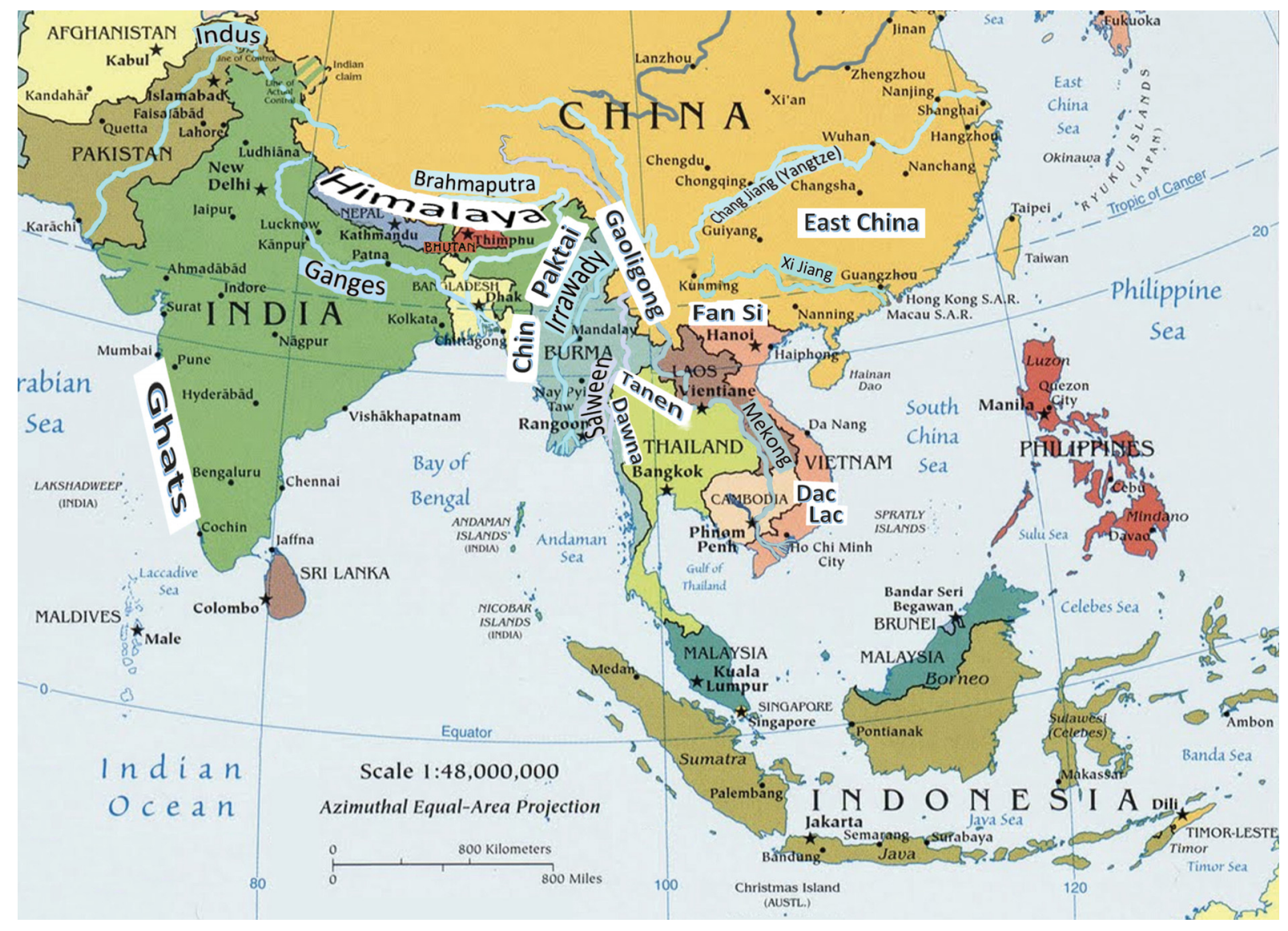

Fig. 100. Map of the Oriental region with main mountain ranges (black letters and white background) and rivers (black letters with coloured background). 
Schweikert (San Francisco), Yngve Brodin (Stockholm), Mei-Ling Chan and Jing-Fu Tsai (Taichung), Jhih-Rong Liao and Shih-Pi Kao (Taipei), Andre van Eck (Tilburg), Axel Ssymank (Wachtberg), Menno van Zuijen (Wageningen) and Chris Thompson, Torsten Dikow and Patricia Gentili-Poole (Washington). The following persons are acknowledged too: Ximo Mengual (Bonn) and Brian Brown (Los Angeles) for making the loan of, respectively, Bogor and Chiang Mai possible, Katsuyoshi Ichige (Ibaraki) for the photos of the type material preserved in the NIAES, Tsung-Hsueh (Bill) Wu \& Shiuh-Feng Shiao (Taipei) for arranging the Taiwanese collecting permits, Neal Evenhuis (Honolulu) for information on Mr Spencer and Chris Palmer (Portsmouth) for the English proofreading. The collection of additional material from Taiwan and the visit to the NHM were made possible by funding through the Uyttenboogaard-Eliassen foundation under numbers SUB.2015.12.06 and SUB.2017.12.05 respectively.

\section{References}

Beffasti L. \& Galanti V. (eds). 2011. Myanmar Protected Areas: Context, current Status and Challenges. Istituto Oikos and BANCA. Milano. Available from https://spectrumsdkn.org/en/library/natural-resource-management-library/50-myanmar-protected-areas -context-current-status-and-challenges/file [accessed 19 Nov. 2018].

Brunetti E. 1913. New and interesting Diptera from the eastern Himalayas. Records of the Indian Museum 9: 255-277.

Brunetti E. 1915. Notes on Oriental Syrphidae; with descriptions of new species. Part 2. Records of the Indian Museum 11 (3): 201-257.

Brunetti E. 1923. Diptera vol. III, Pipunculidae, Syrphidae, Conopidae, Oestridae. In: Shipley A.E. (ed.) The Fauna of British India, including Ceylon and Burma. Taylor and Francis, London.

Claussen C. 1980. Die Schwebfliegenfauna des Landesteils Schleswig in Schleswig-Holstein (Diptera, Syrphidae). Supplement zu Faunistisch Ökologische Mitteilungen 1: 3-79.

Chakravarty S., Ghosh S.K., Suresh C.P., Dey A.N. \& Shukla G. 2012. Deforestation: causes, effects and control strategies. In: Okia C.A. (ed.) Global Perspectives on Sustainable Forest Management. InTech Open Ltd, London. https://doi.org/10.5772/33342

Cox C.B. 2001. The biogeographic regions reconsidered. Journal of Biogeography 28 (4): 511-523. https://doi.org/10.1046/j.1365-2699.2001.00566.x

De Meijere J.C.H. 1914. Studien über südostasiatische Dipteren. IX. Tijdschrift voor Entomologie 57: 137-168.

Ghorpade K. 2015. Hover-flies (Diptera-Syrphidae) documented from the Northwest Frontier of the Indian sub-continent: a circumstantial history and inclusive bibliography. Colemania 50: 1-151.

Hartley J.C. 1961. A taxonomic account of the larvae of some British Syrphidae. Proceedings of the Zoological Society of London 136: 505-573.

Hippa H. \& Ståhls G. 2005. Morphological characters of adult Syrphidae: descriptions and phylogenetic utility. Acta Zoologica Fennica 215: 1-72.

Hippa H., van Steenis J. \& Mutin V.A. 2015. The genus Sphegina Meigen (Diptera, Syrphidae) in a biodiversity hotspot: the thirty-six sympatric species in Kambaiti, Myanmar. Zootaxa 3954 (1): 1-67. https://doi.org/10.11646/zootaxa.3954.1.1

Holt B.G., Lessard J-P., Borregaard M.K., Fritz S.A., Araújo M.B., Dimitrov D., Fabre P-H., Graham C.H., Graves G.R., Jønsson K.A., Nogués-Bravo D., Wang Z., Whittaker R.J., Fjeldså J. \& Rahbek C. 2013. An update of Wallace's zoogeographic regions of the world. Science 339: 74-78. https://doi.org/10.1126/science.1228282 
Huo K.-K. \& Ren G.D. 2006. Descriptions of two new species of Sphegina (Diptera, Syrphidae) from China. Acta Zootaxonomica Sinica 31 (2): 434-437.

Kahrl F., Weyerhaeuser H. \& Yufang S. 2005. An Overview of the Market Chain for China's Timber Product Imports from Myanmar. Implications for Forests and Livelihoods. Forest Trends. World Agroforestry Centre, Yunnan.

Available from http://outputs.worldagroforestry.org/cgi-bin/koha/opac-detail.pl?biblionumber=35401 [accessed 19 Nov. 2018].

Kertész K. 1914. H. Sauter's Formosa-Ausbeute. Syrphidae. II. Annales historic-naturales Musei nationales hungarici 12: 73-87.

Kojima J-I., Saito F. \& Nguyen L.T.P. 2011. On the species-group taxa of Taiwan social wasps (Hymenoptera: Vespidae) described and/or treated by J. Sonan. Zootaxa 2920: 42-64.

Available from http://www.mapress.com/zootaxa/2011/f/zt02920p064.pdf [accessed 19 Nov. 2018].

Kreft H. \& Jetz W. 2013. Comment on “An Update of Wallace's Zoogeographic Regions of the World”. Science 341: 343. https://doi.org/10.1126/science.1237471

Maibach A. 1993. Contribution à l'étude des Syrphidae aquatiques de Suisse occidentale (Insecta: Diptera). PhD Thesis, University of Lausanne, Switzerland.

Min S. 2012. Impacts of Wildlife Trade on Conservation in Kachin State, Myanmar. Traffic Bulletin, Cambridge UK, 24 (2): 57-64.

Available from http://www.bloomassociation.org/en/wp-content/uploads/2016/04/Stan-sea-cucmber.pdf [accessed 19 Nov. 2018].

Mon M.S., Mizoue N., Htun N.Z., Kajisa T. \& Yoshida S. 2012. Factors affecting deforestation and forest degeneration in selectively logged production forest: A case study in Myanmar. Forest Ecology and Management 267: 190-198. https://doi.org/10.1016/j.foreco.2011.11.036

Mutin V.A. 1998. Four new species of the genus Sphegina Meigen, 1822 (Diptera: Syrphidae) from Russia and India. International Journal of Dipterological Research 9 (3): 237-241.

Mutin V.A., van Steenis J., van Steenis W., Palmer C., Bot S., Skevington J., Merkel-Wallner G., van Zuijen M.P., Zeegers T., Ssymank A. \& Mengual X. 2016. Syrphid fauna (Diptera: Syrphidae) of Tumnin river basin, the eastern macroslope of the northern Sikhote-Alin, Russia. Far Eastern Entomologist 306: $1-31$.

Pape T. \& Evenhuis F.C. (eds). 2018. Systema Dipterorum, Version [2.0].

Available from https://diptera.dk/ [accessed on 19 Nov. 2018].

Reemer M., Renema W., van Steenis W., Zeegers Th., Barendregt A., Smit J.T., van Veen M.P., van Steenis J. \& van der Leij L.J.J.M. 2009. De Nederlandse zweefvliegen (Diptera: Syrphidae). Nederlandse Fauna 8, KNNV, Leiden.

Reemer M. \& Ståhls G. 2013. Phylogenetic relationships of Microdontinae (Diptera: Syrphidae) based on molecular and morphological characters. Systematic Entomology 38: 661-688.

https://doi.org/10.1111/syen.12020

Röder G. 1990. Biologie der Schwebfliegen Deutschlands (Diptera: Syrphidae). Erna Bauer Verlag, Keltern-Weiler.

Rotheray E.L. 2013. Differences in ecomorphology and microhabitat use of four saproxylic larvae (Diptera, Syrphidae) in Scots pine stump rot holes. Ecological Entomology 38: 219-229. https://doi.org/10.1111/een.12009 
Rotheray G.E. 1990. Larval and puparial records of some hoverflies associated with dead wood. Dipterists Digest 7: 2-7.

Rotheray G.E. \& Gilbert F.S. 1999. Phylogeny of Palaearctic Syrphidae (Diptera): evidence from larval stages. Zoological Journal of the Linnean Society 127: 1-112.

https://doi.org/10.1111/j.1096-3642.1999.tb01305.x

Shiraki T. 1930. Die Syrphiden des japanischen Kaiserreichs, mit Berücksichtigung benachbarter Gebiete. Memoirs of the Faculty of Sciences and Agriculture 1 (1), Taihoku Imperial University, Formosa.

Shiraki T. 1968. Fauna Japonica, Syrphidae (Insecta: Diptera). Vol. III. Biogeographical Society of Japan, Tokyo.

Stackelberg A.A. 1953. [A short survey of the Palaearctic species of the genus Sphegina Mg. (Diptera, Syrphidae).] Trudy Zoologicheskogo Instituta, Leningrad 13: 373-386. [In Russian, with German summary.]

Stackelberg A.A. 1974. [New species of hover flies (Diptera, Syrphidae) of Siberia and Mongolian People's Republic]. Entomologicheskoe Obozrenie 53: 443-446. [In Russian.]

Ståhls G., Hippa H., Rotheray G., Muona J. \& Gilbert F. 2003. Phylogeny of Syrphidae (Diptera) inferred from combined analysis of molecular and morphological characters. Systematic Entomology 28: 433-450.

Stotz D.F., Harris E.J., Moskovits D.K., Hao K., Yi S. \& Adelmann G.W. (eds). 2003. China: Yunnan, Southern Gaoligongshan. Rapid Biological Inventories. Report No 4. The Field Museum, Chicago, Illinois. Available from http://fm2.fieldmuseum.org/rbi/pdfs/china04/chi04EntireEng.pdf [accessed 19 Nov. 2018].

Takhtajan A., Crovello Th.J. \& Cronquist A. 1986. Floristic Regions of the World. University of California Press, USA.

Thompson F.C. 1966. A new Sphegina from Nepal (Diptera: Syrphidae). Bulletin of the Brooklyn Entomological Society 59: 42-45.

Thompson F.C. 1972. A contribution to a generic revision of the Neotropical Milesinae (Diptera: Syrphidae). Arquivos de Zoologia 23: 73-215.

Thompson F.C. 1999a. A key to the genera of the flower flies (Diptera: Syrphidae) of the Neotropical region including redescriptions of new genera and species and a glossary of taxonomic terms. Contributions on Entomology, International 3: 319-379.

Thompson F.C. 1999b. A new Oriental Sphegina species (Diptera: Syrphidae). Entomological news 110 (4): 206-208.

Thompson F.C. \& Torp E. 1986. Synopsis of the European species of Sphegina Meigen (Diptera: Syrphidae). Entomologica Scandinavica 17: 235-268.

Torp E. 1994. Danmarks Svirrefluer (Diptera: Syrphidae). Danmarks Dyreliv 6. Apollo Books, Stenstrup.

Udvardy M.D.F. 1975. A classification of the biogeographical provinces of the world. IUCN occasional paper 8: $1-48$.

Van Steenis J. 2015. The first Oriental species of the genus Brachyopa Meigen (Diptera: Syrphidae), with a discussion on the Syrphidae fauna of the Indo-Malayan transition zone. Studia Dipterologica 21 (2): 293-300. Available from http://www.studia-dipt.de/data/21293.pdf [accessed 19 Nov. 2018]. 
Van Steenis J., Wu T-H, Ssymank A.M., van Steenis W., Skevington J.H., Young A.D., Palmer C.J., van Zuijen M.P., Lechner-Ssymank B. \& Shiao S-F. In prep. Preliminary results of the 2016 International Taiwan expedition on Syrphidae (Diptera).

Westwood J.O. 1840. Order XIII. Diptera Aristotle. (Antliata Fabricius. Halteriptera Clairv.). In: Westwood J.O. (ed.) An Introduction to the Modern Classification of Insects; Founded on the Natural Habits and Corresponding Organization of the Different Families. Synopsis of the Genera of British Insects: 125-154. Longman, Orme, Brown, Green and Longmans, London. https://doi.org/10.5962/bhl.title.12455

Manuscript received: 8 June 2018

Manuscript accepted: 20 September 2018

Published on: 20 December 2018

Topic editor: Gavin Broad

Desk editor: Kristiaan Hoedemakers

Printed versions of all papers are also deposited in the libraries of the institutes that are members of the EJT consortium: Muséum national d'Histoire naturelle, Paris, France; Meise Botanic Garden, Belgium; Royal Museum for Central Africa, Tervuren, Belgium; Natural History Museum, London, United Kingdom; Royal Belgian Institute of Natural Sciences, Brussels, Belgium; Natural History Museum of Denmark, Copenhagen, Denmark; Naturalis Biodiversity Center, Leiden, the Netherlands; Museo Nacional de Ciencias Naturales-CSIC, Madrid, Spain; Real Jardín Botánico de Madrid CSIC, Spain; Zoological Research Museum Alexander Koenig, Bonn, Germany. 